\title{
AN EXPLORATION OF THE FEASIBILITY OF CONVERTING THE NEW ZEALAND COMMERCIAL BUILDING STOCK TO BE NET ZERO ENERGY
}

\author{
BY SHAAN \\ CORY
}

\begin{abstract}
A thesis
submitted to Victoria University of Wellington in

fulfilment of the requirements for the degree of

Doctor of Philosophy

in

Architecture (Building Science)
\end{abstract}

Victoria University of Wellington

2016 



\section{ACKNOWLEDGEMENT}

I would like to thank the many people who have given me their support over the course of this thesis. I would especially like to thank my supervisors, Dr Michael Donn and Dr George Baird for their guidance, patience, and perspective. Their help from the initial thesis concept through to the output of the final dissertation has been invaluable.

Thank you to all of the funders throughout the duration of my PhD: BEES, Dumont d'Urville NZ-France Science \& Technology Support Programme, John Fitzgerald Memorial Award, and New Zealand Green Building Council. A special thanks to the BEES funders jointly funded by BRANZ from the Building Research Levy; the Ministry of Business, Innovation and Employment (MBIE) from the Public Good Science Fund and Infrastructure and Market Resources and the Energy Efficiency and Conservation Authority (EECA).

Thank you to all who have contributed to the research, from every individual BEES team member, to colleagues, to the IEA Task 40 Annex 52 participants. A special mention to:

Victoria University colleagues: Anastasia Globa, Quintin Heap, Carmeny Field, Clare Dykes, Henry Hsu, Jake Osborne, Anthony Gates, Lee Bint, Alex Hills, Brian Berg, Tavis Cresswell-Wells, and BILD423 students 2013 and 2014. Thank you to Dr Robert Vale for his input after examination.

BEES team members: Nigel Isaacs, Lynda Amitrano, Andrew Pollard, Michael Babylon, Rob Bishop, Michael Camilleri, Kay Saville-Smith, Lee Bint and Alex Hills.

A special thank you to my parents, Steve and Diana, for the good life and support you have provided. Thank you to my brothers (Jamie, Joel and Jayden) and to my friends for helping, supporting and motivating me through the challenge that comes with completing a PhD. A big thank you to Ronald J Knapman for without his influence, higher education would probably have not been a motivation. Ron, thank you for sparking the interest of research and the many hours of time you have given to me throughout my youth. A very special thank you to my fiancée, Bridget Hill, for her unwavering support and her tolerance of the absenteeism while my mind was focussed on writing. 



\section{ABSTRACT}

This thesis explores the feasibility of converting the current New Zealand commercial building stock to Net Zero Energy (NZE). The analysis presented is grounded in real building performance and construction information. The goal was to establish results that are as realistic as possible to actual building performance.

The Net Zero Energy Building (Net ZEB) concept is one of many low energy building movements that respond to the issues of climate change and energy security. The Net ZEB concept strives to reduce demand for energy and then to offset any residual energy consumption with non- $\mathrm{CO}_{2}$ emitting renewable energy technologies. The (re-)design focus for Net ZEBs is to reduce annual energy consumption to be equal to or less than any generated renewable energy. This is an important concept since approximately 40 percent of all energy and emissions worldwide are building related. If all buildings were designed and operated to be NZE, the existing energy can be used by other sectors which will increase energy security. Conversely, reducing the fossil fuel $\mathrm{CO}_{2}$ producing component of the energy consumed by buildings has the benefit of negating building's contribution to climate change.

The Net ZEB concept assumes each building is grid-connected, and balances the energy taken from the grid against the energy put back into the grid over a year. This study exploits the available synergies of the grid connection to achieve NZE for the whole building stock. Thus each individual building does not need to be NZE at the site, but they act as a community to reach NZE collectively. Furthermore, any grid-tied renewable energy does not need to be offset, only the non-renewable portion.

A NZE target was calculated to determine the percentage reduction in current energy consumption needed before the current commercial building stock could be considered NZE. It was found that a 45 percent reduction in primary energy would offset all non-renewable $\mathrm{CO}_{2}$ emitting energy supply currently consumed by the New Zealand commercial building stock.

Previous studies assessing whether converting an entire stock of commercial buildings to NZE is possible used prototypical building energy models. Prototypical models represent a hypothetical average building and have many assumptions about the way a building is operated. This thesis develops a method that takes a representative sample of real commercial buildings and makes calibrated energy models that can be aggregated to represent energy consumption for all commercial buildings in New Zealand. The developed calibration method makes use of as-built building information and a standardised procedure for identifying the inaccurate model inputs which need to be corrected for a building energy model to be calibrated. To further base the process in reality, a set of Energy Conservation Measures (ECM) that had been implemented in real Net ZEBs worldwide was adopted for the proposed retrofits. These ECMs were combined into Net ZEB solution sets for retrofitting the aggregated commercial building models.

Page | ii 
Optimisation of the Net ZEB solution sets was performed on hundreds of models to maximise energy savings. It took over six months for all of the optimisations to be completed.

This thesis demonstrates the estimated New Zealand commercial building stock's energy consumption based upon the calibrated energy models was robust by comparing it to an external estimate. It shows that NZE can be achieved by applying well understood Net ZEB solution sets to the New Zealand commercial building stock. 96 percent of the NZE goal is attainable just through demand reduction without the use of onsite renewable energy generation. The additional four percent of reduction required to meet NZE is easily attainable with onsite renewable generation. Another benefit is that the retrofitted commercial buildings will provide improved thermal comfort for the occupants.

Having established NZE was possible, this thesis concludes with an analysis of the broader implications of achieving the NZE goal. It identifies the next step would be to design a NZE commercial building stock that reduces the stresses on the existing energy infrastructure. The Solution Set adopted was not developed with the interaction of the building and electrical grid in mind. To have a practical implementation of NZE will require costing and community prioritisation. This would be the next phase of work assessing nationwide NZE retrofit.

Page | iii 



\section{CONTENTS}

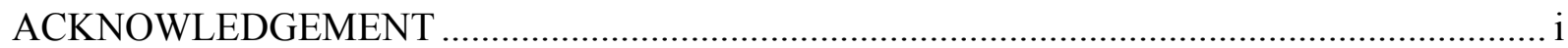

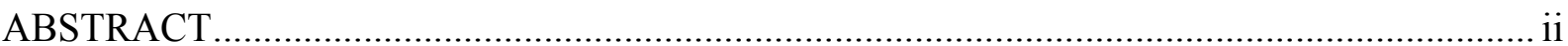

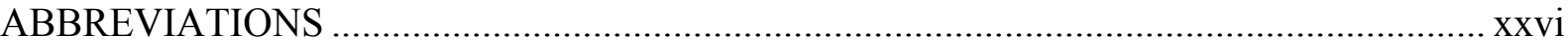

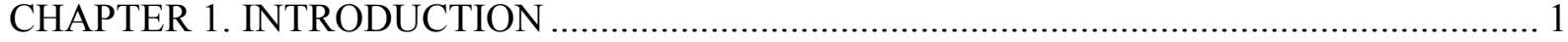

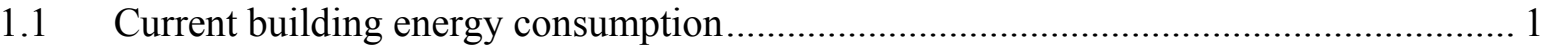

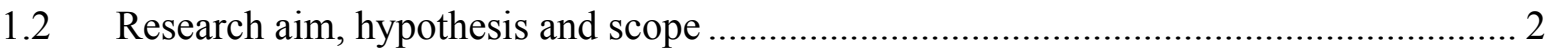

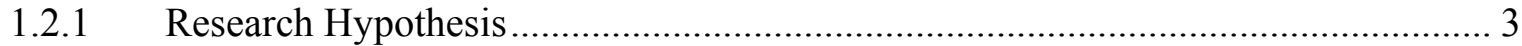

1.2.2 Real buildings, their performance, and existing Net ZEB strategies...................... 3

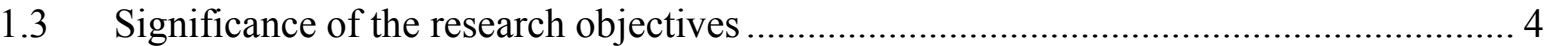

1.3.1 Retrofitting the New Zealand commercial building stock to be Net Zero Energy ... 5

1.3.2 National picture based on calibrated energy simulation models ............................. 5

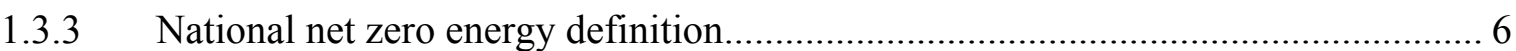

1.3.4 National building retrofit design drawn from working Net ZEB examples ............ 6

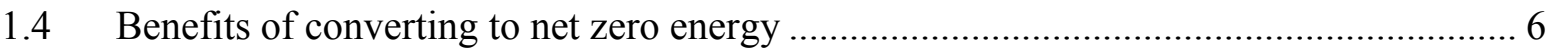

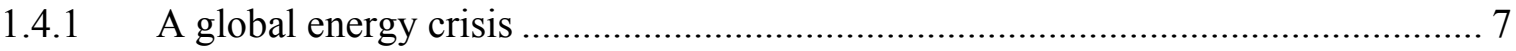

1.4.2 New Zealand's energy and commercial building stock ......................................... 9

1.4.3 Net zero energy building concept and international targets................................. 10

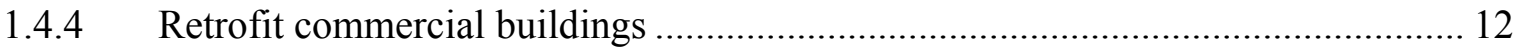

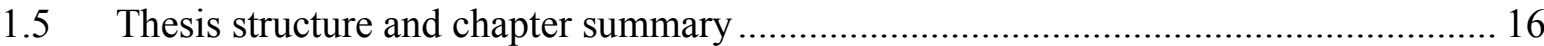

CHAPTER 2. DEFINING NET ZERO ENERGY - BUILDINGS AND SUSTAINABILITY .. 19

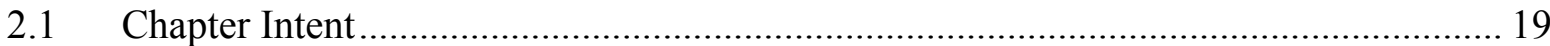

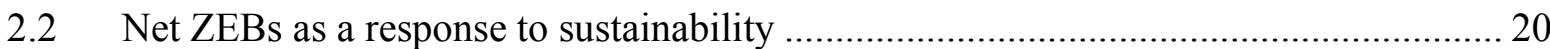

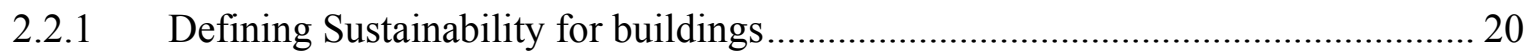

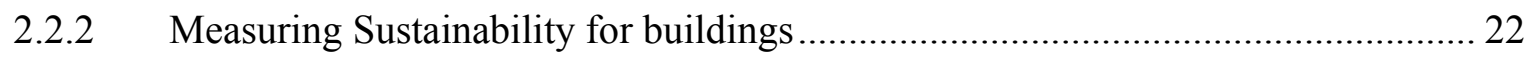

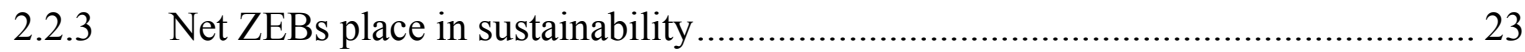

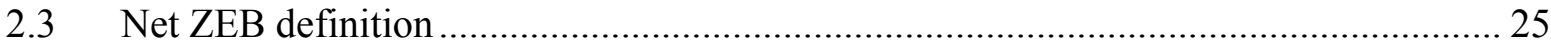

2.3.1 The risk of poorly defined Net ZEB definitions ................................................ 31

2.3.2 The IEA framework: A means of formulating a Net ZEB definition ..................... 32

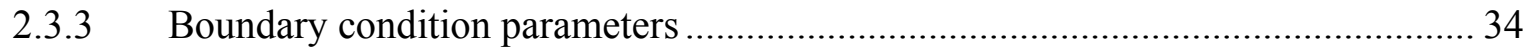

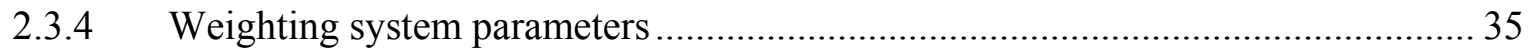

Page $\mid$ iv 


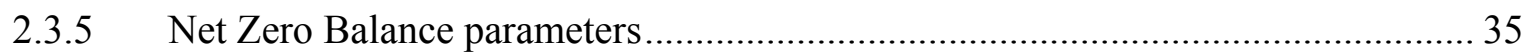

2.3.6 Temporal Energy Match parameters........................................................................ 38

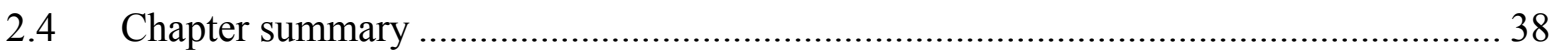

CHAPTER 3. NEW ZEALAND'S UNIQUE ENERGY AND BUILDING CONTEXT........... 40

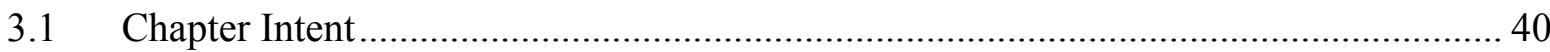

3.2 Grid connection and energy supply in New Zealand ............................................... 40

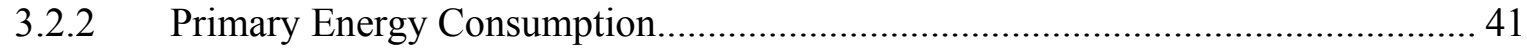

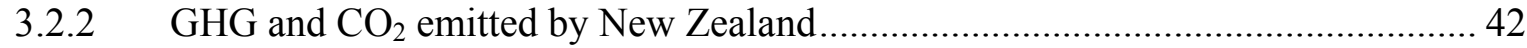

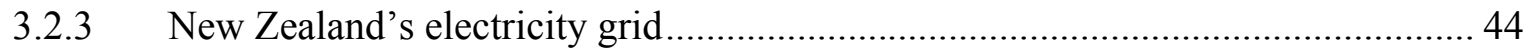

3.3 Site and nature of the New Zealand's Commercial Building Stock ............................ 45

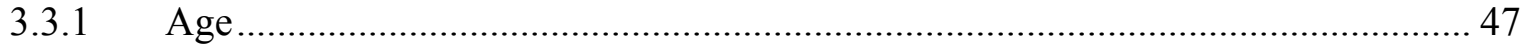

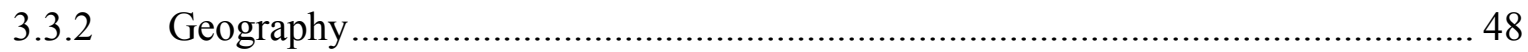

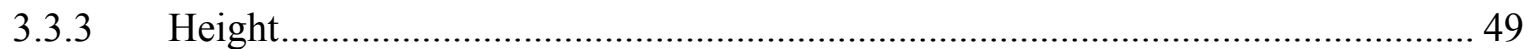

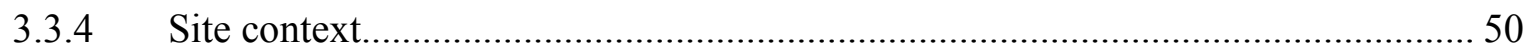

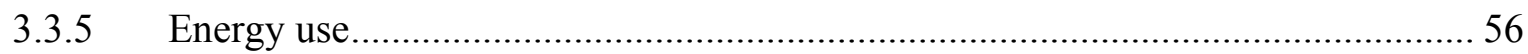

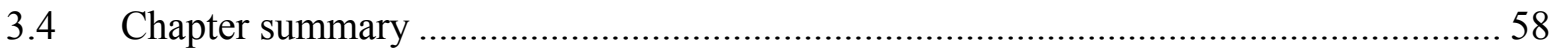

CHAPTER 4. NET ZERO ENERGY IN NEW ZEALAND'S COMMERCIAL BUILDING

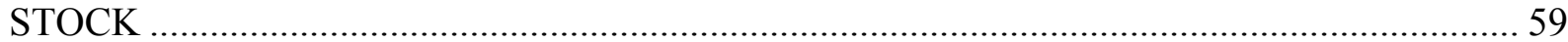

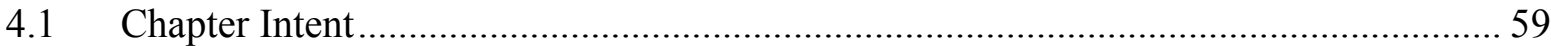

4.2 Basic Net ZEB principles and a summary of the New Zealand context ...................... 59

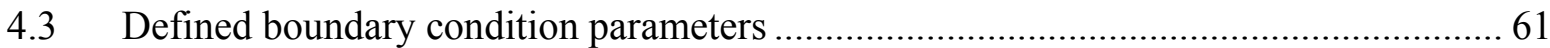

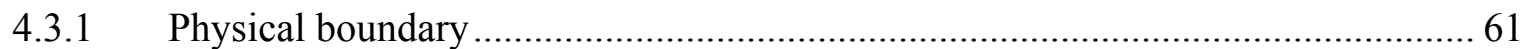

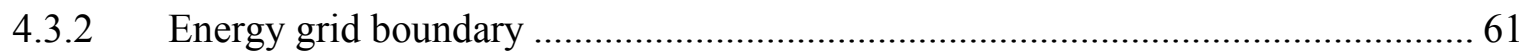

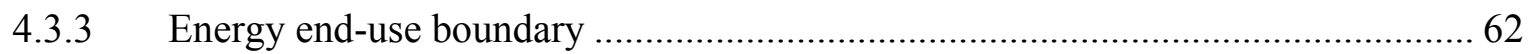

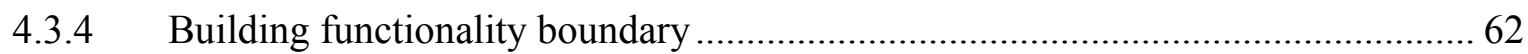

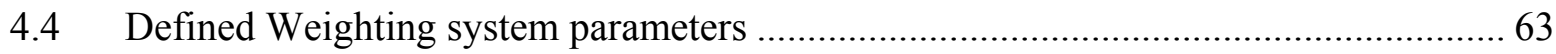

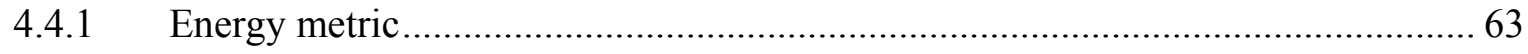

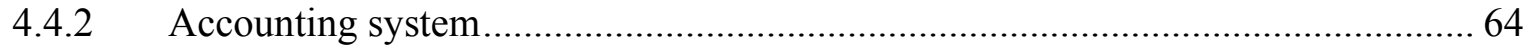

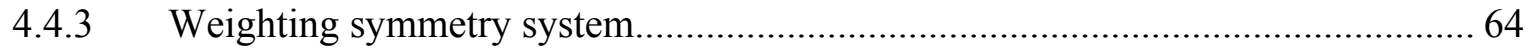

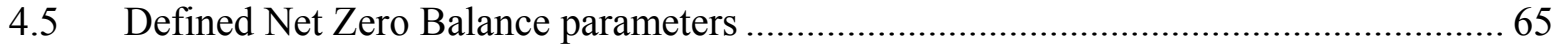

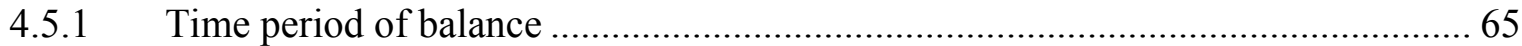

Page | v 


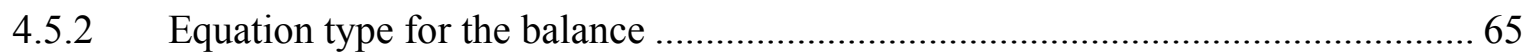

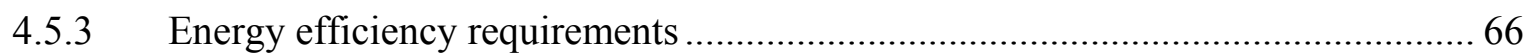

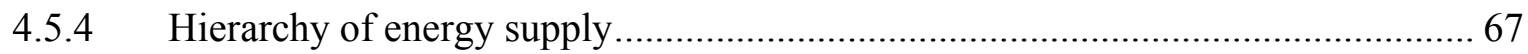

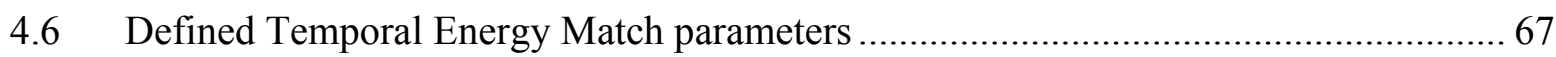

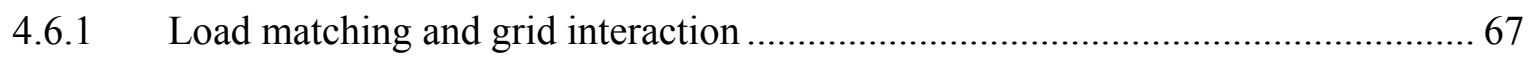

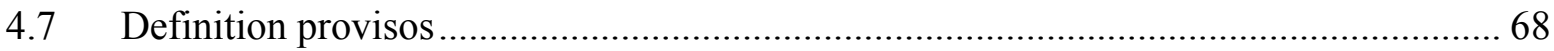

4.8 Quantified target of net zero energy in the Commercial Sector................................... 70

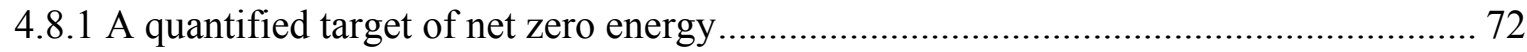

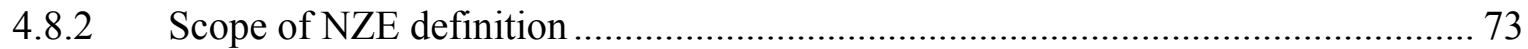

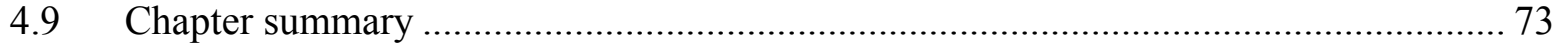

CHAPTER 5. HYPOTHESIS, SCOPE AND OVERARCHING METHODOLOGY ................. 76

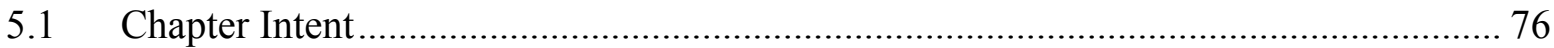

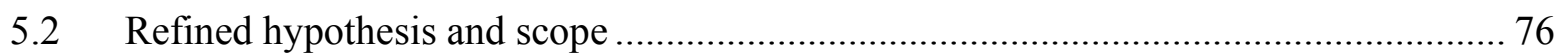

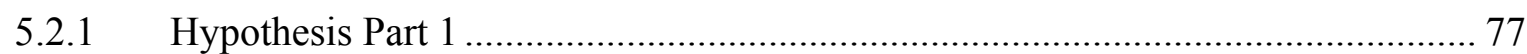

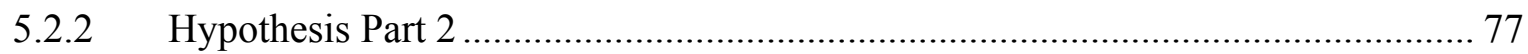

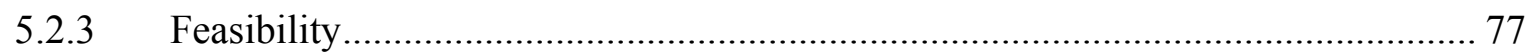

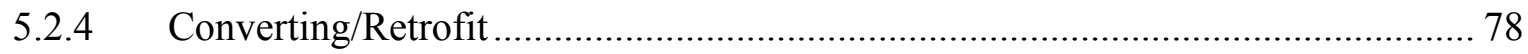

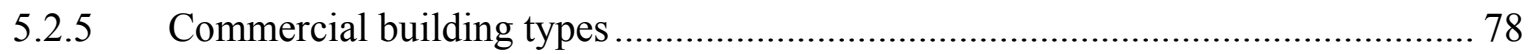

5.2.6 Thermal and energy calculation program ............................................................. 79

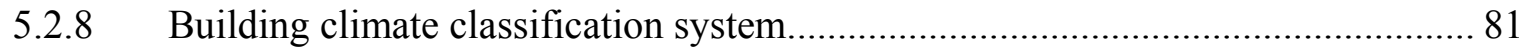

5.3 Overarching methodology: Real, not Prototypical buildings..................................... 91

5.3.1 Representing the current commercial building stock......................................... 93

5.3.2 Assessment of Net ZEB opportunities .............................................................. 100

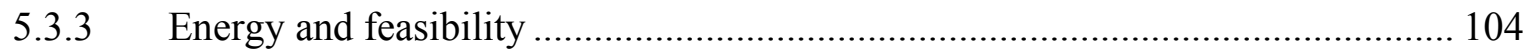

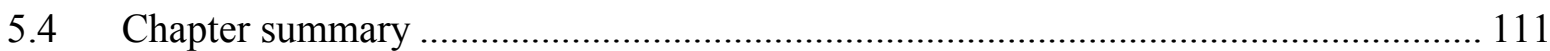

CHAPTER 6. A REPRESENTATIVE SAMPLE OF REAL COMMERCIAL BUILDINGS .. 112

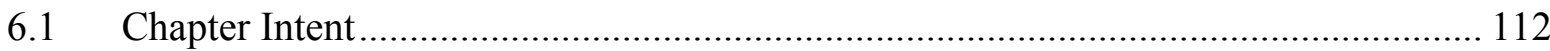

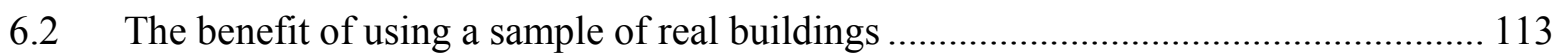

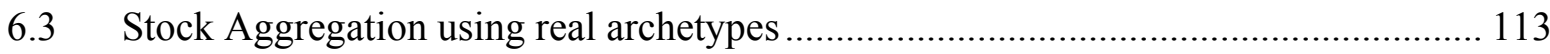

6.4 BEES random sample and data collection of commercial building performance........ 116

6.4.1 QV and business directory information ............................................................ 116

Page | vi 


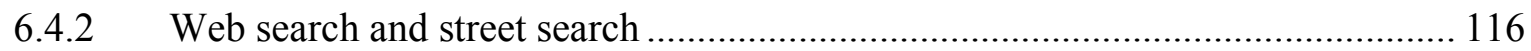

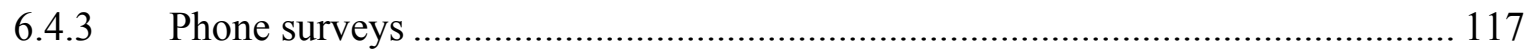

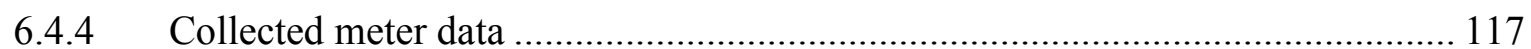

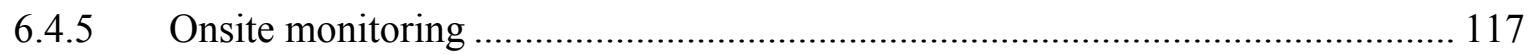

6.4.6 Collected data and dataset sample overlapping ................................................ 117

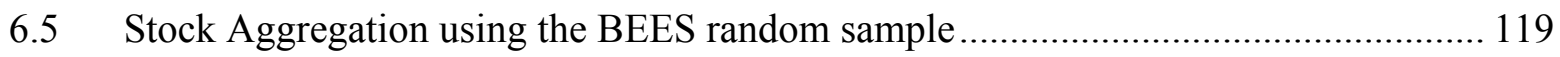

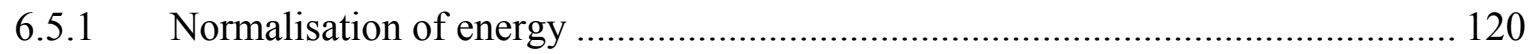

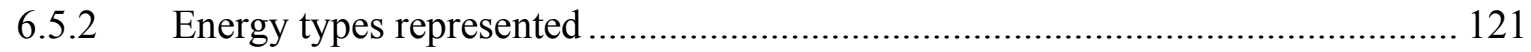

6.5.3 New Zealand Building Climate Aggregation ................................................... 121

6.5.4 Stock Aggregation calculation process ............................................................. 127

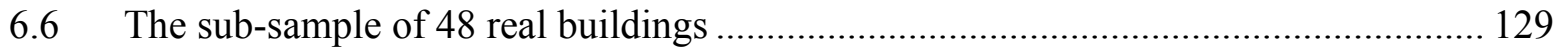

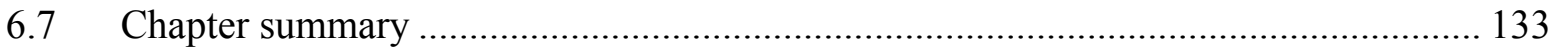

CHAPTER 7. TECHNIQUE FOR MODELLING AN EXISTING BUILDING'S ENERGY

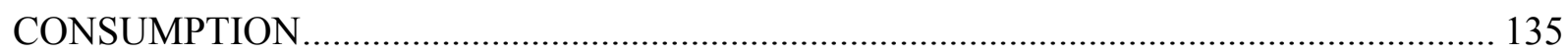

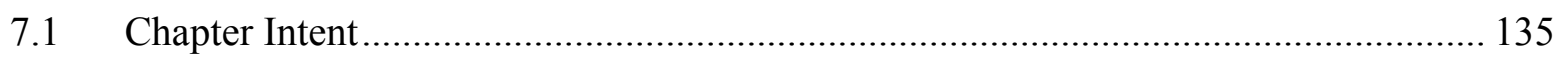

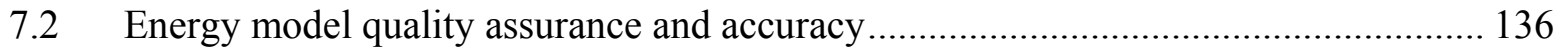

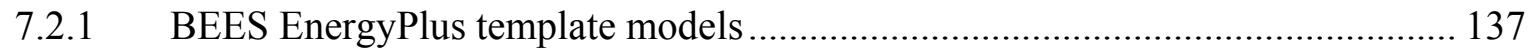

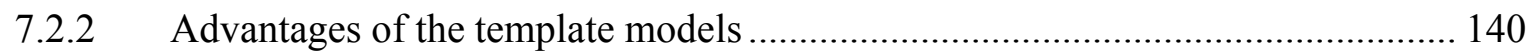

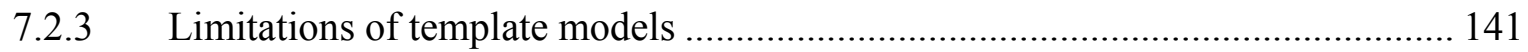

7.2.4 Quality assurance tests of template model simplifications .................................. 142

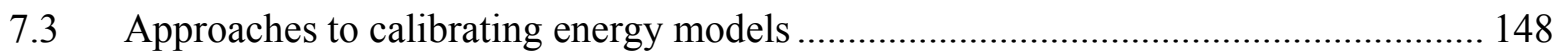

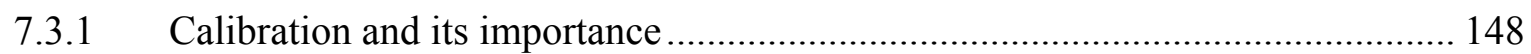

7.4 Hybrid method for calibrating EnergyPlus models of existing buildings .................... 152

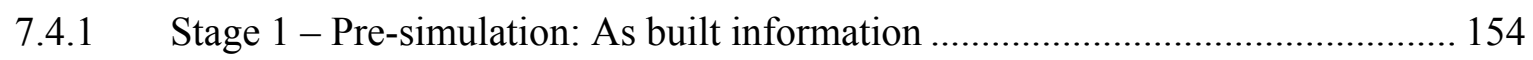

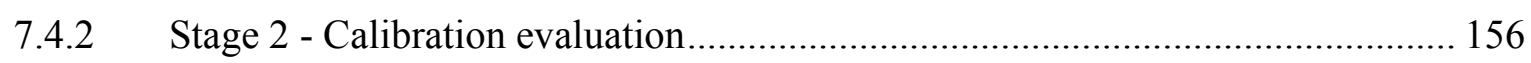

7.4.3 Stage 3 - Post-simulation: identification of incorrect input values ...................... 157

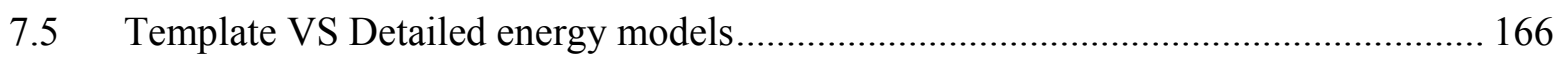

7.5.1 Energy results from Template and Detailed models............................................ 167

7.5.2 Modellers' perceptions of using Template and Detailed models.......................... 171

7.5.3 Template VS Detailed modelling conclusions and implications for calibration

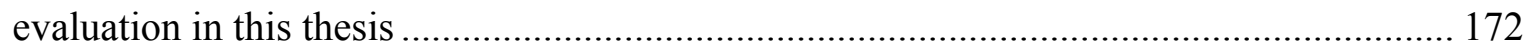

Page | vii 
7.6 Chapter summary.

CHAPTER 8. USING NET ZEB SOLUTION SETS AND THEIR OPTIMISATION FOR NEW

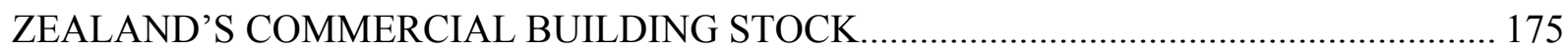

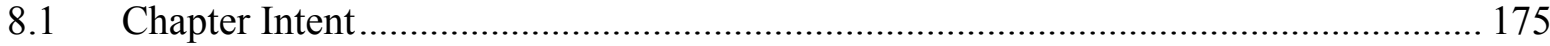

8.2 Establishing and assessing Net ZEB solutions sets using case based reasoning ......... 176

8.2.1 Using Solution Sets as a form of Case-Based Reasoning in design ..................... 178

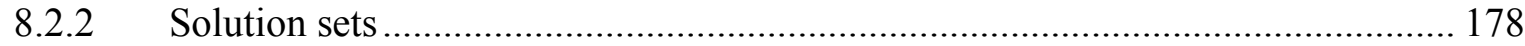

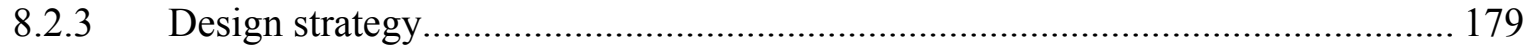

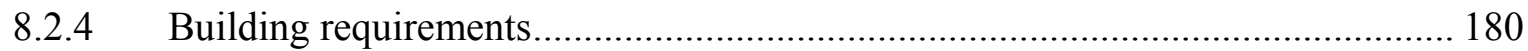

8.2.5 Building requirements and Solution set determinants ........................................ 181

8.2.6 Design hierarchy to enable a Case-Based assessment of existing solution sets to

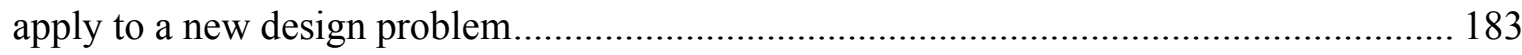

8.3 Solution sets used in 21 case study non-residential Net Zero Energy Buildings......... 190

8.3.1 Suitability assessment of existing solution sets for New Zealand ........................ 191

8.3.2 Design team lessons learned about existing Net ZEBs....................................... 200

8.3.3 Selecting an appropriate refurbishment solution set for retrofitting New Zealand

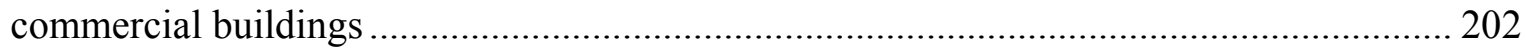

8.3.4 The Energy Conservation Measures that make up the New Zealand Commercial

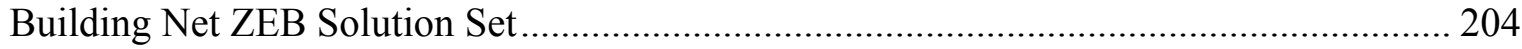

8.4 Optimisation of the Net ZEB refurbishment solution set in the New Zealand

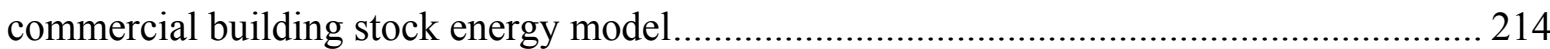

8.4.1 Lessons learned from energy optimisation approach on a small case study......... 215

8.4.2 Method for reducing the computation time of optimisations for a large group of optimisations

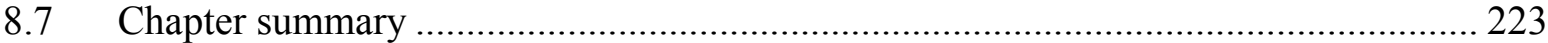

CHAPTER 9. COMMERCIAL BUILDING STOCK ENERGY MODELLING RESULTS ... 226

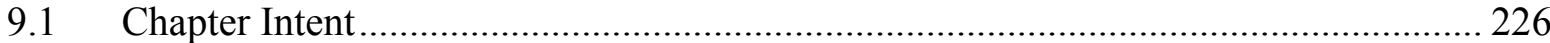

9.2 Modelling and calibration of the 48 case study buildings....................................... 227

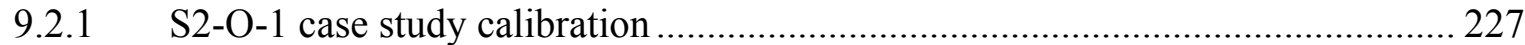

9.2.2 Calibration results for the 48 BEES case study buildings ................................... 236

9.2.3 Stock Aggregation energy consumption estimate................................................ 241

9.3 Quality assurance test of the Stock Aggregation estimate ......................................... 244

Page | viii 


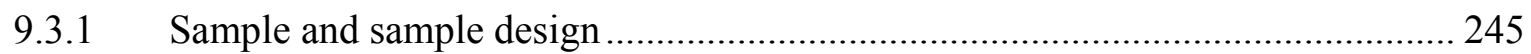

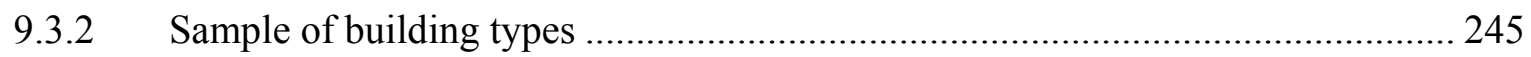

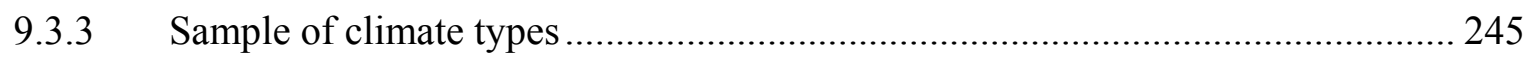

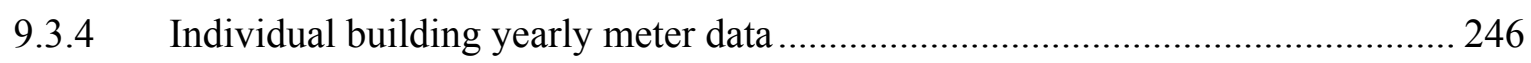

9.3.5 Individual building common and ineligible area and its energy consumption ..... 249

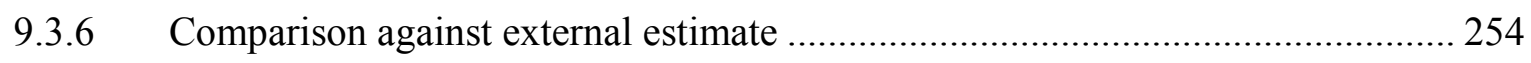

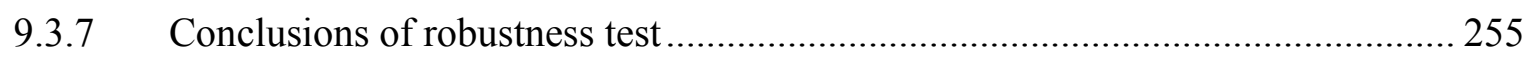

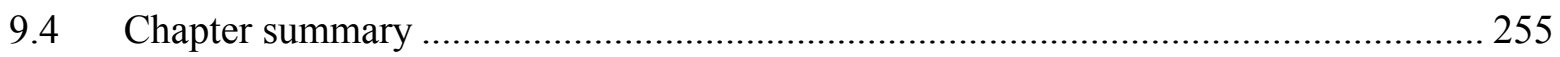

CHAPTER 10. RESULTS OF CONVERTING TO NET ZERO ENERGY .......................... 257

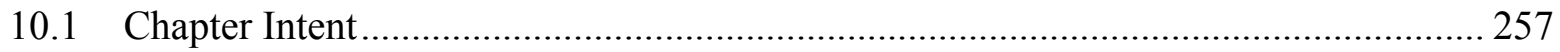

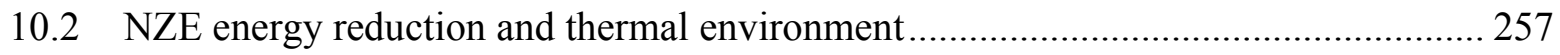

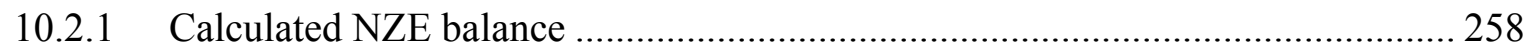

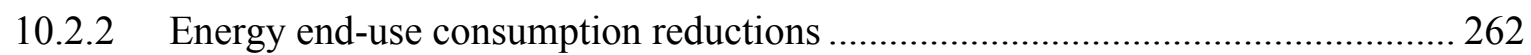

10.2.3 Energy performance of the different building types and sizes ............................ 264

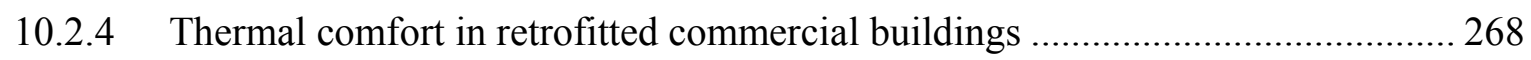

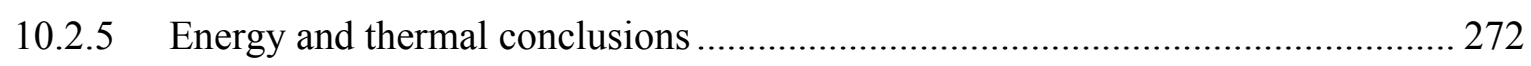

10.3 Ranking of energy conservation measures importance to the Net ZEB solution set ... 274

10.3.1 Difference in ECM effectiveness for building size and types ............................. 277

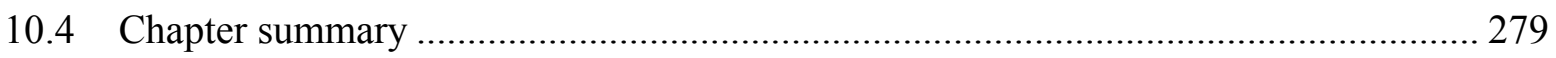

CHAPTER 11. FEASIBILITY OF REACHING NET ZERO ENERGY ................................ 281

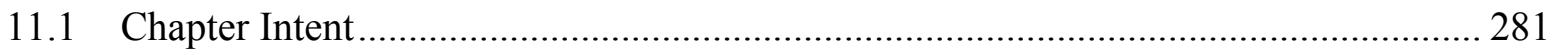

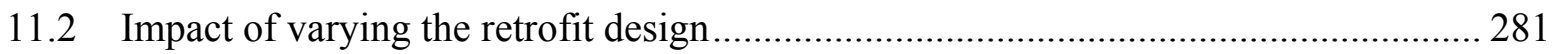

11.2.1 Consequences of heating and cooling set point changes .................................... 283

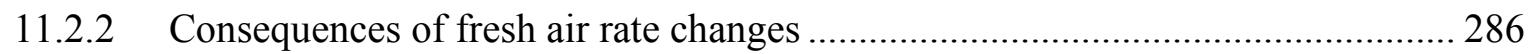

11.2.3 Consequences of task illuminance set point changes ........................................ 288

11.2.4 Consequences of Heat pump system type changes ............................................. 290

11.2.5 Conclusions of the practicality testing for the retrofit design............................. 292

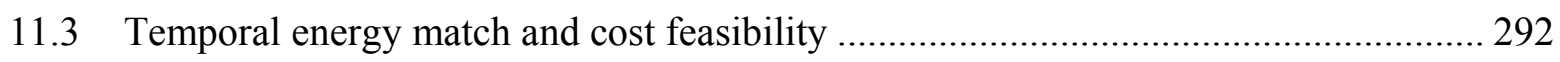

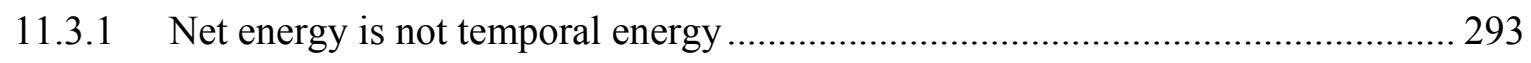

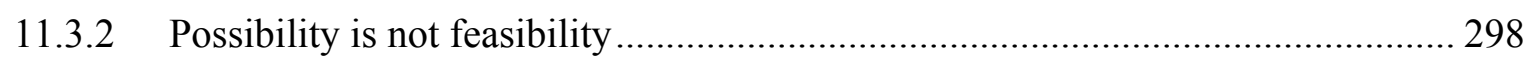

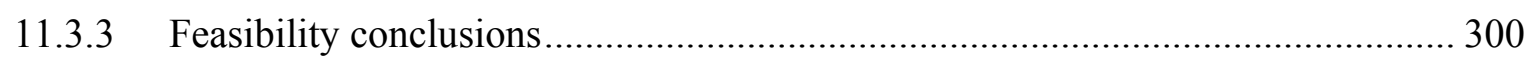

Page | ix 


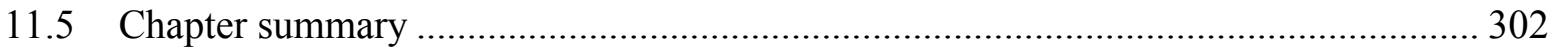

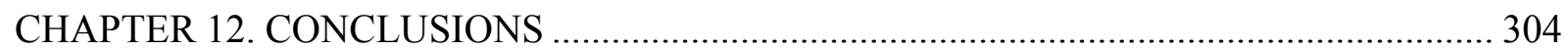

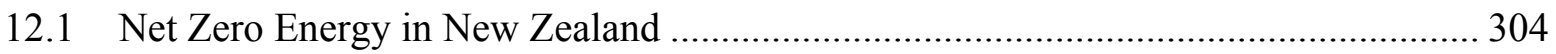

12.2 Proving the Hypothesis Part 1: Method founded on real building performance........... 305

12.3 Proving the Hypothesis Part 2: Net Zero Energy is feasible ..................................... 306

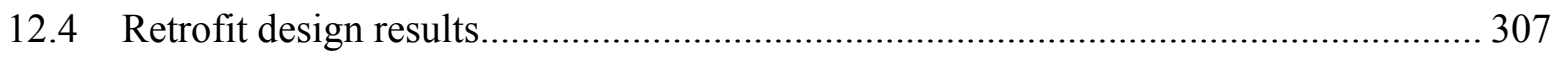

12.4.1 Upgrading the building envelope design is a small saver at a whole building stock scale $\quad 307$

12.4.2 Target large buildings for quick energy savings.............................................. 307

12.4.3 Energy efficient systems inside all commercial buildings are important ............. 307

12.4.4 Net ZEB Solution Set could better consider temporal energy match feasibility .. 308

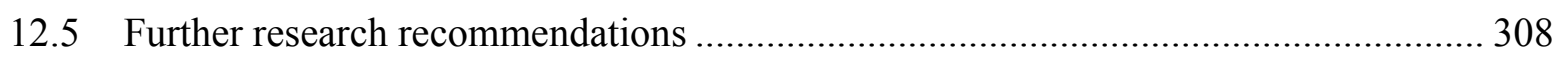

12.5.1 Comparing prototypical stock aggregation to calibrated stock aggregation......... 308

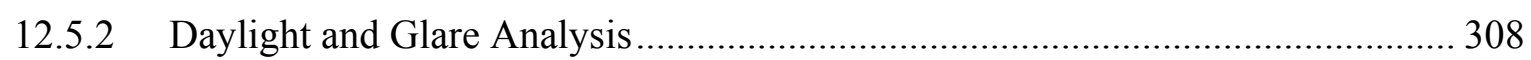

12.5.3 Grid interaction analysis with focus on generation variability ............................ 309

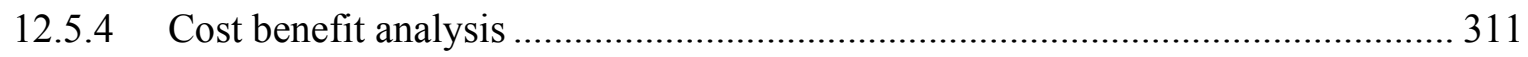

12.5.5 Future of New Zealand Building Standards........................................................ 311

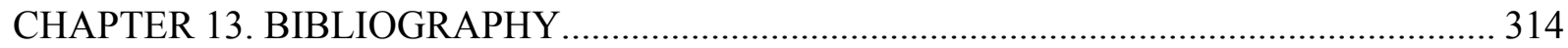

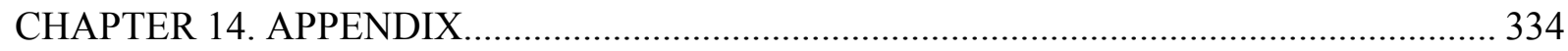

Appendix 14.1 New Zealand commercial building stock Net Zero Energy target ............... 334

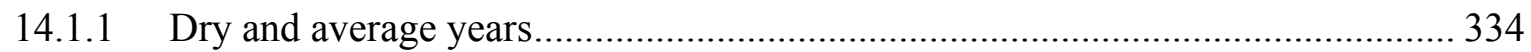

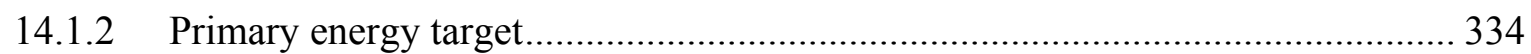

14.1.3 Commercial Sector Primary Energy Factor ........................................................ 337

Appendix 14.2 Lessons learned - survey building information and questions ..................... 337

Appendix 14.2a Characteristics of lessons learned - surveyed buildings .......................... 337

Appendix 14.2b Energy balances for lessons learned - surveyed buildings...................... 338

Appendix 14.2c Survey questionnaire for lessons learned by Net ZEB design teams ...... 339

Appendix 14.3 Impact of energy consumption on stock aggregation using floor area......... 340

14.3.1 Impact of different energy consumption in five percent of all floor area on the stock

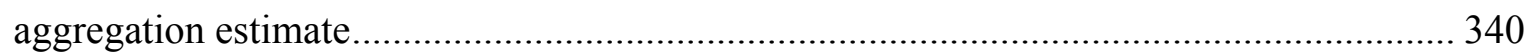

14.3.2 Impact of Lauder's small percentage of floor area on the stock aggregation estimate 341

Page $\mid x$ 
Appendix 14.4 Example of real building information used to create EnergyPlus model of 48

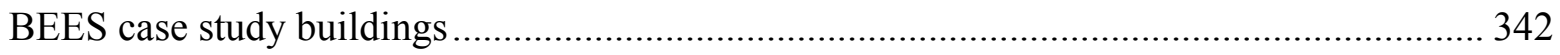

Appendix 14.5 Quality Assurance test modelling assumptions .......................................... 346

Appendix 14.6 Process for creating custom EnergyPlus weather files ................................ 349

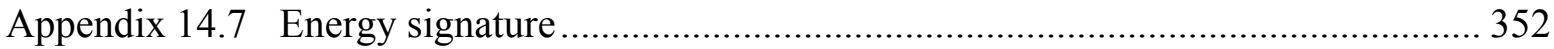

14.7.1 Worked example of creating calibration signatures............................................ 352

14.7.2 Worked example of creating characteristic signatures ....................................... 354

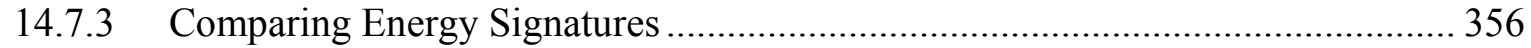

14.7.4 Method used to bin hourly data into temperature groups .................................... 357

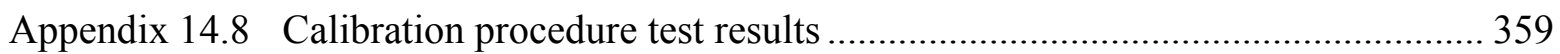

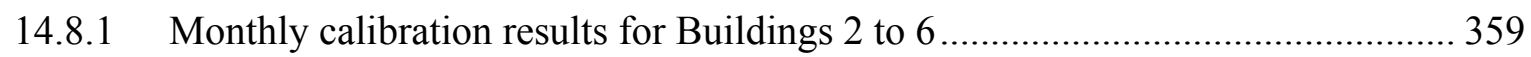

14.8.2 Average number of months that meet the monthly MBE and CV(RSME) across the

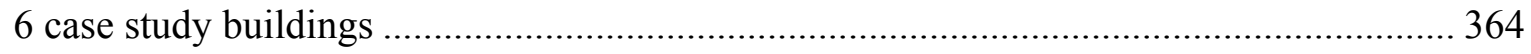

14.8.3 Average annual BE across the 6 case study buildings ....................................... 365

14.8.4 Calibration exercise participants' transcripts regarding the Template and Detailed

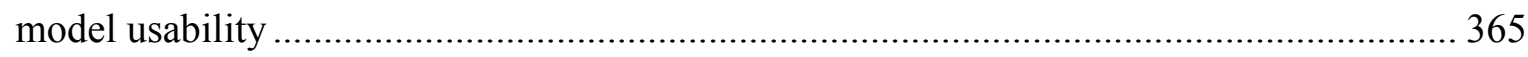

Appendix 14.9 Net ZEB retrofit solution set assumptions................................................. 368

14.9.1 Net ZEB solution set retrofit modelling assumptions and parameters ................. 368

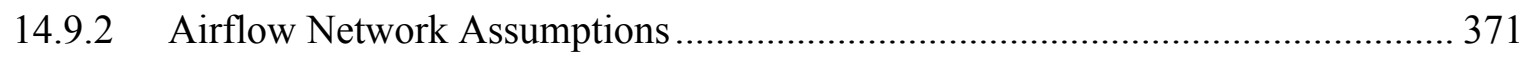

14.9.3 Original and retrofitted Lighting and Equipment Power Density for each of the 48

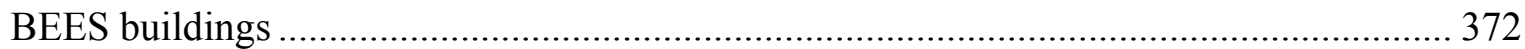

Appendix 14.10 Shading percentage calculation for Quality Assurance Test..................... 374

Appendix 14.11 Linux script for automated non-interactive batch-mode processing of Genopt 375

Appendix 14.12 Initial energy calibration results for 48 BEES building models ................. 376

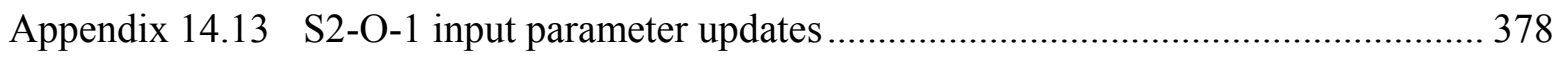

Appendix 14.14 Impact of available meter data on calibration results of 48 BEES building models $\quad 379$

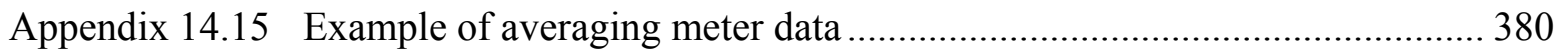

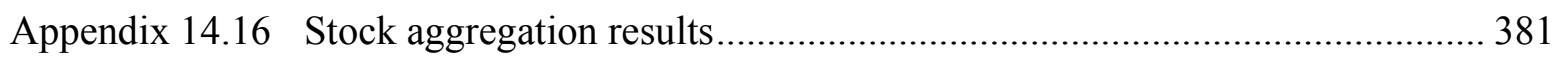

14.16.1 Example calculation of the stock aggregation procedure................................. 381

14.16.2 Current Commercial Building Stock .............................................................. 386

Page $\mid$ xi 
14.16.3 NZE Commercial Building Stock Without Onsite Renewables ....................... 386

14.16.4 NZE Commercial Building Stock With Onsite Renewables ............................. 386

14.16.5 Stock Aggregation results with ECMs removed for ranking of effectiveness.. 386

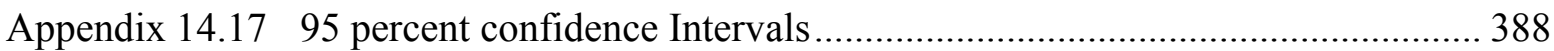

Appendix 14.18 Floor area correction of external studies commercial estimate .................. 390

Appendix 14.19 Heating and cooling degree days for Climate Region 3 ........................... 390

Appendix 14.20 Optimised passive design of retrofitted BEES building models ................ 390

Appendix 14.21 Final energy balance to primary energy balance ….................................... 391

Appendix 14.22 Building and climate average calculation procedure ................................ 392

Appendix 14.23 New Zealand and Commercial Sector energy reductions ......................... 393

Appendix 14.24 Net ZEB retrofits Top 6 most effective ECM effectiveness for different

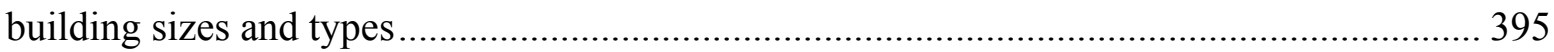

Appendix 14.25 Sensitivity Analysis calculations and results............................................ 398

14.25.1 Comparison of Stock Aggregation from iterations to original NZE .................. 398

14.25.2 Comparison of individual case study buildings to their original NZE.............. 399

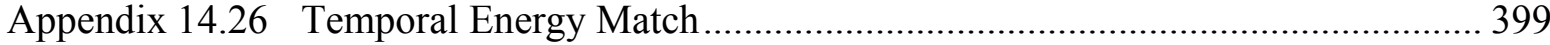

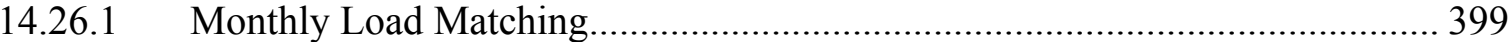

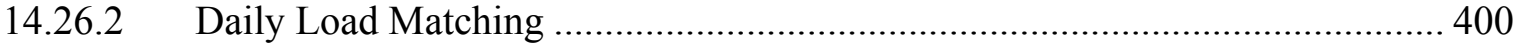

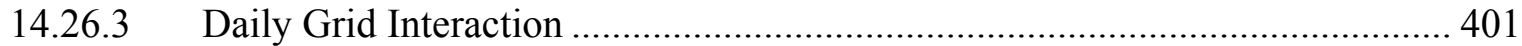

Appendix 14.27 Cost of conserved energy calculation and assumptions ............................ 404

Page | xii 


\section{LIST OF FIGURES}

Figure 1-1: Historical data and predicted future fuel production by fossil fuel type. Image adapted from (García-Olivares and Ballabrera-Poy 2015, p.590) ................................................ 8 Figure 1-2 Historical data and predicted future world population (United Nations Department of Economic and Social Affairs/Population Division 2015, p.2) ............................................... 8 Figure 1-3 : Energy consumed by New Zealand sectors with a split of the equivalent amount of indigenous and imported oil, and Tiwai Point Smelter electricity consumption highlighted. Image created using (Energy Information and Modelling Group 2012) and (Bennett 2007). ................ 9 Figure 1-4 : New Zealand GHG emissions from the energy sector for 2008-2012 (Kyoto Commitment Period One) and the 1990 emissions target year. Graph created using data from (Energy Information and Modelling Group 2012b).

Figure 1-5 : Impact of green retrofit on organisations. Figure adapted from (Charles Lockwood, Nagarajan, and Park 2008).

Figure 1-6 : Global GHG abatement cost curve for the Buildings sector. Figure adapted from

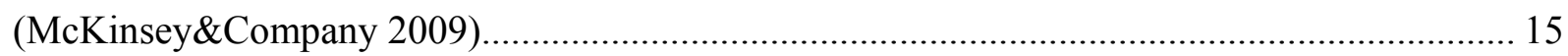

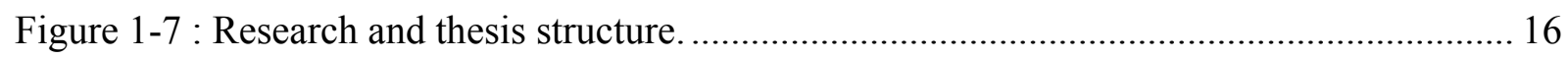

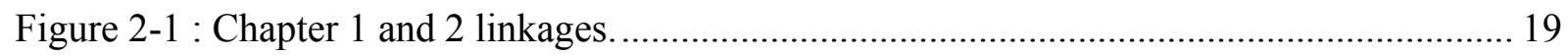

Figure 2-2 : The 'cradle to grave' concept. Figure adapted from (USDA Forest Service 2010;

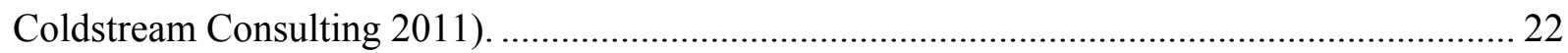

Figure 2-3 : Net ZEB design and definition principle (Sartori, Napolitano, and Voss 2012, p. 222; Sartori et al. 2010; Karsten Voss et al. 2010).

Figure 2-4 : Connection between buildings and energy grids. Figure adapted from (I. Sartori, et al., 2010, p.222).

Figure 2-5: Impact of including or excluding self-consumption in the net zero balance. Figure

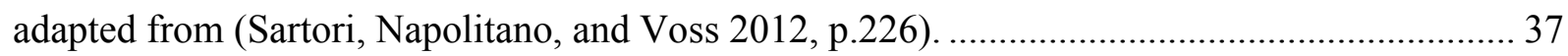

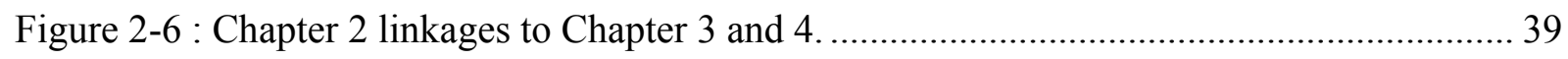

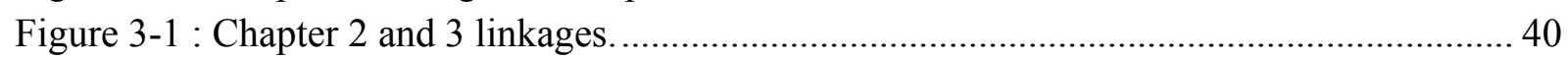

Figure 3-2 : New Zealand and its composition in the context of surrounding geography. Image modified from (Transpower 2013; Google 2013a) .................................................................. 41

Figure 3-3 : 2011 Split of all energy sources consumed by the different New Zealand sectors. Figure created using (Energy Information and Modelling Group 2012b; Bennett 2007)........... 41 Figure 3-4 : $2011 \mathrm{CO}_{2}$ Emissions split by Energy Sector. Figure created using (The Ministry of Economic Development 2013, pp.27-40) .......................................................................... 43

Figure 3-5 : Historical annual net (end-use) electricity generation by fuel type. Figure created using (Energy Information and Modelling Group 2012b, p.103) ............................................... 44 Figure 3-6 : Electricity generation split by generation source for 2011. Figure created using (Energy Information and Modelling Group 2012b, p.102).................................................. 45 Figure 3-7 : Split of energy sources consumed by the commercial sector for 2011. Figure created using (Energy Information and Modelling Group 2012b, pp.20-31)....................................... 45 
Figure 3-8 : Percentage of Commercial Office, Retail and Mixed floor area in different aged buildings. Figure created using (QV 2008).

Figure 3-9: Amount and percentage of floor area located in each region split by floor area size range. Figure created using (BEES 2013b; QV 2008).

Figure 3-10: Amount of floor area in buildings with a different number of storeys in each floor area size range. Figure created using ((BEES 2013b; QV 2008).

Figure 3-11: Amount of floor area in each region in buildings with different number of storey ranges. Figure created using (BEES 2013b; QV 2008).

Figure 3-12 : Percentage of buildings located in urban, suburban, rural areas. Figure created using (QV 2008).

Figure 3-13 : Geometrical relationship between the sun angle ranges, the shading obstruction angle $\gamma$, and the available direct solar radiation at different times of the day.

Figure 3-14 : Percentage of buildings in different floor area size ranges with different degrees of roof shading (Obstruction) from surrounding buildings in the North direction. Figure created using (BEES 2013b; QV 2008).

Figure 3-15 : Geometrical relationship between the sky angle $\theta$ and the obstruction angle $\gamma$, and the percentage of available daylight for differing degrees of sky angle and obstruction angles. Figure adapted from (C. F. Reinhart and LoVerso 2010)...

Figure 3-16: Percentage of buildings of different floor area size ranges with different degrees of shading (Obstruction) on the facades surrounding buildings in the north, south, east and west direction. Figure created using (BEES 2013b; QV 2008).

Figure 3-17 : Energy Types consumed by the commercial building stock (BEES 2013b; SavilleSmith and Fraser 2010). 56

Figure 3-18 : Average Annual Energy Use Intensity for different commercial building characteristics: Building use type, floor area size range, number of storeys, and building age

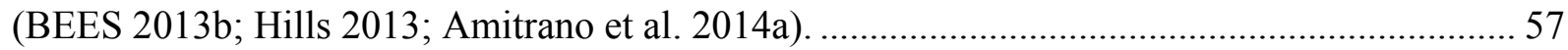

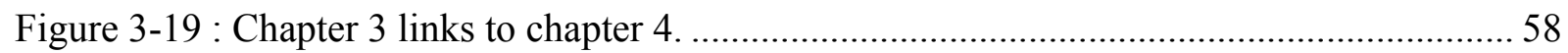

Figure 4-1: Links between chapters in Phase A: Net zero energy in New Zealand. ................... 59

Figure 4-2 : Each sector's allowable split of existing renewable electricity generation. ............ 69 Figure 4-3 : Renewable and non-renewable energy types and associated disadvantages

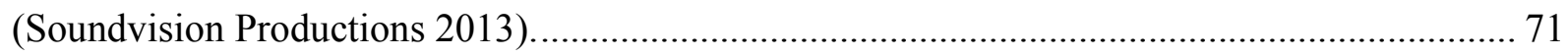

Figure 4-4 : Commercial building stock primary energy consumption breakdown for a dry and wet weather year and associated quantified NZE percentage reduction.................................... 72

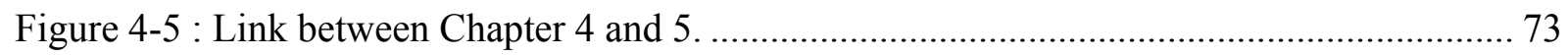

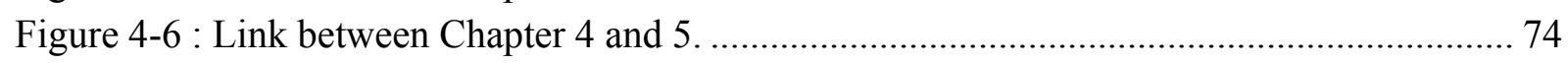

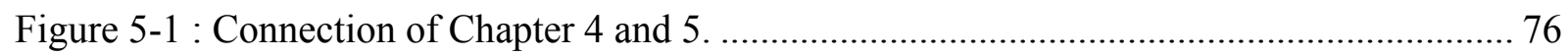

Figure 5-2 : Traditional climate classification using the Ecotect weather tool for Wellington.... 83

Figure 5-3 : Building climate classification simple thermal reference model geometry............. 85

Figure 5-4 : Building climate classification comfort zone ranges and the defined conditioning

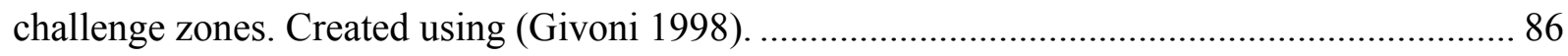


Figure 5-5 : Building climate results for Wellington.

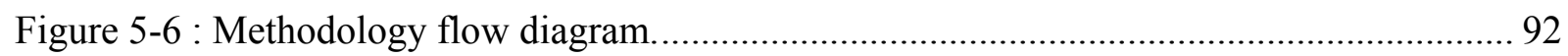

Figure 5-7 : Overarching methodology step 1 - sample of real buildings and a comparison of this thesis research method and previous studies method for representing the current building stock.

Figure 5-8 : Overarching methodology step 2 - modelling technique and a comparison of this thesis method and previous studies method for modelling existing buildings .....

Figure 5-9 : Overarching methodology step 3 - reliable commercial building stock model and a comparison of this thesis method and previous studies methods for building a reliable estimate of a building stocks energy consumption.

Figure 5-10 : Overarching methodology step 4 - Optimising the current commercial building stock energy consumption with an optimised set of ECMs

Figure 5-11 : Overarching methodology step 5 - selecting an appropriate set of Energy Conservation Measures.

Figure 5-12 : Overarching methodology step 6 - Optimised or Net Zero Energy commercial building stock.

Figure 5-13 : Overarching methodology step 7 - testing real building operation variations ..... 106

Figure 5-14 : Overarching methodology step 8 - testing the feasibility of moving towards Net

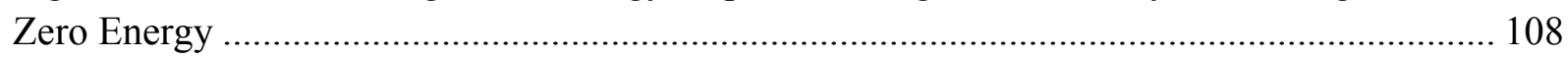

Figure 5-15 : Illustration of incremental costs for retrofitting to NZE. .................................... 109

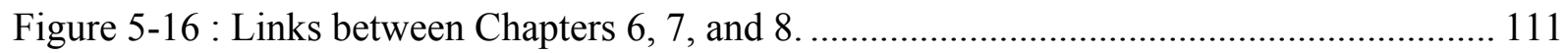

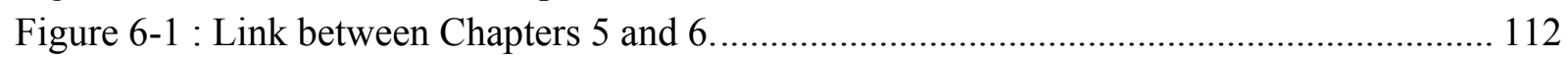

Figure 6-2 : Schematic of Bottom-up Model for Stock Aggregation. Adapted from (Moffat

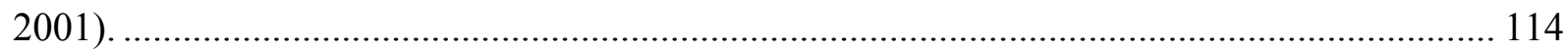

Figure 6-3 : Example of the Stock Aggregation calculation process....................................... 115

Figure 6-4 : BEES sample of 3,000 random commercial buildings (Amitrano et al. 2014a)..... 118

Figure 6-5 : Stock Aggregation real building archetypes.................................................... 119

Figure 6-6 : NZ climate zones and regions. Figure adapted from (U.S. Department of Energy

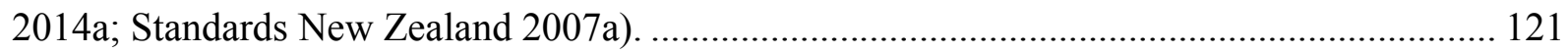

Figure 6-7 : Floor area aggregation decision tree........................................................ 123

Figure 6-8 : Summary of New Zealand's building climate aggregation (QV 2008; BEES 2013b).

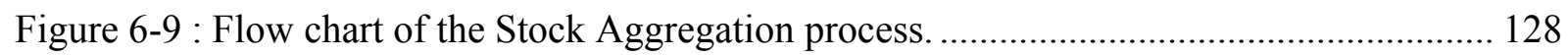

Figure 6-10: Link of chapter 6 to the previous and following chapters.................................... 134

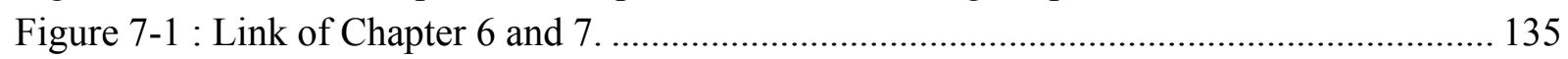

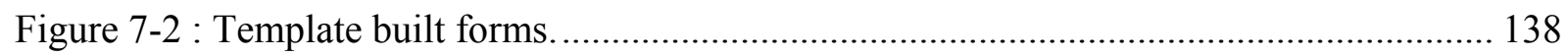

Figure 7-3 : Standardised base case model for the purposes of the QA tests........................... 143

Figure 7-4 : Rectangular shape floor plate to represent a narrow planned building.................. 144

Figure 7-5 : Narrow plan floor plate orientated in two directions. ........................................... 144

Figure 7-6 : US DOE energy models using a single WWR to represent a building's windows. 146 
Figure 7-7 : Coordinates that make up a single WWR.

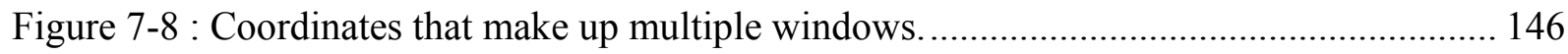

Figure 7-9 : Simplified WWR modelling technique versus Individual Window size and positioning

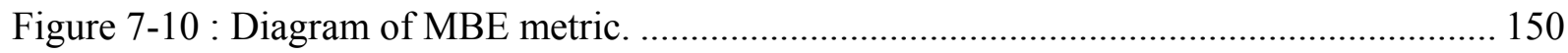

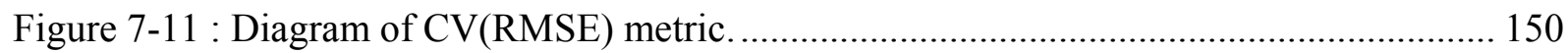

Figure 7-12: Diagram of the developed energy model calibration procedure.......................... 152

Figure 7-13 : Example of non-calibrated and calibrated monthly energy use (theoretical)....... 157

Figure 7-14 : Example individual heating and cooling calibration signatures. ......................... 160

Figure 7-15 : Example space conditioning calibration signature............................................ 160

Figure 7-16 : Example of a Characteristic signature library for heating and cooling set points. 162

Figure 7-17 : Example comparison between a calibration cooling signature and a cooling

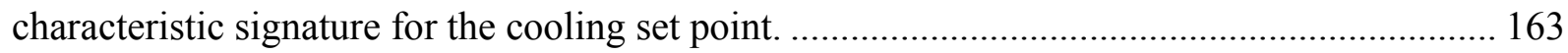

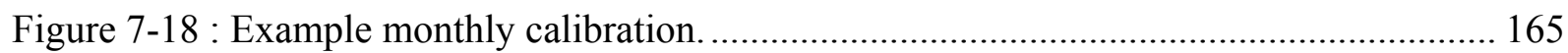

Figure 7-19 : Differences between a real building modelled using the template and detailed

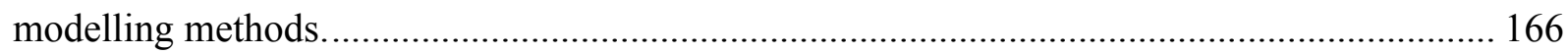

Figure 7-20 : Comparison of Building 1's monthly calibration results between initial and calibrated template and detailed models (refer to Appendix 14.10.1 for the other 5 buildings monthly calibration results).

Figure 7-21 : Number of months that meet the $\pm 5 \%$ MBE calibration limit for each building's initial and calibrated Template and Detailed models.

Figure 7-22 : Number of months that meet the $15 \%$ CV(RSME) calibration limit for each building's initial and calibrated Template and Detailed models.

Figure 7-23 : Annual MBE calibration result for each buildings initial and calibrated Template

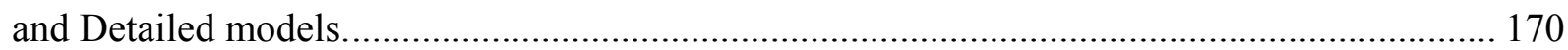

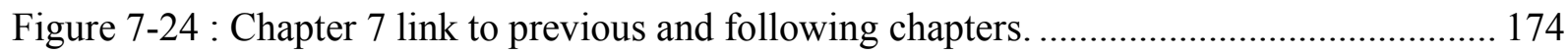

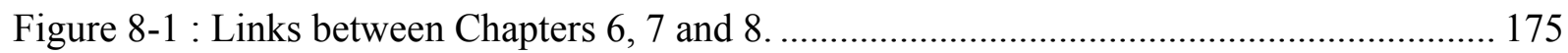

Figure 8-2 : Case study Net ZEB Solution Set for the Pixel Building. Table created using (Garde

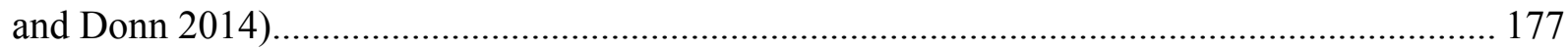

Figure 8-3 : Flow diagram of building design hierarchy for the creation of solution sets. ........ 184 Figure 8-4 : Applying Net ZEB Solution Sets to new or existing Buildings. Images from (Mihaly

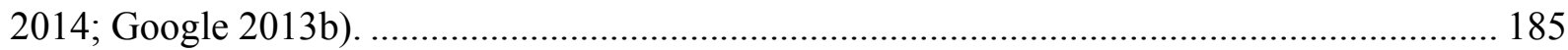

Figure 8-5 : Redesign of ENERPOS building for Christchurch using existing solution sets from other non-residential buildings in a similar climate and site context (Yip and Cory 2013)...... 188 Figure 8-6 : Thermal comfort results from the ENERPOS Redesign for Christchurch (Yip and Cory 2013)

Figure 8-7 : Energy Consumption results from the ENERPOS Redesign for Christchurch (Yip and Cory 2013).

Figure 8-8 : Building Climate Challenge breakdown for all New Zealand and Non-residential IEA Case Study Building Climate Locations. 
Figure 8-9 : Building Climate Potential breakdown for all New Zealand and Non-residential IEA

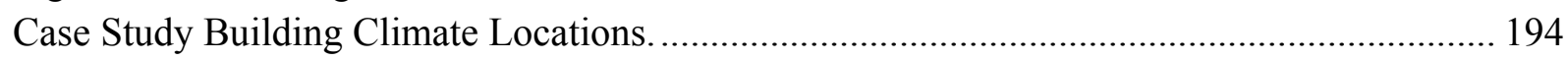
Figure 8-10 : A Non-residential Climate Comparison of Whole Building Solution Set

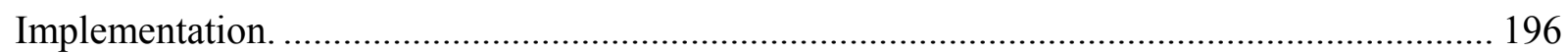

Figure 8-11 : A Non-residential Mixed Heating and Cooling Climate Comparison of Whole

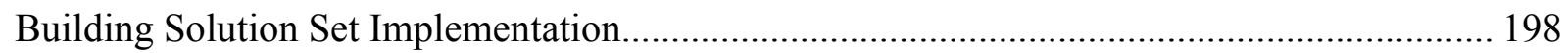
Figure 8-12 : A building size Comparison of Whole Building Solution Set Implementation in Non-residential Buildings in Mixed Heating and Cooling. ...................................................... 199

Figure 8-13 : External insulation added to existing building's construction. ............................... 205 Figure 8-14 : Combination of window type and solar shading used to provide need solar heat gains and daylight levels while excluding unwanted solar heat gains..................................... 206 Figure 8-15: Operable windows provide natural ventilation and cooling. ............................... 207 Figure 8-16 : TDD used in 1-2 storey buildings to provide daylight deep into a building floor plate. Diagram altered from (Inhabitat LLC 2014)................................................................ 208 Figure 8-17 : ECM's used to reduce lighting and equipment energy in the 48 BEES buildings.

Figure 8-18 : Heat pump increased output compared to input. Figure adapted from (Black

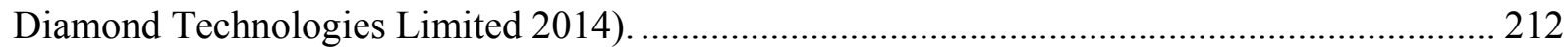
Figure 8-19 : Typical current COP ranges for heat pumps in either heating or cooling modes by

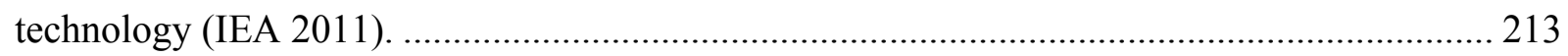

Figure 8-20 : Example Louvre system: Meridian building. Figure adapted from (New Zealand

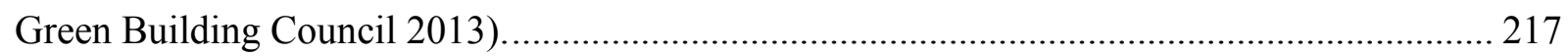

Figure 8-21 : Diagram of the calculation for window shading transmittance. ........................... 217

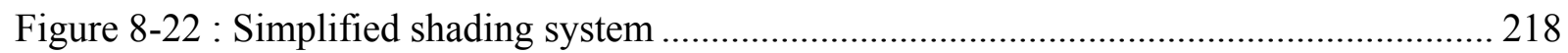

Figure 8-23 : A centred WWR and a WWR situated higher on the façade.............................. 219

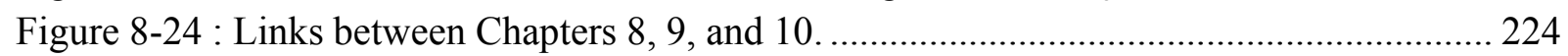

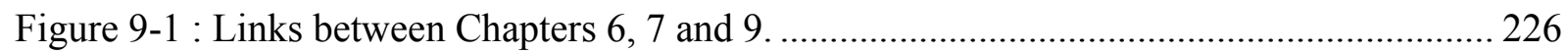

Figure 9-2 : Initial S2-O-1 model monthly calibration performance ........................................ 229

Figure 9-3 Continued : Examples of various differences between the initial energy model and

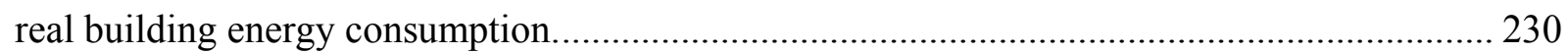

Figure 9-4 : S2-O-1 average hourly building load (excluding HVAC) comparison. ................. 231

Figure 9-5 : S2-O-1-V2 Library of Space conditioning energy signatures. ............................... 233

Figure 9-6 : Heating and cooling set point energy signature comparison for S2-O-1 .............. 233

Figure 9-7: Monthly energy comparison for various S2-O-1 iterations. .................................. 234

Figure 9-8 : Aggregated Energy Consumption for each Building Archetype. ............................ 241

Figure 9-9 : Split of Aggregated Energy Use for each building type, energy end-use, building

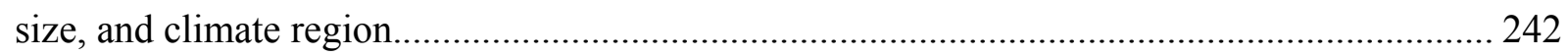

Figure 9-10 : Variation in energy consumption between the yearly meter data used by both estimates. 
Figure 9-11 : Energy Model - calibrated to real buildings monthly energy consumption profile

Figure 9-12 : External estimate - calculated using the real building monthly energy consumption, common and ineligible energy consumption. 250

Figure 9-13 : Section of Example Office building with common and ineligible areas. ............ 251

Figure 9-14 : Section of example Office building with no common and ineligible areas.......... 253

Figure 9-15: Comparison of External and Energy Models stock aggregation estimates........... 254

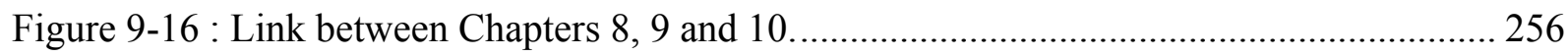

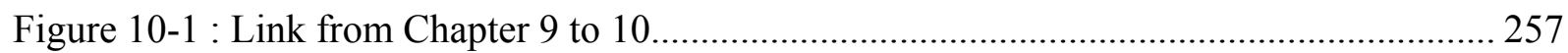

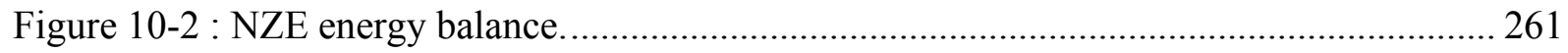

Figure 10-3 : Energy end-use breakdown for the current and NZE retrofit building stocks...... 262

Figure 10-4 : Energy reduction achieved in each energy end-use........................................ 263

Figure 10-5 : Proportion of total demand and net energy reductions contributed from each

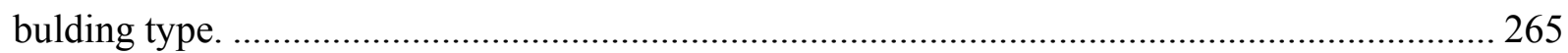

Figure 10-6 : Demand and Net reduction in energy calculated in each building type............... 266

Figure 10-7 : Demand and Net reduction in energy calculated in each building size. ............... 267

Figure 10-8 : Proportion of total demand and net energy reductions contributed from each

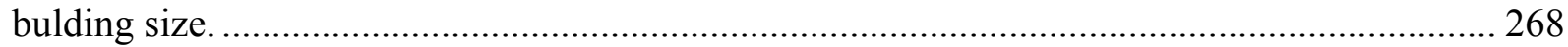

Figure 10-9 : Thermal comfort and energy consumption comparison for case study building S1R-2 which has no HVAC in the current building. ............................................................ 269

Figure 10-10 : Thermal comfort and energy consumption comparison for case study building S1R-4 which uses heating and cooling set points outside of comfort criteria.

Figure 10-11 : Thermal comfort and energy consumption comparison for case study building S4M-3 which uses set points that were within the comfort criteria.

Figure 10-12 : Ranking of most effective to least effective Energy Conservation Measures

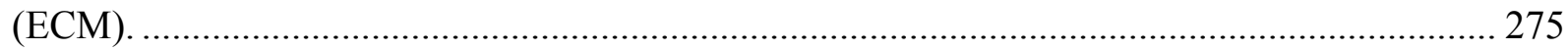

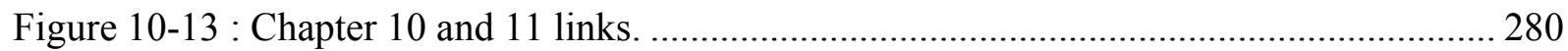

Figure 11-1 : Links of Chapters 8 and 10 to Chapter 11 ....................................................... 281

Figure 11-2 : Energy breakdown for the retrofit set point and three variant set point scenarios.284 Figure 11-3 : Thermal comfort and energy consumption comparison for S1-R-4 with a decreased set point deadband of $19-14^{\circ} \mathrm{C}$. 286

Figure 11-4 : Energy balance for NZE retrofit building stock with split system heat pumps

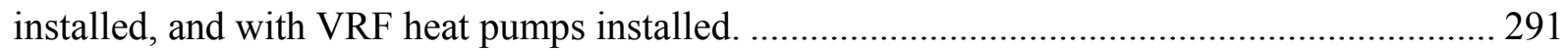

Figure 11-5 : Monthly energy demand and generation for a small and large building. ............. 294 Figure 11-6 : Winter weekday hourly energy profile for the small and large case study buildings.

Figure 11-7 : Summer weekday hourly energy profile for the small and large case study

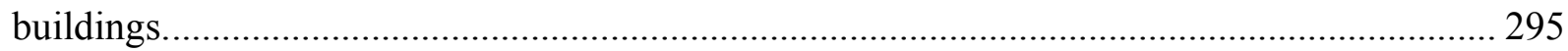

Figure 11-8 : Winter weekday energy demand patterns for the small and large case study buildings compared to the electrical grid demand. 297

Page | xviii 
Figure 11-9 : Summer weekday energy demand patterns for the small and large case study buildings compared to the electrical grid demand.

Figure 11-10 : Cost of conserving by retrofitting to NZE and generating energy with different non-renewable and renewable fuel sources. New generation plant cost information adapted from (U.S. Energy Information Administration 2014b). 300

Figure 11-11 : Illustration of Conducting the Symphony (Lovins et al. 2011, p198). Figure is based on actual renewables data and projected 2050 loadshapes for the US. .......................... 301

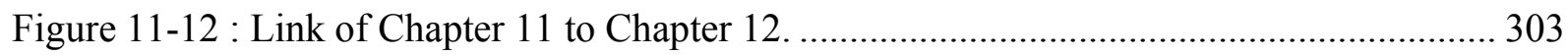

Figure 12-1 : Electrical generation capacity by generation source for 2011 by location. Figure created using (Energy Information and Modelling Group 2012b).

Figure 12-2: Variation of the Hydro water inflow that occurred in three different years (Concept Consulting Group 2003). 310

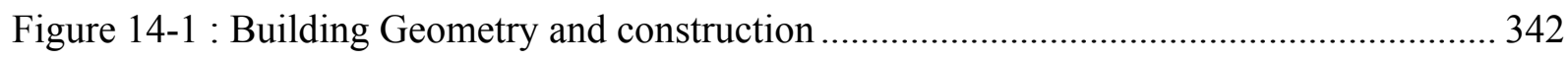

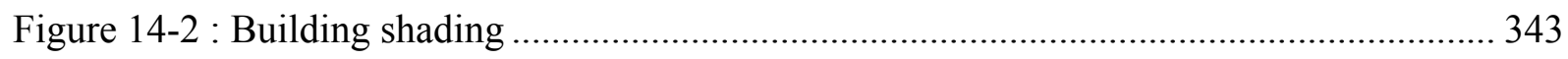

Figure 14-3 : Building load, HVAC, and heating and cooling set points .................................. 344

Figure 14-4 : Building load operation patterns and occupied hours ......................................... 345

Figure 14-5 : Variables and calculation for a calibration signature. Altered from (Bensouda

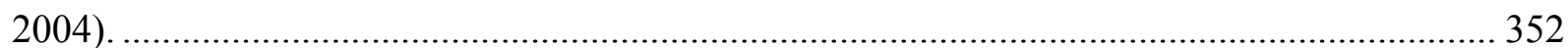

Figure 14-6 : Worked example of a calibration signature. Altered from (Bensouda 2004)...... 353

Figure 14-7 : Variables and calculation for a characteristic signature. Altered from (Bensouda

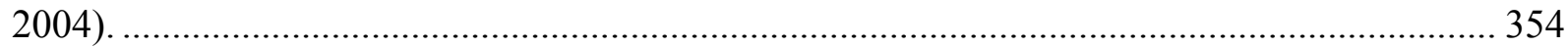

Figure 14-8 : Worked example of a calibration signature. Altered from (Bensouda 2004)...... 355

Figure 14-9 : Comparison of worked examples of energy signatures. Altered from (Bensouda

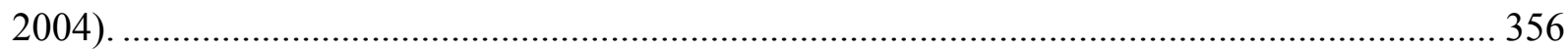

Figure 14-10 : Example of hourly data from monitoring and simulations ................................ 357

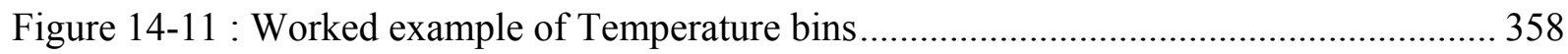

Figure 14-12 : Comparison of Building 2's monthly calibration results between initial and

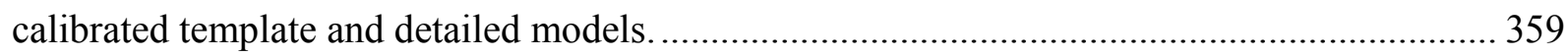

Figure 14-13 : Comparison of Building 3's monthly calibration results between initial and

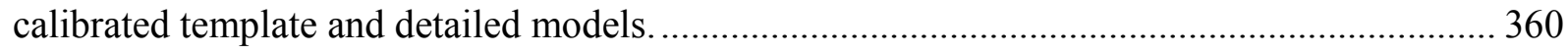

Figure 14-14 : Comparison of Building 4's monthly calibration results between initial and

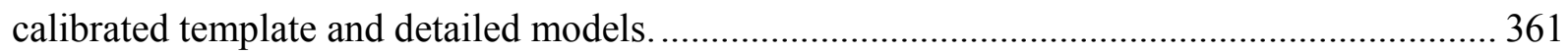

Figure 14-15 : Comparison of Building 5's monthly calibration results between initial and

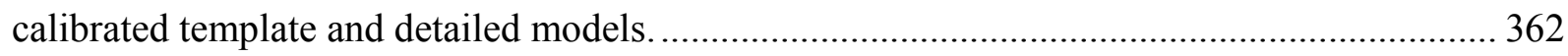

Figure 14-16 : Comparison of Building 6's monthly calibration results between initial and calibrated template and detailed models ........................................................................... 363

Figure 14-17 : Stock Aggregation for each Energy end-use found in separate spreadsheet sheets 386

Figure 14-18 : Thermal performance results for the current S1-R-4 and Net ZEB S1-R-4 energy models. 392

Page | xix 
Figure 14-19 : displays the total number of hours the S1-R-4 building is Too Cold, Comfortable,

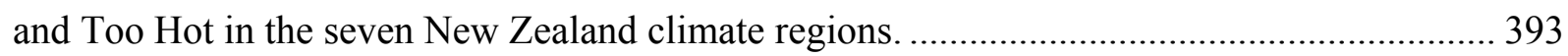

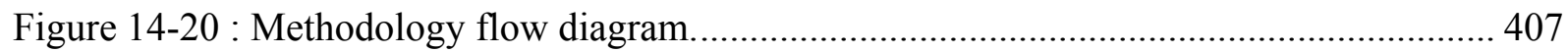

Figure 14-21 : Flow chart of the Stock Aggregation process............................................... 408

Page $\mid x x$ 


\section{LIST OF TABLES}

Table 1-1: Quantified emission limitation or reduction targets as contained in Annex B to the Kyoto Protocol. Table adapted from (UNFCCC 2008). ............................................................ 11 Table 2-1 : Impact of PV systems size for different Net ZEB metrics (Torcellini et al. 2006, p.6).

Table 2-2 : Advantages and Disadvantages of the four common Net ZEB metrics (Torcellini, et

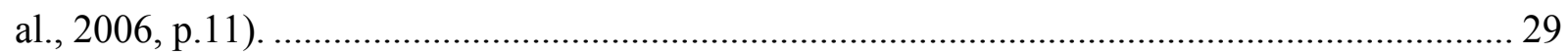

Table 3-1 : Commercial Building Stock Summary. Table created using (QV 2008).................. 46

Table 3-2 : Percentage of buildings in each floor area size range that are 1 to 2 storeys in height.

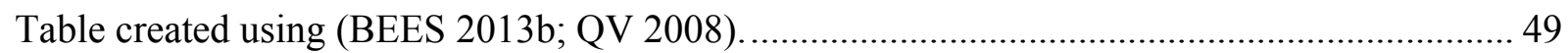

Table 4-1 : New Zealand's energy and commercial building stock attributes. ............................ 60

Table 5-1 : Three retrofit levels. Table adapted from (PNNL, PECI, and U.S. Department of

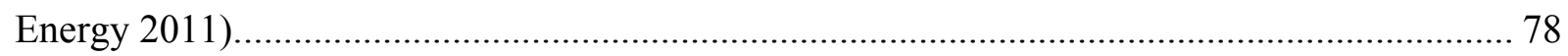

Table 5-2 : Commercial Building Use Type Categories. Table adapted from (Saville-Smith and

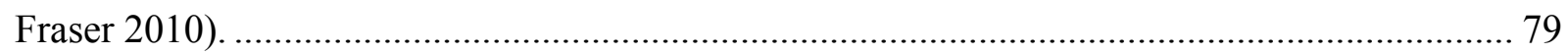

Table 5-3 : Comparison of non-residential climate classifications for 16 locations. Table adapted

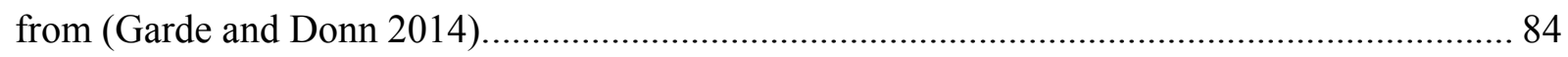

Table 6-1 : Type of information provided by the different data sets. Adapted from (Saville-Smith

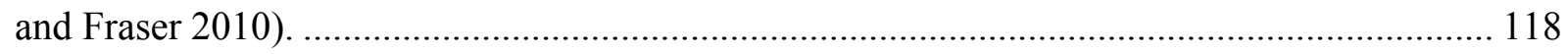

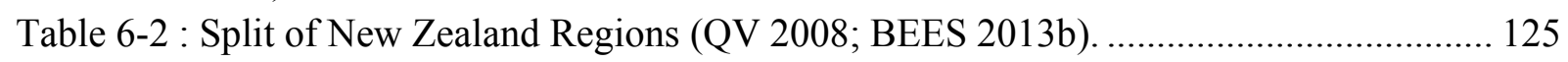

Table 6-3 : Climate indicators comparisons. ........................................................................... 126

Table 6-4 : Monitored - Amount of Building floor area in each commercial building type. (Cory

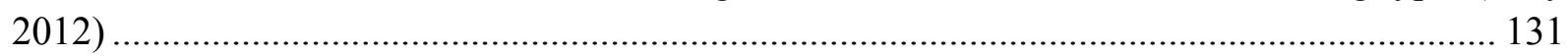

Table 6-5 : Web-search - Amount of Building floor area in each commercial building type. (Cory

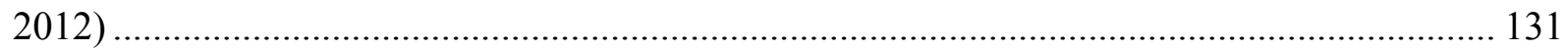

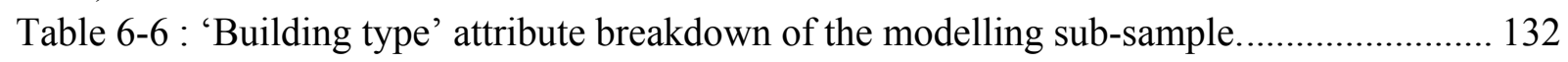

Table 6-7 : 'Number of floors' attribute breakdown of the modelling sub-sample.................... 132

Table 6-8 : 'Number of occupants' attribute breakdown of the modelling sub-sample............. 133

Table 6-9 : 'Number of occupied hours' attribute breakdown of the modelling sub-sample..... 133

Table 7-1 : Energy consumption differences of modelling a deep and narrow floor plate in two

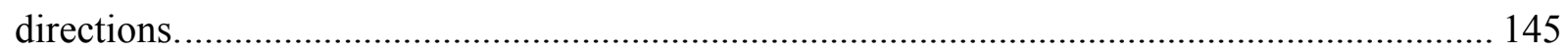

Table 7-2 : Percentage difference between individual window size and placement and single

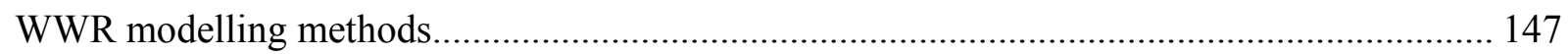

Table 7-3 : Acceptable Calibration Tolerances (ASHRAE 2002) .......................................... 151

Table 7-4 : Input parameters used to generate the set of characteristic signatures..................... 163

Table 8-1 - Comparison of Christchurch and Saint-Pierre climate variables. .......................... 187

Table 8-2 : Final Solution Set assessment. ......................................................................... 203

Table 8-3 : Efficacy comparison between the LED replacement lamps for conventional lamp technologies. Table adapted from (U.S. Department of Energy 2013b)................................. 209 
Table 8-4 : Office Equipment Inventory. Table adapted from (B. A. Thornton et al. 2009; Delmas and Donn 2013).

Table 8-5 : Energy consumption difference between Louvre and Shading Transmittance modelling methods.

Table 8-6 : Energy consumption differences of a single WWR window modelled in the centre of the wall and WWR modelled in a different position.

Table 8-7 : Building parameters being continuously optimised............................................ 221

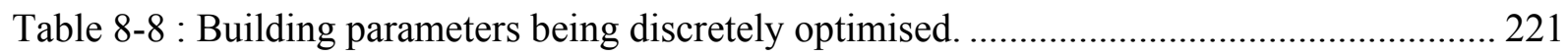

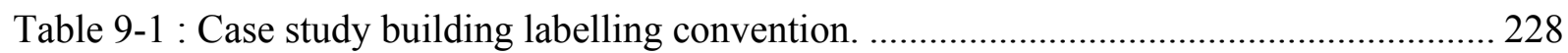

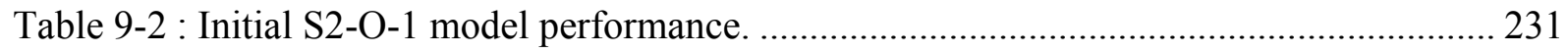

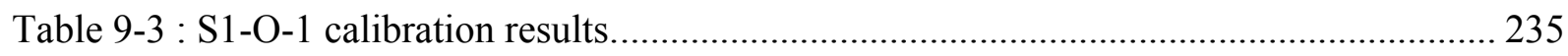

Table 9-4 : Energy model calibration results for buildings with 12 months of meter data. ....... 237

Table 9-5 : Energy model calibration results for buildings with less than 12 months of meter

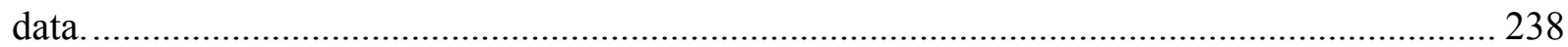

Table 9-6 : Energy model calibration results for buildings with no meter data, only hourly data

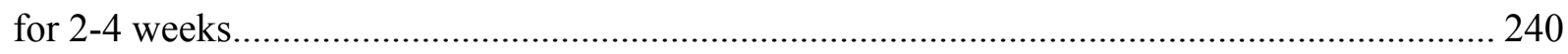

Table 9-7 : Commercial Sector and commercial building stock estimate comparison............... 243

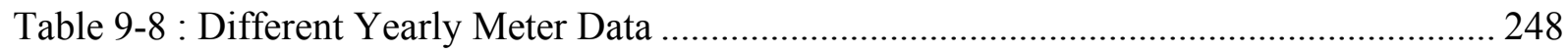

Table 9-9 : BEES Estimate - Example Commercial Office building.......................................... 251

Table 9-10 : Energy Model's estimate - Example Commercial Office building ........................ 252

Table 9-11 : BEES estimate - Example office building, without common or ineligible area.... 253

Table 9-12 : Energy Model's estimate - Example office building, without common or ineligible

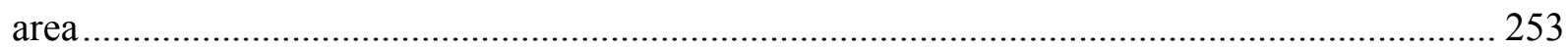

Table 10-1: New Zealand energy reductions achievable by retrofitting commercial building to NZE

Table 10-2: Commercial sector energy reductions achievable by retrofitting commercial building to NZE.

Table 10-3 : Net ZEB retrofits top 6 most effective ECMs effectiveness for different building sizes.

Table 10-4 : Net ZEB retrofits top 6 most effective ECMs effectiveness for different building

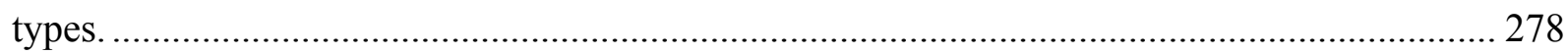

Table 11-1 : Impact of fresh air ventilation rate on the NZE retrofitted commercial building

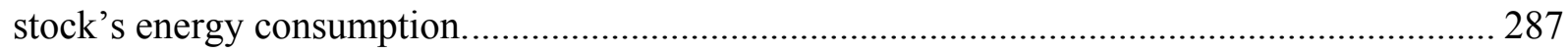

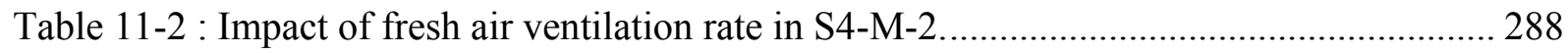

Table 11-3: Impact of office buildings task illuminance set point on the NZE retrofitted commercial building stock's energy consumption.

Table 11-4 : Impact of installing a split and variable refrigerant volume air-to-air heat pump systems in S5-O-4. 
Table 12-1 : comparison of the mandated energy efficiency requirements between NZS 4243, EPBD, ASHRAE 90.1, and IECC. Table created from (Standards New Zealand 2007a; Standards New Zealand 2007b; Laustsen 2008; Department for Communities and Local Government 2013).

Table 14-1 : split of renewable and non-renewable electricity generation observed in the past 5 years (Energy Information and Modelling Group 2012b)

Table 14-2: Final energy supply from the various generation sources in 2008 and their conversion to primary energy .

Table 14-3 : Calculated Renewable and Non-renewable electricity Primary Energy Factors ... 335 Table 14-4 : Commercial Sector Energy Consumption (Energy Information and Modelling

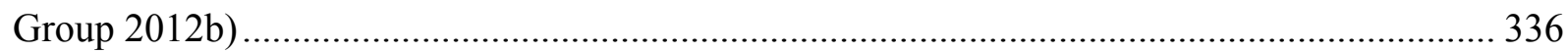

Table 14-5 : calculated primary energy consumption for the commercial sector....................... 337

Table 14-6 : Stock aggregation of with 5 percent of floor area having twice as high energy

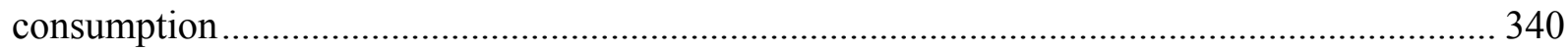

Table 14-7 : Stock aggregation with and without the Lauder/Queenstown climates split ......... 341 Table 14-8 : Material and construction properties (Materials: (Standards New Zealand 2006; Chartered Institution of Building Services Engineers 1999). Construction layers: (Spence 1998))

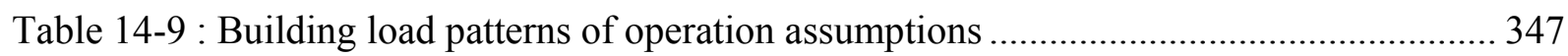

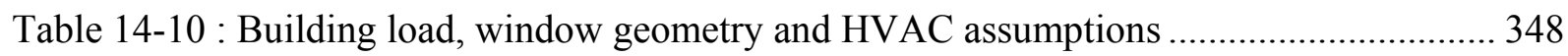

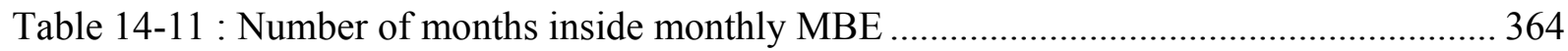

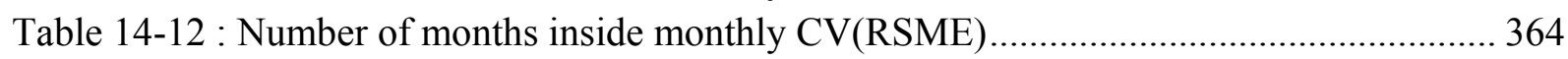

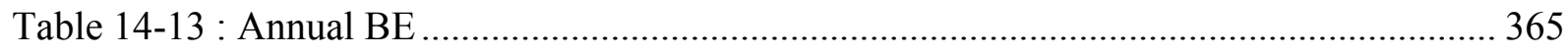

Table 14-14 - Retrofit ECM modelling inputs and associated assumptions............................... 368

Table 14-15 : Airflow Network modelling default assumptions (US DOE 2013b).................. 371

Table 14-16 : original and retrofitted Equipment Power Density, Lighting Power Density, and Miscellaneous Power Density for each of the 48 BEES buildings ........................................... 372

Table 14-17 : North façade: 9am shading transmittance calculation........................................ 374

Table 14-18 : North façade: $12 \mathrm{pm}$ shading transmittance calculation ..................................... 374

Table 14-19 : North façade: $3 \mathrm{pm}$ shading transmittance calculation ...................................... 375

Table 14-20: Initial energy model calibration evaluation of annual energy consumption ........ 376

Table 14-21 : S2-O-1 initial and calibrated input parameters................................................ 378

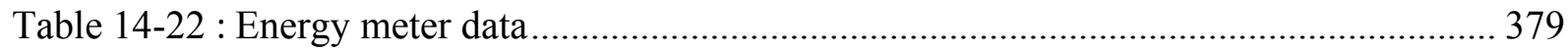

Table 14-23 : Example of averaging monthly meter data for calibration of buildings with no

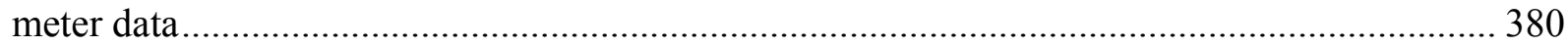

Table 14-24 : The 10 size group 1 energy model energy consumption results .......................... 381

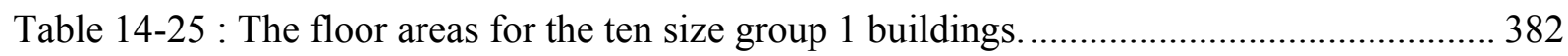

Table 14-26: The ten size group 1energy models' calculated EnPI....................................... 383

Table 14-27 : The calculated average EnPI for each building type in each climate region ........ 383 
Table 14-28 : The amount of each commercial building type's total floor area in each climate

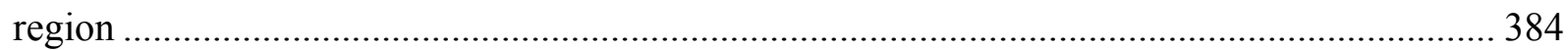

Table 14-29: The total energy consumption for each Size Group 1 building type's building stock in each climate region. 384

Table 14-30 : The aggregated energy consumption for each building type stock in Size group 1 385

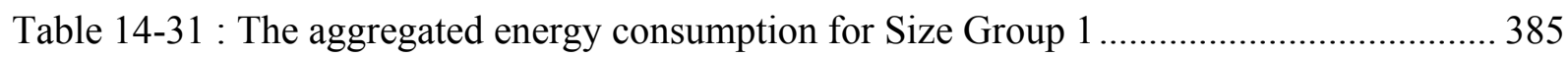

Table 14-32: Average EnPI for different building stock scenarios (type, size, climate)............ 388 Table 14-33 : Calculation of the 95\% confidence interval for different Building Stock Group

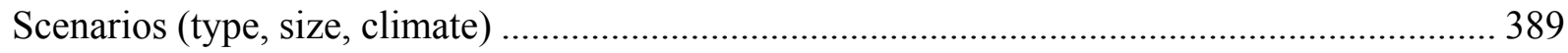

Table 14-34 : Difference in Heating and cooling degree days for Climate Region 3 between 2010 and 2012 (Caughey 2015)

Table 14-35 : The calculation for converting the final energy values to Primary energy for use in the NZE balance. 391

Table 14-36 : Energy consumption by fuel type for New Zealand and the commercial sector. 393 Table 14-37 : Stock aggregated energy consumption and generation, as well as existing grid renewable supply

Table 14-38 : Calculated surplus energy from retrofitting to NZE (with and without Onsite PV)

Table 14-39 : energy reductions achieved from retrofitting to NZE (with and without Onsite PV) 394

Table 14-40 : Reduction in energy consumption by implementing each ECM in different sized buildings 395

Table 14-41 : Ranking of most effective to least effective Energy Conservation Measures (ECMs) for each building size 396

Table 14-42 : Reduction in energy consumption by implementing each ECM in different building types 397

Table 14-43 : Ranking of most effective to least effective Energy Conservation Measures (ECM) for each building type

Table 14-44 : Monthly climate average energy demand and generation for S1-O-1 and S5-O-4

Table 14-45 : Weekday hourly climate average energy demand and generation for S1-O-1 in July and February

Table 14-46 : Weekday hourly climate average energy demand and generation for S5-O-4in July and February

Table 14-47 : Weekday hourly climate average net energy demand and generation for S1-O-1 and S5-O-4, and average weekday electrical grid demand in July 402 Table 14-48 - Weekday hourly climate average net energy demand and generation for S1-O-1 and S5-O-4, and average weekday electrical grid demand in February 403 
Table 14-49: Cost per square metre to construct 15 Net ZEBs and calculated incremental costs.

Table 14-50 : Median incremental cost per square metre to constructed Net ZEBs ................. 404

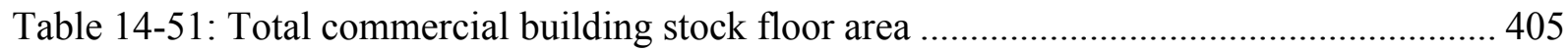

Table 14-52 : Incremental cost investment to retrofit the current commercial building stock to be

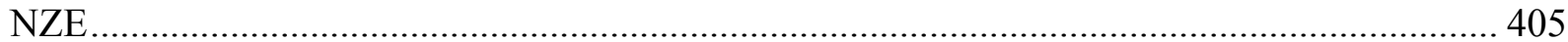

Table 14-53 : Discount rate and Amortization time assumptions............................................. 405

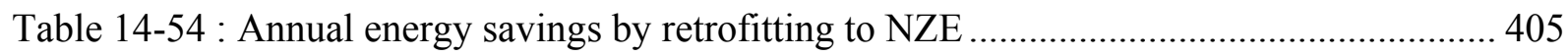

Table 14-55 : Cost of Conserved Energy of retrofitting to NZE ................................................ 405

Table 14-56 : Cost of Generating Energy for different generation plants (U.S. Energy

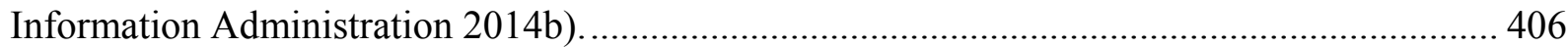




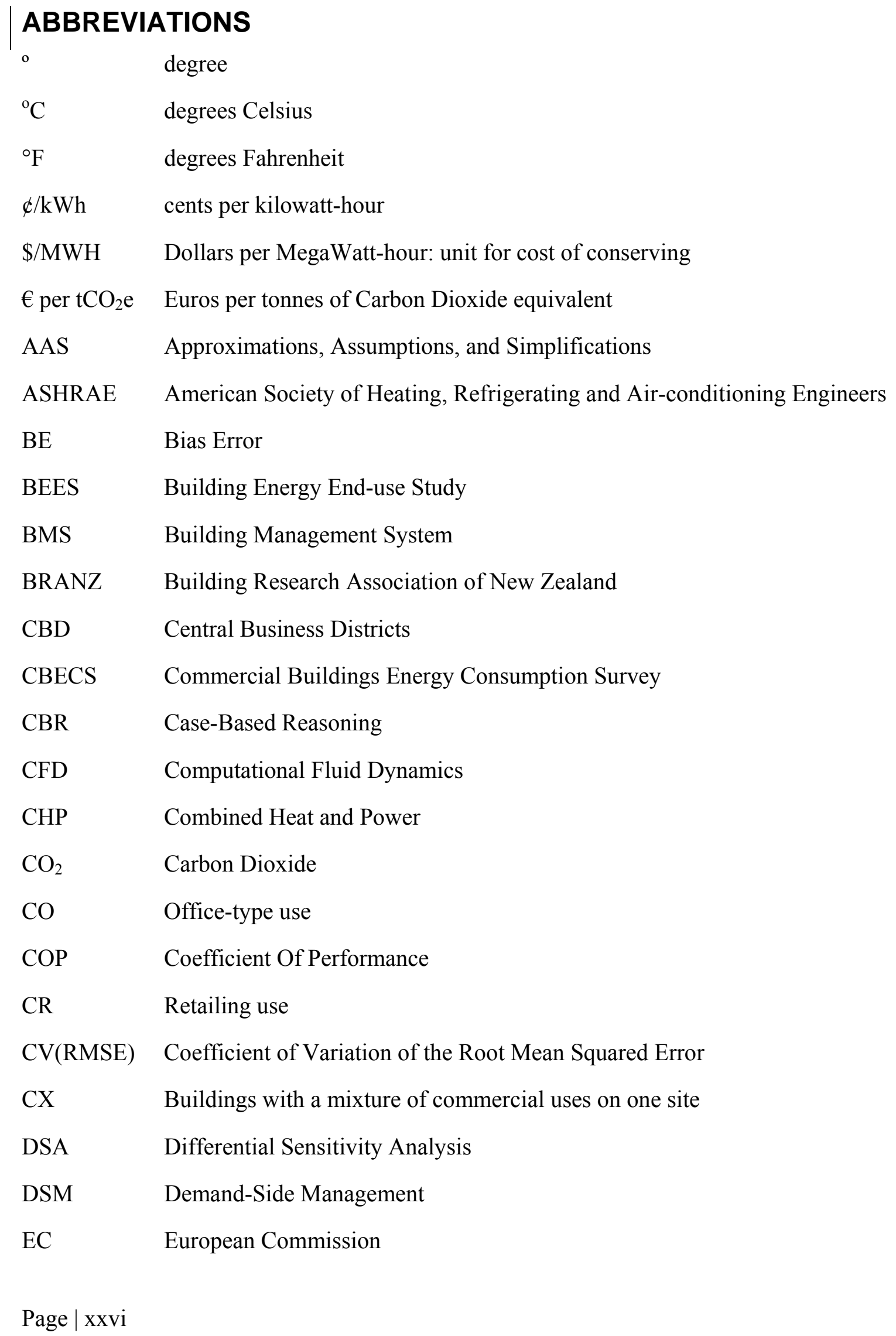


IEA ECBCS Energy Conservation in Buildings and Community Systems (IEA ECBCS joint research agreement)

ECM Energy Conservation Measure

$\mathrm{ECO}_{2} \quad$ Embodied Carbon Dioxide

EPBD Energy Performance of Buildings Directive (EPBD)

EPD Equipment Power Density

EnPI Energy Performance Indicator: measured in $\mathrm{kWh} / \mathrm{m}^{2}$.yr (All EnPIs presented and discussed in this thesis are in final energy)

EU European Union

GHG Greenhouse gas

GWh GigaWatt hour

HVAC Heating, Ventilation and Air-conditioning

IEA International Energy Agency

$\mathrm{km} \quad$ Kilometre

$\mathrm{ktCO}_{2} \quad$ kilo-tonnes of Carbon Dioxide

kt $\mathrm{CO}_{2}$-e kilo-tonnes of Carbon dioxide equivalent

kW kiloWatt

kWh kiloWatt-hours

kWp kiloWatt-peak

LCA Life Cycle Analysis

LED Light Emitting Diode

L/s.p Litres per second per person

$\mathrm{lm} / \mathrm{W} \quad$ Lumens per Watt: unit for lighting efficacy

LPD Lighting Power Density

lux lumens per square metre: Unit of Illuminance

$\mathrm{m}^{2} \quad$ square metres

$\mathrm{m}^{3} / \mathrm{s} \quad$ Metres cubed per second

Page | xxvii 


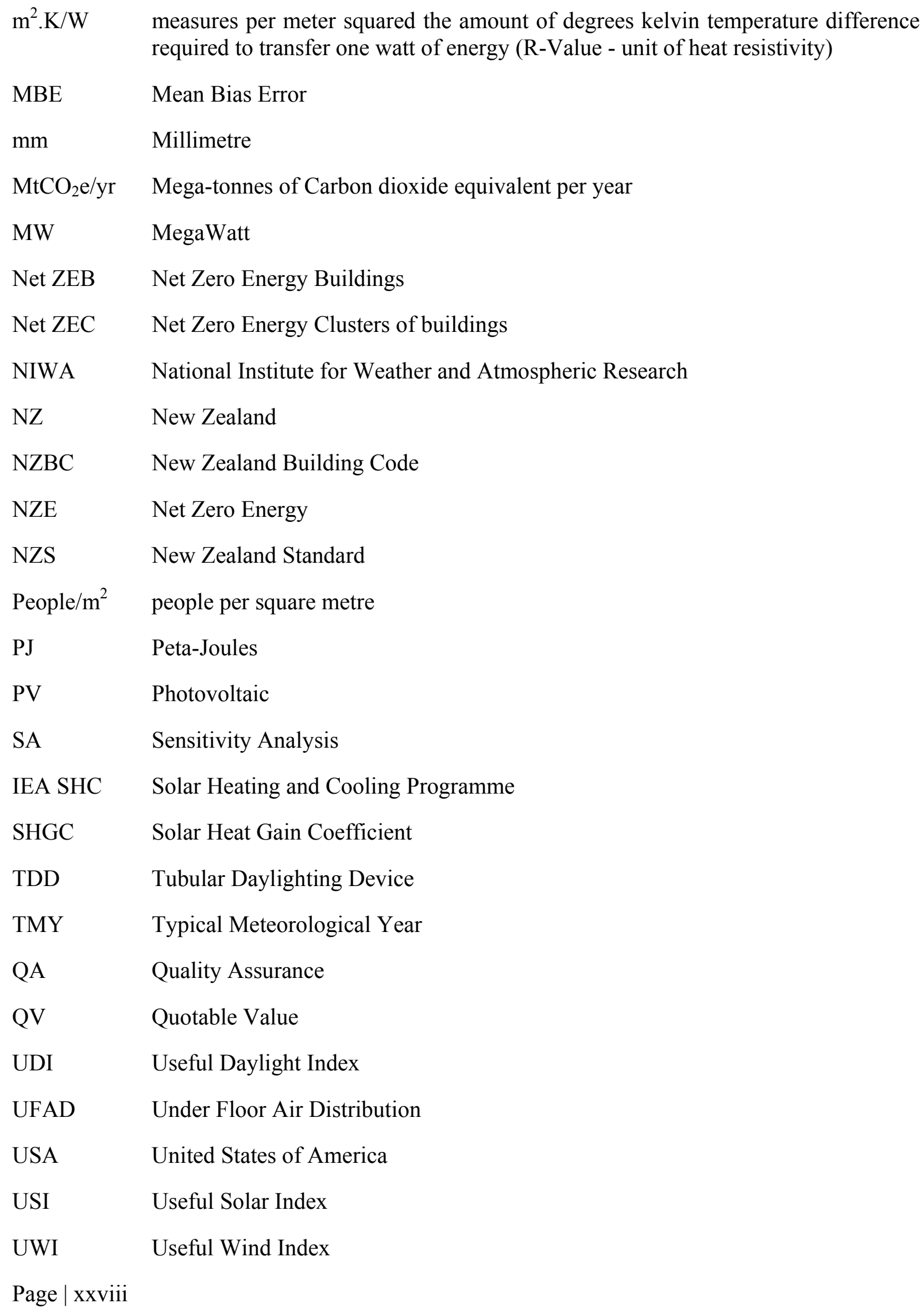


W

$\mathrm{W} / \mathrm{m}^{2}$

$\mathrm{W} / \mathrm{m}^{2}-\mathrm{K}$

WWR

ZEB
Watt

Watts per square metre of floor area

watts per metres squared kelvin (U-Value - unit of heat transfer)

Window to Wall Ratio

Zero Energy Building

Page | xxix 


\section{CHAPTER 1. INTRODUCTION}

It $\underline{I S}$ possible to convert the New Zealand commercial building stock to consume no energy on an annual basis. In doing so it has the potential to free up energy for use elsewhere in the economy and reduce climate change related greenhouse gas emissions. This thesis addresses the question of how to do this net zero energy conversion. It investigates how converting the current building stock to net zero energy has the potential to make a significant change to energy and emissions over a shorter time frame than what would be required to update building codes for new builds. The research was split into three Phases:

- Phase A - Net Zero Energy Buildings and New Zealand.

- Phase B - Procedure for testing Net Zero Energy founded on real building performance.

- Phase $\mathrm{C}$ - Stock aggregation of real building performance and converting towards Net Zero Energy.

The first Phase (A) establishes a definition for what is meant by net zero energy in this thesis. The net zero definition of having no worse than equal balance of generation versus consumption is the subject of considerable debate internationally. In order to construct a definition one needs to account for New Zealand's high renewable infrastructure and the nature of the building stock, as well as the fact that there is a national grid interconnecting all cities, buildings and generation.

The second Phase (B) develops a method to test net zero energy that is grounded in reality. It is the first study of its type that does not use hypothetical representations of a typical building. The second phase is a unique contribution to knowledge because unlike other countries' exercises which have assessed whole building stock upgrades based on hypothetical, average, typical representations of buildings; this study is based on a representative sample of real buildings.

The third Phase $(C)$ is the execution of the method to test the net zero energy definition in a robust way. It applies a series of tests to assess the robustness and reliability of the results, and concludes on the feasibility of moving towards net zero energy.

\subsection{Current building energy consumption}

The earth's climate is unequivocally warming up and it is extremely likely that human civilisation is the cause of climate change (Stocker, Dahe, and Plattner 2013). The largest and most well-known cause is through the use of non-renewable fossil fuel energy that accounts for approximately 80 percent of all energy supplied today (International Energy Agency 2012). Fossil fuels release Greenhouse Gas (GHG) emissions that pollute the atmosphere resulting in a gradual warming of the Earth's climate (Rajkovich, Diamond, \& Burke, 2010). Current discussions indicate that approximately 80 percent of fossil fuels will need to be left in the ground if excessive warming (more than $2^{\circ} \mathrm{C}$ ) is to be avoided (McGlade and Ekins 2015). Furthermore, the world's affordable fossil fuel supply is projected to be largely diminished in the

Page $\mid 1$ 
next 100 years (García-Olivares and Ballabrera-Poy 2015; Douthwaite 2012). To add to the problem, the global population is predicted to continue increasing (United Nations Department of Economic and Social Affairs/Population Division 2015). A larger population means an increase in energy demand and therefore, a reduction of energy demand is needed to provide worldwide energy security.

Over 40 percent of global energy demand and approximately 35-40 percent of all energy-related $\mathrm{CO}_{2}$ emissions result from energy use in buildings (IPCC 2007a). Emissions account for a lower proportion of energy use because not all energy sources have associated $\mathrm{CO}_{2}$ emissions. It is projected that energy and emissions from buildings are going to continue to grow over the next 25 years (U.S. Green Building Council 2007; Lockwood, Nagarajan, and Park 2008). While the building sector creates a large energy problem it also presents a large opportunity for energy savings.

There are many building initiatives which target saving energy in buildings, such as LEED, PassivHaus, and Green Star. Net Zero Energy Buildings (Net ZEB) are promising because not only do they strive to reduce demand for energy, they also strive to offset their residual energy consumption with non- $\mathrm{CO}_{2}$ emitting renewable energy generation technologies (full definition detailed in Chapter 2).

While future building standards, such as those proposed through the European Union (EU), will implement Net ZEBs as the mainstream (European Commission 2008), the fact remains that the current problem was created from existing buildings. Therefore, a critical pathway to reach targets for energy efficiency in the existing building stock would be through reductions in their energy consumption (GBPN 2013). Existing buildings will need maintenance during their life time. If redesigned well during the maintenance process, it could mean net zero energy could be achieved much faster than waiting for these buildings to be demolished and built new under a net zero energy building standard.

\subsection{Research aim, hypothesis and scope}

All international energy infrastructures have energy produced/consumed from non-renewable fossil fuel sources. It is the non-renewable fossil fuel energy sources which emit $\mathrm{CO}_{2}$, increase the rate of climate change and are at risk of depletion. As an abundant fossil fuel supply is not native to every country, the energy dependency of countries that rely on them is continuing to increase. To negate the need for non-renewable fossil fuel energy use in buildings it is proposed that NZE retrofit of a current stock of buildings can reduce energy consumption and $\mathrm{CO}_{2}$ emissions to improve energy security and reduce climate change inducing $\mathrm{CO}_{2}$ emissions.

Current publications and international policy actions focus on individual new building design. They do not propose mandatory changes to existing buildings. In addition, publications and 
policy do not assess and base their calculations on the real performance of existing buildings (ASHRAE 2013; IEA-SHC 2013c). Instead, they use theoretical buildings which may not be representative of how real buildings operate (Deru et al. 2007; Heo, Choudhary, and Augenbroe 2012). This thesis aims to establish a method, founded on real performance data, for lowering the energy use of the entire stock of existing buildings in a country (New Zealand) to a sufficient level that the residual energy demand can be supplied with renewable energies.

The building sector is composed of a number of different building types/uses. The two main types/uses of buildings are residential and non-residential. In this thesis the focus is on nonresidential buildings, in particular, commercial office, retail and mixed use buildings. Residential and non-residential building sectors worldwide and in New Zealand consume similar order of magnitude of energy. Non-residential buildings are less researched and therefore are the topic of this thesis.

\subsubsection{Research Hypothesis}

The research objective was to test the two part hypothesis that:

1) a method founded on real building performance can be used to base the assessment of NZE on reality; and (using this method)

2) it is feasible to convert the New Zealand commercial building stock to be net zero energy.

\subsubsection{Real buildings, their performance, and existing Net ZEB strategies}

The research presented in this thesis fits in the wider context and builds on the work undertaken in two external research projects. As well, the research in this thesis was made significantly more valuable as a result of the information provided by the two external research projects which enabled the results to be grounded in reality using real building information. The two studies were the BEES project and the IEA research Task 40/Annex 52 on Net ZEBs. These studies enhanced this thesis as they provided a means for founding the research on real buildings and real data.

A sample of real buildings was used as a foundation for basing the move to NZE on real buildings. The sample of real buildings was obtained with the support of BEES. The purpose of BEES was to increase knowledge on energy use patterns for the New Zealand non-residential building stock. The research undertaken in this thesis builds on the research of the BEES project by increasing the knowledge on potential energy efficiency upgrade opportunities for the current commercial building stock. The BEES programme was used to provide a greater understanding of how, why, where and when energy and water were used in New Zealand's non-residential buildings based on the interpretation of real data (Isaacs et al. 2009). This real data was collected by the BEES programme through the monitoring of temperature, humidity, light levels, $\mathrm{CO}_{2}$ levels, occupant and equipment schedules, internal loads, and fuel 
consumption within selected premises. This monitored data along with in-depth as-built and building operation information on real commercial buildings was used in this thesis. The information enabled the methodology to be founded on a representative sample of real buildings rather than through theoretical models. Due to this thesis falling inside the scope of the BEES project, the research is focused on a sub-set of the commercial sector's building stock. The sub-set is office, retail and mixed office and retail buildings. The research does not have analysis on the other commercial sector building types such as health, education, hotel and some industrial buildings. However, if the research was proven to be successful it could be applied to the other building types if survey data was available.

A lack of information on Net ZEBs prompted an international research task from 2007-2013 on Net ZEBs. The research task included the participation of seventy building scientists and architects from eighteen different countries. "What was missing was a clear definition and international agreement on the measures of building performance that could inform "zero energy" building policies (IEA-SHC 2013c)." The main objective of the research task was to develop a common understanding on the Net ZEB method of building. One of the actions undertaken to reach a common and universal understanding on the topic, was to use existing netzero, near net-zero and very low energy buildings to investigate whole building net-zero design and technology solution sets (IEA-SHC 2013b). The move to NZE in this thesis is founded on these real existing Net ZEB solution sets. Net ZEB solution sets were obtained from the IEA Task 40 case study buildings. Task 40 supplied data on the real design and technologies implemented in existing Net ZEBs from around the world (Garde and Donn 2014; Garde et al. 2015). The research in this thesis builds on the IEA project by implementing a means of using their Net ZEB solution sets to select an appropriate set of passive design techniques, energy efficient technologies and renewable energy technologies in future building and design projects. This thesis used the Net ZEB solution sets to select appropriate measures to convert the current building stock in New Zealand to be net zero energy.

\subsection{Significance of the research objectives}

It became evident when looking at international policy and research programmes (European Commission 2008; IEA-SHC 2013c) undertaken thus far about Net ZEBs that they focus on individual buildings rather than large groups or communities of buildings. Assessing potential for converting existing buildings is also important as, to date, most energy efficiency building standards have been applied only to new buildings. The problem of high energy use in existing buildings has not been well addressed and standards have played a minimal role. The assessment of retrofitting existing commercial buildings was significant as they are deemed a harder task than building new Net ZEBs (Levine et al. 2012), and due to the nature of commercial buildings, they are more complicated to retrofit to be Net ZEBs than residential buildings. Commercial buildings as a group also consume a similar quantity of energy as residential buildings making their energy use as important as residential building energy use (Johansson et al. 2012).

Page $\mid 4$ 


\subsubsection{Retrofitting the New Zealand commercial building stock to be Net Zero Energy}

The research performed in this thesis had the primary objective of testing a move to net one hundred percent renewable energy consumption across the entire New Zealand commercial building stock. This was significant because it was not just for individual new buildings. The methodology used in this nation-wide refurbishment research enabled the calculation of the potential for a move to NZE, much faster than the approach currently proposed by the European Union (EU) which focuses on new builds. The methodology enables a systematic examination of the feasibility for a 'leap forward' in lowering $\mathrm{CO}_{2}$ emissions globally. It also has the potential to enable national energy policy makers and the energy industry to study the effect of changes in the current energy efficiency building standards. Denmark is planning to undertake one such move with an aim to have 100 percent renewable energy by 2050 (Ministry of Climate, Energy and Building Design and Layout 2013). Denmark is working on a nationwide system to manage the 100 percent renewable energy grid and all its buildings. Denmark's work highlights the significance of the research undertaken in this thesis: "energy demand in both existing and new buildings has to be decreased compared to the present level. All recent plans and proposals for how and when to reach political goals of transforming the existing fossil fuel-based energy system into a 100 per cent renewable energy system or similar include energy conservation in buildings as an important element"(Lund 2013, p.8). This is echoed in recent work studying a high renewable energy infrastructure in the United States of America (USA) (Lovins et al. 2011).

\subsubsection{National picture based on calibrated energy simulation models}

The second primary objective was to ground the assessment to reality by using a national picture based on calibrated energy simulation models that were founded on real building performance. This was important as it created a picture grounded in the real performance of the current building stock, rather than a theoretical picture of building operation and usage patterns. The significance of this was that the models used were not based on opinions, experiences or guesses. Instead, they were built to match the real buildings' as-built construction, loads and operation. Whole-building simulation models have been in use for approximately 30 years and researchers use such tools to represent large portions of the building stock (Griffith et al. 2008). However, most studies do not use energy models matched to real building performance data. Computer simulations are only as useful as the accuracy of the simulations. It is too easy in speculative studies, to create base cases using modelling assumptions that are not based on fact. This is due to a general lack of complete, coherent measured data and information on the buildings (Raftery, Keane, and Costa 2009). These base cases are prototypical and could be considered unreliable and inaccurate. This theoretical modelling practice has created the perception that 'every energy model is wrong' (Overbey 2014). However, energy models, especially those built to match real building performance, are indispensable because they allow modellers to understand, compare and forecast energy consumption in buildings (Overbey 2014).

Page $\mid 5$ 


\subsubsection{National net zero energy definition}

A secondary objective was to formulate a working definition for a NZE commercial building stock. This was significant as currently Net ZEB definitions are intended for individual buildings and not a whole building stock. The definition in this thesis was developed to provide a means of testing and measuring the balance between energy consumed and energy generated before the New Zealand building stock can be considered NZE. However, it also has the potential to enable other countries' energy policy makers to establish a NZE target for a change in their current building stocks. Furthermore, the work performed in this thesis gives architects and the construction industry a quantifiable target of the necessary energy balance an existing building design needs to achieve before it can be considered a Net ZEB.

Another unique feature of this study was its equal focus on the rural, suburban and urban environment and its consideration of the energy reduction and generation potential of clusters/communities of buildings. Fundamental to this focus was the connection of each building to an energy transmission grid. The national grid provides an interesting option for the refurbishment of individual buildings and groups of buildings to be NZE. The focus produced a study on Net ZEBs and Net Zero Energy Clusters/Communities of buildings (Net ZEC) which share renewable resources by both contributing energy to, as well as taking from, the existing grid.

\subsubsection{National building retrofit design drawn from working Net ZEB examples}

Another secondary objective was to further ground the research on real buildings by adopting energy lowering passive design, energy efficient, and renewable energy technologies implemented in real Net ZEBs worldwide. Instead of testing a randomly selected combination of design techniques and technologies, this thesis systematically identified the most appropriate Energy Conservation Measures (ECM) from those that had already been implemented and proven to work in existing Net ZEBs from around the world. This was important because in an ideal condition there is an almost endless number of ECMs that could potentially be used to reduce the energy consumed in a building. This method of using existing ECMs can enable national building energy efficiency policy makers to consider regulating the whole building design, which is essential as some building standards are limited. For example, standards in New Zealand only regulate the thermal resistivity of a building's envelope and the lighting power density in a building (Department of Building and Housing 2011).

\subsection{Benefits of converting to net zero energy}

The conversion of buildings to NZE was assessed as a mass retrofit programme. The retrofit was proposed as a faster route to creating a NZE New Zealand building stock compared to mandating new buildings to be Net ZEBs. Net ZEBs are a method to make a net change nationally that moves towards energy self-sufficiency. The buildings offset their own energy demand with renewable energy generation and may have the potential to eventually offset more energy than they consume.

Page $\mid 6$ 
Net ZEBs are an attractive concept as it is possible that they can reduce one of the main global energy consumers: buildings (U.S. Energy Information Administration 2013b; IPCC 2007a). NZE and energy self-sufficiency are somewhat related. They are related because Net ZEBs mandate renewable energy consumption, and an energy self-sufficient building or nation is achieved if all energy consumption is generated from indigenous energy supply. As a consequence, if a nation needs to import fuels for its successful operation it is not energy selfsufficient. Fossil fuels make up the majority of imported and exported energy globally (U.S. Energy Information Administration 2013b). If fossil fuels did not need to be used for generating electricity or used as a fuel for transport, each country could instead consume the amount of energy it can generate by renewable or natural energies. This would create an energy selfsufficient nation. Energy self-sufficiency can also be a response to sustainable development. Sustainable development is development that meets the need for the present without compromising the ability of future generations to meet their own needs (Brundtland 1987). Thus, if nations create paths that lead to energy self-sufficiency, they are developing a future that does not compromise the ability of future generations. This includes a reduction in GHG emissions. The reduction in polluting energy generating sources can lower the amount of GHG emissions being released into the atmosphere. When the world's fossil fuel supply begins to decline, independence from fossil fuels will become vital to a nation's energy supply and economy.

\subsubsection{A global energy crisis}

The total global energy consumption in 2011 was 149,628 Billion kilowatt-hours (kWh) (U.S. Energy Information Administration 2013b). Non-renewable fossil fuel energy accounts for approximately 80 percent of all energy supplied (International Energy Agency 2012). Figure 1-1 illustrates the prediction that the supplies will peak in the next 20 to 30 years for oil and gas, with coal peaking 20 years after. By 2080 the total fossil fuel energy supply will be under half of the level that is supplied today. With well over half of the energy consumed today sourced from these non-renewable means, a future energy crisis can be predicted. Not to mention the majority of future fossil fuel supply will be made up of coal, which emits high amounts of GHGs (U.S. Energy Information Administration 2015) which is problematic when considering the debate that approximately $80 \%$ of fossil fuels will need to be left in the ground if excessive climate change is to be avoided (McGlade and Ekins 2015). 


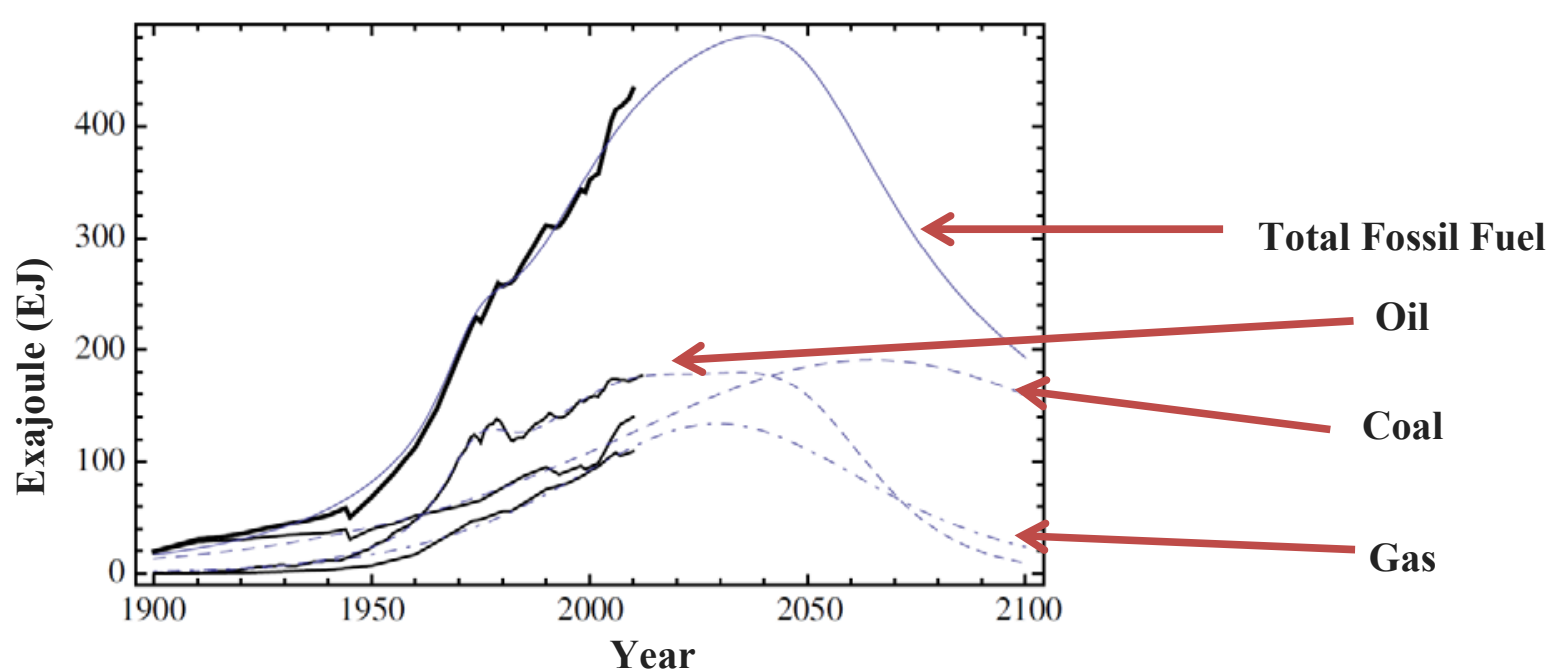

Figure 1-1: Historical data and predicted future fuel production by fossil fuel type. Image adapted from (García-Olivares and Ballabrera-Poy 2015, p.590)

Figure 1-2 displays that it is an extra concerning factor when coupled with an estimated population growth (low population growth projection) to above 9 billion in 2050 (United Nations Department of Economic and Social Affairs/Population Division 2015). This indicates that it will be necessary for buildings to be highly energy efficient, such as Net ZEBs, as a standard way to build if human society wants to carry on living the same lifestyle as today.

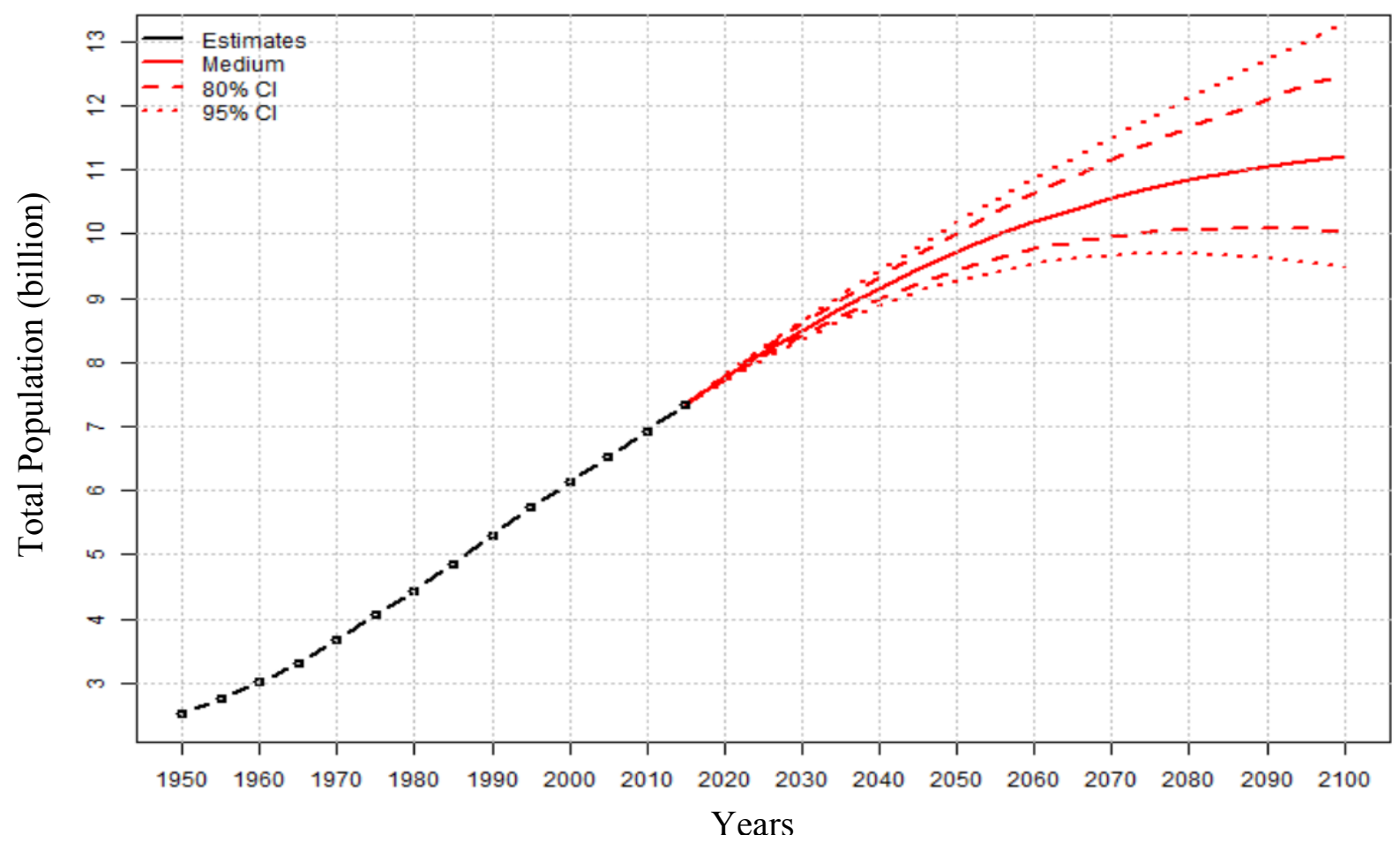

Figure1-2 Historical data and predicted future world population (United Nations Department of Economic and Social Affairs/Population Division 2015, p.2).

Page $\mid 8$ 


\subsubsection{New Zealand's energy and commercial building stock}

New Zealand is a relatively small user when it comes to energy consumption. In $2011 \mathrm{New}$ Zealand accounted for approximately 0.2 percent of the global energy, consuming 227 Billion $\mathrm{kWh}$ (817.75 Peta-Joules (PJ)). However, with a population of only 4 million, or 0.0006 percent of world population, it is a significantly high consumer per capita, ranked in the top 10 countries for electricity consumption worldwide (Modelling \& Sector Trends 2014). New Zealand has a high renewable energy supply infrastructure providing 39 percent of total primary energy supply in 2011. However, 24 percent of New Zealand's primary energy supply is still obtained from imported fossil fuels (Energy Information and Modelling Group 2012b, p.8).

Figure 1-3 displays a breakdown of the energy consumed by different New Zealand sectors. Oil is the single largest fuel consumed. Oil is split into indigenous (black) and imported (red) oil equivalents in Figure 2. The equivalents are not observed consumptions. They are the raw percentages of indigenous and imported oil consumption in New Zealand split evenly across each sector. This is presented to highlight the consequence of having imported oil. Fifty seven percent of all oil consumed in New Zealand is imported (red). Imported oil is mostly consumed as fuel for transport. In addition, a small portion is used to generate electricity and for other purposes (Energy Information and Modelling Group 2012b, pp.104-107). Figure 1-2 highlights that if New Zealand was not able to import half of the oil it currently consumes there would be a large shortfall of energy supply. The shortfall would have biggest ramifications on the transport sector; with other sectors impacted as well.

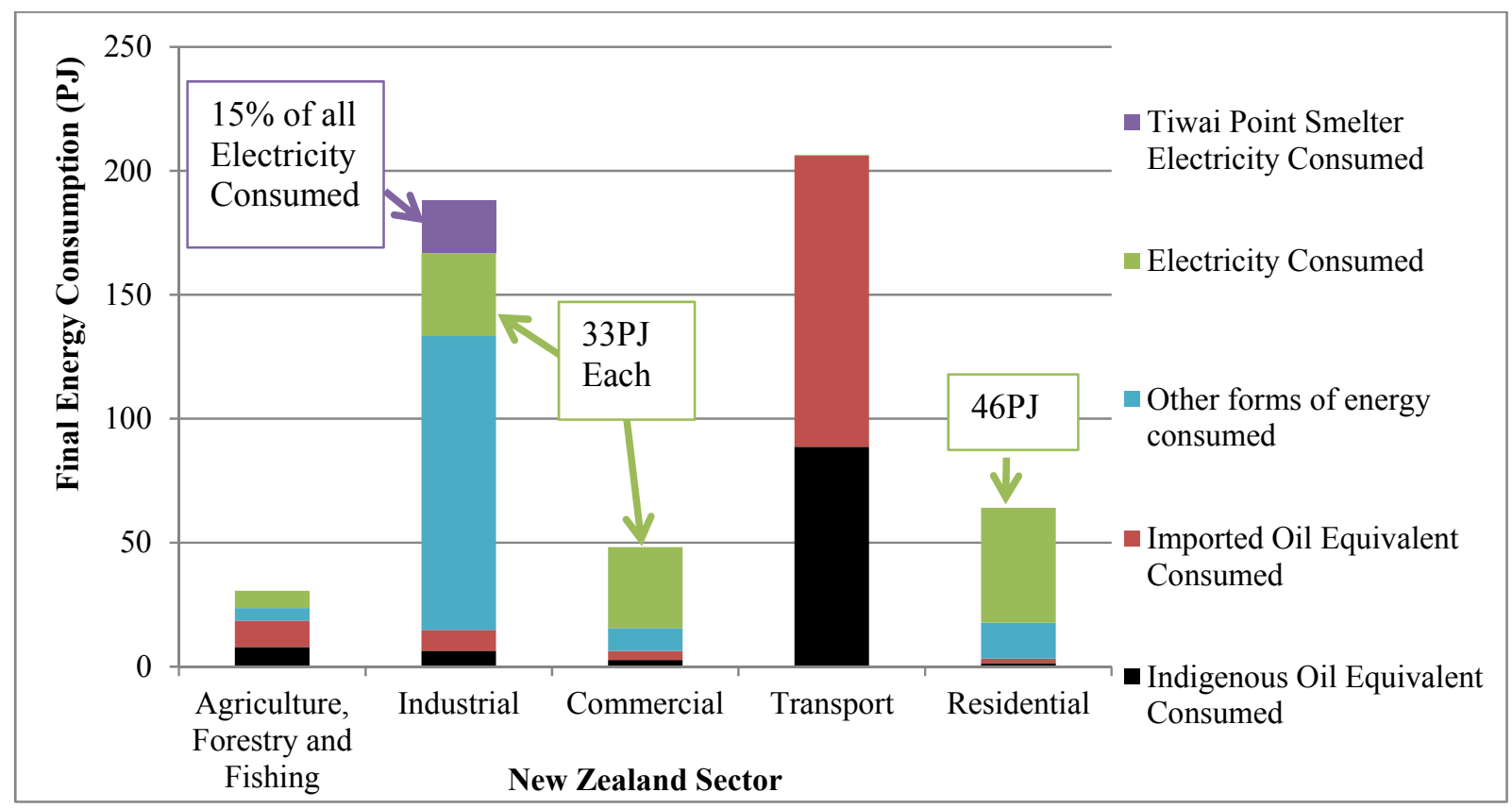

Figure 1-3 : Energy consumed by New Zealand sectors with a split of the equivalent amount of indigenous and imported oil, and Tiwai Point Smelter electricity consumption highlighted. Image created using (Energy Information and Modelling Group 2012) and (Bennett 2007). 
Electricity (green and purple) is the second largest energy type consumed. It accounted for 26 percent of all energy consumed in 2011. The single largest user of electricity is the Tiwai Point Smelter (purple) and is an industrial plant. It consumes approximately 15 percent of all electricity generated in New Zealand (Bennett 2007), and makes up 40 percent of industrial electricity consumption. The largest electricity consuming sector is the residential sector. It consumed 46PJ of electricity in 2011. This is followed by both the commercial and industrial sector both consuming 33PJ. The split of electricity shows that the residential and commercial sectors consume a similar order of magnitude of energy and offer similar possibilities for energy reductions through more efficient building stocks.

\subsubsection{Net zero energy building concept and international targets}

The Net ZEB design principle is currently intended to become a mainstream building standard in many countries globally. The largest conglomerate of countries that is considering this change is the EU. The EU is an economic and political union of 27 member states which are located in Europe. The EU proposes energy and emissions reductions through the implementation of the Energy Performance of Buildings Directive (EPBD). The goal of the EPBD is a 20 percent reduction of energy consumption and greenhouse gas emissions, and increased share of renewable energies by 2020 (European Commission 2008). To help achieve this goal, one of the proposals is to increase the number of low or zero energy buildings across the EU.

The principle of a Net ZEB is: Energy consumed by electrical appliances and space conditioning equipment is offset by renewable energy generation technologies. When the energy generated equals the energy consumed, it is energy neutral or NZE.

The EU's plan is a move to Net ZEBs within the next decade, starting with building codes and standards that enforce Net ZEBs for all new buildings. The EPBD identified Member States (countries who belong to the EU) should set national targets for existing buildings, i.e. to fix minimum percentages of buildings that should be zero energy by 2020 respectively. This is identified and set out in Article 9 of the EPBD:

"Member States shall draw up national plans for increasing the number of buildings of which both carbon dioxide emissions and primary energy consumption are low or equal to zero. They shall set targets for the minimum percentage which those buildings in 2020 shall constitute of the total number of buildings and represent in relation to the total useful floor area. Separate targets shall be set for:

- new and refurbished residential buildings;

- new and refurbished non-residential buildings;

- buildings occupied by public authorities."(European Commission 2008, p.26)

The EPBD's goal of increasing the number of Net ZEBs is a big leap in energy efficiency from current standards. Such a move is a good example of what is needed to reduce the building sector's contribution to the global challenges related to climate change and resource shortages.

Page $\mid 10$ 
The EPBD's goal is a direct response to the emission reduction target the EU agreed upon in the Kyoto Protocol. The Kyoto Protocol is an international treaty that sets binding obligations to reduce emissions of greenhouse gases. The original Kyoto Protocol objective was for each participating country to reduce their overall emissions of GHG by at least five percent below 1990 levels in the commitment period 2008 to 2012 (United Nations 1998). However, the reduction target was amended in 2008. Table 1-1 displays the quantified emission limitation or reduction targets as contained in Annex B to the Kyoto Protocol (UNFCCC 2008). There is a range of targets: countries targeting to reduce GHG emissions below their base year (most countries' base year is 1990); reducing their GHG emissions to that of base year emission levels; and reducing their GHG emissions to slightly higher than levels of their base year. It also falls considerably short of what is needed to halt the rise in $\mathrm{CO}_{2}$ emissions, let alone beginning to reduce them (Najam, Huq, and Sokona 2003; McGlade and Ekins 2015).

Table 1-1 : Quantified emission limitation or reduction targets as contained in Annex B to the Kyoto Protocol. Table adapted from (UNFCCC 2008).

\begin{tabular}{|c|c|}
\hline Country & $\begin{array}{l}\text { Emission limitation or } \\
\text { reduction (expressed in relation to total } \\
\text { GHG emissions in the base year or period } \\
\text { inscribed in Annex B } \\
\text { of the Kyoto Protocol) }\end{array}$ \\
\hline $\begin{array}{l}\text { Austria, Belgium, Bulgaria, Czech Republic, Denmark, Estonia, } \\
\text { European Community, Finland, France, Germany, Greece, Ireland, } \\
\text { Italy, Latvia, Liechtenstein, Lithuania, Luxembourg, Monaco, } \\
\text { Netherlands, Portugal, Romania, Slovakia, Slovenia, Spain, Sweden, } \\
\text { Switzerland, United Kingdom of Great Britain and Northern Ireland }\end{array}$ & $-8 \%$ \\
\hline United States of America & $-7 \%$ \\
\hline Canada, Hungary, Japan, Poland & $-6 \%$ \\
\hline Croatia & $-5 \%$ \\
\hline New Zealand, Russian Federation, Ukraine & $0 \%$ \\
\hline Norway & $1 \%$ \\
\hline Australia & $8 \%$ \\
\hline Iceland & $10 \%$ \\
\hline
\end{tabular}

"As a signatory of the Kyoto Protocol New Zealand had accepted as a target that, for the period 2008 to 2012 (the first commitment period) it would have reduced its greenhouse gas emissions to the level they were in 1990, or take responsibility for excess emissions. (Energy Information and Modelling Group 2012a, p.4)"

Figure 1-4 displays the total kilo-tonnes of Carbon dioxide equivalent $\left(\mathrm{kt} \mathrm{CO}_{2}\right.$-e) emissions from the energy sector for 2008-2012 (the Kyoto Commitment Period) and the 1990 emissions target year. As can be seen, GHG emissions declined from 2009-2011 and increased in 2012. All five years had consistently higher GHG emissions than the 1990 target year, showing New Zealand did not meet the target. If New Zealand were to adopt Net ZEBs as a standard of building, as the EU is doing, the Kyoto target could become more achievable. 


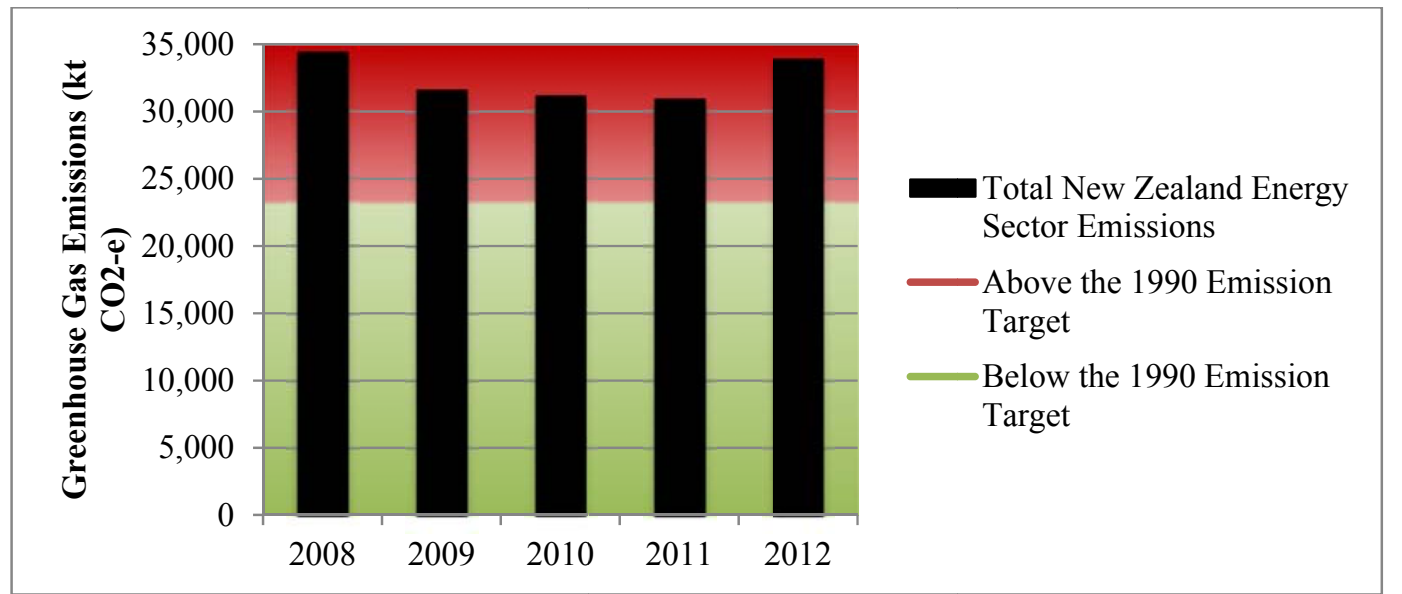

Figure 1-4 : New Zealand GHG emissions from the energy sector for 2008-2012 (Kyoto Commitment Period One) and the 1990 emissions target year. Graph created using data from (Energy Information and Modelling Group 2012b).

It is recognised that new Net ZEBs help in reducing energy consumption and GHG emissions. However, the current emissions problem is caused by existing buildings. National building refurbishment targets are one way to meet international emission targets set in Kyoto within a time frame that is 25-50 years and not centuries. As an example of the problem, existing buildings in the USA outnumber new buildings by more than 100 to 1 . If just the USA is going to reduce its greenhouse gas emissions, the greening of existing buildings must be included (Lockwood, Nagarajan, and Park 2008). Fifteen percent of the USA total $\mathrm{CO}_{2}$ reduction targets, over the coming decade could be met simply by retrofitting and reusing existing buildings rather than demolishing and building new, efficient ones (Huppert 2012).

New Zealand has a higher renewable energy infrastructure than the USA (and Europe). Still, non-renewable $\mathrm{CO}_{2}$ emitting energy sources are consumed in New Zealand buildings. Therefore buildings can provide a means to lower emissions in New Zealand. But, the impact of retrofitting existing building may not have the same potential for a significant impact for reducing emissions in New Zealand compared with the USA.

\subsubsection{Retrofit commercial buildings}

Existing commercial buildings in New Zealand outnumber new buildings by 50 to 1 (BEES 2013b; Hills 2013). Eighty one percent of the existing commercial building floor area in New Zealand is in buildings aged over 13 years (QV 2008). The average Energy Performance Indicator (EnPI) ${ }^{1}$ of buildings over 8 years old is 219 kilowatt-hours per square metre a year $\left(\mathrm{kWh} / \mathrm{m}^{2}\right.$.yr) (BEES 2013b; Hills 2013). Buildings that are less than 8 years old have an average EnPI of $132 \mathrm{kWh} / \mathrm{m}^{2}$.yr (BEES 2013b; Hills 2013). Newer buildings consumed on average approximately 40 percent less energy than their older counterparts. This indicates that new

\footnotetext{
${ }^{1} \mathrm{EnPI}$ is the same as the Energy Use Index (EUI). It is an update in terminology introduced through the 2014 New Zealand Building Standards for energy audits (NZS 3598). The EnPI normalises energy consumption by floor area as a means to compare different buildings energy performance. All EnPI figures discussed and/or presented are in final energy.
}

Page $\mid 12$ 
buildings consume less energy and that there is a high level of opportunity to improve energy efficiency with existing commercial buildings and reduce the impact on the existing energy infrastructure.

When replacing existing buildings with new buildings, the building is demolished and cleared away. This results in a lot of wasted building materials. Additionally, GHG is being emitted while the demolishing, clearing away of the building materials and the transporting of new materials to the site for the new building take place. Refurbishment takes advantage of the existing building structure and materials. The result is a large reduction in embodied energy that is otherwise wasted. Energy Efficient renovation can significantly improve the performance of existing buildings while using less embodied energy over a building life cycle than what would be required for new construction (Frey 2008).

A study performed by Lockwood, Nagarajan, and Park (2008) presented the results from a survey which assessed the impact that a green building retrofit had on an organisation. A green building retrofit does not refer to NZE; however, the benefits of a NZE retrofit are similar. For example, the green building retrofits and NZE retrofit both have goals of achieving:

- Sustainable site strategies that minimize the impact on ecosystems and water resources.

- Energy and atmosphere strategies that better building energy performance through innovative strategies.

- Materials \& resources strategies that encourage the reduction of waste.

- Indoor environmental quality strategies that better indoor environmental comfort.(U.S. Green Building Council 2013)

Figure 1-5 displays the impact a green building retrofit has had on an organisation. Results relate to whether there was an increase, no change or decrease in organisational performance. Overall, the results show that a green retrofit has benefitted the organisation greatly. All aspects questioned had an increase in benefit, except for permit processing time and insurance rates, which showed no change. The largest benefits which concern the building and the occupants were: Employee comfort; Employee well-being; Employee health; Workforce productivity; Occupancy levels; and Property value. 


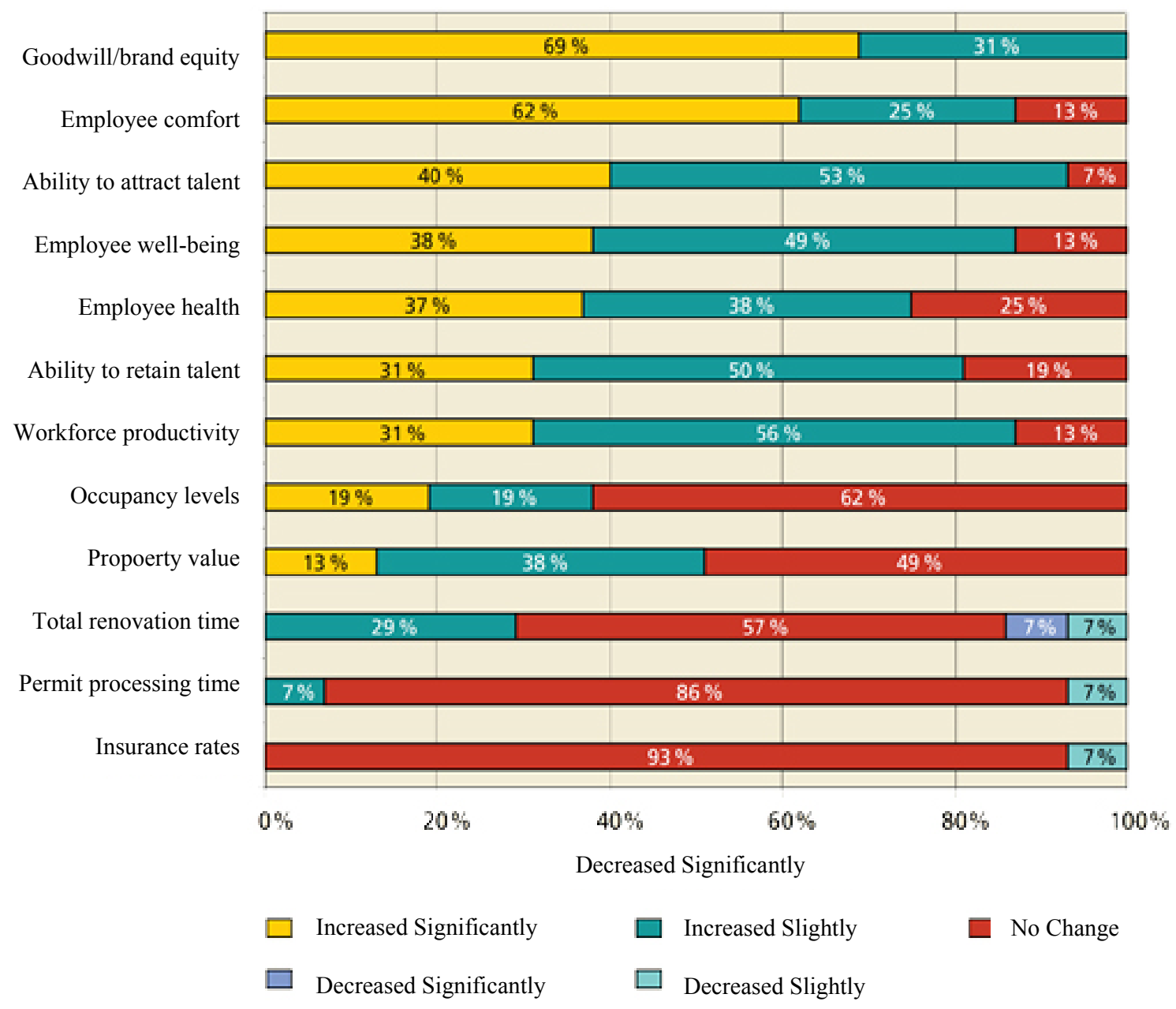

Figure 1-5 : Impact of green retrofit on organisations. Figure adapted from (Charles Lockwood, Nagarajan, and Park 2008).

Extrapolating these benefits to the New Zealand commercial building stock suggests a NZE transformation would lead to more comfortable, healthier and more productive occupants. As well, a greater proportion of the workforce will spend more time generating revenue while at work and the property value of the commercial building stock will increase. The commercial sector would also generate more revenue through an associated reduction in demand for government health services and associated costs.

An additional benefit that was found in the Lockwood, Nagarajan, and Park (2008) study was that 73 percent of survey participants reported they had achieved cost reductions as a result of implementing green measures. The cost savings were achieved through increased efficiency of resource use. An organisation in a green retrofitted building had a lower energy bill than an organisation in a conventional building. The savings would be even larger in a building that is retrofitted to NZE as they effectively consume zero energy annually. 
A study performed by McKinsey\&Company, (2009) assessed different building approaches to reducing greenhouse gas emissions and their relative economics. It offers an insight into the cost effectiveness of various retrofit approaches. Figure 1-6 presents the results in an abatement cost curve. The abatement cost curve provides a quantitative basis for determining what actions would be most effective in delivering emission reductions, and what they could cost. The width of each bar in Figure 1-6 represents the potential of that opportunity to reduce GHG emissions in a specific year compared to the business as usual development (Mega-tonnes of Carbon Dioxide Equivalent per year $\left.\left(\mathrm{MtCO}_{2} \mathrm{e} / \mathrm{yr}\right)\right)$. The height of each bar represents the average cost of avoiding 1 tonne of GHG emissions (Euros per tonne of Carbon Dioxide Equivalent ( $€$ per $\left.\mathrm{tCO}_{2} \mathrm{e}\right)$ ) by 2030 through that opportunity. The graph is ordered left to right from the lowest-cost abatement opportunities (being more cost effective) to the highest-cost (being the least cost effective) (McKinsey\&Company 2009). The measures that are below the zero line are more cost effective than those above the line.

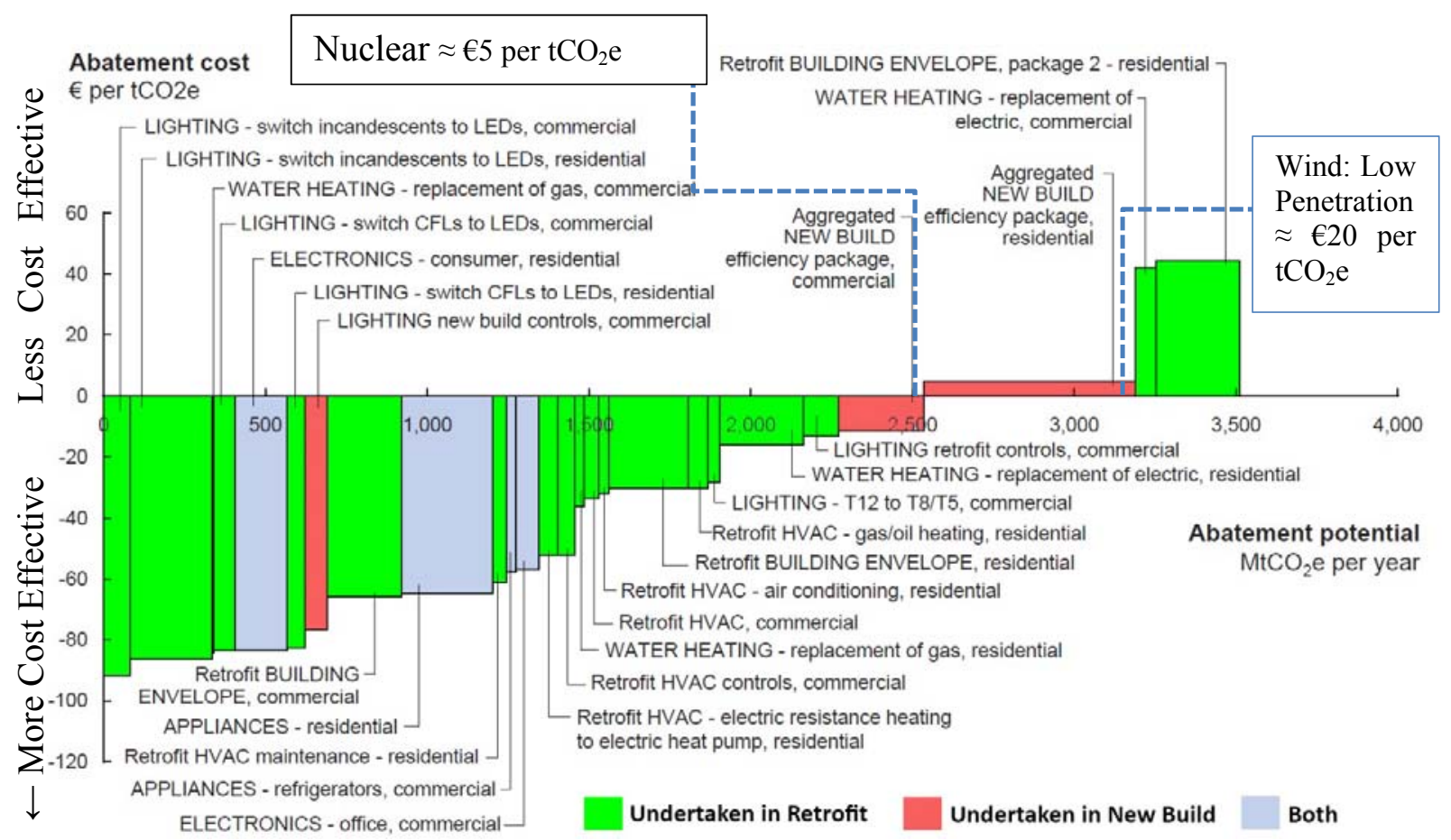

Figure 1-6 : Global GHG abatement cost curve for the Buildings sector. Figure adapted from (McKinsey\&Company 2009).

Figure 1-6 indicates the majority of approaches that can be undertaken in retrofit projects (Green) across the entire global building sector are cost effective (as seen by the large number of measures being below the zero line). Additionally, approaches undertaken in retrofit projects are more cost effective at reducing GHG emissions than approaches undertaken in New Builds (Red). The most effective approaches are the replacement of inefficient lamps with Light Emitting Diode (LED) lamps, retrofitting commercial building envelopes, and retrofitting HVAC systems. The results show that it is possible to upgrade large groups of buildings to reduce 
GHG emissions in a cost effective way. Retrofit projects are also set to get cheaper with a decline in construction cost premiums. "Green construction costs have fallen in the past few years and will continue to fall because of better technology, cheaper materials, and increasing competition among materials providers, construction companies, and certification agencies" (C Lockwood 2009, p.50).

Also highlighted on Figure 1-6 are cost effectiveness for building a new Nuclear or Wind generation infrastructure. Both generation schemes are less cost effective for reducing GHG emissions than the majority of the building retrofit approaches. This indicates that retrofitting buildings (commercial and residential) is more cost effective for reducing GHG emissions than building new energy generation infrastructure.

\subsection{Thesis structure and chapter summary}

Figure 1-7 presents the thesis structure. The thesis is grouped into its three main research phases.

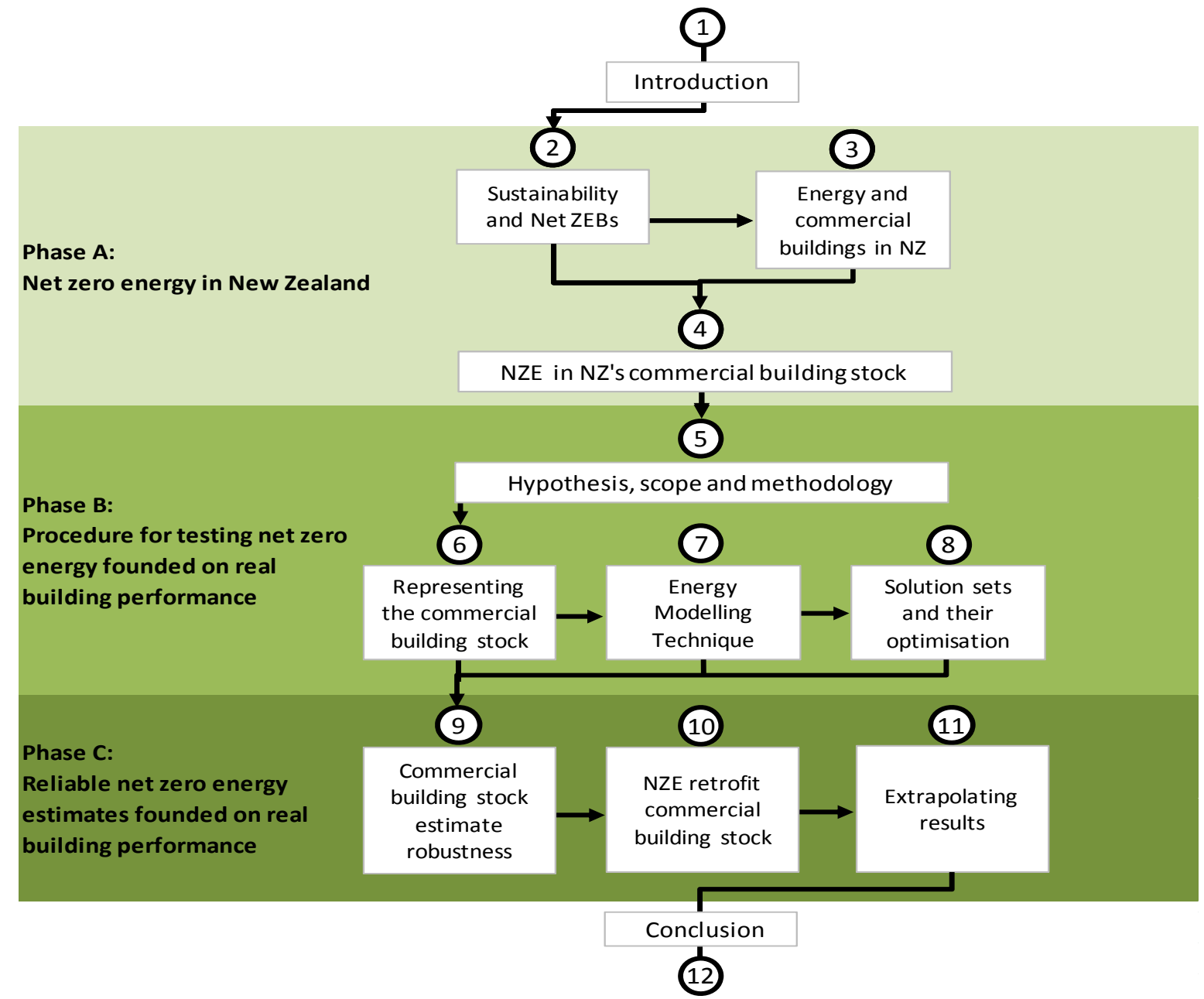

Figure 1-7 : Research and thesis structure.

Page $\mid 16$ 
Research Phase A is described in Chapters 2 to 4.

- Chapter 2 links the global energy crisis and the benefit of NZE refurbishment to sustainability as well as progressing the understanding of Net ZEBs to identify how NZE can be defined for the context of this thesis.

- Chapter 3 presents New Zealand's current energy and commercial building stock to build an understanding of how NZE should be defined for their context.

- Chapter 4 uses New Zealand and its commercial building stock as a case study to develop a working NZE target. The NZE target is based on Chapters 2 and 3. The target is used for measuring when NZE is achieved in the New Zealand commercial building stock.

Research Phase B is addressed in Chapters 5 to 8.

- Chapter 5 begins with the research hypothesis and scope and presents an introduction to the overarching method used to test the hypothesis.

- Chapter 6 outlines the representation of the current commercial building stock using Stock Aggregation and a sample of real buildings.

- Chapter 7 presents the modelling technique for creating energy models which match real commercial buildings.

- Chapter 8 identifies a set of Energy Conservation Measures (ECM) to be used in the retrofit of the real commercial building energy models and outlines their optimisation.

Research Phase C is completed in Chapters 9 to 11.

- Chapter 9 presents the results from applying the modelling technique to the sample of real commercial buildings and their aggregation to represent the current commercial building stock.

- Chapter 10 displays the results of applying the set of ECMs to New Zealand's current commercial building stock.

- Chapter 11 presents case studies that test the feasibility of the proposed conversion to NZE.

- Chapter 12 presents the conclusions from the research performed in this thesis. 

RESEARCH PHASE A

Net ZEBs and

New Zealand

Page $\mid 18$ 



\section{CHAPTER 2. DEFINING NET ZERO ENERGY - BUILDINGS AND SUSTAINABILITY}

\subsection{Chapter Intent}

Net Zero Energy Buildings (Net ZEBs) are a direct response to a desire to design buildings sustainably (Rajkovich, Diamond, and Burke 2010). This chapter examines where Net ZEBs fit into the overall context of sustainability. There is considerable debate as to how to define Net ZEBs. The debate focuses on methods to calculate the balance between energy use and energy generation. In Chapter 1, the need for NZE refurbishment was introduced by presenting the global energy crisis and the benefits of net zero energy refurbishment. In this chapter, the definition of Net ZEBs is examined to establish a means of formulating NZE for New Zealand's unique energy and building context. Figure 2-1 presents these links between Chapter 1 and 2.

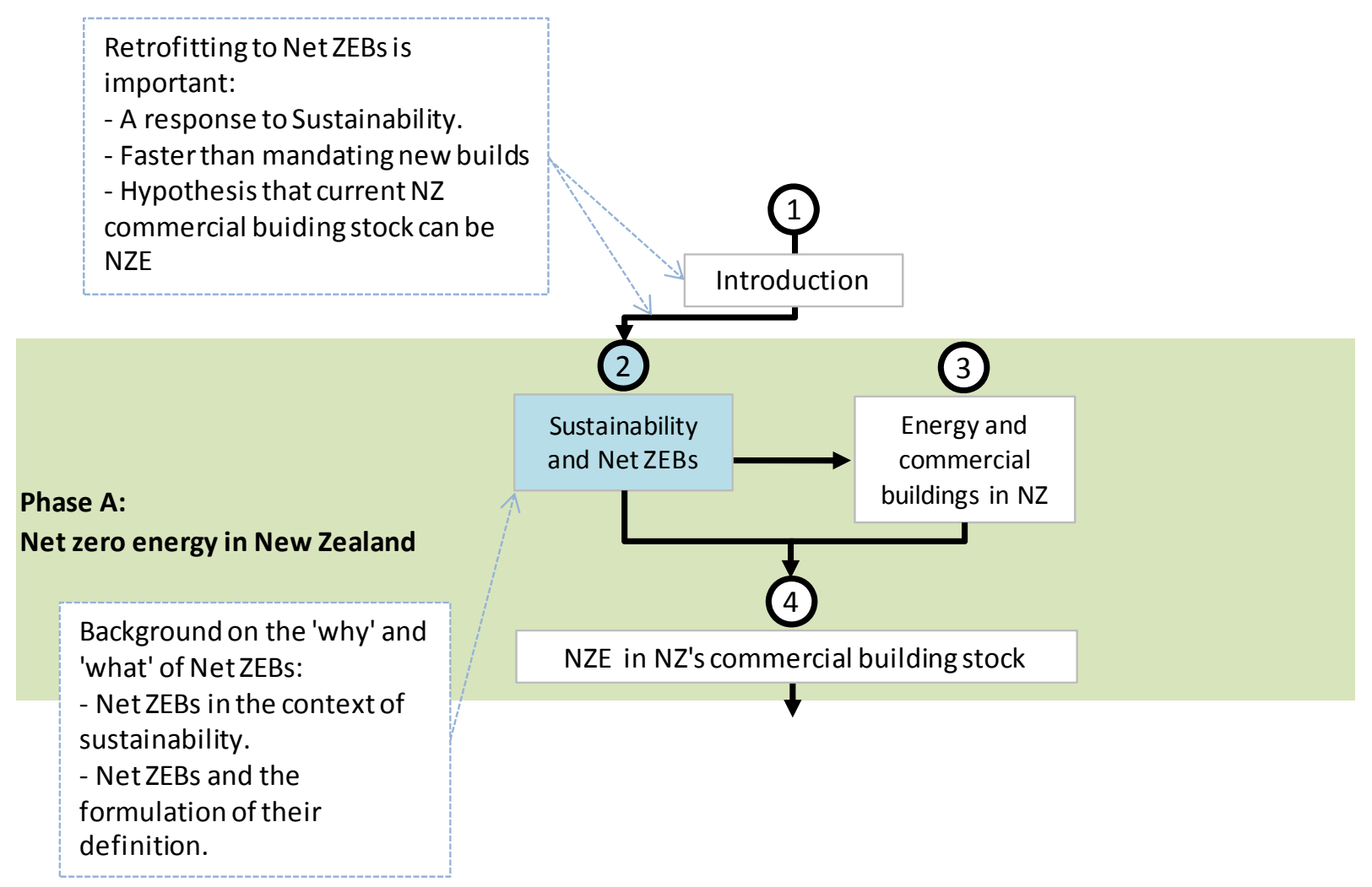

Figure 2-1 : Chapter 1 and 2 linkages. 


\subsection{Net ZEBs as a response to sustainability}

Reducing the environmental impact of buildings is a high priority for tackling climate change and other sustainability challenges (Riedy, Lederwasch, and Ison 2011). Many definitions of sustainability exist and studying the definition of sustainability is a $\mathrm{PhD}$ thesis in itself. Due to this, the work undertaken in Alcorn (2010) is used as the basis of this section's discussion. Alcorn's (2010) PhD thesis "Global Sustainability and the New Zealand House" presents a history of sustainability and sustainable development, and formulates an operational definition of sustainability that enabled the measurement of sustainability, and knowing when its limit has been reached. Alcorn (2010) used the history of the sustainable development debate as a guide in developing his functional definition for sustainability.

\subsubsection{Defining Sustainability for buildings}

The sustainability debate did not really start until the "acceleration of technology and consumption after WWII which fully ignited the environmental movement. ... The application of some technologies was having serious impacts on the environment. ... In 1983, the United Nations established the Brundtland Commission, to investigate deterioration of natural and human resources and propose strategies for achieving sustainable development" (Alcorn 2010, pp. 27-32). The resulting Brundtland (1987) Report, "Our Common Future", included the now familiar definition of sustainable development: "development that meets the needs of the present without compromising the ability of future generations to meet their own needs." This "Brundtland Definition" is often cited as a definition of 'sustainability', however, it too, creates confusion" (Alcorn 2010, pp. 27-32). The main confusion arises as the "Brundtland Definition" did not specify safety margins for the various human/environmental parameters. Therefore, sustainability under the Brundtland definition cannot be measured.

To determine how to measure sustainability, Alcorn looked at what requirements need to be met in order to create a functional definition of sustainability. This was undertaken to determine how to create a functional definition that was measureable and easily understood. Alcorn established that "a functional definition of sustainable development:

1. Preserves the abilities of future and present generations to meet their needs

2. Establishes a clear physical limit (beyond which is unsustainability)

3. Facilitates measurement or quantification

4. Measures by a method appropriate to the present and the long-term future

5. Addresses the biggest concerns

6. Addresses a wide range of concerns

7. Is scientifically well founded

8. Is scientifically clear and simple

9. Is easily understood

10. Is easily translatable to daily decisions

11. Does not require major new research or debate

12. Acknowledges and accommodates conflicting interests in the sustainability debate."

Page $\mid 20$ 
Sustainability aims to limit the amount of environmental damage to a wide range of environments and Alcorn (2010) concluded that climate change in general, and $\mathrm{CO}_{2}$ emissions were the most important aspects to consider, a conclusion which has been echoed in other literature (Crawford 2011). This was identified when looking at the time taken, presently or potentially, for the environment to recover after a particular impact is stopped. Alcorn examined habitat loss, wild food loss, soil loss, energy scarcity, water scarcity, photosynthesis limit, chemical pollution, overpopulation, and climate change associated impacts. All non-climate change impacts would take years, decades or in severe cases centuries to recover. However, climate change associated impacts, in particular atmospheric pollution through $\mathrm{CO}_{2}$, have the potential to persist in its effect from millennia to hundreds of millions of years (Benton 2003). As an example, the loss of the polar ice sheets is a major global change that affects all life on earth with a recovery time likely to be tens of thousands or hundreds of thousands of years (Coxall et al. 2005). Climate change also affects the whole planet, whereas most of the nonclimate change impacts are localised effects.

As a result of these findings, Alcorn's focus for both a definition of sustainability and for a way to measure the sustainability of any activity was associated with climate change. Alcorn (2010) then sought to define a measurable indicator of a limit in order to create a functional definition. What Alcorn (2010) translated sustainability into was: "Sustainability meets the needs of the present without annual $\mathrm{CO}_{2}$ emissions exceeding what the planet can absorb." This definition meets all of the functional definition criteria set out above. It is easily understood, is quantifiable, addresses the biggest as well as a wide range of concerns, does not require any new research, and "safeguards the future automatically by stipulating what the planet can annually sustain - on an indefinite basis - is not exceeded"(Alcorn 2010, p.55).

It should be understood that the definition by Alcorn (2010) is just one way of defining and viewing sustainability. Alcorn (2010) was used due to it being easy to understand and suitable for buildings, but his definition does come with some limitations. The main limitation is that it solely focused on environmental sustainability and did not consider social or economic sustainability. Another limitation is that it focused on the current problem without concern for future problems. For example, fresh water depletion could one day be the next 'global warming' considering that consumption outweighs supply (Abramovitz 1996; World Water Council 2014; Gunther 2009). Also, the definition does not consider the question of resources in general (for example, the future fossil fuels or mineral resources), which could also place a limit on sustainability. However, as this thesis focuses on environmental sustainability through Net ZEBs, it does not pose a real threat to the discussion other than the need to acknowledge and understand that there are other aspects to sustainability outside of buildings which should be considered. 


\subsubsection{Measuring Sustainability for buildings}

In order to understand where Net ZEBs fit into sustainability, the measurement of sustainability needs to be understood. Alcorn's definition provided a ruler that enabled the quantification of when sustainability has been met. In particular, what is being measured was "the amount of $\mathrm{CO}_{2}$ resulting from the provision of goods and services" (Alcorn 2010, p.202). This accounts for $\mathrm{CO}_{2}$ emitted in both direct and indirect energy use. Direct energy use is energy consumed to undertake a process in the form of electricity, geothermal or fossil fuels. Indirect energy use is energy embodied from the making and transporting of materials. It is described as cradle to grave.
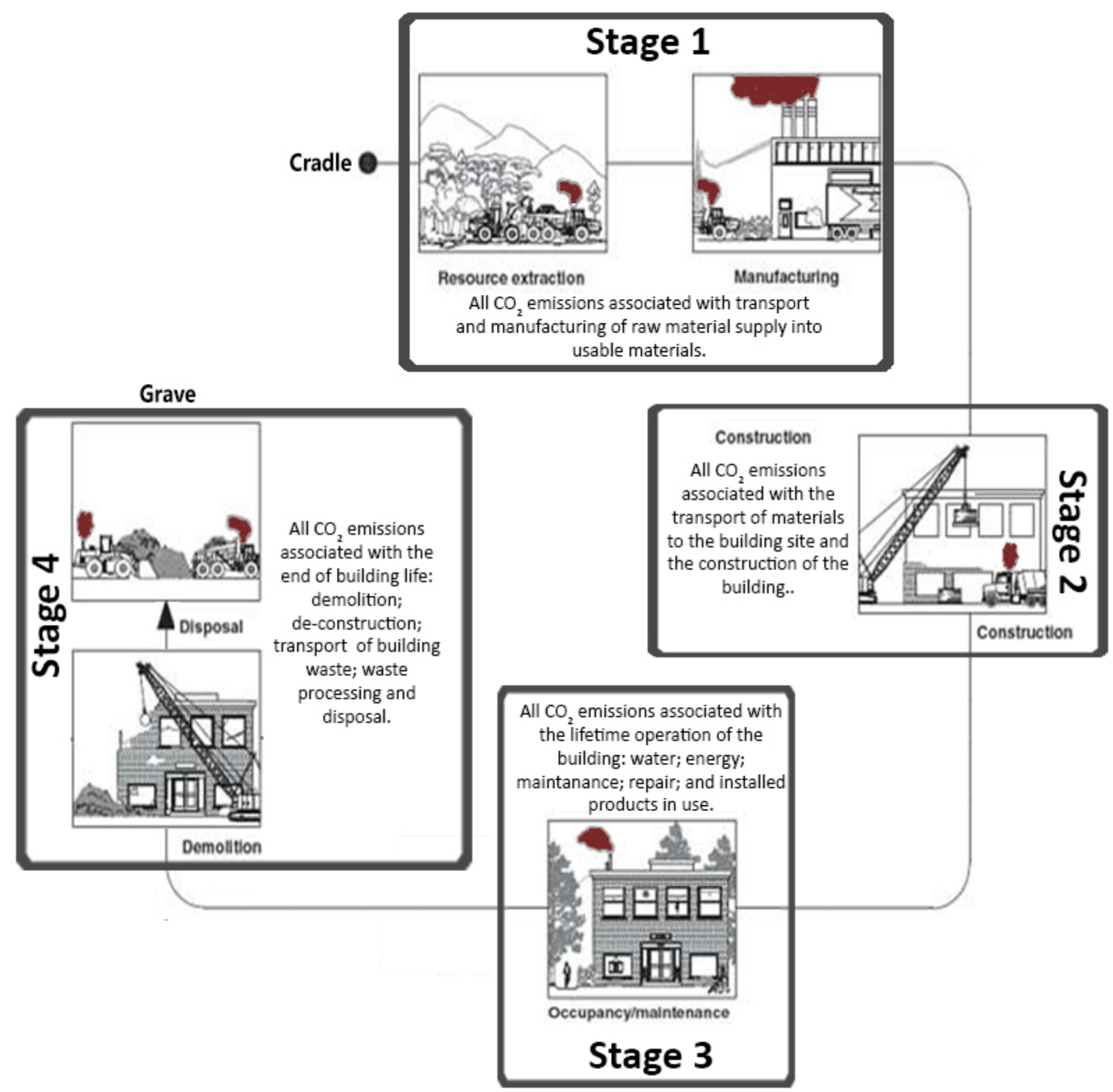

Figure 2-2 : The 'cradle to grave' concept. Figure adapted from (USDA Forest Service 2010; Coldstream Consulting 2011).

Page $\mid 22$ 
Figure 2-2 illustrates the 'cradle to grave' concept and details what is included in each stage of a 'cradle to grave' Embodied $\mathrm{CO}_{2}\left(\mathrm{ECO}_{2}\right)$ analysis. $\mathrm{ECO}_{2}$ analysis measures all $\mathrm{CO}_{2}$ associated with the building and its use. It was the only method for measuring sustainability that fulfils all functional sustainability definition criteria (Alcorn 2010).

Sustainability starts with resource extraction and manufacturing which is dubbed the 'cradle' (Stage 1). This is all $\mathrm{CO}_{2}$ emitted during the process of exploring for and transporting resources to make materials for building components and manufacturing the final building components. The next step is the construction process (Stage 2). This accounts for all $\mathrm{CO}_{2}$ emitted while transporting the building components to a building site and constructing the building. The third step is the use of the building (Stage 3). This is all $\mathrm{CO}_{2}$ emitted throughout the lifetime operation and maintenance of the building. The last step is the end of building life; dubbed the 'grave' (Stage 4). This accounts for all $\mathrm{CO}_{2}$ emitted while demolishing the building, transporting the building waste, processing the building waste, and disposing of the building waste.

\subsubsection{Net ZEBs place in sustainability}

With Alcorn's definition of sustainability and the 'cradle to grave' $\mathrm{ECO}_{2}$ introduced, Net ZEBs can be objectively placed in the overall context of sustainability and sustainable building. Alcorn (2010) determined that per-capita emissions in developed countries need to fall by about 99 percent to be sustainable. Alcorn's thesis assessed residential buildings, but he states that sustainability is not possible "unless the entire world, in its housing, and all other activities, also adopts and adheres to the same per-capita sustainability limit described here" (Alcorn 2010, p.315). This is due to the Jevons paradox which is discussed in Section 4.7. It indicates that the same principles found for Alcorn's (2010) sustainable house are directly applicable to other buildings, such as commercial buildings. It was established that buildings do not have to be fully autonomous, but close to autonomous due to the grid electricity consumption needing to be lowered sufficiently to reduce total emissions to a sustainable level (Alcorn 2010). The most effective way of reaching a sustainable $\mathrm{CO}_{2}$ emissions level is to reduce all buildings' grid electricity use because the grid's non-renewably sourced portion emits substantial amounts of $\mathrm{CO}_{2}$. The reduction of grid electricity consumption is achieved through demand side energy efficiency and supply side renewable energy generation. It was found that renewable energy generation contributed the most to annual $\mathrm{CO}_{2}$ reduction. The next best option was maximising bio-based materials to reduce net $\mathrm{CO}_{2}$, which is achieved by using low $\mathrm{CO}_{2}$ intensive materials, such as timber. Net ZEBs can fit into both categories depending on the boundary of their definition.

Net ZEBs reduce energy demand and consume net 100 percent renewable operational energy (net 100 percent because any non-renewable consumption is offset with renewable generation). In doing so, Net ZEBs reduce $\mathrm{CO}_{2}$ emissions and as such, Net ZEBs as a principle fall into the sustainable building category. Net ZEBs reduce building related $\mathrm{CO}_{2}$ in the 'building use' stage of the 'cradle to grave' stages. The reduction only falls into the building use stage as Net ZEBs 
do not have the prescriptive addition of building from low embodied energy materials. However, if embodied energy was to be added into the balance of non-renewable energy, it would have considerations for the other three 'cradle to grave' stages (refer to Figure 2-2).

This thesis investigates whether existing buildings can be converted to net zero energy (NZE) through refurbishment. Net ZEB refurbishment has implications for all four of the 'cradle to grave' stages: resource extraction; construction process; building use; and the end of the building life. Refurbishment reduces the amount of resource extraction needed to make building materials. This is due to a reduction in new building materials needed to build the Net ZEB, and means there is less $\mathrm{CO}_{2}$ emitted to extract the required retrofit resources when compared to building from new. It results in a lower embodied $\mathrm{CO}_{2}$ of the refurbished building. Similarly, $\mathrm{CO}_{2}$ emitted during the construction process is reduced by reusing existing materials. Reusing existing materials means there are less new building materials required and it further reduces the embodied $\mathrm{CO}_{2}$ of the refurbished building when compared to a new build. $\mathrm{CO}_{2}$ emissions are reduced during the use of the building by firstly reducing the need for energy, and completely offsetting any residual energy use with low or non- $\mathrm{CO}_{2}$ emitting renewable energy generation. By being net zero energy the operating $\mathrm{CO}_{2}$ emissions of the refurbished building are reduced. Instead of completely building a new building at the end of a building's life, this study proposes to refurbish the existing building to be a Net ZEB. This means the end of the building life $\mathrm{CO}_{2}$ emissions are reduced by decreasing the amount of demolition and disposal of materials required, when compared to completely demolishing a building and starting anew. Limiting the amount of old building materials requiring disposal further reduces the embodied $\mathrm{CO}_{2}$ of the refurbished building. If the building was refurbished indefinitely to be a Net ZEB, the end of life $\mathrm{CO}_{2}$ emissions are reduced. However, it is unlikely a building would be refurbished indefinitely, which results in the final building demolition having a similar end of life $\mathrm{CO}_{2}$ impact as a standard building being demolished, unless the refurbished Net ZEB had been constructed from materials with a lower embodied $\mathrm{CO}_{2}$.

True sustainability needs to be undertaken at a national level. All aspects of building need to be sustainable and that means having a reduced need for grid electricity. This highlights the importance of determining whether it is possible to refurbish the existing commercial building stock to be net zero energy. In addition, if it is assessed from another perspective, sustainability is easier to attain when grid electricity is 100 percent renewable (the research does not focus on adding new renewable infrastructure to current grid due to the cost effective discussion in Section 1.4.4). Alcorn (2010) concluded that "New Zealand environmental policy for buildings is focused on the thermal envelope and lighting emissions [in new buildings]. But if policy is to be effective, the focus for emissions reduction should firstly be on reducing emissions associated with grid electricity, on the supply side." Therefore, if the existing commercial building stock energy consumption is provided largely by the renewable portion of the current grid, the building stock will be sustainable. This is one of the aims of reaching NZE in this thesis (refer to Section $4.5)$.

Page $\mid 24$ 


\subsection{Net ZEB definition}

In the past there has been much debate about what was classed as a Net ZEB. Each of the various definitions expressed a couple of main ideas. The most prominent and obvious was that the building needs to consume no energy generated by non-renewable sources over the course of a year. However, in principle this can be a traditional building, which has its energy supplied by a very large renewable energy generation system. If these systems deliver more energy over a year than the building consumes, it is a zero net energy building (Laustsen 2008). Consequently, there was a need to differentiate between a traditional building and a Net ZEB. With this highlighted, a Net ZEB also has a greatly reduced need for energy. The differentiation means that any building with enough onsite renewable energy generation is not a Net ZEB. The building must be low energy and have enough onsite renewable energy generation. Figure 2-3 illustrates the concept and design ideal of a Net ZEB through the use of a balancing graph. Net ZEBs have a greatly reduced demand for energy (horizontal red line), through efficiency gains, and balance the energy demand with energy supplied by renewable technologies (vertical red line) (Sartori, Napolitano, and Voss 2012). This definition was universally agreed.

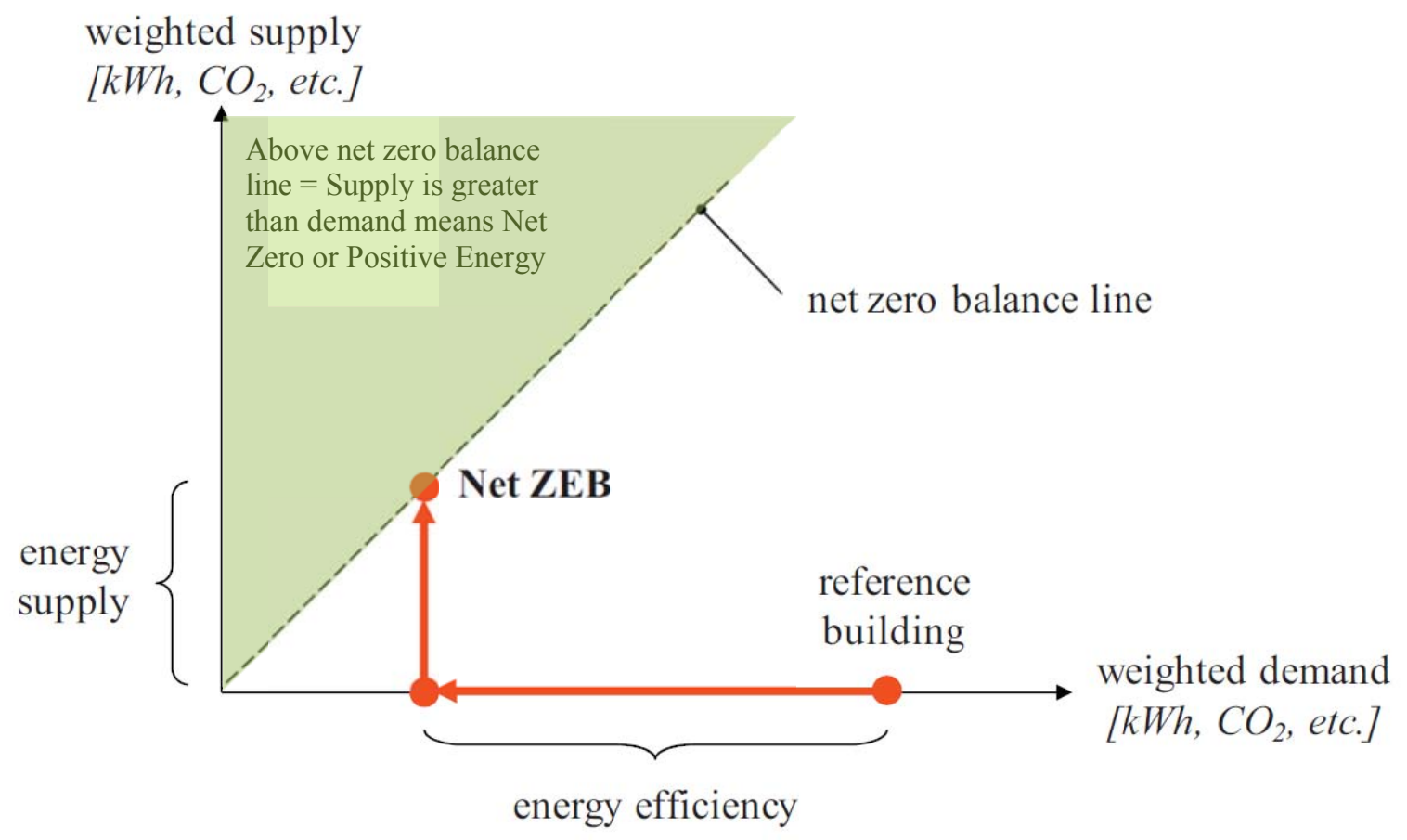

Figure 2-3 : Net ZEB design and definition principle (Sartori, Napolitano, and Voss 2012, p. 222; Sartori et al. 2010 ; Karsten Voss et al. 2010).

This basic principle is simple and seldom debated. Where consensus has been harder to find is in the more detailed aspects of Net ZEBs. "Recurrent issues concern the metric (i.e. primary energy, carbon emissions, etc.) and the items to be considered in the balance (i.e. energy use in the operation of a building, energy embodied in materials and technical installations, etc.)"

Page $\mid 25$ 
(Sartori et al. 2010, p.1). The energy metric is the indicator for what zero energy is measured against. The various metrics produce slightly differing definitions. The differing definitions end up suggesting different optimal design strategies that influence the choices on insulation levels, HVAC system performance, Photovoltaic (PV) or cogeneration system dimensioning, and so on (Sartori, Napolitano, and Voss 2012). Another more broadly debated aspect was the environmentally friendliness requirement for Net ZEBs (whether embodied energy is required to be offset by the renewable energy generation). Also, whether Net ZEBs should be designed to minimise any additional stress on the energy supply infrastructure, by requiring a specific level of load matching or grid interaction (Section 2.3.6) (Sartori, Napolitano, and Voss 2012).

The biggest dispute was what energy metric needs to be equalled to zero and where on the building site to measure the zero. The zero can be measured either at the site or off the site, while the zero can be quantified in four different energy related units or metrics (note: the metrics are not the definition themselves, they are one of many parts of a definition). One study that has taken an in-depth look at the four main energy metrics was undertaken by Torcellini et al. (2006). The four commonly used definition metrics are: net zero site energy, net zero source energy, net zero energy costs, and net zero energy emissions (Torcellini et al. 2006). Each definition metric measures a different energy related indicator and includes:

"Net Zero Site Energy:

A site ZEB produces at least as much energy as it uses in a year, when accounted for at the site.

\section{Net Zero Source (Primary) Energy:}

A source ZEB produces at least as much energy as it uses in year, when accounted for at the source. Source energy refers to the primary energy used to generate and deliver the energy to the site. To calculate a building's total source energy, imported and exported energy is multiplied by the appropriate site-to source conversion multipliers.

\section{Net Zero Energy Costs:}

In a cost ZEB, the amount of money the utility pays the building owner for the energy the building exports to the grid is at least equal to the amount the owner pays the utility for the energy services and energy used over the year.

\section{Net Zero Energy Emissions/Carbon:}

A net-zero emissions building produces at least as much emissions-free renewable energy as it uses from emissions-producing energy sources" (Torcellini, et al., 2006, p.5).

Net Zero Energy Emissions/Carbon Buildings differ from Net Zero Energy Buildings. For instance they can use electricity produced by $\mathrm{CO}_{2}$ free sources, such as large windmills, nuclear power and PV solar systems which are not integrated in the buildings or at the construction site (Mertz, Raffio, and Kissock 2007). 
The study undertaken by Torcellini et al. (2006) used seven case study low-energy commercial buildings to assess the impacts of the four zero energy metrics. Each building was already designed to be low-energy to minimise energy and environmental impacts. The buildings were in different climates and had differing uses. The seven buildings comprised:

- "Oberlin"-The Adam Joseph Lewis Center for Environmental Studies, Oberlin College, Ohio;

- "Zion"-The Visitor Center at Zion National Park, Springdale, Utah;

- "Cambria"-The Cambria Department of Environmental Protection Office Building, Ebensburg, Pennsylvania;

- "CBF"- The Philip Merrill Environmental Center, Chesapeake Bay Foundation, Annapolis, Maryland;

- "TTF"-The Thermal Test Facility, National Renewable Energy Laboratory, Golden, Colorado;

- "BigHorn"-The BigHorn Home Improvement Center, Silverthorne, Colorado; and

- "Science House" Science Museum of Minnesota, St. Paul, Minnesota. (Paul Torcellini et al. 2006, p.5)

The study involved the redesign of each building with the addition of an onsite roof mounted Photovoltaic (PV) system. A PV system was added to assess how much roof area was needed to achieve NZE using the four energy metrics. USA's annual electricity and natural gas site-tosource conversion multipliers were applied to each of the buildings to determine source energy use (Paul Torcellini et al. 2006). The results are presented in Table 2-1. 
Table 2-1 : Impact of PV systems size for different Net ZEB metrics (Torcellini et al. 2006, p.6).

\begin{tabular}{|c|c|c|c|c|c|}
\hline $\begin{array}{c}\text { Building and PV } \\
\text { System (DC } \\
\text { Rating Size) }\end{array}$ & $\begin{array}{c}\text { Site } \\
\text { Energy } \\
\text { Use (w/o } \\
\text { PV) } \\
\text { (MWh/yr) }\end{array}$ & $\begin{array}{c}\text { Source } \\
\text { Energy } \\
\text { Use (w/o } \\
\text { PV) } \\
\text { (MWh/yr) }\end{array}$ & $\begin{array}{c}\text { Actual } \\
\text { Roof Area } \\
\text { (footprint) } \\
\text { (m) }\end{array}$ & $\begin{array}{c}\text { Flat Roof } \\
\text { Area }\left(\mathbf{m}^{2}\right) \\
\text { Needed for } \\
\text { Source ZEB } \\
\text { and Site ZEB } \\
\text { with PV }\end{array}$ & $\begin{array}{c}\text { PV System } \\
\text { DC Size } \\
\text { Needed for } \\
\text { Source ZEB } \\
\text { and Site ZEB }\end{array}$ \\
\hline Oberlin- $60 \mathrm{~kW} *$ & 118.8 & 380.2 & 790 & 1,003 & $120 \mathrm{kWp}$ \\
\hline Zion-7.2 kW* & 91.6 & 293.1 & 1090 & 567 & $73 \mathrm{kWp}$ \\
\hline Cambria-17.2 kW* & 372.1 & $1,190.7$ & 1,602 & 3,457 & $415 \mathrm{kWp}$ \\
\hline CBF-4.2 kW** & 365.2 & $1,142.0$ & 1440 & $\begin{array}{c}\text { 2,352 Source } \\
\text { ZEB 2,382 Site } \\
\text { ZEB }\end{array}$ & $\begin{array}{c}282 \mathrm{kWp} \\
\text { Source ZEB } \\
286 \mathrm{kWp} \text { Site } \\
\text { ZEB }\end{array}$ \\
\hline TTF-No PV** & 83.5 & 192.5 & 929 & $\begin{array}{c}373 \text { Source } \\
\text { ZEB } 516 \text { Site } \\
\text { ZEB }\end{array}$ & $\begin{array}{c}45 \mathrm{kWp} \text { Source } \\
\text { ZEB } 62 \mathrm{kWp} \\
\text { Site ZEB }\end{array}$ \\
\hline BigHorn-8.9 kW** & 490.4 & 901.0 & 3616 & $\begin{array}{c}\text { 1,714 Source } \\
\text { ZEB 2,949 Site } \\
\text { ZEB }\end{array}$ & $\begin{array}{c}206 \mathrm{KWp} \\
\text { Source ZEB } \\
354 \mathrm{kWp} \text { Site } \\
\text { ZEB }\end{array}$ \\
\hline $\begin{array}{ll}\begin{array}{l}\text { Science } \\
\mathrm{kW}^{*}\end{array} & \text { House-8.7 } \\
\end{array}$ & 5.9 & 18.8 & 127 & 93 & $6 \mathrm{kWp}$ \\
\hline
\end{tabular}

*Electric only buildings

$* *$ Electric and gas buildings

For the all-electric buildings (Oberlin, Zion, Cambria, and the Science House), the site ZEB and source ZEB were the same. But for the mixed electric and gas buildings the two definitions result in differing size PV systems. The difference was due to the gas use having a lower primary factor than electricity. It was concluded that each definition has accompanying advantages and disadvantages that make them attractive or unattractive. These characteristics are described in Table 2-2. Two advantages are highlighted. Firstly, the Source ZEB is a better definition for assessing the impact on a national energy system, which is the subject of this thesis. Secondly, as Net ZEBs are a response to sustainability and climate change, it is prudent to identify the advantage of the emission ZEB definition. Emissions account for non-energy differences between fuel types, such as pollution, and greenhouse gases (including $\mathrm{CO}_{2}$ ). 
Table 2-2 : Advantages and Disadvantages of the four common Net ZEB metrics (Torcellini, et al., 2006, p.11).

\begin{tabular}{|c|c|c|c|}
\hline $\begin{array}{l}\text { Definition } \\
\text { Metrics }\end{array}$ & Advantages & Disadvantages & Other Issues \\
\hline Site ZEB & 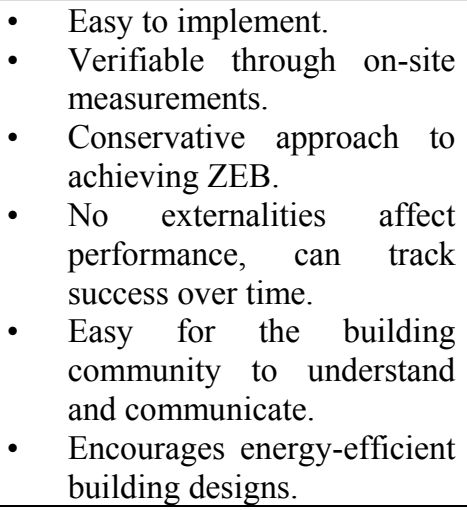 & 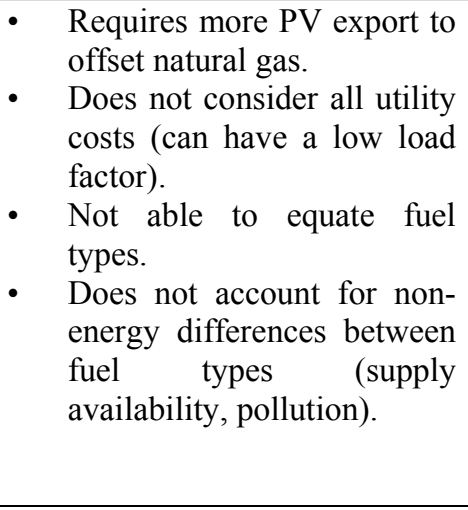 & \\
\hline $\begin{array}{l}\text { Source } \\
\text { ZEB }\end{array}$ & $\begin{array}{l}\text { - Able to equate energy value } \\
\text { of fuel types used at the site. } \\
\text { - Better model for impact } \\
\text { on national energy system. } \\
\text { - } \quad \text { Easier ZEB to reach. }\end{array}$ & 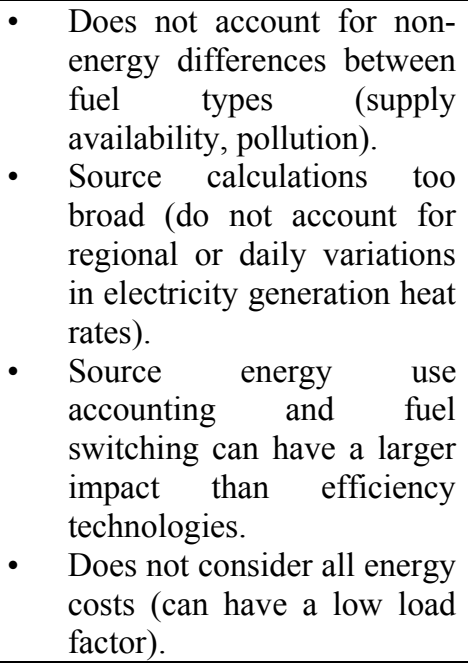 & $\begin{array}{l}\text { - Need to develop site-to- } \\
\text { source conversion factors, } \\
\text { which require significant } \\
\text { amounts of information to } \\
\text { define. }\end{array}$ \\
\hline Cost ZEB & 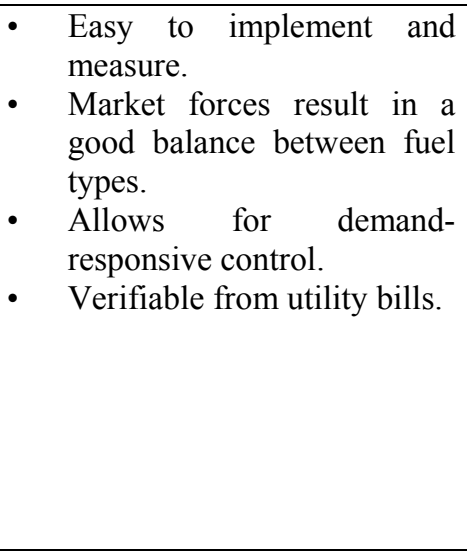 & $\begin{array}{l}\text { - May not reflect impact to } \\
\text { national grid for demand, as } \\
\text { extra PV generation can be } \\
\text { more valuable for reducing } \\
\text { demand with on-site storage } \\
\text { than exporting to the grid. } \\
\text { Requires net-metering } \\
\text { agreements such that } \\
\text { exported electricity can } \\
\text { offset energy and non- } \\
\text { energy charges. } \\
\text { Highly volatile energy rates } \\
\text { make for difficult tracking } \\
\text { over time. }\end{array}$ & 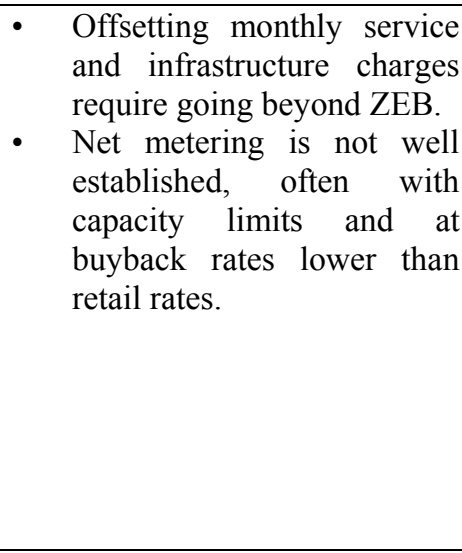 \\
\hline $\begin{array}{l}\text { Emissions } \\
\text { ZEB }\end{array}$ & 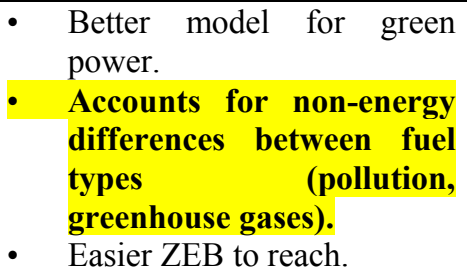 & & $\begin{array}{l}\text { - Need appropriate emission } \\
\text { factors. }\end{array}$ \\
\hline
\end{tabular}


Another slightly different Net ZEB definition is the Net Zero Exergy Building. The Net Zero Exergy approach was not as well published as the other four definitions. The definition is:

\section{Net-Zero Exergy Building}

A building which has a total annual sum of zero exergy transfer across the buildingdistrict boundary in a district energy system, during all electric and any other transfer that is taking place in a certain period of time (Kilkis 2007; Kilkis 2011, p.34) .

The argument was that merely balancing the energy quantity is not good enough; the energy quality (exergy) should be taken into consideration. Taking into consideration the exergy balance instead of energy balance enables the quantification of the compound carbon emissions of a building, therefore accurately rating the building's impact on the environment. Compound $\mathrm{CO}_{2}$ emissions are the direct carbon emission from the building and avoidable secondary carbon emission that is the consequence of the exergy mismatch emission (Marszal et al. 2011). Mismatch, according to the energy grid, refers to unusable onsite renewable energy generation.

An international research project was created due to the lack of agreement on a universal definition. The International Energy Agency's (IEA) Solar Heating and Cooling Programme (SHC) and Energy Conservation in Buildings and Community Systems (ECBCS) Programme has recently completed a research project working on establishing an internationally agreed understanding of Net ZEBs based on a common methodology. The research project objectives were achieved by:

- "The review and analysis of existing Net ZEB definitions and data with respect to the demand and the supply side;

- A study of grid interaction and time dependent energy mismatch.

- The development of a harmonized international definition framework for the Net ZEB concept considering large-scale implications, exergy and credits for grid interaction"(IEA-SHC 2013b).

The main method for establishing an internationally agreed understanding was through the development of a harmonised international definition framework. The harmonised framework describes the relevant characteristics of Net ZEBs in a series of parameters. The parameters form the basis for a methodology for establishing sound Net ZEB definitions in a formal, systematic and comprehensive way. The work being conducted "is on buildings that are connected to an energy infrastructure, i.e. electricity grid, district heating and cooling system, gas pipe network, biomass and biofuels distribution networks, and not any autonomous buildings" (Sartori, Napolitano, and Voss 2012, p.220). This narrows down what is classified as a Net ZEB. An autonomous building is a Zero Energy Building (ZEB), but not a Net ZEB. A group of buildings connected together that are NZE collectively are a Net Zero Energy Cluster (Net ZEC). The working definitions for these three types of Zero Energy Buildings are: 


\section{"ZEB}

A ZEB is a non-grid connected energy efficient (lower energy than typical) building matching its energy needs by on-site generation fully based on renewables.

\section{Net ZEB}

A Net ZEB is a grid connected, energy efficient building that balances its total annual energy needs by on-site generation and associated feed-in credits.

\section{Net ZEC}

A Net ZEC is a cluster of [energy efficient] buildings fulfilling the net zero balance as a whole using the identical, local energy infrastructure. The cluster uses benefits from the economy of scale and levelling out the load and generation profiles of each building" (K Voss et al. 2010, p.3).

It is clear from the definition of the three types of ZEBs that the main variable creating a Net ZEB is a connecting grid, whether it is the national energy infrastructure or between groups of buildings. Each Net ZEB type has differing fundamentals and inherent advantages for individual building owners, as well as a nation's energy infrastructure. Because this thesis is assessing a nation's commercial building stock, the focus ZEB type is Net ZEC: a group of buildings that are net zero energy collectively across the local energy infrastructure. As implied by K Voss et al. (2010), the nation's commercial building stock will take advantage of scale and the levelling out of load and generation profiles of each building to reach the desired net zero energy balance. These aspects are further discussed in Chapter 4 - Net zero energy in New Zealand's commercial building stock.

\subsubsection{The risk of poorly defined Net ZEB definitions}

The generic Net ZEB definition that was recently proposed by European researchers was: all newly constructed buildings must produce as much energy as they consume on-site (European Council for an Energy Efficient Economy (eceee) 2009). This simple definition would create some issues in the building industry as it is unclear as to whether buildings are to be grid connected or off the grid. If it does apply to grid connected buildings, it creates issues for some building and site situations, within and outside of Europe, that make reaching this 'net zero' target unrealistic and in some circumstances, almost impossible.

Risks were highlighted in a study focusing on Net ZEB refurbishment in New Zealand (Cory 2009). The study sought to test the feasibility of refurbishing an urban commercial office building with current technology to be a Net ZEB in Wellington, New Zealand. It was concluded that a building on an open site could generate 25 to 37 percent more energy than a building in an urban setting. It demonstrated how much more economical it would be to place energy generation in an open site or on buildings with no site shading. The site used in that study was a complex of 20 storey buildings on the basis there could be urban sites that would 1) not be able to reach 'net zero'; or 2) would prove to be infeasible as the quantity of energy generation 
needed would be too costly. A Net ZEB definition that does not allow for this issue could have a significant impact on the value of some properties and real estate on a global level. Furthermore, it would waste an enormous amount of resources in generating energy at less than ideal times and situations.

The importance of a well-developed Net ZEB definition is highlighted when considering buildings that are being refurbished. A high-rise commercial building in a dense urban environment and the refurbishment of it are two problematic situations. Firstly, refurbishment projects are accepted as more difficult to reach NZE over newly built projects (Stamats Communications Inc 2007). They are more difficult because the building geometry, size, and layout are pre-determined and not necessarily optimised to save energy. Secondly, a high-rise building has a large facade to roof area ratio and all renewable energy supply technologies must be situated on site. Studies have proven that some multi-storey commercial buildings are not as feasible to be Net ZEBs when compared to single storey buildings (Paul Torcellini et al. 2006). This means, if all renewable energy supply must be on site then reaching NZE is more complicated for some building and site contexts.

\subsubsection{The IEA framework: A means of formulating a Net ZEB definition}

The IEA Net ZEB research project recently finished the development of a harmonised international definition framework for Net ZEBs. The IEA framework evaluated the parameters and the selection of the related options that can be used in a Net ZEB definition. The framework moved away from debating what metric should be used and instead provided the ability to select from a set of parameters within the framework. The IEA definition framework is intended to aid in creating a Net ZEB definition that can be tailored to be consistent with the purposes or the political targets that lie behind the promotion of Net ZEBs (Sartori, Napolitano, and Voss 2012).

The most prominent parties currently intending to use the framework are governments looking to develop legislation for individual new residential and commercial buildings. This thesis aims to investigate the potential role for Net ZEB technologies in the retrofitting of a nation's commercial building stock. Even though the IEA framework was intended for individual buildings, it provided the basic parameters needed to formulate a NZE definition for the New Zealand commercial building stock. There was no need to create an entirely new definition system, but instead the already existing framework proposed by the IEA was worked with. It provided the foundations for the creation of a working commercial building stock refurbishment NZE definition. Four main parameters were discussed and outlined in the IEA definitions framework. The four parameters are: boundary conditions; weighting system; net zero balance; and temporal energy match. The four parameters provide a means for developing a complete and working Net ZEB definition. The four parameters concern building and energy attributes that could ultimately influence how a building is designed in order to achieve the particular definition. The attributes, together with the definition purpose, provide insight into an appropriate Net ZEB definition. The attributes include:

Page $\mid 32$ 
- $\quad$ Site setting (e.g. urban, suburban, or rural);

- Building type (e.g. large or small commercial, large or small residential);

- Nature of the building (e.g. single site, multiple sites, existing building, newly built building, etc...);

- Grid connection (e.g. grid connected, not grid connected, national grid, multi-national grid, centralised, decentralised); and

- Grid energy supply (e.g. largely renewable, largely non-renewable)

The building attributes refer to the nature of the building work, the type of building and the setting. These building attributes impact on the type of ZEB defined as well as the zero energy metric used in the definition. The energy attributes are the state of the grid connection and the existing connected grid tied energy supplies. The energy attributes impact on the energy metric that is being balanced to zero.

Figure 2-4 illustrates the relevant terminology used when dealing with the four parameters, and the building and energy attributes in Net ZEBs.

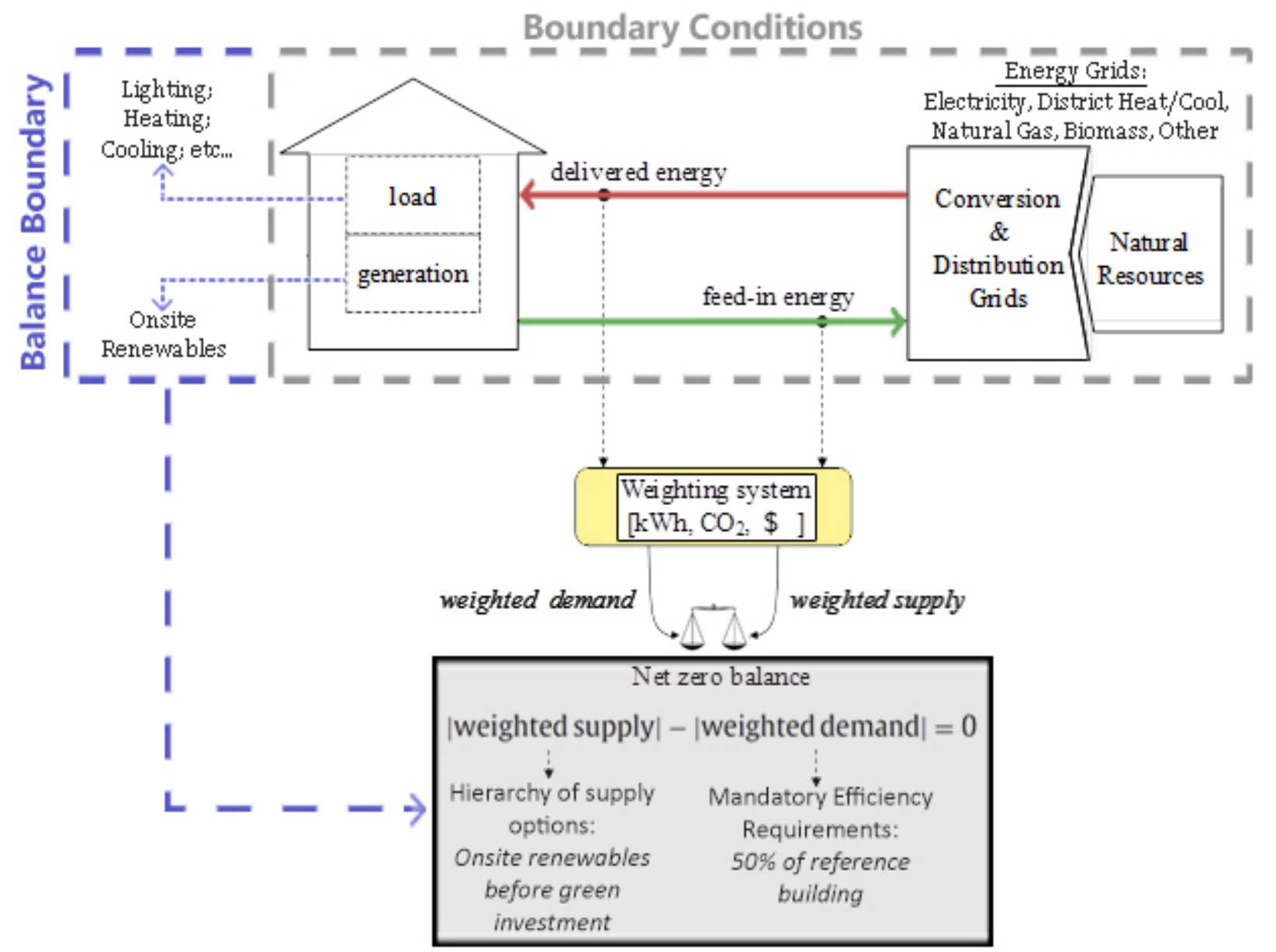

Figure 2-4 : Connection between buildings and energy grids. Figure adapted from (I. Sartori, et al., 2010, p.222).

Page | 33 


\subsubsection{Boundary condition parameters}

The boundary conditions concern the building and energy grid (Figure 2-4 - dashed grey box). The boundary conditions define what makes up the net zero energy balance. The conditions are split into three main elements: the physical boundary, the balance boundary and the boundary functionality.

The physical boundary defines where the load is balanced at, be it a single building or a group of buildings. It includes the boundary definition of the energy grids used in the balance (electricity, heating etc.). The physical boundary is concerned with whether the energy grids are internalised in the site or not, and whether all of the energy grids have a two-way function: can the buildings consume from the grid as well as supply back to the grid (Sartori, Napolitano, and Voss 2012, p.223). The boundary begins with the natural resources (the fuels) being converted into usable energy. For example, gas is used to generate electricity for the electricity grid. Electricity is then distributed to a single or group of buildings through the grid. The delivered energy (red line) is consumed to meet the building(s) load. Onsite renewables generate energy and feed electricity back into the grid (green line) to offset energy consumed.

The balance boundary defines what energy end-uses need to be balanced by renewable energy generation (Figure 2-4 - dashed blue box). The end-uses can be referred to as the items of the balance. The items of the balance define what loads are included in the net zero energy balance. Typically, the end-use loads are related to the building and its users, i.e. heating, cooling, ventilation, domestic hot water, lighting, cooking, plug loads. However, other energy services, such as electric vehicles may also be included. Another major item of balance that needs to be defined is whether any sustainable indicators are included in the net zero energy balance. Sustainable indicators like embodied energy and Life Cycle Assessment (LCA) broaden the scope of Net ZEBs as environmentally friendly and sustainable buildings (Sartori, Napolitano, and Voss 2012, p.223). Not all building loads are included in some building standards. One such national building standard is the French Thermal Regulation which requires only the Heating and cooling, lighting, auxiliaries (pump, fans etc.) and water heating end-uses to be included (RT 2012 2013). As a result, net zero energy is obtained more easily than if all energy end-uses are included. This definition does not result in a real world net zero energy building because the whole building consumption is higher than the onsite renewable energy generation.

Boundary conditions define the functionality of the building. Specifically: the type of building that is designed (residential, non-residential, Hospital, School etc.); space effectiveness (people per square metre); the climate it is located in; and the comfort levels specified in the Net ZEB. Space effectiveness, climate and comfort standards are important to specify because hotter or colder years, different occupant behaviour and comfort needs can cause different energy demands (Sartori, Napolitano, and Voss 2012, p.223). 


\subsubsection{Weighting system parameters}

The weighting system measures the delivered and fed-in energy (Figure 2-4 - solid yellow box) by converting the physical units into other metrics. It also determines whether the metric values are an annual average value or a calculated hourly value. The weighting system is the most crucial aspect in a Net ZEB definition as it defines the metric, the accounting method, and the weighting symmetry used in the net zero energy balance.

The metric defines what energy is being balanced in the net zero balance. Metrics refer to the above mentioned: site (final) energy, source (primary) energy, energy cost and energy emissions. The choice of metric can have a large impact on the resulting design of a building as seen in Tables 2-1 and 2-2. The biggest impact is that each metric can involve different weightings for energy supply and demand.

The accounting method concerns how the energy used and generated onsite is accounted for in the net zero energy balance. The physical unit of the energy used and generated is weighted using the chosen metric (e.g. primary energy or equivalent carbon emission). It is done in order to make the different energy forms comparable and to evaluate the effect of the entire energy chain including the properties of the natural sources, the conversion processes and the distribution grids (Sartori, Napolitano, and Voss 2012, p.224). Accounting methods can be static, dynamic, or semi-dynamic. Static accounting is when average values for a period of time are used to estimate the weighting factors. Dynamic accounting is when weighting factors are estimated using energy prices on an hourly basis. Dynamic and semi-dynamic accounting is important as it helps optimise a building's interaction with the grid (Sartori, Napolitano, and Voss 2012, p.224).

The weighting symmetry identifies whether the supply and demand single unit quantity is the same or not. Exported and delivered energy can be credited symmetrically, which means they have the same weighting factors for both supply and demand or they can be credited asymmetrically. If it is asymmetrical, the building's energy demand can be credited at a higher or lower value when compared to the supply back. This will have a significant impact on the generation capacity, and requires a significant investment cost to achieve the Net ZEB status (Sartori, Napolitano, and Voss 2012, p.224).

\subsubsection{Net Zero Balance parameters}

The net zero balance defines the time period for which energy is measured (the balancing period), the type of balance and whether there are any enforced minimum energy efficiency requirements and/or a hierarchy of renewable energy supply options (Figure 2-4 - solid black box). "For a Net ZEB the balance between import and export over a period of time must be zero, or even positive, i.e. in case embodied energy or embodied emissions in materials have to be balanced off' (Sartori et al. 2010, p.4). 
The balancing period is the interval at which the net zero energy balance is calculated. The interval can range in time from hourly to decades. "The most common and often implicit choice is the yearly balance. Another choice is a balance upon many years, for example, a reference period of 30-50 years after which the building is likely to undergo major renovation works and significantly change its characteristics" (Sartori et al. 2010, p.6). Yearly balances are suitable as they extend across all operation settings with respect to the meteorological conditions of the annual season patterns. "The core principle for Net ZEBs is the balance between weighted demand and weighted supply, generically described in Equation 1" (Sartori, Napolitano, and Voss 2012, p.225):

Equation 1 : Net ZEB Balance:

\section{(Weighted Supply) Energy generation x Exported energy weighting factor - (Weighted Demand) Energy load $x$ Delivered energy weighting factor $\geq 0$}

Equation 1 details the two variables needed to calculate the weighted supply and weighted demand. The variables include the energy, either exported or delivered to the building and the weighting factors for the exported and delivered energy.

The type of balance defines how Equation 1 is calculated. It can be calculated in different ways depending on the energy quantities of interest and the balancing period. Interested energy quantities refer to the delivered and exported energy data that is available. These energy quantities, measured as net values over the interval of their measurement, can be simply inputted into Equation 1 to calculate the weighted supply and the weighted demand. If the result is less than zero, the building is not a Net ZEB. If the result is equal to or greater than zero, it is a Net ZEB.

The other type of balance is one which is used to calculate self-consumption of the energy generated on-site. Equation 2 displays the equation to calculate self-consumption and the balance of the residual energy:

Equation 2 : Self-consumption Net ZEB Balance:

Energy exported $x$ Exported energy weighting factor-Energy delivered $x$ Delivered energy weighting factor $\geq 0$

The difference between Equation 1 and 2 is terminology. Energy generation may not coincide with exported energy due to self-consumption of energy generated onsite, meaning energy generation refers to all energy generated at the building. By comparison, in Equation 2 only the energy generated that is not directly consumed by the building is exported to the grid. Similarly, energy load may not coincide with delivered energy due to self-consumption of energy generated on-site meaning energy load refers to all energy that is consumed by the building. In Equation 2, only the energy required to meet the building load that is not directly supplied from onsite energy 
generation is delivered to the building. This means any energy consumed directly from energy generated onsite is excluded in the Net ZEB balance.

Figure 2-5 displays, on a balancing graph, the impact of including or excluding self-consumption in the net zero balance.

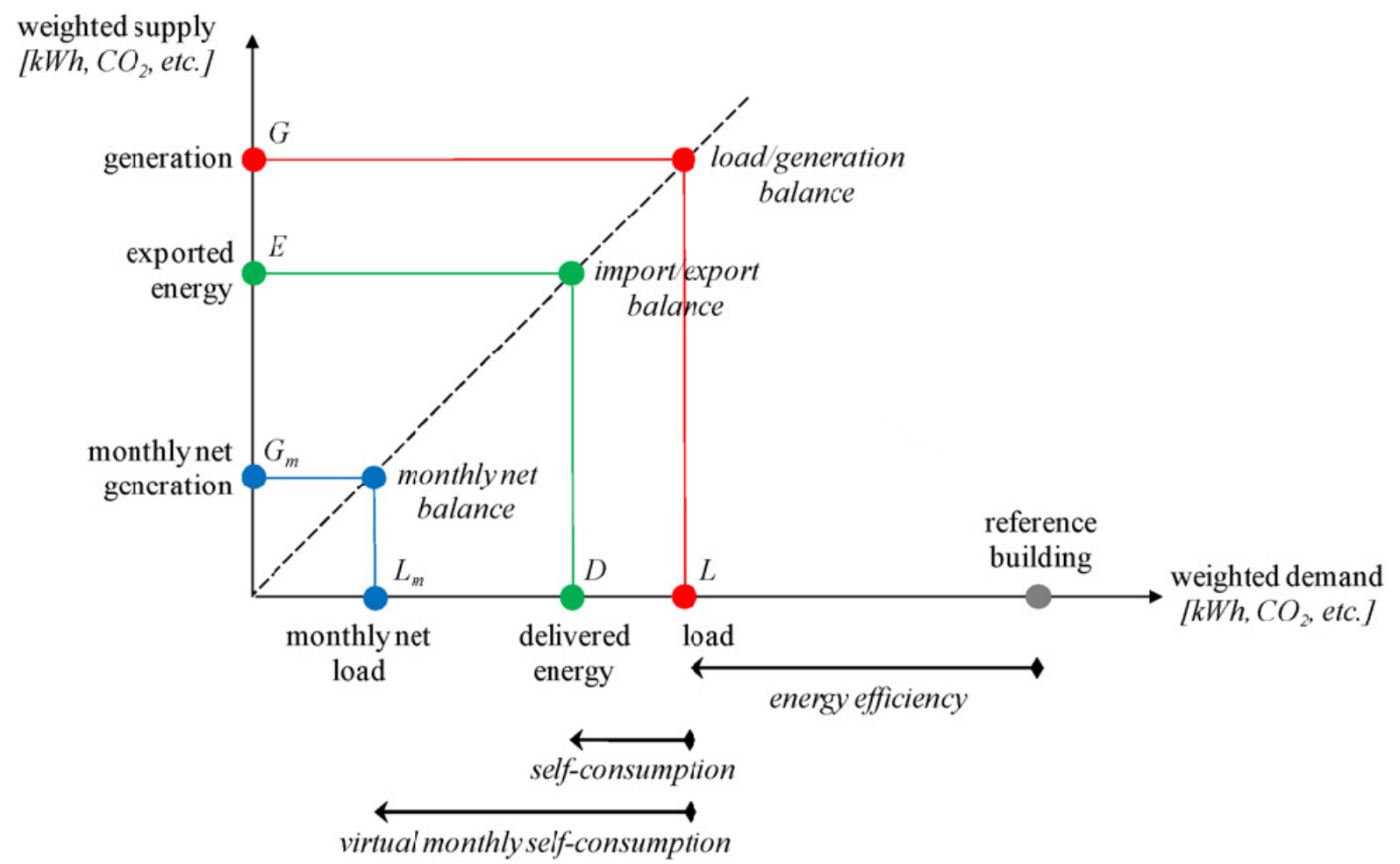

Figure 2-5: Impact of including or excluding self-consumption in the net zero balance. Figure adapted from (Sartori, Napolitano, and Voss 2012, p.226).

The red line displays the balance between the total energy load and the total energy generation over a time interval. The green line displays the balance between the exported energy, minus self-consumption and the delivered energy that is not able to be directly consumed by onsite renewables.

Energy efficiency refers to whether there are any mandatory requirements for an energy demand or consumption limit. Energy efficiency can also restrict the type of energy that a building can consume, such as oil, gas and other fossil fuels. Energy efficiency is similar to national or commercial standards like Energy Star rating schemes, passive house or cost-optimal energy performance levels calculated on the economic life-cycle (Sartori et al. 2010). Requirements are either prescriptive or performance based, or both. "Mandatory efficiency targets could simply require a demand reduction (For example,50 percent) compared to a reference building of the same category (For example, detached house, office, school).(Sartori, Napolitano, and Voss 2012, p.226)" If no requirements are detailed, it is up to the designers to establish a suitable level of energy efficiency.

Page | 37 
Energy supply refers to whether there are specific requirements for energy generation technologies. It defines the location and boundary of the supply options. The boundary refers to whether supply uses onsite or offsite renewable energy technologies, or whether purchasing green electricity or the investment in green projects or funds is acceptable. The latter option is considered a 'soft' renewable option ('soft' as opposed to the 'hard' physical generation of energy) as it pushes responsibility onto another party. There may be a hierarchy of supply options that are prioritised over off-site supply options such as the import of biofuel for cogeneration or purchase of green electricity. Energy supply options could be prioritised on the basis of whether they are: (1) emissions-free and reduced transportation, transmission, and conversion losses; (2) available over the lifetime of the building; (3) highly scalable, widely available, and have high replication potential for future Net ZEBs (Sartori et al. 2010).

\subsubsection{Temporal Energy Match parameters}

The temporal match is the impact of the exchange between the building and the energy infrastructures. It details the match between the used and generated energy load and the interaction this has with the energy grid. "Beside an annual energy or emission balance, Net ZEBs are characterized by their different ability to match the load and to work beneficially with respect to the needs of the local grid infrastructure" (Sartori, Napolitano, and Voss 2012, p.227). The satisfaction of a balance over a period of time (such as a year) is not in itself a guarantee that the building is designed in a way that minimises its environmental impact. In particular, it was a decision of the IEA to insist that Net ZEBs should be designed to work in synergy with the grids and not to put additional stress on the power grid (Sartori et al. 2010).

Load matching and grid interaction are two terms used to discuss the temporal match between energy load needed and energy load generated at the building and the grid's need for the energy exchange. These terms indicate the building's ability to work in synergy with the grid. "When there is a poor correlation between load and generation, e.g. load mainly in winter and generation mainly in summer, the building will more heavily rely on the grid. If load and generation are more correlated, the building will most likely have higher chances for fine tuning selfconsumption, storage and export of energy in response to signals from the grid" (Sartori, Napolitano, and Voss 2012, p.227). However, the most important characteristic is the grid interaction flexibility of a Net ZEB. This is the ability of a Net ZEB to respond to signals from the grid. Grid interaction flexibility comes from being able to adjust building loads, energy generation and storage of energy in order to serve the grid's needs together with the building's needs. For the grid interaction flexibility to be meaningful it has to be evaluated at an hourly level, or preferably at one minute intervals (Sartori, Napolitano, and Voss 2012) .

\subsection{Chapter summary}

Chapter 2 is the beginning of defining what NZE would be for the New Zealand commercial building stock to provide a foundation for testing the study hypothesis that NZE can be achieved. This chapter developed an understanding of NZE. In understanding what Net ZEBs are, the

Page $\mid 38$ 
identification of four sets of parameters provides a means for developing a complete and working NZE definition for the purpose of this thesis. The four sets of parameters are informed by the purpose of the wanted NZE definition, as well as the building and energy attributes of the particular case being defined. In this thesis, the purpose is to convert the whole building stock to be NZE and the case is the New Zealand commercial building stock. This is important because the definition must be practical for the purpose of this thesis, as well as for the New Zealand context.

Figure 2-6 illustrates how Chapter 2 links to Chapters 3 and 4. With the four sets of parameters identified in this chapter, Chapter 3 presents the unique energy and commercial building context of New Zealand. The context details the attributes that will be used to inform the four sets of parameters in Chapter 4. In Chapter 4, a NZE definition for New Zealand's commercial building stock is formulated.

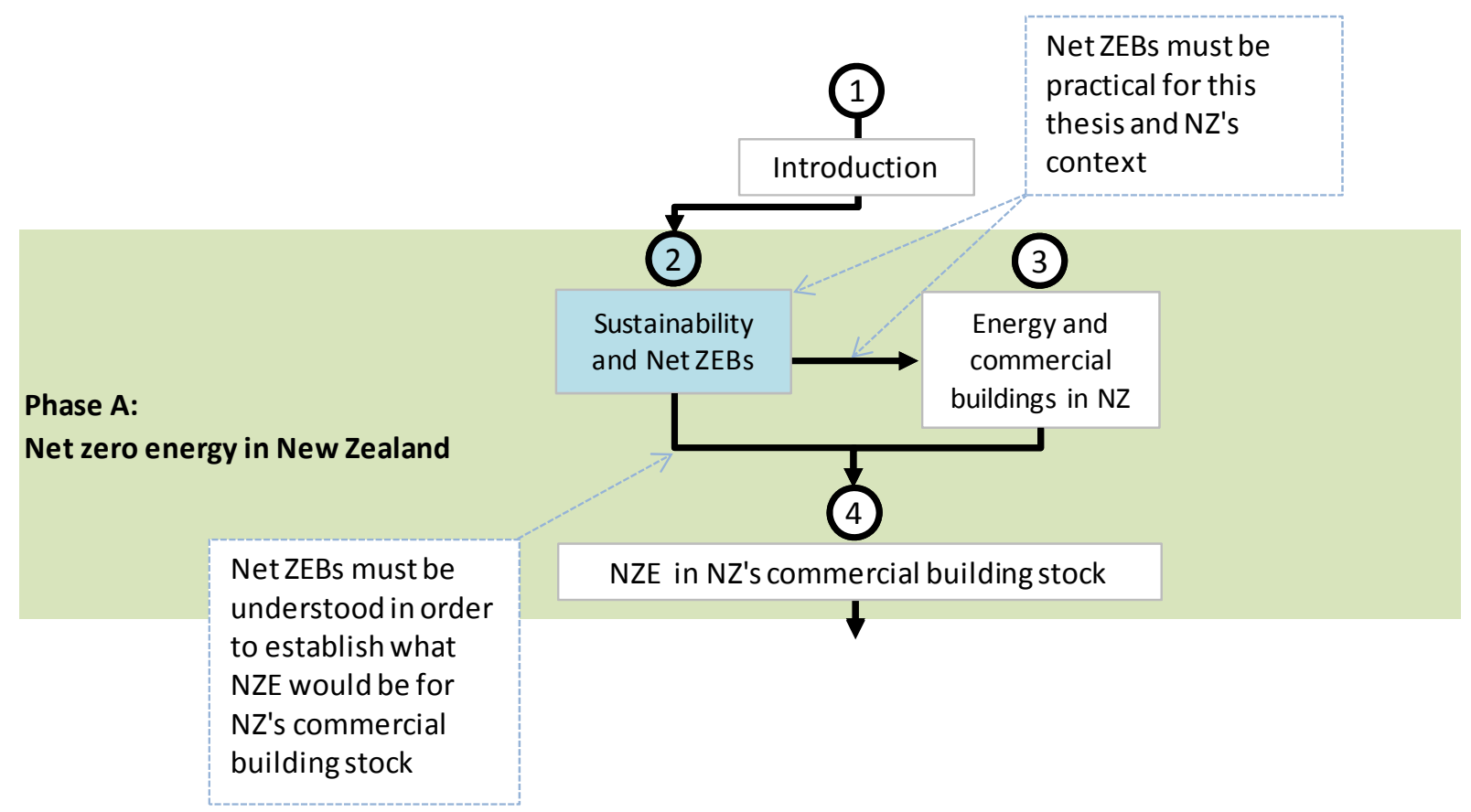

Figure 2-6 : Chapter 2 linkages to Chapter 3 and 4. 



\section{CHAPTER 3. NEW ZEALAND'S UNIQUE ENERGY AND BUILDING CONTEXT}

\subsection{Chapter Intent}

Chapter 3 describes the unique context of New Zealand's energy and building infrastructure. Chapter 2 highlighted the context used to inform the four sets of parameters identified in the IEA Net ZEB definition framework for formulating a definition (Sartori, Napolitano, and Voss 2012). This latter context is presented to understand the Site Setting(s), Building type(s), Nature of the building(s), Grid connection, and Grid energy supply of the current New Zealand energy infrastructure and commercial building stock. Figure 3-1 illustrates the linkages between Chapter 2 and Chapter 3 .

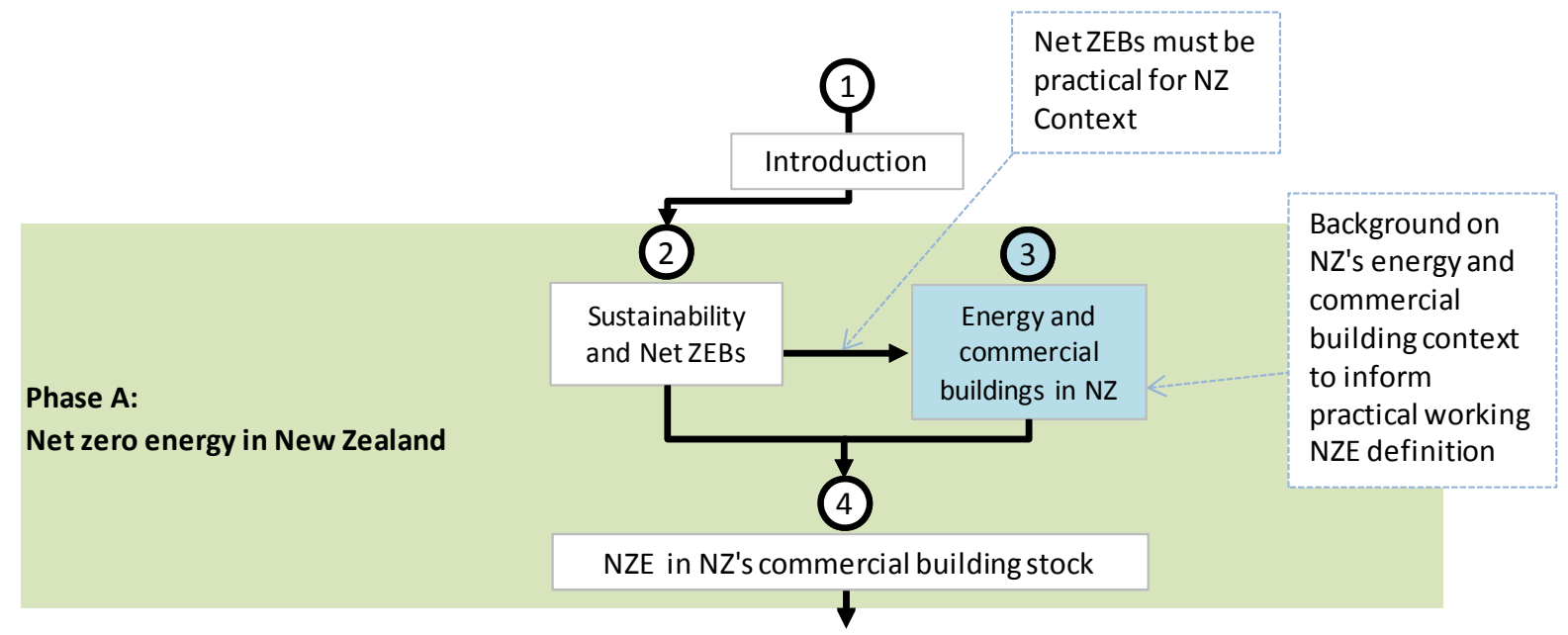

Figure 3-1 : Chapter 2 and 3 linkages.

\subsection{Grid connection and energy supply in New Zealand}

New Zealand is an island country in the South Pacific Ocean. It is comprised of two main landmasses, the North Island and the South Island. New Zealand is isolated geographically, with Australia (2,000km northwest) its closest neighbouring country (Figure 3-2). "As a small land mass surrounded by oceans, New Zealand enjoys a temperate climate with mean annual temperatures ranging from $10^{\circ} \mathrm{C}$ in the south, to $16^{\circ} \mathrm{C}$ in the north, and most of New Zealand has at least 1,800 annual sunshine hours" (Ministry for Culture and Heritage 2013). There is one national electricity grid that is not connected to any other nation, but there is a connection between the North Island and the South Island (Figure 3-2 - Inter-island transmission line) (Energy Information and Modelling Group 2012b). As the electricity grid is nationwide, almost every New Zealand building is connected together. 
Figure 3-2 displays the composition of the national electricity grid. It shows that the generating plants (blue dots) are sited far from the main energy load centres (red dots) in New Zealand, with the largest settlements in each New Zealand region contributing to the main energy loads.

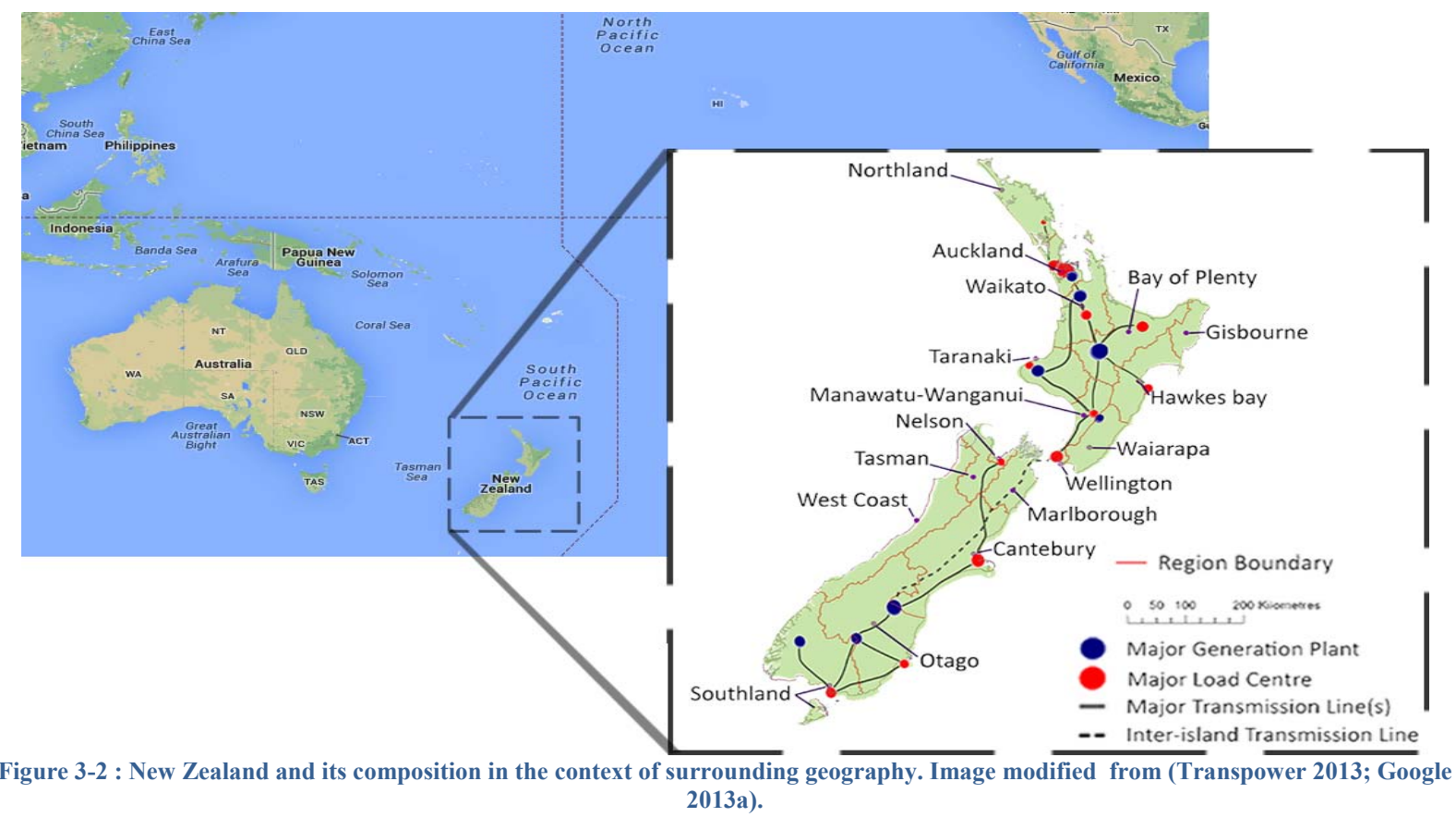

\subsubsection{Primary Energy Consumption}

Figure 3-3 displays the split of energy sources (Oil, Coal, Natural Gas, Direct-use Renewables, and Electricity ${ }^{2}$ ) consumed by the different New Zealand sectors in 2011.

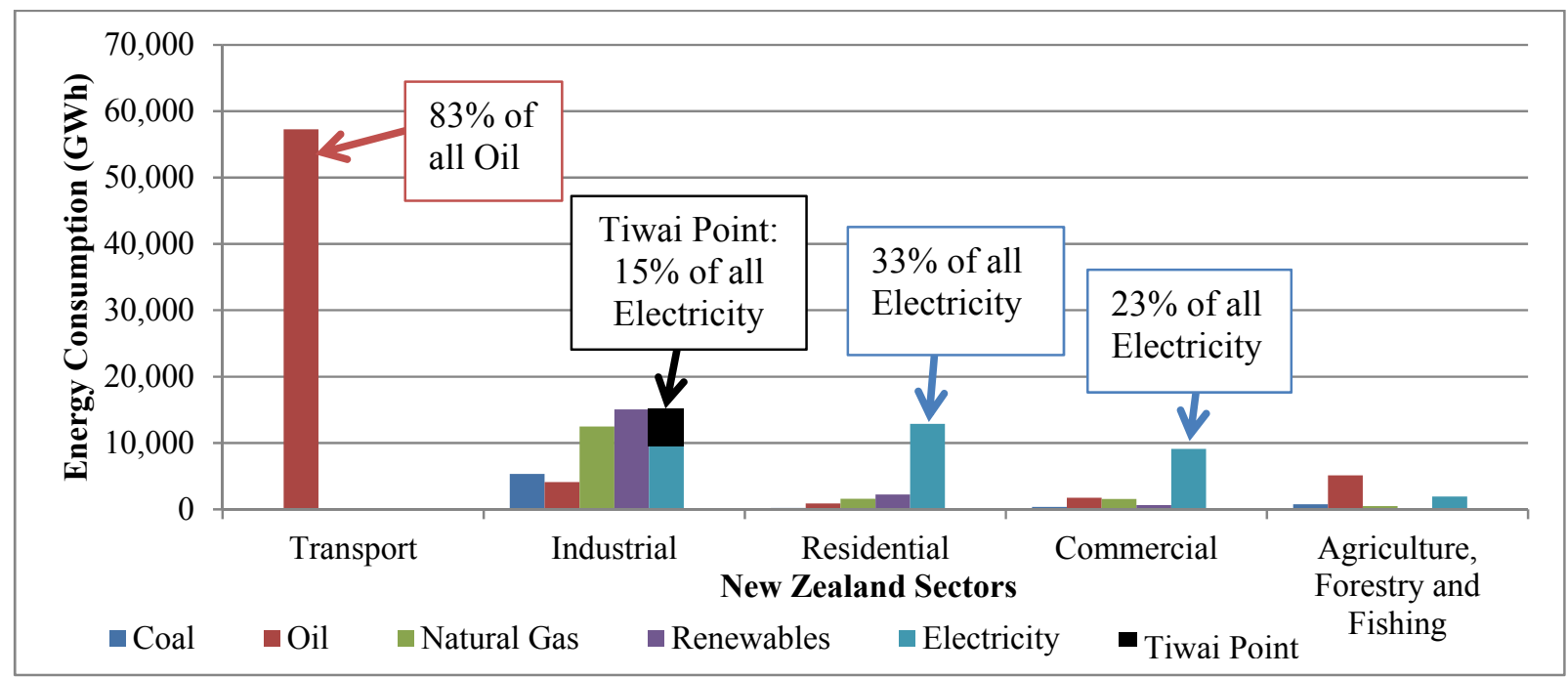

Figure 3-3 : 2011 Split of all energy sources consumed by the different New Zealand sectors. Figure created using (Energy Information and Modelling Group 2012b; Bennett 2007).

\footnotetext{
${ }^{2}$ Renewable electricity generation is not differentiated.
}

Page $\mid 41$ 
Oil (red) was the most dominant fuel consumed and made up 46 percent of all energy used in New Zealand. The second largest fuel consumed was electricity (light blue) making up 26 percent. The third largest fuel was renewables followed by natural gas (green). The largest energy consumer was the Transport sector which consumed 38 percent of all energy. The second largest was the industrial sector consuming 35 percent of all energy. The third largest consumer was the residential sector consuming 12 percent and the fourth was the commercial sector consuming 9 percent (Energy Information and Modelling Group 2012b, pp.20-31).

The transport sector accounted for 83 percent of all oil consumed. The majority of electricity consumed was split relatively evenly across the industrial, residential and commercial sectors. One aluminium smelter located in the South Island was the largest single user of electricity in the country accounting for approximately 15 percent of all New Zealand electricity consumed (Bennett 2007) and 40\% of all industrial electricity consumption. Commercial buildings, which are part of the commercial sector, made up the third largest electricity consumer, consuming 23 percent of the total electricity generated. The total electricity used by the commercial and residential sector was not entirely from their associated building stocks. In the commercial sector, commercial travel and other non-residential building types (building types that are not office, retail or mixed such as health and education buildings) also consume energy.

New Zealand has an indigenous source of fossil fuels. In 2011, all natural gas consumed in New Zealand was indigenous, meaning that no natural gas was imported into New Zealand. In 2011, oil was New Zealand's largest source of energy and there are a number of producing oil fields in New Zealand. However, most of New Zealand's oil is imported. In 2011, net oil import dependency was 57 percent. Net oil import dependency is the percentage of total New Zealand oil consumption that could not be satisfied by indigenous production (Energy Information and Modelling Group 2012b, p.7)."The total amount of coal used in 2011 was 2.8 million tonnes, of which over 0.2 million tonnes were imported, with the remainder coming from local production" (Energy Information and Modelling Group 2012b, p.33). This means that 7 percent of coal is imported. This imported coal ran the North Island coal fired electricity generation plant in 2011.

Renewables are abundant in New Zealand with approximately 77 percent of the national electricity generation sourced from Hydro-electric, geothermal and wind in 2011. Renewable energy was also used for direct-use heat applications around New Zealand, mostly in the form of woody biomass used in the timber industry and in residential homes, geothermal is used directly as a heat source in small quantities in the timber and tourism industries, and domestic heating (Energy Information and Modelling Group 2012b, p.97).

\subsubsection{GHG and $\mathrm{CO}_{2}$ emitted by New Zealand}

Greenhouse Gases (GHG) are gases that absorb and emit radiation within the thermal infrared range. GHGs are the cause of climate change (IPCC 2007b). GHGs are made up from a number of naturally occurring and human-made gases. There are seven gases measured in New Zealand under the Kyoto Protocol including Carbon Dioxide $\left(\mathrm{CO}_{2}\right)$; methane $\left(\mathrm{CH}_{4}\right)$; nitrous oxide $\left(\mathrm{N}_{2} \mathrm{O}\right)$;

Page $\mid 42$ 
carbon monoxide $(\mathrm{CO})$; nitrogen oxides $\left(\mathrm{NO}_{\mathrm{x}}\right)$; non-methane volatile organic compounds (NMVOCs); and sulphur dioxide $\left(\mathrm{SO}_{2}\right)$. In 2011, there was 30,787 kilotonnes of Carbon Dioxide Equivalent ( $\mathrm{kt} \mathrm{CO}_{2}$-) GHG emissions. Of the seven $\mathrm{GHG}$ gases emitted in New Zealand, $\mathrm{CO}_{2}$ was the most important and prevalent. $\mathrm{CO}_{2}$ was responsible for 98 percent of all $\mathrm{GHG}$ emissions in 2011(The Ministry of Economic Development 2013, p.vii). Hence, the focus of all future GHG and emissions analysis in this thesis was based on $\mathrm{CO}_{2}$.

Figure 3-4 displays New Zealand's $\mathrm{CO}_{2}$ emissions split by Energy Sector for 2011. Fifteen percent of all $\mathrm{CO}_{2}$ emissions emitted were from generating electricity. All emissions from electricity generation were produced from thermal electric generation such as coal, gas and oil. This is the second largest single (manufacturing and construction have multiple emitting types) emitter of $\mathrm{CO}_{2}$ across all sectors behind Domestic Road transport which accounts for 38 percent of all $\mathrm{CO}_{2}$ emitted. This makes emissions from electricity generation the second largest area for potential improvements for reducing emissions. Between 1990 and 2011 there was a 32 percent increase in $\mathrm{CO}_{2}$ emissions across all energy sectors, with 3.6 percent of the increase associated with electricity generation and 72 percent from the domestic road transport sector (The Ministry of Economic Development 2013, pp.34-40).

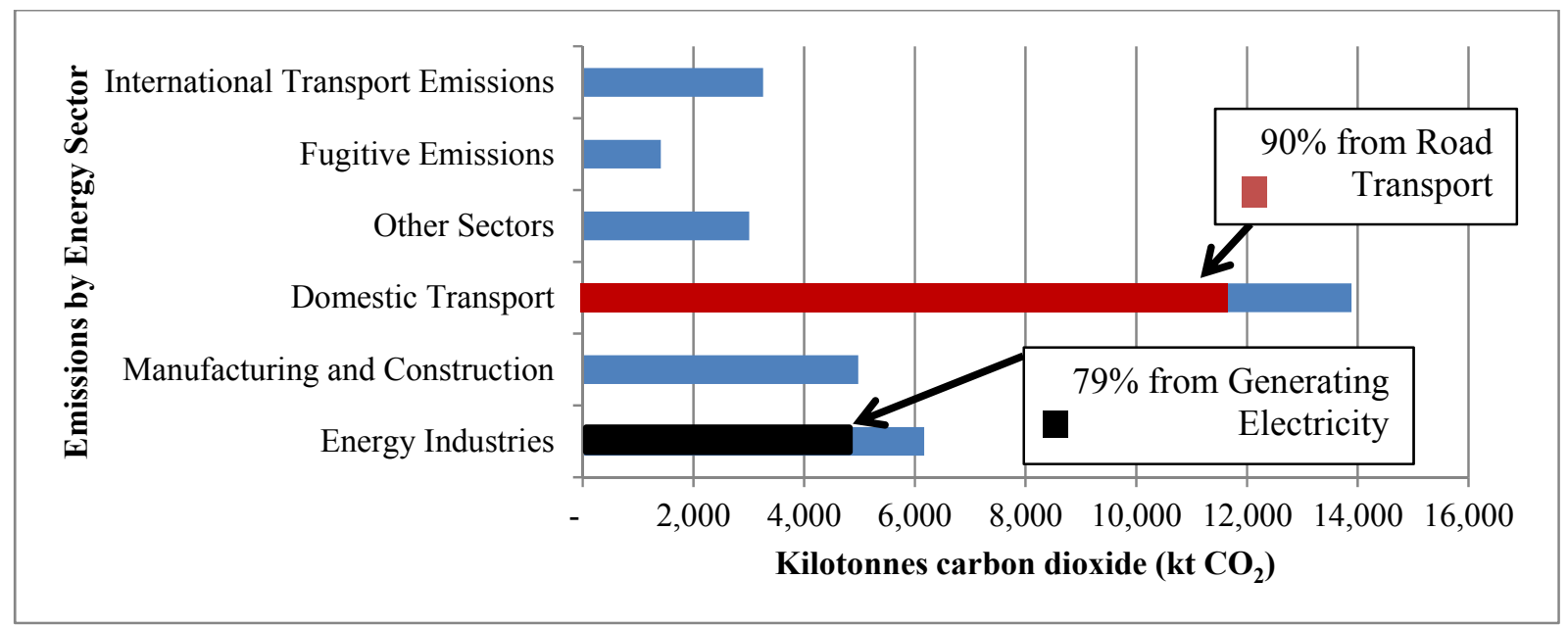

Figure 3-4 : $2011 \mathrm{CO}_{2}$ Emissions split by Energy Sector. Figure created using (The Ministry of Economic Development 2013, pp.27-40). 


\subsubsection{New Zealand's electricity grid}

Figure 3-5 displays the historical electricity generation in New Zealand.

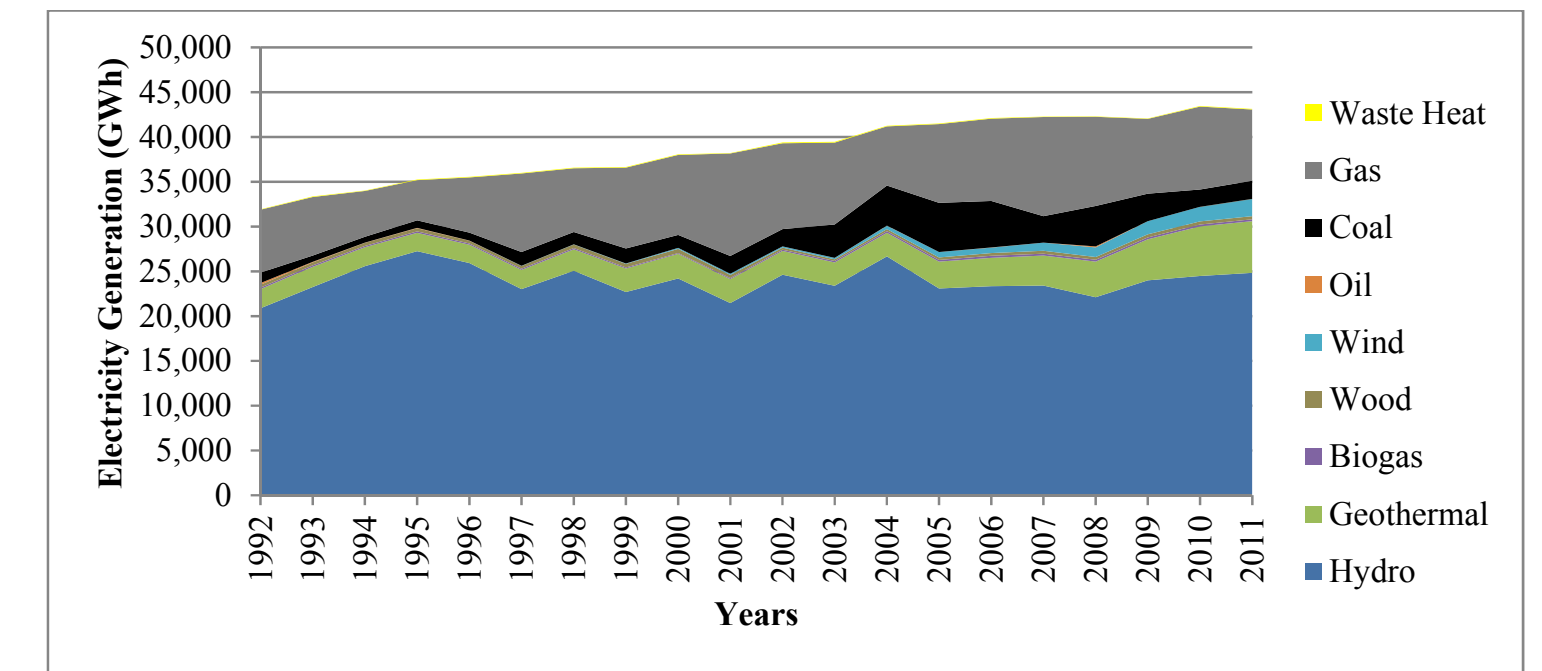

Figure 3-5 : Historical annual net (end-use) electricity generation by fuel type. Figure created using (Energy Information and Modelling Group 2012b, p.103).

Historically, the electricity generation has largely been through hydro-electric generation and this continues to provide the majority of electricity to the national grid today. The portion of renewable electricity generation versus non-renewable tends to fluctuate from year to year. The range has been quite large; with the historical high of 91 percent renewable generation in 1980 and 64 percent renewable in 2001.The largest influence was the growth of electric demand from 1980 to the present. This meant more thermal electricity generation was needed to meet the demand. Another factor was the fluctuation in hydro-electric generation due to the variation in annual rainfall (for more refer to Section 12.5.3).

Average annual electricity demand grew by 0.5 percent from 2007 to 2011. However, since 2011 the electricity demand has dropped and this can be attributed to reduced demand in the wake of the 22 February 2011 earthquake in Canterbury. The reduction in demand primarily affected the commercial and residential sectors which declined by 1.4 percent and 2.3 percent respectively" (Energy Information and Modelling Group 2012b, p.105).

Figure 3-6 shows the percentage of electricity generated from the various fuel sources in 2011. Hydro-electric generation accounted for 58 percent of the total electricity generation, geothermal 13 percent, and wind 7 percent. The hydro-electric generation combined with wind, geothermal and other renewable generation such as solar energy, bio-energy and marine energy, total to 77 percent of all electricity generation. Although such a large percentage was provided through renewable means, the non-renewable electricity generation was very important. This is because all of the non-renewable electricity generation was sourced from fossil fuel thermal plants. "Electricity generation from the combustion of coal, oil and gas plays a crucial role in New Zealand's electricity system by providing baseload, backup and peak load supply.... The North

Page $\mid 44$ 
Island consumes approximately two thirds of the electricity generated in New Zealand, with the Auckland region accounting for around 25 percent of all electricity consumed in New Zealand" (Energy Information and Modelling Group 2012b, p.104).

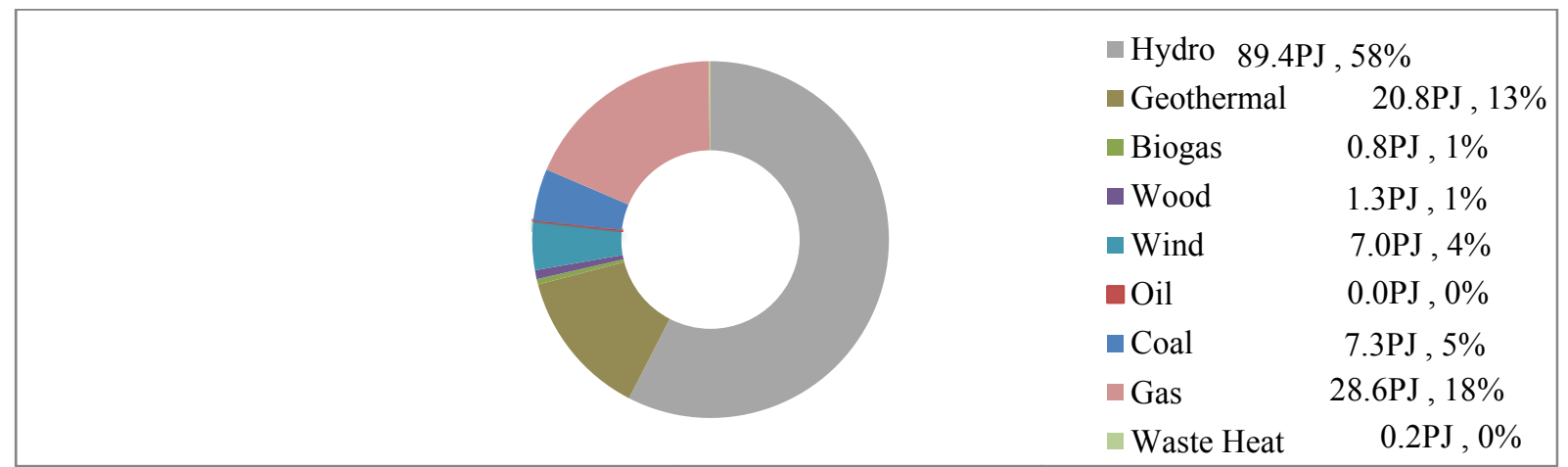

Figure 3-6 : Electricity generation split by generation source for 2011. Figure created using (Energy Information and Modelling Group 2012b, p.102).

Figure 3-7 displays the percentage split of energy types consumed by the commercial sector in 2011.

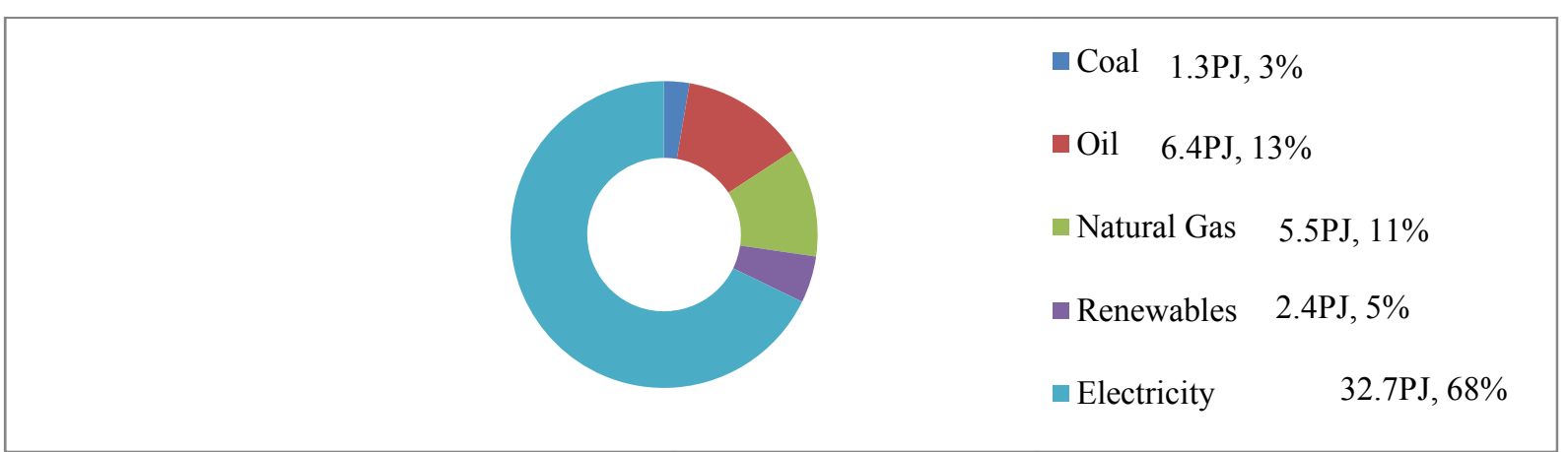

Figure 3-7 : Split of energy sources consumed by the commercial sector for 2011. Figure created using (Energy Information and Modelling Group 2012b, pp.20-31).

Electricity made up the largest proportion, supplying 68 percent of the energy consumed by the commercial sector. Oil was the second highest source accounting for 13 percent of total consumption and was closely followed by natural gas which accounted for 11 percent. Renewables made up 5 percent of commercial energy used with coal making up the remaining 3 percent of energy used. Because all of the generation goes into the same national grid, electricity consumed by the commercial sector was supplied by the same mix of generation types as seen in Figure 3-6.

\subsection{Site and nature of the New Zealand's Commercial Building Stock}

Using the New Zealand Building Energy End-use Study (BEES) information, it was estimated that there were approximately 28,000 commercial buildings in New Zealand that amount to a total floor area of 25.1 million square metres $\left(\mathrm{m}^{2}\right)$ (Isaacs 2011). In this study the commercial building stock floor area was split into groups according to their size. The size of the groups ranged from 17 percent to 24 percent of the total commercial floor area in New Zealand. The floor area was split into groups for statistical purposes (refer to Section 6.5).

Page 45 
Table 3-1 : Commercial Building Stock Summary. Table created using (QV 2008).

\begin{tabular}{|c|c|c|c|c|c|c|c|}
\hline $\begin{array}{c}\text { Building } \\
\text { Type }\end{array}$ & $\begin{array}{c}\text { Floor Area } \\
\text { Size Ranges }\end{array}$ & $\begin{array}{c}5 \text { to } \\
649 \mathrm{~m}^{2}\end{array}$ & $\begin{array}{c}650 \text { to } \\
1,499 \mathrm{~m}^{2}\end{array}$ & $\begin{array}{l}1,500 \text { to } \\
3,499 \mathrm{~m}^{2} \\
\end{array}$ & $\begin{array}{l}3,500 \text { to } \\
8,999 \mathrm{~m}^{2} \\
\end{array}$ & $\begin{array}{c}\text { over } \\
9,000 \mathrm{~m}^{2} \\
\end{array}$ & Total \\
\hline \multirow{5}{*}{$\begin{array}{c}\text { Commercial } \\
\text { Office }\end{array}$} & $\begin{array}{l}\text { Approximate } \\
\text { number of } \\
\text { buildings }\end{array}$ & 3,709 & 997 & 547 & 314 & 131 & 5,698 \\
\hline & $\begin{array}{l}\text { Percentage of } \\
\text { buildings }\end{array}$ & $65 \%$ & $17 \%$ & $10 \%$ & $6 \%$ & $2 \%$ & $100 \%$ \\
\hline & $\begin{array}{l}\text { Total floor } \\
\text { area }\left(\mathrm{m}^{2}\right)\end{array}$ & $1,053,000$ & 987,000 & $1,222,000$ & $1,682,000$ & $1,978,000$ & $6,922,000$ \\
\hline & $\begin{array}{l}\text { Percentage of } \\
\text { floor area }\end{array}$ & $15 \%$ & $14 \%$ & $18 \%$ & $24 \%$ & $29 \%$ & $100 \%$ \\
\hline & $\begin{array}{l}\text { Average Floor } \\
\text { Area }\left(\mathrm{m}^{2}\right)\end{array}$ & 284 & 990 & 2,234 & 5,357 & 15,099 & 1,215 \\
\hline \multirow{5}{*}{$\begin{array}{c}\text { Commercial } \\
\text { Retail }\end{array}$} & $\begin{array}{l}\text { Approximate } \\
\text { number of } \\
\text { buildings }\end{array}$ & 12,806 & 2,365 & 716 & 224 & 113 & 16,224 \\
\hline & $\begin{array}{l}\text { Percentage of } \\
\text { buildings }\end{array}$ & $79 \%$ & $15 \%$ & $4 \%$ & $1 \%$ & $1 \%$ & $100 \%$ \\
\hline & $\begin{array}{l}\text { Total floor } \\
\text { area }\left(\mathrm{m}^{2}\right)\end{array}$ & $3,687,000$ & $2,217,000$ & $1,572,000$ & $1,142,000$ & $2,085,000$ & $\begin{array}{c}10,703,00 \\
0\end{array}$ \\
\hline & $\begin{array}{l}\text { Percentage of } \\
\text { floor area }\end{array}$ & $34 \%$ & $21 \%$ & $15 \%$ & $11 \%$ & $19 \%$ & $100 \%$ \\
\hline & $\begin{array}{l}\text { Average Floor } \\
\text { Area }\left(\mathrm{m}^{2}\right)\end{array}$ & 288 & 937 & 2,196 & 5,098 & 18,451 & 660 \\
\hline \multirow{5}{*}{$\begin{array}{l}\text { Commercial } \\
\text { Mixed }\end{array}$} & $\begin{array}{l}\text { Approximate } \\
\text { number of } \\
\text { buildings }\end{array}$ & 3,446 & 1,318 & 646 & 338 & 98 & 5,846 \\
\hline & $\begin{array}{l}\text { Percentage of } \\
\text { buildings }\end{array}$ & $59 \%$ & $23 \%$ & $11 \%$ & $6 \%$ & $2 \%$ & $100 \%$ \\
\hline & $\begin{array}{l}\text { Total floor } \\
\text { area }\left(\mathrm{m}^{2}\right)\end{array}$ & $1,115,000$ & $1,285,000$ & $1,436,000$ & $1,817,000$ & $1,864,000$ & $7,517,000$ \\
\hline & $\begin{array}{l}\text { Percentage of } \\
\text { floor area }\end{array}$ & $15 \%$ & $17 \%$ & $19 \%$ & $24 \%$ & $25 \%$ & $100 \%$ \\
\hline & $\begin{array}{l}\text { Average Floor } \\
\text { Area }\left(\mathrm{m}^{2}\right)\end{array}$ & 324 & 975 & 2,223 & 5,376 & 19,020 & 1,286 \\
\hline \multirow{5}{*}{$\begin{array}{c}\text { All } \\
\text { Commercial } \\
\text { Buildings }\end{array}$} & $\begin{array}{l}\text { Approximate } \\
\text { number of } \\
\text { buildings }\end{array}$ & 19,961 & 4,680 & 1,909 & 876 & 342 & 27,768 \\
\hline & $\begin{array}{l}\text { Percentage of } \\
\text { buildings }\end{array}$ & $72 \%$ & $17 \%$ & $7 \%$ & $3 \%$ & $1 \%$ & $100 \%$ \\
\hline & $\begin{array}{l}\text { Total floor } \\
\text { area }\left(\mathrm{m}^{2}\right)\end{array}$ & $5,855,000$ & $4,489,000$ & $4,230,000$ & $4,641,000$ & $5,927,000$ & $\begin{array}{c}25,142,00 \\
0\end{array}$ \\
\hline & $\begin{array}{l}\text { Percentage of } \\
\text { floor area }\end{array}$ & $23 \%$ & $18 \%$ & $17 \%$ & $18 \%$ & $24 \%$ & $100 \%$ \\
\hline & $\begin{array}{l}\text { Average Floor } \\
\text { Area }\left(\mathrm{m}^{2}\right)\end{array}$ & 293 & 959 & 2,216 & 5,298 & 17,330 & 905 \\
\hline
\end{tabular}

Page $\mid 46$ 
Table 3-1 summarises the floor area size ranges for each building use type as well as for the whole building stock in 2011. The building use types are split into Office, Retail and Mixed. For more information on each building type refer to Section 5.2.4. The breakdown shows the approximate number and percentage of buildings in each building use and size group category, the total and percentage of total floor area in each building use and size group category and the average floor area of a building in each building size range for each category. The breakdown in Table 3-1 shows that the majority of New Zealand's commercial building stock in 2011 was small grid-tied buildings. Seventy two percent of the commercial buildings were less than $650 \mathrm{~m}^{2}$ and 89 percent are less than $1,500 \mathrm{~m}^{2}$ in floor area. However, the remaining 11 percent (over $1500 \mathrm{~m}^{2}$ ) of buildings represent 59 percent of all commercial floor area. This is significant as these buildings were most likely to be the large energy consumers (refer to Section 3.3.5) within the building stock. Each building type follows the same trend. In 2011, commercial retail buildings made up 10.7 million $\mathrm{m}^{2}$ which was 43 percent of all commercial building floor area. Commercial mixed buildings made up 30 percent and offices made up 28 percent of the total floor area. The average floor area for a commercial mixed and office building $\left(1286 \mathrm{~m}^{2}\right.$ and $1215 \mathrm{~m}^{2}$ respectively) was approximately twice as large as a commercial retail building $\left(660 \mathrm{~m}^{2}\right)$. This indicated that the majority of very large buildings were commercial mixed and office use type buildings, and the majority of small buildings were commercial retail use type buildings.

All further analysis of the commercial building stock attributes presented in this thesis was undertaken using the building floor area shown in Table 3-1. Floor area was used as the metric due to the majority of energy analysis being normalised by floor area and presented as an Energy Performance Indicator (EnPI).

\subsubsection{Age}

Figure 3-8 shows the percentage of commercial office, retail and mixed floor area in buildings of differing ages.

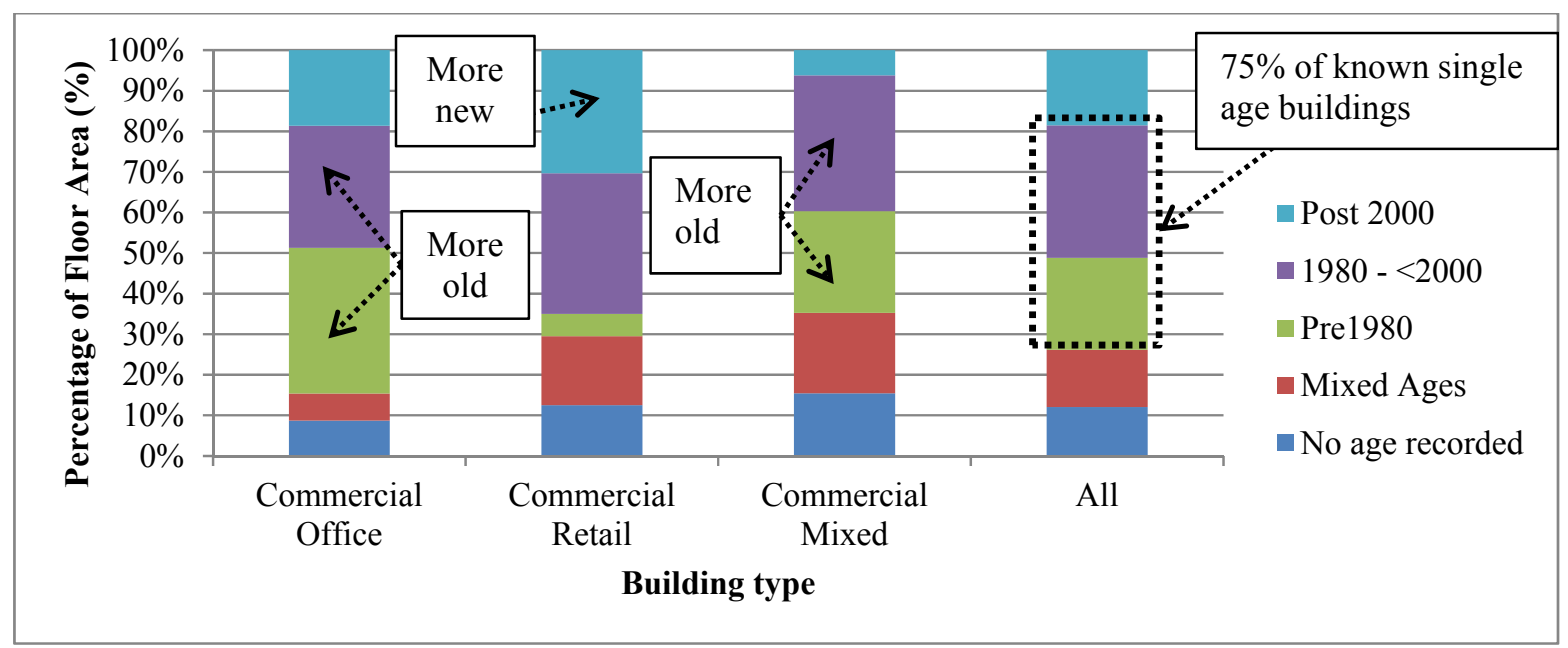

Figure 3-8 : Percentage of Commercial Office, Retail and Mixed floor area in different aged buildings. Figure created using (QV 2008). 
Approximately half (52 percent) of all floor area was attributed to buildings built post-1980. There were also a proportion of buildings where no build year was recorded (12 percent) or where they were of a mixed age (14 percent). Thirty one percent of the floor area in all known single aged commercial buildings was within buildings constructed before 1980, while those buildings constructed during 1980-2000 and post 2000 accounted for 44 percent and 25 percent of total floor area respectively. This indicated that 75 percent of all single aged commercial floor area was in buildings aged 13 years or older. Office and Mixed had a near 50/50 split of post and pre-1980 building floor area. A larger proportion (92 percent post-1980) of retail floor area was in newer buildings. Building age is important as it can indicate when refurbishment is likely to be required as discussed in Section 11.3.2. Buildings constructed before 2000 had already had an upgrade or will be about to approach the age where they need to be upgraded from an energy or rentable condition perspective. Energy upgrades are required because these buildings pre-date strict energy efficiency building code requirements. In addition, the energy performance of a building has likely degraded over the 10 or more years of operation. This means that 75 percent of the floor area within the commercial building stock is approaching an age where it will require a retrofit.

\subsubsection{Geography}

Figure 3-9 displays the amount and percentage of floor area located in each region of New Zealand split by floor area size range (refer to Figure 3-2 for regional map of New Zealand).

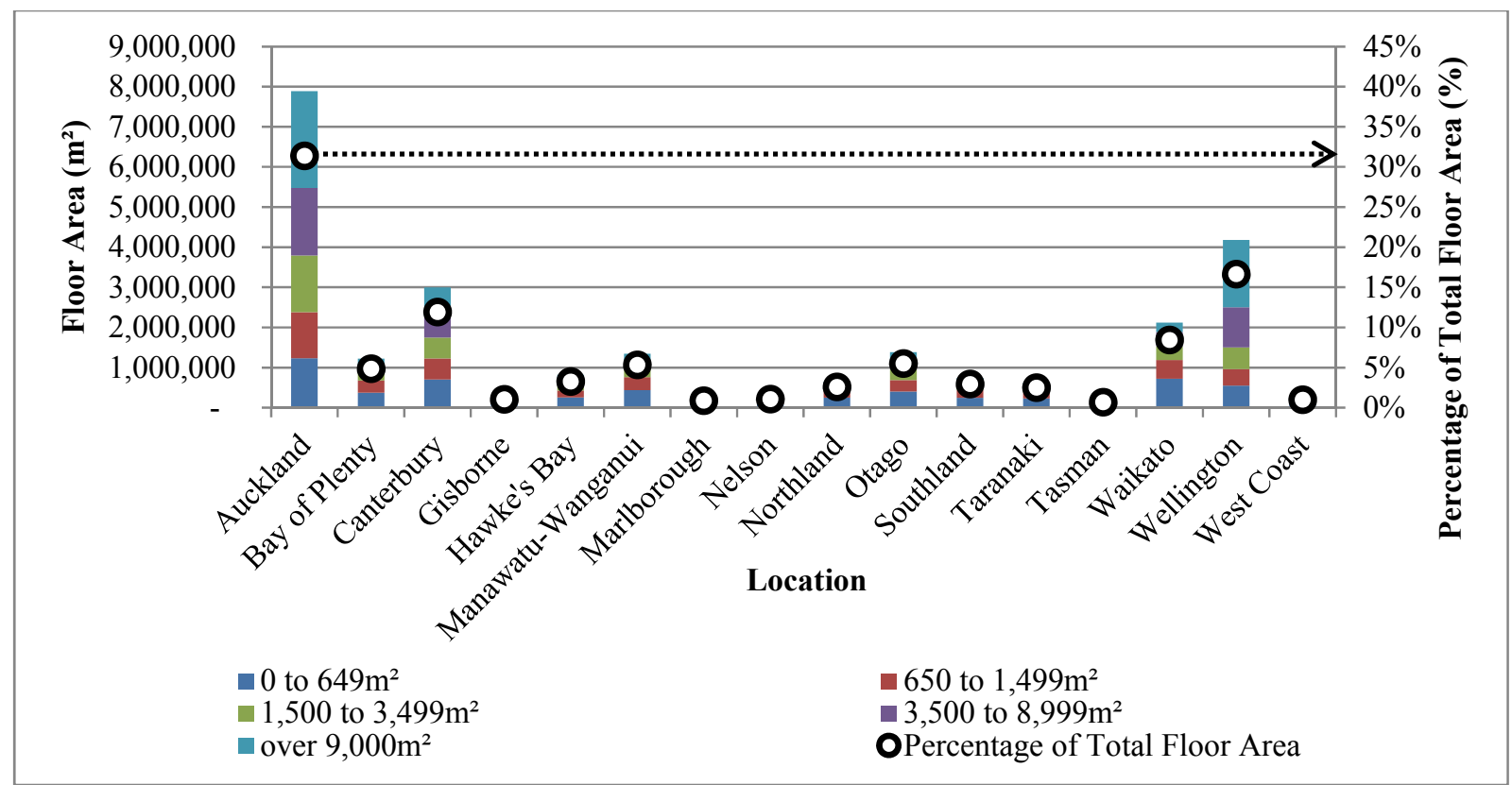

Figure 3-9: Amount and percentage of floor area located in each region split by floor area size range. Figure created using (BEES 2013b; QV 2008).

In 2011, Auckland had the largest commercial floor area with approximately 7.9 million $\mathrm{m}^{2}$ which represented 31 percent of all commercial building floor area in New Zealand. The floor area of commercial buildings in Wellington $\left(4\right.$ million $\left.\mathrm{m}^{2}\right)$ represented 17 percent of the total commercial building floor area in New Zealand. Canterbury had 12 percent of New Zealand's

Page $\mid 48$ 
floor area and equates to approximately 3 million $\mathrm{m}^{2}$. Sixty percent of all commercial floor area was located in these 3 regions. Eighty one percent of large buildings (with a floor area over $9000 \mathrm{~m}^{2)}$ were located in these three regions.

\subsubsection{Height}

Figure 3-10 displays the amount of floor area in buildings according to their height and floor area size range. Table 3-2 shows the percentage of buildings that are 1 to 2 storeys in height in each floor area size range.

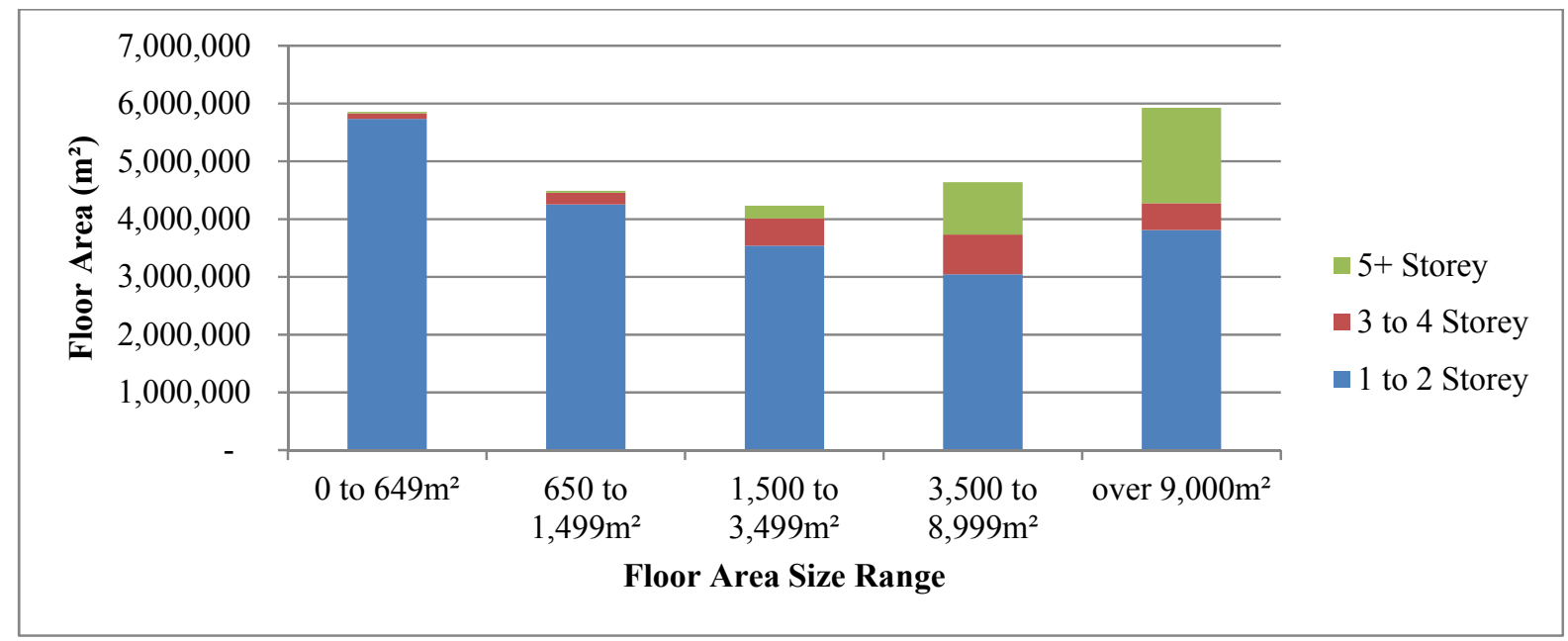

Figure 3-10 : Amount of floor area in buildings with a different number of storeys in each floor area size range. Figure created using ((BEES 2013b; QV 2008).

Table 3-2 : Percentage of buildings in each floor area size range that are 1 to 2 storeys in height. Table created using (BEES 2013b; QV

\begin{tabular}{|c|c|c|c|c|c|c|}
\hline \multirow[b]{2}{*}{ Storeys } & \multicolumn{6}{|c|}{ Floor Area Size Range } \\
\hline & 0 to $649 \mathrm{~m}^{2}$ & $\begin{array}{c}650 \text { to } \\
1,499 \mathrm{~m}^{2}\end{array}$ & $\begin{array}{l}1,500 \text { to } \\
3,499 \mathrm{~m}^{2}\end{array}$ & $\begin{array}{l}3,500 \text { to } \\
8,999 \mathrm{~m}^{2}\end{array}$ & $\begin{array}{c}\text { over } \\
9,000 \mathrm{~m}^{2}\end{array}$ & All \\
\hline 1 to 2 Storey & $98 \%$ & $95 \%$ & $84 \%$ & $66 \%$ & $64 \%$ & $68 \%$ \\
\hline
\end{tabular}

In 2011, the bulk of the commercial building stock was 2 storeys or less (blue bar). Approximately 68 percent of all commercial building floor area was in buildings that are 2 storeys or lower. Ninety eight percent of building floor area in buildings less than $650 \mathrm{~m}^{2}$ was in 1 to 2 storey buildings. Ninety three percent of building floor area in buildings less than $3500 \mathrm{~m}^{2}$ was in 1 to 2 storey buildings. Ninety six percent of all buildings with 3 or more storeys were buildings with floor areas of $3500 \mathrm{~m}^{2}$ or greater. 
Figure 3-11 displays the amount of floor area in different height buildings within the various New Zealand regions. One to two storey buildings are located throughout the whole country (blue bar). However, the taller buildings were mostly located in the three main centres: Auckland, Wellington, and Canterbury. Seventy three percent of all buildings over three storeys and 83 percent of all buildings over five storeys were located in the three main centres

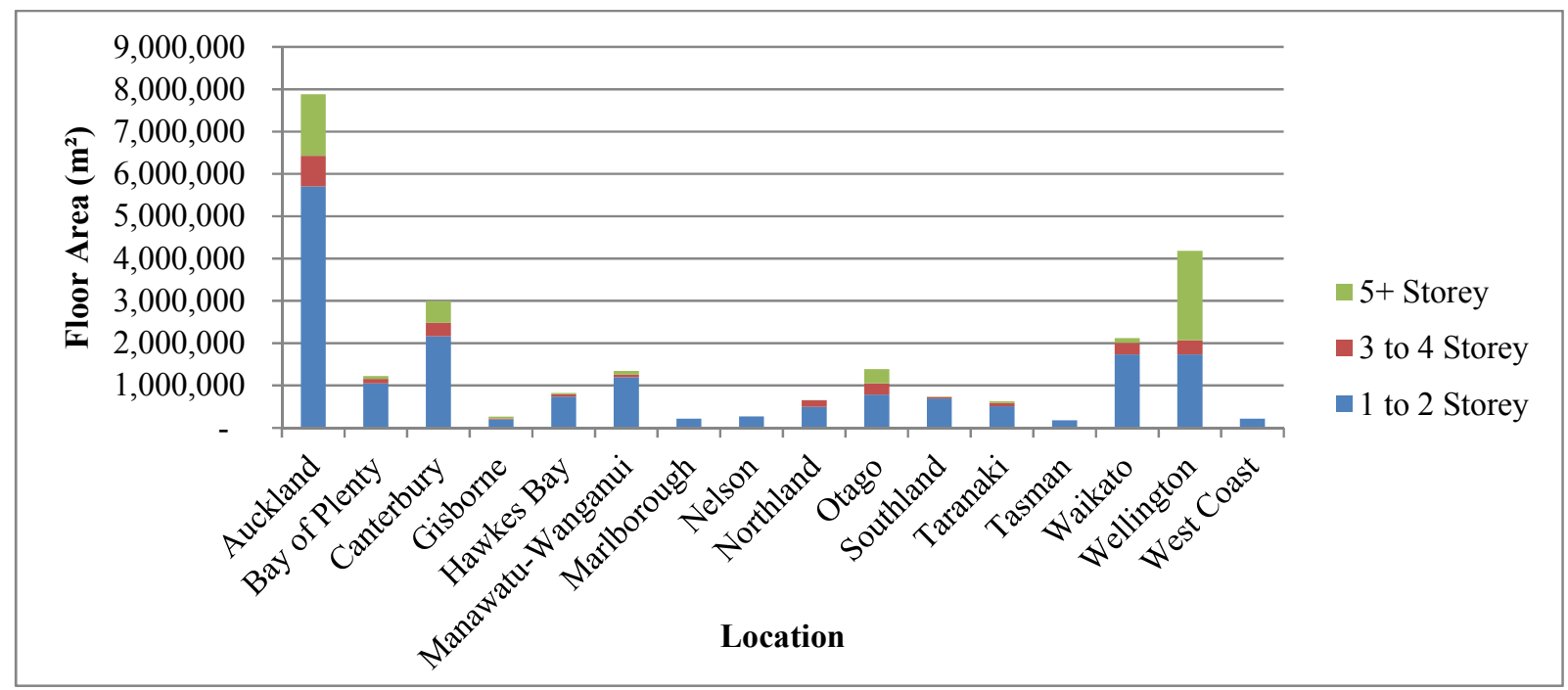

Figure 3-11 : Amount of floor area in each region in buildings with different number of storey ranges. Figure created using (BEES 2013b; QV 2008).

\subsubsection{Site context}

Figure 3-12 presents the breakdown of buildings according to their urban, suburban or rural setting. Urban buildings are located in concentrated urban or semi-urban settlements (Statistics New Zealand 2013). Suburban buildings are properties found within one area with multiple street blocks. Rural buildings are properties that only have one or two main roads passing through the area.

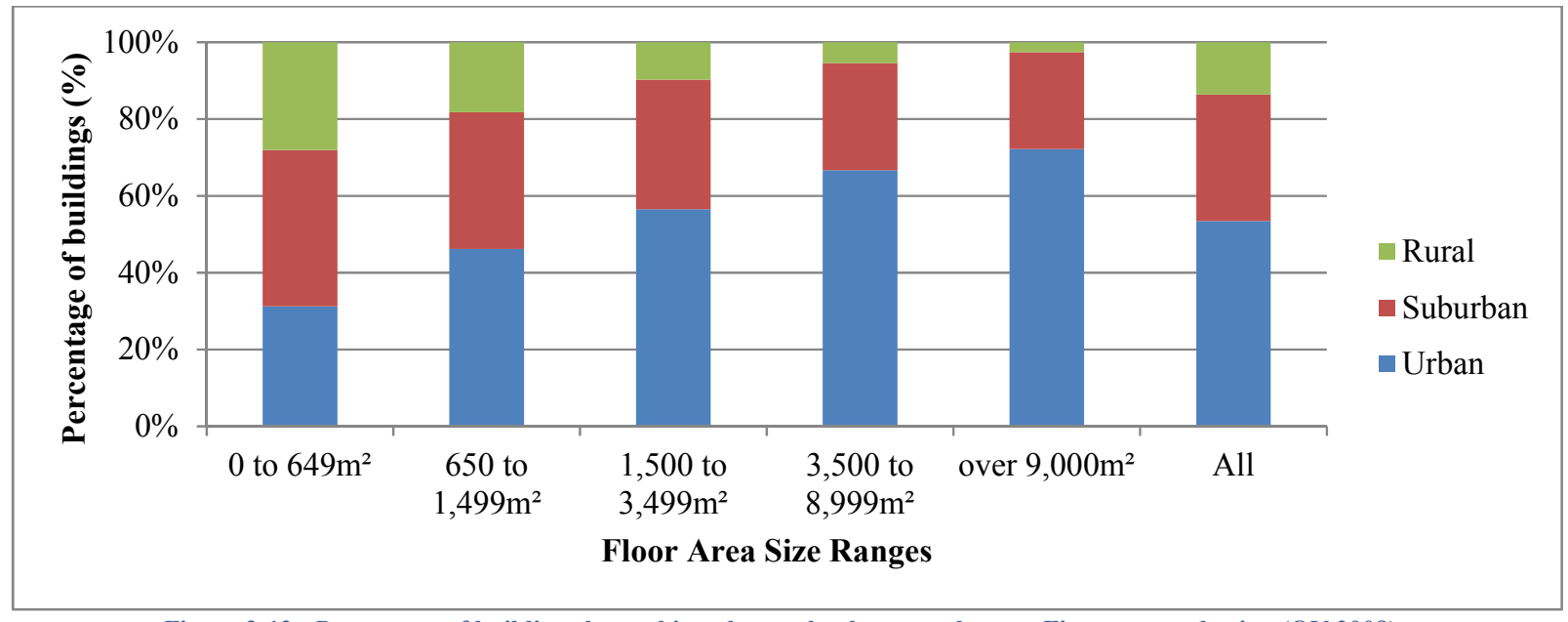

Figure 3-12 : Percentage of buildings located in urban, suburban, rural areas. Figure created using (QV 2008). 
In 2011, the majority of commercial floor area was within buildings located in urban areas (52 percent) and well over half of the larger commercial building floor area $\left(1500 \mathrm{~m}^{2}-9000 \mathrm{~m}^{2}\right.$ and greater) was located in urban areas. This coupled with larger multi-story buildings being located in the three main centres suggested that the larger commercial buildings were located in the Central Business Districts (CBD) of these regions. As a consequence, this creates a difficult situation for retrofitting these large buildings to be Net ZEBs. This difficulty arises from two factors. Firstly, buildings over two storeys are generally accepted as being harder to design to be NZE due to the lower building surface to volume ratio (Hanitsch, Schulz, and Siegfried 2001). There is also a lower roof area to floor area ratio for buildings with two or more storeys which results in less energy generation per square metre of floor area. Secondly, CBDs are more densely built up which causes a lot of site shading. Site shading hinders the performance of daylighting, passive solar heating, and onsite renewable energy generation such as photovoltaic (PV) and wind turbines. Figures 3-14 and 3-16 show an assessment of the amount of site shading from surrounding buildings that occurs across the current building stock, including the impact of shading on possible PV generation, daylighting and passive solar heat gains.

Figure 3-13 illustrates how shading from an opposite or adjacent building impacts on the amount of solar radiation the rooftop receives and the associated effect that site shading has on the potential PV generation capabilities. The impediment to PV generation is inferred from a loss in output when there is less solar radiation being received on the PV surface (SMA Solar Technology AG).

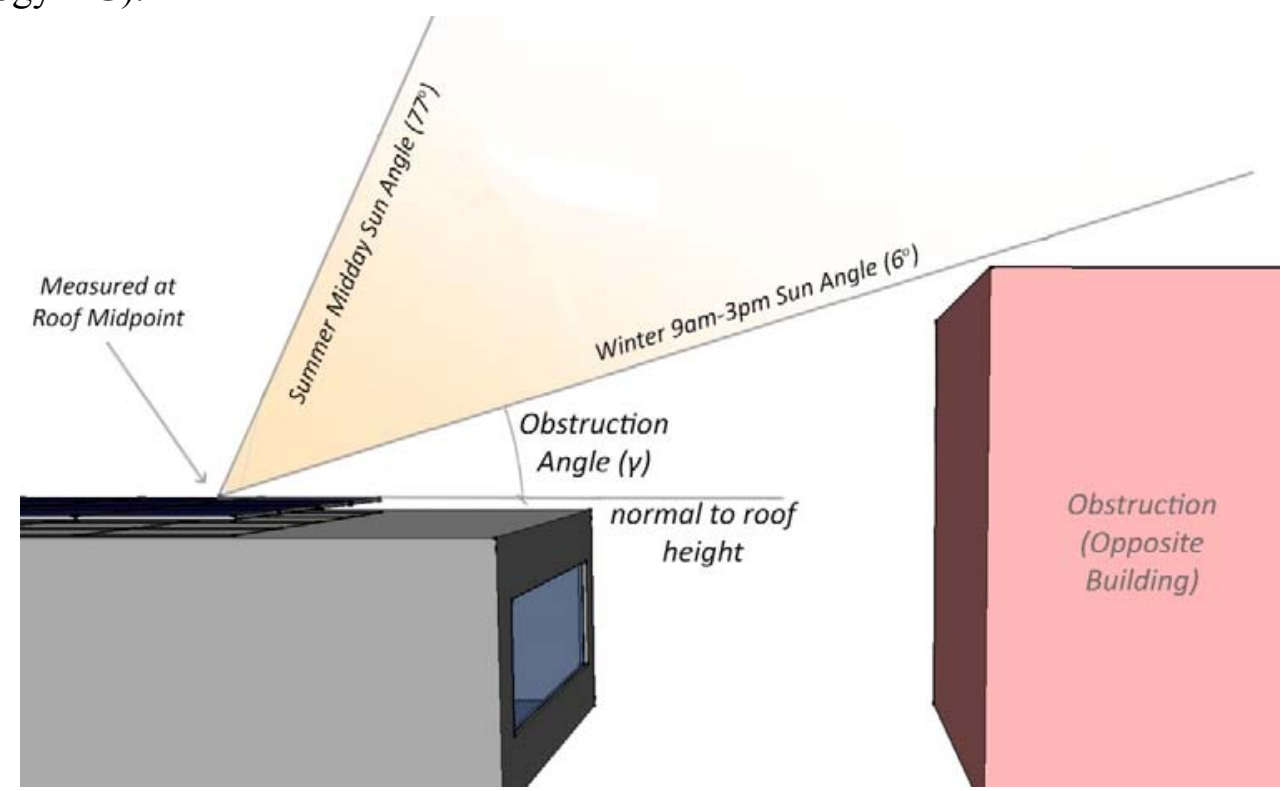

Figure 3-13 : Geometrical relationship between the sun angle ranges, the shading obstruction angle $\gamma$, and the available direct solar radiation at different times of the day.

Figure 3-14 displays the percentage of buildings in different floor area size ranges with different degrees of roof shading (obstruction) from surrounding buildings from a North direction. Each measurement was calculated half way along the roof area which allowed for an even split of roof 
area in the shade and out of the shade. The different degrees of roof shading relate to the solar altitude in New Zealand:

- There is no direct solar radiation between 9am and 3pm in New Zealand in the range of 0-6 degrees of solar altitude. If a building has shading in this range, it does not have any shading from direct solar radiation on the roof between the hours of 9am and 3pm.

- There is direct solar radiation in winter between 9am and 3pm in New Zealand in the altitude range of 6-21 degrees. If a building has shading in this range, it does have shading from direct solar radiation on the roof during winter time between 9am and $3 \mathrm{pm}$.

- There is direct solar radiation in both winter and summer between 9am and 3pm in New Zealand in the altitude range of 22-76 degrees. If a building has shading in this range, it does have shading from direct solar radiation on the roof during winter and summer periods between $9 \mathrm{am}$ and $5 \mathrm{pm}$.

- Seventy seven degrees or higher is above the summer sun angle in New Zealand. If a building has shading in this range, it does not get any direct solar radiation on half of the roof during winter or summer between $9 \mathrm{am}$ and $3 \mathrm{pm}$.

The shading ranges indicate a likely impact to PV energy generation on the roof tops of the whole building stock: $77+$ degrees meaning a severe impact to generation capability, 22-75 degrees equates to a large impact, 6-21 degrees has a small impact, and 0-5 degrees has no impact. Eighty one percent of all buildings have at least a small hindrance to generation capabilities. However, even this small hindrance would make it more practical to generate energy with PV away from the building roof area especially considering the building orientation and form can also hinder PV output. This highlights that community NZE (net zero source energy - Section 2.3) is likely to be more cost efficient than requiring individual buildings to be NZE at the building site (net zero site energy - Section 2.).

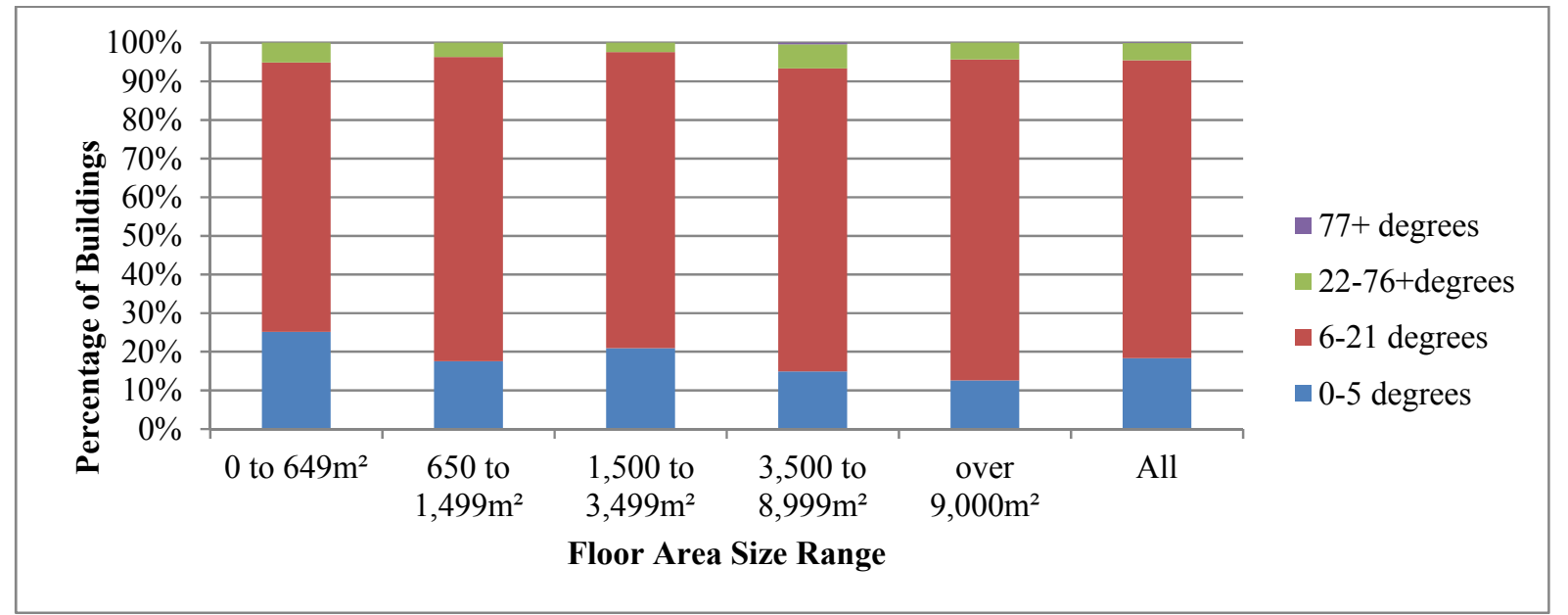

Figure 3-14 : Percentage of buildings in different floor area size ranges with different degrees of roof shading (Obstruction) from surrounding buildings in the North direction. Figure created using (BEES 2013b; QV 2008). 
Figure 3-15 illustrates how the shading from an opposite building (degree of obstruction $(\gamma)$ ) is directly proportionate to how much daylight the building façade receives (Sky angle $\theta$ ) (J Lynes 1979) and as such, the effect of the site shading obstruction on daylight availability for a sky angle of $90^{\circ}$ is zero or 100 percent available daylight (no obstructions $=$ degree of obstruction of $0^{\circ}$ ). Alternatively, for a sky angle of $0^{\circ}$ there is a 90 degree of obstruction and zero percent available daylight (fully obstructed sky $=$ degree of obstruction of $90^{\circ}$ ) (C. F. Reinhart and LoVerso 2010).

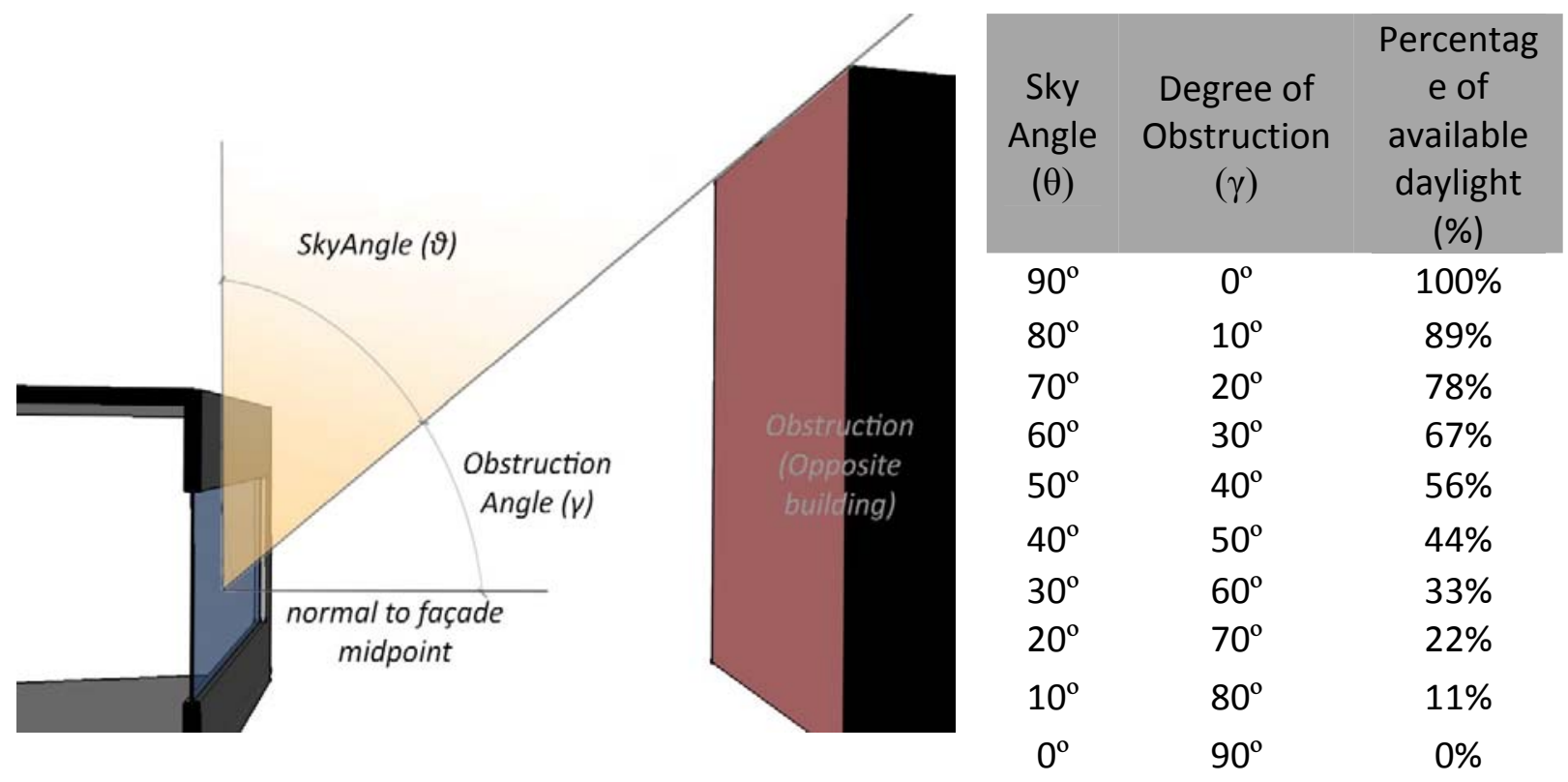

Figure 3-15 : Geometrical relationship between the sky angle $\boldsymbol{\theta}$ and the obstruction angle $\gamma$, and the percentage of available daylight for differing degrees of sky angle and obstruction angles. Figure adapted from (C. F. Reinhart and LoVerso 2010). 
Figure 3-16 displays the percentage of buildings (according to their floor area size) with different degrees of shading (obstruction) on their four facades (north, south, east and west).

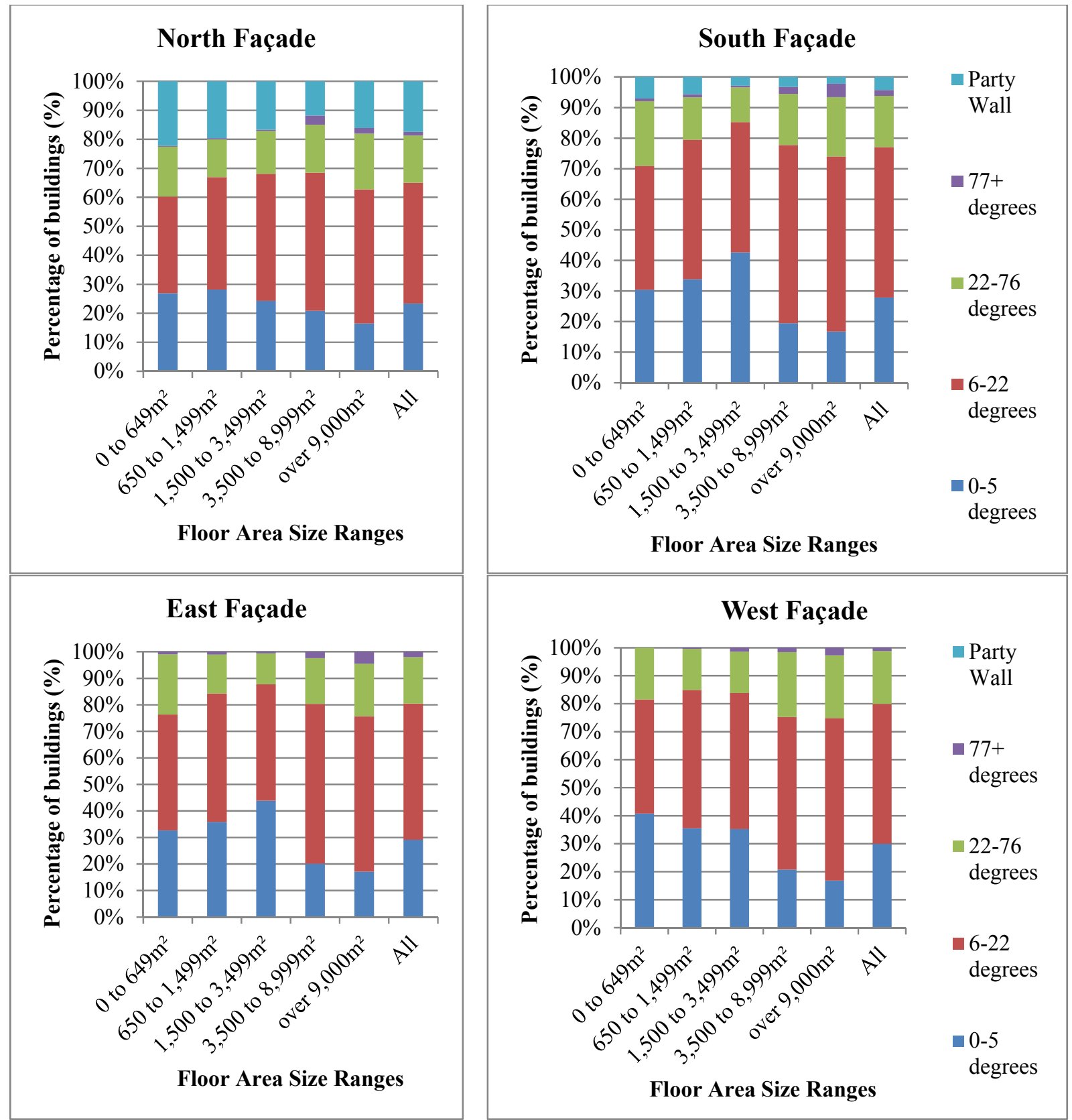

Figure 3-16 : Percentage of buildings of different floor area size ranges with different degrees of shading (Obstruction) on the facades surrounding buildings in the north, south, east and west direction. Figure created using (BEES 2013b; QV 2008).

Each measurement was calculated half way up the façade allowing for an even split of façade area below the shade and above the shade. As noted above, the different degree ranges of facade shading (façade obstruction degree) relate to the sun angle position in New Zealand: 
- There is no direct solar radiation between 9am and 3pm in New Zealand in the range of 0-6 degrees. If a building façade has shading in this range it (1) does not have any shading from direct solar radiation between the hours of 9am and 3pm, and (2) has 100 percent to 93 percent daylight availability;

- There is direct sunshine in winter between 9am and 3pm in New Zealand in the range of 6-21 degrees. If a building façade has shading in this range it (1) does have shading from direct solar radiation during winter time between $9 \mathrm{am}$ and $3 \mathrm{pm}$, and (2) has 93 percent to 77 percent daylight availability;

- There is direct sunshine in both winter and summer between 9am and 3pm in New Zealand in the range of 22-76 degrees. If a building façade has shading in this range it (1) does have shading on from direct solar radiation during winter and summer periods between 9am and 5pm, and (2) has 77 percent to 16 percent daylight availability; and

- Seventy seven degrees or higher is above the summer sun angle in New Zealand. If a building façade has shading in this range it (1) does not get any direct solar radiation during winter or summer between 9am and $3 \mathrm{pm}$, and (2) has 16 percent to 0 percent daylight availability.

The shading range indicates the impact to passive solar heat gains and daylight availability for each façade of buildings in the current commercial building stock: $77+$ degrees meaning a severe impact to daylighting and passive solar heat gains, 22-75 degrees represents a large impact, 6-21 represents a small impact, and 0-5 degrees has very little to no impact.

Across all directions, approximately 26-30 percent of buildings have very little shading (0-5 degrees). This suggests that the majority (70-84 percent) of buildings have obstructions to daylight and direct solar radiation. Whether having no direct solar radiation or daylight is problematic depends on the specific building. 


\subsubsection{Energy use}

Figure 3-17 displays the percentage of buildings that consumed a particular fuel type. The fuel types include Electricity, Natural Gas, Wood, Coal, Oil, Geothermal and Onsite Generation. As is expected, 100 percent of commercial buildings were supplied and consumed electricity. The second most common fuel consumed was Natural Gas (21 percent) and the third was Oil (four percent). Other fuel types were rarely consumed by buildings. Onsite Generation included any form of electricity generation and includes PV and diesel generators. Two percent of buildings had onsite generation.

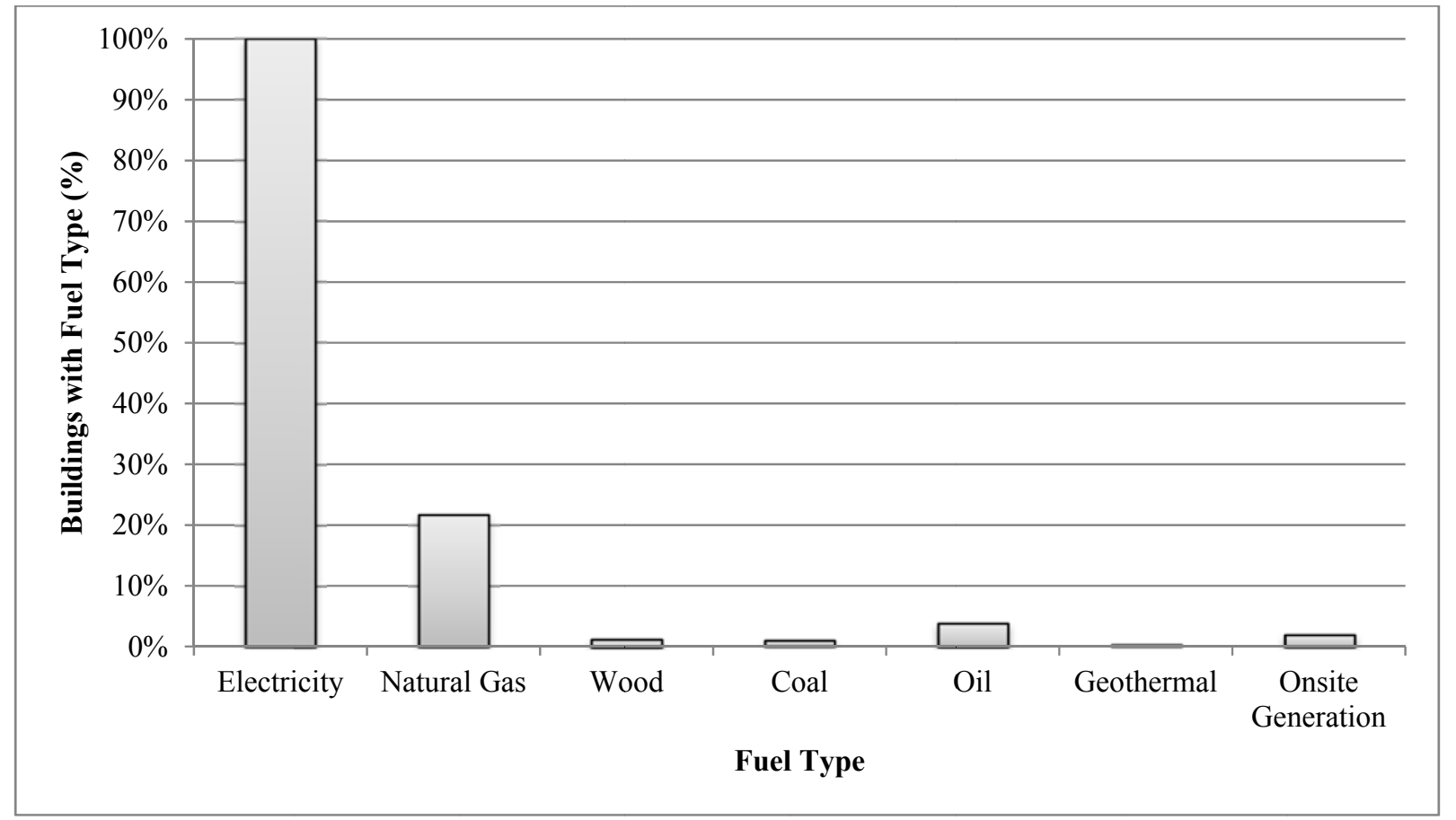

Figure 3-17 : Energy Types consumed by the commercial building stock (BEES 2013b; Saville-Smith and Fraser 2010). 
Figure 3-18 displays the average Energy Performance Indicator (EnPI) for different building attributes. The building attributes presented include building type, building size, building height, building age and site context. These attributes were shown to highlight how they affect the energy use in buildings. The comparison of building use type shows that office and retail buildings had the highest average EnPIs with 185 and $175 \mathrm{kWh} / \mathrm{m}^{2} . \mathrm{yr}$ respectively, followed by mixed buildings with $158 \mathrm{kWh} / \mathrm{m}^{2}$.yr. There was a trend in average EnPI across the building size with the smaller buildings $\left(650-1499 \mathrm{~m}^{2}\right)$ having a lower consumption than the larger buildings $\left(9000 \mathrm{~m}^{2}\right.$ or greater). Two-three storey buildings had the highest EnPI out of the different building height ranges while 1 storey buildings had the lowest. Buildings constructed since 1980 have a significantly lower EnPI, (by almost half) than their pre-1980 counterparts. This highlights the significant impact that retrofitting older inefficient buildings could have. A trend in energy consumption can be seen in the site context attribute. Rural buildings had the lowest energy consumption followed by Suburban buildings. Urban buildings had the highest, indicating that buildings located in urban areas (predominantly large buildings) are the most energy intensive.

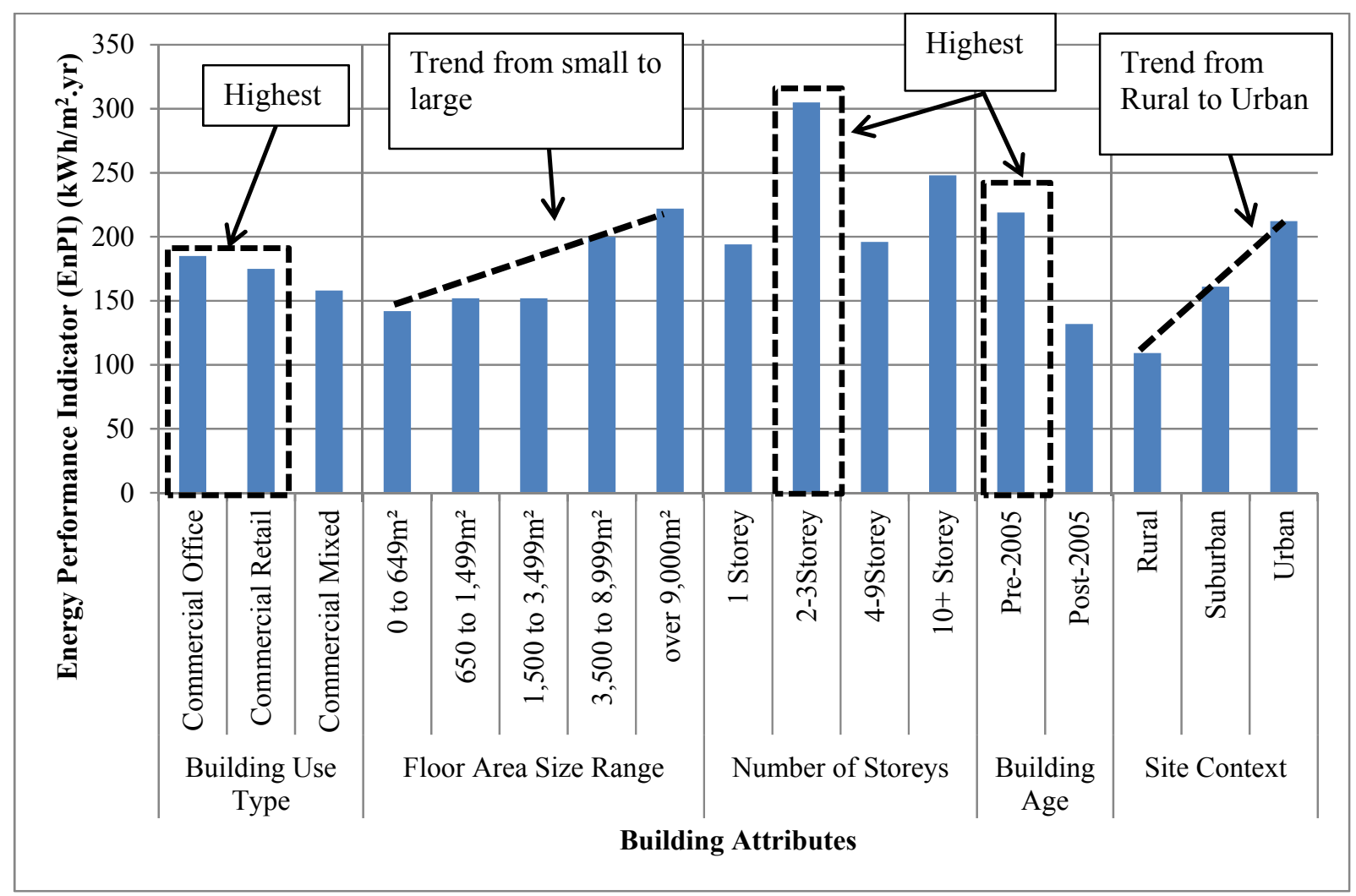

Figure 3-18 : Average Annual Energy Use Intensity for different commercial building characteristics: Building use type, floor area size range, number of storeys, and building age (BEES 2013b; Hills 2013; Amitrano et al. 2014a). 


\subsection{Chapter summary}

Chapter 3 provided the energy and building attributes needed to formulate a NZE definition for this thesis. New Zealand has an existing high renewable energy supply, electricity is consumed by 100 percent of commercial buildings and nearly all commercial buildings are connected together through the national electrical grid. Now that the New Zealand context is understood, Chapter 4 establishes a NZE definition. The definition is formulated using four sets of parameters. They are used to ensure the definition has a practical application for the New Zealand context and this thesis. The context must take into consideration the four sets of definition parameters outlined in the IEA definition framework (Sartori, Napolitano, and Voss 2012), Section 2.3. A practical definition cannot be formulated without this context. Figure 3-19 illustrates how Chapter 3 links to Chapter 4.

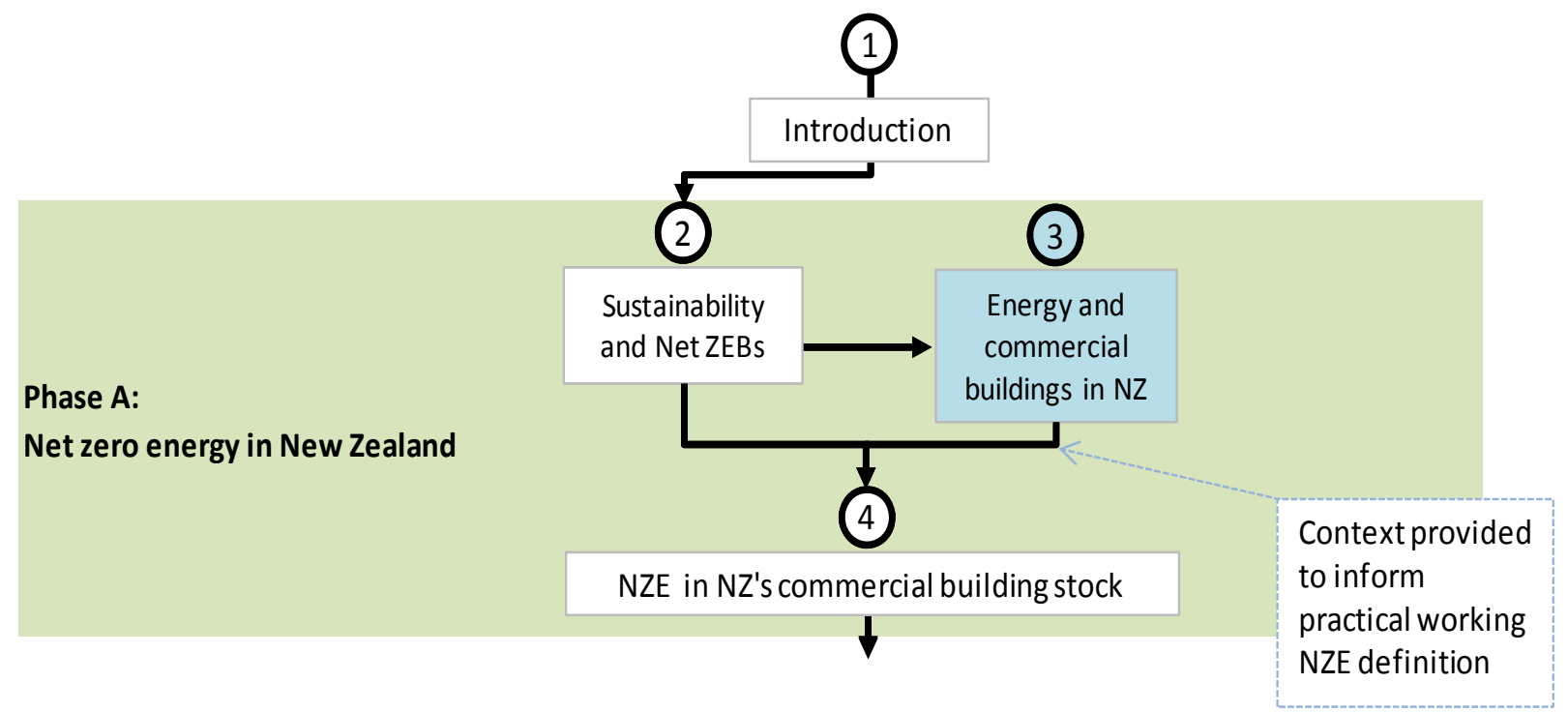

Figure 3-19 : Chapter 3 links to chapter 4. 



\section{CHAPTER 4. NET ZERO ENERGY IN NEW ZEALAND'S COMMERCIAL BUILDING STOCK}

\subsection{Chapter Intent}

Chapter 4 formulates a practical definition for the balance between energy consumed and energy generated in the New Zealand commercial building stock. This balance was formulated using the four sets of parameters, established in Chapter 2 from the IEA definitions framework, and was informed by the energy and building context of New Zealand, described in Chapter 3. Using the IEA definitions framework coupled with the context provides insight into which sets of parameters are most practical for the application of converting the New Zealand commercial building stock to be Net Zero Energy (NZE). Figure 4-1 illustrates the links between the Research Phase A chapters.

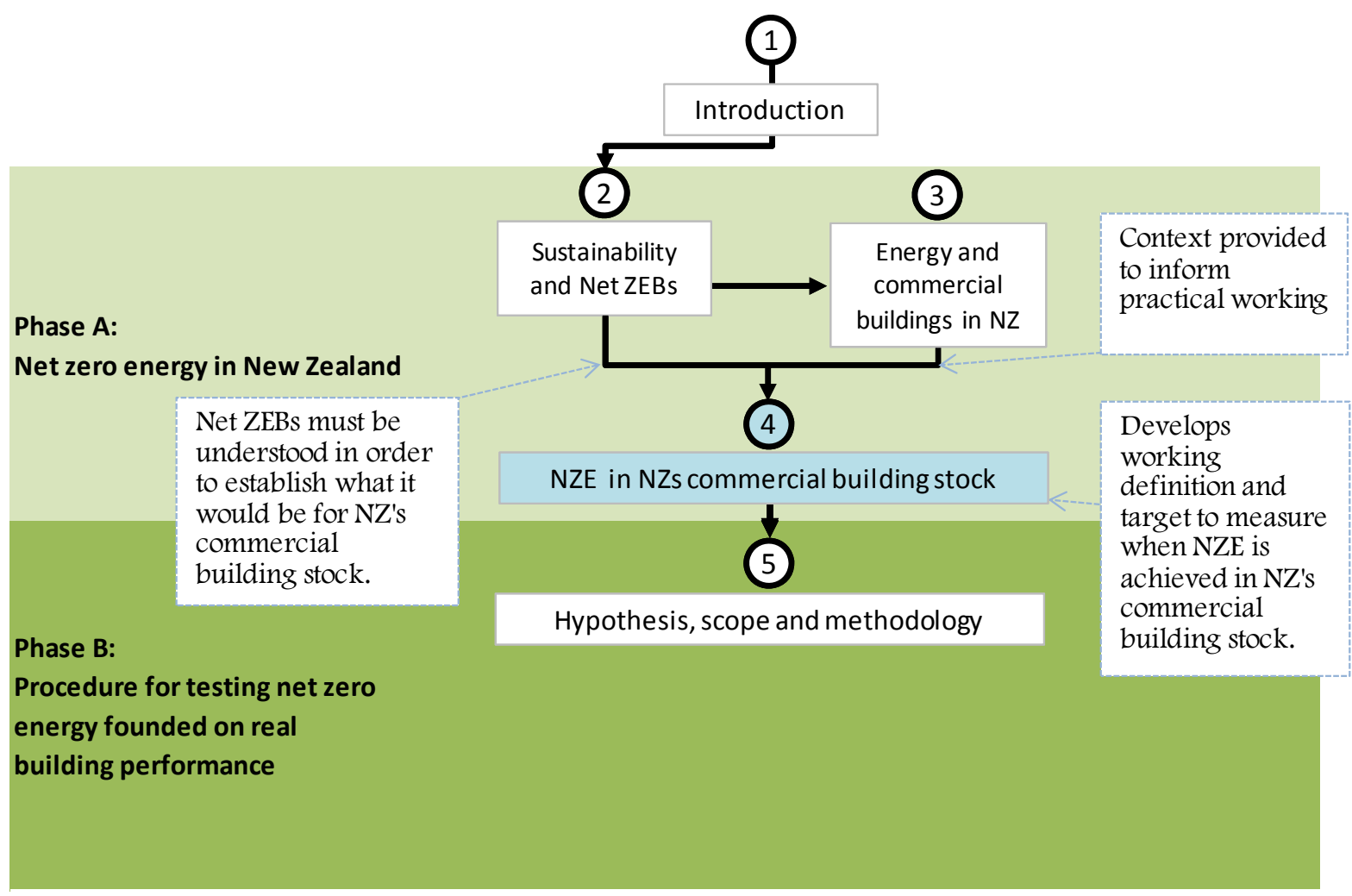

Figure 4-1: Links between chapters in Phase A: Net zero energy in New Zealand.

\subsection{Basic Net ZEB principles and a summary of the New Zealand context}

Two primary principles that must be met for a building or a group of buildings to be considered NZE were established in Chapter 2. If the New Zealand commercial building stock does not meet these two principles it cannot be considered NZE. The principles are: 
1. The building(s) must have a greatly reduced demand for energy (through efficiency gains) and this must be balanced with energy supplied by renewable technologies.

2. The building(s) are not autonomous; they must be attached/tied to a community energy grid.

These two principles describe the basic nature of Net ZEBs and separate them from traditional buildings with large integrated renewable systems (Section 2.2). However, they do not define parameters such as what the building(s) or site boundary is and what energy is included in the balance between consumption and generation as well as many more other parameters. These parameters are defined in this chapter.

Firstly, a summary of the New Zealand energy and building context must be known in order to practically define these other Net ZEB parameters. Chapter 3 identified the attributes displayed in Table 4-1 which relate to the Building type(s), Nature of the building(s)/project, Site Setting(s), Grid connection, and Grid energy supply of the current New Zealand energy infrastructure and commercial building stock:

\begin{tabular}{|c|c|}
\hline $\begin{array}{l}\text { Building type and } \\
\text { Nature of the } \\
\text { building/project }\end{array}$ & 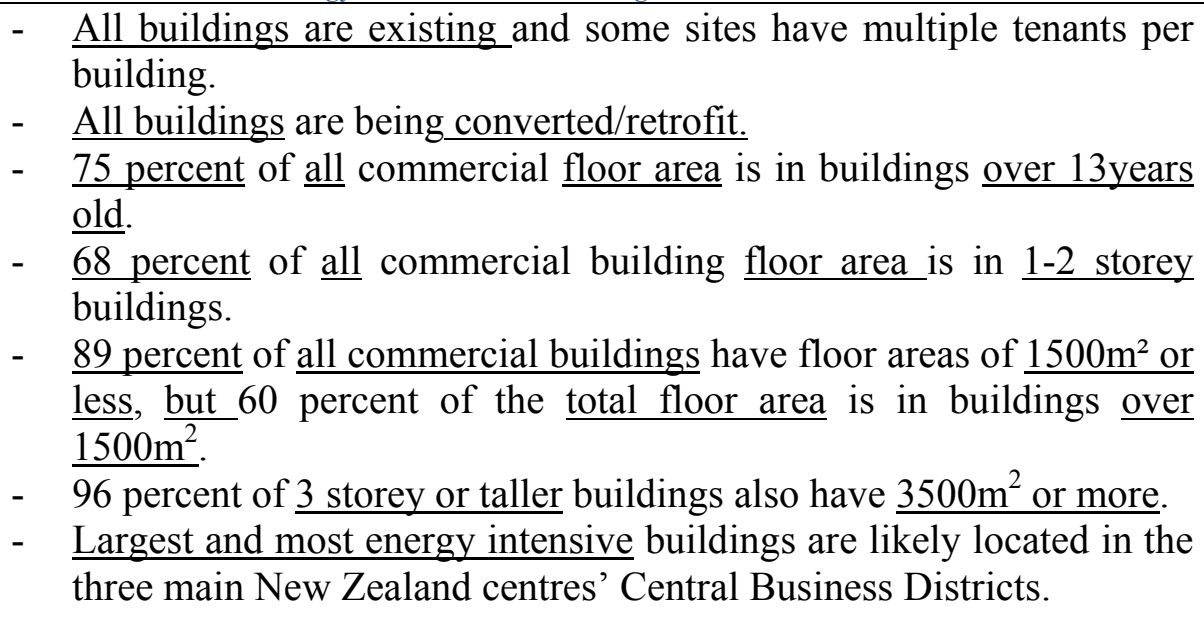 \\
\hline $\begin{array}{l}\text { Site setting and Grid } \\
\text { connection }\end{array}$ & 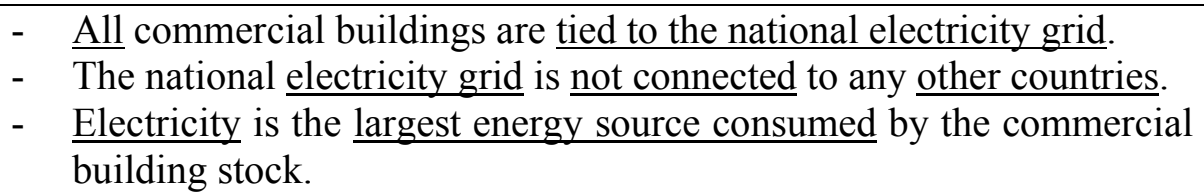 \\
\hline Grid energy supply & $\begin{array}{l}\text { - Commercial buildings are the third highest electricity consumer in } \\
\text { New Zealand. } \\
\text { - New Zealand's electricity is historically generated primarily from } \\
\text { renewable sources with } 77 \text { percent of New Zealand's total electricity } \\
\text { generation in } 2011 \text { was from renewable sources. } \\
\text { - Electricity generation is the second largest single emitter of } \mathrm{CO}_{2} \text { in } \\
\text { New Zealand. }\end{array}$ \\
\hline
\end{tabular}


With the context provided by Table 4-1, appropriate boundary conditions, weighting system, net zero balance and temporal energy match can be defined, as will be described in the following Sections 4.3 to 4.6. Following that, Section 4.7 will present some definition provisos and Section 4.8 will quantify a target for measuring when the NZE is achieved.

\subsection{Defined boundary condition parameters}

The boundary conditions used in the definition are split into three main parameters: the physical boundary; the balance boundary; and the boundary functionality (refer to Section 2.3.3).

\subsubsection{Physical boundary}

A starting point for defining the physical boundary is looking at the ZEB type. In New Zealand all commercial buildings are tied to the same electrical grid. Therefore, they are one large community of buildings and the ZEB type is classified as a Net Zero Energy Community: a community of buildings being refurbished to be NZE. The logic is converting a large group of buildings in one country would be practical if they could use the synergies of the grid connection to achieve the overall aim. It is advantageous to link the large high-rise energy intensive buildings located in dense urban areas with substantial hindrance to onsite energy generation with buildings in more suburban or rural areas which can generate more renewable energy than they need (refer to Section 3.3). The site shading that occurs in urban areas impacts on the onsite energy generation capabilities due to the compromise to their efficiency (Hanitsch, Schulz, and Siegfried 2001). Without the synergies of the grid, it is inevitable that these buildings could not be converted to be NZE.

\subsubsection{Energy grid boundary}

The second boundary parameter is whether all of the energy grids are two-way and whether the renewables are onsite. All New Zealand commercial buildings use the electricity grid as an energy source. Roughly 20 percent of commercial buildings use the gas grid as a source of energy. The New Zealand electricity grid is a two-way connection, while the other primary energy sources (i.e. gas, oil, and coal) are not. Therefore, only renewable electricity can be supplied back to offset any non-renewable energy the commercial building stock consumes. As New Zealand's electricity grid supplies energy to all commercial buildings, it sets the grid and community boundary at the national level. This is reinforced by the fact that electricity generated in the South Island is transmitted to the North Island where it is consumed and as such, a national community of buildings is formed. Refurbishing large groups of buildings in one country would also require the synergies of having the grid connection to achieve the overall aim. The nature of the Net ZEC building type means the community boundary is the whole grid. Hence, renewable energy does not need to be located onsite of each building and community renewable energy generation schemes are allowed. 


\subsubsection{Energy end-use boundary}

The third boundary parameter examines what energy end-uses need to be balanced by renewable energy generation. The study concerns commercial buildings. This implies the boundary is set at the building level. For that reason, a minimum of all operational energy used in commercial buildings needs to be reduced and offset by renewable energy. All operational energy includes energy related to the service of the building and its tenant. The building energy end-uses include heating, cooling, ventilation, domestic hot water, fixed lighting, while the tenant energy end-use is plug loads. The physical boundary set at the community level, transport and the buildings' embodied energy could also be included. However, these have not been included in this study due to the embodied $\mathrm{CO}_{2}$ not being the largest concern. This was concluded in (Alcorn 2010), and is also reinforced by electrical generation being the second largest emitter of $\mathrm{CO}_{2}$ in New Zealand. Additionally, a building's energy consumption is the most commonly reported and viewed as the most important environmental indicator (International Energy Agency 2004, P.3). It is the consensus among most researchers that operational lifecycle emissions have the largest environmental impact accounting for about half of the total energy consumed by developed countries (Ibn-Mohammed et al. 2013; International Energy Agency 2004, p. 3). In New Zealand and Australia, life time operational energy accounts for approximately 90 percent of buildings' carbon emissions (Mithraratne 2007; Ibn-Mohammed et al. 2013). It is important to understand that the embodied energy percentage will make up an increasingly greater proportion of life time emissions with energy efficiency in buildings improving toward NZE. Embodied energy has the potential to approach 100 percent of the lifetime energy use and emissions (Hamilton-MacLaren, Loveday, and Mourshed 2009).

The largest $\mathrm{CO}_{2}$ emitting sector in New Zealand is transport, but it is not included in the balance of this thesis as it would result in the study being of the community and not the buildings. A NZE transport system would only be achievable after the current building and energy infrastructure is converted to 100 percent renewable. Oil is the predominant fuel consumed by transport and the next logical renewable fuel for vehicles to consume is renewable electricity. The evolution of hybrid and electric vehicles in the last decade is an indication of this move towards the use of renewable electricity as the next logical fuel.

\subsubsection{Building functionality boundary}

The last boundary parameter is the building functionality: occupancy, comfort and climate. As the definition is intended for retrofitting existing buildings, the buildings need to be able to, at a minimum, maintain net zero energy with the same level of current occupancy. In addition, the buildings need to be able to, at a minimum, maintain net zero energy for a typical meteorological year for its specific climate. The current buildings may or may not meet what is defined as being thermally comfortable; however, a prerequisite to improving the energy efficiency is to not degrade the building's internal environment and to at least provide acceptable occupant comfort. The comfort criterion to be met is similar to the comfort analysis made in the building climate classification (refer to Section 5.1.7). The comfort criterion is based on recommended internal 
temperatures for health and comfort. The aim is a broad comfort zone for the building based on fit healthy occupants. It does not consider more vulnerable occupants such as the elderly or very young children. For example, if it is a little cool for an occupant, they would put on an extra layer of clothing, or if it is a little warm for an occupant, they would remove that layer of clothing. The comfort range assumes the occupant will adapt and therefore a more adaptive comfort classification is used. Adaptive comfort is the principle of people experiencing the thermal environment in buildings differently and adapting, up to a certain extent, to the indoor conditions (European Commission 2013). Their adaptation depends on their clothing, their activity and general physical condition (Brager and de Dear 1998). However, as commercial buildings are assumed to be air conditioned in reality, the lower and upper limits for the comfort zone are to be those of standard comfort criteria.

The comfort criteria set in this study are a combination of two well-known comfort limits. Givoni, one of the pioneers of adaptive comfort, suggests an extended range of $18-27^{\circ} \mathrm{C}$ (Givoni 1998). ASHRAE 55 recognises the many influencing factors on thermal comfort and suggests an acceptable annual indoor temperature range of $20-26^{\circ} \mathrm{C}$. ASHRAE 55 also gives a more stringent upper limit of $24.5^{\circ} \mathrm{C}$ as the operative temperature (Djongyang, Tchinda, and Njomo 2010; ASHRAE 2010, 55) and as such the lower temperature limit for comfort is $18^{\circ} \mathrm{C}$ and the upper limit is $25^{\circ} \mathrm{C}$. This limit fits within the health limits and allows for occupants to adapt to be comfortable (Bradshaw 2006).

\subsection{Defined Weighting system parameters}

The weighting system is defined using three parameters: the energy metric, the accounting method for the energy metric, and the weighting symmetry of the energy metric.

\subsubsection{Energy metric}

The first weighting system parameter is the energy metric (refer to Section 2.3 for a detailed breakdown of the different metrics). The energy metric establishes what energy is being balanced in the net zero balance. A practical energy metric is ascertained using the New Zealand building and energy context, and the purpose is to retrofit the whole commercial building stock. The site and cost energy metric definitions are not relevant to New Zealand or many (if any) countries for retrofitting groups of large buildings. The ZEB type is a Net ZEC; this means each individual building does not need to be NZE at the site. As it is a large group of buildings being retrofitted and each building has separate owners, net zero cost is not a practical energy metric to use. Furthermore, energy costs do not have any correlation to emissions in New Zealand and the aim of moving towards net zero energy is to reduce GHG emissions. The influences of fluctuating cost prices also means a building may be classed as a Net ZEB now, but may not be in the future. "Using the energy costs could make it almost impossible to design a building, which would be a ZEB through its entire lifetime" (Marszal et al. 2011, p.6). 
Because all of the commercial buildings are tied to the same national grid, using the primary energy metric accounts for the fuel value of the sources supplying that grid. The buildings can then add to the efficient use of the energy resources already attached as it accounts for the losses in conversion and delivery.

Net ZEBs are argued internationally to exist as a means to lower Greenhouse Gas (GHG) emissions (Rajkovich, Diamond, and Burke 2010). A move toward Net ZEBs is a response to the research indicating that atmospheric concentrations of greenhouse gases have increased sharply since the eighteenth century, resulting in a gradual warming of the Earth's climate (Rajkovich, Diamond, and Burke 2010). Net ZEBs' relation to GHGs indicates that the emissions energy metric is also a practical indicator. Given a net-zero emissions building produces at least as much emissions-free renewable energy as it uses from emissions-producing energy sources, the primary energy renewable sources can be accounted for in the emissions balance.

Because this study focuses on energy feasibility, the energy metric used will be primary energy. However, this will be adapted to acknowledge the fact that Net ZEBs are a response to climate change by specifying that no primary $\mathrm{CO}_{2}$ emitting energy can be consumed. The result is a net zero primary energy emissions metric, that does not use an emissions weighting factor. Instead, it uses a primary energy factor that aims to offset any primary energy sources that emit $\mathrm{CO}_{2}$. It should be noted that in New Zealand a large portion of energy consumed is supplied from renewable sources. This will mean reaching net zero primary energy emissions is easier than in other countries which have a higher proportion of energy supplied from non-renewable energy sources.

\subsubsection{Accounting system}

The second weighting system parameter is the accounting method. Primary energy factors are used to define when NZE is reached due to the energy metric. The weighting factor is ascertained as an average value for a specific period of time, in this case annually. The weighting factor is classified as 'Statically accounted' which is the system typically applied to primary energy factors (Sartori, Napolitano, and Voss 2012).

\subsubsection{Weighting symmetry system}

The last weighting system parameter is the weighting symmetry. As this study focuses on community level energy generation, energy is symmetrically accounted. Therefore, the energy consumed (from all energy sources) and energy generated is accounted 1 for 1 . The political and economic mechanisms that might be explored in order to bring this ZEC approach into reality might well use different weightings. In this thesis the feasibility focus is: can the energy balance be achieved. This means the credits are weighted symmetrically and as such the exported energy has a substitution value, which is equal to the average primary weighting factor for the grid (Sartori, Napolitano, and Voss 2012). 


\subsection{Defined Net Zero Balance parameters}

The net zero balance is defined by four parameters: 1) the time period energy is measured for (the balancing period), 2) the type of balance, 3) whether there are any enforced minimum energy efficiency requirements, and/or 4) a hierarchy of renewable energy supply options.

\subsubsection{Time period of balance}

Each commercial building needs to reach NZE for what would be considered a typical meteorological year for its location. For this reason, the energy balance period is calculated over a one year period. A yearly balance is suitable as it covers all building operation settings with respect to the meteorological conditions and also because the core principle for Net ZEBs is the balance between weighted demand and weighted supply over the year (Sartori, Napolitano, and Voss 2012).

\subsubsection{Equation type for the balance}

Chapter 2 established that there are two net zero balance equations used to calculate whether a building is NZE on an annual basis. However, the equations were developed with individual buildings in mind. As this study researches an entire nation's commercial building stock the equations may need to be adapted slightly. The defined energy metric (primary energy emissions) is the tool used to adapt the equations. The commercial building stock is therefore NZE when it only consumes net renewable non- $\mathrm{CO}_{2}$ emitting primary energy.

The IEA definitions framework encourages self-consumption. Self-consumption is measured at monthly or ideally hourly intervals (Sartori, Napolitano, and Voss 2012). Because this study only aims to reach NZE at an annual interval, a detailed self-consumption study is not undertaken. However, to acknowledge the benefits of self-consumption, it is considered to be measured at a national level by utilising the existing grid tied renewable energy in the net zero balance equation. At a national level, self-consumption is considered to be any renewable electricity already consumed by the current commercial building stock. The primary energy emissions metric accounts for the emissions from the grid electricity, but the buildings can use electricity produced by $\mathrm{CO}_{2}$ free sources which are not integrated in the buildings or at the construction site (Mertz, Raffio, and Kissock 2007). This together with the Net ZEC benefits of economy of scale and levelling out the load and generation profiles of each building means NZE is attained by consuming only renewable energy. If the current commercial building stock only consumes renewable, emissions-free, energy that is grid-tied it is therefore defined as a net zero primary energy emissions building stock. This results in the NZE Commercial Building Stock definition being split into two prescriptive criteria: 


\section{A community of buildings which have a greatly reduced demand for energy, and}

2a) the building stock only consumes energy from the country's existing emissions-free renewable energy infrastructure;

OR

2b) if it cannot meet $2 a$, it needs to produce at least as much emissionsfree onsite renewable energy as consumed from emission-producing primary non-renewable energy sources.

Criteria $2 a$ and $2 b$ set up two aims for reaching NZE. The first (2a) is for the NZE retrofitted building stock to consume a quantity of energy that is equal to or less than the quantity of energy currently generated by renewable emissions-free sources on an annual basis. It encourages energy efficiency and self-consumption before additional renewable energy generation. If the retrofit building stock cannot reach this (2b), additional renewable energy generation can be added to reach net zero energy. Consequently, it would be easier for a country with a large renewable energy infrastructure to convert its building stock to be NZE (such as the case for New Zealand). The translation of the prescriptive definition into a NZE balance equation is split into two to reflect the two part prescriptive definition:

Equation 3 - NZE Balance equation:

Current portion of national renewable emissions-free primary energy supply-Commercial building stock primary energy consumption $\geq 0$

Equation 4 - NZE Balance equation:

Current portion of national renewable emissions-free primary energy supply $+\underline{\text { Additional }}$ emissions-free renewable energy supply - Commercial building stock primary energy consumption $\geq 0$

The difference is the underlined additional emissions-free renewable energy supply in Equation 4.

\subsubsection{Energy efficiency requirements}

The need for energy efficiency is built into the definition of a Net ZEB. The IEA framework has no definite guideline as to what energy efficiency reductions are required in order for a building to be considered a Net ZEB. This study cannot answer how much energy efficiency reductions are enough due to all existing buildings having a varying degree of efficiency and energy usage. This makes it hard to define a mandatory minimum requirement for energy efficiency. The emphasis is on energy efficiency over new renewable energy supply and with this in mind, a desirable energy efficiency requirement is for the commercial building stock as a collective to reduce its energy consumption to fit within the existing renewable energy supply infrastructure. The quantification of how much energy needs to be reduced is undertaken in Section 4.8.

Page | 66 


\subsubsection{Hierarchy of energy supply}

The need for a hierarchy of energy supply options is built into the definition of a Net ZEB. The IEA framework has no definite guideline as to which supply options are required in order for a building to be considered a Net ZEB. To guide which supply options should be used, the aim of this study, which is for the commercial building stock energy consumption to fit within the renewable means of the New Zealand renewable energy infrastructure, is used to establish an appropriate hierarchy. By this definition there are restrictions as to what energy fuels commercial buildings can consume. In order to be considered renewable, no non-renewable fuels can be consumed by the building. The non-renewable fuels in New Zealand are: natural gas, oil, and coal. It is assumed in this study that gas use is replaced with renewable electricity and the hierarchy of energy supply options starts with existing grid-tied renewable non- $\mathrm{CO}_{2}$ emitting energy supply. Secondary to this is onsite non- $\mathrm{CO}_{2}$ emitting renewable energy supply. This is based on Net ZEBs prioritising onsite technologies over other options (Sartori, Napolitano, and Voss 2012).

The analysis in this study is a form of worst case scenario. Only onsite renewable energy supply options were assessed. It should be noted that community based energy supply options become more feasible and practical than onsite options for Net ZECs. As a national project it would be more effective to produce community renewable energy supply options than to put renewables onsite of every building. This is highlighted when considering the nature of community site contexts (Section 3.3.4). In urban areas there is both sun and wind shading which causes a reduction in generating capacity of PVs and Wind turbines. PV and Wind turbines can be situated away from the built up areas to allow for maximum generating capabilities. Urban areas should be designed to utilise the advantageous circumstances they are given. For example, Wellington, New Zealand, has a wind farm located within 20 kilometres $(\mathrm{km})$ of the city's location that takes advantage of the wind environment without interruption from the built environment. Given it is common for Net ZEBs to use onsite generation these are analysed exclusively in this study. However, it was important to understand that there will be more cost effective alternatives not assessed in this thesis.

\subsection{Defined Temporal Energy Match parameters}

The temporal energy match assesses the impact of the energy exchange between the building and the energy infrastructure by determining the match between the building load, onsite generation, and grid demand and supply.

\subsubsection{Load matching and grid interaction}

The NZE retrofit in this thesis implements onsite energy generation. This means a certain level of consideration should be given to the matching of load and generation and the interaction of this with the grid. "Mismatches should be dealt with at the aggregated level and not at the individual building level" (Lund 2013, p.8). This would mean analysis of the energy taken from and supplied back to the national grid would need to be undertaken at an hourly interval. This

Page $\mid 67$ 
study has limited itself to reaching NZE at an annual time interval and consequently, load matching and grid interaction are not undertaken at an aggregated level.

Grid interaction flexibility is outside the scope of this thesis. This is due to it being an entirely different thesis subject in itself as it is an analysis of the community energy systems and not the buildings themselves. However, its importance is undeniable. For this reason, tests were undertaken as part of this thesis to indicate the likely load matching and grid interaction of the retrofitted NZE commercial building stock to assess its impact on the current grid. These assessments were undertaken to highlight the feasibility of a move to NZE at a national level. As a full grid analysis was not undertaken, the load matching and grid interaction indices were not used (refer to Section 2.3.6) and instead a pilot study assessing the load, generation and grid demand was used to highlight the likely match and interaction (refer to Section 5.3.3c and 11.3.1a and 11.3.1b).

\subsection{Definition provisos}

The developed practical definition above can only work under certain conditions. These conditions create four provisos which would need to be met in order for it to work in reality. The first proviso concerns the Jevons' Paradox. The Jevons' Paradox is a term which was postulated by an economist named William Stanley Jevons and refers to the impact that more efficient technology has on total energy demand. As efficiency of energy or other resource consuming technologies increases, the total demand for and hence consumption of the resource does not decline, instead it increases (Jevons 1865; Alcott 2005; Alcorn 2010). The Jevons ' Paradox is also known by many other names such as rebound, feedback, take-back, snap back, re-spending, or the Khazzoom-Brookes Postulate (Alcott 2005; Herring 1998). The application of the general ideology of the Jevons' Paradox to Net ZEBs is that as the buildings use energy more efficiently, the use of energy inevitably increases. A coordinated move to NZE is needed otherwise the Jevons' Paradox suggests that the effect to reduce resource use only facilitates an even greater resource use elsewhere (Alcorn 2010). The increase occurs from two aspects:

1. Because Net ZEBs are energy efficient and are cost effective to run, more Net ZEBs can be built. More Net ZEBs means more energy capacity needed and more materials needed to build the new buildings. The only way to prevent this is to cap the number of buildings able to be added to the existing building stock. This study excludes the issue as the building population is limited to the existing commercial building stock. However, the situation needs to be dealt with when considering new commercial buildings.

2. As Net ZEBs are cheaper to run, the people who pay for the energy costs save money. These people can spend their extra money on other areas of their lives. These other areas of their lives all have energy and emissions related to them. For example, people can take more overseas trips. An overseas trip requires fuel to provide the means of travel. With more people taking more overseas trips, the energy use in that 
sector increases and replaces the savings made by the Net ZEBs. The only way to escape this issue is to remove any gains made from efficiency from circulation. Herring (1998) concluded that energy efficiency only works if efficiency gains are removed from circulation, perhaps by taxation which would be used for rehabilitation of natural capital.

The first study proviso is that the retrofit is limited to all commercial buildings at the time of the study, and any gains made through efficiency need to be used for rehabilitation of natural capital. This proviso means that this study has no responsibilities to deal with the Jevons' Paradox other than to accept it exists and that it is outside of the scope of this study.

A move to NZE can only be achieved if all energy using sectors have the same goal of reducing their consumption of non-renewable $\mathrm{CO}_{2}$ emitting energies. The second proviso for a national move to NZE to work in reality would be for each sector to reduce its existing proportion of energy use to within the same proportion of renewable means of the existing infrastructure. As an example, the commercial sector uses 23 percent of all electricity consumed in New Zealand and would therefore get a 23 percent share of the existing renewable electricity generation. As a result each sector would get the share of renewable electricity displayed in Figure 4-2:

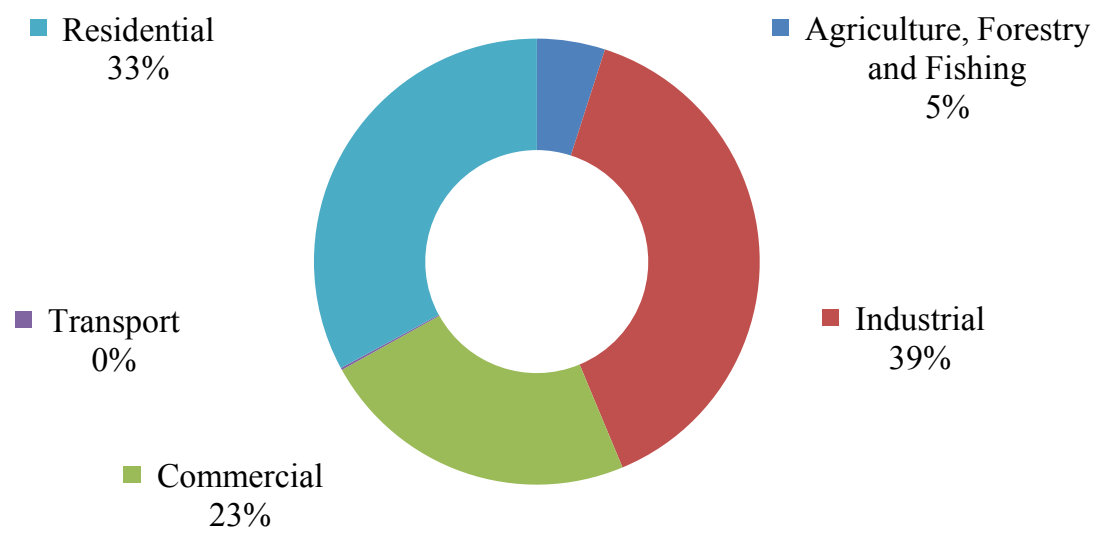

Figure 4-2 : Each sector's allowable split of existing renewable electricity generation.

If a sector cannot meet this requirement, it needs to produce at least as much emissions-free renewable energy as it consumes from emission-producing primary energy sources.

If the existing renewable energy infrastructure cannot provide capacity for the new commercial buildings' demand, the energy infrastructure collapses. Therefore, the third proviso is that it is essential to have a suitable plan for new additional commercial buildings. A suitable plan would result in a different Net ZEB definition for new commercial buildings compared to existing commercial buildings being retrofitted to NZE. An example plan is: all new commercial buildings need to supply as much renewable electricity to the national electricity grid as they 
consume with specific assessment of their load matching and grid interaction. Further analysis is needed for a suitable plan.

The retrofit analysis undertaken in this study takes some account of embodied energy. Existing materials are likely to offset the new materials needed to retrofit to NZE. However, the embodied energy of the conversion is not specifically included in this study's NZE balance and as such the fourth proviso is that new buildings need to have some accounting for embodied energy in the new building NZE balance. Further analysis is again needed for a suitable NZE balance for new buildings, which is also outside the scope of this study.

\subsection{Quantified target of net zero energy in the Commercial Sector}

The formulated definition parameters in Sections 4.3, 4.4, 4.5, 4.6, and 4.7 provide a means of measuring the balance between energy consumed and energy generated to assess if the building stock can be considered NZE. The balance can be quantified in terms of the amount of current energy that must be reduced (through efficiency) and offset (with renewable technologies). The quantified balance provides a target that the retrofit commercial building stock must meet before it can be considered NZE. Quantifying NZE for a community of buildings is slightly different to individual buildings; however, the general concept is the same. The IEA framework net zero balance equation is still followed (Equation 1), but the supply and demand definitions differ. As outlined in Equation 3, the weighted supply is the New Zealand renewable primary energy supply plus any additional onsite renewables and the weighted demand is the primary energy demand of the commercial building stock.

The target is presented as a percentage reduction in current energy consumption. A percentage is used due to the quantification taking place at the commercial sector level and the commercial building stock does not make up the whole sector. The target will identify the percentage of primary energy reduction required to exclude or offset any $\mathrm{CO}_{2}$ emitting non-renewable primary energy currently being consumed by the commercial sector. The percentage is also the proportion the commercial building stock must adhere to.

It is important to understand that by definition, if non-renewable final energy consumption is reduced to 0 percent, then all non-renewable primary energy consumption is reduced to 0 percent also. Therefore, the NZE target is still the same for each indicator. For example, if all nonrenewable final energy is no longer needed there is no longer any primary energy from nonrenewable sources either. The conversion to primary energy is only displaying the reduction in primary energy that will occur if all non-renewable final energy is reduced to 0 percent use.

The emissions accounted for in this study are from $\underline{\mathrm{CO}}_{2}$ emitting non-renewable energy supply. The terminology is important as some renewable energy supply does emit $\mathrm{CO}_{2}$. Figure 4-3 displays a breakdown of various energy types and highlights the GHG (and therefore $\mathrm{CO}_{2}$ ) emitting types.

Page $\mid 70$ 


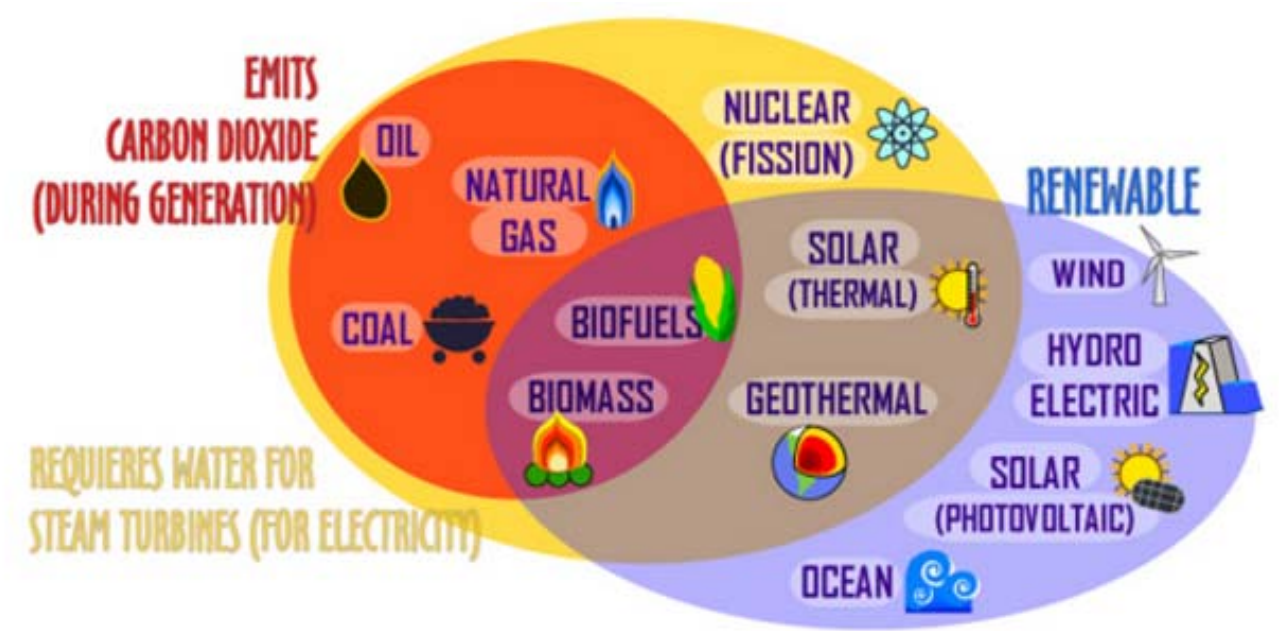

Figure 4-3 : Renewable and non-renewable energy types and associated disadvantages (Soundvision Productions 2013).

As can be seen, just because a source of energy is renewable does not mean it produces little or no greenhouse gas emissions (Soundvision Productions 2013). New Zealand produces a substantial amount of electricity using geothermal (13 percent) and a small portion from Biogas (1 percent) (Energy Information and Modelling Group 2012b). Both geothermal and biogas are defined as a renewable energy source, but have associated emissions (Duffield and Sass 2003; Soundvision Productions 2013). If the definition did not specify only $\mathrm{CO}_{2}$ emitting nonrenewable energy supply, the emissions associated with geothermal and biogas would need to be offset in order for the commercial building stock to be NZE.

However, because the emissions from Geothermal are so small, it is globally accepted that they can be neglected. This is due to geothermal power plants meeting the most stringent clean air standards, and they help to offset the overall release of carbon dioxide into the atmosphere (Holm, Jennejohn, and Blodgett 2012; Duffield and Sass 2003). This decision was made as geothermal power production has significant environmental advantages compared to burning fossil fuels for electrical power production" (Bloomfield, Moore, and Neilson 2003).

The quantified target was derived using the last five years of available national New Zealand energy data. The target represents the maximum amount of $\mathrm{CO}_{2}$ emitting non-renewable energy supply consumed in the past 5 years. The maximum target was established as it did not match the occurrences of an average weather or wet weather year, but a dry weather year. This is important due to the large proportion of hydroelectric generation that supplies New Zealand's electrical grid (which is the main energy consumed by the commercial building stock). When there is a dry year the renewable electricity generation drops and the slack needs to be made up by nonrenewable sources. This difference was highlighted in the analysis. Appendix 14.1 presents the calculations used to quantify the NZE target. 


\subsubsection{A quantified target of net zero energy}

Figure 4-4 presents the split of primary energy consumption for the current commercial building stock in a dry and average weather year.

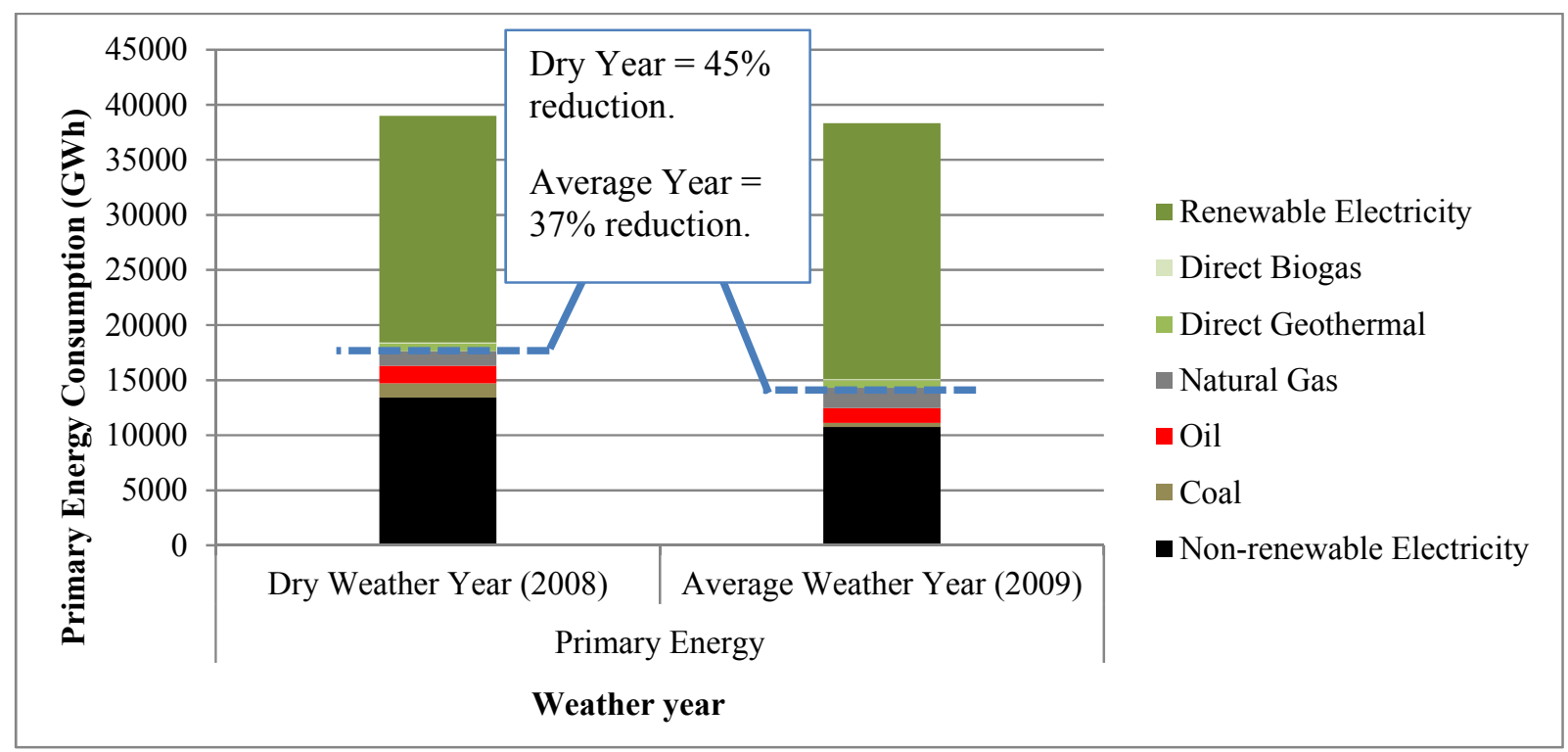

Figure 4-4 : Commercial building stock primary energy consumption breakdown for a dry and wet weather year and associated quantified NZE percentage reduction.

The analysis establishes the quantified percentage target for the reduction in primary energy the current commercial building stock must reach for it to be considered NZE. Alternatively, the target can be thought of as the amount of average energy reduction that each and every commercial building needs to save in order for the entire sector to reach net zero primary energy. It is the average amount as it is likely that not every building can reduce their energy consumption by the specified amount, while other buildings will surpass the limit and make up for the deficiencies of other buildings. Due to Net ZEBs being prescribed as energy efficient buildings first and foremost (with onsite renewable energy to offset residual demand as a secondary prescription) this study's emphasis was on energy efficiency rather than new renewable generation. For that reason, the reductions were aimed to be reached through energy lowering design and technology retrofits. As a last resort onsite renewable energy technologies were used. The percentage reduction was what NZE is measured against as the proviso is that all other commercial consumers reduce their consumption to within the limit to produce a NZE commercial sector.

The dry and average weather years produce a different percentage reduction required. The average weather year calculated a lower percentage target than the dry year. This was due to the large amount of hydroelectric energy supply in New Zealand. For this reason, the dry weather year was used to quantify the reduction needed because it represents the worst case scenario of consumed $\mathrm{CO}_{2}$ emitting non-renewable energy supply that currently occurs. The New Zealand 
commercial building stock will therefore achieve NZE if it reduces its current level of primary energy consumption by 45 percent.

\subsubsection{Scope of NZE definition}

Figure 4-5 aims to illustrate the NZE definition and what it encompasses in a simple way using three labels. The first label shows the scope of the definition data. The definition was created using energy and emissions data for the whole commercial sector. The whole commercial sector includes data for all commercial building types and energy uses. Label 2 details the reduction in primary energy required before the commercial sector and the building stock it encompasses can be considered NZE (a 45\% reduction in primary energy consumption). Label 3 illustrates the split in building types which comprise the commercial sectors building stock and the imposed scope by falling within the scope of the BEES project. Label 3a shows the building types assessed in the BEES project and this thesis, and label $3 \mathrm{~b}$ shows the building types not assessed. The NZE defined $45 \%$ reduction in primary energy is required across both $3 \mathrm{a}$ and $3 \mathrm{~b}$ building types. However, in this thesis the $45 \%$ reduction is being attempted for just the 3 a building types. If successful, future work could apply the methodology and lessons learned to the $3 \mathrm{~b}$ building types. Furthermore, current research by ASHRAE, US Department of Energy, the National Renewable Energy Laboratory and the Pacific Northwest National Laboratory suggest that similar savings that can be achieved in office and retail buildings can also be achieved in the other commercial sector building types (Hospitals, schools, hotels) (ASHRAE 2015; DOE, NREL, and PNNL 2015).

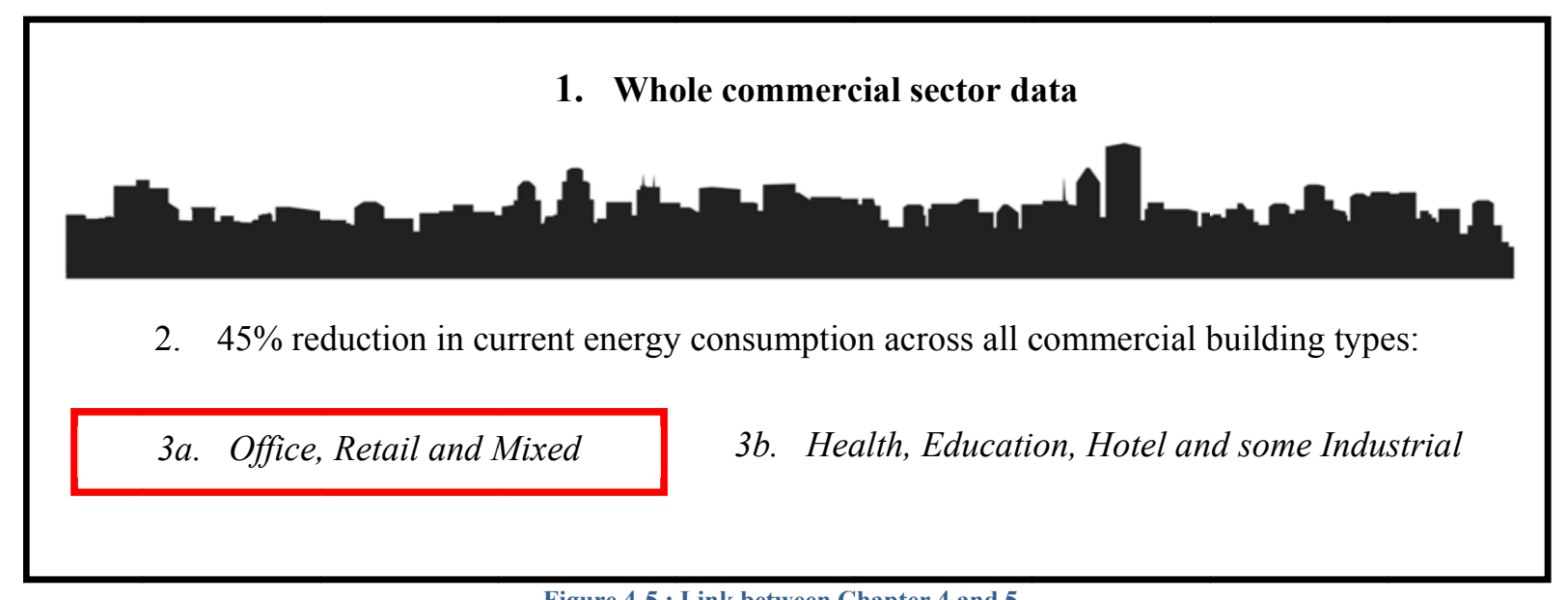

Figure 4-5 : Link between Chapter 4 and 5.

\subsection{Chapter summary}

Chapter 4 defined the parameters needed to establish the nature of the balance between energy consumed and energy generated in order to determine when the New Zealand commercial building stock is NZE. It also determined that a 45 percent reduction in the current primary energy consumption is needed for the commercial building stock to be 
considered NZE. With NZE defined, Chapter 5 uses a set of parameters to refine the research hypothesis and scope, and set the overarching methodology used in this thesis.

Figure 4-6 displays the links between Research Phase A and Phase B.

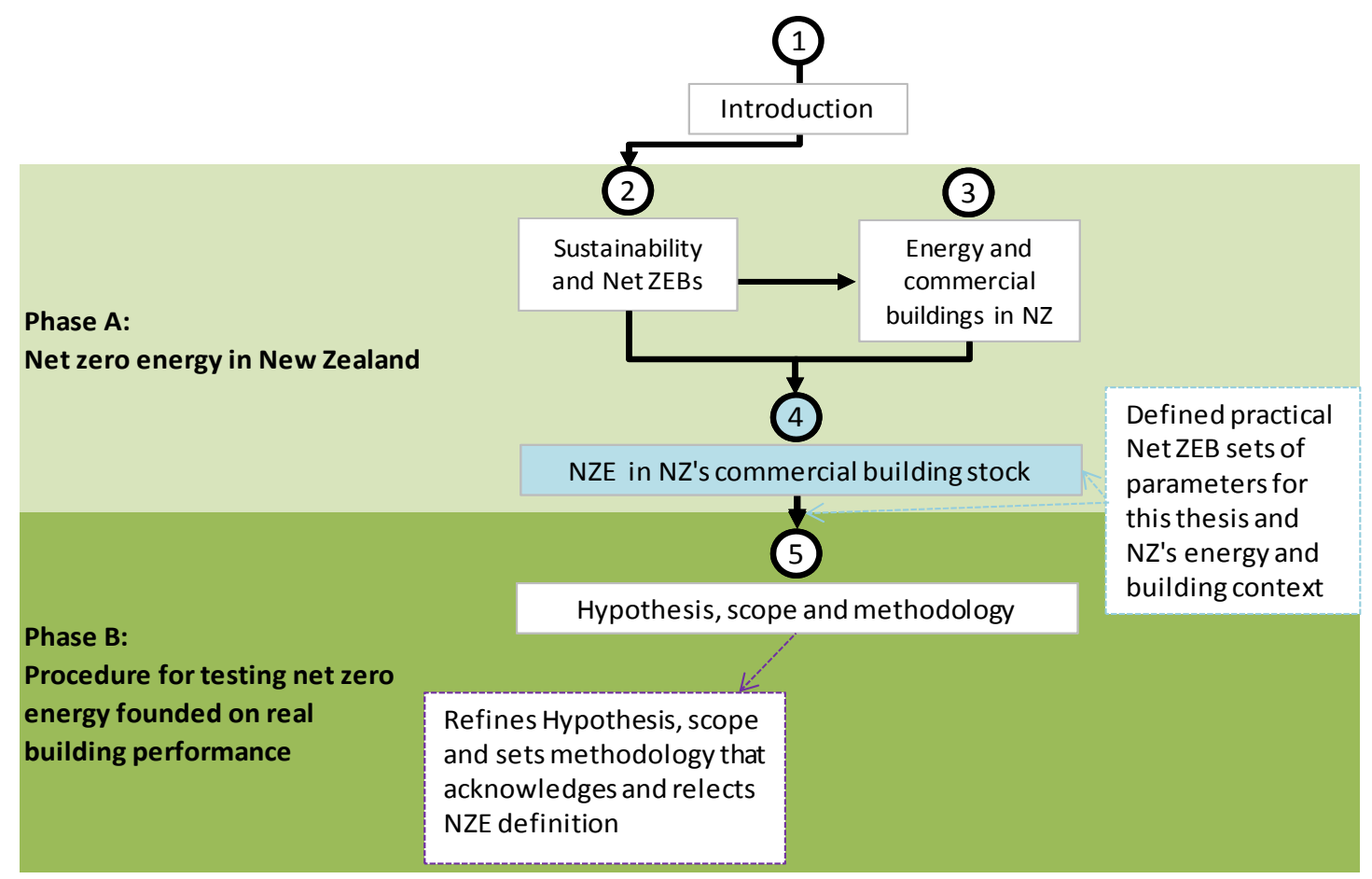

\section{Figure 4-6 : Link between Chapter 4 and 5.}

Chapter 5 begins Phase B which presents a procedure for testing Net Zero Energy that is founded on real building performance. Phase B starts by refining the study hypothesis (in Chapter 5) to reflect the nature of the NZE definition, otherwise it may not be tested correctly. The same applies to the scope as if it does not reflect the NZE definition the analysis undertaken may be outside the parameters of NZE in this thesis. Furthermore, the overarching methodology is affected by the types of analyses needed to test whether the NZE definition for the New Zealand commercial building stock can be met.

The later Chapters in Phase B further develop and explain the procedures introduced in the overarching methodology presented in Chapter 5. 


\section{RESEARCH PHASE B}

\section{Procedure for testing net zero energy}

founded on real building performance

Page $\mid 75$ 


METHODOLOGY

\subsection{Chapter Intent}

Chapter 5 finalises the research hypothesis being tested, outlines the scope of research, and presents the overarching methodology used to test the hypothesis. The refinement of the hypothesis and scope was required as a result of the NZE definition established in Chapter 4. The refinements make the hypothesis testable by using the presented overarching methodology within the scope of the NZE definition. Figure 5-1 displays the links between Chapter 4 and 5 with emphasis on the refinements required to the hypothesis, the scope and the overarching methodology.

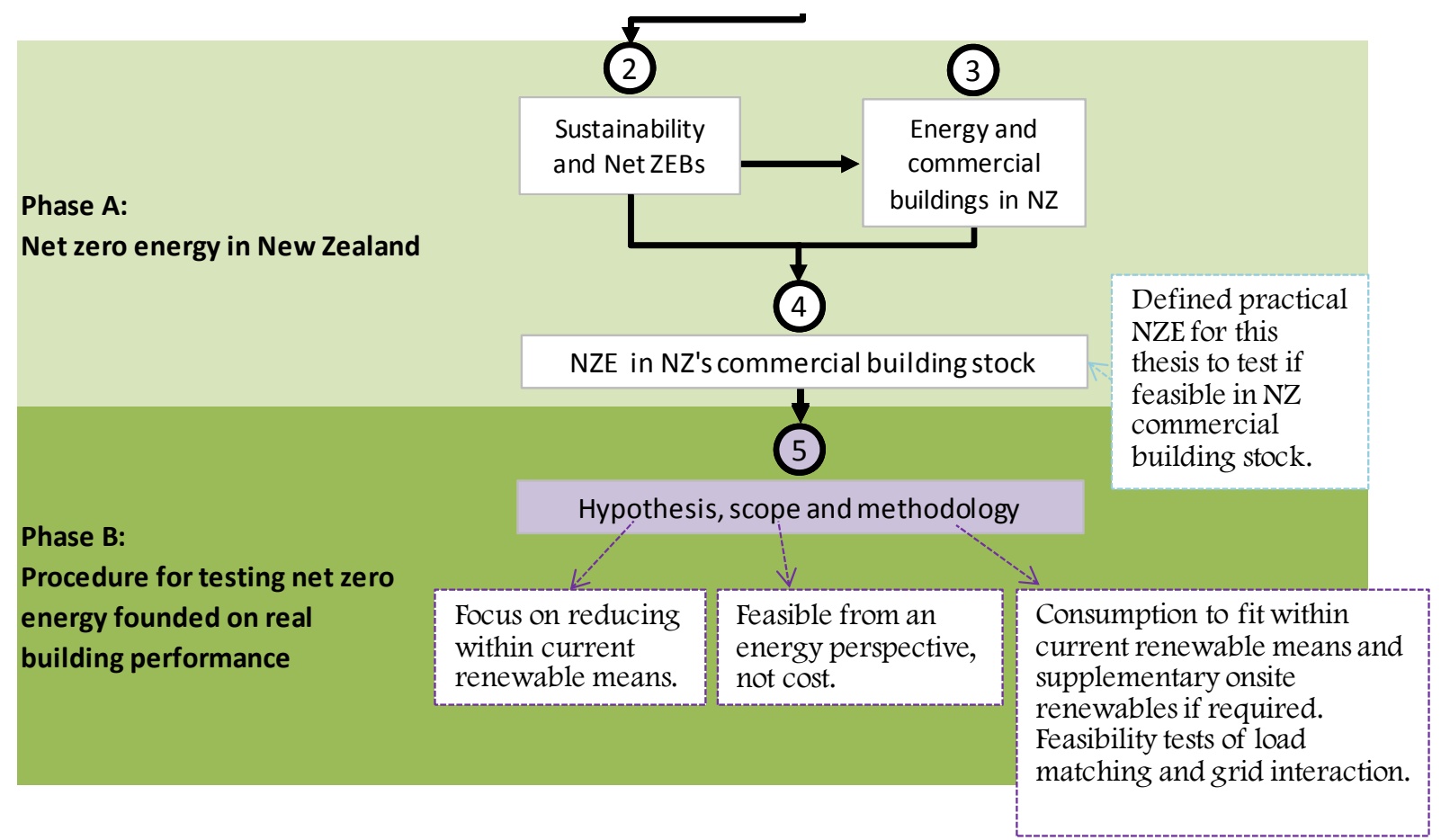

Figure 5-1 : Connection of Chapter 4 and 5.

\subsection{Refined hypothesis and scope}

In Chapter 1 a research hypothesis was proposed which had the objective of proving 1) that a method founded on real building performance can be used to base the assessment of NZE on reality; and (using this method) 2) it is feasible to convert the New Zealand commercial building stock to be net zero energy. The physical boundary, energy metric and balance of energy consumed and generated were not defined in the original hypothesis. The scope of what is meant by "feasible", "convert" or "commercial building stock" was also not defined. These and other aspects are further refined in the following sections of this thesis. 


\subsubsection{Hypothesis Part 1}

Part 1 of the hypothesis remains the same as it was not affected by the NZE definition:

1) It is possible to use a method founded on real building performance to base the retrofit to NZE on reality.

\subsubsection{Hypothesis Part 2}

With the inclusion of the NZE definition to the hypothesis, the refined part two of the hypothesis was developed:

2) It is feasible to convert/retrofit the current electrical grid tied New Zealand commercial building stock to consume net zero $\mathrm{CO}_{2}$ emitting primary energy on an annual basis.

The IEA definition framework states that Net ZEBs are grid-connected buildings (Sartori, Napolitano, and Voss 2012). All New Zealand commercial buildings are connected through the national electricity grid that effectively forms a large community of buildings and because of this the refinement to include the grid tied New Zealand commercial building stock sets the physical boundary at the whole building stock rather than across smaller communities (refer to Section 4.3). Analysing the refurbishment of buildings in an isolated country to be NZE requires that the buildings collectively use the synergies of the grid connection to achieve the overall goal. This means the analysis tests the current mix of building locations, building ages, surrounding site contexts, building uses and building sizes.

The NZE definition developed in Chapter 4 identified that the most practical energy metric and net zero balance is to use $\mathrm{CO}_{2}$ emitting primary energy. The refinement specifies this.

\subsubsection{Feasibility}

The term feasible is used in the thesis hypothesis. In the context of this thesis, feasible refers to whether it is energetically possible to reach NZE. The next logical step for assessing a move to NZE would be to test the economic feasibility. It was also identified in the assessment of Net ZEB definitions that consideration for the load matching and grid interaction of reaching NZE should be given. Due to these points, investigation of the feasibility of the move to NZE will be undertaken by beginning the assessment of the load matching, grid interaction and cost of retrofitting to NZE.

It is important to note that the first concern is operational energy and not embodied energy (as established in Phase A). This conclusion was reached as a consequence of electricity generation being the second largest emitter of $\mathrm{CO}_{2}$, behind transport. For this reason the study focused on operational energy and did not assess the embodied energy in the existing buildings and energy generation plants. 


\subsubsection{Converting/Retrofit}

Converting/retrofitting/refurbishment/renovation can be defined in a number of ways. For the purpose of this research "convert/retrofit" was defined as a form of deep retrofit. Deep retrofit is one of three retrofit methods which include existing building commissioning and standard retrofit. Table 5-1 gives an explanation of the three retrofit types.

Table 5-1 : Three retrofit levels. Table adapted from (PNNL, PECI, and U.S. Department of Energy 2011).

\section{\begin{tabular}{l|l} 
Existing Building Commissioning & Up to 25\% Energy Savings
\end{tabular}}

Significant savings can often be achieved with minimal risk and capital outlay by improving building operations and restructuring maintenance procedures. This process is commonly known as existing building commissioning and office buildings can typically attain $22 \%$ energy savings.(Mills 2009)

Standard retrofit measures are typically component-level replacements of existing equipment for improved energy efficiency. Typically, no one standard retrofit measure will achieve $25-45 \%$ site energy savings, but as a package of measures, this range is easily achievable.

\section{\begin{tabular}{l|l} 
Deep Retrofit & $\mathbf{4 5 \%}$ or higher Energy Savings
\end{tabular}}

Deep retrofits go beyond component level replacements and take an integrated whole-building approach to energy savings. Savings beyond $45 \%$ are achievable when upgrades to the building envelope are combined with retrofits of lighting and mechanical systems.

Using the deep retrofit definition, the retrofit to NZE was refined to be: the alteration of the façade construction layers, the upgrade of the design function for the building façade, the upgrade or replacement of equipment with current energy efficient technologies, and the addition of renewable energy generation technologies. This does not mean altering the building orientation, building plan shape or layout, or demolishing large portions of the building. If the research demolished existing buildings and built new buildings, it would be an entirely different project and therefore, the NZE results of this study are not directly applicable to new buildings. However, the design lessons established may still be applicable to new builds.

\subsubsection{Commercial building types}

The refined research hypothesis states that one of the boundaries in this study focuses on the New Zealand commercial building stock. The building type is defined in order to limit the amount of information required to study the commercial building stock. This study focused on commercial office, commercial retail, and commercial mixed buildings. The three types of commercial buildings were selected to allow the research to fit within the scope of the Building Energy End-use Study (BEES). The BEES study was a "6-year long project monitoring and analysing the energy and water consumption of non-residential buildings around New 
Zealand"(BRANZ Ltd 2013a). The purpose of BEES was to increase knowledge of the energy use patterns in commercial buildings (Isaacs et al. 2009). There are also two other non-residential building types (industrial service and industrial warehouse) which are not included in the scope of this study. The reason for their exclusion is due to a lack of obtained data for them to be considered sufficiently represented.

Commercial buildings can be broken down into many types. In order to be consistent, this study defines commercial buildings in the same way as BEES, with one minor addition. The New Zealand Building Code (NZBC) definition of commercial and communal non-residential buildings was used as the starting point (Department of Building and Housing 2009). The BEES study further refined the types of buildings represented by commercial and communal nonresidential buildings by excluding industrial, all ancillary, outbuildings, and communal nonresidential. This was due to the major resource use of the three commercial building types being associated more with the building itself and its management, rather than the processes that go on within it (like is the case for industrial buildings) (Isaacs et al. 2009). However, the BEES study found that there were some industrial use buildings which had a proportion of commercial office and commercial retail associated with them. This study excludes all industrial use buildings regardless of any other commercial building type being situated onsite. The commercial uses included are found in Table 5-2.

Table 5-2 also displays how the uses are aggregated into the three categories based on the Quotable Value (QV) building use categories.

\begin{tabular}{|c|c|c|}
\hline $\begin{array}{l}\text { Aggregated Commercial } \\
\text { Building Use Types }\end{array}$ & $\begin{array}{l}\text { Use } \\
\text { Types }\end{array}$ & Description/Definition \\
\hline Commercial Office (CO) & $\mathrm{CO}$ & Office-type use \\
\hline \multirow[t]{5}{*}{ Commercial Retail (CR) } & $\mathrm{CR}$ & Retailing use \\
\hline & $\mathrm{CM}$ & Motor vehicle sales and services \\
\hline & $\mathrm{CL}$ & Liquor outlets including taverns \\
\hline & $\mathrm{CS}$ & Service stations \\
\hline & $\mathrm{CT}$ & Tourist-type attractions \\
\hline Commercial Mixed (CX) & $\mathrm{CX}$ & $\begin{array}{l}\text { Buildings with a mixture of commercial uses on one } \\
\text { site }\end{array}$ \\
\hline
\end{tabular}

\subsubsection{Thermal and energy calculation program}

The method developed in this thesis is based on the modelling of real energy performance, using a whole building simulation tool. There are many building energy calculation programs available, such as SUNREL, IES AND DOE-2; however, all simulations undertaken in this study were performed using EnergyPlus Version 7.2. EnergyPlus was selected because:

- It is a widely documented, tested, and validated program (Witte et al. 2001; R. Henninger, Witte, and Crawley 2003; R. H. Henninger, Witte, and Crawley 2004); and 
- It has been used in the latest studies which assess a large number of whole buildings in national building stocks (Griffith et al. 2008; M. P. Deru et al. 2007).

EnergyPlus is an "energy analysis and thermal load simulation program" (US DOE 2013a). It is used to model buildings and their associated loads including Heating, Ventilation and Airconditioning (HVAC); lighting; equipment; and occupancy. Further details of the capabilities of EnergyPlus are explained in the 2001 and 2008 work by (D. B. Crawley et al. 2001; D. B. Crawley et al. 2008). EnergyPlus models the energy flows of a building based on a user's description from the perspective of the building's physical make-up, and associated mechanical and other systems (US DOE 2013a).

EnergyPlus energy calculations have been validated using the BESTEST validation method. Documentation about the BESTEST validation method and how it has been used within EnergyPlus are explained in Neymark's and Henninger's HVAC BESTEST publications (Neymark et al. 2001; Neymark and Judkoff 2002; Neymark and Judkoff 2004; Henninger, Witte, and Crawley 2003). However, two main limitations arise when using EnergyPlus models in the manner they are used in this thesis: the accuracy of the daylight and natural ventilation algorithms is less than the accuracy of specialised computer software.

EnergyPlus calculates daylight illuminance which is used to estimate energy savings. These energy savings can be achieved because an adequate level of illuminance provided by the daylight means electric lighting is not required. EnergyPlus is not a daylight simulation software; it uses a simple daylight algorithm to calculate the likely illuminance in a space. The daylight calculations are performed using the Split Flux method, which is a calculation method for determining the amount of daylight being transmitted into a building (Hopkinson, Longmore, and Petherbridge 1954; Lynes 1968). There are some limitations in the use of the Split Flux method (US DOE 2013b) as it overestimates the level of daylight illuminance in a building space (Versage, Melo, and Lamberts 2010). However in simple cases, such as the modelling technique employed in this thesis, reliability can be found. A study undertaken by Loutzenhiser, Maxwell, and Manz, (2007) compared measured daylight levels with simulated daylighting levels in simple EnergyPlus models. Furthermore, it was shown in a separate study that under certain conditions the EnergyPlus split flux method is more than suitable and accurate for calculating daylight accurately. "EnergyPlus [daylight calculation] methods reliably predicted the illuminance profiles that occurred during overcast days with exterior horizontal blinds" (Gibson and Krarti 2015). Similar conditions were undertaken in this thesis research during the examination of NZE. These studies provided confidence that EnergyPlus's daylighting algorithm does predict daylight illuminance with some accuracy. Also, EnergyPlus was used for the calculations as it provided results in a much shorter simulation time compared to other validated lighting simulation programs, which traditionally have exorbitant simulation times for annual calculations (Reinhart 2011). 
EnergyPlus is not a Computational Fluid Dynamics (CFD) simulation software. It calculates natural ventilation using an airflow network algorithm to estimate the likely amount of outside fresh air that can be vented into the building based on the outdoor conditions and physical make up of windows. A study found that there are issues with the Airflow Network (Lixing 2007). The study validated the airflow network model using several sets of measured data. "The Airflow Network model is currently unable to accurately simulate two way airflows through large horizontal openings" (Lixing 2007, p.970). Because the problem is associated with two-way flows, the EnergyPlus models can only calculate one-way flows accurately. This would likely reduce the impact that natural ventilation would have on the building's energy consumption because it does not model air leaving the building through the same window supplying air to the building. Given this would result in a higher energy use of the model; it was deemed a small limitation and would not overestimate savings made by using natural ventilation. EnergyPlus is also used for the calculations because it provides results in a much shorter simulation time compared to validated CFD programs. Even with the limitations using the Airflow Network, the calculation is superior to the normal assumption that a particular ventilation rate is possible no matter the wind direction and wind speed found in a specific location and building orientation (Deru, Judkoff, and Torcellini 2002; US DOE 2013b). This is due to the Airflow Network using the weather files wind data to calculate a ventilation rate that can be achieved given a particular wind speed and direction in relation to a particular facade's operable window, for every hour of the year.

Overall, EnergyPlus was used for all energy calculations without the aid of external daylight or CFD software. This was due to EnergyPlus being suitably accurate and providing results in a much shorter simulation time compared to other validated Daylight and CFD software. The shorter simulation time was important because of the large number of simulations being performed in this thesis (refer to Section 8.4.2)

\subsubsection{Building climate classification system}

Climate analysis is an essential component of energy conscious design, such as Net ZEBs. This is because currently there are very few locations in the world that offer comfortable climate conditions for people on a year-round basis (The American Institute of Architects 1982c). Climate was used as one of the means to establish what Energy Conservation Measures (ECM) should be used when retrofitting the New Zealand commercial building stock. This thesis proposed a climate classification which accounts for the building, its use/operation, and the external climatic conditions. The classification was needed because of basic flaws in the standard climate classification system. The flaw was that the traditional climate classification systems do not account for buildings with higher internal loads, nor does it account for the construction of the building. The building climate classification system in this thesis assesses the climate as a function of the building use, its construction and its impact on the filtering of the external climate (Cory et al. 2011). The building climate classification is focused on the most relevant space conditioning challenges that building designers have to face and gives the designers an idea 
about the passive design potential in facing those challenges. The classification was used in the assessment of climate throughout this thesis and is described in the following paragraphs.

\subsection{7a Limitations of traditional climate classifications}

Traditional climate classification systems only consider the external climate. This means the interaction between the building and the external climate is neglected. This lack of interaction is a crucial flaw in existing classifications. In addition, traditional climate classifications do not indicate the potential usefulness of the external climate for improving the operation of the building.

One such widely used traditional climate classification is the Köppen-Geiger system. The Köppen-Geiger system labels climate zones using the following three levels:

- Main climates: equatorial, arid, warm temperate, snow, polar (tundra or polar ice)

- Precipitation: desert, steppe, fully humid, summer dry, winter dry, monsoonal

- Temperature degrees: hot arid, cold arid, hot summer, warm summer, cool summer, extremely continental.

Traditional external climate based zoning was explored using the Ecotect climate classification tool (Autodesk Incorporated 2011). Ecotect climate classification overlays a specific location's ambient average monthly maximum temperature onto a psychometric chart and relates the plotted climate to seven aggregated Köppen-Geiger climate labels. "The Ecotect Climate Classification tool divides a Psychrometric chart into regions characteristic of different climate types"(Natural Frequency 2013). The overlaid average monthly maximum temperatures relate to the seven external climate regions: cold; moderate; warm dry; warm humid; hot dry; and hot humid. The average monthly maximum temperatures are shown on the chart as a shaded area between 12 points, which represent each month of the year (Natural Frequency 2013). This means the location's hourly temperatures and humidities all fall within this shaded area.

Figure 5-2 displays an example of the traditional climate classification using the Ecotect weather tool. These classifications are used to highlight appropriate design responses to the climate. As shown in Figure 5-2, Wellington is predominantly below the moderate zone and in the cold climate zone. Wellington is categorised as having a cold climate and therefore it is inferred that all buildings located in this location have heating challenges. 


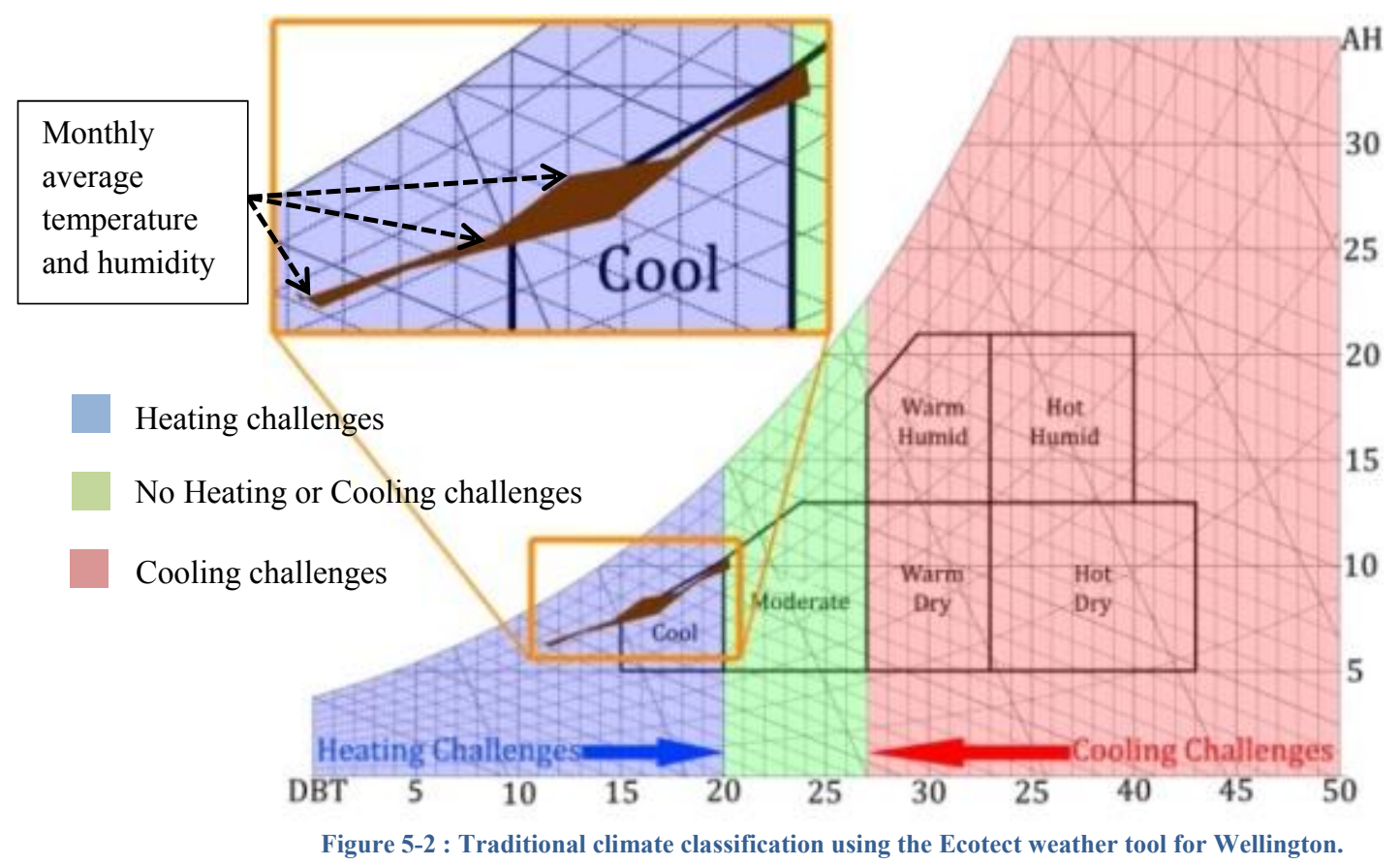

As the traditional classification is only about the external climate, no distinction is made between residential and non-residential buildings, which have different internal loads. It was proven in Cory et al (2011) that a new classification was needed for buildings with high internal loads. This was due to typical non-residential buildings not following the external climate condition trends because non-residential buildings have a high internal load that has associated high internal heat gains. The result was the indoor climate being more cooling focused than the external climate. Cory et al (2011) compared a typical residential and a non-residential building in seven different international climates. In each climate, the non-residential building had more cooling hours than the residential building. All of which resulted in non-residential buildings moving from heating dominated or mixed heating and cooling climates, to being cooling dominated.

Table 5-3 shows a comparison between a traditional climate classification and non-residential building climate classifications for 16 locations. The 16 locations represent the locations of the non-residential buildings selected as case studies in IEA Task 40 (Garde and Donn 2014). The traditional climate type is stated as being (or being a mixture of) the seven aggregated KöppenGeiger external climate labels: cold; moderate; warm dry; warm humid; hot dry; and hot humid. The associated climate challenge is also indicated and is labelled the same as the building climate classification. The building climate classification is stated as being either heating dominated (needs heating for 70 percent or more of the time); mixed heating and cooling (needs a more even split of both heating and cooling; or cooling dominated (needs cooling for 70 percent or more of the time)). Refer to $5.2 .7 \mathrm{~b}$ for a detailed description of what heating, cooling and mixed heating cooling climates are defined as. 
Table 5-3 : Comparison of non-residential climate classifications for 16 locations. Table adapted from (Garde and Donn 2014).

\begin{tabular}{|c|c|c|c|}
\hline & Country & $\begin{array}{c}\text { Traditional climate type and } \\
\text { challenges }\end{array}$ & $\begin{array}{c}\text { Non-residential building climate } \\
\text { challenges }\end{array}$ \\
\hline 1 & Zaragoza, Spain & $\begin{array}{l}\text { Predominately Cold and Moderate } \\
\text { (Heating Dominated) }\end{array}$ & Mixed Heating and Cooling \\
\hline 2 & Monheim, Germany & Predominately Cold (Heating Dominated) & Mixed Heating and Cooling \\
\hline 3 & Dijon, France & Predominately Cold (Heating Dominated) & Mixed Heating and Cooling \\
\hline 4 & Terre Saint, Reunion & $\begin{array}{l}\text { Moderate and Warm Humid (Cooling } \\
\text { Dominated) }\end{array}$ & Cooling Dominated \\
\hline 5 & Paris, France & Predominately Cold (Heating Dominated) & Mixed Heating and Cooling \\
\hline 6 & Saint Pierre, Reunion & $\begin{array}{c}\text { Moderate and Warm Humid (Cooling } \\
\text { Dominated) }\end{array}$ & Cooling Dominated \\
\hline 7 & Nantes, France & Predominately Cold (Heating Dominated) & Mixed Heating and Cooling \\
\hline 8 & Bolzano, Italy & $\begin{array}{l}\text { Predominately Cold and Moderate } \\
\text { (Heating Dominated) }\end{array}$ & Mixed Heating and Cooling \\
\hline 9 & Geneva, Switzerland & Predominately Cold (Heating Dominated) & Mixed Heating and Cooling \\
\hline 10 & $\begin{array}{l}\text { Wellington, New } \\
\text { Zealand }\end{array}$ & Predominately Cold (Heating Dominated) & Mixed Heating and Cooling \\
\hline 11 & Melbourne, Australia & $\begin{array}{c}\text { Predominately Cold and Moderate } \\
\text { (Heating Dominated) }\end{array}$ & Mixed Heating and Cooling \\
\hline 12 & Berlin, Germany & Predominately Cold (Heating Dominated) & Mixed Heating and Cooling \\
\hline 13 & Innsbruck, Austria & Predominately Cold (Heating Dominated) & Mixed Heating and Cooling \\
\hline 14 & Lisbon, Portugal & $\begin{array}{l}\text { Mixed Cold, Moderate, and Warm Dry } \\
\text { (Mixed Heating and Cooling) }\end{array}$ & Mixed Heating and Cooling \\
\hline 15 & Singapore & $\begin{array}{l}\text { Moderate and Warm Humid (Cooling } \\
\text { Dominated) }\end{array}$ & Cooling Dominated \\
\hline 16 & San Francisco, USA & $\begin{array}{c}\text { Predominately Cold and Moderate } \\
\text { (Heating Dominated) }\end{array}$ & Cooling Dominated \\
\hline
\end{tabular}

The traditional climate classification in Table 5-3 indicates that a large number of the external climates were predominantly cold and were therefore heating dominated climates. However, once the non-residential building use, with its associated high internal loads, and the local building code insulation levels were taken into consideration, the cold climates become mixed heating and cooling climates, or cooling dominated climates. This was due to the higher internal heat gains that result in a larger proportion of cooling hours.

\subsection{7b Building climate classification assessment method}

The building climate classification uses thermal simulation to calculate the interaction between the external climate and a reference building. The reference non-residential building has the following features:

- very simple thermal model geometry (Figure 5-3);

- typical window to wall ratio and no shading system;

- minimum insulation values and infiltration rates required from the local/national building standards;

- typical occupant load and schedules;

- standard profile for internal loads; 
- lighting level for main building function (Standards New Zealand 2007b) (CEN 2011);

- thermal comfort acceptability range (Givoni 1998); and

- A Typical Meteorological Year (TMY) weather file is used to simulate the external climatic conditions.

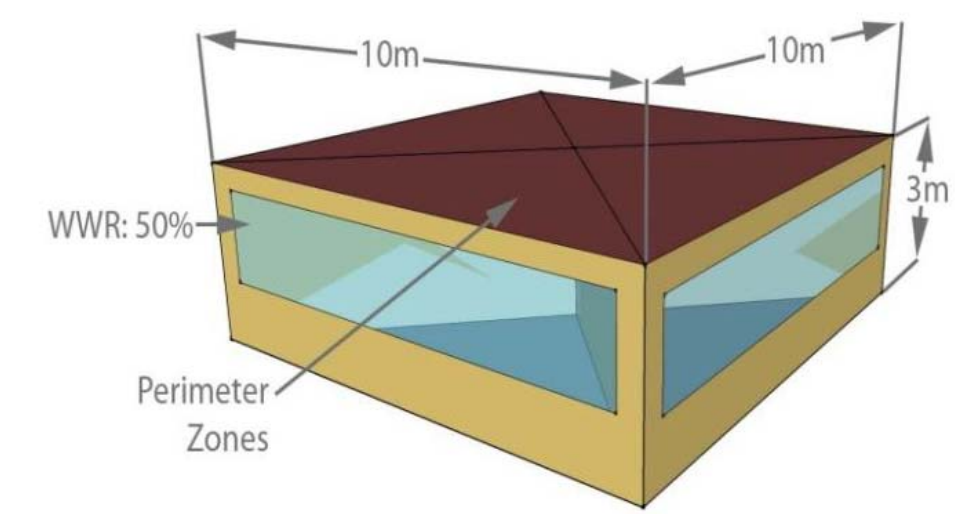

Figure 5-3 : Building climate classification simple thermal reference model geometry.

A reference building model is created for each selected location and simulations are run in EnergyPlus in "free running" mode with the TMY weather file. "Free running" is a simulation that examines how the building design and internal gains alter the internal environment. This is because "free running" has no added heating or cooling input other than solar radiation gained by the sun. The building climate classification is based on the number of discomfort hours experienced due to overheating, under-heating and humidity.

The comfort zone was set by temperature and humidity comfort bands based on internal temperatures and humidity for health and comfort recommended by Givoni (1998). Givoni recommended that comfort bands account for adaptive comfort from seasonal acclimatisation and occupant behaviour such as adding or removing layers of clothing. 
Figure 5-4 displays the building climate classification comfort zone ranges, and the defined conditioning challenge zones (heating zone, cooling humidifying zone, cooling dehumidifying zone).

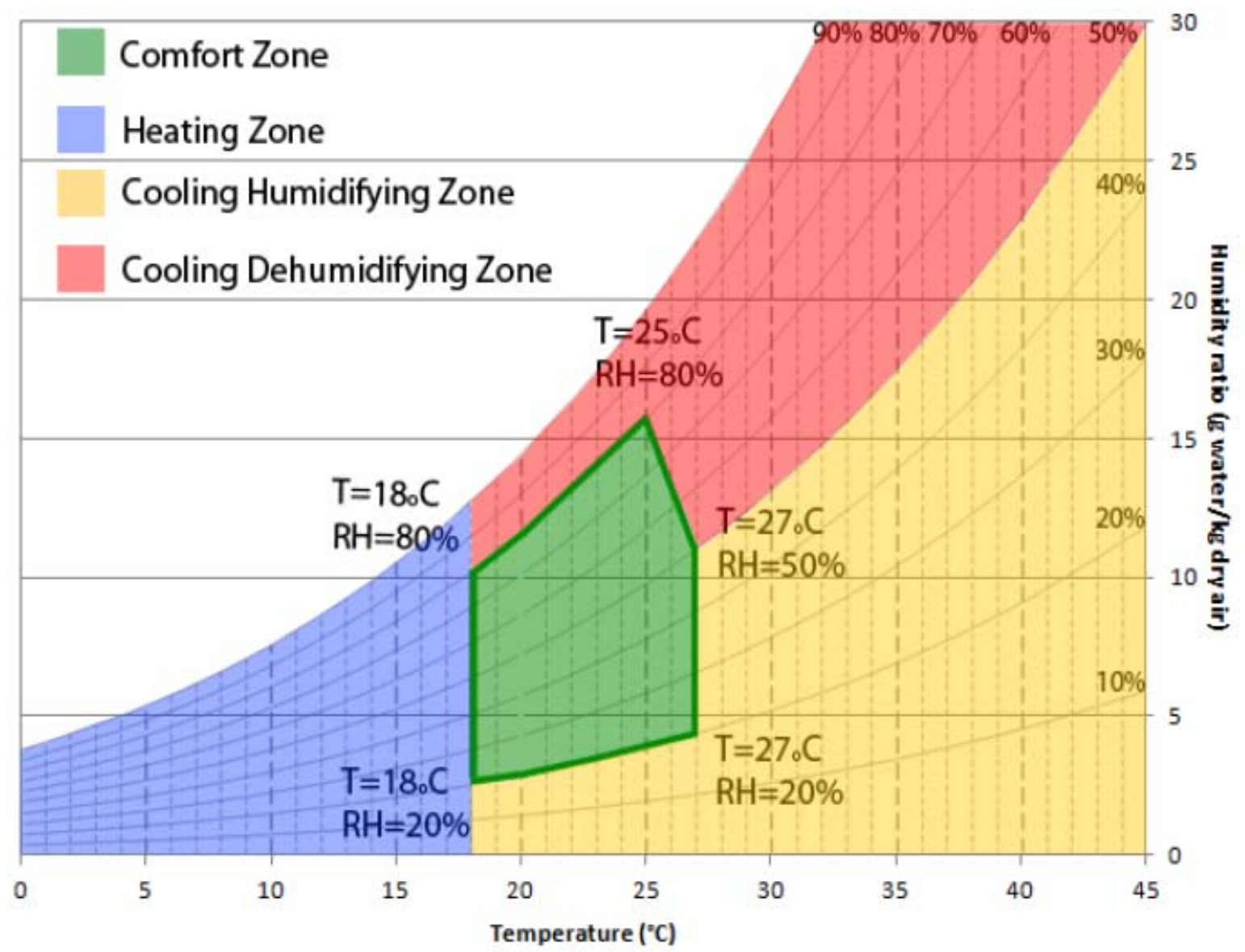

Figure 5-4 : Building climate classification comfort zone ranges and the defined conditioning challenge zones. Created using (Givoni 1998).

The building climate indicator is dependent on the percentage of discomfort hours during the occupation period. The occupation period for non-residential buildings was assumed to be between the hours of $8 \mathrm{am}$ to $6 \mathrm{pm}$. The building climate classification's main climate labels were split into three temperature and three humidity climate challenges. The temperature challenges are:

- Heating dominated: if more than 70 percent of the discomfort hours experienced during occupied hours are predominately low temperatures that require heating (heating zone ranges (blue) in Figure 5-4)

- Cooling dominated: if more than 70 percent of the discomfort hours experienced during occupied hours are predominately high temperatures that require cooling (cooling zone ranges (yellow and red) in Figure 5-4)

Page $\mid 86$ 
- Mixed heating and cooling: if discomfort hours are low for less than 70 percent and high for less than 70 percent meaning a more balanced split between heating and cooling is required (heating and cooling ranges (blue, yellow, and red) in Figure 5-4).

The humidity challenges are:

- Dehumidifying dominated: if more than 70 percent of the discomfort hours experienced during occupied hours are due to high humidity (cooling dehumidifying zone ranges (red) in Figure 5-4)

- Humidifying dominated: if more than 70 percent of the discomfort hours experienced during occupied hours are due to low humidity (cooling humidifying zone ranges (yellow) in Figure 5-4)

- Mixed dehumidifying and humidifying: if discomfort hours are experienced during low humidity for less than 70 percent and high humidity for less than 70 percent (cooling dehumidifying and humidifying zone ranges (yellow and red) in Figure 5-4)

While a traditional climate classification does not include an assessment of the potential usefulness of the external climate to buildings, the building climate classification has three additional indicators which aim at assessing the potential for gains through daylight, natural ventilation and solar heating.

The Useful Daylight Index (UDI) is calculated by counting the number of hours during the occupation period that are useful for daylighting the building throughout the year. The useful daylight hours were defined as the hours when illuminance is within a range considered "useful" for the occupants (between 100 and 2000 lux) (Nabi and Mardaljevic 2006). The reference building (Figure 5-3) is modelled with electric light switches and photo sensor controls, placed in each perimeter zone. "The UDI scheme is applied by determining the annual occurrence of daylight illuminances that:

1. Are within the range defined as useful (i.e. 100-2000 lx);

2. Fall short of the useful range (i.e. less than $100 \mathrm{~lx}$ );

3. Exceed the useful range (i.e. greater than 2000 lx)"(Nabi and Mardaljevic 2006, p.906).

Only the useful and not useful ranges are displayed in the building climate classification. They are presented as a single indicator of the annual amount of useful and non-useful daylight in the building for the tested climate.

The Useful Wind Index (UWI) is defined as the number of hours when wind driven, or wind and stack driven cross-ventilation can increase the number of comfort hours by decreasing the number of cooling hours. This increase and decrease indicates the potential improvement made by utilising the wind climate and therefore, useful wind is defined as wind having the potential to 
cool the indoor temperatures to within a comfortable range (i.e. $18-27^{\circ} \mathrm{C}$ ). Natural ventilation is modelled by the AirflowNetwork in EnergyPlus. The window and its opening controls are based on:

- An assumption that 85 percent of the windows can be opened;

- No mechanical ventilation being simulated to assess the potential for wind on the indoor climate only;

- Natural ventilation assumed to be used once the indoor temperature has reach $23^{\circ} \mathrm{C}$;

- Natural ventilation having the ability to be used for 24 hours a day; and

- Natural ventilation not being used if the exterior temperature is greater than the indoor temperature.

The Useful Solar Index (USI) is used to classify the potential use of the direct solar radiation in each location, as well as the potential need to exclude direct solar radiation in each location. It assesses whether solar shading is vital, or whether there is a need for solar heat gain to heat the building. To estimate the USI, the location's external direct solar radiation data is matched to the hours that are below the heating set point and above the cooling set point. The index only measures the solar gains needed to reach the lower comfort limit $\left(18^{\circ} \mathrm{C}\right)$, and exceed the upper comfort limit $\left(27^{\circ} \mathrm{C}\right)$. The result is an index that indicates what percentage of the time solar radiation is useful in reaching comfortable temperatures, as well as what percentage of time solar radiation is not useful. Non-useful solar can be a hindrance to the building as it can cause excessive solar heat gains which increase the need for cooling. 


\subsection{7c Example building climate classification}

Figure 5-5 displays the building climate results for Wellington, New Zealand. If the split of heating and cooling hours (green bar) occurs within the boundary of either CD, MHC or HD, the climate is Cooling Dominated (CD), Mixed Heating and Cooling (MHC) or Heating Dominated (HD). The markers from $\mathrm{A}$ to $\mathrm{E}$ aid in the results discussion below. Wellington was chosen as an example because it was one of the main cities in New Zealand where a high proportion of the country's commercial building floor area is located.

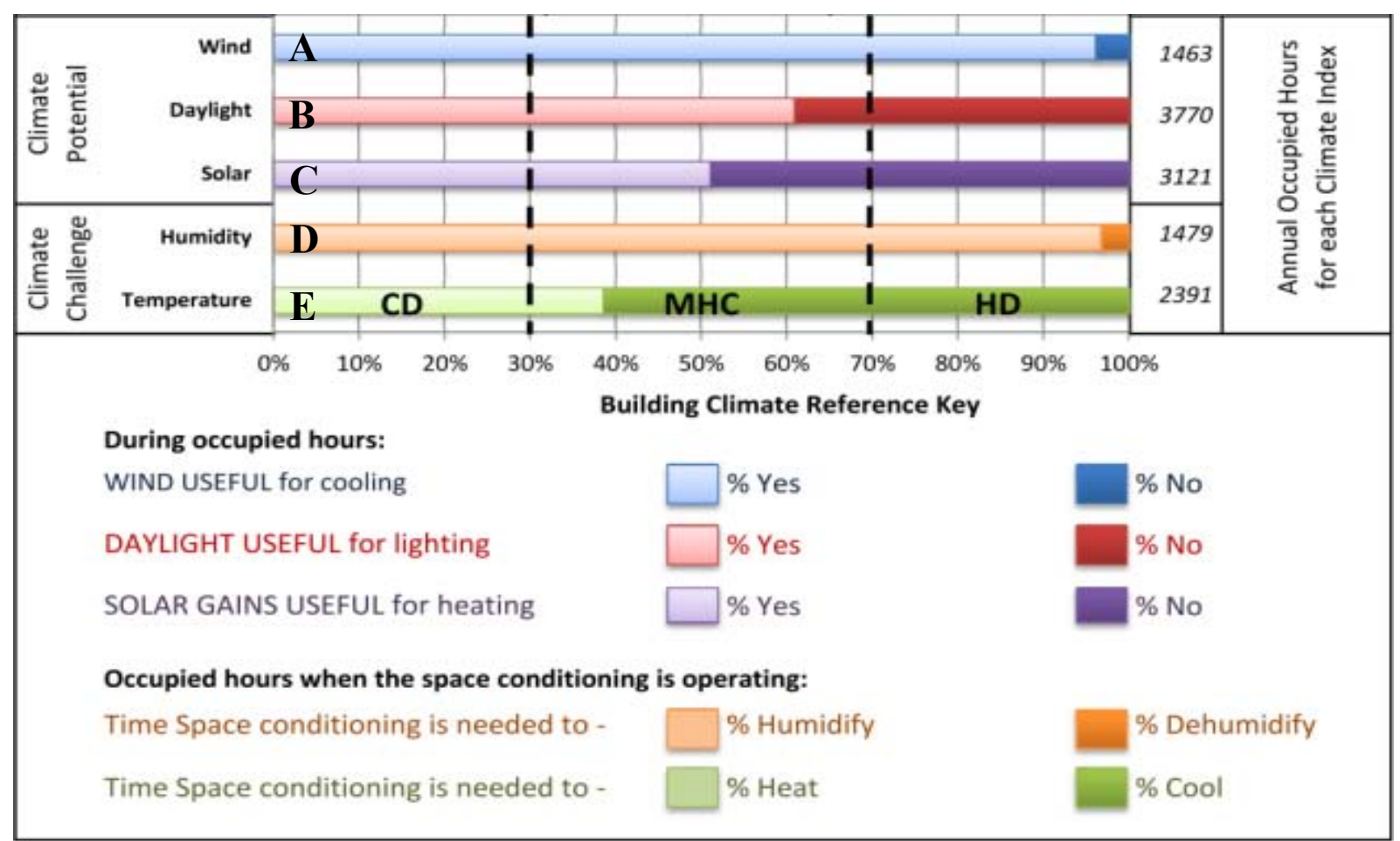

Figure 5-5 : Building climate results for Wellington.

The classification results for Wellington shows a mix of 38 percent heating and 62 percent cooling hours, and approximately 96 percent humidifying hours (Markers D and E). As there are less than $\mathbf{7 0}$ percent heating and cooling hours the building climate was classified mixed heating and cooling. UWI shows that the wind climate in Wellington is very useful (Marker A). The UWI index represents the reduction in the number of cooling hours achievable by using the outdoor wind and air for natural ventilation. Using the wind climate in Wellington can reduce the number of cooling hours by 96 percent. The UDI shows that 61 percent of the occupied hours have useful daylight (Marker B). This suggests that daylight can provide adequate lighting levels for occupant tasks, reducing the need for energy use. The USI also indicates that there is useful solar for 52 percent of the year (Marker C) and reinforces that buildings need direct solar heat gains as well as protection from excessive solar heat gains.

Overall the Wellington non-residential building climate can be classified as having: 
- $\quad$ Space Conditioning Challenge: Mixed heating and cooling;

- Humidity Challenge: At times too dry - humidifying challenges;

- Solar Challenge: Need for solar heat gains and need to protect against solar heat gains - mixed useful and non-useful solar challenges;

- Daylight Challenge: OK daylighting potential - mixed useful and non-useful daylight challenges; and

- $\quad$ Wind Challenge: Wind potential for cooling - a useful wind climate.

Wellington's climate results indicate that the simple thermal climate challenges for designers of commercial buildings are focused on both heating and cooling the building, as well as humidifying issues (Marker D). The climate is well suited to natural cooling as incorporating natural ventilation has the potential for saving energy in Wellington (Marker A). Daylight can be used to reduce energy consumption; however, careful daylight design would need to deal with the non-useful daylight of 39 percent (Marker B). The non-useful daylight, which is defined as being very low daylight or high daylight illuminance levels, could result in discomfort glare for occupants of the building. By assessing the useful solar index it was established that there is a need for solar heat gains to passively heat buildings, as well as a need for solar protection against excess solar heat gains overheating the building. This is shown through an almost 50 percent split of the useful solar and not useful solar (Marker C) and indicates that good access to solar heating in the winter and solar shading are essential to prevent the overheating from excessive solar heat gains in summer.

Because this thesis is researching non-residential (commercial) buildings and the potential suitability of Net ZEB passive designs for reducing energy, the above outlined building climate classification is used. The reason for using this building climate classification is highlighted when comparing the building climate results for a non-residential building in Wellington to traditional climate classification results (Figures 5-2, 5-5 and Table 5-3). The building climate classification suggests that a non-residential building is more cooling orientated than conventional classifications suggest because the internal temperatures are warmed by the building use and its activity. 


\subsection{Overarching methodology: Real, not Prototypical buildings}

This section outlines the overarching methodology used in this thesis. The methodology is discussed with reference to previous studies that detail the refinement of previous methodologies to better represent real buildings and the whole commercial building population in New Zealand.

The assessment of the technical potential for energy efficiency upgrades to a commercial building stock is most commonly a quantitative assessment. For example, the answer is calculated as a number which defines whether the buildings are more energy efficient when compared to a current case. Quantitative research examines variables that can be measured so that numbered data can be analysed using statistical procedures (Creswell 2009). To test this study's hypothesis, the methodology used both qualitative and quantitative forms in tandem to improve the overall strength of the research (termed a mixed approach) (Creswell 2009). It is seen as a mixed approach because it implements the use of performance data, survey information, statistical analysis, case studies, open-ended questions and thematic analysis (Creswell 2009; Grbich 2007). However, the overarching methodology is weighted towards quantitative analysis. It primarily uses performance data and statistical analysis to prove the hypothesis, and uses surveys and thematic analysis to clarify or to further critique aspects of the research.

The overarching methodology used in this thesis used a basic framework for the analysis which was adopted from Griffith et al. (2008) and Deru et al. (2007). Griffith et al. (2008) presents the 'Methodology for Modelling Building Energy Performance across the Commercial Sector' in USA. The outcome of the Griffith et al. (2008) study was a set of reference commercial building models that were prototypical buildings. These models were used by Deru et al. (2007) in the "Assessment of the Technical Potential for Achieving Net Zero-Energy Buildings in the Commercial Sector" in the USA. Deru et al. (2007) applied known technologies to each of the reference models to assess whether reaching NZE in the commercial sector was possible. The detailed methodology in this thesis refined a number of methodological aspects. Firstly, the definition of NZE was refined in this thesis. Deru et al. (2007) tested whether each building could be a net zero site energy building. This would require all energy consumed at the site to be offset with onsite renewable energy generation. This thesis assessed the commercial building stock at a community level, making the emphasis not solely on each individual building. Secondly, Deru et al. (2007) used prototypical reference buildings to represent new buildings. The study assessed the potential of new commercial buildings being NZE, not existing buildings. This thesis is not projecting what new buildings can achieve, but instead projecting what could be achieved in existing buildings. Lastly, the prototypical reference buildings represent an "average" building in an open area. The building energy models used in this thesis were a representative sample of real buildings. The models represent real buildings, not hypothetical theoretical buildings. The result was a methodology that was grounded in reality rather than being based on a theoretical scenario. 

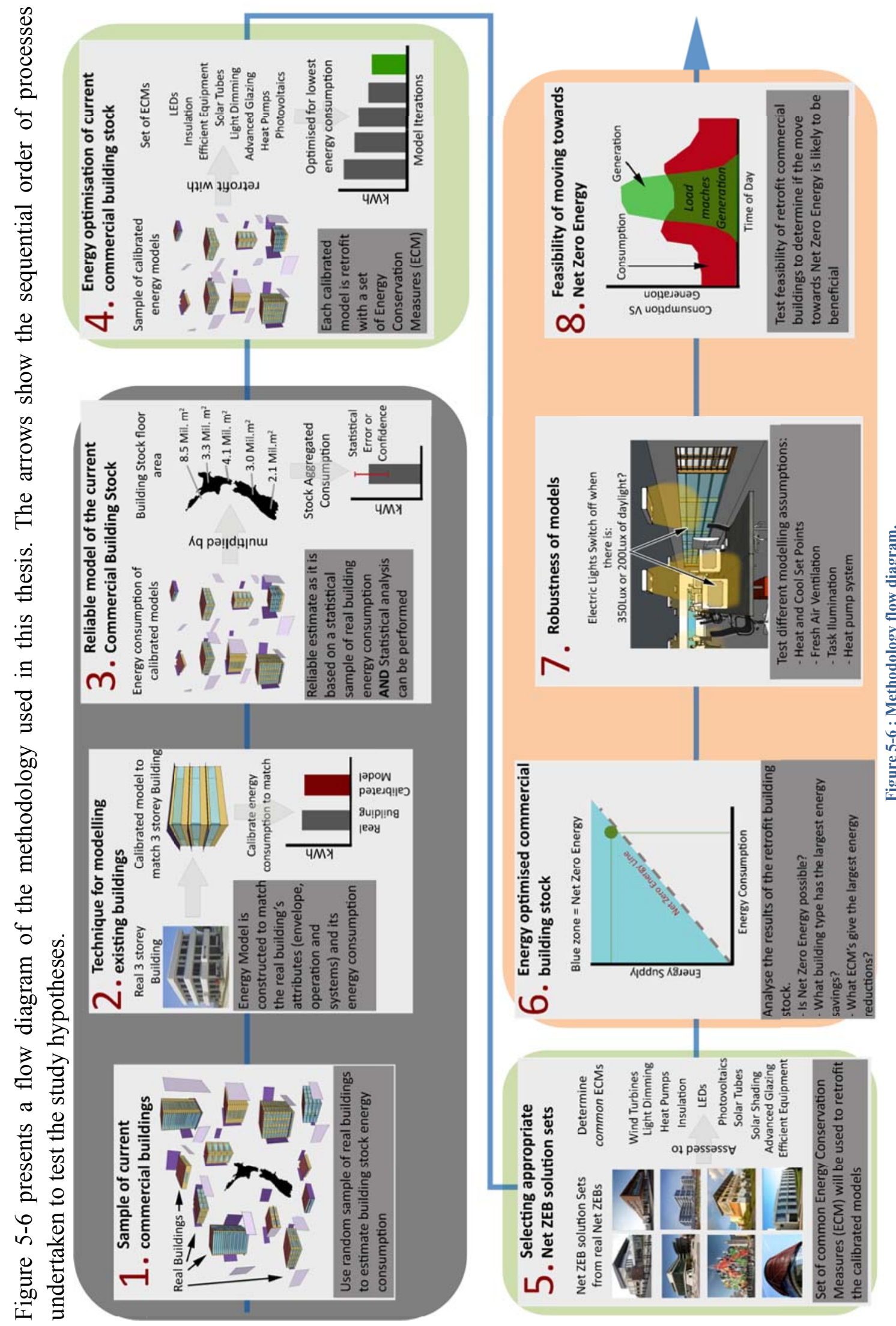

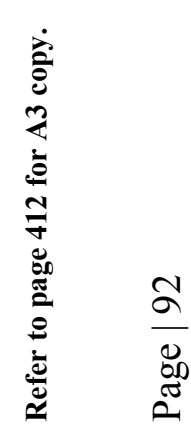


The research methodology has eight main steps which form three methodological stages:

Stage 1 (grey background) builds a representation of the current commercial building stock and is undertaken during steps 1,2 and 3.

Stage 2 (green background) optimises the current commercial building stock model to reduce the energy consumption and is undertaken during steps 4 and 5.

Stage 3 (orange background) assesses the energy and feasibility of the optimised commercial building stock and is undertaken during steps 6,7 and 8 .

As the overarching methodology follows the standard means of testing a change across an entire building stock (Moffat 2001; Griffith et al. 2008; M. P. Deru et al. 2007; Huang and Franconi 1999), each stage and step was undertaken regardless of whether there was a positive or negative result. The result just carries forward to the next step and the analysis is performed. Each stage and step is discussed in the following sections. The discussion outlines how the methodological steps have been undertaken in the past and how they were undertaken in this thesis.

\subsubsection{Representing the current commercial building stock}

The first stage in the study methodology was to represent the current commercial building stock. A well-established method undertaken to represent buildings or groups of buildings is to use Whole Building Simulation. Whole Building Simulation is fundamental for forecasting energyrelated performance and enables informed decisions on building design changes (A Gates, Cory, and Donn 2012; Bellenger 2011). Whole building simulation has been used for approximately 30 years and researchers have used such tools to represent large portions of the building stock (Griffith et al. 2008). The earliest research undertaking large scale whole building simulation to assess large portions of a commercial building stock was performed in the 1980s and early 1990s (Briggs, Crawley, and Belzer 1987; Briggs, Crawley, and Schliesing 1992; D. Crawley and Schliesing 1992). The type of research is referred to as stock aggregation. Stock aggregation is a bottom-up model, meaning that it produces a model at the micro-scale, e.g. buildings, instead of a top-down model that starts at the macro-scale, e.g. economy (Moffat 2001). Stock aggregation can be used to:

1. "Highlight areas where substantial potential exists for improvement in resource use and economic efficiency;

2. Allow for quick "what-if?" analysis;

3. Allow policy makers to optimize regulations and market incentives to achieve specific targets;

4. Analyse how policies in one area, like energy security, or housing affordability, can affect other impacts from buildings, like air pollution, or energy demand; and

5. Develop priorities for research and development" (Moffat 2001, p.2). 
All five uses of stock aggregation can be related to the outputs of this thesis, with points 1, 2, 5 being directly undertaken in Chapters 9, 10, and 11. The research procedure undertaken is no different to the Moffat (2001) methodology. It uses a bottom-up whole building simulation model to perform a type of stock aggregation to build a representation of the current New Zealand commercial building stock.

However, the representation of the current commercial building stock was undertaken in two stages, one of which did differ from the Moffat (2001) and previous study methods, such as (Griffith et al. 2008; Briggs, Crawley, and Belzer 1987; Briggs, Crawley, and Schliesing 1992; Crawley and Schliesing 1992; Deru et al. 2007). The first stage differed from the previous studies due to the sampling of the current building stock used to identify what whole building simulation models were required to be built in order to adequately represent it, rather than using prototypical buildings. The second stage was the same as previous studies as it involved the use of a whole building simulation computer program to represent the commercial buildings. The refinements to the process are discussed in the following sections.

\subsection{1a Sample of current commercial buildings}

This section reviews within the context of the over-arching methodology: i) why a sample of buildings was required; and ii) how the approach in this research differs from previous research. For detail about the sampling process, stock aggregation process, and the resulting sample of buildings refer to Chapter 6 .

Figure 5-7 illustrates step 1 in the overarching methodology and the difference between the methods for representing the current commercial building stock in this thesis compared to those in previous studies. Previous studies have used prototypical or normative building models to represent different building types and sizes. Prototypical building models are not real buildings. Instead, each model forms a typical model of a specific building type (For example, office, retail, school etc.) and size (For example, small, medium or large). The prototypical models are "synthetic buildings compiled from statistical data from building surveys or conclusions from previous such studies. In other words, these prototypes are not real buildings, but hypothetical constructs with size, shell construction, window area, HVAC system type, operating schedules, etc., based on the mean or prevailing condition among statistical samples" (Huang and Franconi 1999, p.3). Previous studies used survey information to determine the typical or average building attributes in order to form the prototypical building models. As an example, Huang and Franconi (1999) used 1998 Commercial Buildings Energy Consumption Survey (CBECS) data to build 120 prototypical whole building simulation models and Griffith et al. (2008) used the 2003 CBECS data to build 4,820 prototypical whole building simulation models. "CBECS is a national sample survey that collects information on the stock of U.S. commercial buildings, their energy-related building characteristics, and their energy consumption and expenditures" (U.S. Department of Energy 2013a). CBECS surveyed 5,215 buildings across USA which were statistically sampled and then weighted to represent the entire stock of commercial buildings. Griffith et al. (2008) used the average CBECS data for floor area, number of floors, number of

Page $\mid 94$ 
employees, operating hours, type of heating and cooling system, type of windows, and many other variables to build their prototypical building models. Finally, the models were weighted to indicate how many additional buildings of each type made up the building stock. This was then then aggregated to calculate the overall energy consumption of the building stock (Griffith et al. 2008).

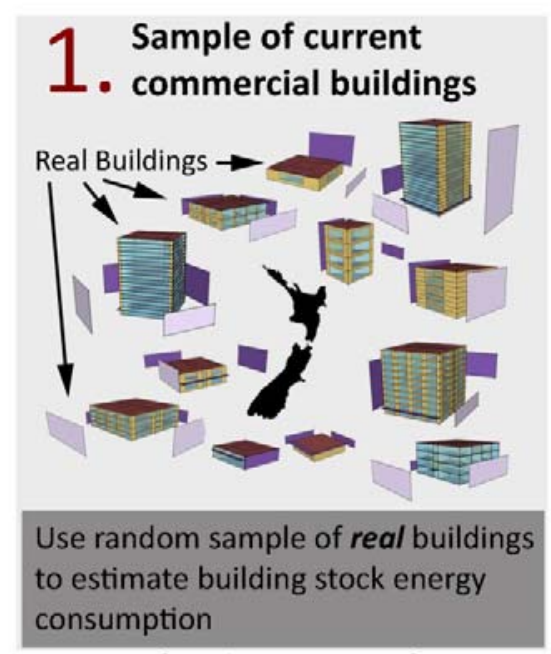

Thesis Research

- 17 different building models (for offices - there were more if retail and mixed use buildings were included), which have the real building attributes of 17 different real office buildings in New Zealand.

- Each building is built to the real building size, site shading (purple surfaces), construction, building load and operation, and HVAC system of each real New Zealand office building.

- Each real building model was simulated in seven New Zealand climates.

These combined with the other real commercial building type models, the sample of models will account for $100 \%$ of all commercial floor area and estimate $100 \%$ of the total building population's energy consumption

Figure 5-7 : Overarching methodology step 1 - sample of real buildings and a comparison of this thesis research method and previous studies method for representing the current building stock.

\section{Prototypical current commercial buildings}

Theoretical "Typical" Buildings

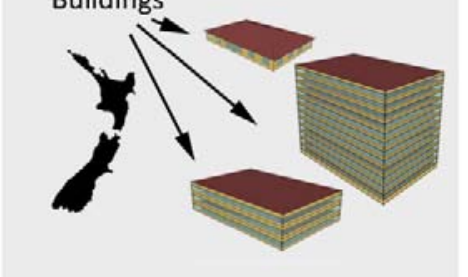

Set of theoretical "typical" or

"Average" buildings to estimate building stock energy

consumption

\section{Previous Studies}

- 3 different sized prototypical office building models.

- Consist of typical/average office building attributes for building size construction, building load and operation, and HVAC systems.

- Consist of many assumptions regarding the building loads and use of the buildings.

- Do not assess site shading.

- Each prototypical model was simulated in sixteen USA climates.

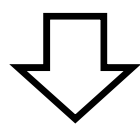

With these combined with the other commercial type prototypical building models, the models only account for $62 \%$ of all commercial floor area and estimate $65 \%$ of the total building population's energy consumption.

Two disadvantages were identified in this process. Firstly, the prototypical models did not capture the variation in some building attributes. Griffith et al. (2008) found that the number of floors was not well represented, which had a significant impact on reaching the ZEB goal. The site shading from the surrounding built environment was also not well captured. The largest impact of this was found in urban areas. The methodology undertaken in this thesis aimed to capture the variation in the building attributes in New Zealand in a representative way. Griffith et 
al's (2008) method using prototypical buildings only captured 62 percent of the USA building population floor area, and represented only 65 percent of its total energy consumption (Griffith et al. 2008). The remaining floor area and energy consumption could not be represented using the prototypical modelling method as this was made up of buildings with significantly varied sizes, internal loads, and operation.

The second disadvantage of the Griffith et al. (2008) and Deru et al. (2007) method was that "the large number of models increased computing requirements, which prohibited the evaluation of large numbers of scenarios with different technologies and practices" (Deru et al. 2007, p.90). Deru et al. (2007) simulated approximately 100,000 models, resulting from the different combinations of building sizes type, climate and energy lowering design and technology. The method undertaken in this thesis will have the same disadvantage; however New Zealand has fewer climate types than the USA which aids in lowering the number of models and simulation time.

The methodology used in this thesis uses a small random sample of real commercial buildings established in the BEES building sample set. None of the buildings that make up the BEES building sample were chosen for a reason. Each building in the full sample of commercial buildings was assigned a number and a random number generator was used to choose which buildings were contacted. Not every building which was contacted replied to be included in the study, so more random buildings were chosen to increase the sample size. The sample was also random because it was made up of buildings with random attributes such as size, height, construction, occupants and so on. A random sample is a form of statistical survey that has a scientific and objective procedure. The sample is expected to be representative of the population and can be used to obtain information about populations (Sukhatme and Sukhatme 1970). In this case the population is of buildings and the sample method used "makes it possible to estimate the population totals, averages or proportions while reducing at the same time the size of the survey operations"(Sukhatme and Sukhatme 1970, p.1). Another distinct advantage of the random sample approach is that it is a statistical approach that permits the user to estimate the likely level of uncertainty in the aggregation process.

The random sample was used to obtain information about the energy consumption of commercial buildings, which could then be used to aggregate and represent the energy consumption of the whole population of commercial buildings in New Zealand. The sample of buildings was aggregated by building type and size as well as the building's performance across different New Zealand climates. This differed from previous studies as a number of real commercial buildings were used in the stock aggregation instead of a small number of prototypical buildings.

\subsection{1b Technique for modelling existing commercials}

This section reviews within the context of the over-arching methodology: i) why a specific technique for modelling existing buildings was required; and ii) how the modelling approach in 
this research differs from previous research. For detail about the modelling process, calibration process, and quality assurance of the models refer to Chapter 7.
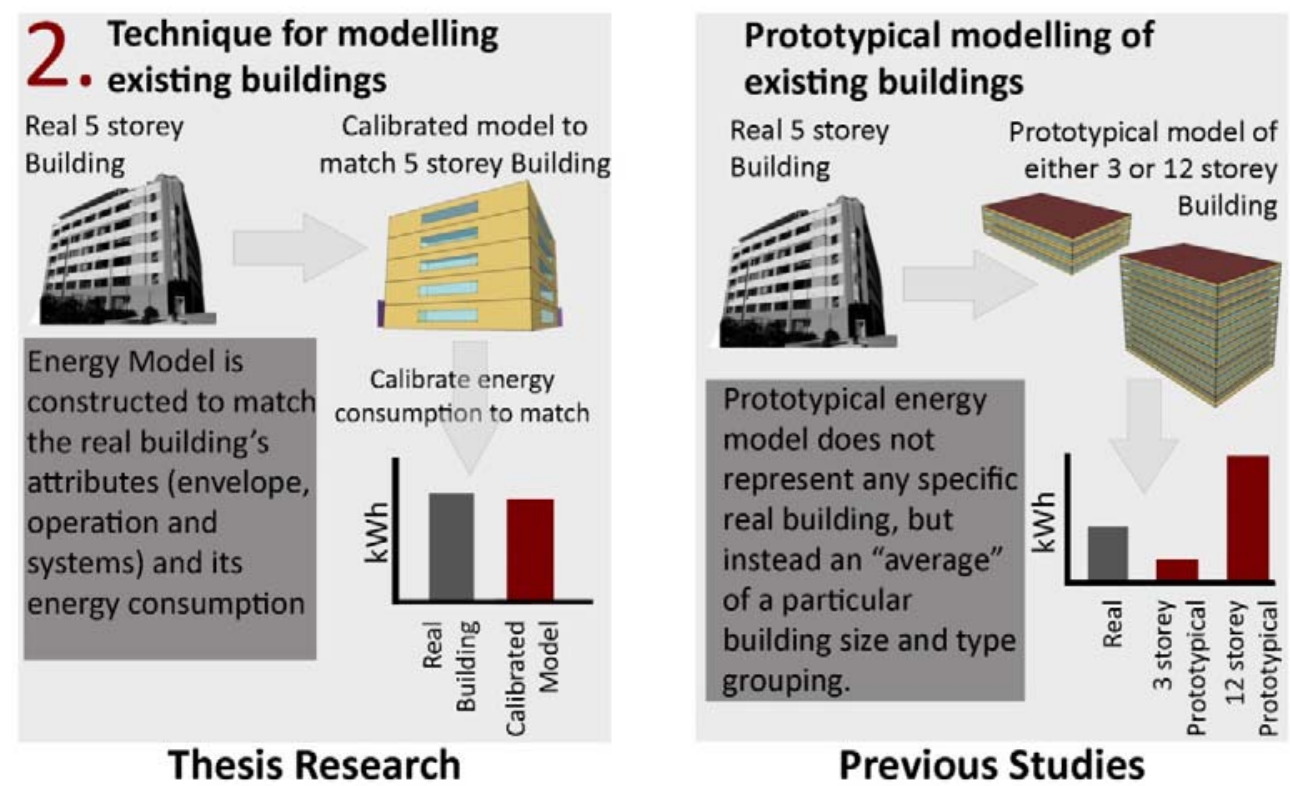

Figure 5-8 : Overarching methodology step 2 - modelling technique and a comparison of this thesis method and previous studies method for modelling existing buildings

Figure 5-8 illustrates step 2 in the overarching methodology which is the technique for modelling existing commercial buildings in this thesis. The figure also shows a comparison to the technique used in previous studies which also assess upgrades across an entire building stock. Whole building simulation models of the sample of real buildings were created to complete the stock aggregation. The models formed a base scenario for the current commercial building stock and from which the assessment for the potential of a move to a more energy efficient commercial building stock could be undertaken. However, computer simulations are only as useful as the accuracy of the simulations. In speculative studies, it is too easy to create base cases using modelling assumptions that are not established on fact. The goal of this study was to use an energy modelling technique that reduced the Approximations, Assumptions, and Simplifications (AAS) in the modelling technique. "Approximations, assumptions, and simplifications are defined as follows:

- Approximation: A mathematical quantity that is close in value to but not the same as a desired quantity.

- Assumption: Something that one accepts as true without question or proof.

- Simplification: The process of making something less complicated and therefore easier to do or understand" (Maile et al. 2010, p.8).

The reduction in AAS is achieved by using calibrated energy models that match real buildings. Calibrated energy models reduce the limitations that previous studies have had. The limitation of 
previous studies was due to calculations being based on prototypical models that have an uncertain level of unreliability and inaccuracy. The unreliability and inaccuracy refer to the difference between the AAS used in the models and reality. This amount of inaccuracy is not measureable as the prototypical buildings cannot be compared to any independent standard of accuracy. The whole building simulation models in previous studies have also required much more detail about buildings than was available in their survey data (such as CBECS). In order to fill in the gaps, researchers/modellers have used literature sources, probabilistic assignments, and engineering judgment to complete the modelling of the prototypical buildings (Griffith et al. 2008; Huang and Franconi 1999). As a consequence, "many of the details of the survey buildings are unknown and were therefore generated synthetically" (Deru et al. 2007, p.12). Furthermore, as multiple modellers have constructed the prototypical building models, it is expected that the models vary greatly depending on the experience and intent of their authors (Huang and Franconi 1999).

It has been suggested that detailed on-site measurements would be invaluable in aiding to better represent real buildings to improve the model generation and accuracy of stock aggregated estimates (Griffith et al. 2008). The on-site measurements, undertaken by the BEES team, improve the models in this thesis. The monitored data informs the amount of building load use and how the building is operated in reality. On-site energy consumption data has been used to calibrate the models to reality as well as to refine the model inputs so that they are a real representation of commercial buildings.

The methodology undertaken in this study refined the model generation process. The methodology used a set of template simulation models to reduce the number of available parameters required to be input to create the simulation models. In doing so, it reduces the variances in the models when different people are modelling the buildings. The use of template models builds a Quality Assured simulation process (Donn 1999). The set of templates that formed the basis of this approach were based on New Zealand building information and were a simplified version of real New Zealand commercial buildings. The template models were populated with New Zealand relevant materials, constructions, loads, and Heating, Ventilation, and Air Conditioning (HVAC) systems (BRANZ Ltd 2013b; A Gates 2013). The template models were then altered using the as-built and operational building information data to closely match the real commercial buildings. A standardised model creation method constrains the user of the computer energy simulation program to data input that is based on measured data; and a standardised calibration minimises undocumented manipulation of the simulation file to achieve the desired results.

Real on-site measurements were used to create whole building simulation models that match each real commercial building from the BEES random sample. This calibration process ensured the reliability of the building models is not based on the opinions or experiences of the modeller. A model is calibrated when the simulation results closely match the real energy consumption of the building. To match the simulation to the energy consumption, the modeller calibrates the Page $\mid 98$ 
parameters of a simulation model to match their actual counterparts in the building (Heo, Choudhary, and Augenbroe 2012). This approach is a widely accepted method for analysing existing buildings (Raftery, Keane, and Costa 2011; Raftery, Keane, and Costa 2009; Bensouda 2004; Reddy 2005; Turner and Reichmuth 2009; Ahmad and Culp 2006; Yoon, Lee, and Claridge 2003; Haberl, Culp, and Claridge 2005; Nexant Inc 2008). The method for calibration undertaken in this thesis had the added advantage of a systematic process developed for this thesis. The end result is a set of real commercial building simulation models that can be used to form a representative commercial building stock model. This model formed the base case to assess the potential for a move to a NZE commercial building stock.

\subsection{1c Reliability of current commercial building stock estimate}

This section describes two measures for testing the reliability of the commercial building stocks energy consumption estimate within the context of the over-arching methodology. Refer to Chapter 9 for the commercial building stocks energy consumption estimate and reliability of the estimate. Figure 5-9 illustrates step 3 in the overarching methodology and shows the difference between the commercial building stock estimate calculated in this study and those found in previous studies, with particular focus on how the estimate can produce statistical error or confidence ranges.

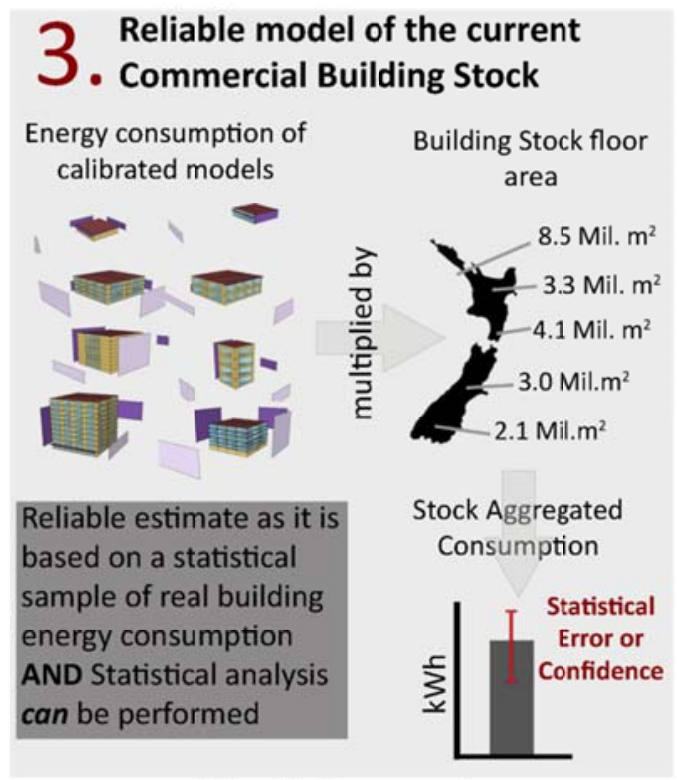

Thesis Research

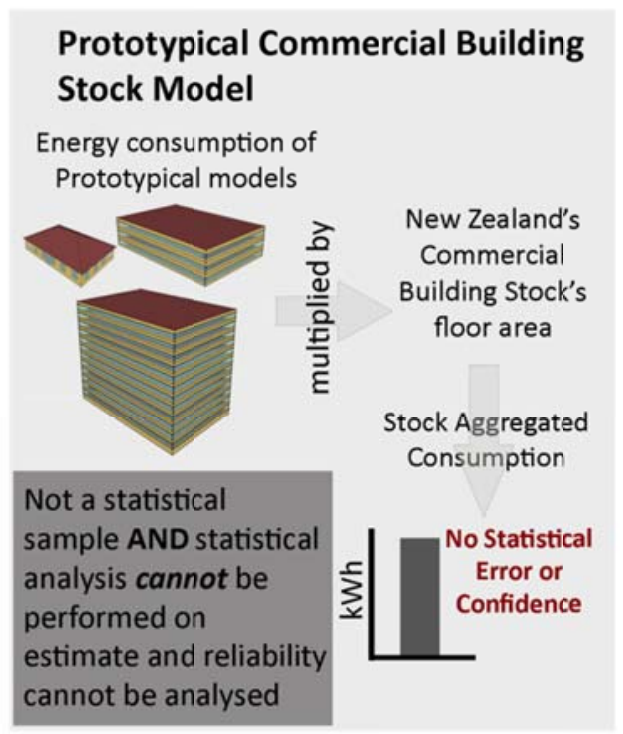

\section{Previous Studies}

Figure 5-9 : Overarching methodology step 3 - reliable commercial building stock model and a comparison of this thesis method and previous studies methods for building a reliable estimate of a building stocks energy consumption.

The estimate in thesis was reliable because it was founded on a statistical sample of buildings, whereas previous studies were not (Sukhatme and Sukhatme 1970). This enabled two measures that were undertaken to estimate the reliability of the stock aggregated estimate. The first measure was able to be performed due to the sampling methodology used in this thesis, as shown 
in Figure 5-7. The first measure was the calculation of a confidence interval for the estimate. The confidence interval specifies the range that the estimate is 95 percent confident to be correct (Statistics How To 2014; Urdan 2010). Another way of perceiving the confidence interval is that there is a 1 in 20 chance that the Stock Aggregation estimate is outside of the upper and lower confidence interval error bars. The confidence interval is used because the larger population's energy consumption is unknown (Statistics How To 2014; Urdan 2010). The results presented in this study represent the building energy consumption performance of the group of 48 buildings used in the Stock Aggregation. However, it is expected that the result using a different sample would remain within the 95 percent confidence interval 95 times out of 100 . Producing a confidence interval is a refinement on previous studies and further highlights the reliability of the method developed in this thesis. Previous studies could not produce a confidence interval because their prototypical buildings were not a statistical sample of buildings, whereas this thesis did use a scientific sample of buildings.

The second measure was the comparison of this study's stock aggregation estimate against an externally calculated energy consumption estimate for New Zealand's commercial building stock. This was the method used in previous studies to assess the accuracy of their estimates (Griffith et al. 2008). The comparison is a quality assurance process for the difference between the estimate in this thesis and an estimate made by another independent study. The external estimate was from BEES and was based on a larger, but still representative sample of buildings. The estimate was formulated using real measurements and annual bill information. There were some differences in the way the two estimates were calculated that are discussed in Chapter 9. Even with the differences created by the assumptions, the BEES estimate provided a basis for determining whether the estimate calculated in this thesis was within a quality assured reliable limit. The estimate calculated in this study was not considered quality assured if the 95 percent confidence interval was distinct to the BEES estimate 95 percent confidence interval. This was chosen as the reliability limit due to there being variances in calculation procedures. It was also chosen because there were defined ranges that each estimate was confident to be within. These ranges of variance can be accounted for and should be included in the range of reliability.

\subsubsection{Assessment of Net ZEB opportunities}

The second stage of the methodology is to assess opportunities for reaching NZE. There are two aspects that need to be considered when assessing opportunities. The first is deciding how the opportunities will be tested using whole building simulation. The second is deciding which energy lowering techniques are going to be tested.

\subsection{2a Optimisation of the existing commercial building stock}

This section briefly outlines the energy optimisation technique incorporated into this thesis within the context of the over-arching methodology. For detail about the optimisation process, the selected Energy Conservation Measures (ECM) and how it these are implemented across the sample of buildings refer to Chapter 8 . 
Figure 5-10 illustrates step 4 in the overarching methodology which is the optimisation of the current commercial building stock to reduce energy consumption. The methodology proposes the optimisation of the whole building simulation EnergyPlus models. The term optimisation in this thesis involved two steps. Firstly, the optimisation of the current commercial building stock meant it is being retrofitted using ECMs to be NZE (presented in Chapter 8). Secondly, a set of the ECMs were optimised to increase their energy lowering potential using an optimisation software (presented in Section 8.4). In both situations, energy optimisation maximises the energy reduction achievable in the EnergyPlus models. The energy optimisation was undertaken by firstly identifying the appropriate ECMs to use, and then optimising their design to maximise the energy reduction. ECMs are any passive

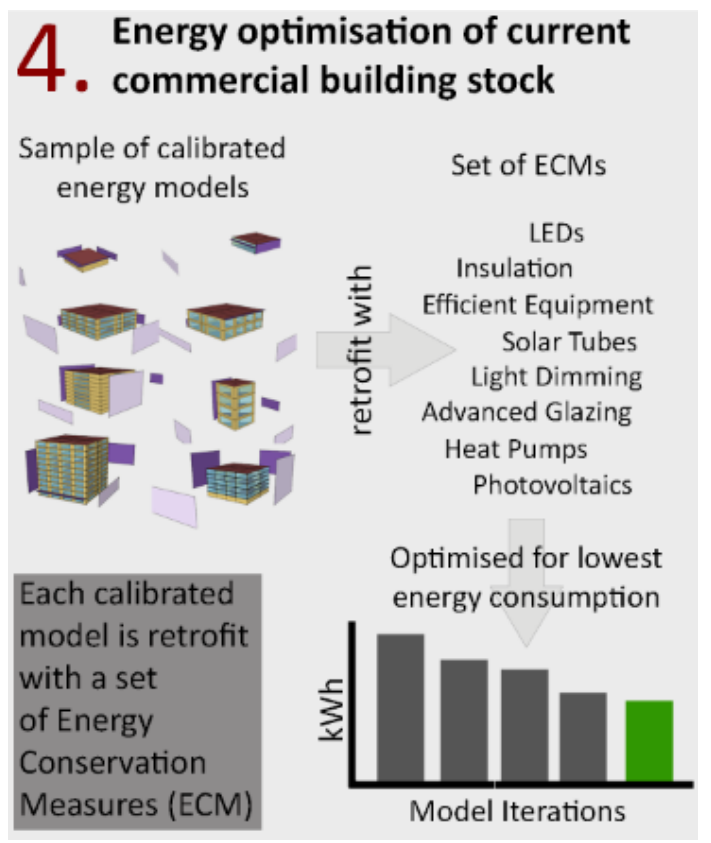

Figure 5-10 : Overarching methodology step 4 - Optimising the current commercial building stock energy consumption with an optimised set of ECMs design, energy efficient, or renewable energy technology that can be used to reduce energy consumption in a building. The ECMs implemented in real IEA case study Net ZEBs from around the world were assessed to select suitable sets for retrofitting New Zealand commercial buildings (Section 5.3.2b, 5.3.2c and Chapter 8 for the detailed methodology on the ECM assessment based on information gathered from Garde and Donn (2014)). Once the ECMs were selected, they were added to the EnergyPlus models by using various model input parameters. The second energy optimisation was undertaken to find the optimum design parameters for the ECMs in each building context. To perform this design parameter optimisation one could run a parametric analysis, where multiple simulations are tested to establish which input change reduces the most energy (DesignBuilder Software Ltd 2010). This can be very time consuming. In addition, if the number of parameters being varied exceeds two or three, the analyst will have difficulty in understanding the interaction of the system parameters and as such will find it difficult to make an educated guess that leads to further improvement (Wetter 2000). Given this, only limited improvement could be achieved. Instead of parametrically testing a range of input parameters, this study used a general optimisation program called GenOpt (Lawrence Berkeley National Laboratory 2011). GenOpt runs as many EnergyPlus simulations as it needs to determine the optimum combination of building input parameters for lowering the annual energy consumption. The user defines the minimum and maximum values of certain building parameters and GenOpt automatically completes as many EnergyPlus simulations (typically hundreds) as it needs to establish the optimum set of building parameters for lowering the annual energy 
consumption (Wetter 2000; Wetter 2004). Once the optimum input parameters are calculated, the EnergyPlus model is optimised for energy reduction.

\subsection{2b Selecting appropriate Net ZEB solution sets}

This section describes within the context of the over-arching methodology: i) how appropriate ECMs were selected; and ii) how the approach in this research differs from previous research. Refer to Chapter 8 for detail about the process of selecting the ECMs used to retrofit the building stock in this thesis.

Figure 5-11 illustrates step 5 of the overarching methodology which is the selection of ECMs to use to retrofit the commercial building stock.

In an ideal condition, there is almost an endless number of ECMs that could be used to reduce energy consumption in a building. Previous studies, such as M. P. Deru et al. (2007); Heo, Choudhary, and Augenbroe (2012), refer to design guides which provide advice regarding the types of ECMs that could be used. The premise of the methodology undertaken in this thesis (presented in chapter 8) was that the most appropriate ECMs, at any given time, are the design techniques and

\section{Selecting appropriate 5. Net ZEB solution sets}

Net ZEB solution Sets from real Net ZEBs

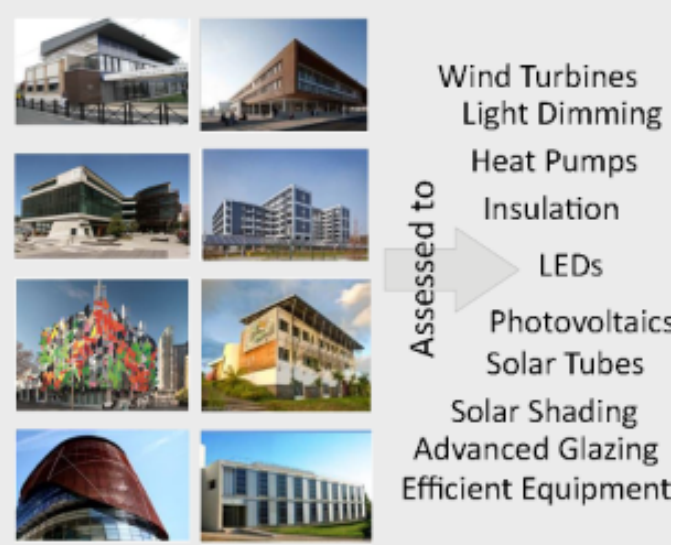

Set of common Energy Conservation Measures (ECM) will be used to retrofit the calibrated models

Figure 5-11 : Overarching methodology step 5 - selecting an appropriate set of Energy Conservation Measures technologies that were already implemented and working in existing Net ZEBs around the world.

These ECMs and sets of ECMs, referred to as solution sets, can be assessed to provide design advice to designers to reduce energy consumption. A number of studies have used solution sets to identify suitable energy lowering ECMs to implement into a building design. IEA Task 40 published Net ZEB solution sets in different building types and climate (IEA-SHC 2013b, 40). These Net ZEB solution sets provide insight into how to design Net ZEBs of a particular building type and in a particular climate. A PhD summer school used these IEA case study solution sets to redesign buildings to be NZE. The summer school study concluded that assessing and using existing Net ZEB solution sets was a good starting point for redesigning buildings to reach NZE (refer to Section 8.2.5a). One further study by Rajapaksha, Hyde, and Groenhout, (2012) developed an approach to determine bioclimatic solution sets for an energy efficient retrofit for buildings in warm climates. However, the definition of a solution set differed and was not useful for the analysis in this research. 
5.3.2c A study of design team lessons learned regarding currently used Net ZEB solutions

To aid in identifying a range of suitable energy conservation measures, an interview format was developed and administered to existing Net ZEB design teams to determine the lessons learned from their experience with real Net ZEBs (the results of which are presented in Section 8.3.2). The survey was completed in two different ways. In some cases face to face interviews were conducted with design team members while in other cases design team members filled out the survey themselves. Seven teams were interviewed. Not all of the members of the design team completed the questionnaire for three of the seven teams interviewed. The design teams were from different countries, climates and building sizes: one team in New Zealand, three in France, one in Reunion Island, and two in USA. The buildings are part of the IEA Task 40 Net ZEB database (Garde and Donn 2014). The buildings were used due to the design teams' availability to respond to the survey. Refer to Appendix 14.2 for more information on each Net ZEB.

The survey sought to identify a list of lessons. It did not seek to count how often certain design techniques or technologies occurred per building. Given no average or other summary statistics were to be derived, the sample size was selected to reveal a comprehensive list. Nielsen and Landauer, (1993) suggest that when consulting experts, some 80 percent of all the lessons will have been identified after only 5 to 7 individual experts are consulted. Using this approach, five to seven Net ZEB design teams were used as case studies for establishing lessons learned.

The questions included in the survey were predominantly open-ended. This allowed the design teams to more easily articulate their experiences and gave room for their opinions to be displayed. It was accepted that this was an exploratory study, and therefore statistical analysis were not necessary as respondents gave different degrees of detail in their answers.

The interview form contained 13 questions and was separated into three different lessons-learned phases to maintain structure and consistency (Appendix 14.2). This structure was drawn from a literature review on previous lessons learned studies (P Torcellini et al. 2006; Brown 2009; Garde, Ottenwelter, and Bornarel 2012). The phases included 1) the Net ZEB design process; 2) Net ZEB design and technological solutions; and 3) post-construction evaluation of the building. "The data collected was presented in an aggregated thematic form to avoid the need for identifying any participants individually"(Grbich 2007). Thematic analysis is achieved by grouping and clustering statements from each interviewee.

The participating design teams were made up of architects, engineers and other building professionals who had existing knowledge of well-known design principles. For example, the teams were aware of problems related to 1) condensation issues with chilled beams from natural ventilation in humid conditions leading to drips on occupants; and 2) combining occupancy controls with the BMS (Building Management System) decreasing efficiency as occupants alter the optimal control setting. Responses were centred on pressing intellectual issues relating to 
design and operating Net ZEBs, which go beyond the reflection of their existing knowledge of the industry.

\subsubsection{Energy and feasibility}

The third stage of the methodology was to assess the energy and feasibility of reaching NZE. The resulting energy consumption from retrofitting to NZE quantifies whether the study hypothesis was proven: can NZE be achieved? The feasibility (local infrastructure and cost) of retrofitting to NZE will answer whether it would be practical to make a move towards NZE. As the methodology follows the standard means of testing a change across an entire building stock, each stage and step is undertaken regardless of whether there is a positive or negative result. The result just carries forward to the next step and the analysis is performed. The assessment was broken into three areas: highlighting where substantial potential exists for improvement in energy use (results reported in Chapter 10), the consequences of design variables (robustness of models, (results reported in Section 11.2), and an indication of the practicality/feasibility of a move towards NZE (results reported in Section 11.3).

\subsection{3a Energy optimised commercial building stock}

This section outlines how the results of NZE retrofit are used to determine if NZE is achieved, as well as how the results are further analysed to show which building typologies and ECMs have the largest potential for reducing energy consumption. For the detailed results of retrofitting to NZE refer to Chapter 10.

Once the commercial building stock was optimised to lower energy consumption, it was analysed to determine if it can reach NZE. Figure 5-12 illustrates step 6 of the overarching methodology which is the analysis of retrofitting the commercial building stock to be NZE.

The analysis performed in Chapter 10 was split into four assessments:

1. NZE balance;

2. Building typologies and energy end-use breakdown

3. Importance of individual ECMs; and

4. Thermal comfort.

The NZE balance analysis used equation 3 and 4 (Section 4.5.2), and the quantified NZE target (Section 4.8) to compare the optimised energy consumption against the existing renewable energy generation in New Zealand. If the optimised energy consumption is equal

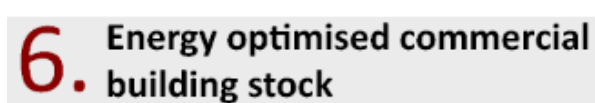
building stock Blue zone $=$ Net Zero Energy
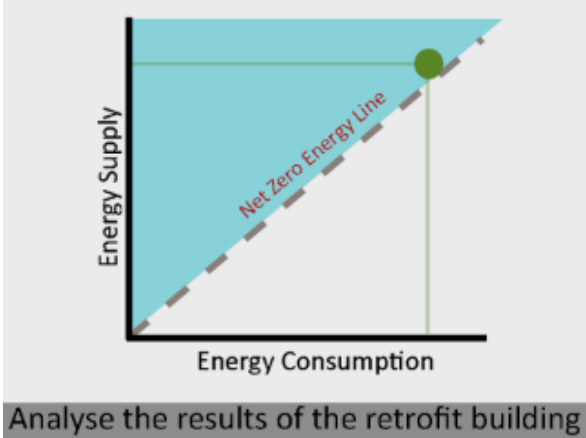
stock.

- Is Net Zero Energy possible?

- What building type has the largest energy savings?

- What ECM's give the largest energy reductions?

Figure 5-12 : Overarching methodology step 6 Optimised or Net Zero Energy commercial building stock to or lower than the existing renewable energy generating capabilities, it is NZE.

Page | 104 
The energy analysis looked in more detail at what building typologies and energy end-uses can achieve higher energy reductions. The analysis highlighted where the largest potential energy savings exist in commercial buildings and the building stock as a whole. The building typologies assessed included the building use types and the building size. The energy end-uses assessed were heating, cooling, fans/pumps, lighting and equipment.

Each ECM was ranked to identify the importance it had to the overall Net ZEB solution set. The ranking was achieved by removing each ECM in turn from the solution set. The energy consumption of the whole solution set was compared to that of the solution set with the removed ECM. The ECM with the largest decrease in energy efficiency was deemed the most important solution and was ranked as number one. The ECM that had the second largest decrease in energy efficiency was deemed the second most important solution and was ranked as number two. This was completed for each solution until a full ranking was calculated.

Thermal comfort was assessed because it was identified in the IEA definition framework criteria that Net ZEBs should not hinder thermal comfort in buildings (Chapter 2). Section 4.3.4 defined the comfort criteria used in this thesis. The thermal comfort assessment was undertaken for three case study buildings. These case study buildings were representative of three different modes of heating and cooling in the current New Zealand commercial building stock (refer to Section 10.2.4 for these modes). The assessment only considered the hours when the building was occupied and conditioned. The thermal comfort analysis determined the number of hours that were too cold, comfortable, or too hot in each modelled zone of the case study building. The number of hours for each zone that were too cold, comfortable, or too hot were averaged to determine the number of hours at a building scale.

This averaging was performed for each case study building in each climate. The number of hours that were too cold, comfortable, or too hot were established for each climate and then added together to determine a New Zealand region-wide climate comfort assessment. This showed how NZE retrofit performs in different New Zealand climates. If the hours of discomfort were greater in the optimised commercial building stock model than the model of the current commercial building stock, optimised design hinders the thermal comfort. If it was less the optimised design improves comfort.

These analyses were undertaken to better understand and critique the resulting retrofitted building stock. It is a standard technique used in previous studies (Griffith et al. 2008; M. P. Deru et al. 2007; Huang and Franconi 1999).

\subsection{3b Testing the optimised commercial building stock robustness}

This section details how the retrofitted models' robustness was tested within the context of the over-arching methodology. For the results of the robustness tests refer to Chapter 11. 
Figure 5-13 shows step 7 in the overarching methodology which was a series of tests performed

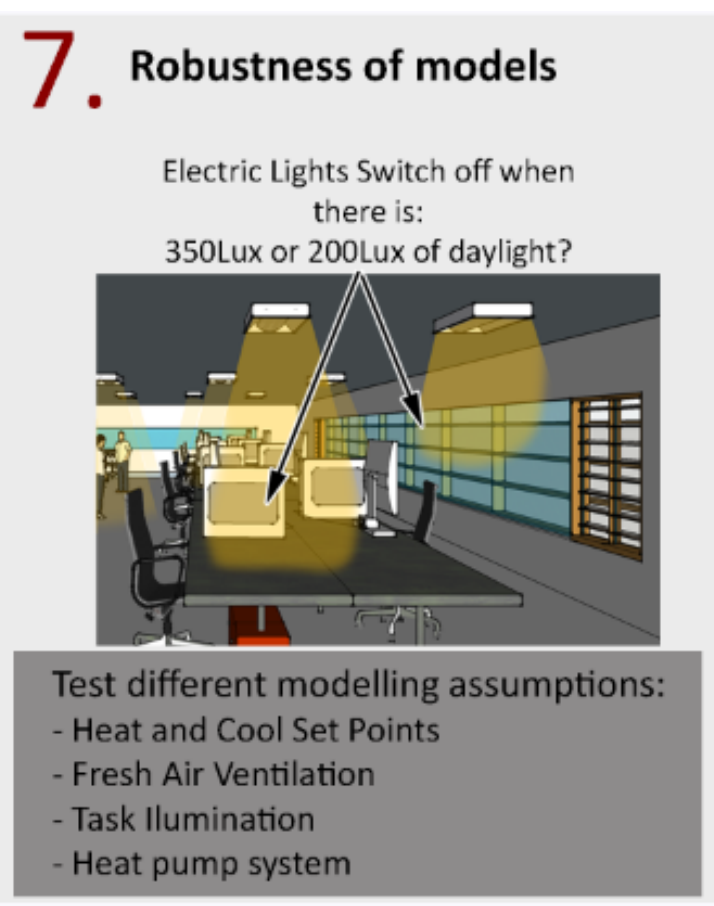

Figure 5-13 : Overarching methodology step 7 - testing real building operation variations to investigate the robustness of the retrofitted building models.

The robustness tests (performed and reported in

Section 11.2) applied variations to the proposed set of ECMs used to retrofit the commercial building stock. The variations of the proposed design were tested due to how real operation of buildings could differ to the design operation implemented in this thesis. The tests demonstrate the sensitivity of the proposed design parameters by changing the parameters in the model and then comparing the result to the original optimised commercial building stock model energy consumption result. This shows the impact that changing parameters can have on energy consumption and whether this had implications on the overall aim of reaching NZE or not.

Simulation results can only be as accurate as their input (Corrado and Mechri 2009). In any research that utilises energy models to calculate the performance of buildings, Assumptions Approximations and Simplifications (AAS) will be required, and given the NZE retrofit building stock was an un-built project, some parameters were established using AAS. AAS in the modelling technique were reduced by calibrating the energy simulations to the real building performance. Calibration was used to build a reliable building case for the current commercial building stock. However, the NZE retrofit energy models were a yet to be built project and as such, some unknowns about that building must be estimated for the models (Rosenbaum 2003). AAS imposes a certain level of uncertainty on the predicted results and their relation to performance in reality. As the retrofit building energy models implemented an un-built Solution Set, AAS were made to construct a complete building that operates in a theoretical manner. These AAS were not founded on personal opinion or judgements; they were formulated using the lessons learned and previous literature on suitable inputs to use. For example, the heating and cooling set points were based on thermal comfort literature and lessons learned from existing Net ZEBs. However, heating and cooling set points in real buildings can differ to those tested in this research. For this reason, the retrofit ECMs that are subject to variations in real buildings were analysed. The tests assess the impact their change would have on the final result. The AAS tested were:

1. Heating and cooling set points.

2. Outdoor fresh air ventilation rate. 
3. Task illuminance set point.

4. Heat pump system types.

The method used to test the variations of the above retrofit AAS parameters (performed in Section 11.2) was similar to a Sensitivity Analysis (SA). SA is the study of variation in the output of a model that can be attributed to different sources of variation in model input and is an important technique as it determines the effect that uncertainties have on predicted results (Saltelli, Chan, and Scott 2000; Macdonald and Strachan 2001). In this study the model output was energy consumption derived from the retrofitted building energy models. Different sources of variation in this study arose from the AAS used in the creation and analysis of NZE retrofitted building energy models.

Two main forms of SA could be used, Local or Global. Local sensitivity analysis is focused on the effects of uncertain inputs around a point (or base case), whereas global sensitivity analysis is more interested in the influences of uncertain inputs over the whole input space (Tian 2013; Mara and Tarantola 2008). The SA performed in this study was similar to Local SA or Differential Sensitivity Analysis (DSA). "Local sensitivity analysis belongs to the class of the one-factor-at-a-time methods. Sensitivity measures are usually calculated when one factor is changed and all other factors are fixed" (Tian 2013, p.414). The DSA method was implemented in this study as it had the advantage of the analysis being straightforward, interpreted easily and requiring less simulation runs than a global sensitivity analysis (Tian 2013).

The DSA method was used to assess the effect that a change to the four ECM AAS inputs had on the commercial building stock energy consumption. The SA implemented in this study was adapted from a general approach suggested by Lam and Hui, (1996). It is summarised as below:

1. Formulate a base case - in this study the base case is the retrofit NZE commercial building stock energy simulation models.

2. Identify parameters of interest - in this study they relate to the AAS conditions.

3. Determine what simulation outputs are to be investigated - In this study they were the commercial building stock predicted energy consumption for each ECM AAS analysis.

4. Introduce perturbations to the selected parameters one at a time.

5. Study the corresponding effects of the perturbations on simulation outputs.

\subsection{3c Feasibility of retrofitting towards NZE}

This section outlines the two aspects that will determine if moving towards NZE is practical: i) temporal energy match, and ii) cost. Refer to Chapter 11 for the results from each assessment. 
Figure 5-14 shows step 8 in the overarching methodology which is to assess the feasibility of retrofitting towards NZE. Figure 5-14 illustrates a load matching analysis which is performed as one of the feasibility assessments.

\section{Temporal energy match feasibility}

In earlier chapters of this thesis, it was established that this thesis is the first step in a feasibility study to investigate whether it is possible to energetically achieve the NZE goal. It was identified that two Net ZEB definition parameters should be considered when defining NZE. These parameters include the load matching and grid interaction and relate to the temporal energy match of the retrofit commercial building stock. Whether NZE was achieved or not did not hinder this analysis. This was due to the nature of Net ZEBs. They consume

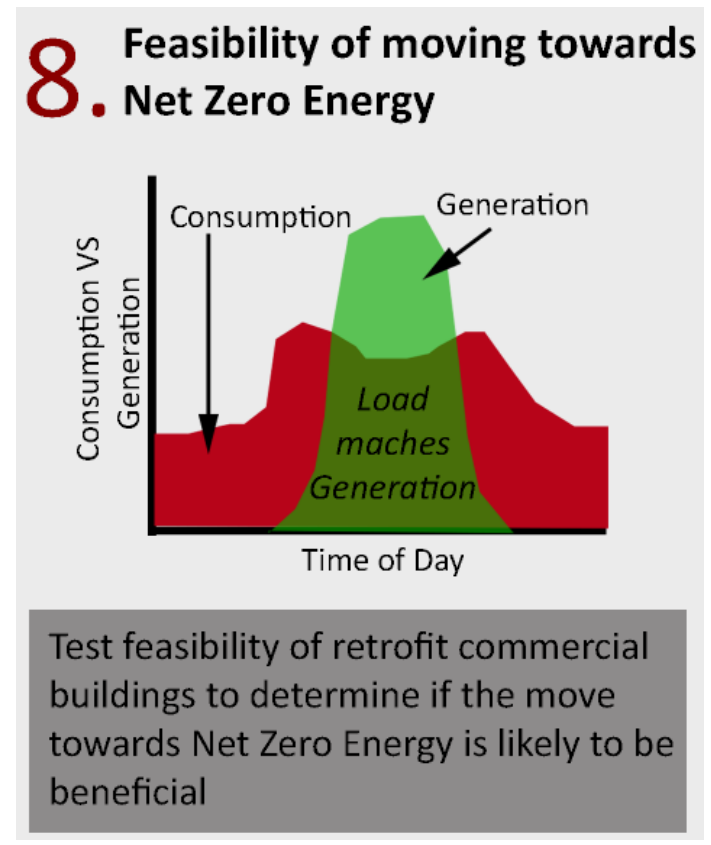

Figure 5-14 : Overarching methodology step 8 - testing the feasibility of moving towards Net Zero Energy and generate energy regardless of whether they reach net zero energy or not.

The temporal energy match assessment (undertaken in Section 11.3.1) aimed to establish the likely match or interaction between the energy load of the retrofit commercial building stock and the energy supplied to the buildings from the electrical grid. The match or interaction is considered positive if:

- the building generates onsite energy during peak energy demand time intervals, both on a monthly scale and a daily scale; and

- the building's peak demand was not during the peak demand of the existing grid.

The load matching assessment was performed by displaying the monthly and hourly energy consumption profiles against the generation profiles (Figure 5-14). The comparison of the consumption against the generation highlighted whether there was a mismatch between when the building consumes most of its energy relative to when it generates most of its energy. The monthly profile established whether there was a seasonal mismatch, and whether there was a diurnal mismatch. If there was a seasonal or diurnal mismatch between consumption and generation the building stock will not be as flexible to the national electrical grid demand. Similarly, the grid interaction analysis simply compared the building's net exchange to the existing grid's winter and summer energy demand trends from 2013. It showed the basic fluctuations of the energy exchange between the retrofit buildings and the grid. The assessment enabled the identification of the daily and seasonal fluctuations in energy exchange between the buildings and the grid, as well as whether the buildings' demand for energy coincides with the 
peak demand of the other energy consumers attached to the grid. For further detail on the analyses refer to Section 11.3.1.

These did not comprehensively investigate the associated feasibility of retrofitting to NZE. However, the studies performed (reported in detail in Section 11.3.1) were adequate to determine a general conclusion regarding whether load matching was likely and to show the possible scale of grid interaction between the buildings, the building stock and the grid. It was not comprehensive because a load matching and grid interaction assessment would identify the flexibility of the building(s) to adapt to signals from the grid (Sartori, Napolitano, and Voss 2012; Karsten Voss et al. 2010). A comprehensive study would calculate whether a flexible NZE retrofit building stock would be able to respond to signals from the grid by implementing Demand-Side Management (DSM), as well as integrating appropriate onsite storage options to maximise the usefulness of onsite generation (Karsten Voss et al. 2010). A comprehensive study requires detailed time of use information for the national energy infrastructure and would require a considerable number of calculations. This time would have considerably extended the already six month calculation time experienced in this study if this grid interaction analysis had been planned (refer to Section 8.4.2).

\section{Cost feasibility}

Once the building stock was retrofitted, the next step in a feasibility study is a cost assessment. For this reason, a cost analysis of retrofitting to NZE was undertaken in this thesis. The cost feasibility assessment, reported in Section 11.3.2, compared the likely investment cost of retrofitting to NZE to that of building a new power station. The results indicate the cost of conserving energy against the cost of generating energy. As the retrofit was proposed to replace a typical maintenance upgrade (refer to Section 11.3.2), the cost of investment would be the cost difference between a typical upgrade and a NZE upgrade. This cost difference can also be referred to as the incremental cost of retrofitting toward NZE.

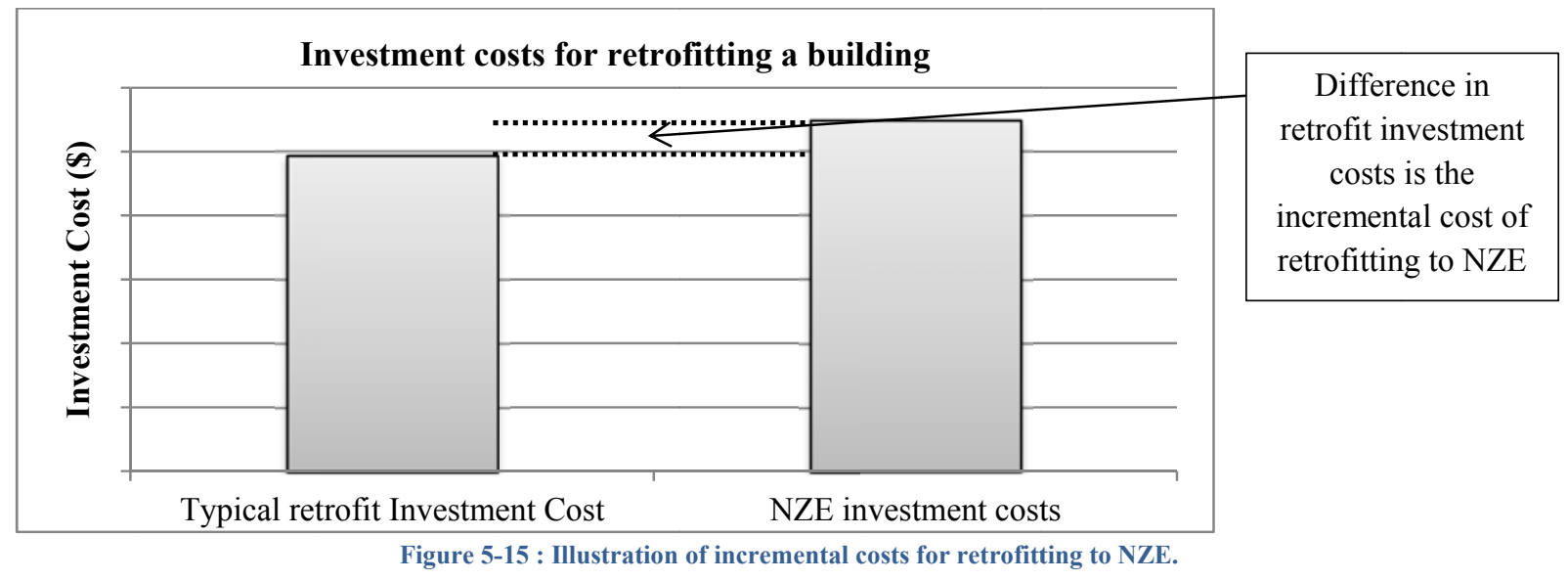

Figure 5-15 diagrammatically illustrates the incremental cost concept. Incremental cost is defined as being the additional expense incurred as a result of taking a particular action (Farlex 
Inc 2014; AllBusiness.com Inc 2014; Hunt 2008). In this case, the additional expense would be incurred from the extra cost of adding the Net ZEB solution set to the typical retrofit.

The cost of conserved energy was calculated as the amount of investment cost required per unit of energy saved over a period of time (Meier 1984; Meier 1982). The investment costs used in the cost of conserved energy assessment were calculated as the typical cost of constructing 15 existing Net ZEBs from around the world (Garde and Donn 2014) and the incremental costs of retrofitting to NZE instead of retrofitting to a typical building. Two incremental costs were applied to the two retrofitting scenarios: demand-side NZE retrofit only; and demand and supplyside retrofit (refer to Section 10.2 for more information on the two scenarios). The incremental cost that was applied to the demand-side NZE retrofit was four percent (Hunt 2008). Four percent was established from what a typical incremental cost has been for low energy and green buildings based on published literature (Hunt 2008). Costs for low energy and green buildings were used as they do not include onsite generation technologies. The incremental cost that was applied for the full NZE retrofit was ten percent. Ten percent was established from typical incremental cost for Net ZEB buildings established in published literature (NBI Institute 2012). This means the investment cost was calculated as four or ten percent of the total typical cost of constructing the 15 existing Net ZEBs from around the world. The costs of conserved energy, in Section 11.3.2, were derived using the calculation method from Meier, (1984).

The cost of generating energy was presented, in Section 11.3.2, as the investment cost required per unit of energy generated over a period of time. The investment cost used included the costs required for buying new land, and building and maintaining a new power plant (U.S. Energy Information Administration 2014b; U.S. Energy Information Administration 2014a). The results for the cost of generating electricity were established in the Annual Energy Outlook 2014 with projections to 2040 developed for the U.S government (U.S. Energy Information Administration 2014a) and hence were not accurate representations for New Zealand. However, these were presented as indicative measures for the feasibility comparison. Future cost assessments for NZE could develop New Zealand relevant figures; however this was outside the scope of this study.

The cost assessment had many assumptions and as such the results were indicative. For example, the four and ten percent incremental cost figures were obtained from both new and retrofit low energy and Net ZEBs. There is no distinction between incremental costs of building new and refurbishing. Furthermore, the base cost of building a Net ZEB does not separate the costs of building new or refurbishing to be a Net ZEB. The base cost is made up of cost information from both new and refurbishment projects (cost information for each Net ZEB was gather by the IEA Task 40 research project and published in (Garde and Donn 2014)). The cost analysis results were intended to highlight the likely feasibility rather than provide an accurate measure for retrofitting to NZE and building new generation plants. 


\subsection{Chapter summary}

Chapter 5 refined the research hypothesis and scope as a response to the nature of NZE in New Zealand as defined in Chapter 4. It also outlined the overarching methodology which is a refinement of a process used in Griffith et al. (2008) and Deru et al. (2007) to enable the established results to be grounded in reality. Two refinements of the methodology are: the current commercial building stock is represented using energy models that match the energy performance of a sample of real commercial buildings; and the energy models that match real commercial buildings are retrofitted to NZE using a set of ECMs that are found to be already proven to work in Net ZEBs from around the world. Using these two refinements, the results of the study are founded on real building performance. Three steps used to found results on real building performance data are further detailed in Chapters 6, 7, and 8. Figure 5-16 displays the links between Chapter 5 and the following three Chapters.

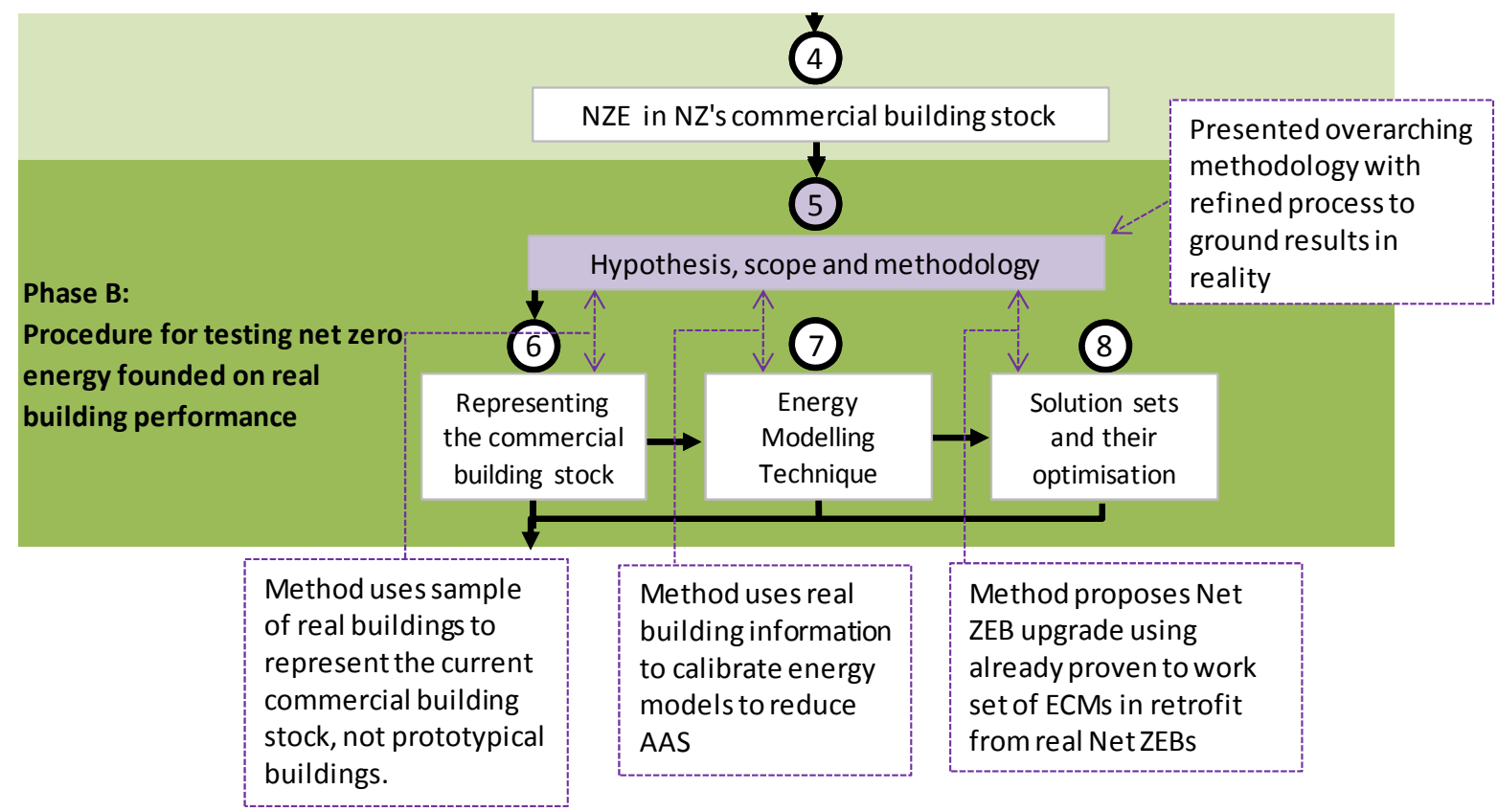

Figure 5-16 : Links between Chapters 6, 7, and 8.

Chapter 6 details the procedure for representing the current commercial building stock using a sample of real buildings. This links on from Section 5.3.1a which introduced the need for sampling real buildings and how this differed from previous studies. Chapter 7 describes the modelling technique used to construct energy models of the real commercial buildings. It also presents quality assurance results of the modelling technique. It links on from Section 5.3.1b which introduced the need for quality assurance in modelling, and calibrating whole building simulation models against real buildings and how this differs from previous studies. Chapter 8 follows on from Section 5.3.2b to assess Net ZEB solution sets to identify a set of working ECMs for use in the retrofit of the commercial building stock. 


\section{CHAPTER 6. A REPRESENTATIVE SAMPLE OF REAL COMMERCIAL BUILDINGS}

\subsection{Chapter Intent}

Chapter 6 presents a detailed methodology for establishing a sample of real commercial buildings to represent the New Zealand commercial building stock. It is the first stage in representing the current commercial building stock as outlined in Chapter 4. The representation is achieved by using a stock aggregation process. The process is a refinement of the method proposed by Moffat (2001). The refinement refers to the use of a statistical sample of real buildings to represent the commercial building stock. It allows for the estimation of the population totals, averages and proportions of energy consumption of the real building stock. It is a more stringent, reliable, "scientific and objective procedure" (Sukhatme and Sukhatme 1970, p.1) for calculating the energy consumption of a population of buildings when compared to the previously used prototypical building method.

Figure 6-1 illustrates the connection between Chapters 5 and 6 with reference to the particular methodology aspects detailed in this chapter.

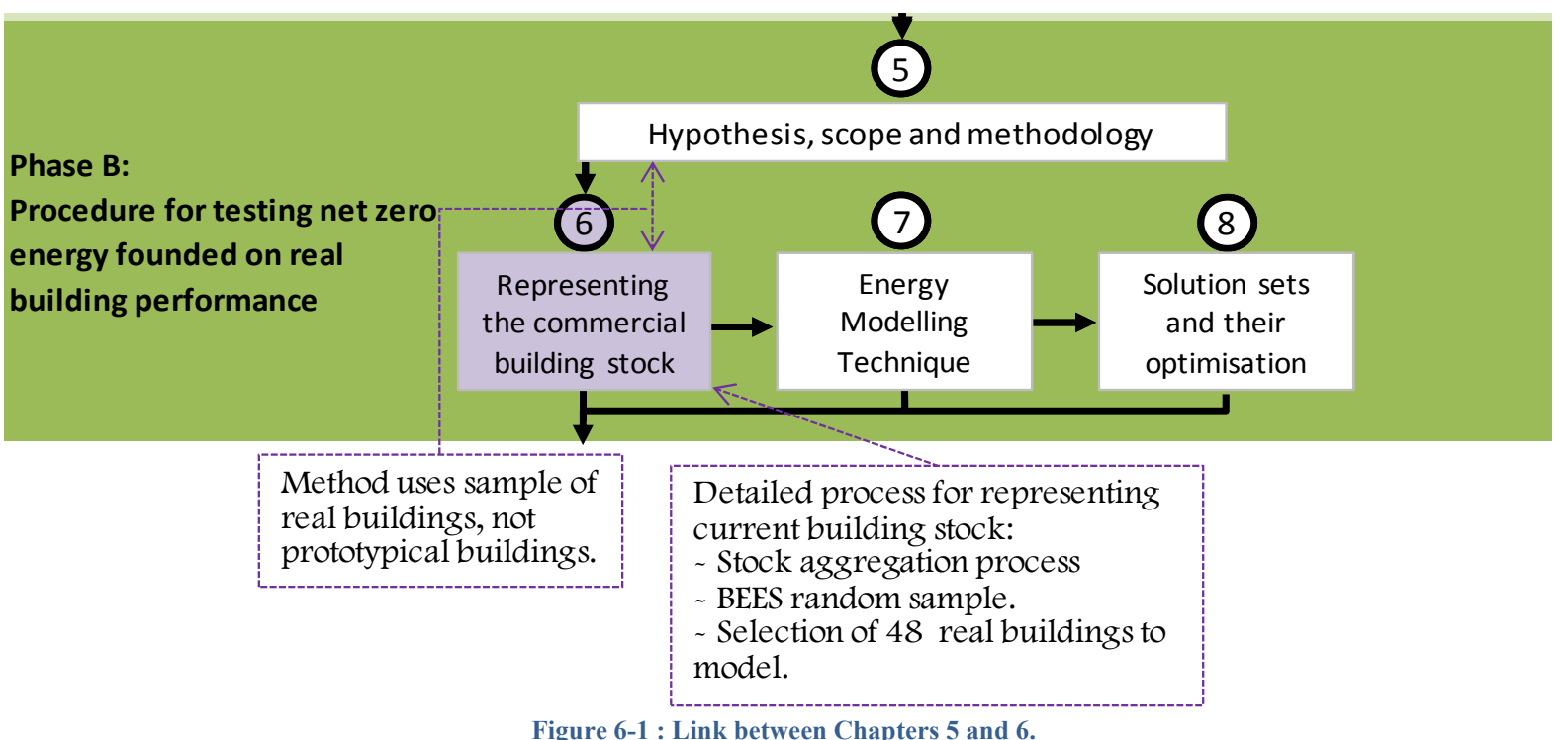

Three features of the methodology used in this thesis are outlined in more detail in this chapter. The first section outlines the aggregation of the case study buildings to represent the energy consumption of the entire commercial building stock. The aggregation was a bottom-up process which used the energy consumption of a sample of 48 commercial buildings to represent the energy consumption of the whole commercial building population in New Zealand. The second section outlines the BEES random sample and data collection of commercial building performance. It also presents the aggregation method using a sub-sample of the BEES building sample to aggregate energy consumption. The sub-sample of BEES buildings was used to build energy models that match the real buildings. The third section presents the selection of 48 case

Page | 112 
study buildings used to represent the commercial building stock. The selection of 48 buildings was made by analysing two larger samples of 3000 and 800 buildings. The analysis was performed to assess the distribution of the building attributes within the larger BEES samples. A selection of 48 buildings was made in which the distribution of building attributes in the smaller sample replicated the distribution in the larger samples. This replication ensured that the selection of modelled buildings was an accurate representative sample which was not made up of too many building attribute outliers.

\subsection{The benefit of using a sample of real buildings}

Using a sample is a statistical fundamental for obtaining information about a population of any nature (for example, people, cars, buildings etc.). The method used in this study was no different. A sample of real buildings was used to aggregate energy consumption to calculate the energy consumption of the entire commercial building stock population. The method used in this thesis differs from previous studies as it did not use a sample of prototypical buildings (Griffith et al. 2008; Heo, Choudhary, and Augenbroe 2012). Section 5.3.1 describes the benefits of using real buildings instead of prototypical buildings, which are not real buildings, but hypothetical synthetic buildings compiled from statistical data of surveyed buildings (Huang and Franconi 1999).

The sample of real buildings used in this thesis was a random statistical sample. Random samples have various beneficial and important properties. The most important aspect of random samples is that they calculate accurate and mathematically unbiased estimates (Sukhatme and Sukhatme 1970). It is possible to yield estimates closer on average to the true values using a nonrandom sample. While the estimates established using a non-random sample may end up more accurate, there is no way to calculate the bias or precision of the estimate. In the case of previous studies using the prototypical building method (non-random sampling); the sample estimates were established by using a larger external random sample to create an "average" building (in terms of size and construction). The results obtained from these "average" buildings were then compared against the overall energy consumption estimates (from the external random sample) to assess the accuracy of the prototypical estimates. However, the issue of calculating the bias of the prototypical estimate still remained. In addition, the composition of a prototypical building sample is influenced by the personal judgment of those responsible for their selection (Sukhatme and Sukhatme 1970). This means a non-random sample may end up echoing the judgment of the past individual authors as to what is "typical" in a building, rather than what is actually measured or monitored as the "typical" in a building. This is the main limitation of previous studies using this method and is the point of difference in the methodology implemented in this thesis.

\subsection{Stock Aggregation using real archetypes}

A Stock Aggregation process using the sample of real commercial buildings was undertaken to represent the whole commercial building stock. "Stock Aggregation refers to the process of 
evaluating the performance of a building stock using environmental assessments of components of the stock" (Moffat 2001, p.1). This thesis estimates the total energy use of commercial buildings in New Zealand by multiplying the energy estimates for a sample of representative buildings within the commercial building stock by the proportion of the total number of such buildings within the stock (Moffat 2001). The process is referred to as a 'bottom up' approach. The approach is appropriate for analysing the potential of buildings to become NZE because any performance measurements that can be analysed at the 'bottom', or at an individual building or specific technology level, can be aggregated upwards and used to evaluate the performance of a building stock (Moffat 2001). The stock aggregation process is performed using the energy consumption from calibrated energy models of the real commercial buildings (more detail on the energy modelling technique is presented in Chapter 7).

Figure 6-2 displays a flow diagram of the 'bottom-up' approach used for the Stock Aggregation process.

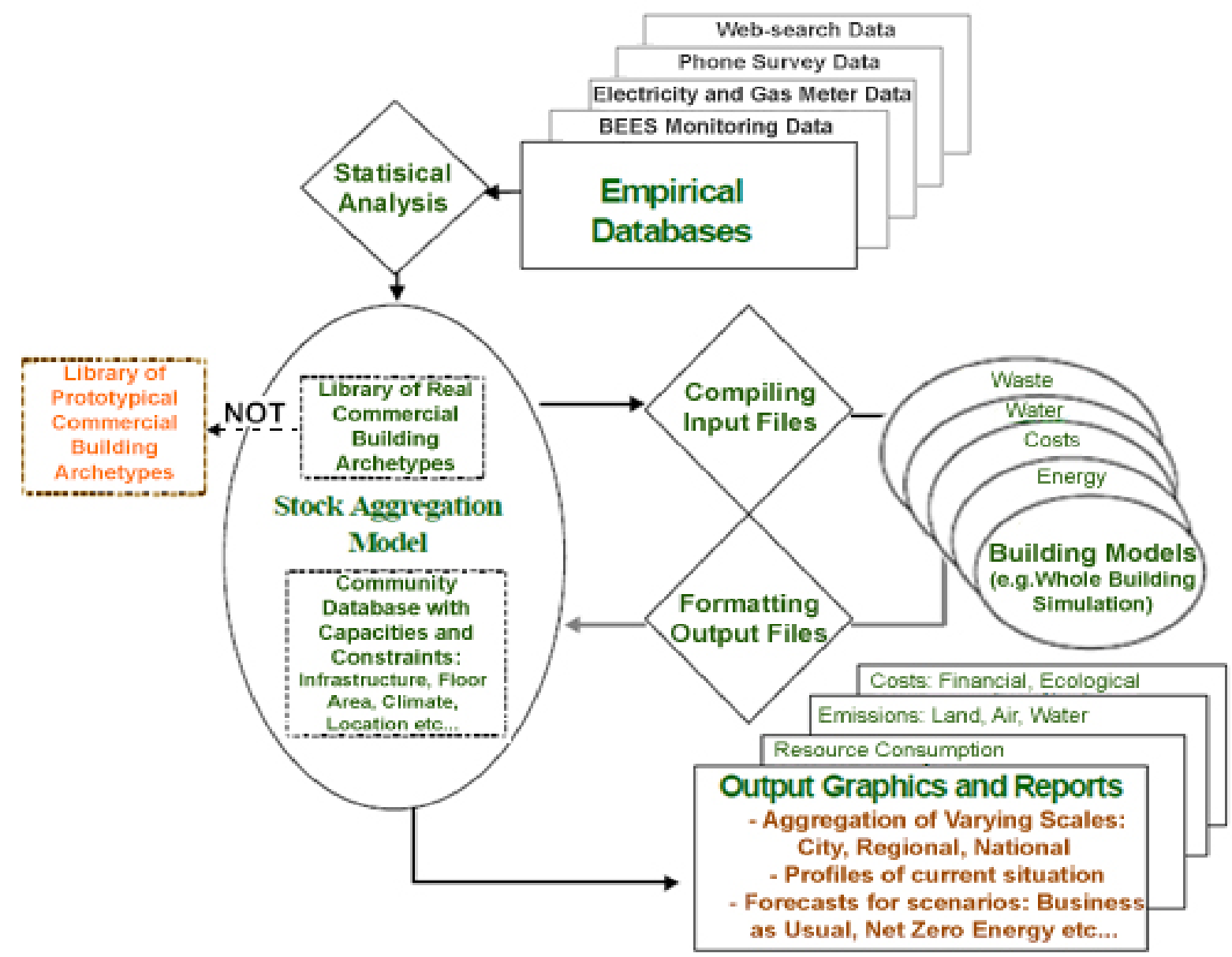

Figure 6-2 : Schematic of Bottom-up Model for Stock Aggregation. Adapted from (Moffat 2001).

As a starting point, an empirical database that can be statistically analysed to produce a library or sub-sample of individual building archetypes is required. These archetypes are the key point of

Page | 114 
difference between the research undertaken in this thesis and the work of previous studies. By definition, archetypes are a typical, ideal, or classic example of something. Previous studies have used this definition and created prototypical buildings that represent one square metre of typical floor area for the commercial building stock (Moffat 2001). In this thesis, the individual building Archetypes were real commercial buildings found in the building stock (defined as 'real building archetypes' in Figure 6-2).

The real building archetypes included in this thesis consisted of many building variables such as the building floor area, materials, constructions, number of occupants, internal equipment loads, patterns of use, and HVAC systems. Separate archetypes are generally established to reflect the different categories of use for buildings (Moffat $2001 \mathrm{pg} 18$ ), such as different building types and building sizes. The same process was used in this thesis; however, multiple representations (energy models) of a real building were established within the different use categories (type and size) rather than one prototypical representation.

An empirical database is a survey of the current building stock. The objective of an empirical database is to create a discrete number of unique archetypes that reflect the entire stock under analysis, within the constraints of the data available. It is generally necessary to establish between 30 and 50 archetypes in order to represent any given building stock (Moffat 2001 p.21). The empirical database used in this thesis was obtained from the BEES project. The archetypes included in the empirical database (created from the datasets of the BEES surveys) represent a sample of real buildings.

\section{Building Population (All Sizes and Types)}

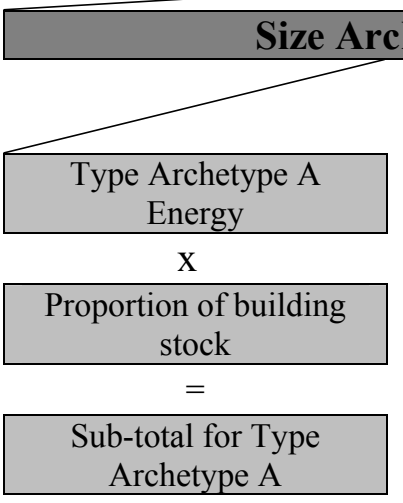

Sub-total for Size Archetype 1

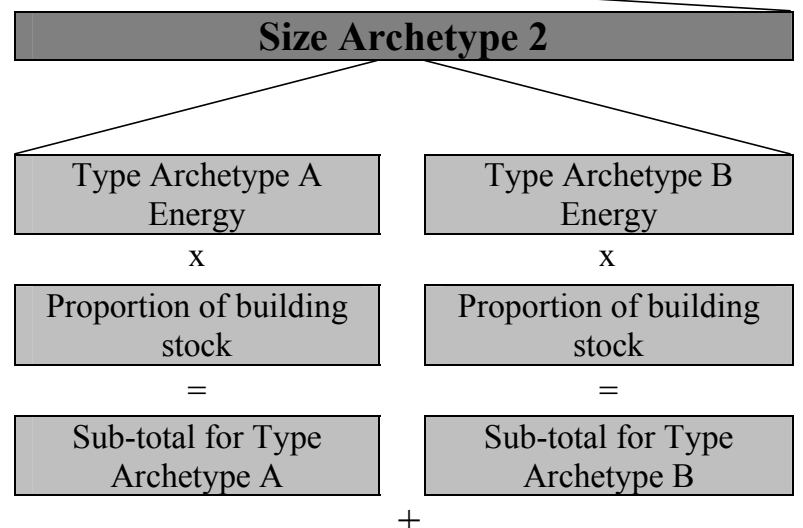

Sub-total for Size Archetype 2

\section{Total for Building Population}

Figure 6-3 : Example of the Stock Aggregation calculation process

Figure 6-3 illustrates the aggregation process in flow chart form using two example archetypes (size and type). The building archetypes were used to estimate the attributes of the entire Page | 115 
population. The process included a simple multiplication of the building archetypes by the proportion of buildings they represent.

The Stock Aggregation estimate involved two steps:

1. "Sub-totalling by multiplying the results from each archetype by the number of buildings or by the floor area it represents, and

2. Totalling the sub-totals for each archetype to arrive at a Stock Aggregation" (Moffat 2001, p.1).

Refer to Appendix 14.16.1 for a worked example of the process used to calculate the current energy consumption of the commercial building stock.

\subsection{BEES random sample and data collection of commercial building performance}

To meet the objectives of the BEES programme (for BEES objective refer to Section 5.2.6), five forms of data collection were used. The five forms created five data sets, which comprised: the Quotable Value (QV) and business directory information; web search and street-search; phone surveys; collected meter data; and on-site monitoring. They form a collection of BEES datasets which were used as auxiliary datasets in this thesis. The five datasets provided in-depth statistical information about the characteristics of a sample of New Zealand commercial buildings. Each dataset contained differing sample sizes and differing levels of information about each building. The smaller the sample size, the more detailed the building information provided. The smallest sample size contained information that was sought by physically entering the building and monitoring its operation (such as daylight illuminance levels and energy consumption), while the largest sample size contained data from an existing online database that was populated using basic information about each building (such as the building type and floor area).

\subsubsection{QV and business directory information}

$\mathrm{QV}$ is a comprehensive and up to date database of property information administered by New Zealand company, PropertyIQ (QV 2008). The QV database provided the complete dataset of commercial buildings in New Zealand, from which the other four datasets (outlined below) were drawn. QV provided a large range of basic overview information about each commercial building including the building type, age, floor area and location. Business directory refers to online business listing databases such as 'finda' which is a New Zealand business directory, listings and reviews website (finda limited 2013).

\subsubsection{Web search and street search}

Web-search uses internet search engines and online databases to trace any businesses located at a given street address. Using Google Earth (Google 2013a) and Google Street View (Google 2013b), building information was collected for approximately 3,000 randomly selected buildings from the QV database. The building information collected included various building categories Page $\mid 116$ 
such as building floor plate area, building height and inter-storey height, estimated glazing percentage on visible façades, estimated building construction types and estimated overshadowing (Isaacs et al. 2010).

\subsubsection{Phone surveys}

Phone Surveys included interviews of businesses that occupied a selected group of buildings. Of the 1,949 premises selected for the phone survey, 848 were completed, across 412 buildings (Saville-Smith and Fraser 2010; Amitrano et al. 2014a). The survey collected information regarding the number of occupants, number of office and miscellaneous appliances, hours of operation, and the energy and water consumption of the building.

\subsubsection{Collected meter data}

Meter data was collected for 240 buildings. The meter data refers to the monthly billing of electricity and gas for each building.

\subsubsection{Onsite monitoring}

One hundred and one buildings had on-site monitoring of their indoor environments and energy use (Amitrano et al. 2014a). Real time-of-use data was collected through detailed monitoring over a two week period. The data captured included temperature, humidity, light levels, $\mathrm{CO}_{2}$ levels, occupant and equipment schedules, internal loads, and fuel consumption within selected premises (Isaacs et al., 2010).

\subsubsection{Collected data and dataset sample overlapping}

Table 6-1 displays the type of information and the associated data set used to provide the information for both the BEES study and for this thesis to establish the attributes of the commercial building stock.

It is important to note that due to monitoring being conducted at a premise level, it was not possible for all monitored buildings to participate in the phone survey or to be analysed via web search. "A Premises corresponds to a specific business, occupying any amount of floor area, located within a Building Record" (Isaacs et al. 2009, p.30). A building may therefore contain multiple commercial premises. The cross-participation of premises in the Phone Survey with the other data sets (Web-search, Meter data, Monitored) is most important in multi-premise buildings. For example, if a premise had been onsite monitored but not phone surveyed, there is less information about the whole building compared to a building that had been onsite monitored and phone surveyed. If a building has only one premise, the onsite monitoring covers the whole building. However, if a building has more than one premise, the onsite monitoring may only cover a small portion of the building. 
Table 6-1 : Type of information provided by the different data sets. Adapted from (Saville-Smith and Fraser 2010).

\begin{tabular}{|c|c|c|}
\hline Information & Information & Sourced by which Data Set \\
\hline Building & $\begin{array}{l}\text { Age } \\
\text { Number of Floors } \\
\text { Size of floor plate } \\
\text { Total building floor area } \\
\text { Building materials } \\
\text { Other Building characteristics }\end{array}$ & $\begin{array}{l}\text { QV } \\
\text { Web-search/Onsite Monitoring } \\
\text { Web-search/Onsite Monitoring } \\
\text { Web-search/Onsite Monitoring/QV } \\
\text { Web-search/Onsite Monitoring } \\
\text { Web-search/Onsite Monitoring }\end{array}$ \\
\hline Location & $\begin{array}{l}\text { Region } \\
\text { City } \\
\text { Suburb }\end{array}$ & $\begin{array}{l}\text { QV and Business Directory } \\
\text { QV and Business Directory } \\
\text { QV and Business Directory }\end{array}$ \\
\hline Use & $\begin{array}{l}\text { QV Classification } \\
\text { Business names, phone number, postal } \\
\text { address } \\
\text { Business types }\end{array}$ & $\begin{array}{l}\text { QV } \\
\text { Business Directory } \\
\text { Business Directory/Web-search/Onsite } \\
\text { Monitoring }\end{array}$ \\
\hline Occupation & $\begin{array}{l}\text { Total number of businesses } \\
\text { Businesses per floor } \\
\text { Employees per business } \\
\text { Hours of use per business }\end{array}$ & $\begin{array}{l}\text { Business Directory/Phone Survey } \\
\text { Phone Survey } \\
\text { Phone Survey } \\
\text { Phone Survey }\end{array}$ \\
\hline $\begin{array}{l}\text { Building operation, } \\
\text { appliances and end-use } \\
\text { consumption }\end{array}$ & $\begin{array}{l}\text { Types of appliances } \\
\text { Count of appliances } \\
\text { Hours of use of appliances } \\
\text { Energy End-use consumption }\end{array}$ & $\begin{array}{l}\text { Onsite Monitoring } \\
\text { Onsite Monitoring } \\
\text { Onsite Monitoring } \\
\text { Onsite Monitoring } \\
\end{array}$ \\
\hline Suppliers and billing & $\begin{array}{l}\text { Electricity } \\
\text { Water } \\
\text { Gas } \\
\text { Other fuels }\end{array}$ & $\begin{array}{l}\text { Building Energy Supplier/Phone Survey } \\
\text { Building Energy Supplier/Phone Survey } \\
\text { Building Energy Supplier/Phone Survey } \\
\text { Building Energy Supplier/Phone Survey }\end{array}$ \\
\hline
\end{tabular}

Figure 6-4 displays the overlapping surveys of the sample of all 30,000 buildings in the QV database of all commercial buildings in New Zealand.

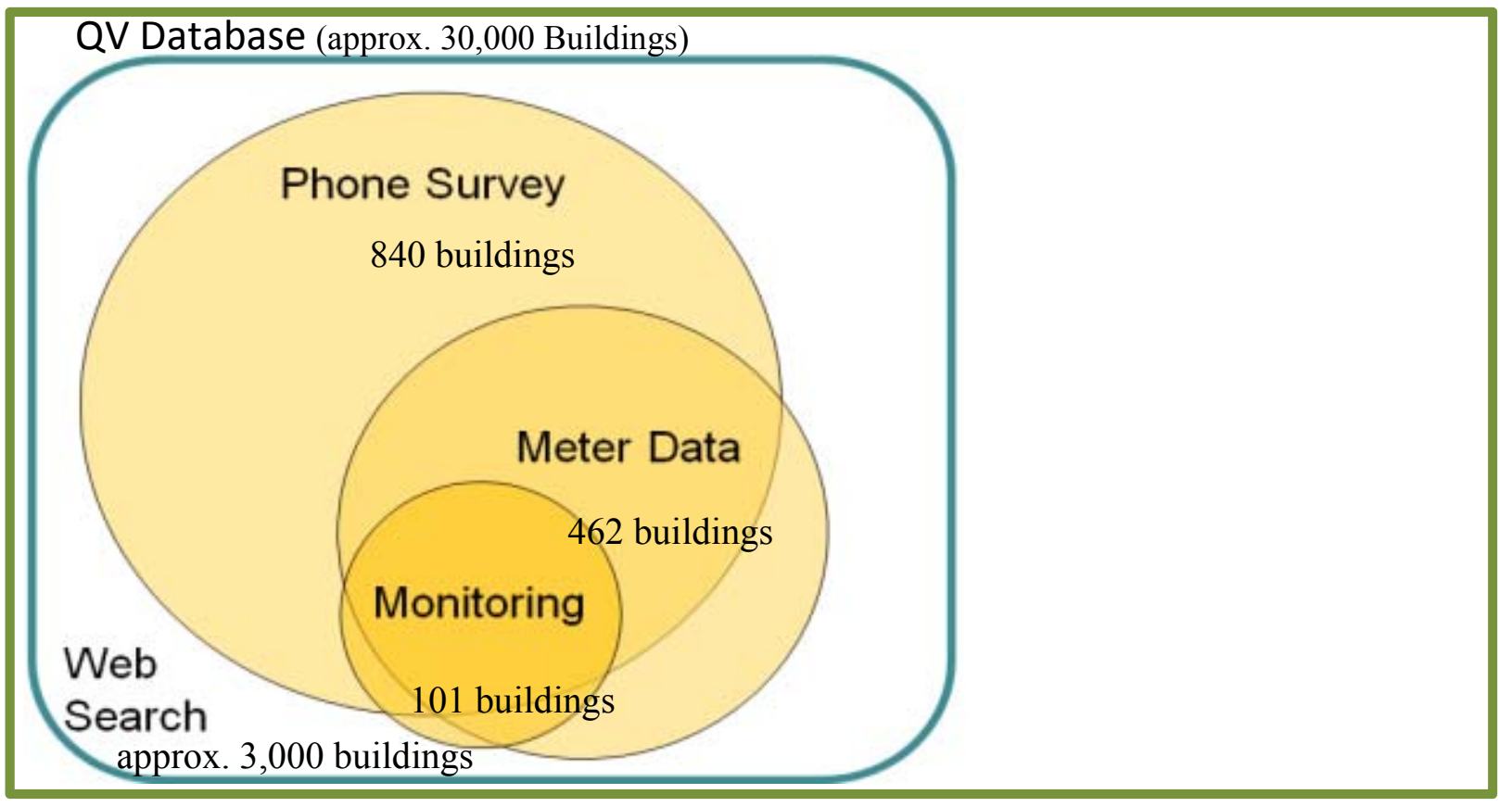

Figure 6-4 : BEES sample of 3,000 random commercial buildings (Amitrano et al. 2014a).

Page $\mid 118$ 
This thesis required a sample of buildings to be modelled in order to estimate the energy consumption of the New Zealand commercial building stock and assess scenarios to move to NZE. This sample was drawn from monitored buildings that contained very detailed information to inform the energy models.

\subsection{Stock Aggregation using the BEES random sample}

Various building archetypes are needed to perform the Stock Aggregation. In this thesis there are three basic archetypes used (as suggested in Moffat (2001)). Figure 6-5 displays the three building archetypes used in the Stock Aggregation process. These comprise building size, building type and building climate. In order to keep the sample size small, and because their sub estimates were not required, other archetypes, such as construction and building height, were not included. However, as the sample used was random, they were statistically represented. There is also no energy consumption archetype used in this thesis as energy consumption is the estimate being sought, although average and extreme energy users were statistically represented in the random sample.

\section{Five Building size Archetypes}

\begin{tabular}{|l|l|l|l|l|}
\hline Size group 1 & Size group 2 & Size group 3 & Size group 4 & Size group 5 \\
\hline 5 to $649 \mathrm{~m}^{2}$ & 650 to $1,499 \mathrm{~m}^{2}$ & 1,500 to $3,499 \mathrm{~m}^{2}$ & 3,500 to $8,999 \mathrm{~m}^{2}$ & over $9,000 \mathrm{~m}^{2}$ \\
\hline
\end{tabular}

2. Sub-divided by Three Building Type Archetypes

\begin{tabular}{|l|l|l|}
\hline Commercial Office & Commercial Retail & Commercial Mixed \\
\hline Office-type use & $\begin{array}{l}\text { Retailing use, Motor vehicle } \\
\text { sales and services, Liquor } \\
\text { outlets including taverns, } \\
\text { Service stations, Tourist-type } \\
\text { attractions }\end{array}$ & $\begin{array}{l}\text { Buildings with a mixture of } \\
\text { commercial uses on one site }\end{array}$ \\
\hline
\end{tabular}

3. Sub-divided by New Zealand's Building Climates

\begin{tabular}{|c|c|c|c|c|c|c|}
\hline Building & Building & Building & Building & Building & Building & Building \\
Climate 1 & Climate 2 & Climate 3 & Climate 4 & Climate 5 & Climate 6 & Climate 7 \\
\hline
\end{tabular}

Figure 6-5 : Stock Aggregation real building archetypes.

The building size archetype reflects the way the sample was split in the BEES project. This method of splitting the sample up is called stratified sampling (Sukhatme and Sukhatme 1970). Using stratified sampling, the building stock was split into five quintiles, with each quintile representing approximately 20 percent of all the commercial building floor area in New Zealand. The variability of the sample is better represented using stratified sampling as it increases the precision of the estimate (Sukhatme and Sukhatme 1970).

Page $\mid 119$ 
The splitting of the building stock created five different building size archetypes (Figure 6-5). The three commercial building types established in the BEES study formed a sub-group of archetypes that included offices; retail; and mixed use buildings. Climate is a factor that influences energy use and building design (ASHRAE 2006) and as such, the last archetype is building climate (refer to Section 5.2.7 for the building climate method).

To form a national picture, the aggregation of the building archetypes was made up of several successive stages dealing with the building size, the building type and climate. "To achieve flexibility in forecasting resource use and represent any given building stock, it is usually necessary to create 30 to 50 archetypes" (Moffat 2001, p.21). This thesis included a sample of approximately 48 real commercial buildings to perform the Stock Aggregation. The 48 buildings were made up of a cross section of differing building sizes and building types with an initial spilt of ten buildings in each size archetype. This was done to ensure an equal representation of buildings in each quintile of commercial building stock floor area.

The average energy consumption of each combination of building size, type and climate archetype was then sub-totalled to calculate the energy consumption that those buildings of that particular size, type and climate have. In statistics, the subtotalling by building size, building type and climate is referred to as Post-Stratification. Post-Stratification is used to improve the precision of a simple random sample (Sukhatme and Sukhatme 1970).

Due to the relatively small sampling size of this thesis, the Moffat (2001) method for representing climate was used. This involved the post stratification of climate by simulating all 48 buildings in each New Zealand climate and then subtotalling. This differs slightly from how the building size and building types were subtotalled as the climate of the real sampled buildings were not used in the Stock Aggregation.

\subsubsection{Normalisation of energy}

Subtotalling of the different building archetypes was performed using a normalised energy metric. The total energy consumption represented the raw energy performance of a building throughout a year. The energy consumption was normalised when divided by the building floor area. The Energy Performance Index (EnPI) is a metric expressed in "kilowatt hours per square metre of net floor area per year" (Standards Association of Australia and Standards New Zealand 2014, p.5). The unit was derived for building standards, audits and/or energy statistics, and is commonly used as a standard normalised metric of the energy performance for a sample of buildings. The amount of energy per unit of floor area allows for a reasonable estimate to be made for the typical energy consumption of buildings. It can also be scaled up for larger sets of buildings with the same characteristics, such as size, type and climate. The EnPI is also a useful tool for aggregating heterogeneous energy behavioural subsectors/subcategories to a larger representative category of buildings, as undertaken in Stock Aggregation. For this reason, building archetype subtotalling was performed by multiplying each archetype's average EnPI by the proportion of the total building stock floor area that the archetype made up.

Page $\mid 120$ 


\subsubsection{Energy types represented}

The two energy sources used in the Stock Aggregation were electricity and gas. This was because they were the main energy sources consumed by commercial buildings (100 percent of buildings consume electricity and 20 percent of buildings consume gas) (Saville-Smith and Fraser 2010). The total EnPI for electricity and gas were combined in this study to reduce subtotalling, irrespective of building consumption ideally being separated into different metrics according to the energy form delivered to a site. The limitation reduced the analysis available and did not allow the assessment between buildings of the same archetype with very different direct fuel consumptions ${ }^{3}$.

\subsubsection{New Zealand Building Climate Aggregation}

With the building size and type archetypes clearly defined, New Zealand's building climates were defined to determine the climate archetypes. Figure 6-6 displays the way in which two authorities split New Zealand into climate regions.

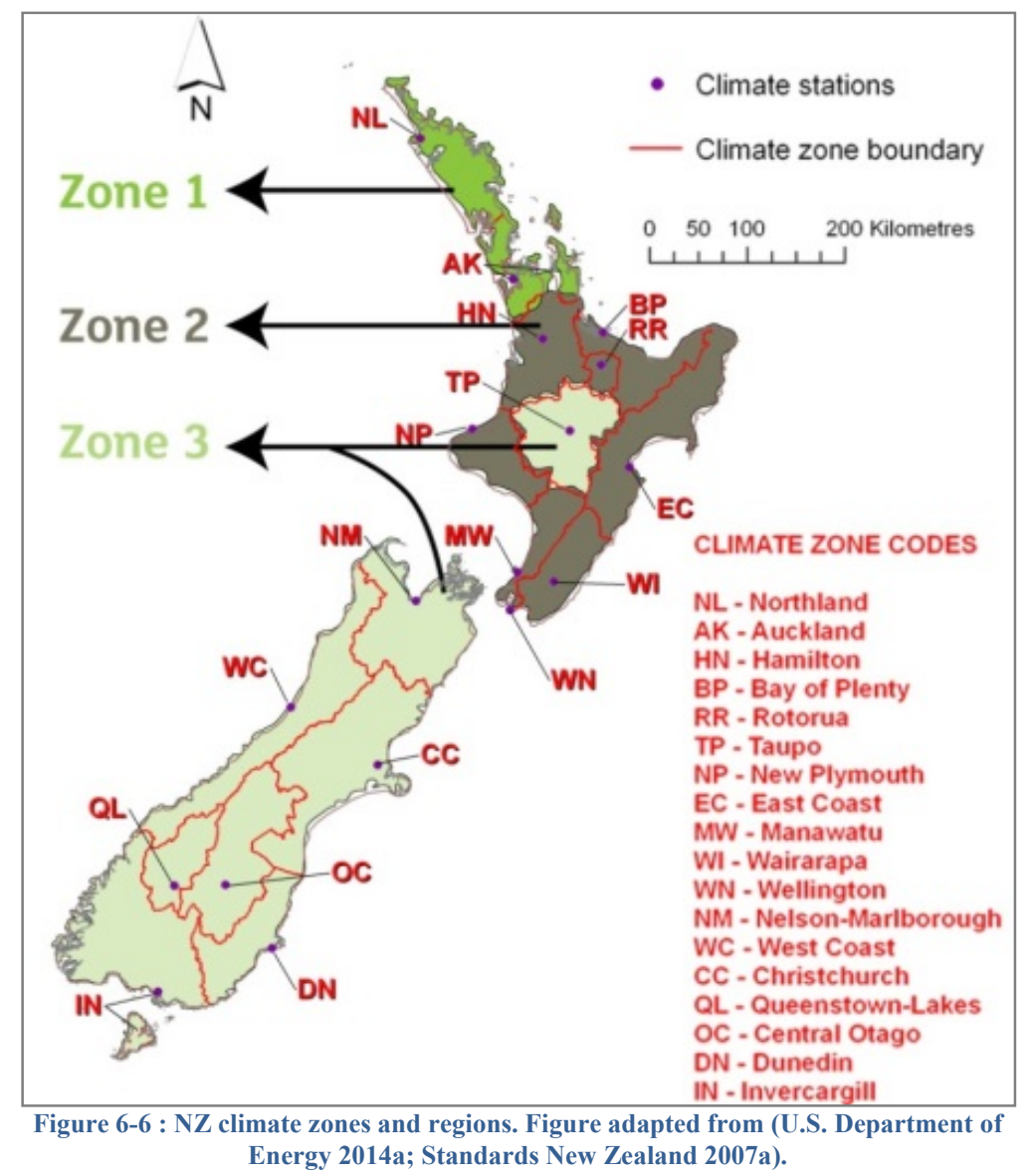

\footnotetext{
${ }^{3}$ The efficiency of each fuel type and their corresponding building system (e.g. gas boiler) was built into the whole building thermal simulation models used in the stock aggregated process. Hence, the efficiency of the fuel and system were determined and accounted for, but were not differentiated in this thesis to reduce processing time.
}

Page | 121 
The NZBC divided New Zealand into three climate zones. However, in 2011 there were eighteen climate regions which have associated weather files. The New Zealand Energy Efficiency and Conservation Authority (EECA) developed these 18 Typical Meteorological Year (TMY) weather files for their Home Energy Rating Scheme (HERS) (Liley et al. 2008). Typical Meteorological Year (TMY) weather files represent a typical year's weather occurrence for a location (US DOE 2013a). HERS used the weather files to assess the influence of external climate on residential buildings in New Zealand. Cory et al. (2011) established that large commercial buildings are not solely influenced by the external climatic conditions. They are also largely influenced by their internal conditions due to the high internal heat gains and loads. The use of all 18 climate regions would likely be excessive for the purposes of representing the entire commercial building stock. The amount of potential unnecessary simulations for buildings with similar climates was reduced by decreasing the number of climates studied in this thesis. This was done through an aggregation process.

The climate aggregation process considered that the amount of floor area and the similarities between climate regions were deciding factors of whether two climates should be aggregated. Floor area was used as a measure of how much influence a different climate will have on the Stock Aggregation process (Stock aggregation being the process of summing the energy consumption for the whole building stock, and climate aggregation being the process of combining two or more climate regions' floor area together). The more commercial floor area in a climate zone, the greater the impact the difference in climate will have on the aggregated result. 
Figure 6-7 illustrates the decision process for determining whether two or more climate regions were aggregated.

\section{Does the climate location represent more than $5 \%$ of the whole commercial building stock's floorarea?}

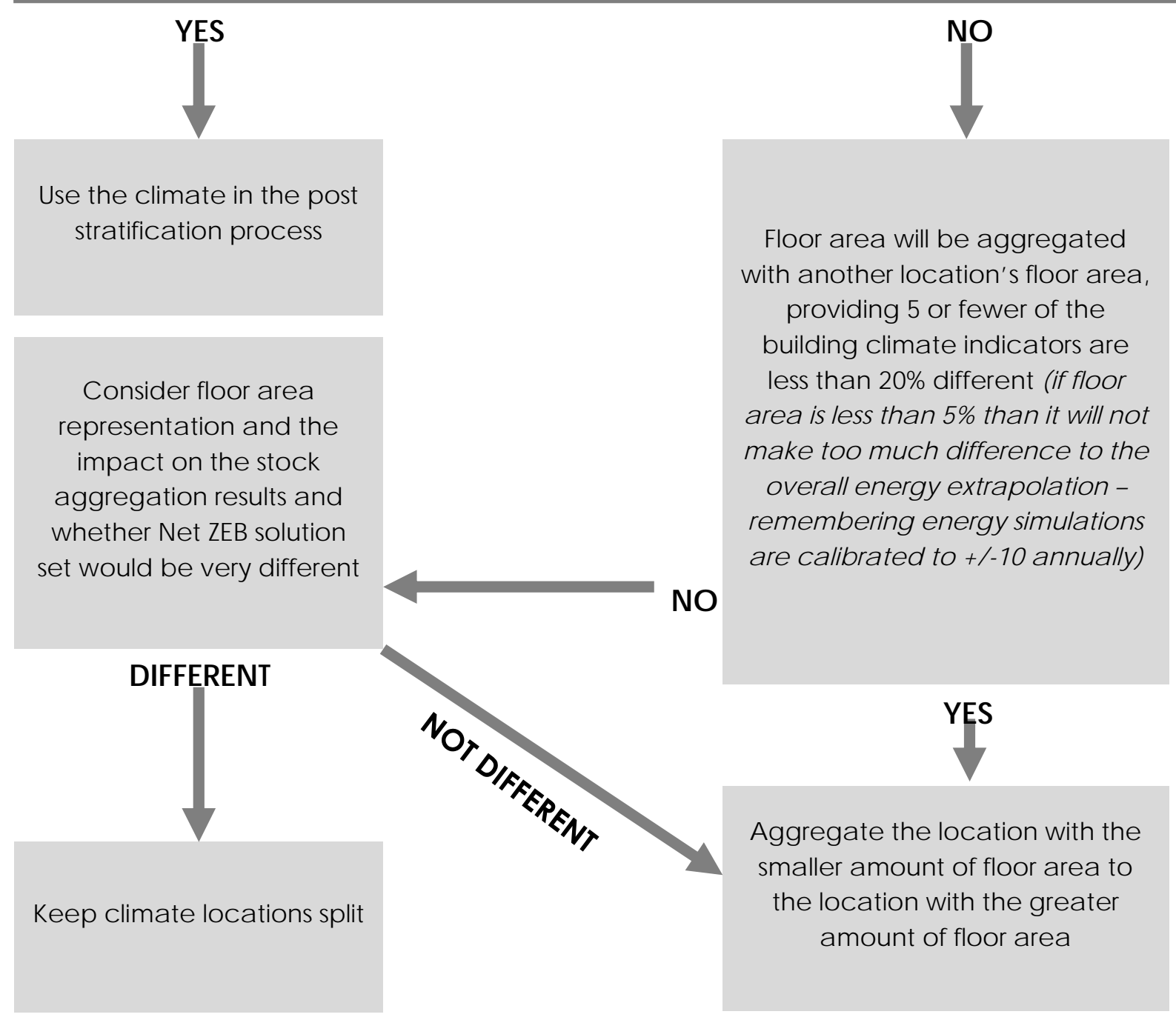

Figure 6-7 : Floor area aggregation decision tree.

There were two deciding factors for aggregating different locations for the purpose of post stratifying by climate, the amount of floor area located in each climate region and whether their climates are similar. Floor area needed to be considered as it made up part of the Stock Aggregation calculation. Stock Aggregation was undertaken by multiplying the EnPI by floor area in each New Zealand climate region. The amount of floor area in each region varied significantly and each region represented a different percentage of the country's total commercial floor area. If two regions separately contained only a small percentage of the floor area, but their climates were similar, the two climates were aggregated.

Page $\mid 123$ 
Any region with less than five percent of the New Zealand commercial building floor area was considered for amalgamation with another climate region. Five percent was used as it was a relatively small percentage of floor area when compared to New Zealand's largest region (Auckland) which contained 40 percent of the total floor area of the commercial building stock, and New Zealand's second largest region (Wellington) containing 25 percent of the total floor area. The remaining floor area was split across the rest of the country (Table 6-2). If the energy consumed by five percent of the floor area was twice as high as the rest, it would only produce a five percent difference in aggregated energy consumption (Appendix 14.3.1). By comparison, if the represented floor area was less than five percent it would not produce a large difference in the aggregated energy consumption. A five percent limit was derived from suitable figures of calibration levels for energy simulation models (refer to Section 7.3). If a simulation model for a building was going to be no greater than \pm 5 percent different to reality, it was not deemed relevant to represent a smaller fraction of floor area that could impact on the aggregation process.

The similarities between climate regions that had the potential to be grouped were identified using the Building Climate Classification. The classification uses thermal simulation to identify the predominant design challenges posed by a climate. It uses climate indicators that not only assess the external conditions of a location, but also the building activity and thermal performance of a reference building in accordance with the building code minimum performance level. The building climate indicators are temperature, humidity, solar radiation, daylight, wind, and comfort hours.

An arbitrary figure of $+/-20$ percent of each building climate indicator was used to determine if two climates were similar. The $+/-20$ percent figure was used as a benchmark because the climates to be aggregated made up a small percentage of total commercial floor area and also because climate is considered to only have a minor effect on the overall Stock Aggregation result compared to the amount of floor area. There needs to be less than a $+/-20$ percent difference between the different climate indicators for two climates to be considered similar. As a judgement criterion, if all six indicators were within $+/-20$ percent, the two climates were deemed similar enough to be aggregated. In addition, if less than five of the climate indicators were within $+/-20$ percent, the two locations could be considered to be aggregated, however, this needed to be weighed up against the amount of floor area in each climate region to decide whether the impact on the Stock Aggregation result would be significant. The location with the greater floor area was used in the aggregation process. The other climate with the lesser floor area would not be directly represented, but would instead be represented by the similar climate. 
Table 6-2 displays the breakdown of regions for the purposes of the EnergyPlus weather files and the amount of floor area in each corresponding region.

Table 6-2 : Split of New Zealand Regions (QV 2008; BEES 2013b).

\begin{tabular}{|c|c|c|c|c|}
\hline Groupings & EnergyPlus Weather & $\begin{array}{c}\text { Floor Area Region } \\
\text { Split }\end{array}$ & $\begin{array}{l}\text { Amount of Floor area } \\
\left(\mathrm{m}^{2}\right)\end{array}$ & $\begin{array}{c}\text { Percentage of total } \\
\text { floor area (\%) }\end{array}$ \\
\hline \multirow{2}{*}{1} & Northland & Northland & 302,314 & $1.0 \%$ \\
\hline & Auckland & Auckland & $11,795,550$ & $39.7 \%$ \\
\hline \multirow{4}{*}{2} & Waikato & \multirow{2}{*}{ Waikato } & \multirow{2}{*}{$1,552,710$} & \multirow{2}{*}{$5.2 \%$} \\
\hline & Taupo & & & \\
\hline & Tauranga & \multirow{2}{*}{ Bay of Plenty } & \multirow{2}{*}{$1,333,598$} & \multirow{2}{*}{$4.5 \%$} \\
\hline & Rotorua & & & \\
\hline \multirow{3}{*}{3} & Napier & East Coast / Napier & $1,422,058$ & $4.8 \%$ \\
\hline & Nelson & Nelson & 319,580 & $1.1 \%$ \\
\hline & West Coast & West Coast & 42,674 & $0.1 \%$ \\
\hline \multirow{2}{*}{4} & Taranaki & Taranaki & 408,307 & $1.4 \%$ \\
\hline & Manawatu & Manawatu-Wanganui & 928,269 & $3.1 \%$ \\
\hline \multirow{2}{*}{5} & Waiarapa & \multirow{2}{*}{ Wellington } & \multirow{2}{*}{$7,444,195$} & \multirow{2}{*}{$25.1 \%$} \\
\hline & Wellington & & & \\
\hline 6 & Christchurch & Canterbury & $2,866,521$ & $9.7 \%$ \\
\hline \multirow{4}{*}{7} & Dunedin & \multirow{3}{*}{ Otago } & \multirow{3}{*}{880,116} & \multirow{3}{*}{$3.0 \%$} \\
\hline & Lauder & & & \\
\hline & Queenstown & & & \\
\hline & Invercargill & Southland & 396,107 & $1.3 \%$ \\
\hline
\end{tabular}

The main difference between the EnergyPlus weather file regions and the floor area regions was there are multiple EnergyPlus weather file regions per floor area region. Due to a small percentage of floor area being located within some regions, it was decided by BEES that these could be combined. This was the case for four regions including Waikato, Bay of Plenty, Wellington and Otago. There was also one instance where two floor area splits were joined to represent one EnergyPlus weather file region. This was due to an EnergyPlus weather file not being created for that area of New Zealand. For this reason, the East Coast floor area region was joined with Napier's floor area for geographical reasons. Given that floor area located in East Coast makes up such a small percentage of the total building stock floor area ( 0.4 percent), it was not considered a concern. The following geographical regions were aggregated if they had similar climates due to them containing a small amount of commercial floor area and/or are geographically situated close to a region with a large percentage of floor area:

1. Northland and Auckland

2. Tauranga, Rotorua, Taupo, and Waikato

3. East Coast-Napier, West Coast and Nelson

4. Manawatu and Taranaki 


\section{Wairarapa and Wellington}

6. Christchurch-Canterbury

7. Dunedin, Lauder, Queenstown and Invercargill.

Table 6-3 displays the results of the comparison of building climate indicators between each climate region. The majority of the climate comparisons had differences of less than 20 percent between all six climate indicators. Two of the comparisons (Manawatu/Taranaki and Wellington/Wairarapa) had five indicators within $+/-20$ percent difference. One climate comparison (Dunedin/Lauder) only had four indicators within $+/-20$ percent difference, indicating: that the climates in these two areas can vary substantially.

\begin{tabular}{|c|c|c|c|c|c|c|c|c|c|c|c|c|}
\hline \multirow{2}{*}{$\begin{array}{l}\text { Groupings } \\
\text { Indicators }\end{array}$} & \multirow{2}{*}{$\begin{array}{l}1 \\
\mathrm{NL} / \\
\mathrm{AK}\end{array}$} & \multicolumn{3}{|c|}{2} & \multicolumn{2}{|c|}{3} & \multirow{2}{*}{$\begin{array}{c}4 \\
\mathrm{MW} \\
\text { / NP }\end{array}$} & \multirow{2}{*}{$\begin{array}{l}5 \\
\text { WN/ } \\
\text { WI }\end{array}$} & \multicolumn{3}{|c|}{7} & \multirow[b]{2}{*}{$\begin{array}{l}\text { Location } \\
\text { Abbreviations }\end{array}$} \\
\hline & & $\begin{array}{l}\mathrm{HN} \\
\text { / BP }\end{array}$ & $\begin{array}{l}\text { HN } \\
\text { / RR }\end{array}$ & $\begin{array}{l}\mathrm{HN} \\
\text { / TP }\end{array}$ & $\begin{array}{l}\text { EC / } \\
\text { NM }\end{array}$ & $\begin{array}{l}\text { NM / } \\
\text { WC }\end{array}$ & & & $\begin{array}{l}\text { OC / } \\
Q L\end{array}$ & $\begin{array}{l}\text { DN } \\
\text { / IN }\end{array}$ & $\begin{array}{l}\text { DN / } \\
\text { OC }\end{array}$ & \\
\hline $\begin{array}{l}\text { Temperature } \\
\text { (Heating } \\
\text { hours) }\end{array}$ & $-1 \%$ & $6 \%$ & $-12 \%$ & $-17 \%$ & $-6 \%$ & $-18 \%$ & $3 \%$ & $-5 \%$ & $1 \%$ & $-7 \%$ & $11 \%$ & $\begin{array}{l}\mathrm{NL}=\text { Northland } \\
\mathrm{AK}=\text { Auckland } \\
\mathrm{HN}=\text { Waikato } \\
\mathrm{BP}=\text { Tauranga }\end{array}$ \\
\hline $\begin{array}{l}\text { Humidity } \\
\text { (Cooling } \\
\text { Humidify } \\
\text { hours) }\end{array}$ & $-17 \%$ & $1 \%$ & $-3 \%$ & $-7 \%$ & $0 \%$ & $2 \%$ & $4 \%$ & $-2 \%$ & $0 \%$ & $3 \%$ & $-1 \%$ & $\begin{array}{c}\mathrm{RR}=\text { Rotorua } \\
\mathrm{TP}=\text { Taupo } \\
\text { MW = Manawatu }\end{array}$ \\
\hline $\begin{array}{l}\text { Solar (Useful } \\
\text { hours) } \\
\text { Daylight } \\
\text { (Useful hours) }\end{array}$ & $2 \%$ & $1 \%$ & $-11 \%$ & $-8 \%$ & $-3 \%$ & $-13 \%$ & $-4 \%$ & $-8 \%$ & $-3 \%$ & $-4 \%$ & $14 \%$ & $\begin{array}{c}\text { NP }=\text { New } \\
\text { Plymouth } \\
\text { WN }=\text { Wellington } \\
\text { WI }=\text { Waiarapa } \\
\text { EC }=\text { East Coast }\end{array}$ \\
\hline $\begin{array}{l}\text { Wind (Useful } \\
\text { Hours) }\end{array}$ & $2 \%$ & $0 \%$ & $-8 \%$ & $4 \%$ & $-11 \%$ & $-7 \%$ & $-21 \%$ & $-23 \%$ & $-14 \%$ & $3 \%$ & $31 \%$ & $\begin{array}{c}\mathrm{NM}=\text { Nelson } \\
\mathrm{WC}=\text { West Coast }\end{array}$ \\
\hline $\begin{array}{l}\text { Comfort } \\
\text { hours }\end{array}$ & $2 \%$ & $4 \%$ & $15 \%$ & $5 \%$ & $1 \%$ & $9 \%$ & $15 \%$ & $9 \%$ & $6 \%$ & $-3 \%$ & $-22 \%$ & $\begin{array}{c}\mathrm{OC}=\text { Lauder } \\
\mathrm{QL}=\text { Queenstown }\end{array}$ \\
\hline $\begin{array}{l}N^{\circ} \text { of factors } \\
(<20 \%)\end{array}$ & 6 & 6 & 6 & 6 & 6 & 6 & 5 & 5 & 6 & 6 & 4 & $\begin{array}{c}\mathrm{DN}=\text { Dunedin } \\
\mathrm{IN}=\text { Invercargill }\end{array}$ \\
\hline
\end{tabular}

The difference in climate comparisons arose due to location factors, with Dunedin being a coastal region while Lauder is situated inland. In order to accurately assess an individual building in each of these regions, their climates would need to be split in two. However, the amount of floor area located in these two regions was minimal, accounting for $257,893 \mathrm{~m}^{2}$ which represents 0.9 percent of the total floor area of the commercial building stock. This means the energy consumption differences that arose had little impact on the overall Stock Aggregation results. As an example, a theoretical test aggregation was made with and without the climates split. If the energy consumption in Lauder was twice as high as the energy consumption across the rest of the country, it would make a 0.9 percent difference to the aggregated annual energy 
consumption (refer to Appendix 14.3.2). Given this is not statistically significant, the climate was combined and represented by Dunedin.

As a result of the findings above, the 18 available climate regions were reduced to seven climate regions which were representative of the climate similarities and floor area amongst the national commercial building floor area. In conclusion, six out of the seven climate regions have five percent or more of the total floor area for the entire commercial building stock.

Figure 6-8 summarises the aggregation process and the final climate regions used in the Stock Aggregation process.

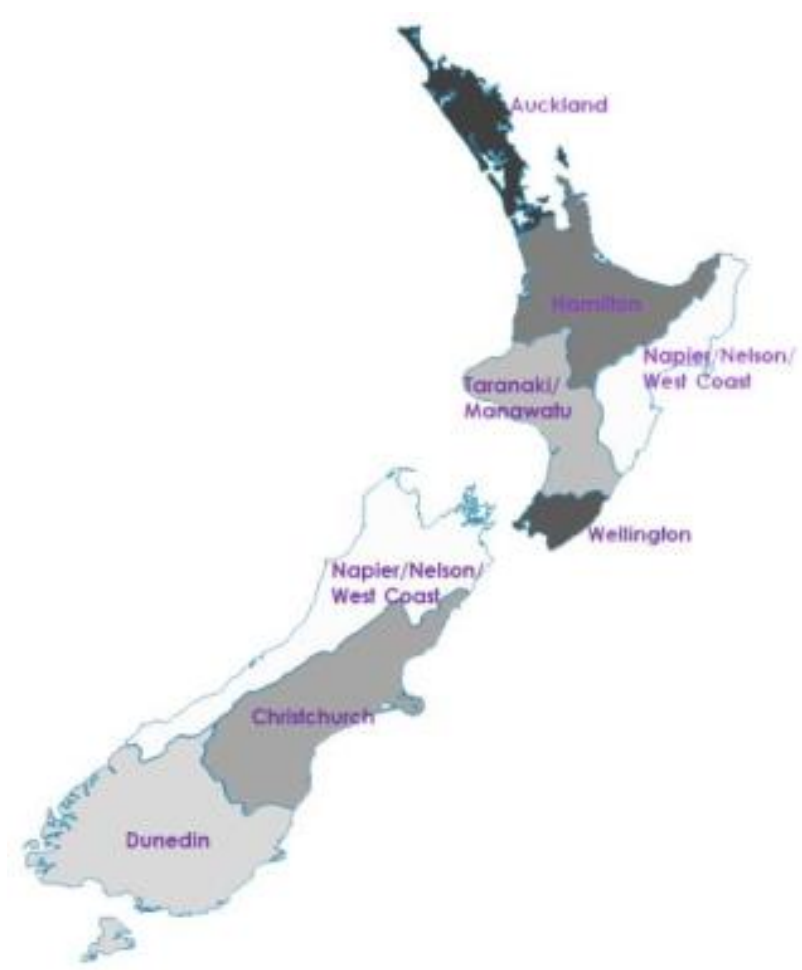

\begin{tabular}{|c|c|c|c|}
\hline $\begin{array}{l}\text { Aggregated } \\
\text { group and } \\
\text { New Zealand } \\
\text { Commercial } \\
\text { Building } \\
\text { climates }\end{array}$ & $\begin{array}{c}\text { Weather file } \\
\text { used }\end{array}$ & $\begin{array}{c}\text { Amount } \\
\text { of floor } \\
\text { area }\left(\mathrm{m}^{2}\right)\end{array}$ & $\begin{array}{l}\% \text { of } \\
\text { floor } \\
\text { area }\end{array}$ \\
\hline $\begin{array}{l}\text { Northland / } \\
\text { Auckland }\end{array}$ & Auckland & $\begin{array}{c}12,097,86 \\
3\end{array}$ & $41 \%$ \\
\hline $\begin{array}{l}\text { Waikato / } \\
\text { Tauranga / } \\
\text { Rotorua / } \\
\text { Taupo }\end{array}$ & $\begin{array}{l}\text { Waikato } \\
\text { (Hamilton) }\end{array}$ & $2,886,308$ & $10 \%$ \\
\hline $\begin{array}{c}\text { East Coast - } \\
\text { Napier / } \\
\text { Nelson / West } \\
\text { Coast }\end{array}$ & $\begin{array}{l}\text { Napier - East } \\
\text { Coast }\end{array}$ & $1,784,312$ & $6 \%$ \\
\hline $\begin{array}{l}\text { Manawatu / } \\
\text { Taranaki }\end{array}$ & Manawatu & $1,336,576$ & $5 \%$ \\
\hline $\begin{array}{l}\text { Wellington / } \\
\text { Waiarapa }\end{array}$ & Wellington & $7,444,195$ & $25 \%$ \\
\hline $\begin{array}{c}\text { Christchurch - } \\
\text { Canterbury }\end{array}$ & $\begin{array}{l}\text { Christchurch } \\
\text { - Canterbury }\end{array}$ & $2,866,520$ & $10 \%$ \\
\hline $\begin{array}{c}\text { Dunedin / } \\
\text { Lauder / } \\
\text { Queenstown / } \\
\text { Invercargill }\end{array}$ & Dunedin & $1,276,223$ & $4 \%$ \\
\hline
\end{tabular}

Figure 6-8 : Summary of New Zealand's building climate aggregation (QV 2008; BEES 2013b).

\subsubsection{Stock Aggregation calculation process}

With all of the real building and climate archetypes identified, the Stock Aggregation calculation process was then finalised. The Stock Aggregation process was used to estimate the building population's energy consumption. Figure 6-9 displays a flow chart of the procedure for calculating the Stock Aggregation sub-totals and total energy consumption. 
a

\begin{tabular}{|c|c|c|c|c|c|c|c|c|c|c|}
\hline \multirow{2}{*}{$\begin{array}{c}\text { Splitof Building } \\
\text { Types } \\
\text { (Example isfor }\end{array}$} & \multicolumn{3}{|c|}{ Office } & \multicolumn{4}{|c|}{ Retail } & \multicolumn{3}{|c|}{ Mixed } \\
\hline & Building1 & Building2 & Building3 & Building4 & Building5 & Building6 & Building7 & Building8 & Building9 & Building10 \\
\hline $\begin{array}{l}\text { Ell of each } \\
\text { building }\end{array}$ & $\begin{array}{c}\text { EUl of } \\
\text { Building1 } \\
\text { simulated in } \\
\text { Climatel } \\
\text { (kWh/m2.yr) }\end{array}$ & $\begin{array}{c}\text { EUl of } \\
\text { Building2 } \\
\text { simulated in } \\
\text { Climatel } \\
\text { (kWh/m2.yr) }\end{array}$ & $\begin{array}{c}\text { EUl of } \\
\text { Building3 } \\
\text { simulated in } \\
\text { Climatel } \\
\text { (kWh/m2.yr) }\end{array}$ & $\begin{array}{c}\text { EUl of } \\
\text { Building } 4 \\
\text { simulated in } \\
\text { Climatel } \\
\text { (kWh/m2.yr) }\end{array}$ & $\begin{array}{c}\text { EUl of } \\
\text { Building5 } \\
\text { simulated in } \\
\text { Climatel } \\
\text { (kWh/m2.yr) }\end{array}$ & $\begin{array}{c}\text { EUl of } \\
\text { Building } 6 \\
\text { simulated in } \\
\text { Climatel } \\
\text { (kWh/m2.yr) }\end{array}$ & $\begin{array}{c}\text { EUl of } \\
\text { Building } 7 \\
\text { simulated in } \\
\text { Climatel } \\
\text { (kWh/m2.yr) }\end{array}$ & $\begin{array}{c}\text { EUl of } \\
\text { Building8 } \\
\text { simulated in } \\
\text { Climatel } \\
\text { (kWh/m2.yr) }\end{array}$ & $\begin{array}{c}\text { EUl of } \\
\text { Building9 } \\
\text { simulated in } \\
\text { Climate1 } \\
\text { (kWh/m2.yr) }\end{array}$ & $\begin{array}{c}\text { EUl of } \\
\text { Building } 10 \\
\text { simulated in } \\
\text { Climate1 } \\
\text { (kWh/m2.yr) }\end{array}$ \\
\hline
\end{tabular}

\begin{tabular}{|c|c|c|c|}
\hline $\begin{array}{c}\text { Average EUI } \\
\text { perbuilding } \\
\text { type }\end{array}$ & $\begin{array}{c}\text { Average Office building EUl in Climate1 } \\
\text { (kWh/m2.yr) }\end{array}$ & Average Retail building EUl in Climate1 (kWh/m2.yr) & $\begin{array}{c}\text { Average Mixed building EUl in Climate1 } \\
\text { (kWh/m2.yr) }\end{array}$ \\
\hline
\end{tabular}
type
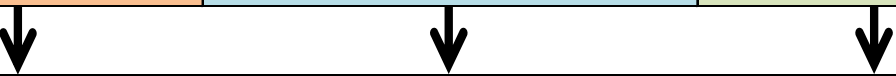

Total Energy

Average Office building EUl in climate
zonel $(\mathrm{kWh} / \mathrm{m} 2 . \mathrm{yr})$

Consumption $X$ Office Building Floor area in Climatel (m2)

perbuilding

type

=Total Office building Energy Consumption

in Climate1 ( $\mathrm{WWh}$ )

Strata1

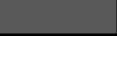

Climate1

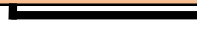

Average Retail building EUl in climate zone1 ( $\mathrm{kWh} / \mathrm{m} 2 . \mathrm{yr})$

$X$ Retail Building Floor area in Climate1 (m2)

$=$ Total Retail building Energy Consumption in Climate1 (kWh)

(kWh/m2.yr)

in Climate1 (kWh)

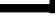

al Office building Energy Consumption in Climatel (kWh)

+ Total Retail building Energy Consumption in Climatel (kWh)

+ Total Mixed building Energy Consumption in Climatel (kWh) Total Energy Consumption in Climate1

\begin{tabular}{|l|l|}
\hline Climate 2 & Repeat calculations for Climate2 \\
\hline Climate 3 & Repeat calculations for Climate3 \\
\hline Climate 4 & Repeat calculations for Climate4 \\
\hline Climate 5 & Repeat calculations for Climate5 \\
\hline Climate 6 & Repeat calculations for Climate6 \\
\hline Climate 7 & Repeat calculations for Climate7 \\
\hline
\end{tabular}

$\downarrow$

+Total Energy Consumption in Climate2

+ Total Energy Consumption in Climate 3

+ Total Energy Consumption in Climate4

+ Total Energy Consumption in Climate5

+ Total Energy Consumption in Climate6

+ Total Energy Consumption in Climate 7

$=$ Total Energy Consumption in Strata 1

h Strata3

Strata5

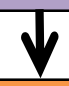

Repeat calculations for Strata2

Repeat calculations for Strata3

Repeat calculations for Strata 4

Repeat calculations for Strata5

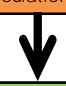

Whole

Buildings

Energy

Consumption

Total Energy Consumption in Strata 1

+ Total Energy Consumption in Strata2

+ Total Energy Consumption in Strata3

+ Total Energy Consumption in Strata4

+ Total Energy Consumption in Strata5

$=$ Whole Building Energy Consumption

Figure 6-9 : Flow chart of the Stock Aggregation process.

\section{Refer to page 413 for $\mathrm{A3}$ version}


The aggregation process displayed is only suitable when using a sample of real building archetypes and not prototypical buildings. The aggregation process involved:

1. The sub-division of each size archetype by building type archetype;

2. Each of the 48 buildings being simulated in one of the seven climates identified to be used in the aggregation process;

3. The calculation of the average EnPI per building type by dividing the total energy by the total floor area present in the climate region;

4. The calculation of the total energy consumption per building type by multiplying the average EnPI by the total floor area present in the climate region;

5. The calculation of the total energy consumption per climate by adding up the office, retail and mixed types' energy consumptions;

6. Stages a, b, c, d and e were repeated for the other six climates;

7. The calculation of the total energy consumption per size archetype by adding up the total energy consumption of each climate;

8. Stages a, b, c, d, e, f and g were repeated for the other four size archetypes; and

9. The calculation of the whole NZ building stock's energy consumption by adding up the total energy consumption per Size Group.

\subsection{The sub-sample of $\mathbf{4 8}$ real buildings}

A representative sub-sample of 48 buildings was selected from the 101 BEES monitored buildings to enable energy models to be constructed. Forty eight were selected due to time constraints meaning it was not possible to model all 101 buildings. The aim was to select from each BEES size group, a modelling sub-sample of ten buildings which contained a range of various building attributes that influence on their energy performance. Forty eight buildings in total were selected. Only eight of the largest BEES building size range (building size group $5=$ buildings over $9000 \mathrm{~m}^{2}$ ) had monitored data available.

The selection of the sub-sample of 48 buildings was a purposeful sub-sampling. This was due to the sub-sample of 48 buildings representing the distribution of building attributes across the larger sample of BEES buildings in the auxiliary data set (in this case the auxiliary data set was the web-search and phone survey datasets). This sub-sampling is also known as two-stage sampling (Sukhatme and Sukhatme 1970). The sub-sample was selected by determining the correct proportion of building attributes to make up the modelling sample of buildings in order to represent the larger sample of BEES buildings in the auxiliary data sets. In statistics, the auxiliary data sets are referred to as a "cluster" (Sukhatme and Sukhatme 1970, p.262). This means the trends of building characteristics in both samples are similar and enables a fair representation of the larger sample of buildings and the whole population of buildings. In statistics, the building attributes are referred to as "elements" (Sukhatme and Sukhatme 1970, p.262). Once the building characteristics were identified, a random building from the 101 monitored buildings matching those characteristics was selected for the sub-sample. The study to

Page $\mid 129$ 
determine the sub-sample was undertaken to improve the aggregated estimate of the smaller subsample of buildings to be energy modelled.

The study compared the distribution of building attributes across the sample of 81 BEES onsite monitored buildings to the distribution of the BEES Web-search and Phone survey datasets. An improvement in the estimate of the sub-sample was made by identifying a similar proportioned sample of buildings that were found in the larger random sample datasets. The aim of the comparison was to identify 48 of the 81 BEES onsite monitored buildings to make a reasonable representation of the larger BEES datasets. The comparison of the building attributes was also used to identify any under-representations in the modelling sub-sample. As there were only 8 buildings in the sample of the largest building size range (over $9000 \mathrm{~m}^{2}$ ), no comparison analysis was undertaken as these were all included in the modelling sub-sample. The sub-sample was deemed a reasonable representation if the range of characteristics in the sub-sample followed the range of characteristics of the larger BEES data sets. The comparison enabled a selection of a sub-sample of random buildings from the BEES random sample to use in the Stock Aggregation process.

The building attributes assessed all impact on the energy consumption of commercial buildings. The attributes include:

1. Commercial building type - split into Office; Retail; and Mixed.

2. Building height - the number of floors per building split into commercial building type groups. The number of floors refers to a certain range of floor numbers a building has, such as 1 storey, 2 storey, or a 10+ storey building.

3. Number of occupants - calculated at the premise level and split by commercial building type. The number of occupants refers to a certain range of occupants that occupy a specific building type, such as 1 occupant, 2 occupants, or 3-5 occupants that occupy a specific premise.

4. Number of occupied hours - calculated at the premise level and split by commercial building type. The number of occupied hours refers to the hour range that a building is occupied for, such as a specific building being occupied for 1-4 hours, 5-8 hours, or 9-12 hours.

The attributes were broken down for each BEES building dataset (monitored; and web-search or phone survey). The breakdown was performed for each BEES building size range, and compared the total amount of floor area.

To demonstrate the comparison of building characteristics, the comparison for building type in the BEES size range $5-650 \mathrm{~m}^{2}$ is presented in Tables 6-4 and 6-5. Table 6-4 shows the total BEES monitored building floor area for each commercial building type in BEES size group 1. 
Table 6-5 displays the total BEES web-search building floor area for each commercial building type in BEES size group 1.

\begin{tabular}{l|c|c|c}
\multicolumn{3}{|c|}{ Table 6-4 : Monitored - Amount of Building floor area in each commercial building type. } \\
\hline Building type & $\begin{array}{c}\text { Building floor } \\
\text { area }\end{array}$ & $\begin{array}{c}\text { \% of Building } \\
\text { floor area }\end{array}$ & $\begin{array}{c}\text { Representation } \\
\text { needed across } \\
\text { 10 buildings }\end{array}$ \\
\hline Office (CO) & 1,610 & $25 \%$ & $\mathbf{3}$ \\
\hline Retail (CR) & 3,135 & $50 \%$ & $\mathbf{5}$ \\
\hline Mixed (CX) & 1,570 & $25 \%$ & $\mathbf{2}$ \\
\hline Total & 6,315 & $100 \%$ & $\mathbf{1 0}$ \\
\hline
\end{tabular}

\begin{tabular}{l|c|c|c|}
\multicolumn{4}{|c}{ Table 6-5 : Web-search - Amount of Building floor area in each commercial building type. } \\
\hline (Cory 2012) \\
\hline Building type & $\begin{array}{c}\text { Building of } \\
\text { floor area }\end{array}$ & $\begin{array}{c}\text { \% of Building } \\
\text { floor area }\end{array}$ & $\begin{array}{c}\text { Representation } \\
\text { needed across } \\
10 \text { buildings }\end{array}$ \\
\hline Office (CO) & 31,049 & $22 \%$ & 2 \\
\hline Retail (CR) & 75,544 & $54 \%$ & 5 \\
\hline Mixed (CX) & 32,572 & $23 \%$ & 2 \\
\hline Total & 139,165 & $100 \%$ & 9 \\
\hline
\end{tabular}

The tables are split by column for each commercial building type (CO, CR, and CX). The columns show a breakdown of the total amount of floor area, the percentage of total floor area that each building type makes up, and the split of buildings required to be modelled in order to represent this data if 10 BEES buildings were to be used in the modelling sub-sample. The cells are coloured from red to orange to green, with red representing the smallest number and green representing the largest number. This indicates which groups need to be most greatly represented through energy simulation. The numbers in bold show the distribution of building attributes that the sample of 10 size group 1 buildings need to represent. They are only shown in one table because they display the distribution of building types used in this thesis.

The number of specific commercial building types modelled was derived from the web-search dataset. This was because the web-search dataset was the larger of the two samples of commercial buildings (3,000 buildings) and therefore provided a more precise representation of the building stock (more precise because the larger the sample, the larger the cross section of the population being surveyed (Sukhatme and Sukhatme 1970)). However, because the number of buildings did not equal 10 (and 10 buildings from size group 1 needed to be energy modelled), the BEES monitored dataset was used. The percentage of office and mixed floor area included in the BEES dataset was similar to the percentages drawn from the web-search dataset. With this identified, it was established that retail buildings have the greatest floor area, accounting for 50 percent of both datasets. Office and mixed have an almost equal share of the remaining floor area 
(25 percent). This means that if 10 Size Group 1 buildings were to be modelled; five of those buildings would need to be retail, three office, and two mixed.

Using the process above, the same comparisons for building height, number of occupants and occupied hours for BEES size range $5-650 \mathrm{~m}^{2}$ (Size Group 1) and other size ranges (Size Group 2, 3, and 4) were made (Cory 2012). The following tables provide a summary of the number of buildings out of the selected 48 buildings in the modelling sub-sample that contained each characteristic.

Table 6-6 presents the number of commercial buildings types in each BEES size range grouping that made up the modelling sub-sample. The commercial building use type was separated into the three categories, Office, Retail, and Mixed.

\begin{tabular}{|c|c|c|c|c|c|}
\hline \multicolumn{2}{|c|}{ Building Type } & Office & Retail & Mixed & All \\
\hline \multirow{5}{*}{ 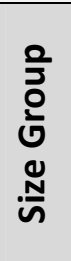 } & 1 & 3 & 5 & 2 & 10 \\
\hline & 2 & 2 & 5 & 3 & 10 \\
\hline & 3 & 3 & 4 & 3 & 10 \\
\hline & 4 & 5 & 2 & 3 & 10 \\
\hline & 5 & 4 & 1 & 3 & 8 \\
\hline \multicolumn{2}{|c|}{ Totals } & 17 & 17 & 14 & 48 \\
\hline
\end{tabular}

Table 6-7 presents the number of floors in each building within the different BEES size range groupings that make up the modelling sub-sample. When assessing the buildings based on the number of storeys they have, the breakdown identified buildings that had 1, 2, 3, 4, 5-9, or 10+ floors. As was expected, the buildings in size group 1 were all low height, while the size group 5 contained buildings with the highest number of floors. Size groups 2 to 4 contained buildings with a range of different floors. Overall, the most common building heights were 1, 2, and 5-9 storey buildings. It was found in the web-search data set that not all size group 1 buildings were 1 storey. This caused an under-representation in the modelling sub-sample, but could not be helped due to the fact that no onsite measurements were undertaken for size group 1 buildings that were taller than 1 storey.

Table 6-7 : 'Number of floors' attribute breakdown of the modelling sub-sample.

\begin{tabular}{|c|c|c|c|c|c|c|c|c|}
\hline \multicolumn{2}{|c|}{ Number of floors } & 1 & 2 & 3 & 4 & $5-9$ & $10+$ & All \\
\hline \multirow{5}{*}{ 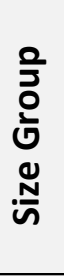 } & 1 & 10 & - & - & - & - & - & 10 \\
\hline & 2 & 5 & 5 & - & - & - & - & 10 \\
\hline & 3 & 4 & 3 & 1 & 2 & - & - & 10 \\
\hline & 4 & 2 & 2 & - & 2 & 4 & - & 10 \\
\hline & 5 & - & - & - & - & 3 & 5 & 8 \\
\hline \multicolumn{2}{|c|}{ Totals } & 21 & 10 & 1 & 4 & 7 & 5 & 48 \\
\hline
\end{tabular}

Page $\mid 132$ 
Table 6-8 presents the average number of occupants in each building within the different BEES size range groupings that make up the modelling sub-sample. Given occupancy numbers were based on the premise level data collected, it was assumed that the premise was representative of all premises within the building and equal comparisons were made. Although most premises have 3 to 5 and 6 to 10 occupants, the variation of occupancy numbers in each premise allowed for a fairly even distribution of occupancy to be selected within the 48 buildings.

\begin{tabular}{|c|c|c|c|c|c|c|c|c|c|c|}
\hline \multicolumn{2}{|c|}{ Occupancy Numbers } & 1 & 2 & 3-5 & $6-10$ & $\begin{array}{l}11- \\
20\end{array}$ & $\begin{array}{c}21- \\
50\end{array}$ & $\begin{array}{l}51- \\
100\end{array}$ & $\begin{array}{c}101- \\
300\end{array}$ & All \\
\hline \multirow{5}{*}{$\begin{array}{l}\text { 윽 } \\
\text { ㅇํㄴ } \\
\text { N } \\
\text { ज }\end{array}$} & 1 & - & 1 & 7 & 2 & - & - & - & - & 10 \\
\hline & 2 & - & 2 & 3 & 2 & 2 & 1 & - & - & 10 \\
\hline & 3 & - & 1 & 2 & 4 & 2 & - & - & 1 & 10 \\
\hline & 4 & - & 1 & 1 & 2 & - & 1 & 2 & 3 & 10 \\
\hline & 5 & - & - & - & 1 & 1 & 2 & 3 & 1 & 8 \\
\hline \multicolumn{2}{|c|}{ Totals } & 0 & 5 & 13 & 11 & 5 & 4 & 5 & 5 & 48 \\
\hline
\end{tabular}

Table 6-9 presents the number of occupied hours in each building within the different BEES size range groupings that make up the modelling sub-sample. As with the occupancy numbers, the operational hours were based on premise level data. The operation hours were based on the scheduled time that the majority of occupants are within the premise. Occupancy times were used to represent the building operation as this was the time that the majority of lighting and plug load equipment was in operation. It is assumed that central services and HVAC plant were likely to follow the same trend as occupancy hours.

Table 6-9 : 'Number of occupied hours' attribute breakdown of the modelling sub-sample.

\begin{tabular}{|c|c|c|c|c|c|c|c|}
\hline \multicolumn{2}{|c|}{ Occupancy Hours } & $1-4$ & $5-8$ & $9-12$ & $13-16$ & $17-20$ & All \\
\hline \multirow{5}{*}{ 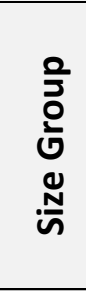 } & 1 & - & 6 & 4 & - & - & 10 \\
\hline & 2 & - & 3 & 7 & - & - & 10 \\
\hline & 3 & 1 & 3 & 5 & 1 & - & 10 \\
\hline & 4 & - & 2 & 6 & 1 & 1 & 10 \\
\hline & 5 & - & - & 8 & - & - & 8 \\
\hline \multicolumn{2}{|c|}{ Totals } & 1 & 14 & 30 & 2 & 1 & 48 \\
\hline
\end{tabular}

\subsection{Chapter summary}

Chapter 6 described the method for representing the current New Zealand commercial building stock using a random sample of real buildings and a Stock Aggregation method (Moffat 2001). The method used various building archetypes to represent portions of the building stock. The building archetypes were multiplied by the portion of the building stock that they represent to establish a total energy consumption figure for the whole commercial building

Page $\mid 133$ 
stock. Chapter 6 also determined a sub-sample of 48 real commercial buildings found in the New Zealand commercial building stock that will make up the building archetypes used in the stock aggregation process. The use of real building archetypes means they are not prototypical buildings that represent an 'average' or 'typified' building. Instead, the real building models offer an advantage over prototypical buildings in that their energy performance can be cross checked to reality. Figure 6-10 displays the link between Chapters 6 and 7 .

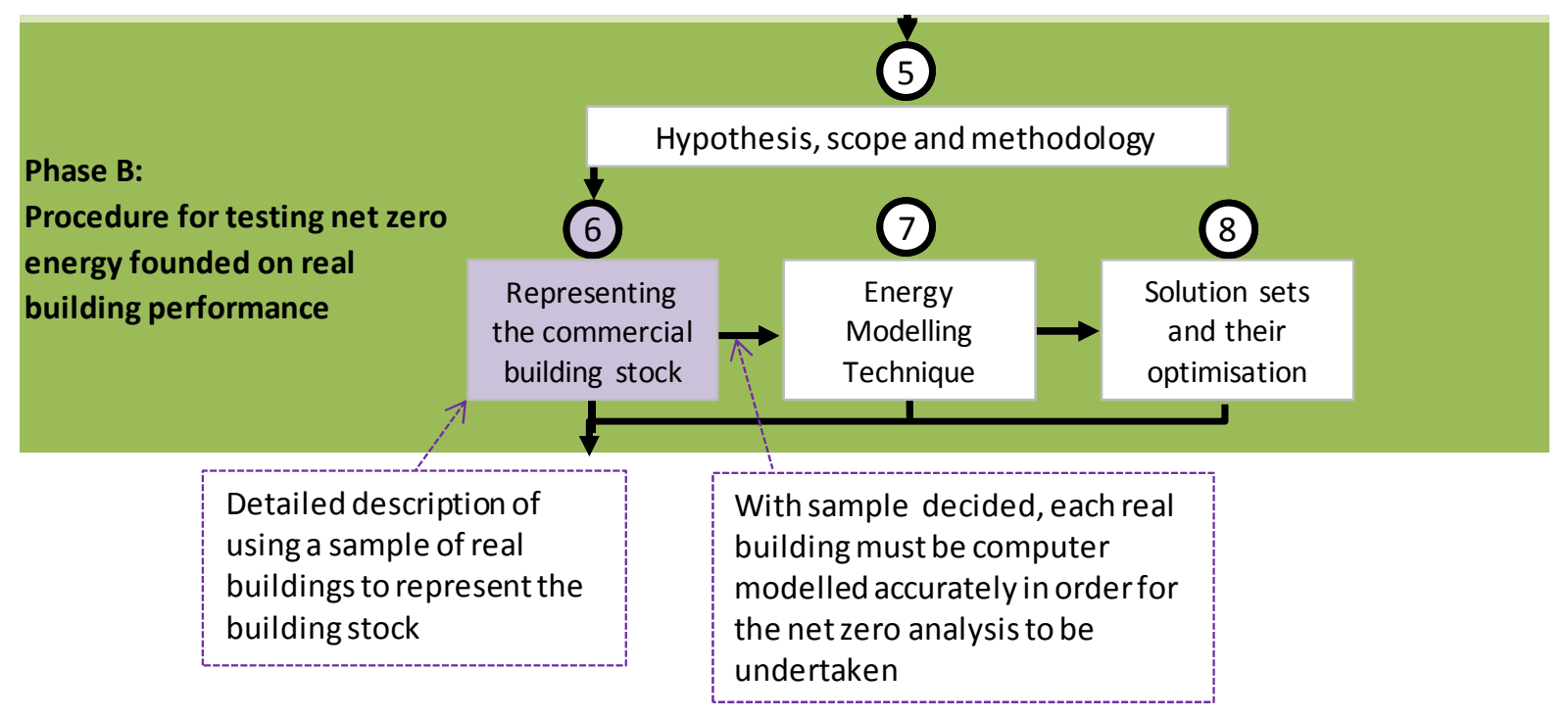

Figure 6-10 : Link of chapter 6 to the previous and following chapters.

With the aggregation and sub-sample of buildings established, the next step is to detail the method for creating energy models that represent the real buildings. These energy models will estimate the energy consumption for each of the 48 real buildings established in Chapter 6 and is used in the stock aggregation process to calculate the building stock's energy consumption. The energy models are then retrofitted to be NZE and re-entered into the stock aggregation process to calculate the retrofitted building stock's energy consumption. Chapter 7 develops and details an approach for accurately modelling the real buildings' performance that is systematic to implement. 



\section{CHAPTER 7. TECHNIQUE FOR MODELLING AN EXISTING BUILDING'S ENERGY CONSUMPTION}

\subsection{Chapter Intent}

Chapter 7 presents a tested and quality assured method for building calibrated energy models that represent the sample of 48 BEES case study buildings established in Chapter 6 . The energy performances of the calibrated energy models were used in the stock aggregation process outlined in chapter 6 to represent the current building stock. Figure 7-1 illustrates this link between Chapters 6 and 7. Energy modelling for buildings, in both new and renovation based projects, is fundamental for forecasting energy related performance of a design and to provide an evaluation of the design's feasibility. It allows for the quick and easy assessment of many design variations to identify an optimised design for lowering energy consumption in buildings.

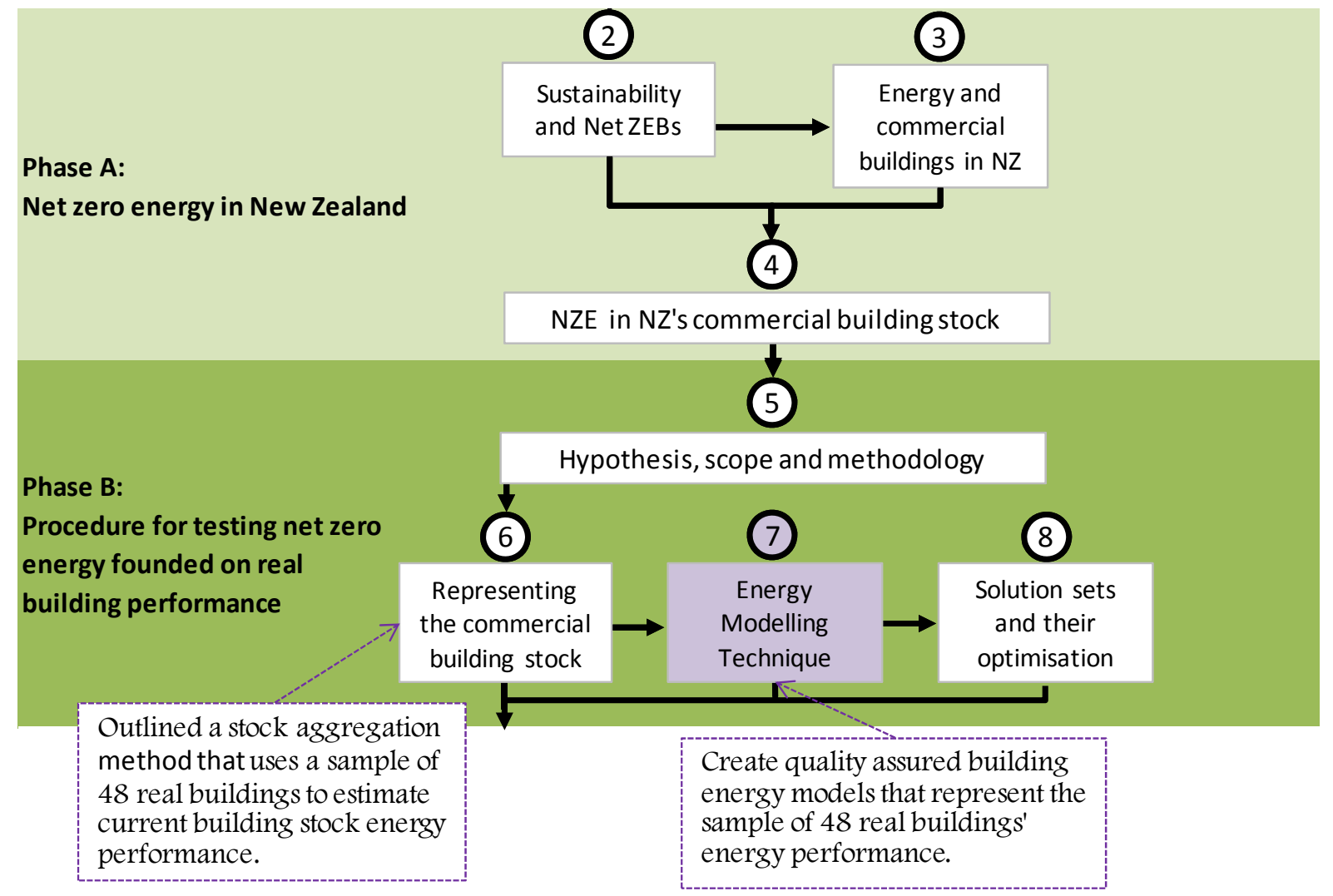

Figure 7-1 : Link of Chapter 6 and 7.

Section 7.2 introduces quality assurance in energy modelling and describes the type of modelling being proposed in this thesis. The type of modelling is template modelling. Template models speed up the modelling process because they already contain a lot of building information which reduces the amount of data a modeller needs to input. Sections 7.3 and 7.4 outline energy model 
calibration and the procedure for calibration undertaken in this thesis. Section 7.5 presents results of a Quality Assurance test of the template and calibration process proposed in this research.

\subsection{Energy model quality assurance and accuracy}

A quality assured energy model is one that is systematically evaluated to minimise the risk of error and to ensure simulations are accurate (Chartered Institution of Building Services Engineers 1998). Quality Assurance (QA), in this study, was an energy model that aims to match the energy performance of a real building. If the model was calibrated to match the performance of a real building, it was therefore considered accurate and minimised risk of error. However, it was identified in Donn (1999) that there are various problems preventing clarity around a quality assured model. To improve the QA of the energy models created and used in this study, a standardised template energy model and calibration technique were developed. Template models were a simplified version of a real building and were populated with NZ relevant materials, constructions, loads and HVAC systems (BRANZ Ltd 2013b; A Gates 2013). Template models enforced a standardised model creation method that limited the user of the computer energy simulation program to data input that is based on measured data. A standardised calibration procedure also minimised undocumented manipulation of the simulation file to achieve the desired results (Cory, Gates, and Donn 2011).

Template models and calibration provide a solution to three QA issues:

\section{QA problem}

- Time limitations to prepare and construct the model (Donn 1999).

- There is no clear guidance as to the important features of a building that should be modelled well, and the features whose effect on predicted performance is insignificant in the final models (Donn 1999).

- There are minimal quality control systems that allow the simulation user to ensure the relevance and accuracy of their recommendations from the final models (Donn 1999).

\section{Template model and standardised calibration QA} response

As template models are already populated with a library of typical inputs for New Zealand buildings, it reduces the amount of input required to build a final model. By doing so, it reduces the time it takes to model a real building.

Template building models have simplified inputs compared to a detailed building model. The simplifications are of features (such as window location and specific building load location) that do not affect the performance of the final model dramatically. See section 7.2.4 and 7.5.1 for results of a comparison between detailed and template models.

A standardised calibration procedure prevents the tweaking of inputs that have no bearing on the real building attributes and that may have impacted on the differences between the energy model and reality. The final calibrated models provide accurate results that aid in making accurate recommendations. 
Even with the above responses to QA, the QA foundation work was still undertaken in constructing the calibrated energy models. QA foundation work included the double checking of data values entered to ensure the correct building attributes were being modelled and the computer program being used (EnergyPlus) was validated using BESTEST (R. Henninger, Witte, and Crawley 2003; R. H. Henninger, Witte, and Crawley 2004).

\subsubsection{BEES EnergyPlus template models}

Energy modelling studies in the BEES project resulted in the development of a template modelling process and a set of NZ relevant template models (Cory, Hsu, and Donn 2009). The aim of the template models was to reduce the difficulties associated with energy modelling, particularly improving the ease and speed at which models can be created and tested to produce reliable results, as well as test Energy Conservation Measures (ECM) (Cory, Hsu, and Donn 2009). The quickness and ease of modelling were achieved by minimising the number of user inputs required to model a building. The initial idea of the New Zealand relevant template models was for them to be adaptations of the US Department of Energy (DOE) benchmark/ reference models (P Torcellini et al. 2008; M. Deru et al. 2011). This meant that the DOE benchmark models had to be adjusted to better match New Zealand built forms, constructions, internal loads, and operational schedules (Cory, Hsu, and Donn 2009). The templates were built to incorporate data collected from BEES and therefore incorporated properties and input values that were consistent with current building practices in New Zealand. The BEES Templates included in-built geometry, materials, constructions, schedules of use, building loads and HVAC systems.

Appendix 14.4 displays an example of the real building information used to construct and alter a template EnergyPlus model to represent the 48 BEES case study buildings. The real building information was collected by BEES during their detailed site visits. The data used to construct each of 48 energy models was stored internally with the BEES project for confidentiality reasons (BEES 2014b).

\subsection{1a Building Geometry/Thermal zones}

Energy simulation templates are typically only made up of materials, constructions and schedules (Attia 2011). However, the BEES templates endeavoured to have standard building geometries, which were based on the work of Steadman et al. (2000) and adapted from the BEES building surveys. Initially, ten built form geometries were established, but this was reduced to five because only five forms were recorded in the various BEES data collection processes (BRANZ Ltd 2013b). 
Figure 7-2 presents the five template model built forms with a description of what they were found to represent in real New Zealand buildings. Each built form is shown in single storey form and does not represent a final building.

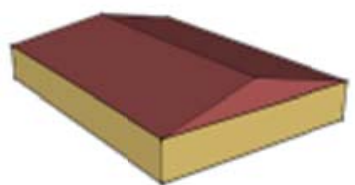

- Single Roomed buildings: Halls, Warehouses, residential converted into commercial buildings.

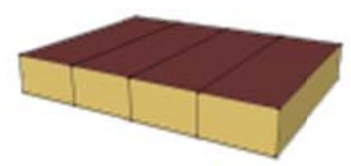

- Row of Single Roomed buildings: Retail strip, converted Residential buildings, mixed retail and office strip.

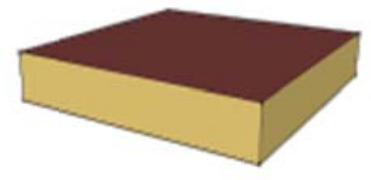

Open Plan buildings less than $14 \mathrm{~m}$ in width: Halls, Warehouses, converted residential buildings, small open plan offices, and small open plan retail buildings.

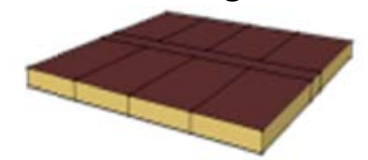

- Cellular Strip buildings: Hotels, Motels, Apartments, cellular office building.

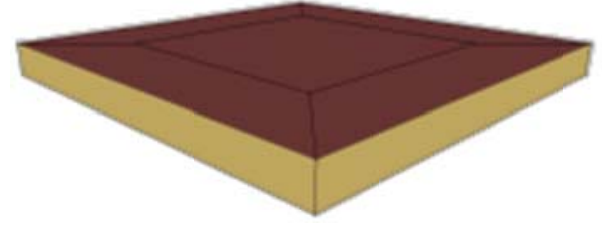

- Open Plan buildings greater than $14 \mathrm{~m}$ in width: Large Open Plan offices.

Figure 7-2 : Template built forms.

The built forms are square in nature and are scaled to match a building's floor area, fabric surface area and building space volume. The built forms are scaled by stretching the length, width and height of each floor, and duplicating the bottom floor and stacking it on top to represent multiple floors (refer to figure 7-6 for an example of a completed template model). This means they have the same amount of roof, floor and façade area as the real building. Energy and thermal calculations use the building's surface area and space volume to calculate the various heat gains and losses through the building envelope (The American Institute of Architects 1982a; The American Institute of Architects 1982b) and therefore, the simplified template form will not impact greatly on the calculation of thermal heat gains and losses for a real building.

\subsection{1b Materials and constructions}

The BEES template models contain New Zealand relevant construction materials for the energy modeller to select the building construction that most closely matches the real building. The material thermal properties data is ascertained from NZS 4214-Methods of determining the total thermal resistance of parts of buildings or CIBSE Guide A (Standards New Zealand 2006; Chartered Institution of Building Services Engineers 1999). The construction layers were 
determined from common building constructions (Spence 1998). The modeller selects the most appropriate construction that matches a particular building.

\subsection{1c Schedules of operation}

There were a number of schedules that needed to be updated to match the real buildings being represented in the energy models. Schedules are the patterns of use for people and building loads. They define when and how many occupants are in a space as well as when and how much building load is turned 'on' in a space. The schedules built into the models represented the "typical" patterns of use found in the three commercial building types: Office, Retail, and Mixed (Cory, Donn, and Pollard 2014). The built-in Schedules needing to be updated included:

- Infiltration - a constant (infiltration is always occurring).

- Activity - the metabolic rate, in Watts, that occupants are emitting as an internal heat gain.

- Clothing - the clothing level of occupants at varying times of the year.

- Air Velocity - the speed of air movement in each thermal zone.

- HVAC Schedule - time period for when the HVAC system is turned 'on'.

- Thermostat - heating and cooling set points to which the indoor air is conditioned.

- Occupancy - time period when people occupy the building.

- Lighting - time period when the internal electric lighting is turned 'on'.

- Office Equipment - time period when the internal electric office equipment is turned 'on'.

- Miscellaneous Equipment - time period when the internal electric miscellaneous equipment is turned 'on'.

- DHW - time period when the DHW is turned 'on'.

- Lifts - time period when the lifts are turned 'on'.

- Ventilation - time period when air is ventilated in and out of the buildings through windows or mechanical ventilation.

\subsection{1d Building loads}

As well as the "typical" patterns of use, the BEES template models contained the "typical" building load densities (Cory, Donn, and Pollard 2014). The energy modeller needed to update the building loads to match the loads found in the building. In template models, the building loads are a total load per square metre of floor area $\left(\mathrm{W} / \mathrm{m}^{2}\right)$. The building loads required to be updated included:

- Occupants (People/ $\left.\mathrm{m}^{2}\right)$

- Lighting $\left(\mathrm{W} / \mathrm{m}^{2}\right)$

- Office equipment $\left(\mathrm{W} / \mathrm{m}^{2}\right)$

- Miscellaneous equipment (W/ $\mathrm{m}^{2}$ (gas and electric))

- $\operatorname{DHW}\left(\mathrm{W} / \mathrm{m}^{2}\right)$ 
In the same way that the energy and thermal calculations use the building surface areas and volumes to estimate the heat gains and losses, building loads were calculated using the amount of load spread across the floor area and the patterns of use for when the loads were turned 'on' (The American Institute of Architects 1982a; The American Institute of Architects 1982b). If the average building load was turned 'on' for the average amount of time, the template modelling method of building loads would not impact on the calculation for the amount of energy consumed and internal heat gained in the real building by the building loads.

\subsection{1e Heating, Ventilation and Air Conditioning}

EnergyPlus enables the use of HVAC templates. HVAC templates are built from a small number of simplified inputs which EnergyPlus expands to create a more complete and detailed HVAC system. There are a number of templates available and these are discussed in the EnergyPlus documentation (US DOE 2013). The HVAC templates have a number of pre-set default values for HVAC system parameters, for example the Boiler Efficiency, Chiller Efficiency, Fan Efficiency, and Coefficient Of Performance (COP). To speed up the modelling process, the BEES template models made use of the HVAC templates. The BEES templates contained the common HVAC systems installed throughout New Zealand with updated default input parameter values that were representative of the commonly installed systems in New Zealand (A Gates 2013). The energy modeller updated the HVAC parameters to match the as-built specifications of the real buildings. The last step in creating a completed template model is therefore the selection of the HVAC template that matches the building being modelled. Seven HVAC system types were identified by Gates (2013) and were: Split System Heat Pump, Variable Air Volume (VAV) with boiler and chiller; VAV with electric heat; Fan Coil Unit (FCU) common; FCU Poor; Packaged Air Handling Unit, and Chilled beams.

\subsubsection{Advantages of the template models}

The advantages of using the template models were established during the initial testing stages. One test involved two users modelling twelve buildings using the same data set. Both users had beginner level experience in thermal modelling. Both users were given the above stated template models and used the standardised procedure for modelling each building (BRANZ Ltd 2013c). The two users produced results which indicated the user input errors and variation of data interpretation. Overall, the difference in the calculated annual energy consumption between the two modellers ranged from 0 to 24 percent. It is worth noting that 8 of the 12 buildings that were modelled only had 0 to 5 percent difference (Cory, Gates, and Donn 2011). Following this, the two modellers sought to resolve the differences in the models. The aim was to reduce the differences within an appropriate time interval. Within the timeframe given, the modellers reduced the differences to within the 0 to 10 percent range. The differences in results were due to:

- "different materials assigned to surfaces;

- Building shape slightly different [due to inaccuracy of modeller following building plans];

Page | 140 
- Building orientation slightly different [two methods of changing orientation result in different results, as well as inaccuracy of one method using a map];

- Various internal [building] loads missing;

- Extra surfaces mistakenly being modelled; and

- Geometry differences of +/-0.5m" (Cory, Gates, and Donn 2011, p.1477).

The installation of incorrect internal building loads created the largest difference in energy consumption. Even with the differences in some models, the study concluded that the template models provided a process that reduced differences in user related errors and maintained a level of consistency between multiple users. Both users indicated that they thought the template modelling style was valuable because it meant there were considerable time savings when modelling multiple buildings (due to fewer variables needing to be input). The standardised modelling method used in the template models also increased the consistency between different modellers compared to the detailed models (Cory, Gates, and Donn 2011). Also, using the template modelling procedure was found to reduce the number of modelling errors throughout model creation (refer to Section 7.5.2a).

Quality Assurance tests were also performed to test the simplified nature of the template modelling technique (Section 7.2.4). Further development of the template models included the investigation of how much input detail was needed to produce reliable/calibrated results (including a sensitivity analysis to understand the influence of particular modelling parameters) (A Gates, Cory, and Donn 2012), and the creation of complex HVAC systems to best match common New Zealand systems (A Gates 2013). The last step was to compare the calibration of a template model against a detailed building model to assess the accuracy of the template modelling method (Section 7.5).

\subsubsection{Limitations of template models}

The limitation of using the template modelling method was that the outcomes did not provide detail in terms of specific spaces within the building. This primarily relates to the conditioning and operation of spaces/rooms (this issue was expanded on in Gates, Cory, and Donn (2012)). For this reason, the models were not able to identify individually good or poor performing spaces within the building. This also related to rooms that were operated independently, such as energy intensive server rooms.

The main limitations of the template modelling method included:

- All zones were operated and controlled equally;

- Equipment load breakdowns per room were not available (total loads monitored);

- Inability to match individual room temperatures.

These limitations also arose due to the building geometry's simplified nature (built forms were simplified representations of building geometry: Section 7.2.1a). In particular: 
- The predetermined zoning that did not match a particular building's space/room layout prevented the analysis of any specific building rooms;

- Building loads were entered as an average load spread across all modelled building floor area (Because of this, the models do not report on overheating in intensive zones, such as a large number of computers in server room);

- Building load pattern of use schedules were entered as an average, and the different load types for all zones were assigned with the same load schedule; and

- The building HVAC properties, such as heating and cooling set points, were the same in all thermal zones.

Although there were significant advantages to using the template modelling method, the limitations need to be noted. The limitations of the models have been explained to provide a clear understanding of what the models could not be used for. Although labelled as limitations, they did not have a detrimental effect on the calculation of the energy performance in this study (refer to Section 7.5.1).

The limitations do not allow for building space level amount of differentiated information, but it was not a limitation in the accuracy of the data produced. The use of real data collected on each BEES building enabled the models to be adequately calibrated to ensure accuracy (refer to Section 7.5.1). The real data pertained to the building attributes; such as the building pattern of use schedules, building load densities and fuel consumption.

\subsubsection{Quality assurance tests of template model simplifications}

A number of the building model simplifications were tested as a measure of QA. The tests highlighted the impact that the simplifications can have on the energy results of a building. It is worth noting that the tests were of a relatively simple nature and were presented only to be an indication that the simplifications do not alter energy results greatly. The proposed simplifications should therefore be assessed on a project by project basis as they can impact on the accuracy of results. There are a range of these simplifications made in the template modelling method, but they make a small difference when compared to calibrating a simulation to real energy use when compared to all of the other factors in the model (such as heating and cooling set points and the amount of installed lighting or equipment).

Figure 7-3 displays the standardised building model that was used to carry out the QA tests. It was a simple office building built from one of the BEES template models (BRANZ Ltd 2013b) made up of four perimeter thermal zones and one core thermal zone. The building had $1000 \mathrm{~m}^{2}$ of floor area, and was $31.6 \mathrm{~m}$ in length and width, and $3 \mathrm{~m}$ in height. The template had New Zealand typical values assigned for the zone loads, patterns of use, constructions and HVAC system based on the BEES data for a typical office building of that size (Cory, Donn, and Pollard 2014). The QA tests were carried out using the Wellington, New Zealand, Typical Meteorological Year (TMY) EnergyPlus weather file (U.S. Department of Energy 2014b).

Page $\mid 142$ 


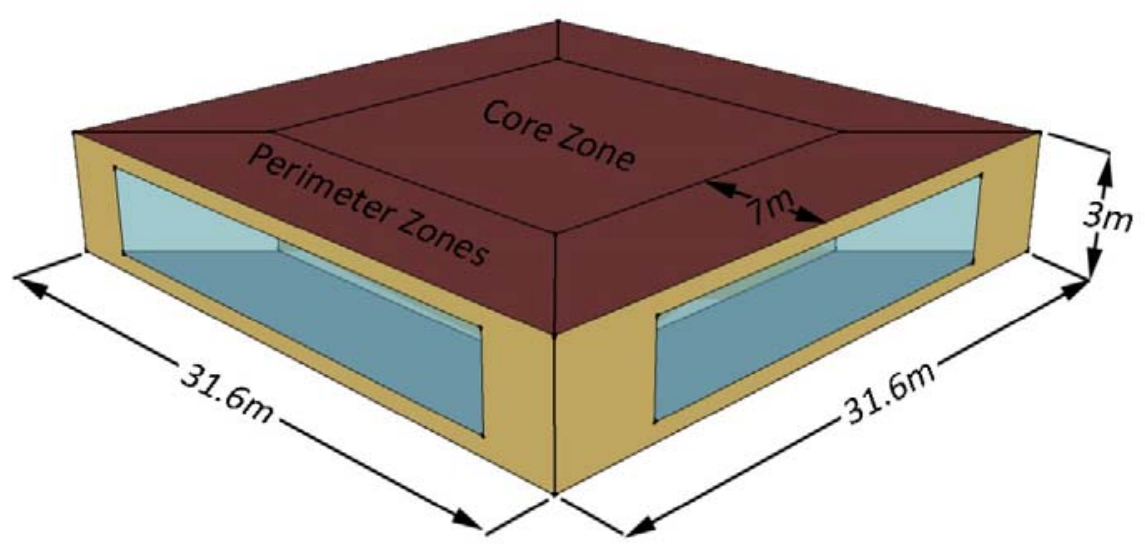

Figure 7-3 : Standardised base case model for the purposes of the QA tests.

The QA tests assessed the impact of using the modelling simplifications in a building with and without electric light dimming controls. Electric light dimming controls use a light sensor to measure the light level in a space and then adjust the dimming ballast in the electric lights to maintain the desired level of illumination (Gregg D. Ander 2013b). The amount of electric light output is therefore lowered as a function of the amount of natural light present in a space (ASHRAE 2006; Gregg D. Ander 2013b). This was tested to see the simplification's impact on both heating and cooling, and the lighting energy consumption and as such, the test was carried out using two sets of the standardised building models. The first set of models had no electric light dimming while the second did, with light controls placed $2.9 \mathrm{~m}$ away from the external wall (Choi, Song, and Kim 2005). The tests were performed for a single storey building because the higher ratio of roof and floor area to wall and glazing area meant any changes in energy consumption would be greater than in a multi-storey building model. Appendix 14.5 presents the full list of model assumptions.

\subsection{4a Energy difference in deep and narrow plan}

The template modelling method proposes the use of a square building footprint matched to a building's footprint area. The technique was derived from the theory introduced by Steadman et al. (2000). Steadman et al. (2000) suggested that if an energy model matched a building's footprint in a square form, there was no difference in the quantity of building surface areas (floor, walls, and roof) compared to a model with a different floor plate shape and hence, the thermal calculations that were performed using the building's surface areas were not hindered greatly. Steadman et al. (2000) also found that only a small percentage of a building stock is not rectangular in shape. This means that at a building stock level, the representation of odd shaped building footprints is not of great concern. The issue with not representing different floor plate shapes is that narrow shaped buildings are not modelled. A test was performed that highlighted the differences between two models of the same building footprint area, but with one built using a square footprint, which represents a deep plan (Figure 7-3), and the other built with a rectangular footprint, which represents a narrow plan (Figure 7-4). The reason why modelling a square footprint building is attractive is that it reduces the time needed to adapt a template model 
to match the size of a real building, with only the scale of the building requiring alteration, not the shape.

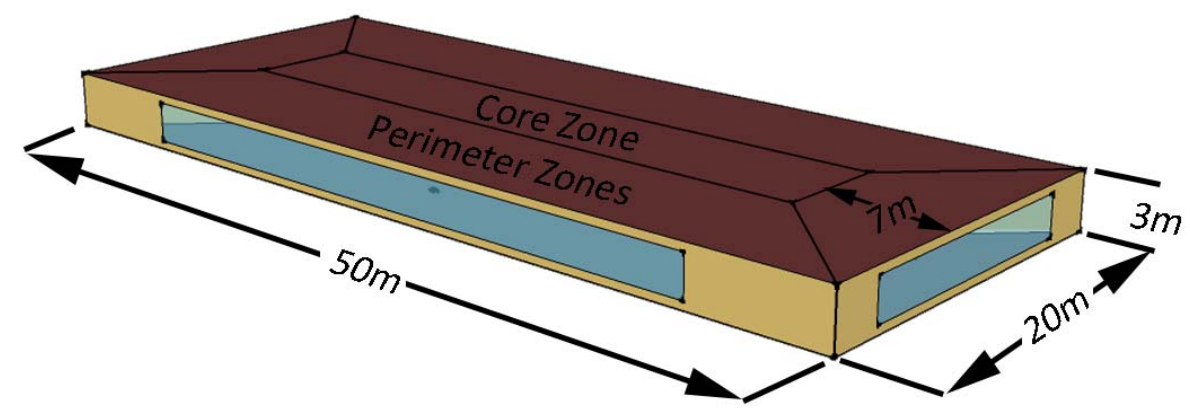

Figure 7-4 : Rectangular shape floor plate to represent a narrow planned building.

\section{Orientated in the Both:}

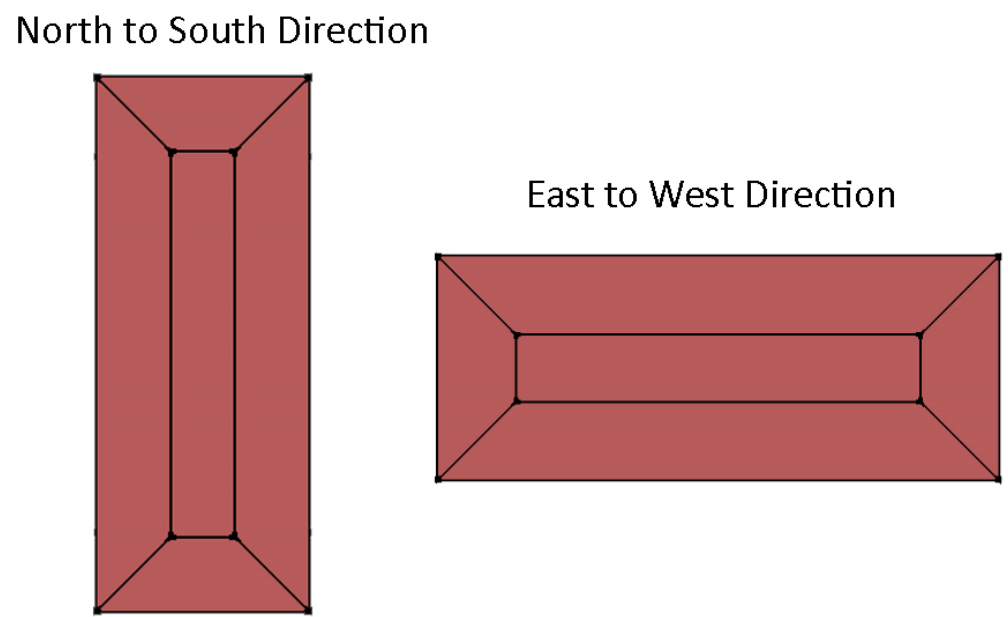

Figure 7-5 : Narrow plan floor plate orientated in two directions.

To complete the test, the standardised model (Figure 7-3) was altered to represent a rectangular building footprint (Figure 7-4). The rectangular building floor plate had the same floor area as the square floor plate (or $1000 \mathrm{~m}^{2}$ with a length of $50 \mathrm{~m}$, and a width of $20 \mathrm{~m}$ and a height of $3 \mathrm{~m}$ ). The rectangular floor plate was orientated in two directions, east to west, and north to south (Figure 7-5). The two orientations were tested to highlight any differences in energy consumption that can occur from differently orientated building shapes. Figure 7-5 displays the altered standardised model to match the same footprint area, but in a rectangular floor plate shape and with the two tested orientations. 
Table 7-1 displays the energy consumption differences of modelling different building floor plates in two directions. Cells were coloured red if the energy use differences were over \pm 5 percent.

Table 7-1 : Energy consumption differences of modelling a deep and narrow floor plate in two directions.

\begin{tabular}{l} 
Difference between Square and Rectangle Floor plate shape orientated in East to West \\
Direction \\
\hline
\end{tabular}

Results indicate that having a different floor plate shape simulated a difference in energy which was less than 5 percent of the total energy consumption, regardless of whether there was light control installed. However, the energy end-uses varied in different magnitudes depending on whether there was a light dimming control. Lower energy end-use differences were seen in the east to west direction compared to the north to south direction. The energy end-uses differed by \pm 10 percent in the east to west direction and \pm 17 percent in the north to south direction, highlighting that the end-use energy consumption differed considerably. However, the total energy consumption did not differ significantly from the calibration limit of $+/-5$ percent (refer to Section 7.3). This demonstrated that modelling a square floor plate shape instead of a different floor plate shape would provide suitably accurate total energy consumption while speeding up the modelling process. However, it should be noted that larger energy differences were seen at an individual energy end use level.

\subsection{4b Centred WWR}

The template modelling method proposes using a single window per thermal zone that is sized to match the WWR of a building on each facade. The technique was derived from assessing the US DOE reference commercial buildings which utilise this technique (P Torcellini et al. 2008; M. Deru et al. 2011). 
Figure 7-6 displays images of a number of the US DOE reference buildings using the single WWR technique.
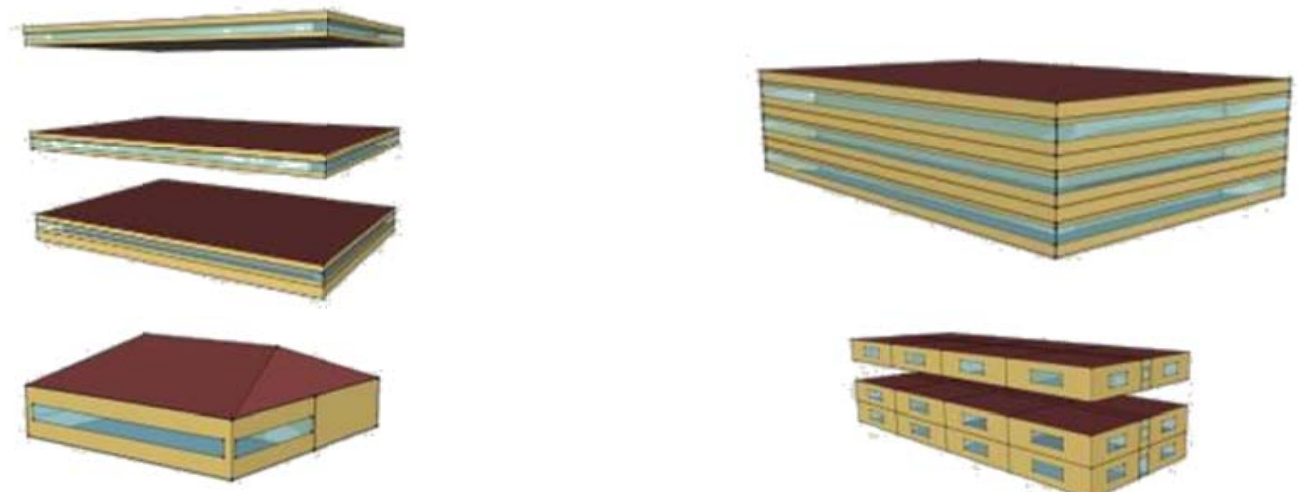

Figure 7-6 : US DOE energy models using a single WWR to represent a building's windows.

A test was performed that assessed the impact of modelling a single placed window matching the same WWR on energy consumption (Figure 7-7) compared to modelling individually placed windows of different sizes and positions (Figure 7-8). The reason for testing the methods was to highlight whether the single WWR could adequately represent the energy consumption compared to a model with the correct size and positioning of windows. The benefit of using the single WWR window was that it reduced the modelling time. This time reduction was generated from not needing to model the correct size of every individual window and placement on each facade. For example, a building may have five individual windows on one façade which are all slightly different in size and in different positions on the facade. These windows will all have different geometrical coordinates that need to be calculated to ensure they are correctly modelled on the façade. This increases the modelling time when compared to modelling a single window of the same WWR placed in the centre of the façade that only needs one set of geometrical coordinates.

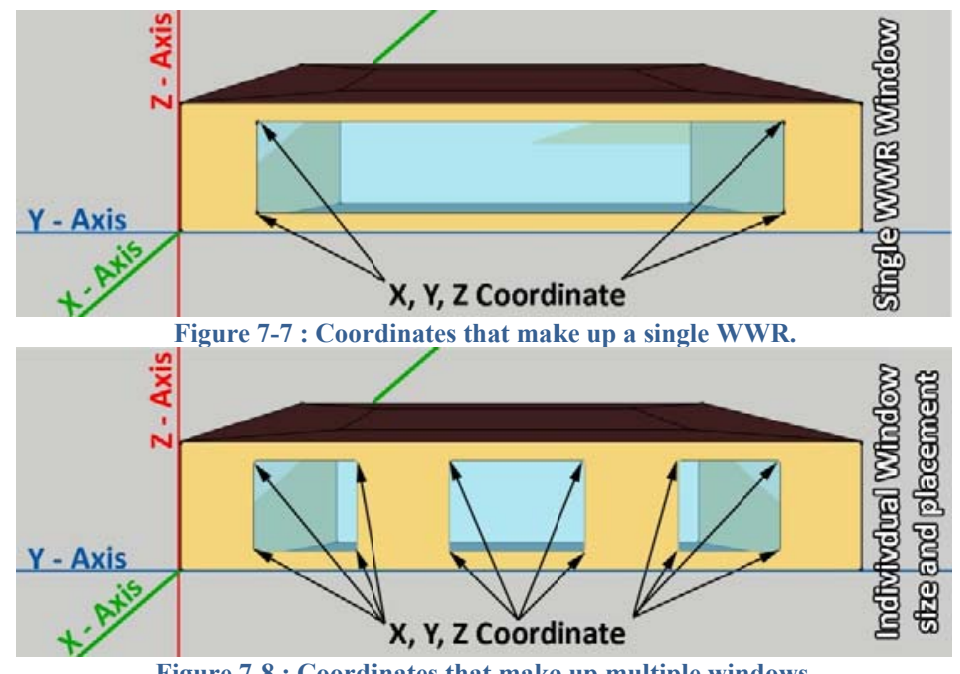

Page | 146 
To complete the test, the standardised model (Figure 7-3) was adapted to include either the single WWR modelling technique, or the individual window size and placement technique. Figure 7-9 displays the individual window and single WWR window modelling techniques tested. As can be seen, the two models consisted of the same WWR but with different window geometry configurations. There were either three or four smaller windows on one model, and one larger WWR window on the other.

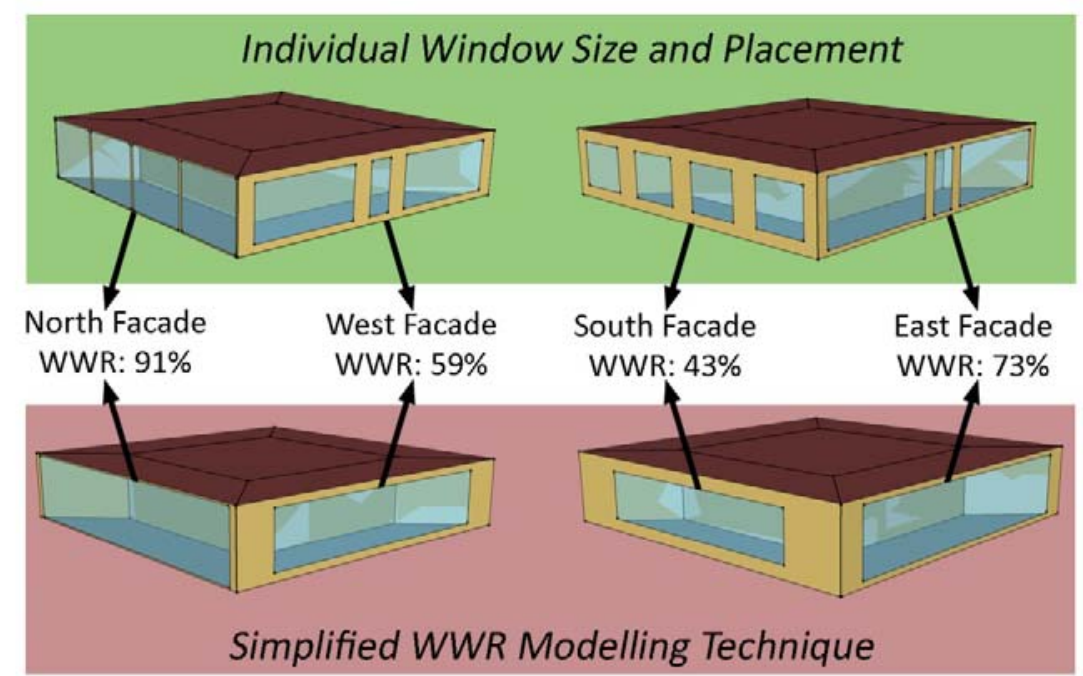

Figure 7-9 : Simplified WWR modelling technique versus Individual Window size and positioning.

Table 7-2 displays the energy consumption differences of modelling individual windows when compared to modelling a single WWR window.

Table 7-2 : Percentage difference between individual window size and placement and single WWR modelling methods.

\begin{tabular}{|l|r|r|r|r|r|r|}
\hline & \multicolumn{1}{|c|}{ Total } & \multicolumn{1}{c|}{ Cooling } & \multicolumn{1}{l|}{ Heating } & Lighting & Equipment & \multicolumn{1}{l|}{ Fans } \\
\hline $\begin{array}{l}\text { Without Light } \\
\text { Dimming }\end{array}$ & $0.2 \%$ & $0.7 \%$ & $0.6 \%$ & $0.0 \%$ & $0.0 \%$ & $0.7 \%$ \\
\hline With Light Dimming & $0.3 \%$ & $0.8 \%$ & $-0.3 \%$ & $1.2 \%$ & $0.0 \%$ & $0.8 \%$ \\
\hline
\end{tabular}

Results indicated that by placing windows individually versus placing them as a single WWR window simulates a difference in energy which was less than 1 percent in total energy consumption, regardless of whether there were light controls installed or not. All energy enduses had differences within \pm 1 percent, except for lighting. Lighting was impacted the most by the two window modelling methods, but only when there was an electric light dimming control modelled. However, it was only slightly over one percent different (1.2 percent). These differences in energy consumption were negligible when compared to the specified calibration limit of $+/ 5$ percent (refer to Section 7.3), and proved that modelling a single WWR window would be suitably accurate and aided in speeding up the modelling process. 
As shown from the results of the two QA tests of assessing the rectangular floor plate shape and centred WWR window placement, the impact that the template modelling simplifications have on total building energy consumption was small. It suggests that if the installed lighting, equipment and HVAC system are correct, the simplifications will not hinder the matching of simulated energy consumption to real building energy consumption. This is also expanded on in Section 7.5 which compares calibrated template models (with their simplifications) to models that match the real buildings' geometry as closely as possible.

\subsection{Approaches to calibrating energy models}

A unique feature of this thesis was that the analysis was based on real buildings. The real buildings refer to the 48 BEES case study buildings used in the stock aggregation procedure (Chapter 6), with energy models matched to the real performance data of the building. A calibration process was used to ensure the energy model matched the real building and its energy performance. The ultimate aim of calibrating the models was to attain a simulation match of \pm 5 percent (MBE, Mean Bias Error) monthly or \pm 10 percent (MBE) hourly compared to the real energy consumption, as recommended in ASHRAE Guideline 14:2002 (Haberl, Culp, and Claridge 2005). However, Nexant Inc (2013), suggested that "specific calibration goals should be set for each project based on the appropriate level of effort". Therefore, if a model is very difficult to calibrate to the recommended level, the acceptable tolerance of the MBE should be increased based on the known level of error in the data used to construct the model (Nexant Inc 2008).

\subsubsection{Calibration and its importance}

The calibration of an energy simulation model consisted of matching the simulated energy consumption results to the building's real energy consumption, using hourly monitored data and/or monthly metered bills. The measured performance data is required to be matched to the simulated data when calibration is complete. "It must include the same physical factors (e.g. thermal load, energy consumption, whole building or system-based, hourly, daily, or monthly) over the same period of time" (Bensouda 2004, p. 7). Two calibration metrics exist to assist in determining whether a simulation is calibrated:

- "MBE - Mean Bias Error. The MBE indicates how well the energy consumption is calculated by the model as compared to the measured data. Positive values indicate that the model over calculates actual values; negative values indicate that the model under calculates actual values. However, it is subject to cancellation errors, where the combination of positive and negative values serves to reduce MBE. To account for cancellation errors, the CV(RSME) is also needed" (Nexant Inc 2008, p.4-20). MBE was calculated using Equation 5: 


$$
\begin{gathered}
M B E=\frac{\sum_{i=1}^{N}\left(\hat{Y}_{i}-Y_{i}\right)}{N} \\
M B E(\%)=\frac{M B E}{\bar{E}}
\end{gathered}
$$

Where $N$ is the number of samples (data points), $i$ (data interval) goes from the first data point (January) to the last (December). $\hat{Y}$ is the simulated energy use value and $Y$ is the actual value, $\hat{Y}$ minus $Y$ for a certain month is the residual for that month (ASHRAE GUIDE 14-2002, p. 20). $\bar{E}$ is the value of the actual energy use.

- "CV(RMSE) - Coefficient of Variation of the Root Mean Squared Error. This value indicates the overall uncertainty in the prediction of whole-building energy usage. The lower the CV(RMSE), the better the calibration. This value is always positive"(Nexant Inc 2008, p.4-20). CV(RMSE is calculated using Equation 6:

$$
\begin{gathered}
\text { Equation 6: } \\
R M S E=\sqrt{\frac{\sum_{i=1}^{N}\left(\hat{Y}_{i}-Y_{i}\right)^{2}}{N}} \\
C V(R M S E)=\frac{R M S E}{\bar{Y}} \\
C V(R M S E)(\%)=\frac{C V(R M S E)}{\bar{E}}
\end{gathered}
$$

Where $\mathrm{N}$ is the number of samples, $i$ (data interval) goes from the first to the last data point. $\hat{Y}$ is the simulated energy use value and $Y$ is the actual value. $\bar{Y}$ is the mean value of the actual energy use. Dividing the RMSE with the mean of actual use calculates the CV(RMSE) (ASHRAE 2002). $\bar{E}$ is the value of the actual energy use. 
Figure 7-10 illustrates how the MBE metric was performed using a diagrammatical wave of energy difference between a simulation and real measured data. The difference varies from being a positive value (over calculating energy) to a negative value (under calculating energy). When the differences are summed up, the negative values are subtracted from the positive values. It highlights the cancellation errors occurring with the MBE metric.

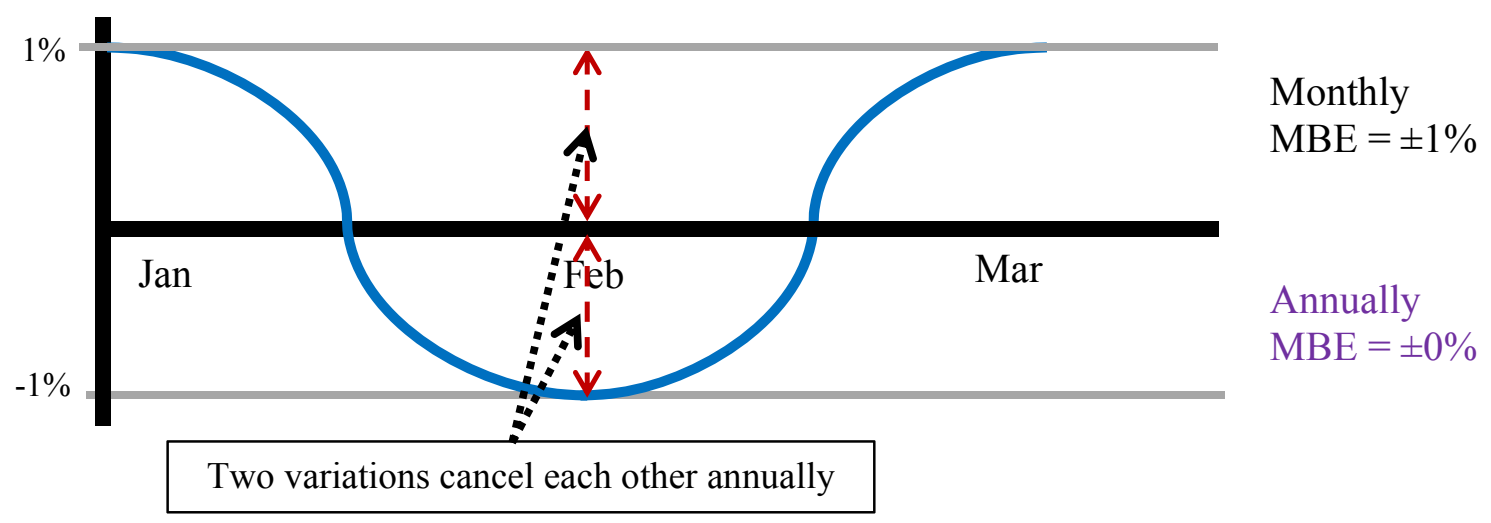

Figure 7-10 : Diagram of MBE metric.

Figure 7-11 illustrates how the CV(RMSE) metric is performed using the same diagrammatical wave of energy use difference. All differences are squared to make them positive values. Therefore, the maximum difference, or uncertainty, in energy use can be identified using the CV(RMSE) equation and no cancellation errors occur.

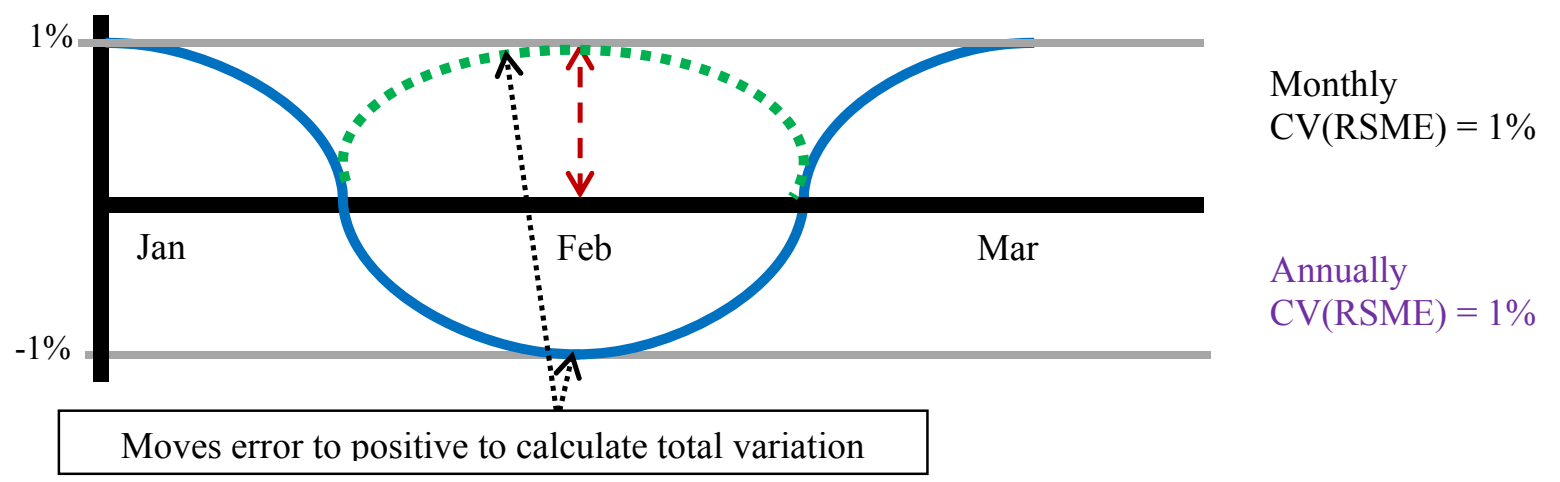

Figure 7-11 : Diagram of CV(RMSE) metric.

The recommended acceptable calibration tolerance values for each approach are displayed in Table 7-3. These values are provided by ASHRAE Guideline 14:2002. However, while it is unknown if the values for acceptable tolerance of a calibrated model were developed through experimentation, they are sensible values when looking at the impact that various Energy Conservation Measures (ECMs) can have on the energy consumption in buildings. For example,

Page $\mid 150$ 
"increasing the external wall insulation by 60 percent will reduce the total building's energy consumption by 1.5 percent for high-rise buildings and 1.4 percent for low-rise buildings"(Kim 2010, p.79). Because of this small change in total energy consumption as a result of testing the ECM, the results can be lost within the differences of a non-calibrated model. The difference refers to the energy consumption difference between the simulated and the real building performance. To avoid this situation a calibrated model must have a low margin of error in comparison to reality.

Table 7-3: Acceptable Calibration Tolerances (ASHRAE 2002).

\begin{tabular}{|c|c|c|}
\hline Calibration Type & Calibration Metric & $\begin{array}{c}\text { Acceptable Calibration } \\
\text { Tolerance* }\end{array}$ \\
\hline Monthly & MBE $_{\text {Month }}$ & $\pm 5 \%$ \\
& CV(RMSE $\left._{\text {month }}\right)$ & $15 \%$ \\
\hline Hourly & MBE $_{M_{\text {Mnth }}}$ & $\pm 10 \%$ \\
& CV(RMSE $\left._{\text {month }}\right)$ & $30 \%$ \\
\hline \multicolumn{2}{|c|}{ *Lower values indicate better calibration } \\
\hline
\end{tabular}

In support of this acceptable tolerance for a calibrated model, Bensouda (2004) states that "[modelling] efforts have been quite successful in achieving simulated results that agreed with the measured consumption, typically to less than 5 percent on an annual basis. Agreement within 5 to 10 percent has often been achieved on a monthly basis, and sometimes on a daily basis" (Bensouda 2004, p. 5).

However as previously stated, an acceptable calibration tolerance can be decided on a project by project basis: "Specific calibration goals should be set for each project based on the appropriate level of effort" (Nexant Inc 2008, p.4-20). A suitable calibration tolerance for the purpose of this study is discussed in Sections 7.4 and 7.5.

Matching simulation results to real data is especially important when modelling existing buildings. This is due to differences between simulation results and measured consumption being able to reach 100 percent (Norford et al. 1994), or even 150\% (Ahmad 2003). "These errors are not thought to be due to errors in the simulation software itself or to undescribed input parameters but to errors in the input assumptions for a particular building, due to misunderstanding of the building's design or the differences between design and as-built conditions or operations"(Bensouda 2004, p.4). Software errors are minimised as they are validated using the BESTEST method (R. H. Henninger, Witte, and Crawley 2004). 


\subsection{Hybrid method for calibrating EnergyPlus models of existing buildings}

Figure 7-12 displays a graphical representation of the method for calibrating energy models in this study.

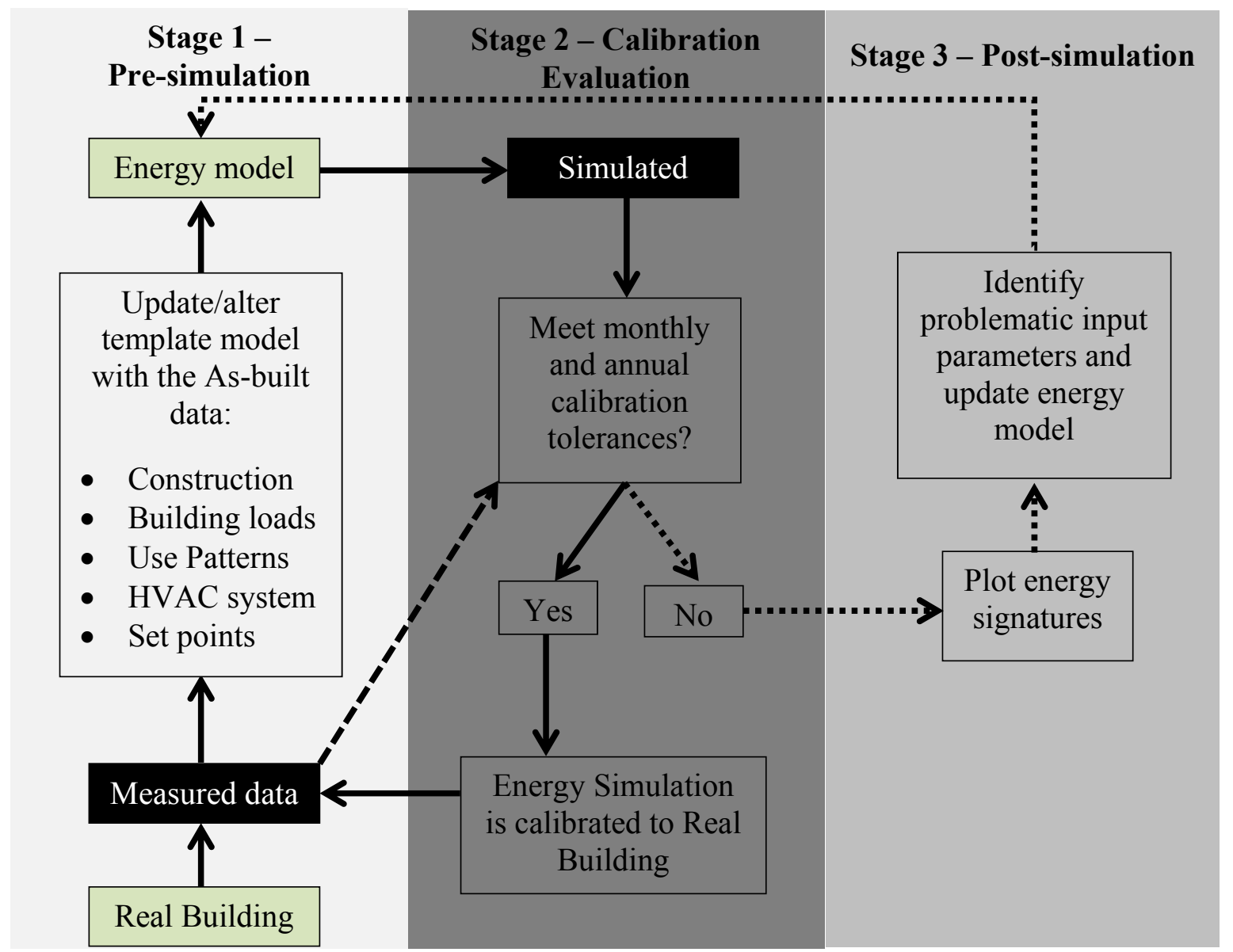

Figure 7-12 : Diagram of the developed energy model calibration procedure.

This thesis used a combination of two calibration methods to create a calibration tool that matched the 48 energy models to their 48 BEES case study building counterparts used in the Stock Aggregation process. There was only approximately two weeks of hourly data available for each of the 48 BEES case study buildings, the calibration focused specifically on that time period. A challenge was to produce a calibrated model for all months of the year based on this short monitored time period of how the building's lighting, equipment and HVAC loads were supplied and operated. For this reason, the two methods were combined into one systematic process that 1) reduced the user input in identifying the reasons why the building simulation did not match the real building's energy performance, and 2) enabled both an hourly and monthly 
calibration check. The method firstly used genuine as-built information and measured data to input correct parameters for the initial simulation model so that it closely represented the real operation of the building (Raftery, Keane, and Costa 2009). It secondly used "calibration and characteristic signatures, which characterise the difference between measured and simulated performance and identifies the likely input parameters that need to be corrected for a calibrated model" (Bensouda 2004, p. 1).

The developed method calibrates an energy model in three stages:

Stage 1 - Pre-simulation: Pre-simulation was undertaken by using the information gathered from a site survey of the real BEES case study building. It detailed the information needed to create a calibrated energy calculation model prior to running any simulation calculations. It "involves a process of using genuine as-built information, surveys, and measured data to update the input parameters of the initial simulation model so that it closely represents the real operation of the building" (Raftery, Keane, and Costa 2009, p.1199). The survey information was used to choose and update a BEES template model to match how the building was constructed and operated in reality. The as-built information used to construct the initial model (in the case of this study, an updated BEES template model) detailed the correct constructions, occupancy use patterns, building loads and their patterns of use, HVAC system and its correct attributes, and heating and cooling set points. Once the model was updated, it could then be simulated.

Stage 2 - Calibration evaluation: Once the model was simulated it was evaluated to assess whether it was calibrated. The calibration evaluation involved assessing whether the simulated energy consumption matched the real building energy consumption within specified tolerances. The specified tolerances were made up of set monthly and/or annual MBE and/or CV(RMSE) metric limits (Section 7.3). If the model met the required monthly and annual tolerances, it was calibrated. If it did not meet the required monthly and annual tolerances, the model was not calibrated and underwent post-simulation calibration.

Stage 3 - Post-simulation: The non-calibrated model was used to plot energy signatures. Energy signatures are graphical representations of the differences in heating and cooling energy consumption expressed as a ratio to the maximum baseline heating and cooling energy consumption and plotted as a function of the ambient temperature (Wei, Liu, and Claridge 1998; Bensouda 2004). These energy signatures were used to identify any incorrect modelling input values and aid in determining more appropriate values to use (for example refer to Section 7.4.3). This method was developed over a number of years and is a combination of various calibration methods. Three independent calibration techniques produced by Bronson et al. (1992), Manke and Hittle (1996), and Thamilseran (1999) vary in method, but were combined to produce a working method for the final post simulation technique. The final post simulation technique, produced by Wei, Liu, and Claridge (1998) and furthered by Bensouda (2004), combined the first three methods which identify potential 
input parameters that are not correctly modelled. This method was used after a model performed the initial energy simulation calculations and was evaluated not to be calibrated.

Calibrating a model, post-simulation, included comparing each BEES building's heating and cooling calibration signatures (Section 7.4.3a) to pairs of heating and cooling characteristic signatures (Section 7.4.3b). The heating and cooling characteristics helped to identify the incorrect model input parameter(s) that needed to be changed/updated to achieve a matching simulation (Bensouda 2004). The benefit of using the energy signatures method was it meant the calibration was not based on the modeller's opinions or experiences. Instead it was based on a scientific process for identifying the incorrect input parameters.

The use of the calibration signatures was only able to be applied to the buildings with installed space conditioning systems. In the case of buildings that did not have space conditioning, the post-simulation calibration only involved the alteration of internal loads (such as lighting and equipment) that had been under or overestimated. Once the incorrect model input parameter was identified, it was updated in the non-calibrated model, resimulated and underwent the Stage 2 - Calibration Evaluation again. The process was repeated if the model did not meet the calibration tolerances. If the model did meet the tolerances, it was considered calibrated.

\subsubsection{Stage 1 - Pre-simulation: As built information}

The first stage in the calibration process used in the modelling of the 48 BEES case study buildings was to obtain as-built data of each building and then to update the EnergyPlus template models to match this as closely as possible.

\subsection{1a Building geometry/Thermal zones}

As detailed by Raftery, Keane, and Costa (2009), the pre-simulation calibration process insists on the need to match thermal zones to the building's actual floor plan. However, the template modelling process developed during the BEES project did not match the thermal zoning of individual spaces within the building. Hence, it was not performed.

\subsection{1b Materials and constructions}

As-built material and construction data is also required by the Raftery, Keane, and Costa (2009) calibration process. Obtaining such data for already built buildings can be difficult. The method used to identify the materials and construction for each of the 48 case study buildings was through observation. The actual material properties data (thermal resistance, specific heat, conductivity, and density) could not be measured; therefore a database of New Zealand material properties was used. Each EnergyPlus template model had a choice of predefined materials which were compiled to match commonly used construction materials within New Zealand commercial buildings. As a result, the likely construction applied to each building model was inferred from onsite observations provided by the BEES team. 


\subsection{1c Schedules of operation}

Schedules of use for the lighting, plug-loads, hot water, miscellaneous equipment, and HVAC systems were calculated using collected data on occupant usage and the monitoring of the operations in the buildings. These ensured the operation of the various building systems was modelled more accurately. The lighting, plug-loads, domestic hot water, and miscellaneous equipment were input as an average weekday and weekend load. The average hourly loads for both weekdays and weekend days were calculated using the energy end-use monitoring data provided by the BEES project.

\subsection{1d Building loads}

The building loads, such as lighting and other equipment, were provided by the monitored energy data measured in each case study building. The monitored data ensured that correct asbuilt internal loads were modelled. The lighting, plug-loads, domestic hot water, and miscellaneous equipment were input as the maximum building energy end-use load. The maximum loads were calculated from the hourly measurements of each end-use during the monitoring period undertaken in the BEES project.

\subsection{1e Heating, Ventilation and Air-conditioning}

The HVAC system energy consumption was expected to have a large impact on the overall calculated energy performance (U.S. Energy Information Administration 2013a). As this building aspect had the least information obtained in the BEES study, it further complicated the modelling. Observations made in the BEES project provided the type of HVAC system present in each building. However, the precise HVAC appliances installed in the building were not obtained. Assumptions about appliance efficiencies were taken from a study performed by Gates (2013), which surveyed New Zealand HVAC experts to identify what types of HVAC systems are typically installed in standard, non-energy efficient, and energy efficient New Zealand commercial buildings. The survey also asked what the associated efficiency and system properties were for the various HVAC systems. The above mentioned details were developed into a set of EnergyPlus HVAC template systems that were able to be applied to each case study building.

\subsection{1f Time of use weather files}

The final step in the pre-simulation process was to create an EnergyPlus weather file which matched the location and timeframe for which the building performance data was collected. Each case study building was located in different areas, and metered and monitored data was collected at different time periods. As the weather files had been created for individual years and locations, each building was matched to the weather file based on time of monitoring and geographic location. The weather data was obtained from the many NIWA weather stations located around New Zealand (NIWA 2013; NIWA 2011) and the process developed by (Gates 2011) was 
followed (process in Appendix 14.6). ${ }^{4}$ The closest weather station was used to create the time of use weather files.

\subsubsection{Stage 2 - Calibration evaluation}

Unlike the work performed by Bensouda (2004), which solely used calibration signatures based on hourly measurements to match the simulation to reality, the calibration method performed in this study also used monthly energy consumption data to further clarify any incorrect input parameters. Monthly simulated energy consumption was compared to the real monthly energy consumption collected from each building's monthly metered energy bills. The comparison was used to determine whether the model matched reality. Additionally, the monthly trends helped to clarify the amplitude of change that needed to be made to any problematic input parameter. It also helped to identify problems with monthly schedules of internal equipment, and heating and cooling systems.

A calibration tolerance decision needed to be made regarding when the simulation was considered to be at an acceptable level of calibration. As hourly calibration analysis could only be performed for a two week period out of the year (due to monitored data availability), the calibration was assessed at a monthly interval. Furthermore, as the Stock Aggregation estimated annual energy consumption of the building stock, an annual calibration tolerance was also set, and for that reason the hourly data was used strictly to identify potential problematic input parameters, but not as an indicator of whether the simulation was calibrated. A simulation was therefore calibrated when it reached a match of \pm 5 percent MBE of the monthly energy consumption in kWh (ASHRAE 2002). However, as Nexant Inc (2013) suggests, "Specific calibration goals should be set for each project based on the appropriate level of effort" and known level of data error, this study made an allowance for not all months being within \pm 5 percent MBE. The aim was to have no more than three months outside the \pm 5 percent limit (refer to Section 7.4.3, critique 2 and response 2 for more information). However, a heuristic process was undertaken by the modeller as to whether this was achievable given the building data provided for the building. The systematic process for making the judgement for whether to stop or not was based on whether:

- $\quad$ most (8-9) months were calibrated;

- the seasonal patterns in energy consumption throughout the year followed those of the real buildings; and

- the total annual energy difference was no greater than \pm 5 percent Bias Error (BE) (refer to Section 7.5.3 as to reasoning).

It should be noted that the annual BE tolerance of \pm 5 percent was not an MBE figure, but the pure difference in energy consumption between the simulated and real building's energy use. This was due to the Stock Aggregation using the annual energy use in its calculations, with any

\footnotetext{
${ }^{4}$ This data was commissioned by EECA from NIWA (the NZ Government weather research organisation).
}

Page | 156 
difference aggregated up to the whole building stock estimate. If the MBE was assessed, it would not show the true amount that the simulation differs from the real building's energy consumption. The annual tolerance of \pm 5 percent was calculated using Equation 7 :

$$
\begin{gathered}
\text { Equation } 7: \\
\text { Bias Error }(\%)=\left(\hat{Y}_{i}-Y_{i}\right) \div Y
\end{gathered}
$$

$\hat{Y}$ is the simulated annual energy use value and $Y$ is the actual annual energy use value. Results are expressed as the total percentage difference between the simulated energy use and the real energy use (Taylor 1997; Holton 2014).

A more lenient calibration tolerance was required due to the lack of measured data on occupant behaviour and how the building loads were used across the entire year. The lack of data was likely to be one of the main reasons for a model being outside of the calibration limit as it was one aspect that could not be monitored to provide reliable data (other than a two week period during one year).

Figure 7-13 displays an example comparison for energy consumption of a theoretical noncalibrated model and a theoretical calibrated model.

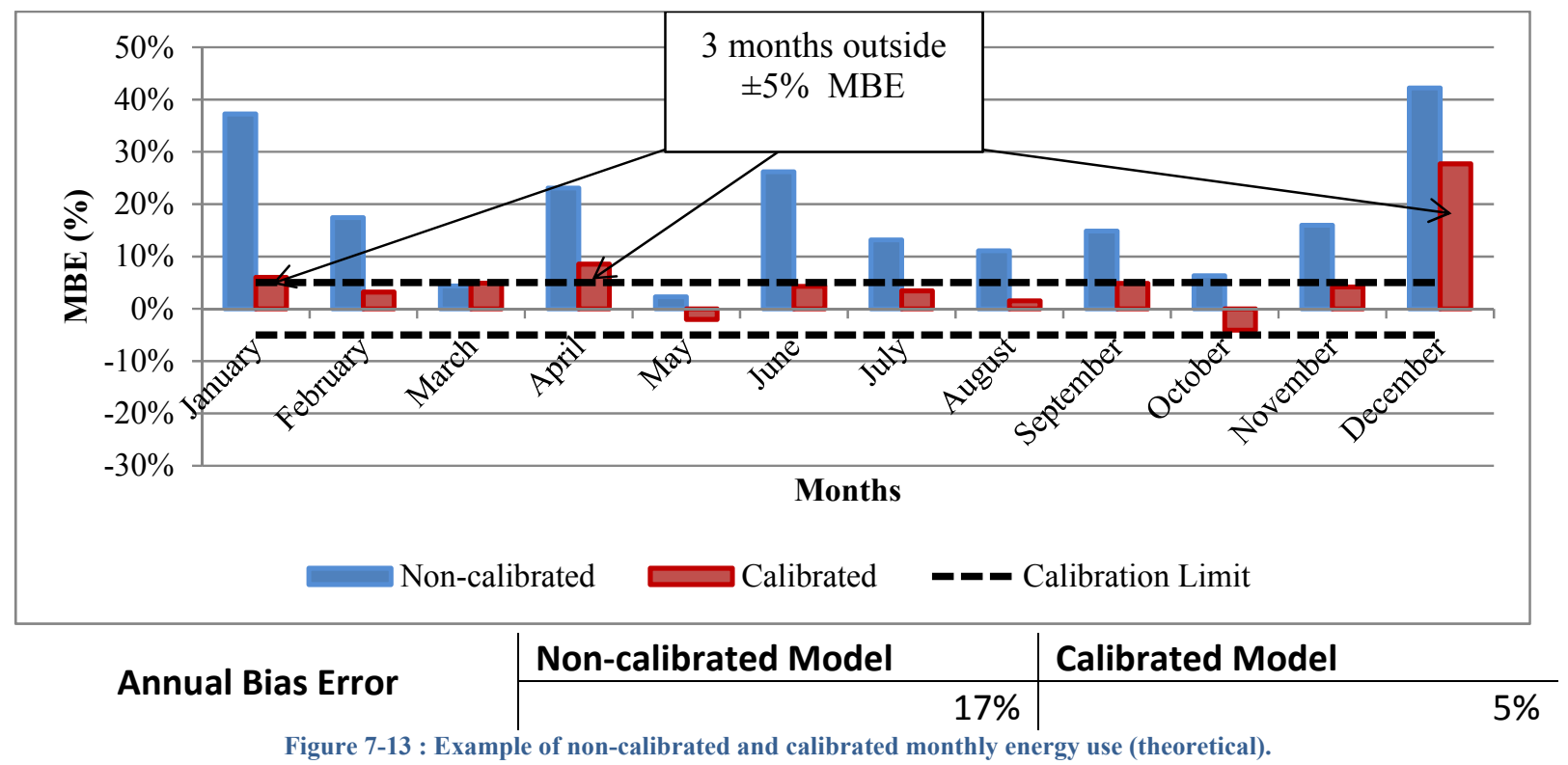

\subsubsection{Stage 3 - Post-simulation: identification of incorrect input values}

The second stage in the calibration process may not be needed for every case study building. By implementing the first stage of calibration, the aim was that some building models may already match their real building's monthly energy consumption to within \pm 5 percent. However, due to the monitored data only being provided for a two week period, it was unlikely that the simulations would match this immediately. In the event of the building models not reaching the desired calibration requirements, a process for identification of which building input(s) were 
likely to be incorrect was undertaken. This process used the "energy signatures" method outlined by Bensouda (2004), and monthly energy bills. Two types of signatures were created. The first was the calibration signature which represented a normalised difference between the heating and cooling energy consumption of the real building and the energy model being calibrated (Section 7.4.3a). The second was the characteristic signature which represented a normalised difference between the heating and cooling energy consumption of the energy model being calibrated and the same energy model, but with a single input parameter iterated (Section 7.4.3b).

Heating and cooling calibration signatures were generated for each case study building using the monitored and simulated heating and cooling energy consumption. The heating and cooling calibration signatures were compared to a library of characteristic signatures which were generated for each case study building's location and HVAC type. Trends of mismatching simulated results were obtained by comparing monthy simulated energy consumption with the real monthly energy bills for each building. The identified monthly trends helped in understanding what the problem input parameter was and to what degree on an annual scale the problem input parameter(s) were created.

Coakley, Raftery, and Keane (2014) reviewed and categorised different energy modelling calibration approaches. They highlighted two critiques of the energy signature method which have been responded to in the proposed procedure in this chapter.

Critique 1 - Firstly, "this type of parameter tuning is typical of the general approach to model calibration, and while it may serve to produce a model which demonstrates sufficient overall accuracy when compared to measured data, it is probably not a good representation of the actual building being analysed. It is also highly dependent on analyst knowledge and skill, data availability, and allowed time-frame."

Response 1 - This thesis author agrees with the critique and this is why 'Stage 1 Pre-simulation: As-built information' was performed. By constructing the model using as-built information, the model represented the building as close as possible before the energy signatures were considered. The energy signatures were only primarily used to tune the HVAC system which was the information of the least reliability from the BEES study. This was not the case in Bensouda (2004) which performed the energy signatures on a variety of building inputs without any apparent recognition of the input information reliability and the likelihood of the changed inputs in relation to the as-built real buildings.

Critique 2 - Secondly, "the satisfaction of hourly ASHRAE calibration criteria is quite difficult, even when high levels of measured data are available. It is also questionable as to whether it is even useful (or appropriate) to fine-tune a model to a very high degree of accuracy when employing generalised model assumptions and typical operation profiles." 
Response 2 - As noted in the previous response, this thesis author agrees with the critique and this is why a high level of calibration was not performed. The models were not calibrated to match at an hourly interval, but were instead captured at monthly and annual intervals. The energy signatures were only used to support the identification of problematic inputs in a systematic way, which did not rely heavily on modeller/analyser opinions. The lower level of calibration also aided in reducing the time-frame needed to calibrate the models.

\subsection{3a Heating, Cooling, and Space Conditioning Calibration Signatures}

The heating and cooling calibration signatures graphically represent the normalised difference between measured and simulated heating and cooling energy consumption as a function of the outdoor air temperature (Bensouda 2004). Each building's heating and cooling calibration signatures were calculated using the real monitored and simulated hourly heating and cooling energy consumptions. The calibration signature values for heating and cooling energy consumption were calculated for each data point using the following equations:

$$
\text { Equation 8: }
$$

$$
\text { Cooling Calibration signature value }=\left(-R^{c} / M^{c}\right) \times 100
$$

$\mathrm{R}^{\mathrm{c}}=$ Cooling residual energy

$\mathrm{M}^{\mathrm{c}}=$ Maximum measured cooling energy

$$
\text { Equation 9: }
$$

Heating Calibration signature value $=\left(-R^{h} / M^{h}\right) \times 100$

$\mathrm{R}^{\mathrm{h}}=$ Heating residual energy

$\mathrm{M}^{\mathrm{h}}=$ Maximum measured heating energy

Equation 10:

Where Residual $=$ Simulated energy consumption - Measured energy consumption

A worked example can be found in Appendix 14.7. 
"Heating and cooling calibration signature values are then plotted versus ambient temperature" (Bensouda 2004, p. 15). Figure 7-14 displays the heating and cooling calibration signatures for an example building. The graphed trends were compared to the trends in the characteristic signature library. The pair of calibration signatures (heating and cooling) were compared to the characteristic signatures for the corresponding climate and HVAC type (Bensouda 2004).
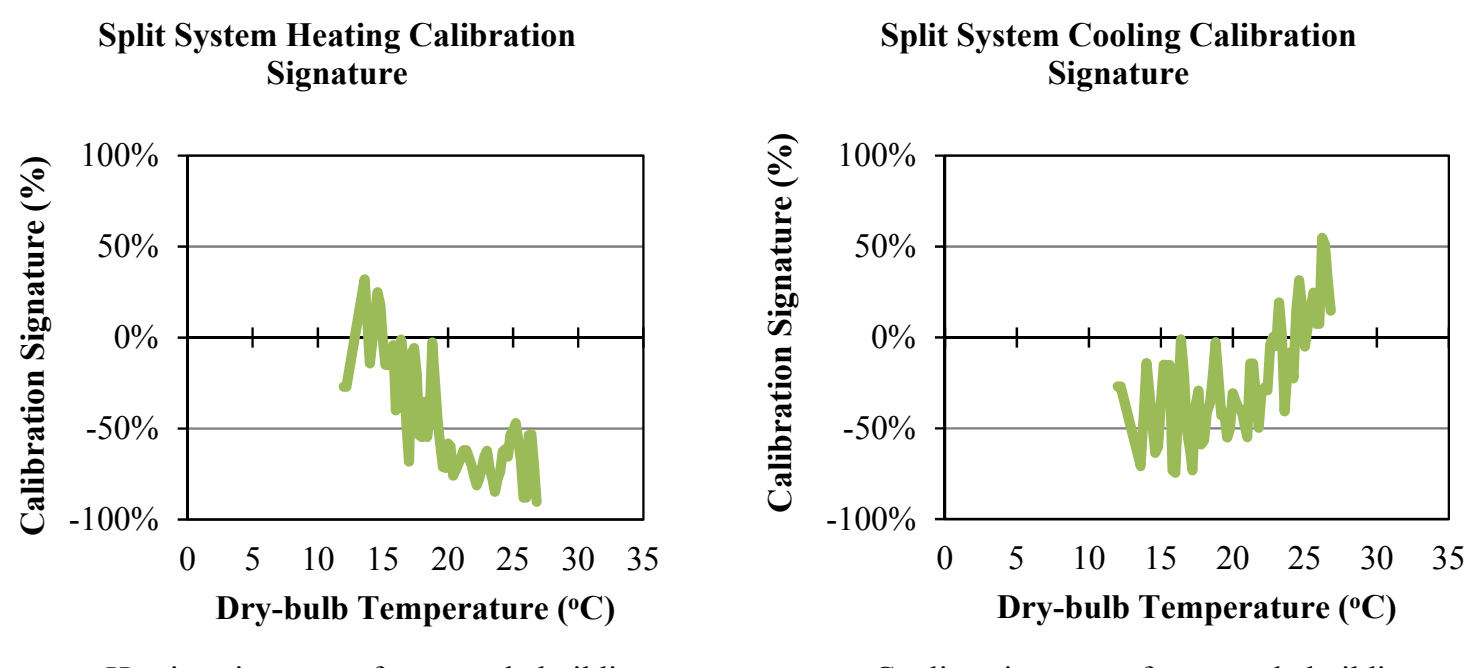

Heating signature of case study building

Cooling signature of case study building

Figure 7-14 : Example individual heating and cooling calibration signatures.

For the purposes of calibrating the 48 BEES case study buildings, a new calibration signature was created - the space conditioning calibration signature (Figure 7-15).

Split System Space Conditioning Calibration Signature

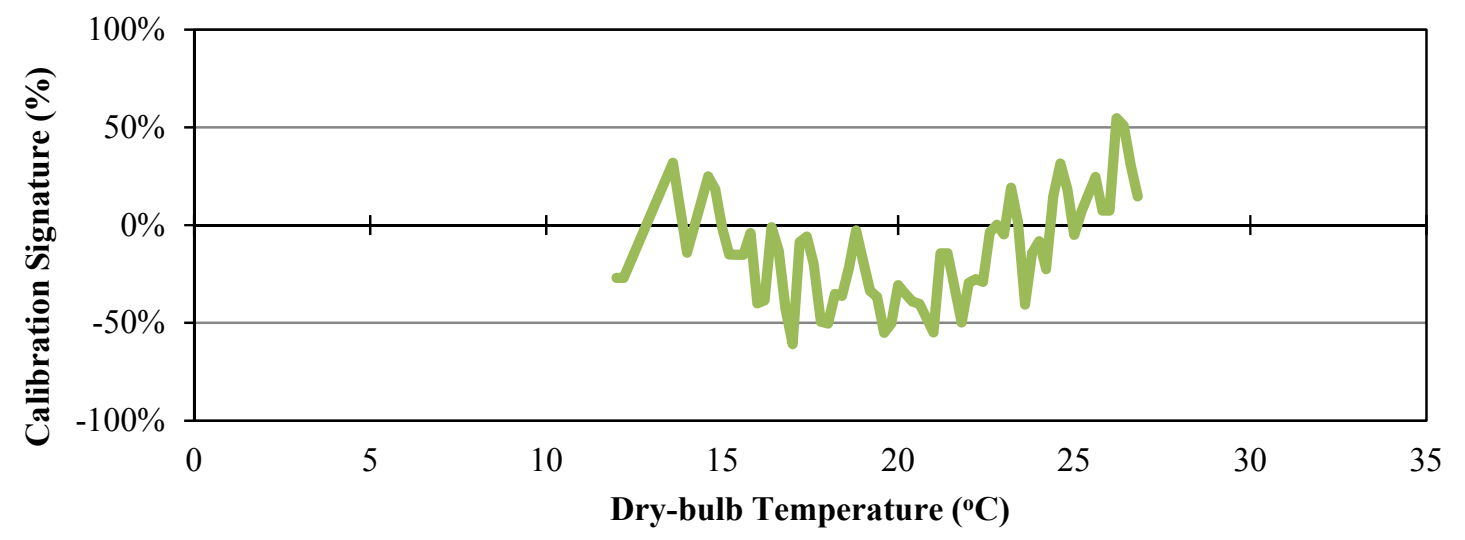

Space conditioning signature of case study building

Figure 7-15 : Example space conditioning calibration signature.

Space conditioning calibration signatures were developed because some of the BEES buildings monitored data did not have their heating and cooling energy consumption monitored separately. This was the case for measured data from heat pumps and air conditioners. For this reason, the

Page | 160 
simulated heating and cooling consumptions were added together to represent the space conditioning energy consumption of the buildings. The space conditioning calibration signature was graphed in the same way as the individual heating and cooling calibration signatures and also formed a graphed trend that was used to identify discrepancies between measured and simulated consumption. The calibration signature values for space conditioning energy consumption were calculated for each data point as follows:

Equation 11:

Space Conditioning Calibration signature value $=\left(\left(-R^{c}+R^{h}\right) /\left(M^{c}+M^{h}\right)\right) \times 100$

$\mathrm{R}^{\mathrm{c}}$ and $\mathrm{R}^{\mathrm{h}}=$ Cooling and Heating residual energy respectively

$\mathrm{M}^{\mathrm{c}}$ and $\mathrm{M}^{\mathrm{h}}=$ Maximum measured cooling and heating energy respectively

\subsection{3b Heating, Cooling, and Space Conditioning Characteristics}

Characteristic signatures are the normalised differences between a baseline model (in this case it was the energy model being calibrated) and a model with a particular input parameter varied. The normalised difference was graphed as a function of the ambient temperature. "Characteristic signatures present the impact of an input parameter on heating and cooling energy consumption as the percent change relative to the maximum baseline heating and cooling energy consumption respectively" (Bensouda 2004, p. 19). Each characteristic signature forms a unique graphed trend. "By creating a library of shapes for certain known changes introduced by individual simulation input parameters, clues can be provided to the analyst to identify what simulation input errors may be causing the discrepancies between measured and simulated consumption" (Bensouda 2004, p. 17).

The characteristic signature values for heating, cooling and space conditioning energy consumption were calculated for each data point as follows:

Equation 12:

Cooling Characteristic signature value $=\left(-C^{c} / B^{c}\right) \times 100$

$\mathrm{C}^{\mathrm{C}}=$ Change in cooling energy consumption

$\mathrm{B}^{\mathrm{c}}=$ Maximum baseline cooling energy consumption

Equation 13:

Heating Characteristic signature value $=\left(-C^{h} / B^{h}\right) \times 100$

$\mathrm{C}^{\mathrm{h}}=$ Change in heating energy consumption

$\mathrm{B}^{\mathrm{h}}=$ Maximum baseline heating energy consumption 
Space Conditioning Characteristic signature value $=\left(\left(-C^{c}+C^{h}\right) /\left(B^{c}+B^{h}\right)\right) \times 100$

$\mathrm{C}^{\mathrm{c}}$ and $\mathrm{C}^{\mathrm{h}}=$ Change in Cooling and Heating energy respectively

$\mathrm{B}^{\mathrm{c}}$ and $\mathrm{B}^{\mathrm{h}}=$ Maximum measured cooling and heating energy respectively

Equation 15:

Where $\quad$ Change in = Energy consumption of Energy model with iterated input parameter Energy consumption of Energy model being calibrated

"The change in energy consumption was taken as the cooling or heating energy consumption value from the [energy model] simulation with the changed input minus the baseline value [in this case the energy model being calibrated] at the same temperature. The denominator was the maximum baseline energy consumption determined over the entire range of ambient temperatures contained in the weather file being used" (Bensouda 2004, p. 18).

Figure 7-16 displays an example characteristic signature library for an example building.

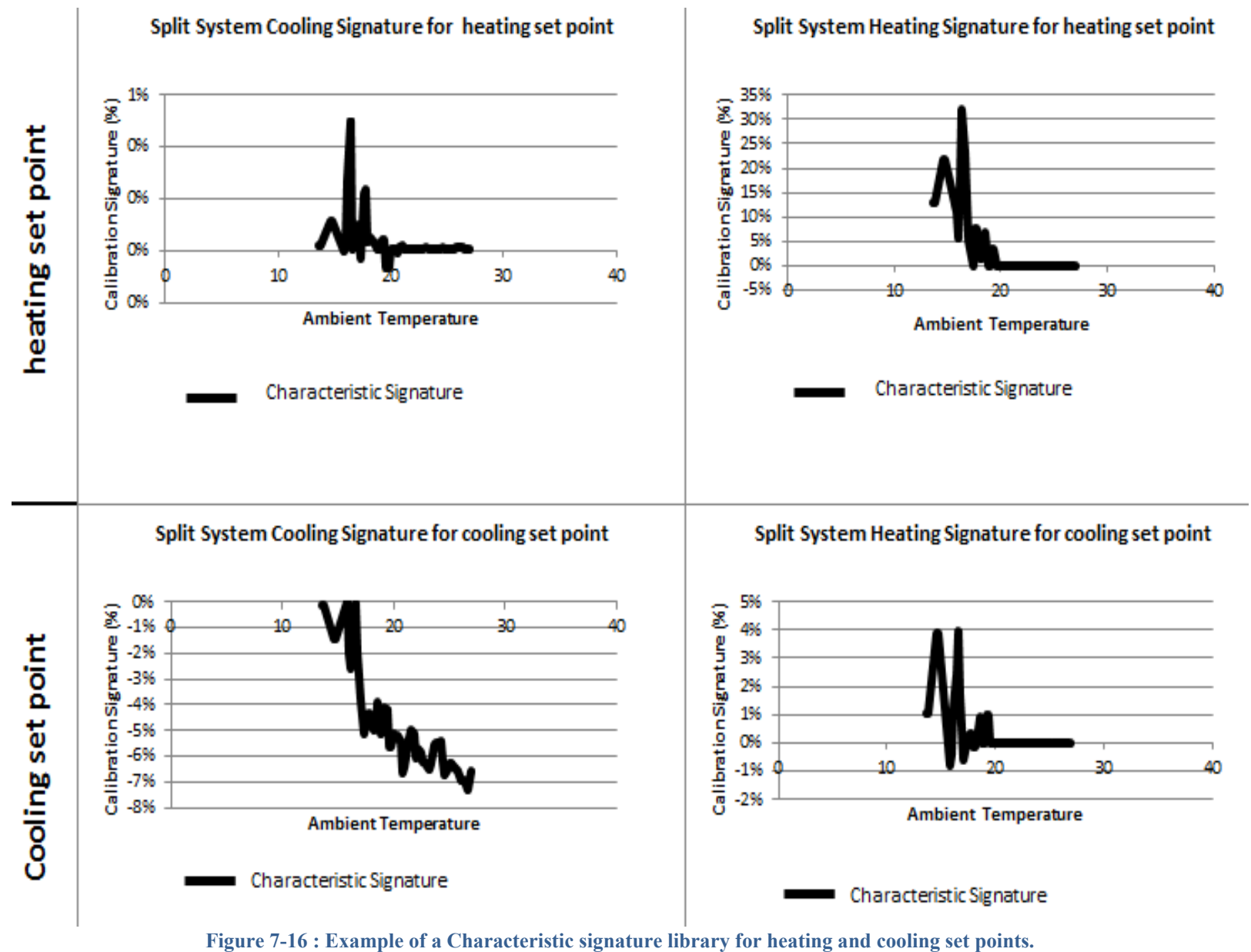

Page $\mid 162$ 
As can be seen, the signatures formed a library of graphed trends that the building's calibration signatures (from Section 7.4.3a) were compared against. A set of characteristic signatures were created for each building as the type of HVAC system and the location simulated in creates different energy signatures (Bensouda 2004).

Figure 7-17 displays an example comparison between an example building's calibration cooling signature and a cooling characteristic signature for the cooling set point. Both the calibration and characteristic signature shapes have similarities. They are both situated in the negatives and they both have a downward trend towards higher ambient temperatures. It indicates that the cooling set point is likely to be one input parameter that is incorrect.

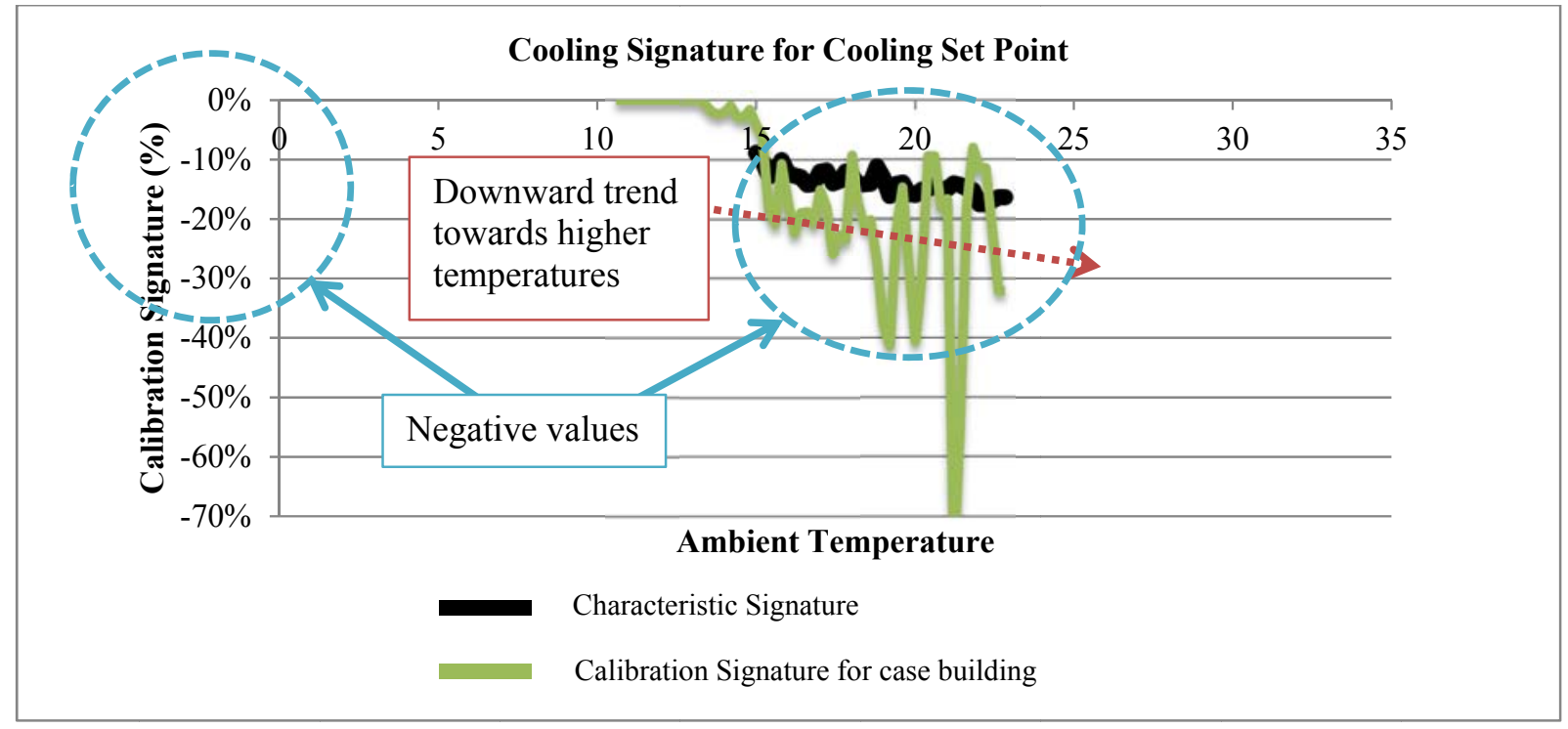

Figure 7-17 : Example comparison between a calibration cooling signature and a cooling characteristic signature for the cooling set point.

\subsection{3c Signature library}

The characteristic signature library was generated for a list of input parameters that could potentially create the differences between the real monitored energy consumption and the simulated energy consumption. The input parameters that were tested in the BEES case study buildings are outlined in Table 7-4.

These ten input parameters were chosen as they were important to the energy performance of buildings (Bensouda 2004) and were the least trusted and least reliable data obtained on each

Table 7-4 : Input parameters used to generate the set of characteristic signatures.

\begin{tabular}{|c|}
\hline Characteristic parameters \\
\hline Internal Loads $\left(\mathrm{W} / \mathrm{m}^{2}\right)$ \\
\hline Floor area $\left(\mathrm{m}^{2}\right)$ \\
\hline Insulation $\left(\mathrm{m}^{2} \cdot \mathrm{K} / \mathrm{W}\right)$ \\
\hline Outdoor air $\left(\mathrm{m}^{3} / \mathrm{s}\right)$ \\
\hline Heating set point $\left({ }^{\circ} \mathrm{C}\right)$ \\
\hline Cooling set point $\left({ }^{\circ} \mathrm{C}\right)$ \\
\hline Heating COP/Efficiency \\
\hline Cooling COP/Efficiency \\
\hline
\end{tabular}
building in the BEES project. The reliability issues arose from the model inputs being drawn from observation and assumptions, rather than measurements or measurements that were not 
entirely complete. Measurements are required to give 100 percent trust and reliability in the input parameters used. The type of data collected in the BEES project also did not entirely match the data that was typically required to construct reliable energy models under the 'M\&V Guidelines: Measurement and Verification for Federal Energy Projects' adopted in the USA (Nexant Inc 2008, p. 43). For example, the boiler efficiency was not obtained during the onsite survey and measurements.

The initial model made was iterated with each of the input parameters (found in Table 24) either increased or decreased. Inputs were increased or decreased depending on whether the initial model was over or under-simulating the energy use compared to the real building's energy performance. The magnitude of change to the input parameter was calculated using the initial model's MBE for the monitored month. If the MBE was -15 percent, the input parameter was altered to gain approximately -15 percent of the simulated energy. For example, if the heating was under-simulating by 15 percent, the heating set point was then increased to roughly make a 15 percent difference. This ensured the characteristic signature for the heating set point displayed a shape that under simulated the heating energy in the initial model compared to the iterated model.

\title{
7.4.3d Determining the magnitude of change needed to correct problem input
}

Once an input parameter was identified as being problematic, it needed to be adjusted to correct the mismatch between simulation and reality. Bensouda (2004) performed this by testing various input parameter ranges parametrically to determine the most appropriate input value to use. An example is taken from a case study performed by Bensouda (2004) to illustrate how it was performed:

\begin{abstract}
"In the characteristic signature of [Bensouda (2004) case study], the cold deck temperature was decreased by $2^{\circ} \mathrm{F}\left[0.55^{\circ} \mathrm{C}\right]$, which caused an increase of about $7 \%$ at low temperatures for both heating and cooling. Since the increase is of about 4\% and $7 \%$ respectively for the heating and cooling calibration signatures, the cold deck temperature should be decreased by about 1 to $2^{\circ} \mathrm{F}\left[0.27^{\circ} \mathrm{C}\right.$ to $\left.0.55^{\circ} \mathrm{C}\right]$. Different values between $53^{\circ} \mathrm{F}\left[11.6^{\circ} \mathrm{C}\right]$ and $54^{\circ} \mathrm{F}\left[12.2^{\circ} \mathrm{C}\right]$ were tested during the first iteration and the heating and cooling RMSE values were summed and a minimal value was sought. The best result was obtained by decreasing the cold deck temperature from $55\left[12.7^{\circ} \mathrm{C}\right]$ to $53.6^{\circ}\left[12^{\circ} \mathrm{C}\right]$ "'(Bensouda 2004, p.74).
\end{abstract}

This study undertook a similar process. The magnitude of change is roughly identified and variations were tested, however, it was not parametrically tested to find the value that provided exact results. The process was stopped as soon as the simulation was within an acceptable tolerance range for a monthly calibration. The aim in the study performed by Bensouda (2004) was to produce a calibration signature trend that is flat, i.e. 0 percent difference at all ambient temperatures. As there was only approximately two weeks of hourly data available for each of the 48 BEES case study buildings, the calibration focused specifically on that time period. A

Page | 164 
challenge was to produce a calibrated model for all months of the year based on this short monitored time period. As the calibration signatures were not as helpful for the time periods outside of the two week monitored period, the monthly trends were used to help correct the identified problem inputs and help identify further incorrect input parameters.

Figure 7-18 displays an example of the monthly calibration procedure. It displays an example step graph of the real building's energy consumption (black line) with \pm 5 percent calibration limits (black dotted lines), as well as the simulated data from an initial model (Purple line). The initial model's energy signatures were plotted and it was identified that the building loads and heating and cooling set points were incorrect. The initial model was iterated with increased building loads (red line). The adjustment increased the monthly energy consumption closer to the real energy performance of the building. The model was further iterated using an adjusted heating and cooling set point schedule (orange line). The adjustment increased the simulated energy use towards the real energy performance. The heating and cooling set points were further adjusted (grey line) until the simulation matched the real energy performance and was calibrated.

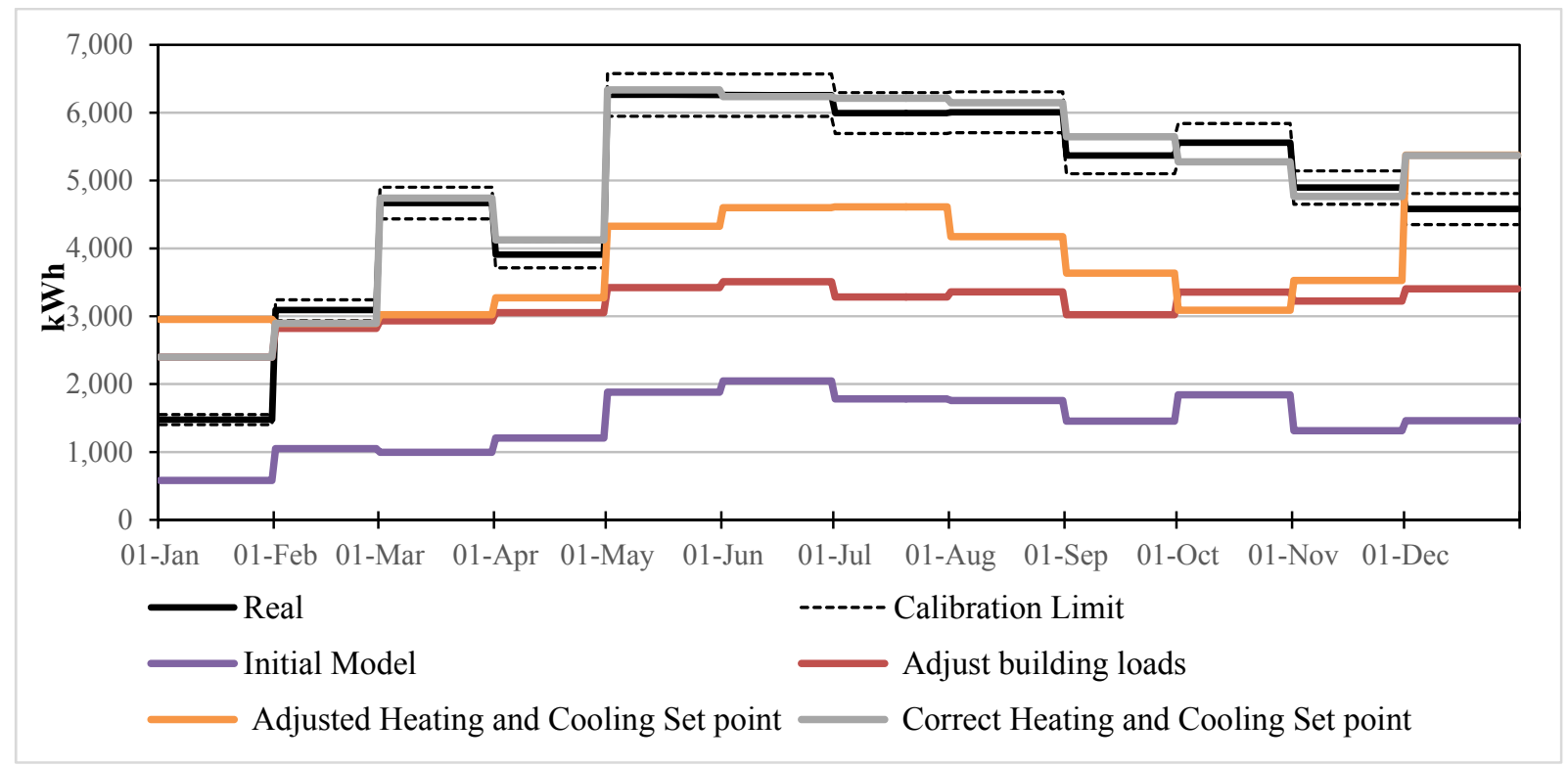

Figure 7-18 : Example monthly calibration. 


\subsection{Template VS Detailed energy models}

Detailed energy models are building models that match the real building's physical, geometrical, building load, patterns of use, and HVAC system attributes precisely or as precisely as possible. Figure 7-19 illustrates the differences between the two model types: Template and Detailed.

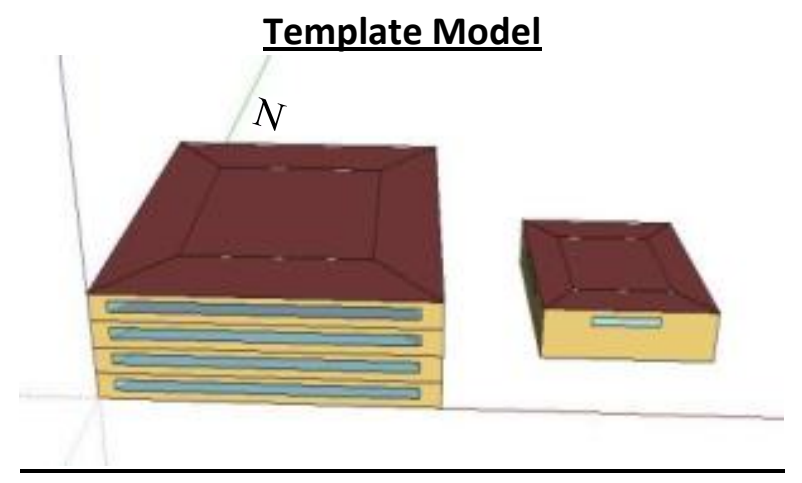

- Square Built form stretched to floor area

- WWR Glazing Area

- Site shading

- Solar Shading

- Matched Construction and materials

- All loads and associated schedules

- Matched HVAC Template with as built inputs (such as, set points, air flow network, efficiencies etc...)

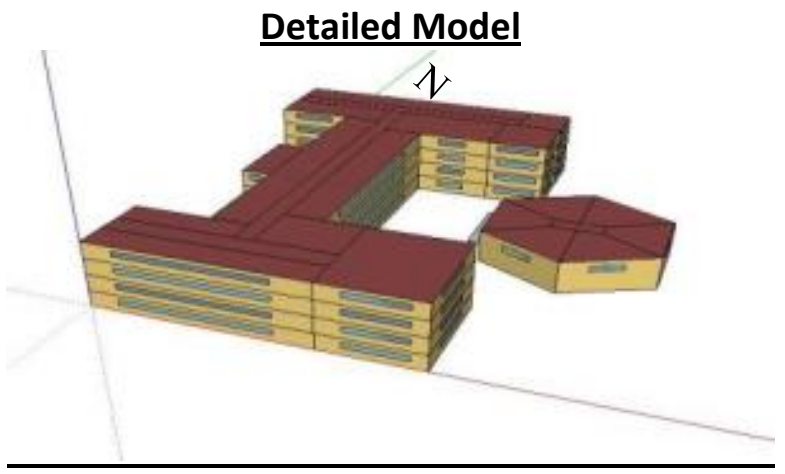

- Real building form and appropriate thermal zones

- As Built Glazing Area and position

- Site shading

- Solar Shading

- Matched Construction and materials

- Loads and associated schedules in specific thermal zones

- Matched HVAC Template with as built inputs in specific zones (such as, set points, air flow network, efficiencies etc...)

Figure 7-19 : Differences between a real building modelled using the template and detailed modelling methods.

The points in bold highlight the differences between the two modelling methods:

1. The template models had simplified geometry, average loads and patterns of use across the simplified thermal zoning, and all zones had the same HVAC properties.

2. The detailed models had detailed building geometry that matched the building form and layout, with the exact building loads, patterns of use and HVAC properties in each of the thermal zones.

Due to the simplifications in the Template modelling method, tests were undertaken to: a) determine whether they could be calibrated to match real buildings, and b) what were the likely errors when compared to a detailed model. The tests highlighted the potential risks with the template modelling method. They were also a Quality Assurance (QA) test for the modelling method proposed in this thesis and indicated whether the level of calibration wanted was achievable. 


\subsubsection{Energy results from Template and Detailed models}

A test comparing the energy results of a template model and a detailed model was undertaken to assess whether the template modelling method simplifications affect the whole building's energy performance. The test was part of a teaching exercise which tasked six different beginner level experience modellers to simulate six buildings using the same modelling and calibration procedure proposed in this thesis over a 30 hour period. The aim of the study was to model and calibrate a template and detailed model of the same building. The results enabled the decision of whether the template models performed as well as detailed models, and whether the calibration limit was achievable with the use of a template model. The buildings were labelled 1 to 6 for comparative purposes. Two model states for both template and detailed models were assessed:

- Initial Model - the first energy model built by each modeller to represent their building from the pre-calibration technique which used real as-built building information. This model represents the as-built building information and has not been altered using the energy signatures calibration procedure.

- Calibrated Model - the final energy model that was adapted from the initial model using the post-calibration technique which was used to identify the problematic model inputs that caused the differences between simulation and reality. This model represents the asbuilt building information from the initial model, but has been altered using the energy signatures calibration procedure which identified the incorrect model parameters causing the difference between the simulation and the real building's energy consumption.

The two model states showed the difference between building a model straight from as-built data (Section 7.4.1), and then how much closer the calibration signatures (Section 7.4.3) can get the model to match reality. Simulated energy consumption was compared to the real building's energy performance at a monthly and annual interval to assess the state of calibration. The aim of the models was to simulate to within \pm 5 percent MBE and/or 15 percent CV(RSME) (see Section 7.3 for what these terms refer to) of the real building's monthly energy consumption to achieve a suitable level of accuracy.

Figure 7-20 presents the comparison of Building 1's monthly calibration results between the initial and calibrated template (Blue) and detailed (Red) models with reference to the calibration limits (Black dotted line). The calibration results are presented as the percentage difference between the real building's monthly energy consumption and the energy model's energy consumption. It is an illustration of the calibration evaluation performed by all six participants (the other five buildings' calibration results are in Appendix 14.8.1). Figure 7-20 shows the two calibration metrics (MBE and CV(RSME) with associated calibration tolerance (ASHRAE 2002) for the initial and calibrated model states for Building 1's template and detailed model types. The comparison aims to display the performance of each model type (template and detailed) at an initial and calibrated state with reference to the calibration tolerance. 


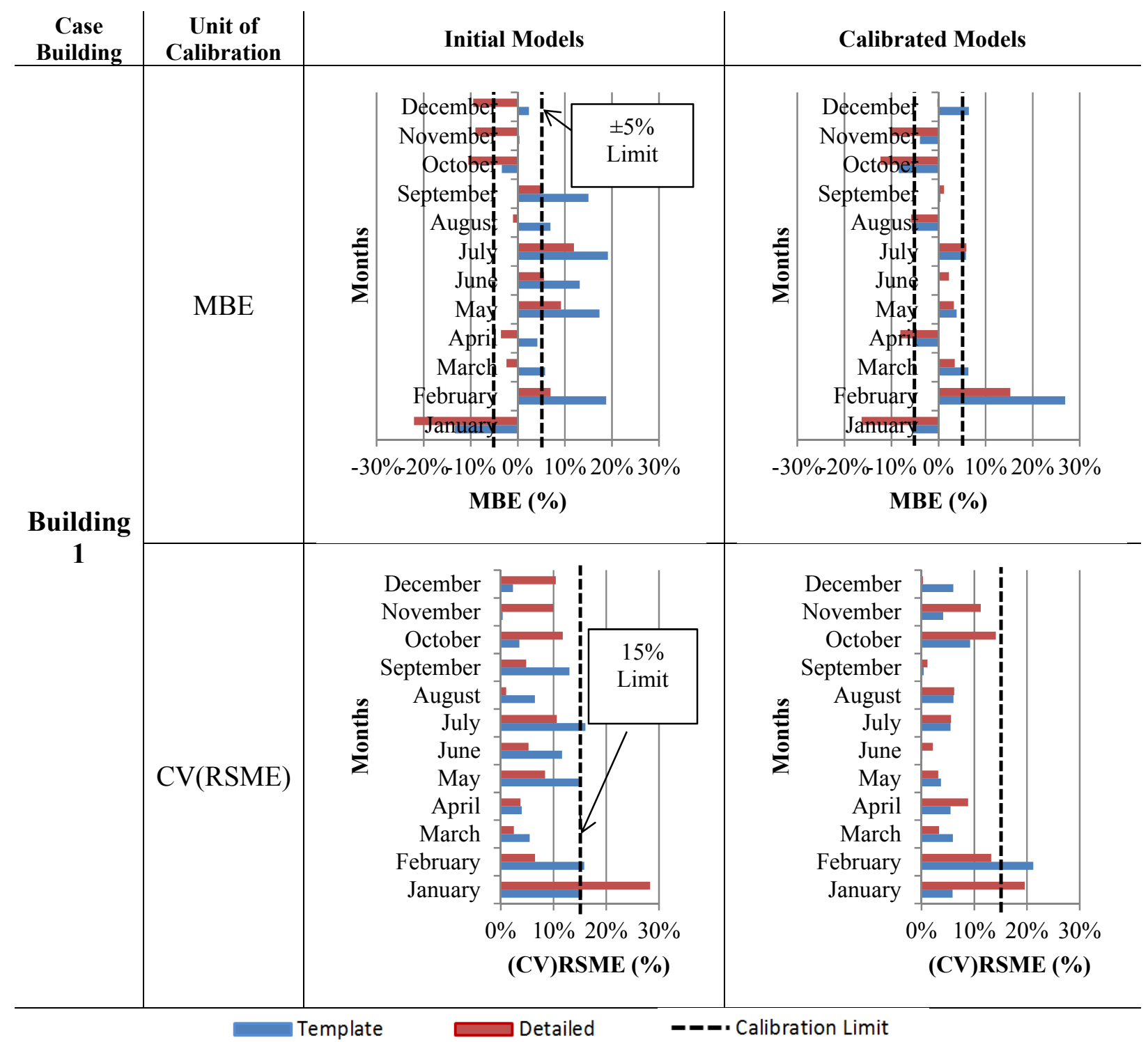

Figure 7-20 : Comparison of Building 1's monthly calibration results between initial and calibrated template and detailed models (refer to Appendix 14.10.1 for the other 5 buildings monthly calibration results).

As can be seen, the monthly energy results between the initial and calibrated models varied between months. The results between the template and detailed models also varied. Generally, the initial detailed models performed better by matching the real building energy consumption more closely. Once both models were calibrated using the energy signatures procedure, the differences between a template and detailed model were smaller (up to 10 percent different for calibrated and 17 percent different when not calibrated (the initial models)). This trend was seen for all 6 buildings (Appendix 14.8.1). It shows how beneficial the energy signature procedure was for calibrating energy models. 
Figures 7-21 and 7-22 display the number of months that were within the MBE and CV(RSME) calibration limits for initial and calibrated template and detailed models.

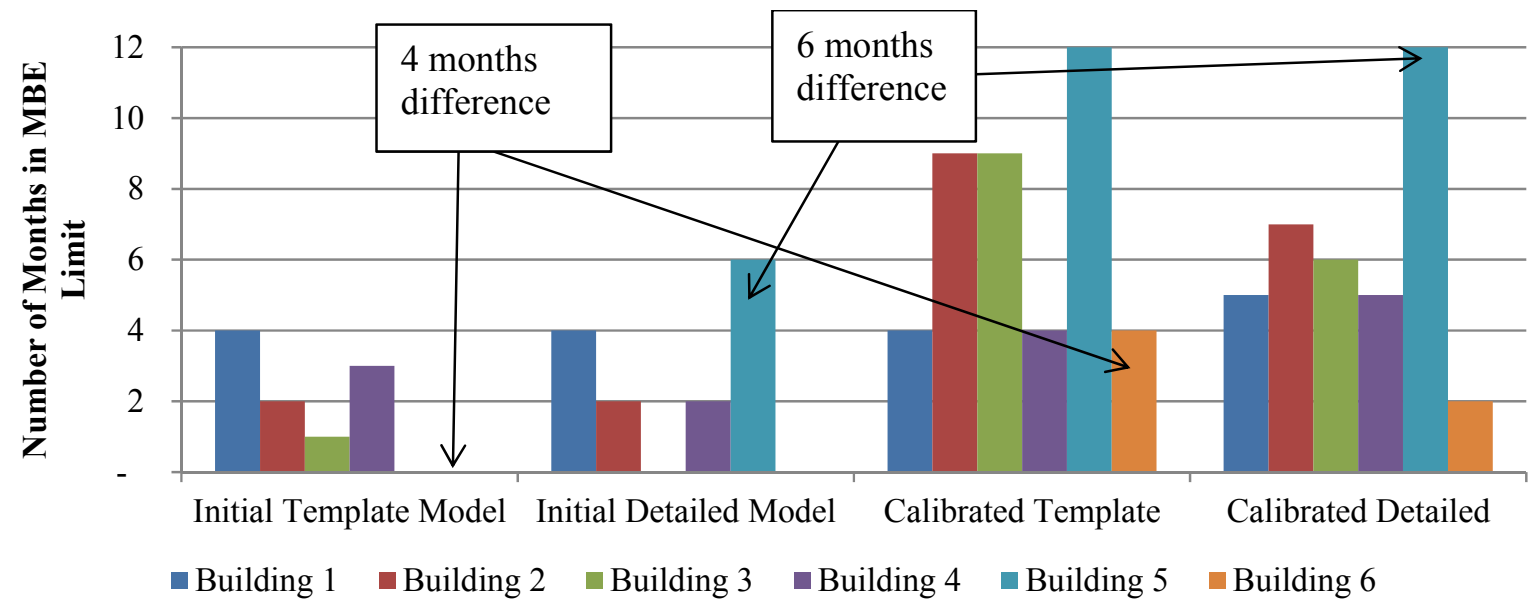

Figure 7-21 : Number of months that meet the $\pm \mathbf{5} \%$ MBE calibration limit for each building's initial and calibrated Template and Detailed models.

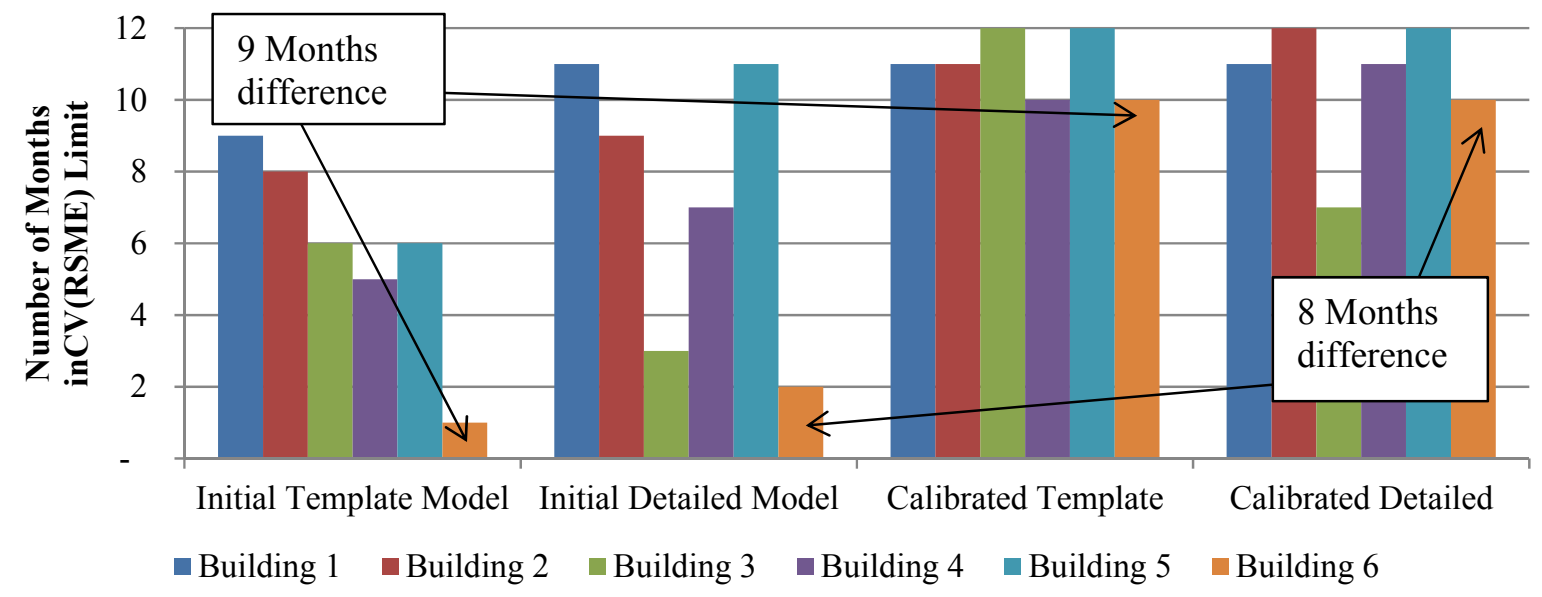

Figure 7-22 : Number of months that meet the $15 \%$ CV(RSME) calibration limit for each building's initial and calibrated Template and Detailed models.

Not all calibrated building models met the calibration limits. The CV(RSME) calibration limit was met across more months of the year compared to the MBE limit. The reason for this is because it was harder to mimic the exact patterns of use of the building for all months of the year. For example, the exact operation of equipment and HVAC could not be predicted, meaning there would always be a problem with simulating it. The MBE limit of \pm 5 percent was met across all six case studies on average for 6 months for the detailed models and 7 months for the template models (Appendix 14.8.2). Whereas, the CV(RSME) fell within the 15 percent limit, on average, for 11 months for both detailed and template models (Appendix 14.8.2).

The differences between the template and detailed models varied at both an initial (up to 9 months) and calibrated stage (up to 8 months). Across the 6 buildings, there was a mixture of performances and it was difficult to conclude if one modelling method was better than the other.

Page | 169 
However, what can be concluded is that the template model's simplifications did not affect the estimation of energy consumption in an existing building any more than a detailed model. This means that the simplifications used to increase the speed of modelling did not present a limitation in accuracy.

To further assess the calibration result, Figure 7-23 displays a comparison of the annual Bias Error (BE) results for a template and detailed model at the initial and calibrated stages (for explanation of BE refer to Section 7.4.2).

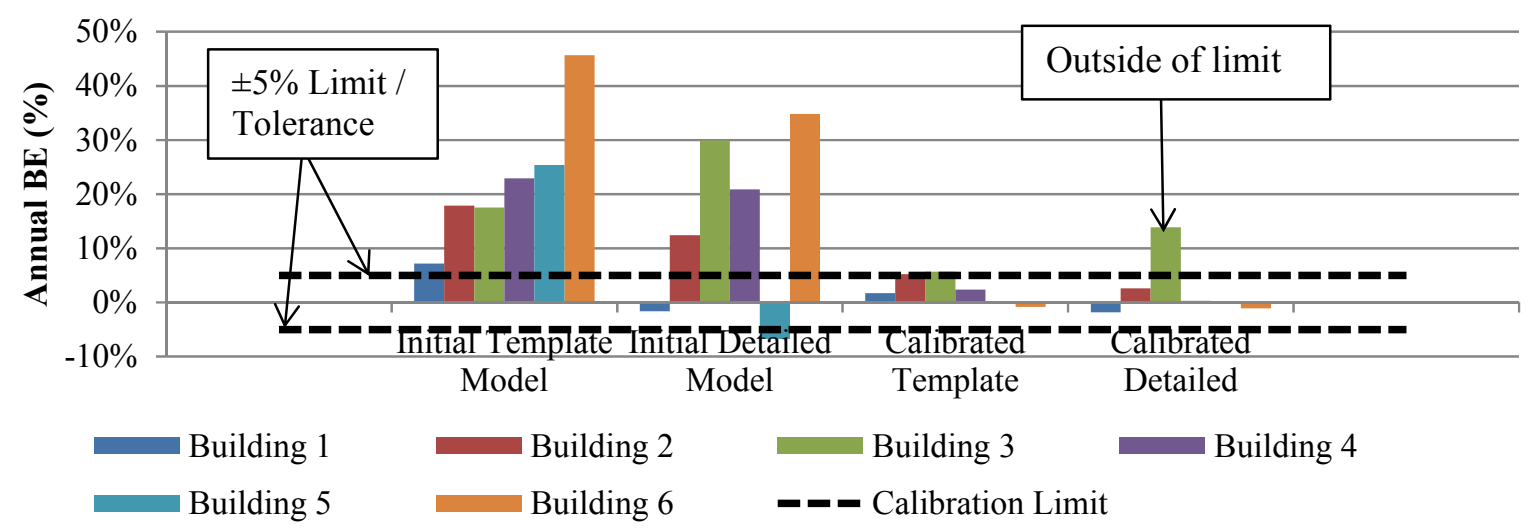

Figure 7-23 : Annual MBE calibration result for each buildings initial and calibrated Template and Detailed models.

As can be seen, all but one (Building 3) calibrated building model met the BE calibration limit. The five buildings that met the BE limit did not have atriums, but Building 3 (which did not meet the BE limit) had a large atrium in its design. ASHRAE guideline 14-2002 notes that for buildings with large atriums, (Building 3's atrium accounted for approximately 20 percent of the building plate floor area) where the "internal temperature stratification is significant and thermal convection is an important feature of the heating and cooling system" (Haberl, Culp, and Claridge 2005, p.5) it is likely that calibration of these buildings would not be possible. Given not a single one of the 48 BEES case study buildings being modelled in this research has an atrium; the Building 3 result can be ignored. On average, the BE for both the template and detailed model types was 3 percent ${ }^{5}$ across all buildings (Appendix 14.8.3).

The differences between the initial detailed models' simulation results and the real buildings' energy consumption were less when compared to the initial template models' simulation results and the real buildings' energy consumption. However, the results at an initial model stage did not show that one model type was better than the other at representing an existing building. This was concluded as both template and detailed models either met the calibration limits in the initial models or they did not (except Building 5's CV(RSME)). This indicates that there was an equal problem in representing the building's energy use in both model types when just using as-built

\footnotetext{
${ }^{5}$ Average BE is calculated by assuming all differences are positive values. This is done to exclude the cancellation of negative and positive values.
}

Page $\mid 170$ 
data (only using stage 1 in the calibration method), and means that the post-simulation calibration technique using the calibration signatures was paramount. Without using the calibration signatures, only one detailed model met the BE limit, two template models met the CV(RSME limit, and three detailed models met the CV(RSME) limit.

\subsubsection{Modellers' perceptions of using Template and Detailed models}

Each modeller who participated in the calibration exercise was asked to discuss the usability of the template and detailed models. The discussion points of the two model types were compared to establish which modelling type was considered more usable. "Usable" refers to the ease and speed to create a model of a building. The results were used to test the theory that template models increase the speed of model generation without hindering the accuracy of the simulation results (Cory, Gates, and Donn 2011). The discussion is split into two sections which focused on 1) Ease of modelling, and 2) Speed of modelling. The discussion that follows is a summary of the findings. Full transcripts of each participant's notes are found in Appendix 14.8.4.

\subsection{2a Ease of modelling}

Consensus across five of the six participants was that modelling with the template model was easier than using the detailed model. The template model was simpler to calibrate due to its lesser complexity. More than one participant highlighted the ease of building the template model as opposed to the detailed model and its usefulness, especially when considering both models were within acceptable calibration limits. It was suggested that the template model also had advantages for other users as it was easier to understand. This shortened the time needed to find any modelling errors.

The ease of using the template model was due to it being simple "to set up" and it also had the added advantage that it ended up resulting in similar levels of calibration to the detailed model. It was found that the template models' ease of use was due to the simple process of using them. The particular process was the scaling of geometry to match the size of the real building, floors being added to match building height, the simplification of internal walls, ease of surface matching, and changing the building loads and schedules for occupants, lighting, hot water, lifts etc. This process made the modelling process easy to perform and quick to get a model simulating without reducing the result accuracy. It also "eliminated the need to resolve errors", which saved time in generating a completed model.

\subsection{2b Speed of modelling}

The general consensus (five of the six participants) was that modelling with the template model was much quicker. It was stated that "time spent on developing the model, both setting up the geometry as well as developing the systems needed in the models, favours using template models. This confirms the general conclusion of Cory, Gates, and Donn (2011)."

The speed of modelling with template models compared to detailed models was considerable. Participants found that using the template models was up to 2 to 7 times faster to create a calibrated model due to 60 percent of the information needed already being in-built, and only

Page $\mid 171$ 
slight adjustment being needed to match the real buildings. Detailed models had no in-built information so they needed to be constructed from scratch with all information entered, geometry drawn and construction types defined. This process was slow and took participants longer to create a calibrated detail model.

The main gains in the template modelling speed were seen in the creation of geometry as it was more time consuming to create for the detailed model. This was due to the template model having regular geometry which allowed the model to be easily surface matched. By comparison, the detailed model was more challenging to build as there were irregular shapes which needed to be surface matched. Surface matching is the process of connecting two surfaces (walls, floors or ceilings) to one another (refer to (NREL - Commercial Buildings Research and Software Development 2010)). If both surfaces were not touching and were not the exact same size and construction, they did not match, and hence, if the template model reduced the errors in surface matching, the modelling speed increased. Another area where speed was increased was in the creation of patterns of use for different building loads. In the detailed model, there could be a new pattern of use schedule for each zone, whereas, in the template model there was only one pattern of use schedule that represented the average patterns of use in the whole building. However, in some circumstances, all other building parameters were the same between the template and detailed model, except for any separate heating and cooling set point. Therefore, the time which it took to apply these input parameters was the same for both the template and detailed models meaning the time which it took to complete those input parameters in a template and detailed model did not vary greatly.

Another area where modelling time was reduced was in the post-simulation energy signature technique. Calibration took longer for a detailed model when compared to a template model. This was because of the extra zones that needed a change in input parameters in multiple places. This led to human error, which in turn meant it took longer to fix the errors.

\subsubsection{Template VS Detailed modelling conclusions and implications for calibration evaluation in this thesis}

In conclusion, the detailed and template models at the initial model stage performed equally as well as each other and the template models performed equally as well, if not better when they were calibrated. This indicates that' as long as the correct building loads, patterns of use, floor area, fabric surface area, and space volume were averaged and modelled correctly, a template model could be calibrated to match reality. This means that if the goal is to model an existing building quickly, a template model will increase the speed of modelling, reduce the potential for error, ease the general problem of geometrical representation and remain sufficiently accurate.

As stated previously, Nexant Inc (2013) suggests that when a lack of monitored data presents a problem with calibrating a model, "specific calibration goals should be set for each project based on the appropriate level of effort". As the six buildings did not reach the required MBE and CV(RSME) calibration limits for all 12 months of the year, the results of the six case studies

Page $\mid 172$ 
were used to determine whether the original calibration tolerance set in Section 7.3 and 7.4 was achievable. The original calibration tolerance aimed to have no more than three months outside the $+/-5$ percent tolerance; the seasonal trend needed to be represented; and the total annual energy difference needed to be no greater than \pm 5 percent BE.

The MBE monthly limit was met for over 8 months in three of the six template models tested in the above study. The CV(RSME) was reached for at least 10 months of the year in all six template models. The annual MBE and CV(RSME) was reached in all cases where an atrium was not present. Due to these results and the fact that the results were obtained by beginner modellers, the original calibration tolerance for the 48 BEES models was acceptable.

To conclude on the Modellers' perceptions of template and detailed modelling methods, one participant's thoughts are presented:

"If the option was available the author would always use the template models because it saves modelling time, saves error fixing time and provides a valuable resource of likely HVAC parameters."

\subsection{Chapter summary}

Chapter 7 established a method for modelling real building performance that was quality assured and accurate. The process used a combination of two energy model calibration techniques. The method firstly used genuine as-built information and measured data to input correct parameters for the initial simulation model so that it closely represented the real operation of the building (Raftery, Keane, and Costa 2009). It secondly used an energy signatures process which characterises the difference between measured and simulated performance to aid in identifying the likely input parameters that need to be corrected in the model (Bensouda 2004). The model is calibrated when the simulated monthly energy consumption of eight months is within \pm 5 percent of the real building's monthly energy consumption for those same eight months, as well as the simulated annual energy consumption being within \pm 5 percent of the real building's annual energy consumption. The method presented aimed to solve the first focus for the energy modelling in this thesis; which was to have energy models that match the energy performance of 48 real commercial buildings monitored by the BEES project. 
Figure 7-24 illustrates the link between Chapters 7 and 8.

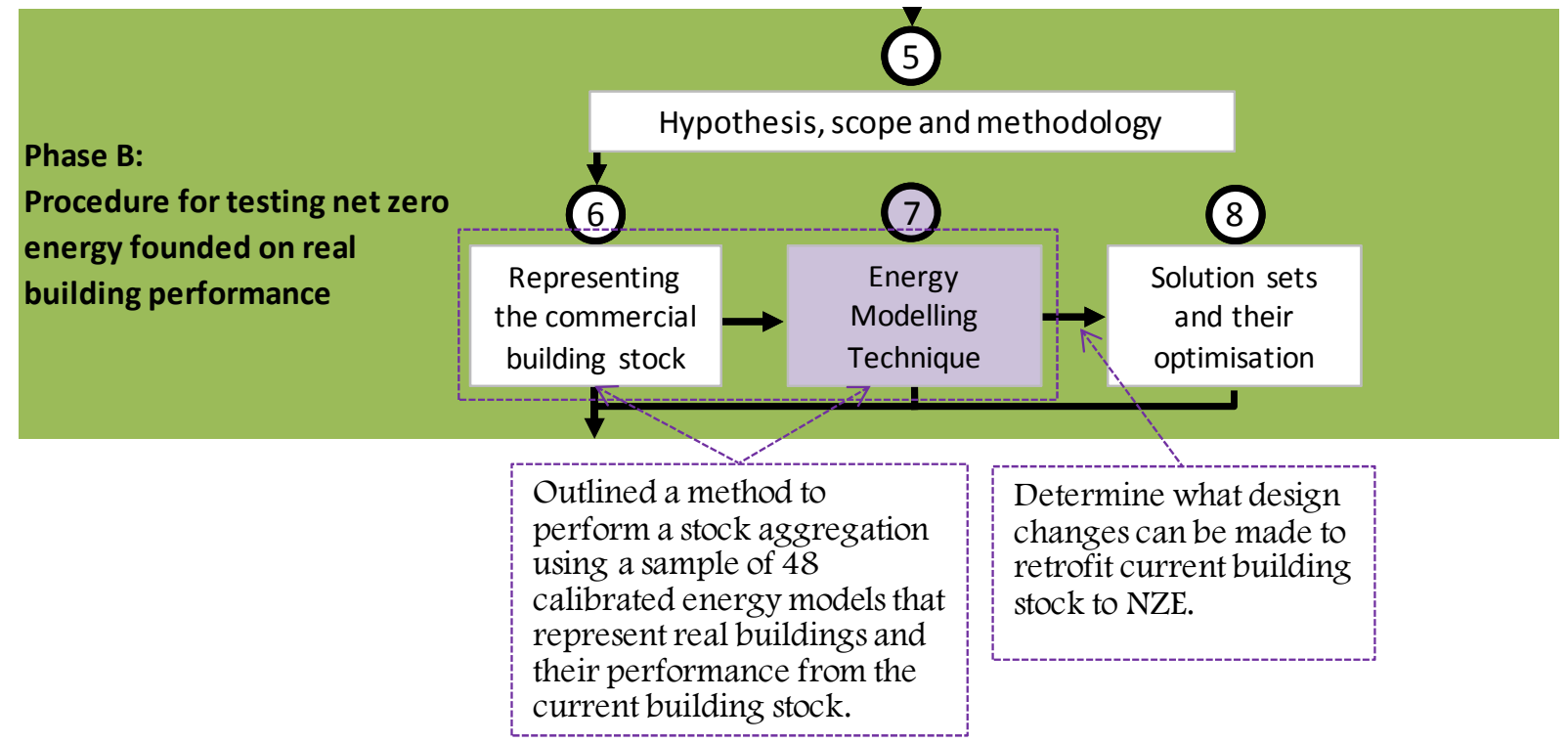

Figure 7-24 : Chapter 7 link to previous and following chapters.

The second focus for energy modelling was to assess retrofit design changes. However, the design changes required for the retrofit must first be known. Chapter 8 establishes which design changes should be used to retrofit the current commercial building stock to be NZE. It does so by assessing what design measures are already proven to work in existing Net ZEBs worldwide. 


\section{CHAPTER 8. USING NET ZEB SOLUTION SETS AND THEIR OPTIMISATION FOR NEW ZEALAND'S COMMERCIAL BUILDING STOCK}

\subsection{Chapter Intent}

\section{Chapter 8 investigates Net ZEB solution sets to be used for the Net Zero Energy (NZE)}

retrofit/redesign of the current New Zealand commercial building stock. The Net ZEB solution sets will be applied to retrofit/redesign of the 48 calibrated energy models, created using the process presented in Chapter 7 . The retrofitted/redesigned 48 calibrated energy models will be used in the stock aggregation process (presented in Chapter 6) to determine the energy performance of the NZE retrofit commercial building stock. A decision is also made regarding what design changes are required to retrofit/redesign the buildings. Figure 8-1 displays the links between Chapters 6, 7 and 8 .

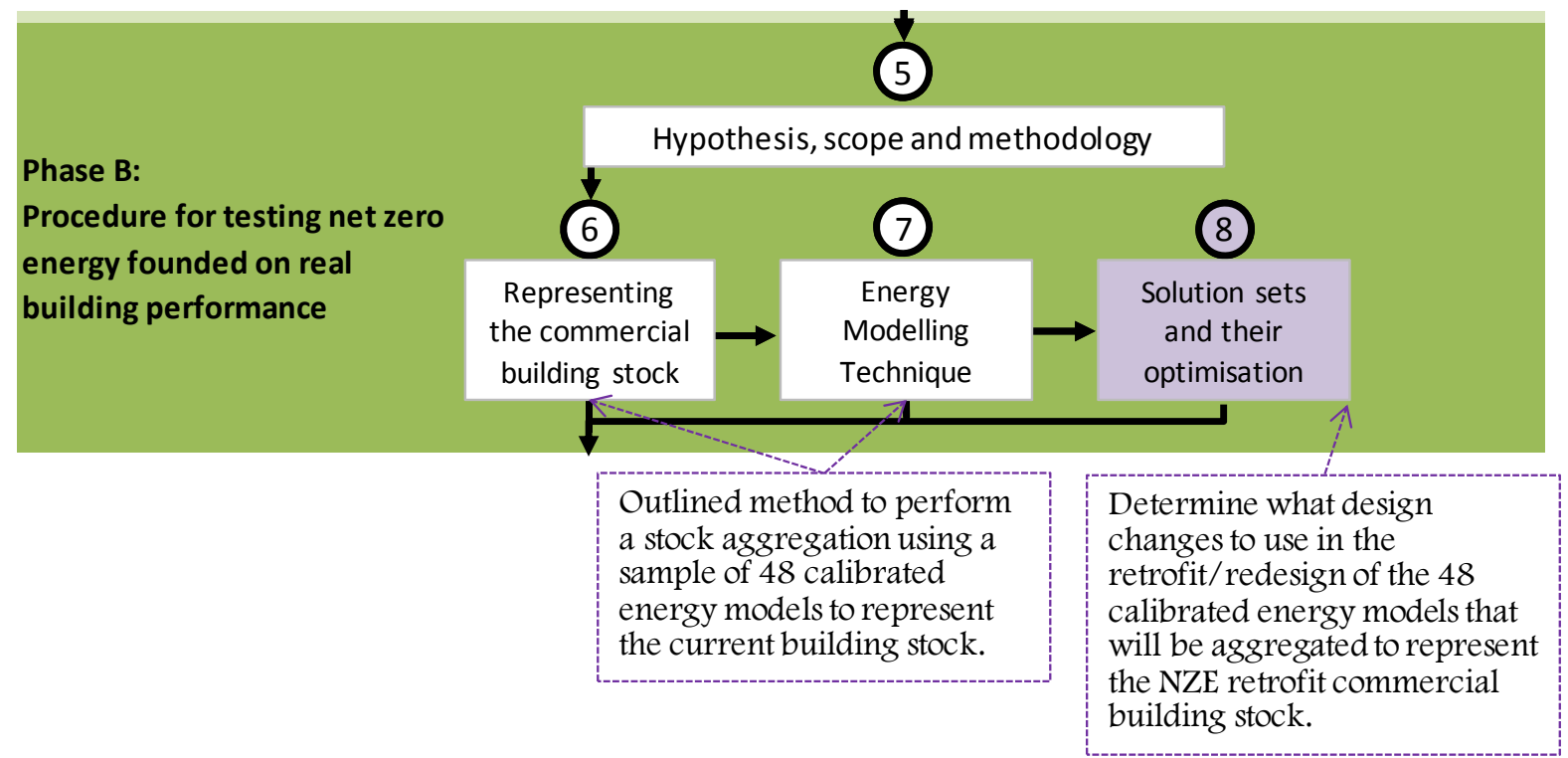

Figure 8-1 : Links between Chapters 6, 7 and 8.

The International Energy Agency, Task 40 Subtask C, had the aim of "developing Net ZEB solution sets and guidelines with respect to building types and climate"(IEA-SHC 2013b). There was much debate regarding how a solution set should be defined. This chapter provides an assessment of Net ZEB solution sets currently found to be in use in the Task 40 case study buildings and identifies an appropriate set of ECMs for the retrofit of the New Zealand commercial building stock. There is almost an endless number of design changes that could be used to reduce energy in buildings. The most appropriate design changes, at any given time, are the design techniques and technologies that are already implemented and that are working in existing buildings around the world. The intention of this chapter is for existing solution set cases to be defined and assessed. The purpose of assessing solution set cases is to determine whether

Page $\mid 175$ 
New Zealand's commercial buildings can reuse a similar, already working, set of design measures to achieve NZE. As a result, this study used the existing Net ZEB solution sets as a guide to retrofitting the New Zealand commercial building stock.

Section 8.2 outlines what Net ZEB solution sets are and how they will be used in this research to retrofit the 48 energy models which represent the New Zealand commercial building stock. Section 8.3 analyses a group of real Net ZEBs from around the world to determine an appropriate set of Energy Conservation Measures to use for retrofitting the current New Zealand commercial building stock. Section 8.4 proposes how the optimisation of the passive design measures is undertaken to maximise energy reductions.

\subsection{Establishing and assessing Net ZEB solutions sets using case based reasoning}

Figure 8-2 displays a case study solution set implemented in an existing Near Zero or Net Zero Energy Building as an aid for discussing solution sets. The case study solution set is from the Pixel Building located in Melbourne, Australia (Grocon 2014). The Pixel building was used as an illustration because it was in a climate location similar to New Zealand (Section 8.3.1), and also because it was a commercial office building. This illustrated that at a basic principle, Net ZEB solution sets are a set of Energy Conservation Measures (ECM) used in a building to achieve net zero energy consumption. ECMs are any building design technique, technology, equipment, system, or measure implemented that reduces the consumption of energy in a building (SBE 2014), such as the solar shading and natural ventilation seen in the Pixel building's solution set (Figure 8-2).

It should be noted that the Pixel Building is not the base case being studied. The base case being studied is the solution set implemented. Hence, any critique of the base case is performed at the individual ECM level and is found in Section 8.3.

Any critique of whether each building is/was net zero energy was performed by the IEA task 40 project from which the solution set information was drawn (IEA-SHC 2013a; IEA-SHC 2013c; Garde and Donn 2014). IEA Task 40 incorporated net zero, near zero and low energy buildings. Therefore, not all buildings were Net ZEBs. 


\begin{tabular}{|c|c|c|c|c|c|c|c|c|}
\hline \multicolumn{2}{|c|}{$\begin{array}{l}\text { Whole Building Solution Set - The set of solutions used to } \\
\text { lower the energy consumption of the whole building. }\end{array}$} & \multicolumn{7}{|c|}{$\begin{array}{l}\text { Building Requirement Solution Set - The set of } \\
\text { solutions used to lower the energy needed for } \\
\text { particular building requirements. }\end{array}$} \\
\hline Building Type & Non residential - Office & \multirow{5}{*}{ 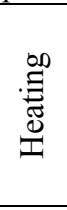 } & \multirow{5}{*}{$\begin{array}{l}\stackrel{50}{\Xi} \\
: \\
0\end{array}$} & \multirow{5}{*}{ 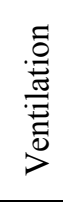 } & \multirow{5}{*}{$\stackrel{.00}{.00}$} & \multirow{5}{*}{ 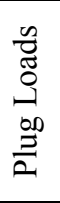 } & \multirow{5}{*}{ 离. } & \multirow{5}{*}{ 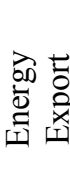 } \\
\hline Climate Type & Mixed Heating and Cooling & & & & & & & \\
\hline Site Context & Urban Centre & & & & & & & \\
\hline Building Size & 4 Storey, $1085 \mathrm{~m}^{2}$ & & & & & & & \\
\hline Occupant Density & 0.1 number of person $/ \mathrm{m}^{2}$ & & & & & & & \\
\hline \multirow{6}{*}{$\begin{array}{l}\text { Passive Design } \\
\text { ECMs }\end{array}$} & $\begin{array}{l}\text { Optimised Building Form } \\
\text { > Volume to Surface Ratio }\end{array}$ & $\checkmark$ & $\checkmark$ & $\checkmark$ & $\checkmark$ & & & \\
\hline & $\begin{array}{l}\text { Improved/Advanced Envelope } \\
>\text { High Mass } \\
>\text { Green Roof and/or Facade }\end{array}$ & $\checkmark$ & $\checkmark$ & & & & & \\
\hline & $\begin{array}{l}\text { Advanced Daylighting Measures } \\
>\text { Large amounts of glazing }\end{array}$ & & & & $\checkmark$ & & & \\
\hline & $\begin{array}{l}\text { Maximization of Passive Solar Heat } \\
\text { Gain }\end{array}$ & $\checkmark$ & & & & & & \\
\hline & $\begin{array}{l}\text { Solar Shading } \\
>\text { External shades fixed }\end{array}$ & & $\checkmark$ & & $\checkmark$ & & & \\
\hline & $\begin{array}{l}\text { Natural Ventilation } \\
>\text { Night cooling } \\
>\text { Cross Ventilation }\end{array}$ & & $\checkmark$ & $\checkmark$ & & & & \\
\hline \multirow{7}{*}{$\begin{array}{l}\text { Energy Efficient } \\
\text { ECMs }\end{array}$} & $\begin{array}{l}\text { Energy Efficient Lighting } \\
\text { > Low Lighting Power Density } \\
>\text { LED } \\
\text { > High Efficiency Fluorescents }\end{array}$ & & & & $\checkmark$ & & & \\
\hline & $\begin{array}{l}\text { Advanced Lighting Controls } \\
>\text { Electric Light Daylight Dimming } \\
>\text { Occupancy Sensors }\end{array}$ & & & & $\checkmark$ & & & \\
\hline & $\begin{array}{l}\text { Efficient Office Equipment } \\
\text { > Low Electric Equipment Power } \\
\text { Density } \\
\text { > High efficiency laptops } \\
\text { > LED Screens }\end{array}$ & & & & & $\checkmark$ & & \\
\hline & $\begin{array}{l}\text { Integrated Monitoring } \\
\text { > Energy / Load Management }\end{array}$ & & & & & $\checkmark$ & & \\
\hline & $\begin{array}{l}\text { Efficient HVAC Equipment } \\
>\text { Gas-fired chiller/heat pump }\end{array}$ & $\checkmark$ & $\checkmark$ & & & & & \\
\hline & Heat and Energy Recovery Ventilation & $\checkmark$ & $\sqrt{ }$ & $\sqrt{ }$ & & & & \\
\hline & $\begin{array}{l}\text { Radiant Structure } \\
>\text { Water Cooled and/or Heated Floors }\end{array}$ & & $\checkmark$ & & & & & \\
\hline \multirow{3}{*}{$\begin{array}{l}\text { Renewable Energy } \\
\text { ECMs }\end{array}$} & Biogas Boiler for Domestic Hot Water & & & & & & $\checkmark$ & \\
\hline & On site Photovoltaics & & & & & & & $\sqrt{ }$ \\
\hline & Windpower (onsite) & & & & & & & $\sqrt{ }$ \\
\hline
\end{tabular}

Figure 8-2 : Case study Net ZEB Solution Set for the Pixel Building. Table created using (Garde and Donn 2014). 


\subsubsection{Using Solution Sets as a form of Case-Based Reasoning in design}

In order to identify a set of ECMs to use in the retrofit of the New Zealand commercial building stock, this thesis proposed the use of existing Net ZEB solution sets as a guideline. The idea of using solution sets as a guideline is considered in the design world as a form of Case-Based Reasoning (CBR). Case-based reasoning (CBR) is a problem solving approach based on the reuse of specific past experiences (Maher and de Silva Garza 1997). In CBR, a new problem is solved by finding and re-using an existing solution from a similar previously developed case (Maher and de Silva Garza 1997; Aamodt and Plaza 1994). CBR finds a previous situation which solved a similar problem and re-uses the knowledge in a new context. The idea is that there is no need to recreate things from the beginning when it is possible that someone already has invented these things/solutions/objects/systems/measures before (Mann 2005).

The use of past cases or examples aids to identify solutions to a design problem. For the purposes of solution sets, CBR reuses and adapts already implemented and working solutions in a set of case buildings, to a new design context (Kolodner 1991). In the case of this thesis, the solutions were a set of ECMs, while the new design context was the New Zealand commercial building stock. Case-based reasoning to identify a useful solution set was attractive as there were a large number of ECMs that could be used to reduce energy. The objective for re-using previously implemented solutions was to reduce time and effort in the redesign process (Krueger 1992) and hence, a solution set case-based methodology provided a way to easily and quickly generate a set of ECMs for reducing energy in buildings (Kolodner 1991).

It is worth noting that there is controversy regarding the effect of the CBR design approach on design innovation. According to Hua, Faltings, and Smith, (1996); Sun and Faltings, (1994) the re-use of case-based solutions can lead to innovative design. While, according to Kolodner, (1991) CBR design limits the explored space of solutions and can potentially lessen design innovation. It was decided that the potential for lessened innovation was acceptable given this research aimed to establish results on the real performance of existing buildings and reusing ECMs from existing buildings continues that idea.

To create a guideline for enabling the analysis and use of Net ZEB solution sets, various existing building design guidelines were reviewed. The review was undertaken to identify how and why a solution set was settled upon and why it worked in particular cases. A CBR system, or methodology, for assessing solution sets could then be determined and implemented to identify a set of ECMs for use in the retrofit of commercial buildings in New Zealand.

\subsubsection{Solution sets}

Using the solution sets displayed in Figure 8-2 for example; Net ZEB solution sets included passive design ECMs, energy efficiency ECMs, and renewable energy ECMs that were used to achieve the design goal of being NZE. In addition, smaller groups of ECMs provided an energy efficient response to the requirement for heating, cooling, ventilation, lighting, plug loads, water heating and exported energy.

Page $\mid 178$ 
Consequently, two categories of solution sets were settled upon:

Whole Building Solution Set:

The set of ECMs used to lower the energy consumption of the whole building.

\section{Building Requirement Solution Set:}

The set of ECMs used to lower the energy needed for a particular building requirement (e.g. heating, cooling, lighting, plug loads etc.).

\subsubsection{Design strategy}

Design strategies were used to meet the goal of being NZE. Design strategy is the energy planning of the building design options that can be applied to achieve an overall goal, either through passive or active means (ASHRAE 2006). The first step was to define the overall goal of the building. The overall goal for a building relates to the design objective; for example, green design or net zero energy design. If the design goal is not established before the design process has begun, and if the building is not designed with the intent of the required outcome, the desired results will never be achieved (ASHRAE 2006). With a design goal set, design strategies can be formulated to reach the goal. Design strategies are used to mitigate or reduce the need for energy in a building. Three design strategies can be employed using three ECM types:

- Passive design ECMs;

- Energy efficient ECMs; and

- Renewable ECMs.

Design strategies implement a mixture of passive design ECMs, energy efficient ECMs, and renewable ECMs. Passive design ECMs require no direct energy input (unlike the case of active design measures). These design measures incorporate passive solar design, natural ventilation and advanced daylighting measures. Passive design can improve a building's energy performance in the areas of heating, cooling and lighting (Daniels 1997). Energy efficient ECMs focus on reducing the use of energy in the building through more efficient means and are therefore considered active energy measures - they use energy, but in an efficient way. Energy efficient ECMs are used in harmony with the passive design ECMs to produce a higher performing energy efficient building. The passive design ECMs maximise the potential for a high-performance building, although it is the energy efficient ECMs that actually make the building a high-performance building (LANL Site Planning and Construction Committee 2002). In general, low-energy or high-performance buildings rely on passive and energy efficient ECMs to reach their intended goal. Net ZEBs are similar to these; but they need to offset their annual energy demand with renewable energy measures. Renewable energy ECMs use renewable energy sources to generate energy. "By definition, a renewable energy source is a fuel source that can be replenished in a short amount of time" (ASHRAE 2006). The annual energy demand of an already low-energy building can be offset through the renewable energy generation using these replenishing energy sources.

Page $\mid 179$ 


\subsubsection{Building requirements}

There are a number of requirements that a building needs to fulfil. The requirements directly relate to the occupants and their use of the building. The requirements include the provision of comfortable temperatures for the users of the building, and the capability for any tasks to be performed in the building. The requirements are catered for with the use of energy. Energy is used to heat and cool the building in order to make it comfortable for occupants. Energy is also used to provide enough light for the occupants to perform their tasks. These requirements directly relate to energy driving factors, with their elements used to calculate a building's energy consumption (space loads, operating loads, and Heating Ventilation and Air-conditioning (HVAC) system loads). Space loads, or heating and cooling loads, determine the amount of energy which must be added to or extracted from a space to maintain thermal comfort (The American Institute of Architects 1982a).

Space loads are affected by the:

- Occupant heat gains;

- Lighting heat gains;

- Equipment heat gains;

- Solar heat gains;

- Ventilation/infiltration heat gains or losses; and

- Envelope heat gains or losses.

The HVAC system loads refer to the amount of energy required to convert fuel or electric energy to heating or cooling effect to meet the space loads (The American Institute of Architects 1982a). For the purposes of analysing solution sets, space loads and HVAC system loads were combined into one requirement, space conditioning. This was due to both having implications only on the space conditioning energy use and not on operating loads energy use. Building operating loads determine the amount of energy required to operate the lighting, equipment, hot water, and other equipment in the building to perform functions or activities (The American Institute of Architects 1982a). As a result, two groups of building requirements exist, space conditioning requirements and building operating load requirements.

\subsection{4a Space conditioning requirements}

Space conditioning requirements are influenced by the external climate and the type of building. The tempering of the outside climate extremes introduces the requirement for systems to condition the building's internal spaces to keep occupants comfortable. Appropriate internal environmental conditions are set by the building type, and are affected by the internal heat gains in building spaces. "Internal heat gains are produced by heat given off within a building by occupants, lights and equipment. In many buildings, internal heat gains are the major source of heat gain" (The American Institute of Architects 1982a). As a result, the building type creates challenges for conditioning the internal space. Space conditioning in a building is split up into 
heating, cooling, and ventilation requirements, meaning space conditioning challenges could be differentiated into heating requirements, cooling requirements, and ventilation requirements.

\subsection{4b Building operating load requirements}

Operating loads include the electrical loads for lights and equipment. Equipment includes lifts, computers, printers etc, as well as process loads such as food service or dry cleaning (The American Institute of Architects 1982a). The building operating load requirements are influenced by the building type. The hours of operation and occupancy impact on how much and for how long lighting, equipment, and hot water are required. Building operating loads were split into lighting, plug load, and water heating requirements. As Net ZEBs need to generate energy to feed back into the local energy grid, an extra building operating load (energy export) was added, meaning the building operating load requirements could be differentiated into lighting, plug load, water heating; and energy export.

\subsubsection{Building requirements and Solution set determinants}

Building design guides acknowledge that not all ECMs can work in all buildings. This is because there are factors which affect how and why a building uses energy. These factors relate to the circumstances of a particular building and the requirements the building must fulfil in order to provide a suitable indoor environment for the occupants. These factors also influence the building design and impact on the ECMs used in a final solution set and because they impact on the ECMs that are used in a particular solution, they are considered solution set determinants. Solution set determinants create the need for the building requirements (the indoor building environment must be comfortable and it must provide what is needed for occupants to complete their tasks). Design guidelines refer to three determinants that influence whether a building is comfortable and whether it enables occupant tasks to be undertaken. These include:

- Climate;

- Site Context; and

- Building type.

Climate and site context are factors that need to be assessed to prescribe occupant comfort criteria. If the external climate is cold, the building may be cold and require heating in order to make it comfortable for the occupants. Building type can have large implications on energy use as it defines what loads need to be present and when the loads are required. For example, if a building is used for food sales it must provide equipment to store and display food, while also providing comfortable conditions for occupants.

\subsection{5a Climate}

The weather plays a crucial role in the design of buildings and this is no exception for Net ZEBs. "Climatic factors are those conditions, features, or influences external to the building that can have an impact on the building" (ASHRAE 2006). The climatic factors need to be assessed so that an understanding can be determined of how the proposed building will need to temper the extremes of weather (e.g. a building in a hot humid country will be designed differently to a Page $\mid 181$ 
building located in an arctic country). Many design guides split locations up into climate zones. "The purpose of categorizing geographical areas by climate is to develop a manageable number of guidelines for energy-conscious design" (The American Institute of Architects 1982c). This suggests that for the purpose of establishing Net ZEB solution sets, buildings needed to be split up by logical climate zones/differences. This helped to differentiate useful existing Net ZEB examples that could be used as design guidelines for a specific set of climate variables, from those that were not useful. The climate analysis is considered a pre-design consideration because it impacts on the various ECMs that can be utilised in a building's design. "Regional guidelines, which cater for the different climate zones, are especially helpful in the programming and schematic phases of design (pre-design), where basic energy-conserving strategies are selected"(The American Institute of Architects 1982c). If for example, a building was to be designed off-the-grid, the energy generation capabilities of a specific location would need to be assessed and if a particular location did not get many sunshine hours, solar energy generation would be a less viable option than other technologies. Within regional climate datasets there are weather variables that need to be assessed. Climate variables important to buildings include a location's temperature; humidity, solar radiation, wind and rainfall.

\subsection{5b Site context}

Climate needs to be assessed in parallel with the site analysis. This is due to the surrounding site context altering regional weather variables. "The urban climate differs from that of its surrounding territory, and there is a strong relationship between urban forms and spaces and strategic energy-efficient urban design."(Energy Research Group 1999, p.48). Surrounding site contexts can have a large impact on the climate at a specific site as described by Energy Research Group (1999):

- Large towns to tend be considerably warmer than the surrounding countryside;

- Because of the obstacles to wind flow presented by buildings and other structures, air movement in towns tends to be slower on average but more turbulent than in the countryside;

- Buildings and other urban structures obstruct direct sunlight to some degree and whether this is a benefit or detriment depends on the other parameters of the microclimate and design intention of the building.

Since the microclimate is a variant of the regional climate characteristics at a site, there may be an altered scheme for an energy conserving design. "The climate characteristics of a site obviously have an impact on how the building performs, especially its energy performance and impact on its surroundings" (ASHRAE 2006). In terms of Net ZEB design, an urban site can bring issues relating to the generation of renewable energy and natural ventilation. An example of this is excessive solar shading from surrounding buildings at a specific site, which can result in lower levels of insolation and the exclusion of photovoltaic (PV) energy generation as a viable option. Another example is the impact that turbulent wind flows can have on wind turbine power generation.

Page | 182 


\subsection{5c Building type}

The building type is a predetermined variable because it is known prior to the design. The building type must be known due to the different purposes for which buildings are created. The building type determines many factors, such as the design temperatures; physical space availability; the need for maintaining separate thermal temperature zones; the availability of energy; hours of operation; and occupancy (The American Institute of Architects 1982b). These factors determine the various criteria and internal environmental conditions of the building, for instance comfort criteria and the amount of internal heat gains present. Therefore, catering for the building type plays a part in determining which solutions can be implemented in the building. This is easily demonstrated when comparing the occupancy and hours of use of a stand-alone residential home to a multi-story office building. A multi-story office building could be designed for large occupant densities with hours of use being between 7:00am-7:00pm, while a detached single family residence could only be occupied by a few people during non-working hours. This could produce two very different internal gain values, design temperatures and thermal temperature zones. In addition, the building type can have implications with regard to its size. Residential buildings are typically smaller in size, for example a detached house, while commercial buildings can range from being small in size to large in size, for example a small retail shop or a large retail mall or high-rise office building. The building size can impact on the types of ECMs that can work. For example, PV may not be suitable for a high-rise office building as there could be very little roof area to generate a substantial amount of energy to offset the building's energy consumption.

\subsubsection{Design hierarchy to enable a Case-Based assessment of existing solution sets to apply to a new design problem}

The outcome of the building design guideline review was an understanding of the design hierarchy under which ECMs and solution sets are chosen. Figure 8-3 displays the solution set hierarchy.

This shows that the hierarchy begins with an existing building's whole solution set. Each building's solution set is made from a combination of ECMs. The ECMs address the building requirements in an energy efficient manner by using particular building design strategies including Passive design; Energy efficient; and Renewable. Smaller sets of ECMs address the building requirements. Space conditioning is required to keep the building's internal environment comfortable for the occupants while building operating loads are required for the occupant to perform his or her tasks. The design hierarchy culminates in three building requirement and solution set determinants. They are considered determinants because they set the building requirements. The amount of energy needed to provide each building requirement is impacted on by these three determinants. The climate, site context, and building type all impact on the amount of energy it takes to keep the occupants within a building comfortable as well as how much energy is required for the occupants to complete their tasks. 


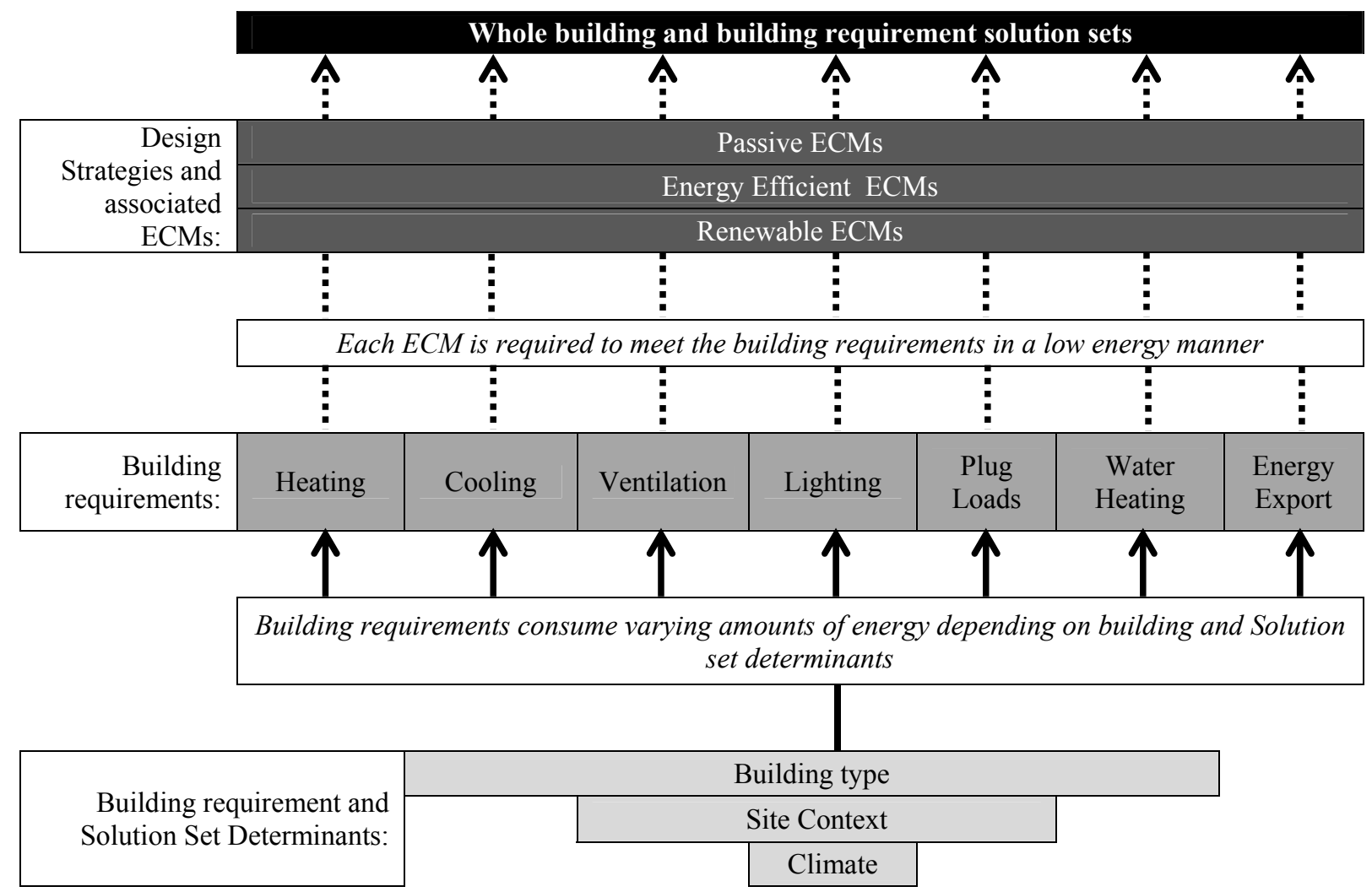

Figure 8-3 : Flow diagram of building design hierarchy for the creation of solution sets.

The building requirement and solution set determinants enable an assessment for determining what ECMs/solution set to reuse. A CBR system for assessing and reusing existing buildings solution sets was identified using the three determinants: climate, site context and building type. The determinants enabled the CBR system to be used. The system was broken down into three major aspects which were adapted from the list of aspects specified in Maher and de Silva Garza (1997). Maher and de Silva Garza (1997) specified the aspects that should be taken into consideration when creating a CBR system for assessing and reusing previous cases solutions in design projects. The three aspects included:

1) how each solution set could be represented;

2) how each solution set was recalled; and

3) how each solution set was reused and adapted for a new case.

The three aspects were informed by using the three determinants which tie all solution sets together. Each solution set was represented and recalled according to the climate, site context and building type the case (solution set) belonged to. A solution set was then reused and adapted to match the particular climate, site context and building type the new solution set was intended for. 
Figure 8-4 exemplifies the process used for the reuse of existing solution sets to a new building case/project.

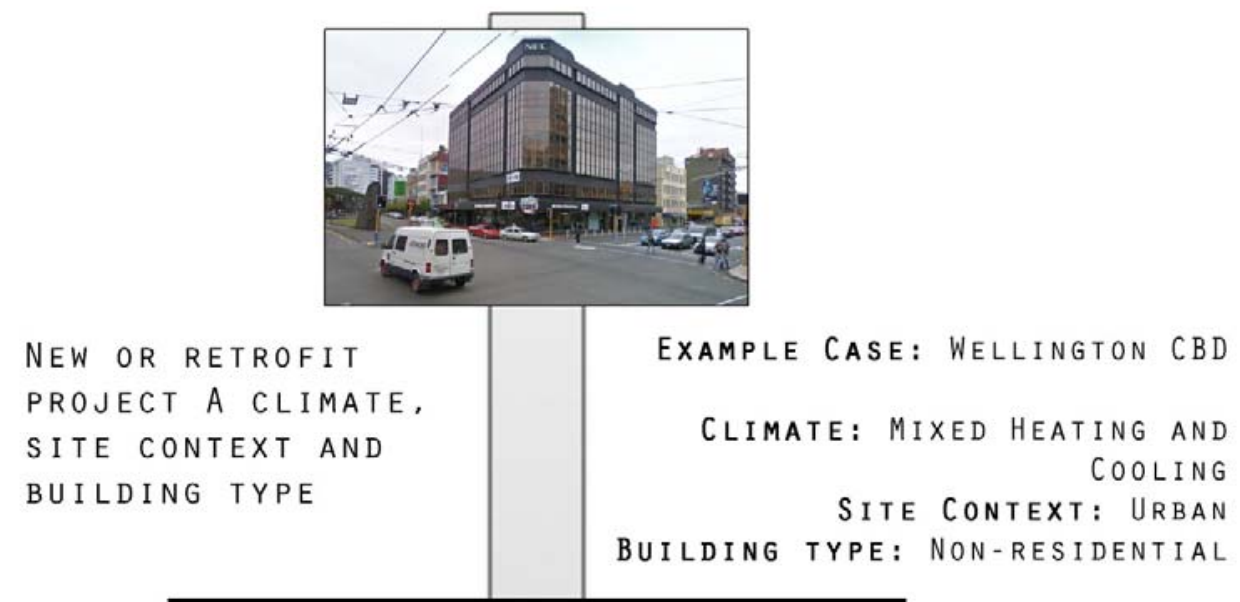

\section{BUILT OR RETROFIT WITH:}

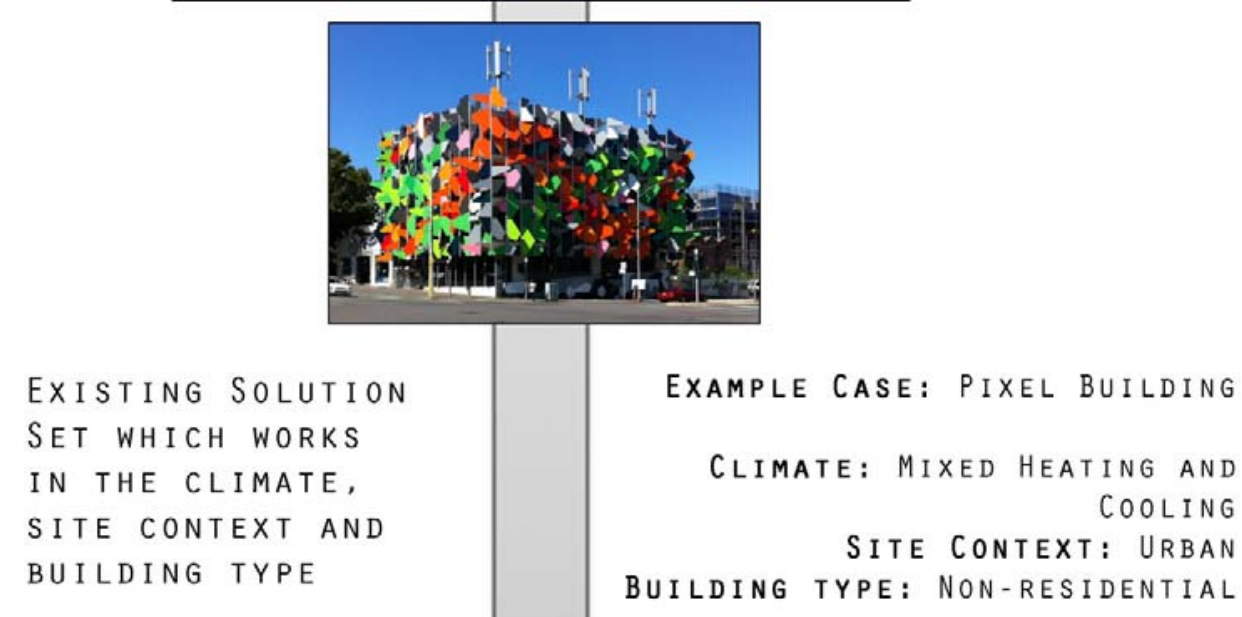

\section{WILL RESULT WITH NET ZEB.}

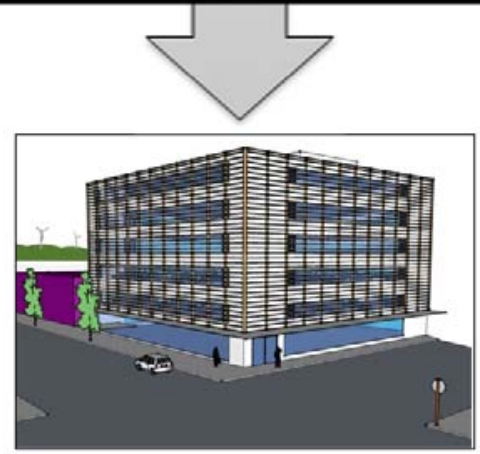

Figure 8-4 : Applying Net ZEB Solution Sets to new or existing Buildings. Images from (Mihaly 2014; Google 2013b).

The assessment of the reusability of a solution set to another building starts with and relies on the three determinants: the climate, site context and building type. For example, the Wellington 
Central Business District (CBD) is used as the site for a new non-residential (commercial) building project. To establish an appropriate solution set, an existing solution set is identified that already works within the Wellington CBD climate, and that is consistent with the site context and building type. This is based on the premise that if a solution set is used for a specific climate, site context and building type, it should work in another building with a similar climate, site context and building type. As an example, the Pixel building's solution set was designed to achieve NZE in a similar climate, site context and building type as the Wellington CBD and hence, if the Pixel building's solution set was reused and adapted for the Wellington CBD project design, it would result in a Net ZEB.

8.2.6a Working example of solution set analysis and application to one new design case

The case base assessment of existing Net ZEB solution sets formed the curriculum for a $\mathrm{PhD}$ summer school in Corsica during October 2012. This summer school was carried out under the support of the IEA SHC Task 40 / ECBCS Annex 52. The summer school had four groups of PhD candidates tasked with redesigning different Net ZEBs. The aim for each group was to study the impact of climate on Net ZEB solution sets by relocating an existing Net ZEB to a different climate and redesigning it to once again be Net ZEB. The overall goal of the summer school was to be a proof of concept for assessing the viability of using the Net ZEB solution sets to redesign buildings to be Net ZEBs. The PhD summer school methodology was based on the case based assessment outlined in this Chapter and was split into three stages:

1. Establishing what was important in the current Net ZEB's circumstances by systematic removal of individual building challenge 'solutions.' A model was used to simulate the current Net ZEB in its current climate to assess the existing energy circumstances and what the main energy drivers were.

2. Changing the climate to see to what extent the original solution set was climate dependent. The current building was then simulated in the new climate and compared to the current building circumstances to assess how the climate interacted with the current building's solution set.

3. Using existing solution sets from other Net ZEBs in similar climates, site contexts and building types to make the building Net ZEB in this new climate. Net ZEB solution sets from existing non-residential Net ZEBs in a similar climate and building type were used to redesign the current building to reach Net ZEB again.

One of the group's results is presented as an example of the outcomes from the summer school. The group was supplied with the ENERPOS Building (French acronym for POSitive ENERgy) with the aim of redesigning it to be NZE in Christchurch New Zealand (Yip and Cory 2013). ENERPOS is a $681 \mathrm{~m}^{2}$ (net) educational building in Saint-Pierre, Reunion Island, a cooling dominated climate, in the Indian Ocean. The building was relocated to Christchurch, New Zealand, a mixed heating and cooling climate, with the challenge of redesigning it to be Net ZEB again. 
Table 8-1 below presents a comparison of the Christchurch and Saint-Pierre climate variables.

Table 8-1 - Comparison of Christchurch and Saint-Pierre climate variables.

\begin{tabular}{|l|l|l|}
\hline property & Original climate (Saint-Pierre) & New climate (Christchurch) \\
\hline Location & $21.3^{\circ} \mathrm{S}, 55.5^{\circ} \mathrm{E}$ & $43.5^{\circ} \mathrm{S}, 172.5^{\circ} \mathrm{E}$ \\
\hline Outdoor temperature range & $21^{\circ} \mathrm{C}$ to $27^{\circ} \mathrm{C}$ & $-4^{\circ} \mathrm{C}$ to $32^{\circ} \mathrm{C}$ \\
\hline Outdoor relative humidity & 68 to $72 \%$ & 60 to $80 \%$ \\
\hline Global horizontal irradiation & $\begin{array}{l}427 \text { to } 672 \mathrm{Wh} / \mathrm{m}^{2} \quad \text { (Average } \\
\text { hourly) }\end{array}$ & $\begin{array}{l}190 \text { to } 482 \mathrm{Wh} / \mathrm{m}^{2} \text { (Average } \\
\text { hourly) }\end{array}$ \\
\hline Daily horizontal illumination & $27 \mathrm{klux}$ to $42 \mathrm{klux}$ & $18 \mathrm{klux}$ to $52 \mathrm{klux}$ \\
\hline Wind speed range & 2 to $3 \mathrm{~m} / \mathrm{sec}$ & 3 to $5 \mathrm{~m} / \mathrm{sec}$ \\
\hline
\end{tabular}

The results established that the ENERPOS building was cooling focused. On relocation to Christchurch, the building required a substantial amount of heating energy and had reduced PV generation capabilities. It was identified that the goal of the solution set analysis should rectify these problems. The solution set analysis used existing Net ZEBs built in mixed heating and cooling climates to inform the redesign changes. New ECMS were identified that focussed on reducing heating and lighting consumption. Reducing lighting consumption was important due to the loss in PV generation and meant that if just the heating problem was rectified, it would still result in excess energy needing to be consumed from the grid. Five common features across five existing Net ZEBs formed a suitable heating challenge solution set as a starting point for the redesign of ENERPOS. This solution set was comprised of: increased passive solar access; insulation of the whole envelope and exposed thermal mass; glazing allowing for solar gains; electric light dimming; and a reconfiguring of the rooftop PV array. 
Figure 8-5 illustrates the findings and redesign (in red text) of the ENERPOS building using the additional ECMs identified.

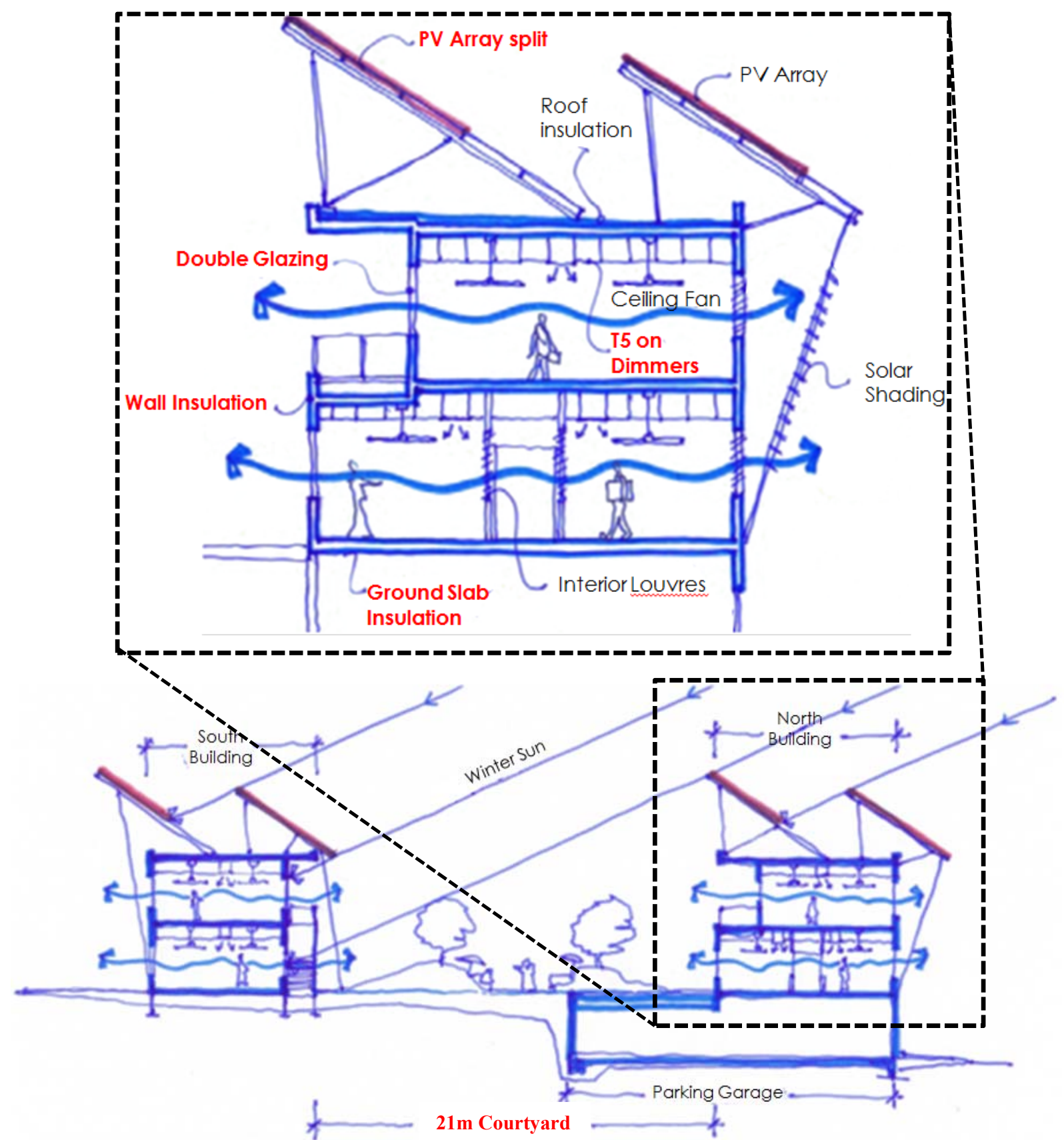

Figure 8-5 : Redesign of ENERPOS building for Christchurch using existing solution sets from other non-residential buildings in a similar climate and site context (Yip and Cory 2013).

Figures 8-6 and 8-7 present the thermal comfort and energy performance results of the initial design and redesign of the ENERPOS building located in Christchurch. As shown, the results of the redesign were positive. The building went from having a large number of hours that were uncomfortable for building occupants to being comfortable for almost 100 percent of the 
occupied hours. The redesigned building had almost no heating energy consumption from the added insulation, thermal mass, and passive solar heat gain access. The reconfigured PV array increased the generation capabilities of the system meaning with the electric lighting dimming reduced lighting consumption; the net energy consumption was below zero. The results showed that the addition of a heating solution set established from existing Net ZEBs in a similar climate to Christchurch enabled the ENERPOS Building to once again be a Net ZEB in the Christchurch climate.

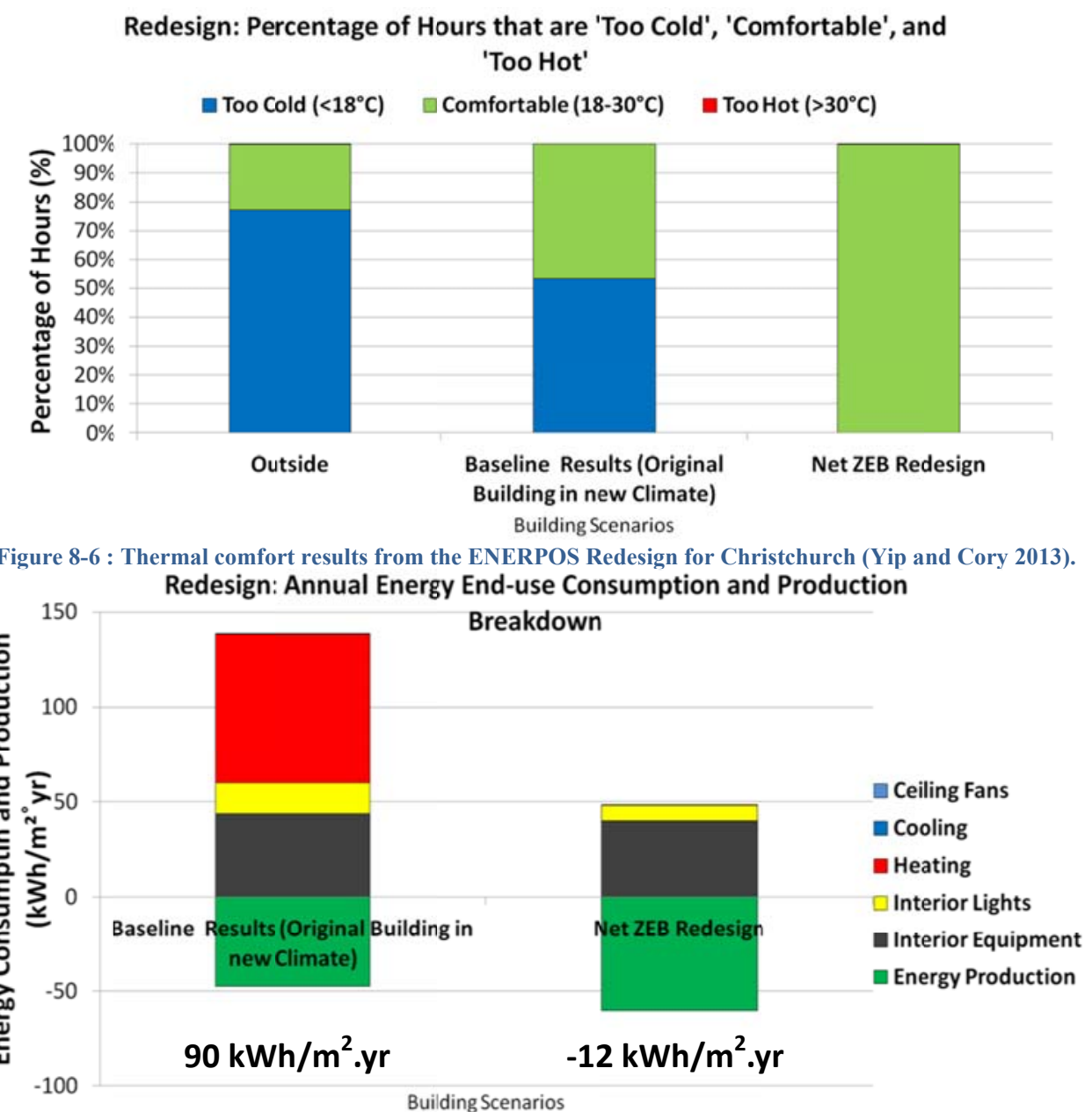

Figure 8-7 : Energy Consumption results from the ENERPOS Redesign for Christchurch (Yip and Cory 2013).

Overall, the summer school results concluded that the use of existing building solution sets was a good starting point for redesigning buildings to be net zero energy, and that they could be used to design new Net ZEBs. The Net ZEB redesign exercise showed that following precedents from existing solution sets for the climate and building type being considered provides a clear starting point for building redesign to net zero energy. Without the precedents, there could potentially be an unlimited number of design and technological options that could be used to redesign a building. The example of the ENERPOS Building being redesigned to be net zero energy 
using precedents provided the proof of concept for using CBR to assess solution sets to apply to the New Zealand commercial building stock retrofit.

\subsection{6b Second stage solution set assessment: Cost and Feasibility.}

The aim of re-using solution sets was to provide an already working set of ECMs within the brainstorming stage of a project. It aimed to reduce the number of ECMs that could be identified to a list of ECMs that have already been found to work in a particular building. However, the next step in a project would be to assess the cost effectiveness and technical feasibility for the solution set. Cost effectiveness indicates whether a solution set pays itself back within a reasonable amount of time (PNNL, PECI, and U.S. Department of Energy 2011).Technical feasibility refers to the capability of the proposed solution set to be a viable option, in a constructed and/or cost sense (Project Auditors 2014). Cost and feasibility are partly determined by the building requirement and solution set determinants, and partly by the individual building project circumstances. For example, each building project brief has its own cost budget to adhere to and therefore, the cost and feasibility analysis would be performed once the set of ECMs is chosen. Existing solution sets have already been reduced from a larger list of possible ECMs to a smaller list that are cost effective and feasible (PNNL, PECI, and U.S. Department of Energy 2011) meaning the ECMs should already be relatively cost effective and technically feasible in that particular climate, site context and building type.

In the case of this study, the solution sets were still assessed to see if they were technically feasible in a retrofit project. This included a decision of whether a particular ECM could be used in an existing building design or whether it was outside the scope of the type of works being proposed. For example, if an ECM required half of the building to be demolished, it was considered outside the scope of the study and could not be implemented in the final solution set. Once the solution sets were established and implemented, they were assessed to see if they were capable of converting the current building stock to be NZE, and whether they did this in a cost effective manner (analysis performed in Chapter 11).

\subsection{Solution sets used in $\mathbf{2 1}$ case study non-residential Net Zero Energy Buildings}

The IEA task 40 project's database was made up of 30 case study buildings, with 21 of the projects being non-residential buildings. To determine an appropriate set of ECMs for use in converting New Zealand's commercial buildings (non-residential buildings) to NZE, the 21 nonresidential buildings in the Task 40 projects database were assessed. Seven of the 21 nonresidential buildings formed a smaller group of buildings which were used to determine any lessons learned once the buildings were constructed and operated. The lessons learned were extracted from the design teams using the methodology described in Section 5.2.3c. The gathered lessons learned related to the design process of Net ZEBs, the ECMs used in the Net ZEB, and the post-construction evaluation of Net ZEBs. 


\subsubsection{Suitability assessment of existing solution sets for New Zealand}

Because the solution sets were taken from existing building cases, their analysis was a form of CBR in design. Using CBR theory and a developed understanding of solution sets, it was established that a particular solution set will work in a particular climate, site context, and building type. An assessment presented in Sections 8.3.1a and 8.3.1b identified a set of ECMs that could be used to retrofit the New Zealand commercial building stock. The assessment firstly compared the New Zealand climates and the climates from which the 21 non-residential Net ZEBs were located. The climate assessment identified solution sets that work in a similar climate and building type to that of New Zealand's commercial building stock. Once a set of existing Net ZEB solution sets were identified, they were assessed to establish a combination of working ECMs to form a solution set to use in the retrofit of New Zealand's commercial buildings. The combination of ECMs was decided upon by the uptake rate they were used in the range of nonresidential buildings in a similar climate to New Zealand's.

A preliminary criterion for solution sets to be included in the CBR assessment is that the buildings be net zero, near zero or low energy buildings (as defined by the IEA Task 40 research project). The buildings were/are either designed to be or are in operation net zero, near zero or low energy buildings and for this reason they were included in the CBR analysis. Debating or critiquing the buildings further is not performed in this thesis. This is due to the focus being on the set of ECMs. The analysis of individual ECMs and whether they work in reality were undertaken using the CBR analysis (Section 8.3.1) as well as deriving the lessons learned by the design teams of the Net ZEBs (Section 8.3.2). Furthermore, this critique of whether each building is/was net zero energy was performed by the IEA task 40 project from which the solution set information was drawn (IEA-SHC 2013a; IEA-SHC 2013c; Garde and Donn 2014).

With this said, it is acknowledged that a building designed to be net zero energy does not mean it is/will be net zero energy in reality. This is due to the assumptions that can be made in the design process and how they differ to real building operation (refer to Section 5.3.1b). However, with only design data available for some buildings, they were included in the CBR analysis.

\subsection{1a New Zealand and IEA case study Net ZEB locations climate analysis}

A climate analysis was performed to determine which of the 21 Net ZEB solution sets worked in a similar climate to New Zealand's. The climate analysis examined the seven New Zealand and 21 IEA Net ZEB building climates, using the Building Climate Classification method to assess which building solution sets were suitable and whether there were any extreme differences in climate.

Figure 8-8 and 8-9 display the non-residential building climate breakdown for each of the New Zealand climates used in the Stock Aggregation procedure and each of the IEA case study Net ZEB locations. Figure 8-8 shows the number and percentage of comfort hours (in black) and building climate challenges (temperatures in green and humidity in orange) for each climate. Figure 8-9 shows the building climate potential (solar in purple, daylight in red, and wind in 
blue) for each climate. A rectangular plot was overlaid on each building climate challenge and potential graph to highlight the range of climate variability across the New Zealand climates. The range can be directly compared to the IEA case study Net ZEB climates.

As seen in the comfort plot (Figure 8-8), New Zealand climates had on average 38 percent more comfort hours than the IEA case study Net ZEB climates. This, coupled with the smaller range of climate variability displayed by the overlaid brown rectangular plot on each graph, suggested that New Zealand's climates were more moderate than some IEA Net ZEB locations. This was especially noticeable in Northland and Auckland which both had on average 52 percent more comfort hours than the IEA Net ZEB locations. However, from a comfort hour perspective, there were four New Zealand climates that were comparable to four IEA climates. One of these climates was for Wellington, New Zealand (the Meridian Building). Pixel AU is located in Melbourne, Australia and was the other climate that had similarities with New Zealand Climates. The other two IEA climates with similar comfort hours were extreme cooling climates which differ greatly to the New Zealand climates. Fourteen out of the 18 IEA climates had heating and cooling challenges and humidity within the same range as New Zealand. All 14 climates also had similar percentages of heating and cooling hours to New Zealand.

The commonalities were similar for the building climate potentials (Figure 8-9). When assessing the useful solar potential in the New Zealand climates it was seen that some New Zealand climates have less solar gains than the IEA locations, and some required more protection from excess solar gains. The majority of IEA locations' useful daylight potential fell inside the New Zealand useful daylight climate range. Two IEA climates had less useful daylight than the New Zealand climates, while two had more non-useful daylight. New Zealand's wind climate was more suitable for natural cooling than most of the IEA climates. This was determined by the higher percentage of useful wind in New Zealand's climates compared to the IEA climates. This suggested that the outdoor conditions in New Zealand were usually suitable to cool buildings all year round and supports the theory that New Zealand climates are more moderate than the IEA climates.

The climate challenges and potentials did not vary dramatically in New Zealand and were mostly Mixed Heating and Cooling climates. The two Cooling Dominated climates even had 20 percent or more heating challenge and were not considered an extreme cooling climate like the climates that the Enerpos, Ilet du Centre, and ZEB BCAA case study Net ZEBs are situated in. This indicated that the New Zealand solution sets would still need to address some heating challenges and hence, the solution set to be implemented in the refurbishment of New Zealand commercial buildings was influenced by the IEA case study Net ZEBs located in Mixed Heating and Cooling climates. 


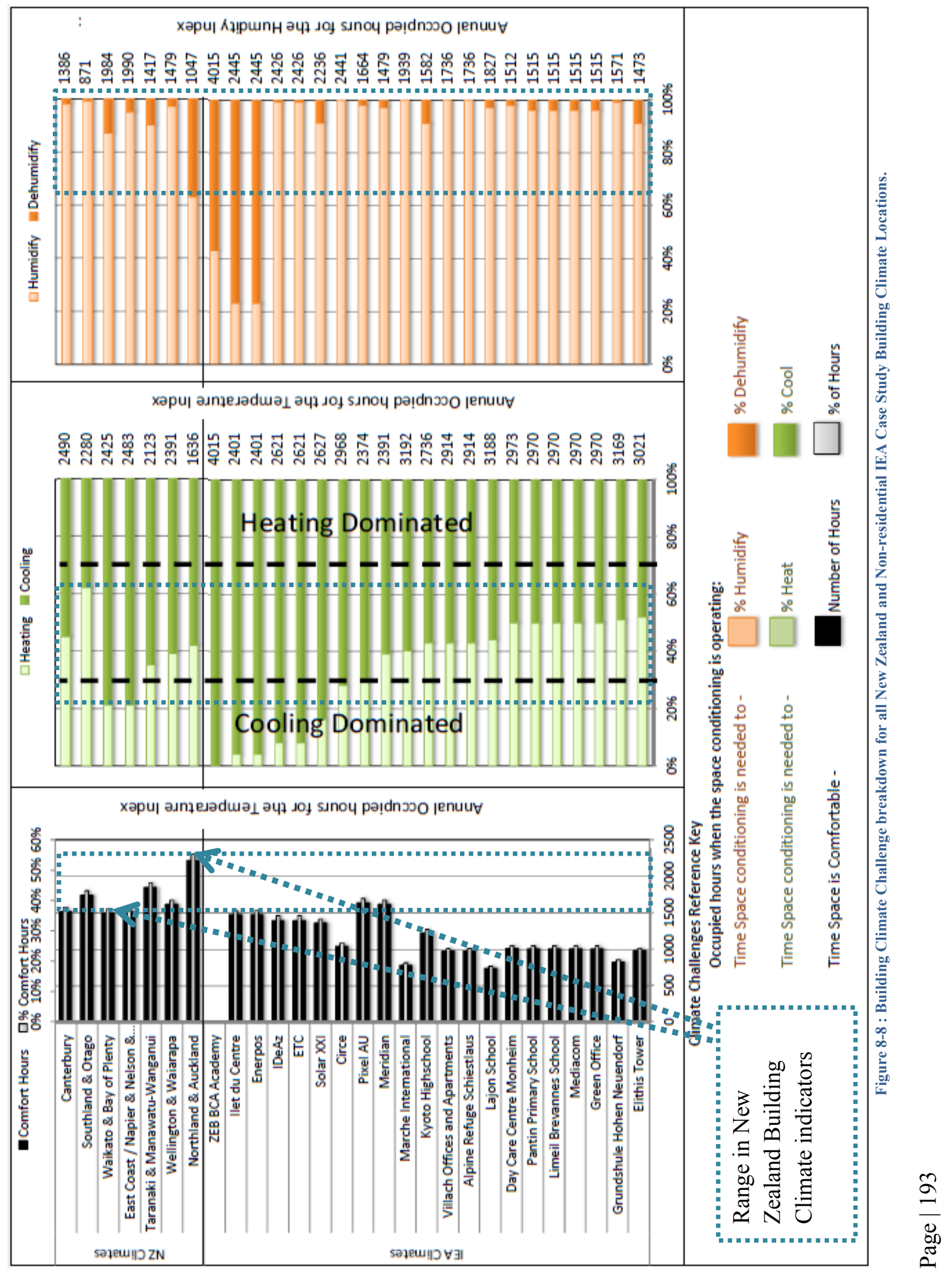




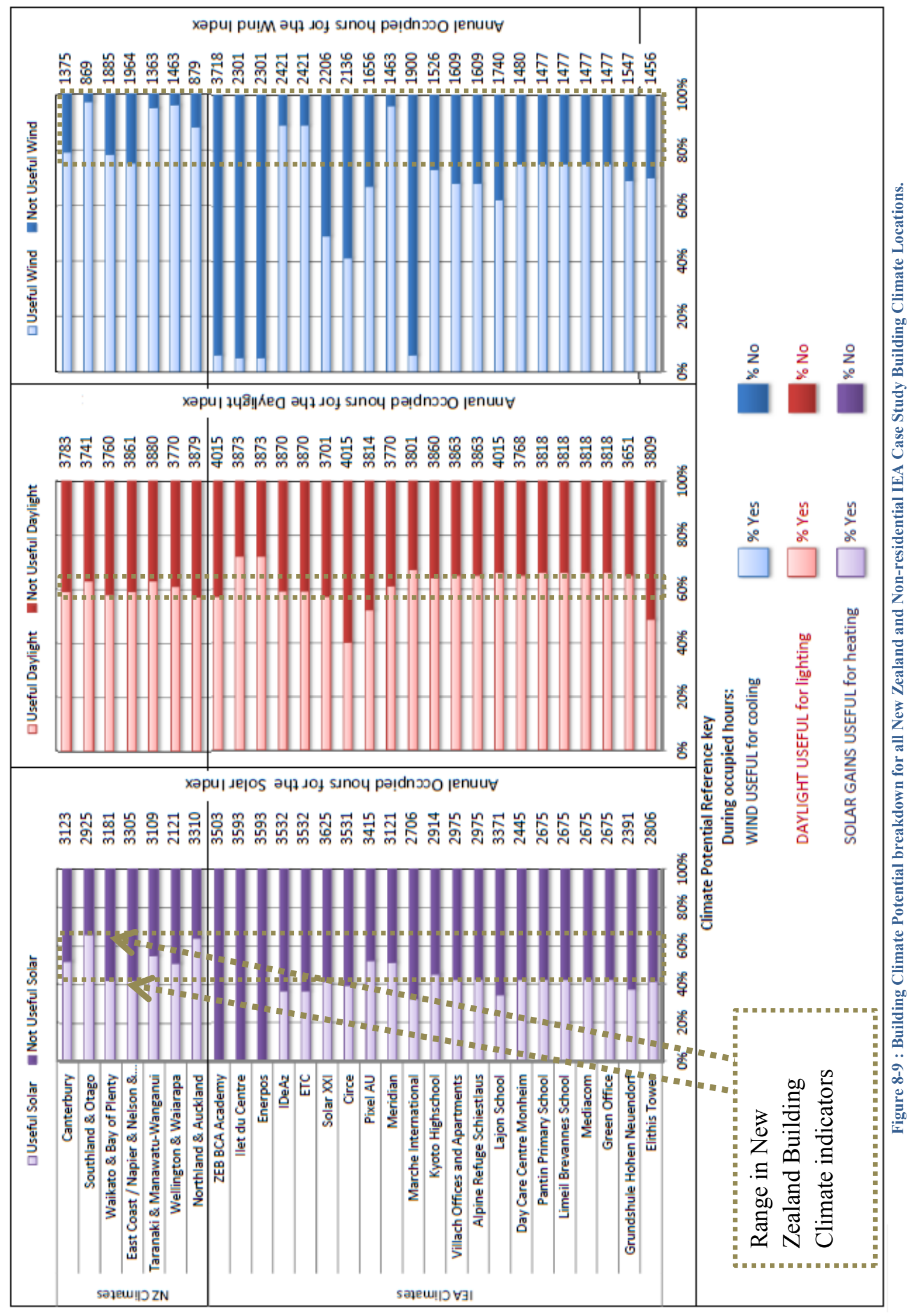

$\frac{5}{8}$ 


\subsection{1b Analysis of 21 suitable existing Net ZEB solution sets}

The climate analysis concluded that Mixed Heating and Cooling climate based buildings would form the cases to provide solution sets for New Zealand commercial buildings. Net ZEB solution sets in cooling dominated climates were also assessed to provide further lessons on cooling solution sets and the 21 non-residential Net ZEB solution sets determined what ECMs were applicable to New Zealand and which should be used to form the New Zealand commercial building retrofit solution set. An assessment of the type of solution sets found across the IEA case study Net ZEBs was undertaken to determine which ones should be used in the two climate types, three site contexts and four building sizes. The assessment identified if there were any major differences between existing solution sets needing to be allowed for in the production of a Net ZEB solution set to be implemented in this study. The Net ZEB solution sets were attained from the IEA Task 40 STC database (Garde and Donn 2014; IEA-SHC 2013c).

To aid in the assessment, a working definition was proposed for what was to be considered an ECM that should be included in the New Zealand commercial building solution. An ECM was considered for the final Net ZEB retrofit solution set if it was implemented in 25 percent or more of the example Net ZEBs. This meant that the ECM was implemented in five or more of the 19 case study Net ZEBs in a mixed heating and cooling climate. Five or more was used due to the ideology presented by (Nielsen and Landauer 1993). When the ideology is adapted for the purpose of CBR, it is: 80 percent of all the lessons will have been identified after only 5 to 7 individual base cases are consulted. For this reason, if an ECM was implemented in five or more of the 19 case study Net ZEB solution sets in a mixed heating and cooling climate, that ECM was used to retrofit the New Zealand commercial building stock. 
Figure 8-10 displays a comparison between the percentage uptake of ECMs in the IEA Net ZEBs located in Cooling Dominated (blue), and Mixed Heating and Cooling (red) climates. The dotted box overlaid onto the graph displays the ECM's used in over 25 percent of the buildings. They were highlighted to show the trends in solution set uptake between climates. The Cooling dominated climate was displayed to establish if the cooling solution set varied significantly between climates.

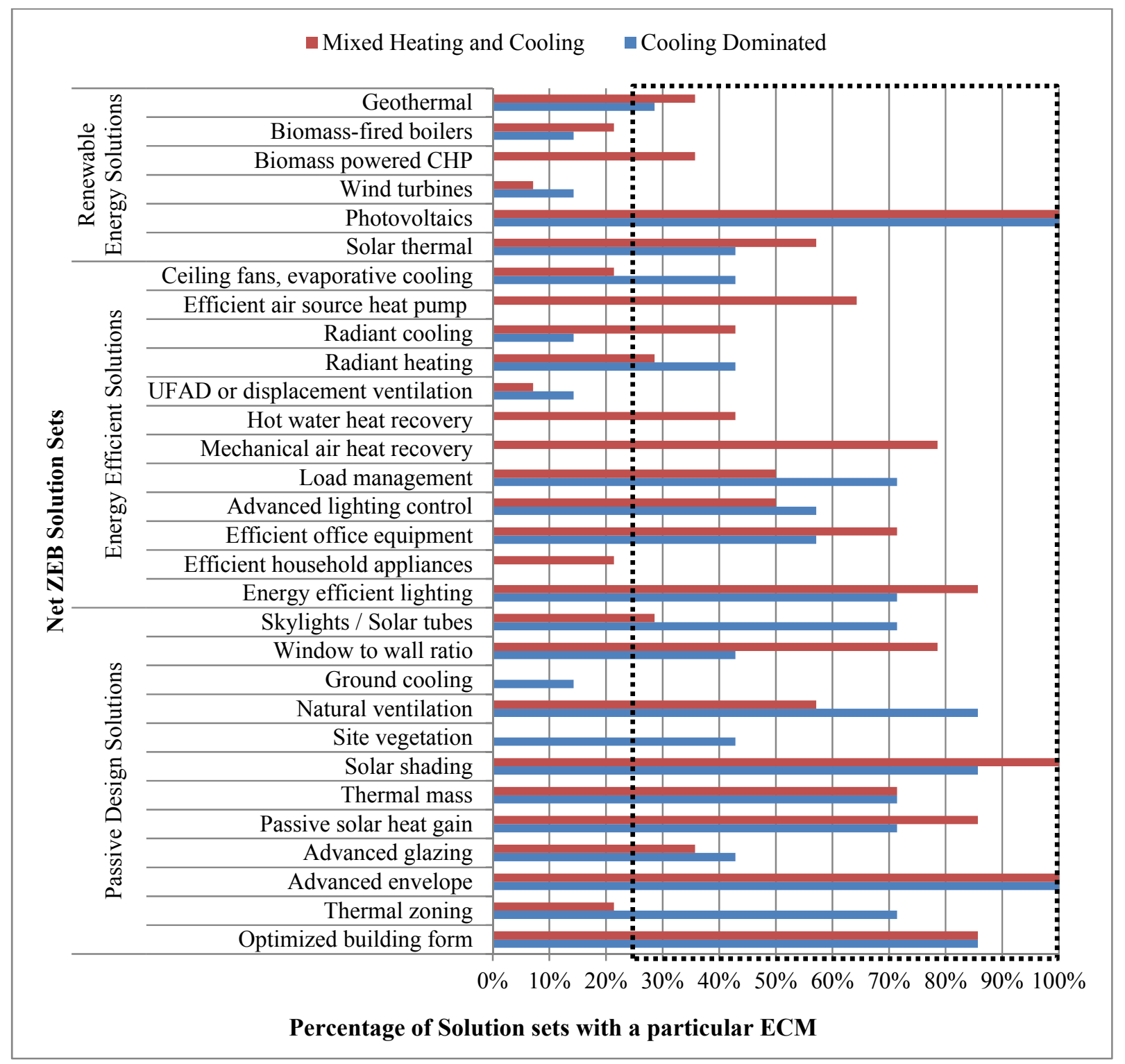

Figure 8-10 : A Non-residential Climate Comparison of Whole Building Solution Set Implementation.

Twenty solutions were used in 25 percent or more of the Net ZEBs in a Cooling Dominated climate while 21 were used in a Mixed Heating and Cooling climate. If an ECM was used in more than, or less than, 25 percent of the buildings in both climates it was considered not climate 
specific. This was seen in 15 of those ECMs that were implemented in 25 percent or more of the buildings. An example of a climate specific solution was Ground cooling. Ground cooling was only found in a Cooling Dominated climate. Mechanical ventilation heat recovery, hot water heat recovery, efficient air source heat pump, and Biomass fired CHP were only found in Mixed Heating and Cooling climates. Because buildings in hot climates do not require a lot of heating, it was assessed that heat recovery and CHP would not be as effective as they would be in cooler climates.

The results indicated that the solution sets did not differ greatly between Net ZEBs in the different IEA climates. With this concluded, a final solution set could be applied to all buildings in different New Zealand climates. However, because all seven New Zealand climates had at least a 20 percent portion of the heating challenge, those ECMs that were generally only used in cooling dominated climates were excluded. 
Figure 8-11 displays a comparison between the percentages of ECM uptake in each of the IEA Net ZEBs located in an Open Site (blue), Suburban Site (red), and Urban Site (green). ${ }^{6}$ Eighteen ECMs in an open site, 24 ECMs in a suburban site, and 22 ECMs in an urban site were implemented in over 25 percent of buildings. 20 of those ECMs were implemented in over 25 percent of buildings regardless of their site context. It indicates that solution sets did not differ greatly between Net ZEBs in different site contexts. With this concluded, a final solution set was reused, but adapted for, all site contexts.

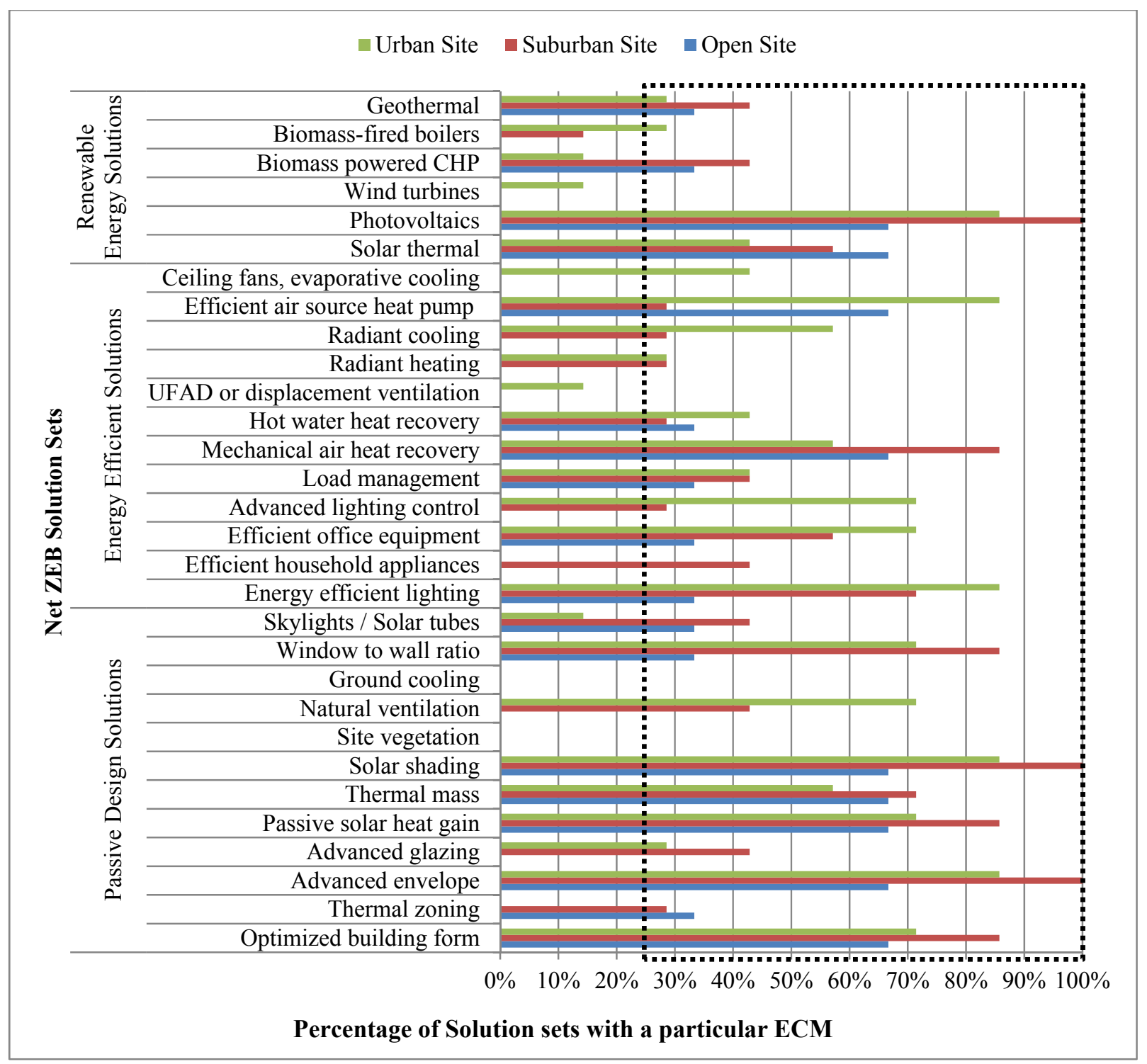

Figure 8-11 : A Non-residential Mixed Heating and Cooling Climate Comparison of Whole Building Solution Set Implementation.

\footnotetext{
${ }^{6}$ Note: Lajon School was located on a mixed open/suburban site. For this reason it was assessed within both site context types.
}

Page | 198 
Figure 8-12 displays a comparison between the percentage uptake of ECMs in the IEA Net ZEBs that are small (blue), medium (red), large low-rise (green), and large high-rise (purple) buildings. The dotted box overlaid onto the graph displays the ECMs used in over 25 percent of the buildings. The size categories were defined by the size characteristics of the BEES sample buildings:

- Small - less than $650 \mathrm{~m}^{2}$ and 1-2 Storeys in height.

- Medium - between $650-3500 \mathrm{~m}^{2}$ and 1-4 Storeys in height.

- Large Low-rise - greater than $3500 \mathrm{~m}^{2}$ and 1-3 Storeys in height.

- Large High-rise - greater than $3500 \mathrm{~m}^{2}$ and greater than 4 Storeys in height.

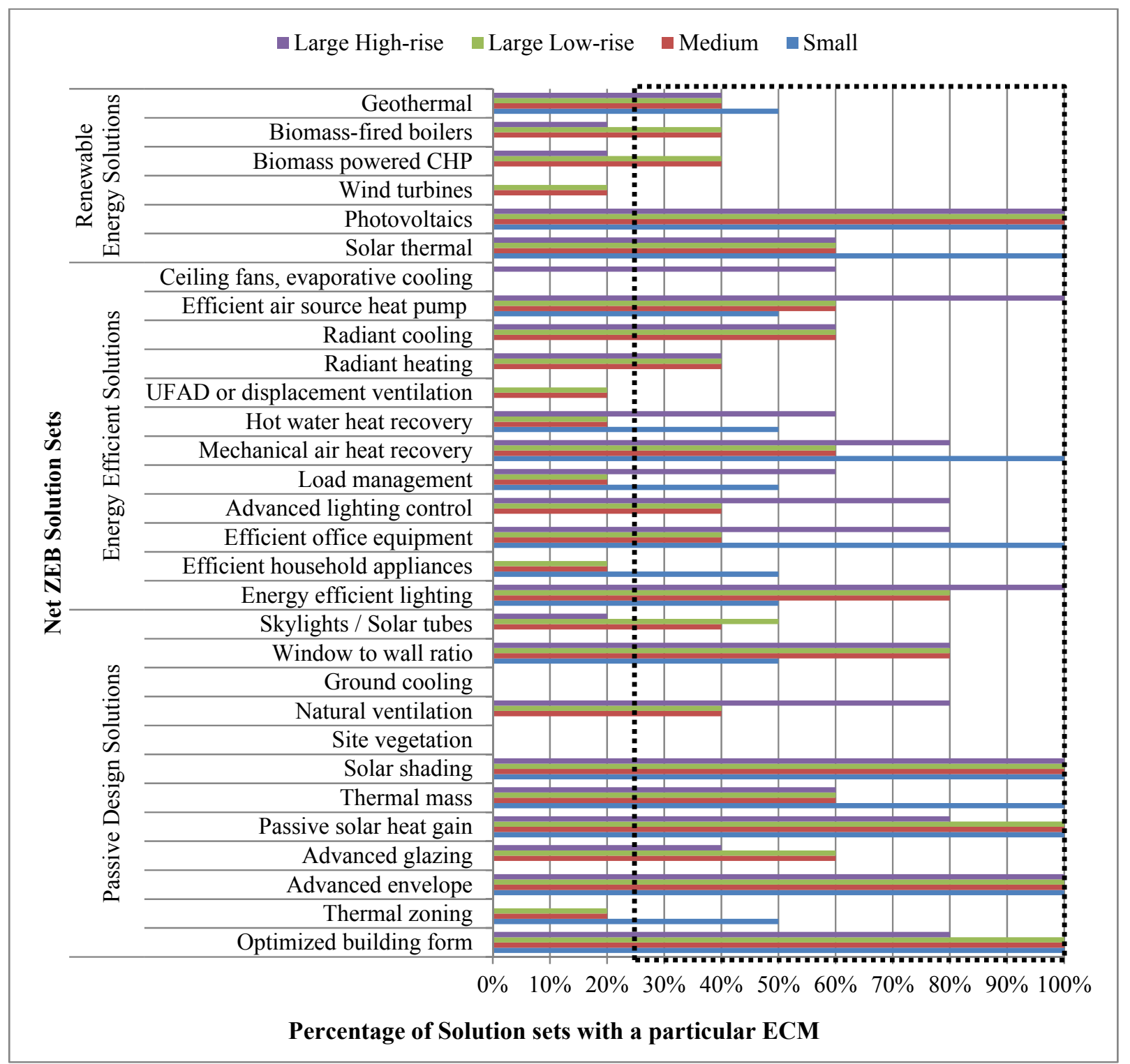

Figure 8-12 : A building size Comparison of Whole Building Solution Set Implementation in Non-residential Buildings in Mixed Heating and Cooling. 
Seventeen ECMs in small buildings, 21 ECMs in medium buildings, 21 ECMs in large low-rise buildings, and 21 ECMs in large high-rise buildings were implemented in over 25 percent of buildings. Thirteen of those ECMs were implemented in over 25 Percent of buildings, regardless of their size. This indicated that solution sets did not differ significantly between different sized Net ZEBs. However, when they did differ, it was due to the limitation of the ECM. For example, skylights and solar tubes were not implemented in small buildings. This was most likely due to a sufficient amount of daylight reaching all areas of the building without the use of skylights/solar tubes. The same could be inferred for large high-rise buildings which have a lower implementation rate when compared to large low-rise buildings. This is due to skylights/solar tubes only being effective for the top 1-2 storeys, meaning they would be less effective in highrise buildings.

The final solution set was then drawn at the climate level. ECMs which were implemented in 25 percent or more of the case study solution sets in a mixed heating and cooling climate were included in the final solution set. ECMs were also tailored to their building size to ensure practical energy savings, such as the case for skylights/solar tubes in small buildings that already have enough access to daylight or large high-rise buildings where they would be less effective.

\subsubsection{Design team lessons learned about existing Net ZEBs}

Analysis of interviews with seven Net ZEB building design teams provided an insight into the design process and the ECMs used in Net ZEBs. Information was extracted from the design teams regarding the performance of ECMs, and the most important design and operation aspects required to reach net zero energy. These lessons and guidelines should be taken into account when designing future Net ZEBs. These guidelines and lessons were split into the three following sections: Net ZEB design process, Net ZEB ECMs, and post-construction evaluation of Net ZEBs.

\subsection{2a Net ZEB Design process}

Net ZEB design process lessons help future designers understand how to meet the goal of building a Net ZEB in reality. The lessons learned by the design teams included:

- To achieve the goal of designing a Net ZEB, the aim of net zero energy needed to be decided upon from the very early design stages

- The design targets need to be scrutinised carefully. What is included in the Net ZEB energy balance? Are only the building utilities (heating, cooling, lighting) included, or are the user utilities (plug loads) also included (which would result in a building not being a Net ZEB in reality)?

- There was a definite hierarchy when designing Net ZEBs. First priority was to save as much energy passively through the design of the building, then use energy efficient technologies to enhance the energy savings, and then think about offsetting the residual energy consumption with renewable energy. 


\subsection{2b Net ZEB ECMs}

A major lesson concerning the Net ZEB ECMs was concerning a shift in the main energy enduse consumers in Net ZEBs. In three of the buildings the office equipment alone used up to 50 percent of the buildings' total energy consumption. One technique said to work well at reducing the office equipment energy end-use was to install laptops instead of desktop computers. Laptops use less energy compared to traditional desktop computers. Some interesting techniques were used to lower the energy consumption in the case study Net ZEBs, with the three most prominent being:

- Using ceiling fans to ventilate and cool the building: Installing no active cooling, as natural ventilation and ceiling fans are sufficient to keep the occupants comfortable. This was true regardless of climate as proven by case study buildings implementing this in a heating and cooling climate and an extreme cooling climate (tropical climate).

- Occupant behaviour was seen as a passive conservation feature. In one case it was said that the most important design feature was to alter the behaviour of the occupants to be more energy conservative (For example, making sure occupants used the installed computer load controls).

- Rethinking the space task lighting allowances and using occupant task lighting, including 6W LED desk lamps with occupancy sensors to provide for occupant lighting needs rather than lighting whole space during afterhours.

o Rethinking the general room task lighting level and considering setting the task lighting allowances to 200lux instead of 300lux. One design team interviewed occupants regarding this 200 lux limit and it was reported to be suitable.

\subsection{2c Post-construction Evaluation of the Net ZEBs}

Some interesting guidelines were established regarding what the design teams would and would not do in future buildings. The guidelines focused on specific solutions, in particular energy efficient and renewable energy technologies.

- It is suggested to research more efficient equipment and to use a central unit with only the screens in the office space.

- It is recommended to not use the slab as a radiant heating source, especially if the slab is not insulated.

- The cost benefits of having automated or manual adjustment and controls should be presented to the client to help them clearly understand the cost of using each system.

- Be wary of the weather files being used in the design of solar shadings, as they may not match reality well. 
8.3.2d Implications of Net ZEB lessons learned on a final solution set for New Zealand commercial buildings

The lessons learned from Net ZEB design teams had implications on the final set of chosen ECMs to be used in retrofitting New Zealand's commercial building stock. The first implication was that the Net ZEB goal was set and defined before analysis commenced. NZE included all energy end-uses, both building and user utilities, and was measured at the community level (Chapter 5). The second implication was that a design hierarchy was followed. This was achieved by optimising the final set of passive design ECMs to save as much energy as possible through passive means. The third implication was the option to exclude ECMs from the design if they did not work practically within the scope of retrofitting the buildings. For example, having an optimised building form could have been hindered by a retrofit scope indicating that large portions of the building could not be demolished. The fourth implication was energy efficient equipment was researched to provide most energy efficient options for computers as well as other appliances. The fifth implication was that a radiant floor slab was not used. The sixth implication was automated controls were used in the energy models to ensure energy savings are not based on occupant behaviour.

\subsubsection{Selecting an appropriate refurbishment solution set for retrofitting New Zealand commercial buildings}

With existing solution sets assessed and lessons provided on the design of Net ZEBs established, a final solution set was determined. After analysing the solution sets used in 21 Net ZEB case study buildings, it was decided that there was only a need for one solution set. This was due to all building climates having a mixture of heating and cooling challenges and also because there were no major differences between the types of ECMs used in non-residential buildings in different site contexts and building sizes. However, some differences occurred between building size and hence, the way the solution set was applied to each of the 48 BEES buildings differed depending on their size.

Table 8-2 shows the Solution Set that was made up of ECMs implemented in over 25 percent of the 21 Net ZEB case study buildings in a mixed heating and cooling climate. The table also contains comments regarding how and whether each ECM was used in the retrofit of the 48 BEES buildings. 


\begin{tabular}{|c|c|c|}
\hline & $\begin{array}{l}\text { ECMs used in over } 25 \% \text { of Net ZEB } \\
\text { case study solution sets }\end{array}$ & $\begin{array}{l}\text { Is ECM in the New Zealand Commercial Building Net ZEB } \\
\text { Refurbishment Solution Set and reason for adaptation or } \\
\text { exclusion }\end{array}$ \\
\hline \multirow{10}{*}{ 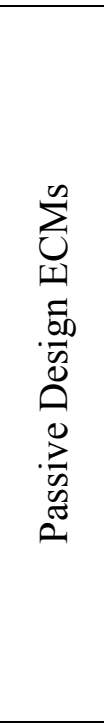 } & Optimized building form & $\begin{array}{l}\text { No, outside of retrofit scope as buildings could not be } \\
\text { reshaped or re-orientated. }\end{array}$ \\
\hline & Thermal zoning & $\begin{array}{l}\text { No, outside of retrofit scope as buildings could not be } \\
\text { reshaped or re-orientated. Also, energy model } \\
\text { representation of buildings does not allow it. }\end{array}$ \\
\hline & Advanced envelope & Yes \\
\hline & Advanced glazing & Yes \\
\hline & Passive solar heat gain & Yes \\
\hline & Thermal mass & $\begin{array}{l}\text { No, outside of retrofit scope as buildings could not be } \\
\text { reshaped or re-orientated, this includes replacing } \\
\text { whole construction. }\end{array}$ \\
\hline & Solar shading & Yes \\
\hline & Natural ventilation & Yes \\
\hline & Window to wall ratio & Yes \\
\hline & Skylights/Solar tubes & Yes, only in buildings that were 1-2 storeys in height. \\
\hline \multirow{7}{*}{ 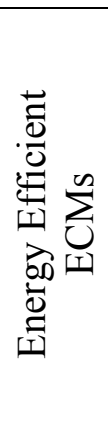 } & Energy efficient lighting & Yes \\
\hline & Efficient office equipment & Yes \\
\hline & Advanced lighting control & Yes \\
\hline & Load management & No, outside scope of NZE definition. \\
\hline & Radiant heating and cooling & $\begin{array}{l}\text { No, outside of retrofit scope as building structure } \\
\text { could not be altered. }\end{array}$ \\
\hline & Mechanical air heat recovery & Yes, in combination with heat pumps. \\
\hline & $\begin{array}{l}\text { Efficient air source heat } \\
\text { pump }\end{array}$ & Yes \\
\hline \multirow{4}{*}{ 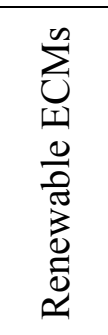 } & Solar thermal & $\begin{array}{l}\text { No, differentiation in the hot water energy end-use in } \\
\text { the } 48 \text { BEES buildings was not } 100 \text { percent reliable. }\end{array}$ \\
\hline & Photovoltaics & Yes \\
\hline & Biomass powered CHP & $\begin{array}{l}\text { No, efficient air source heat pump was implemented in } \\
\text { more buildings and was chosen over CHP. }\end{array}$ \\
\hline & Geothermal & $\begin{array}{l}\text { No, outside of retrofit scope as buildings as requires } \\
\text { space outside scope of site boundary. }\end{array}$ \\
\hline
\end{tabular}

The highlighted red cells in Table 8-2 display ECMs that could not be used in the final solution set. They were not used due to the limitations posed from the refurbishment concept of the study. The first limitation was that the building could not be reoriented or reshaped in any way and as such, optimising the building's form was not included in the final solution set. Because over 80 percent of all the Net ZEB case study buildings implement an optimised building form, it was suggested that this could be integral in achieving net zero energy. Many of the other ECMs' performance would be amplified when used in combination with an optimised building form. For

Page $\mid 203$ 
example, daylighting and natural ventilation would be enhanced in a shallow plan building when compared to a deep plan building. The performance would have been enhanced because more floor area has access to natural lighting and natural cooling resulting in less electrical lighting and cooling. This limitation also made Geothermal unfeasible. Geothermal uses the ground as a heat sink to improve the performance of a heat pump. Geothermal requires an underground piping network which may or may not be practical within a building's boundary and for this reason, it was not tested. The second limitation was that the building structure could not be altered. Consequently, it made a structure based radiant heating or cooling system unfeasible. The third limitation was imposed by the NZE definition that retrofitted buildings must provide the same function and level of service as they currently provided. This meant Load management (refer Table 23) was not tested as it potentially could have altered the building's service provision.

Two further ECMs were not implemented. Biomass fuelled CHP (refer Table 23) was not tested. This was due to two other ECMs (efficient air sourced heat pump and photovoltaic system) fulfilling the purpose of CHP and with each ECM implemented in a higher percentage of the assessed Net ZEBs than CHP. Solar thermal hot water was not implemented because the hot water energy use was not separately modelled in all of the 48 BEES energy models. It was not modelled separately due to limitations of the detailed energy use monitored data that was supplied by the BEES study. The data did not differentiate the hot water energy use from internal equipment.

The highlighted orange cell (refer Table 8-2) shows the ECM that was adapted and implemented for different building sizes. Skylights/Solar tubes had the best effect in 1-2 storey buildings, and as such were only implemented in buildings with 1-2 storeys that were deep enough to require them.

The result is thirteen of the twenty one ECMs in Table 8-2 were used in the final solution set implemented in this thesis.

\subsubsection{The Energy Conservation Measures that make up the New Zealand Commercial Building Net ZEB Solution Set}

Thirteen individual ECMs make up the solution set that was used to refurbish the New Zealand commercial building stock. Each ECM was added to each of the 48 BEES building calibrated energy models to enable the testing of NZE. The retrofitted energy model results were Stock Aggregated using the approach detailed in Section 6.5. A brief description of the ECMs is provided below (some of the thirteen individual ECMs have been grouped together to form 9 sections). Appendix 14.9 outlines the modelling input parameters and assumptions used to retrofit the 48 BEES models with the following ECMs.

\subsection{4a Advanced envelope and glazing}

An advanced envelope refers to well-insulated walls, floors and roofs. Insulation is important as it reduces the amount of heat flow through the building envelope. The reduction in heat flow Page $\mid 204$ 
refers to heat gains and losses which are the transmission of heat through the envelope induced by temperature differences (The American Institute of Architects 1982a). The transfer of heat through the envelope can reduce or increase the temperature inside the building resulting in the need for artificial heating or cooling. Insulation reduces the transmission of heat by increasing the thermal resistance of the building's fabric. A higher thermal resistance reduces the transmitting capability of heat through a building. There are numerous different insulation systems that can be used in a building envelope, such as internal insulation, external insulation, and vacuum insulation.

The Solution Set insulation used in this study was an external insulation system. The external insulation system was a simple layer of insulating material, such as polystyrene, attached to the existing external façade of a building. Figure 8-13 illustrates how the insulation system was retrofitted to each of the 48 BEES buildings. It is worth noting that given the retrofit scope does not mean removing sections of the building, insulation was not added beneath the existing floor construction.

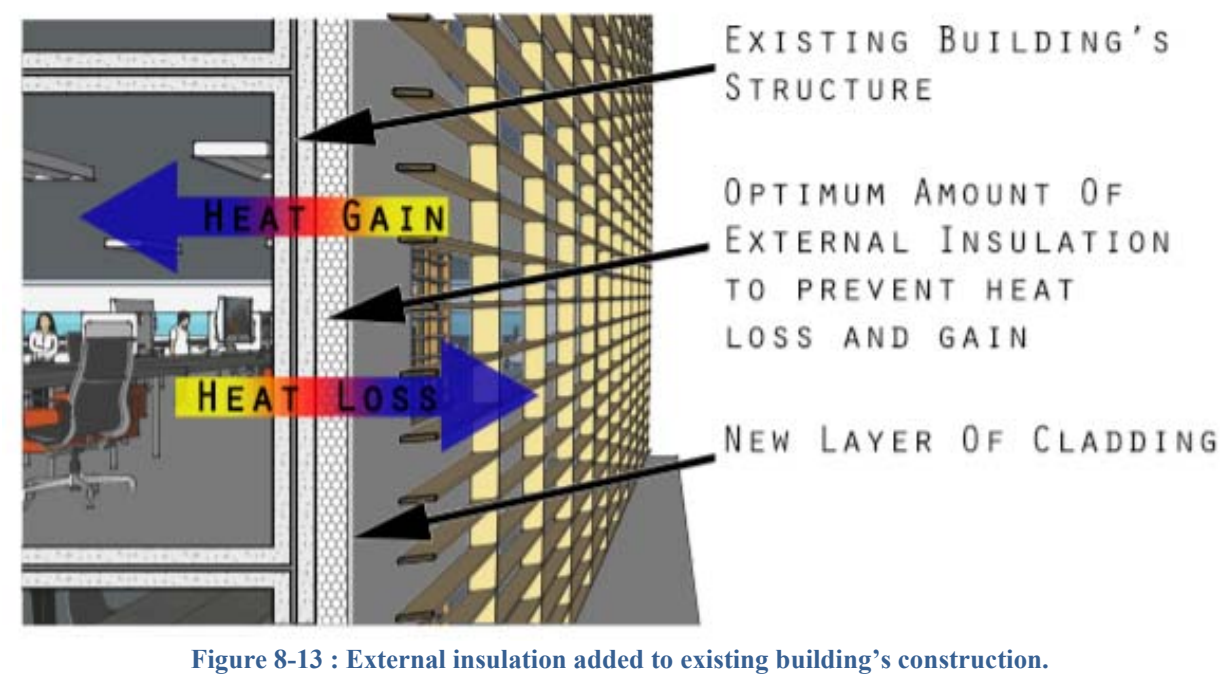

Advanced glazing works in the same way as an advanced envelope; it reduces the transmission of heat flows through the envelope. However, windows also provide daylight and solar heat gains into the building. Daylight is beneficial for reducing energy use as it can reduce the amount of electric lighting needs. Solar heat gains can be beneficial for reducing energy as they provide free heat to increase the temperature of the building spaces. However, excess solar heat gains can be a hindrance as the building space becomes too warm and needs to be mechanically cooled and hence, optimum window design is important in reducing energy consumption in buildings. Advanced glazing can result in lower heat loss, less air leakage, and warmer window surfaces that improve comfort and reduce energy consumption (Gregg D. Ander 2013c). Three aspects of window design create opportunities for saving energy. These include its insulation, represented 
as a U-Value (unit of thermal transmittance), its visible transmittance, and its solar heat transmittance, represented by its Solar Heat Gain Coefficient (SHGC).

Figure 8-14 illustrates how the advanced glazing is combined with solar shading to provide an optimum level of passive solar heat gain into the building space (optimum SHGC), while also reducing the heat gain and losses through the envelope (good U-Value) without hindering daylight performance (optimum visible transmittance). Section 8.4.1c presents the different windows used in the retrofit.

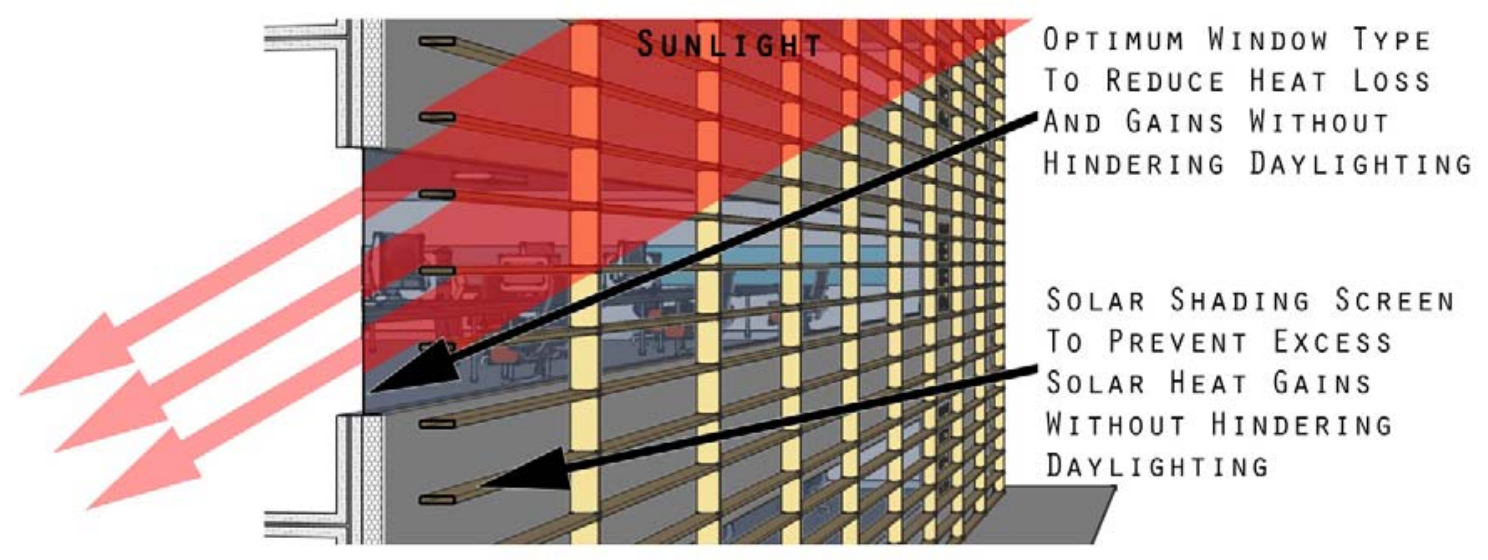

Figure 8-14 : Combination of window type and solar shading used to provide need solar heat gains and daylight levels while excluding unwanted solar heat gains.

\subsection{4b Solar shading}

Solar shading is an important design technique used in successful daylight design. Beyond adding windows to a space, daylighting involves the careful balancing of heat gain and loss, glare control, and variations in daylight availability (Gregg D. Ander 2013a). Solar shading is utilised to balance heat gains and losses by reducing excess solar heat gains without jeopardising the required solar heat gains. Buildings heat up when solar heat gains penetrate into building spaces. If there are excess solar heat gains, the building will heat up too much and will require mechanical cooling, which uses energy. To reduce energy consumption induced by excess solar heat gains, solar shading is therefore implemented. Solar shading uses shading elements to block the solar heat from entering the building. Shading can be provided by natural landscaping or by building elements such as awnings, overhangs, fins and louvres (Prowler 2013). Figure 8-14 illustrates the solar shading technique (louvre system) used to reduce the access of solar heat gains into the 48 BEES buildings. Section 8.3.1a presents the method to model the addition of the louvre system to each of the 48 BEES buildings.

\subsection{4c Passive solar heat gain}

Passive solar heat gain refers to the sun's heat energy. Passive solar heating systems utilise the solar heat gain to heat building spaces for free. Typically, passive solar heating involves:

- The collection of solar energy through properly-oriented windows;

Page $\mid 206$ 
- The storage of solar heat energy in thermal mass, such as concrete slabs, brick walls, or tile floors;

- The distribution of the stored solar heat energy back to the building spaces when required through the natural convection and radiation; and

- Window specifications to allow for optimum solar heat gain coefficient.(Fosdick 2013)

The Solution Set used all three of the above aspects. However, as the construction of the 48 BEES buildings was unchanged, the performance of the passive solar heating in each of the buildings differed. For example, a building that was constructed out of concrete could perform better than one which was not.

\subsection{4d Natural ventilation}

Natural ventilation uses the natural forces of wind and buoyancy to deliver fresh air into buildings (Walker 2013). Natural ventilation utilises open-able/operable windows to allow outside (natural) air to enter the building. The naturally vented air is used to increase thermal comfort which reduces the need for mechanical ventilation and cooling (Liddament 1996). Figure 8-15 illustrates operable windows that allowed the 48 BEES buildings to utilise natural ventilation to reduce energy consumption. Appendix 14.9.2 outlines the natural ventilation modelling inputs and assumptions used to retrofit the 48 BEES models.

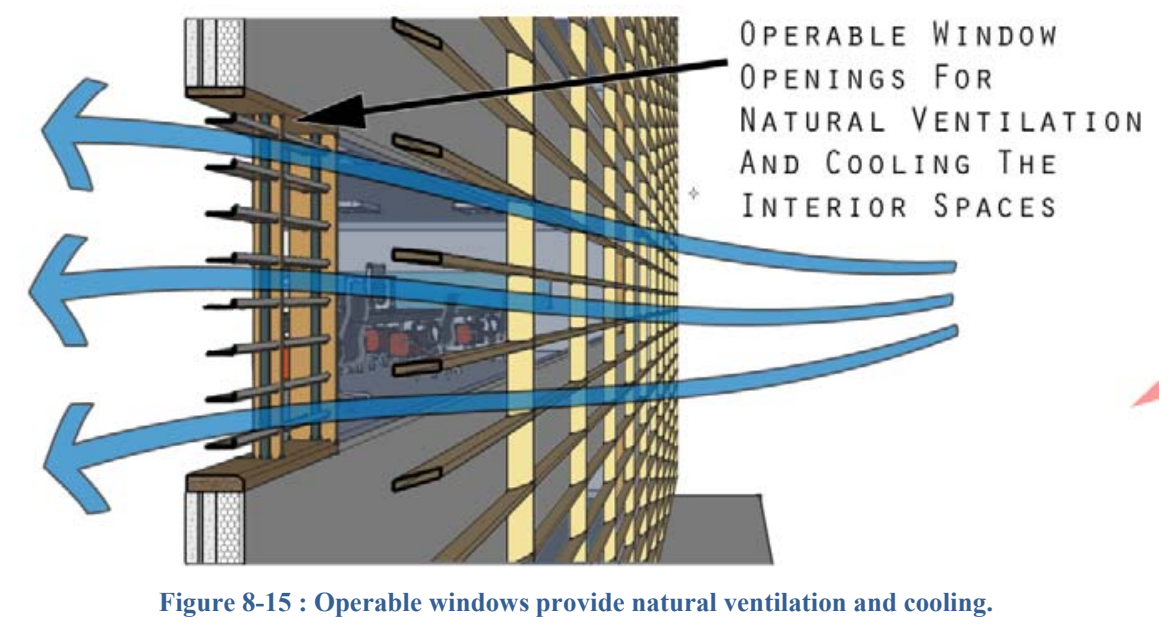

\subsection{4e Window to wall ratio (WWR) and Skylights / Solar tubes}

Window to Wall ratio is the size of the glazed area as a fraction of the wall façade area. A larger WWR allows for more daylight to enter the building to be used to reduce electric light consumption. However, if the window is too large, unwanted heat gain and losses can occur to the detriment of the saved electric light energy consumption. For this reason, the WWRs in the 48 BEES buildings were optimised to establish an appropriate sized window that would provide enough daylight to reduce lighting energy use; provide enough solar heat gains to reduce heating energy use; and reduce the heat flows (solar heat gains, envelope heat gains and losses) to reduce heating and cooling energy use. Figure 95 illustrates how the WWR worked with the electric 
lighting system to reduce energy in the 48 BEES buildings. Section 8.4 .1b presents the method used to retrofit the WWR in the 48 BEES buildings.

Skylights/Solar tubes provide the same opportunities as WWR. They provide daylight to reduce the need for electric lighting. Skylights refer to a simple glazed opening on a roof surface and pose the greatest threat of excess solar heat gains. High sun angles mean skylights allow direct sunlight, or solar heat energy, to penetrate into the building. In summer it can cause excess solar heat gains and increase the need for mechanical cooling. There are options which reduce this overheating risk, such as saw tooth skylights and solar tubes. Given the use of solar tubes (which are a type of Tubular Daylighting Device (TDD)) was specified in the Net ZEBs, they were the focus of the retrofit in this thesis.

Figure 8-16 displays the TDD device used in the retrofit of the 48 BEES buildings and illustrates how they work.

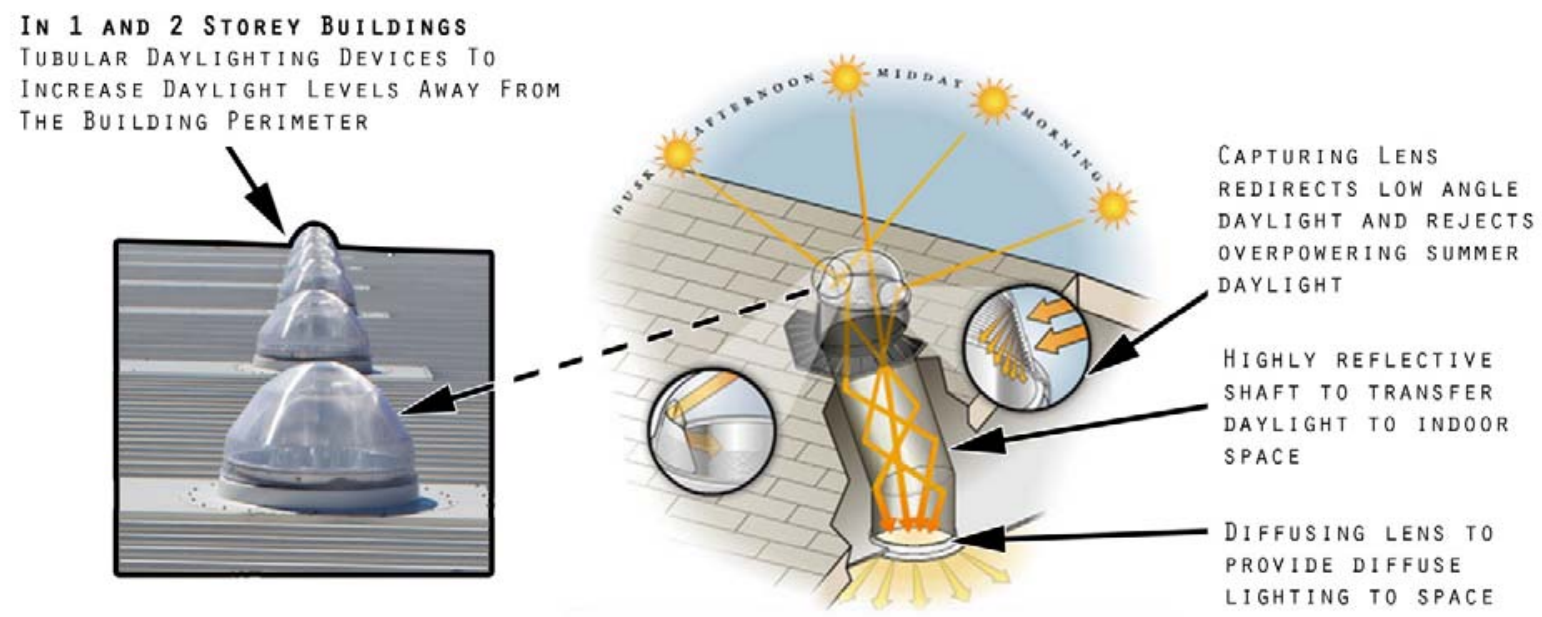

Figure 8-16 : TDD used in 1-2 storey buildings to provide daylight deep into a building floor plate. Diagram altered from (Inhabitat LLC 2014).

TDD devices employ a daylight redirection technique and use a highly reflective film on the interior of a tube to channel light from a lens at the roof, to a lens at the ceiling plane. TDDs allow for greater daylight penetration into a space with reduced heat gains and losses. The reduction in heat flows can be attributed partly to TDDs being smaller than a typical skylight, and partly to them having a higher thermal resistance than skylights. Another advantage of using TDDs is that they can provide light to lower building levels than skylights as they are effective at redirecting light up to $15 \mathrm{~m}$ (Solatube International Inc 2009). TDDs were installed as an ECM for BEES buildings with 1-2 storeys.

\subsection{4f Energy efficient lighting and advanced lighting control}

Energy efficient lighting refers to low energy electric lighting sources. The low energy lighting sources provide the same level of illumination, but consume less energy in doing so. There are 
numerous light types of varying efficiency available and implemented across the New Zealand commercial building stock. LED lamps are the newest addition to the list of energy efficient light sources and have a number of advantages, such as being very low energy and having the ability to be dimmed without hindering the light quality (David Nelson 2013; U.S. Department of Energy 2013b).

Table 8-3 provides a list of LED replacement lamp types for the more conventional lighting types with each lighting type's efficacy.

Table 8-3 : Efficacy comparison between the LED replacement lamps for conventional lamp technologies. Table adapted from (U.S.

\begin{tabular}{|c|c|c|c|c|}
\hline $\begin{array}{c}\text { Replaced } \\
\text { conventional } \\
\text { lamps }\end{array}$ & $\begin{array}{l}\text { Luminous } \\
\text { Efficacy (in } \\
\operatorname{lm} / \mathbf{W})\end{array}$ & $\begin{array}{l}\text { LED } \\
\text { replacement } \\
\text { lamps }\end{array}$ & $\begin{array}{l}\text { Luminous } \\
\text { Efficacy (in } \\
\operatorname{lm} / \mathbf{W} \text { ) }\end{array}$ & $\begin{array}{c}\text { Percentage } \\
\text { increase in } \\
\text { efficacy }\end{array}$ \\
\hline $\begin{array}{l}\text { Compact } \\
\text { fluorescent lamp }\end{array}$ & 73 & \multirow{2}{*}{$\begin{array}{l}\text { Replaced with } \\
\text { LED A19 lamp } \\
\text { (warm white) }\end{array}$} & \multirow{2}{*}{94} & $29 \%$ \\
\hline Incandescent & 15 & & & $527 \%$ \\
\hline Halogen & 20 & $\begin{array}{lr}\text { Replaced } & \text { with } \\
\text { LED } & \text { PAR38 } \\
\text { lamp } & \text { (warm } \\
\text { white) } & \end{array}$ & 78 & $290 \%$ \\
\hline $\begin{array}{l}\text { Linear } \\
\text { fluorescent } \\
\text { system }\end{array}$ & 108 & $\begin{array}{l}\text { Replaced with } \\
\text { LED troffer } \\
\text { (warm white) }\end{array}$ & 118 & $9 \%$ \\
\hline $\begin{array}{l}\text { High intensity } \\
\text { discharge system } \\
\text { (low watt) }\end{array}$ & 104 & \multirow{2}{*}{$\begin{array}{l}\text { Replaced with } \\
\text { LED high/low- } \\
\text { bay fixture } \\
\text { (warm white) }\end{array}$} & \multirow{2}{*}{119} & $14 \%$ \\
\hline $\begin{array}{l}\text { High intensity } \\
\text { discharge system } \\
\text { (high watt) }\end{array}$ & 115 & & & $3 \%$ \\
\hline
\end{tabular}

The efficacy of a light source is defined as "the ratio of power input to light output - or more technically, emitted flux (lumens) divided by power draw (watts)" (U.S. Department of Energy 2013c). The higher the efficacy, the more energy efficient the lighting source is. Because LED lamps have a higher efficacy, they were used to retrofit the current lighting in the New Zealand commercial building stock to be more efficient. The retrofit was calculated using the count of lamps in each of the 48 BEES buildings ascertained during the survey of each building. The counts of each lamp type were used to calculate a decrease in the installed lighting load if each conventional lighting type was replaced with the LED lamp types displayed in Table 8-3. Appendix 14.9.3 displays the original and reduced Lighting Power Density for each of the 48 BEES buildings.

Advanced lighting controls refer to daylight-responsive electric lighting controls. Advanced lighting controls are important because: 
"To be effective, daylighting must be integrated with electric lighting design. In particular, daylighting must be coupled with efficient electric lighting controls if net energy savings are to be realized. As part of a daylighting design, consider the use of continuously dimming fixtures controlled by luminous sensors. (Gregg D. Ander 2013b)"

The advanced lighting controls dim electric lighting depending on the amount of daylight on a working plane. They are essential as no daylighting design will save any energy unless the electric lights are dimmed or turned off when there is sufficient illumination from daylight (Gregg D. Ander 2013a). "Daylight-responsive lighting controls consist of continuous dimming or stepped ballasts in the light fixtures, and one or more photocells to sense the available light and dim or turn off the electric lighting in response. (Gregg D. Ander 2013a)" Dimming controls were installed in each of the 48 BEES buildings. Dimming controls continuously adjust the electric lighting by modulating the power input to lamps to complement the illumination level provided by daylight (Gregg D. Ander 2013a). The lighting controls work with an illuminance set point to dim the electric lights. The illuminance set point used in the 48 BEES buildings was 350 Lux in Offices and 500 Lux for Retail to meet the New Zealand Standard recommended illuminance level (Standards Association of Australia and Standards New Zealand 2006). These values also meet international recommendations (CIBSE 2002).

Figure 8-17 shows an illustration of how the lighting ECMs complemented each other and how they worked together to reduce a building's energy consumption.

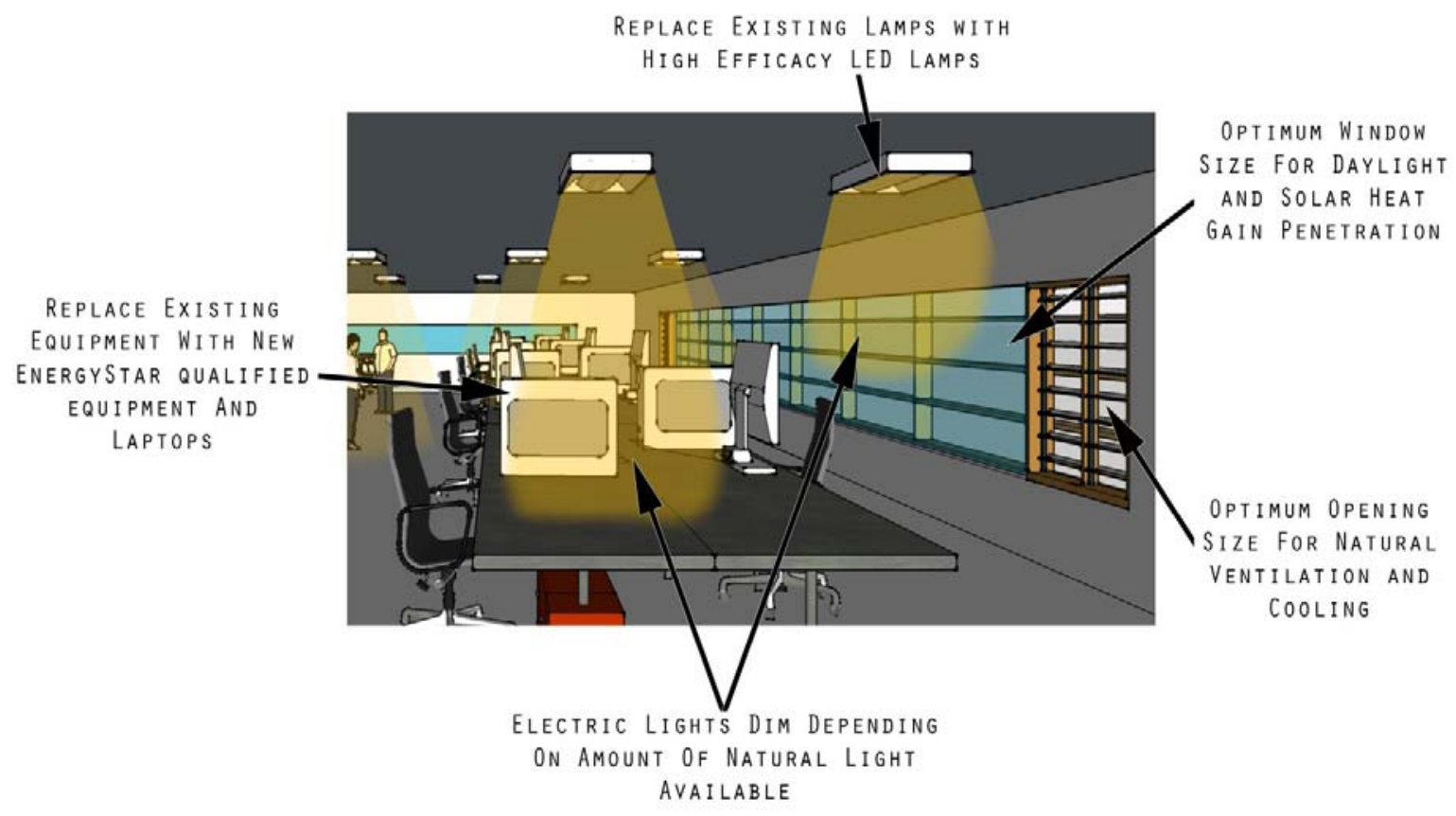

Figure 8-17 : ECM's used to reduce lighting and equipment energy in the 48 BEES buildings.

Page $\mid 210$ 


\subsection{4g Energy efficient office equipment}

Energy efficient office equipment is implemented in the same way as energy efficient lighting. The energy efficient office equipment provides the occupant with appliances to perform the same tasks, but the equipment consumes less energy in doing so. Energy efficient office equipment was implemented in the 48 BEES buildings by replacing the current equipment with more energy efficient versions. This was calculated by using the count of each equipment type and calculating the reduction in installed power density achieved with the more efficient appliances.

Table 8-4 displays the reduction in energy use of the installed appliance by replacing the current appliances with energy star rated appliances. The table displays a current performance for an individual appliance, determined by Thornton et al. (2009) and where available the BEES Monitored Data set, and the performance of EnergyStar rated appliances of the same type.

Table 8-4 : Office Equipment Inventory. Table adapted from (B. A. Thornton et al. 2009; Delmas and Donn 2013)

\begin{tabular}{|c|c|c|c|}
\hline Appliance type & $\begin{array}{l}\text { Current Power } \\
\text { Wattage (each) }\end{array}$ & $\begin{array}{ll}\text { EnergyStar } \quad \text { Rated } \\
\text { Appliance Power } \\
\text { Wattage (Each) } \\
\end{array}$ & $\begin{array}{l}\text { Percentage } \\
\text { reduction for } \\
\text { installed appliance }\end{array}$ \\
\hline $\begin{array}{l}\text { Computers } \\
\text { and monitor }\end{array}$ & $69 W^{*}$ & 17W (Laptop) & $75 \%$ \\
\hline Computer servers & $80-100 W^{*}$ & $54 \mathrm{~W}$ & $22 \%$ \\
\hline Printers & $215 \mathrm{~W}$ & $180 \mathrm{~W}$ & $16 \%$ \\
\hline Photocopiers & $1100 \mathrm{~W}$ & $500 \mathrm{~W}$ & $55 \%$ \\
\hline Stand alone faxes & $35 \mathrm{~W}$ & $17 \mathrm{~W}$ & $51 \%$ \\
\hline \multicolumn{4}{|c|}{ Miscellaneous Equipment } \\
\hline Cook tops or ovens & $3375 \mathrm{~W}^{*}$ & $2550 \mathrm{~W}$ & $24 \%$ \\
\hline $\begin{array}{l}\text { Refrigerators and } \\
\text { Freezers }\end{array}$ & $76 \mathrm{~W}$ & $65 \mathrm{~W}$ & $14 \%$ \\
\hline $\begin{array}{l}\text { Commercial } \\
\text { Refrigerators and } \\
\text { Freezers }\end{array}$ & $4500 \mathrm{~W}^{*}$ & $2925 \mathrm{~W}$ & $35 \%$ \\
\hline Dishwashers & $2946 W^{*}$ & $2446 \mathrm{~W}$ & $17 \%$ \\
\hline Water coolers & $82 W^{*}$ & $45 \mathrm{~W}$ & $45 \%$ \\
\hline Microwaves & $1326 W^{*}$ & $600 \mathrm{~W}$ & $55 \%$ \\
\hline
\end{tabular}

*Typical loads found in BEES Monitored Data Set

It is worth noting that the most common appliances found in office buildings were computers. It was proposed in this thesis that desktop computers be replaced with laptops as this was suggested by all of the Net ZEB design teams. The lessons learned from Net ZEB design teams indicated that energy consumption from office equipment was the largest energy end-use in Net ZEBs. They suggested that using laptops is a good way to reduce the office equipment energy end-use in Net ZEBs. Therefore, EnergyStar Rated Laptops will replace the current computers, for both desktop and laptops and accordingly, the EnergyStar Rated Appliance Power Wattage 
was for a laptop. Appendix 14.9.3 displays the original and reduced Equipment Power Density for each of the 48 BEES buildings.

\subsection{4h Efficient air source heat pump and Mechanical air heat recovery}

Heat pumps were the most commonly installed HVAC appliance across the 21 case study Net ZEBs. Air source heat pumps use renewable energy from the surrounding ambient air and energy (e.g. electricity or gas) to raise the temperature in a space for heating or cooling (AREA Science Park and Jožef Stefan Institute 2013). Heat pumps come in a range of sizes with applications in residential and non-residential buildings. As was suggested by all Net ZEB design teams, the heating and cooling needs in Net ZEBs are dramatically reduced due to the passive nature of the design. This means HVAC sizes can be small, making heat pumps an attractive option for conditioning Net ZEBs spaces. Furthermore, heat pumps are among the most efficient HVAC appliances currently available. This is because they provide more heating and cooling output than energy (electricity) needed for it to be generated. Figure 8-18 illustrates the concept of heat pumps providing more heating or cooling than electricity required.

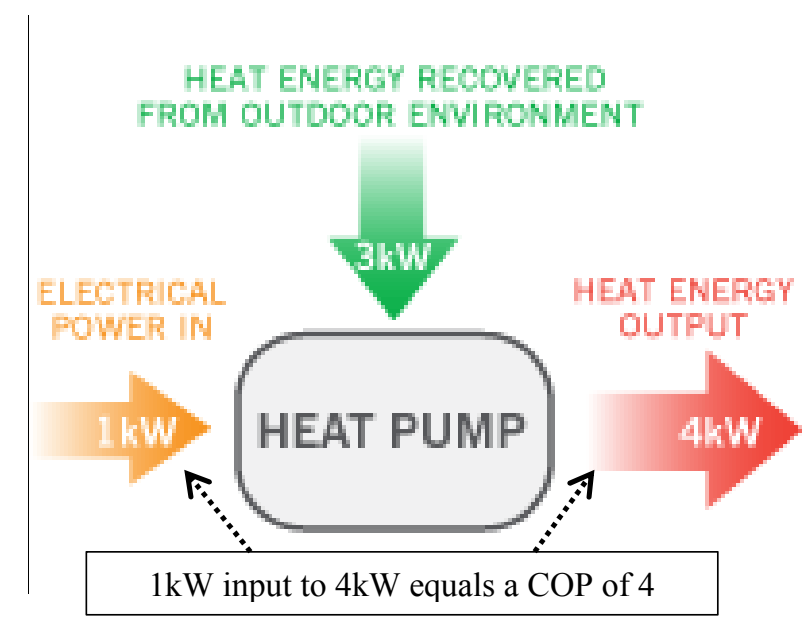

Figure 8-18 : Heat pump increased output compared to input. Figure adapted from (Black Diamond Technologies Limited 2014).

The increased output efficiency is referred to as the Coefficient Of Performance (COP). The heat pump "COP is defined as the relationship between the power $(\mathrm{kW})$ that is drawn out of the heat pump as cooling or heat, and the power $(\mathrm{kW})$ that is supplied to the compressor" (GRUNDFOS Holding A/S 2014). For example, if the COP is 4, it means the heat pump will turn 1 unit of electricity into 4 units of heating or cooling energy (Figure 8-18). Therefore, it provides more heating or cooling energy than the electricity required to generate it.

Figure 8-19 displays a range of COPs for different heat pump appliance types. As can be seen, Air sourced (air to air) heat pump COPs range from 2 to 6 . Questions about the quality of energy provided by heat pumps were not considered in this research as exergy was not used as the NZE energy metric and is outside the scope of this study (Section 2.3.2 and 4.4).

Page $\mid 212$ 


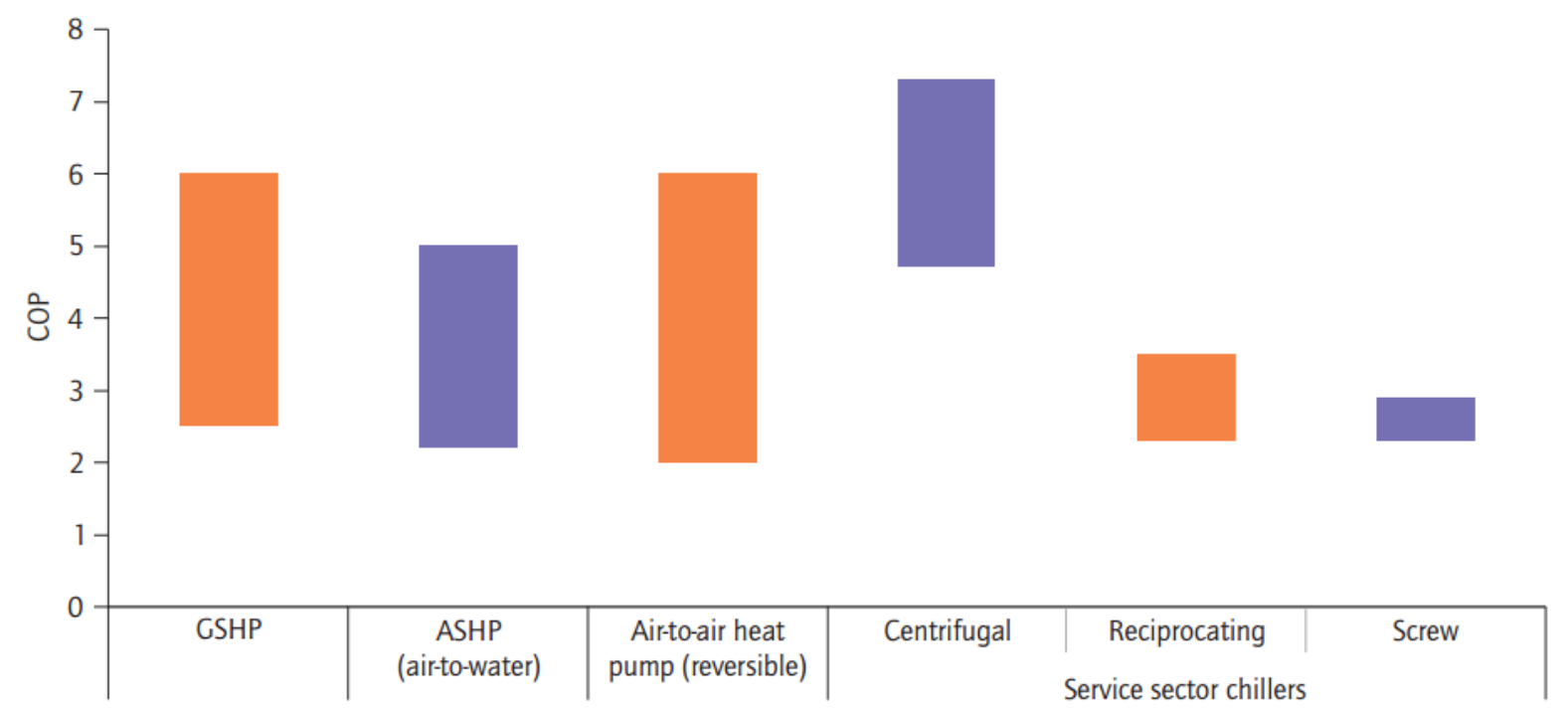

Figure 8-19 : Typical current COP ranges for heat pumps in either heating or cooling modes by technology (IEA 2011).

To further increase the efficiency of the HVAC system, mechanical air heat recovery ventilation can be implemented. Mechanical ventilation involves the continued removal of exhaust air from buildings, with the exhaust air replaced with fresh or 'supply' air. If the supply air taken from outside the building is below the desired indoor temperature it must be heated, which requires the use of energy (Woodroof 2009). "Heat recovery is a process of continuously preheating incoming cool supply air by warming it with the outgoing exhaust air" (AREA Science Park and Jožef Stefan Institute 2013, p.64). "The basic principle of operation is that outgoing stale air and incoming fresh air pass through a heat exchanger so that the warm air gives up its heat to the cool airstream. In winter, the outgoing warm air heats the incoming cold air; in summer, the incoming warm air gives up its heat to the outgoing cold air" (AREA Science Park and Jožef Stefan Institute 2013, p.64). The recovered heat reduces the heating energy needed to bring the supply air up to a comfortable temperature.

The heat pump system modelled in the 48 BEES buildings was an air source split system heat pump with heat recovery. The system was modelled using the BEES HVAC split system template developed by Gates (2013).

\subsection{4i Photovoltaics}

Photovoltaic (PV) cells convert solar radiation into electricity that can be used directly by a building, stored in a battery for later use or sold directly to a power grid. The PV cells are connected together to create a PV module and make up a PV system. PV modules are rated on a wattage of energy generated basis or efficiency. For example, a 150 Watt (W) module will generate $150 \mathrm{~W}$ in the $1000 \mathrm{~W}$ incident standard test conditions or it has an efficiency of 15 percent. There are a range of available PV sizes, with the most common high-efficiency module being approximately 200-220W (Roe 2014; NREL 2014)

Page $\mid 213$ 
Because the sun is the energy source, the more direct the PVs face to the sun; the more energy can be generated. PVs can be situated flat or tilted towards the sun on a building's roof or façade and can be connected to a sun tracking system that follows the sun path throughout the day. PVs can generate energy in direct and diffuse sunlight, although their output is diminished in diffuse light conditions. "Flat PV modules do not need direct sun to work and can generate 50 to 70 percent of their rated output under bright overcast conditions"(SEANZ 2014). Photovoltaic electricity often matches peak demand very well especially when peak demand occurs during sunlight hours (U.S. Department of Energy Federal Energy Management Program 2013). PV is an attractive option given offices and retail buildings commonly have their working hours during daytime. The 48 BEES buildings were retrofitted with a PV system comprised of flat $200 \mathrm{Watt}$ modules (the most common high efficiency PV (Roe 2014; NREL 2014)) covering 50 percent of their roof area (Deru et al. 2007).

\subsection{Optimisation of the Net ZEB refurbishment solution set in the New Zealand commercial building stock energy model}

Fundamental to the Net ZEB design process is the need to firstly reduce energy consumption of the building before offsetting with renewable energy generation. To automate this energy lowering design process, a building design optimisation program was used. The optimisation program used in this study was GenOpt. "GenOpt is an optimization program for the minimization of a cost function that is evaluated by an external simulation program"(Lawrence Berkeley National Laboratory 2011). In the case of this thesis, the cost function being minimised was energy consumption, and the external simulation program was EnergyPlus. The cost function being reduced was the annual energy consumption of buildings, which was defined in GenOpt by Eq. 16:

Equation 16:

Where:

$$
\mathrm{E}=\mathrm{E}_{\text {Heat }}+\mathrm{E}_{\mathrm{Cool}}+\mathrm{E}_{\mathrm{Fan}}+\mathrm{E}_{\text {Lighting }}+\mathrm{E}_{\text {Equipment }}
$$
$E \quad=$ annual whole building energy consumption
$E_{\text {Heat }} \quad=$ annual building heating energy consumption
$E_{\text {Cool }} \quad=$ annual building cooling energy consumption
$E_{\text {Fan }} \quad=$ annual building fan/ventilation energy consumption
$E_{\text {Lighting }}=$ annual building electric lighting energy consumption
$E_{\text {Equipment }}=$ annual building electric equipment energy consumption

GenOpt varied a set of input parameters in the EnergyPlus model. The input parameters were a set of building design variables, such as insulation or shading length. GenOpt varied the building design variables in EnergyPlus as many times as was required to determine the set of optimum input parameters to reduce energy consumption. The GenOpt output provided the input building design parameters tested during each of the EnergyPlus simulation iterations and the energy 
consumption results using those parameters. The GenOpt output culminated in the optimum input building design parameters and the energy consumption results achieved with them.

To complete the modelling technique used in this study, a pilot study was undertaken to test and determine a standardised optimisation methodology that could be replicated for all 48 BEES models being optimised in the seven New Zealand climates. The pilot test investigated the optimisation of a new commercial building design in Christchurch, New Zealand. The full energy reduction and optimised building attribute results can be found in Cory et al. (2012). However, the main objective in terms of this thesis was to establish whether all building design attributes needed to be optimised. This was important as the more parameters to be optimised; the longer the optimisation process would have taken. The lessons learned from the study were used to develop the optimisation methodology undertaken in this thesis.

\subsubsection{Lessons learned from energy optimisation approach on a small case study}

The lessons learned from the pilot study identified a methodology for the application of the optimisation software GenOpt. The first lesson identified was that a two phase optimisation process was needed to test building design options as well as optimise various building design parameters. Phase 1 was the installation of non-optimised design options, such as efficient lighting, efficient equipment and lighting controls, which did not need to be optimised. Phase 2 was the optimisation of design options that vary depending on the building, site context, and climate; such as insulation, window size, and solar shading size. The non-optimised building design options, such as the use of natural ventilation and lighting controls, could have been automated and completely optimised within the model, but this would have been detrimental in terms of the extended computation time needed to complete the optimisation.

The second lesson was that separate energy models should be constructed for different types of the same system and optimised separately. It was seen when testing different options of the same design attribute, such as different solar shading types (for example: overhangs, fins, and louvres). Furthermore, each shading type (overhang, fin and louver) had multiple parameters to optimise, such as the depth of shade, the height of shade, and the extension of the shade past window jambs. This caused two issues: 1) three models needed to be optimised per building - one for each shading system; and 2) consistency in the optimisation process was not the same between each building design. As a result, the amount of time it took to optimise one building design was more than three times longer than if one design option was optimised. To combat this time intensive problem and keep a consistent modelling methodology between building models, a simplification was tested in the way the shading was modelled. The simple shading modelling technique used the Shading Coefficient which mimicked different shading types. This meant that a single geometry's shading coefficient was optimised instead of individual overhangs, fins or louver systems. The test results of a comparison between the differences in the two shading techniques indicated that a simple shading modelling technique accurately represented a real shading system to within \pm 2 percent of annual energy end-use consumption and \pm 1 percent 
annual total energy consumption in a standardised base case building. Results are found in Section 8.3.1a.

The third lesson was the process in which GenOpt varied parameters during an optimisation, in particular, the optimisation of the WWR. Windows in Template models were modelled as a WWR centred in the wall. GenOpt moved the sill and head of the window up and down independently to establish the optimum WWR for a specific case building. The problem was that the WWR may not have been centred once it was optimised and this was inconsistent with how the Template models were created. This had implications on the solar heat gains and daylighting energy being modelled. A test was derived to compare the differences between the template WWR method and the Genopt WWR optimisation process. The results identified that if an optimised WWR was not placed centrally on all four façades, the energy consumption could vary by up to \pm 6 percent of annual energy end-use consumption and \pm 1 percent annual total energy consumption in a standardised base case building. Results can be found in Section 8.3.1b.

Two tests that were undertaken for Quality Assurance (QA) are presented below to exemplify the impact the optimisation simplifications had on energy consumption. The tests used the same standardised base case building as the QA tests undertaken in Section 7.2.4 to compare the energy consumption results for:

1. The simple shading technique against a real solar shading system; and

2. Centred WWR technique against a differently placed WWR of the same size.

\subsection{1a Simplified shading modelling technique}

The aim of the shading modelling QA test was to assess whether modelling a simplistic single shade with varying transmittance generates different energy consumption results when compared to a modelled louvre shading system. The reason for testing the simplified shading modelling method was to assess whether it could accurately represent the shading system of a real building. The simplified shading modelling technique was used to reduce the modelling and optimisation computation time. The time reduction was generated through the use of a simplistic shading system with varying transmittance rather than modelling the many louvres which made up that system. For example, a building may have a louvre system on its facades. The louvre system can be composed of hundreds, if not thousands, of individual shade panels, as seen in Figure 8-20 which displays a real louvre system on the Meridian building in Wellington (New Zealand Green Building Council 2013). It would take a significant amount of time to model the entire set of individual shading elements. However, if the louvres were instead represented by a simplistic single layered shading system, to a satisfactory level of accuracy (less than $+/-5$ percent of annual energy consumption established by using the calibration goal as a baseline); it could significantly reduce the time taken to model the building.

Page $\mid 216$ 


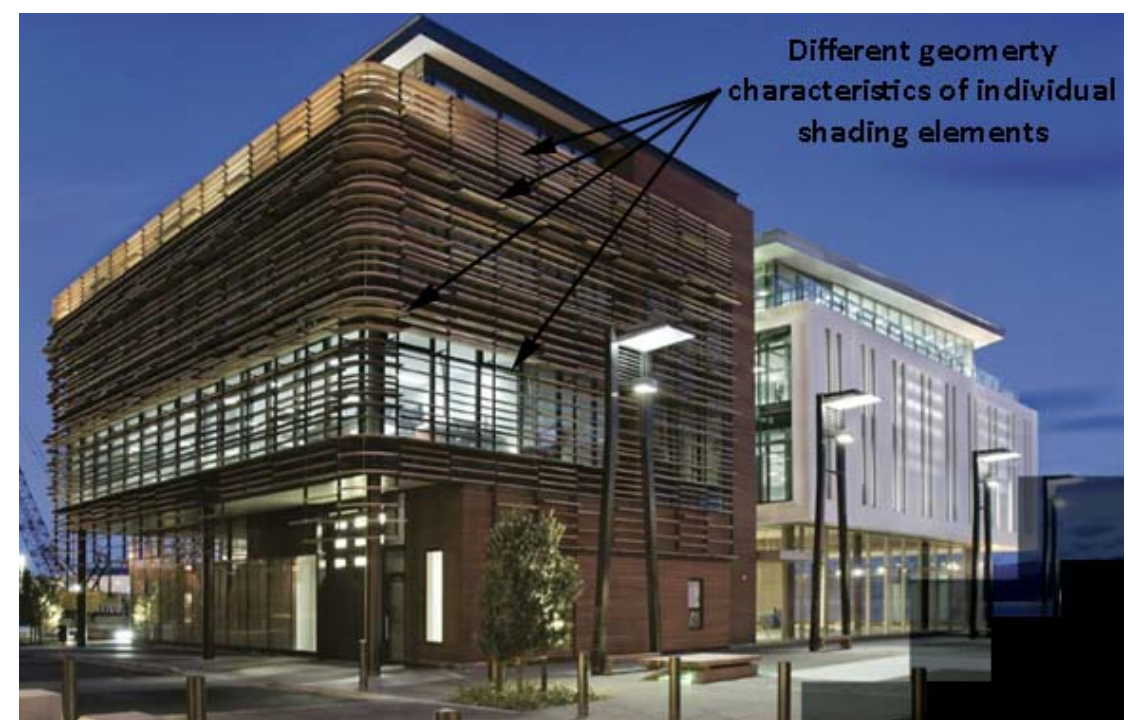

Figure 8-20 : Example Louvre system: Meridian building. Figure adapted from (New Zealand Green Building Council 2013).

The base case model (both with and without electric light dimming controls) was adapted to include either the simple shading modelling technique, or the louver shading system. Figure 8-21 displays the louvre shading system installed.

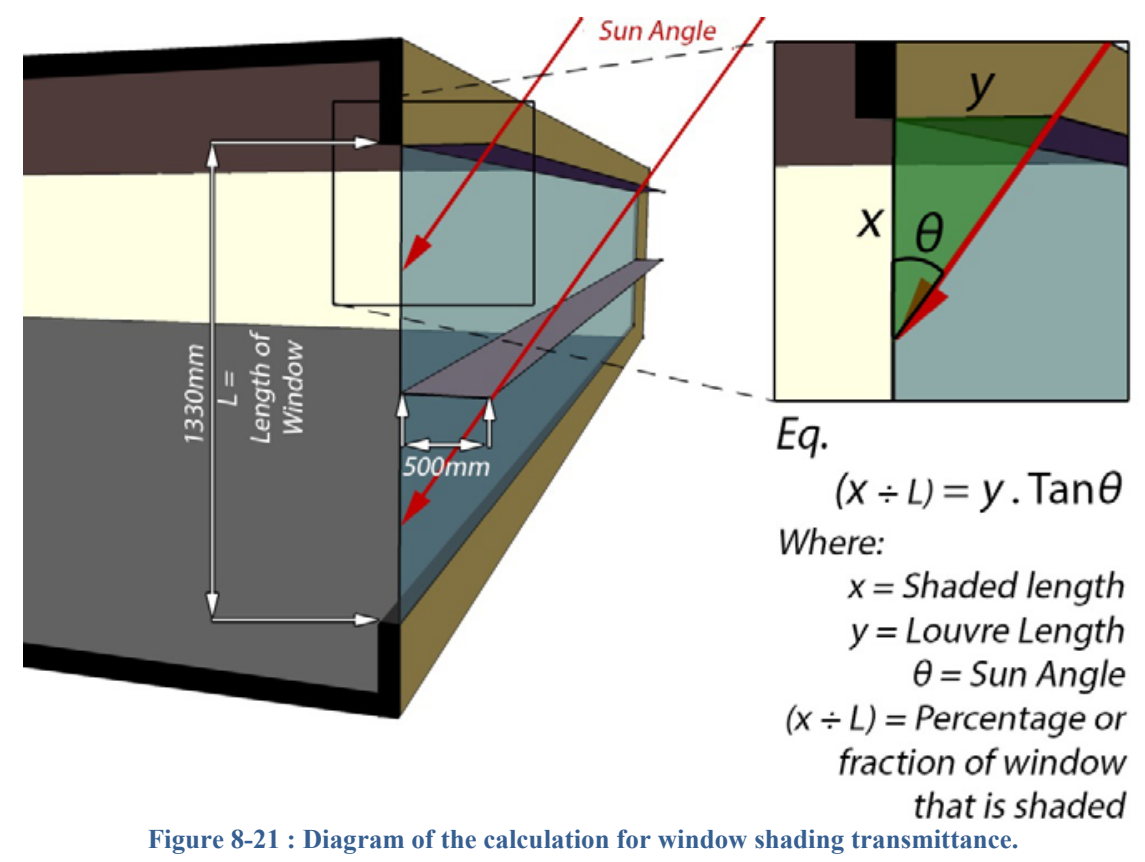

It consisted of two $500 \mathrm{~mm}$ shading elements, one placed at the top of the window (or window head), and the other placed at the midway point of the window height (or window jamb). Figure 8-22 displays the simplified shading system installed. It consisted of one shading layer placed $200 \mathrm{~mm}$ away from the building's façade. It was placed this far away from the façade to ensure no sunlight could enter around the edges of the shading layer and into the interior spaces. The

Page $\mid 217$ 
shading layer was coupled with a shading transmittance schedule which was built into the energy model. The shading transmittance schedule varied the amount of sunlight and daylight transmission through the shading layer for different times of the day and month. The shading transmittance schedule was made up of values which mimicked the amount of direct sunlight availability to the window of the louvre shading system. Figure 8-21 diagrammatically displays the trigonometry equation (Math Open Reference 2009) used to calculate the sunlight availability and shading transmittance.

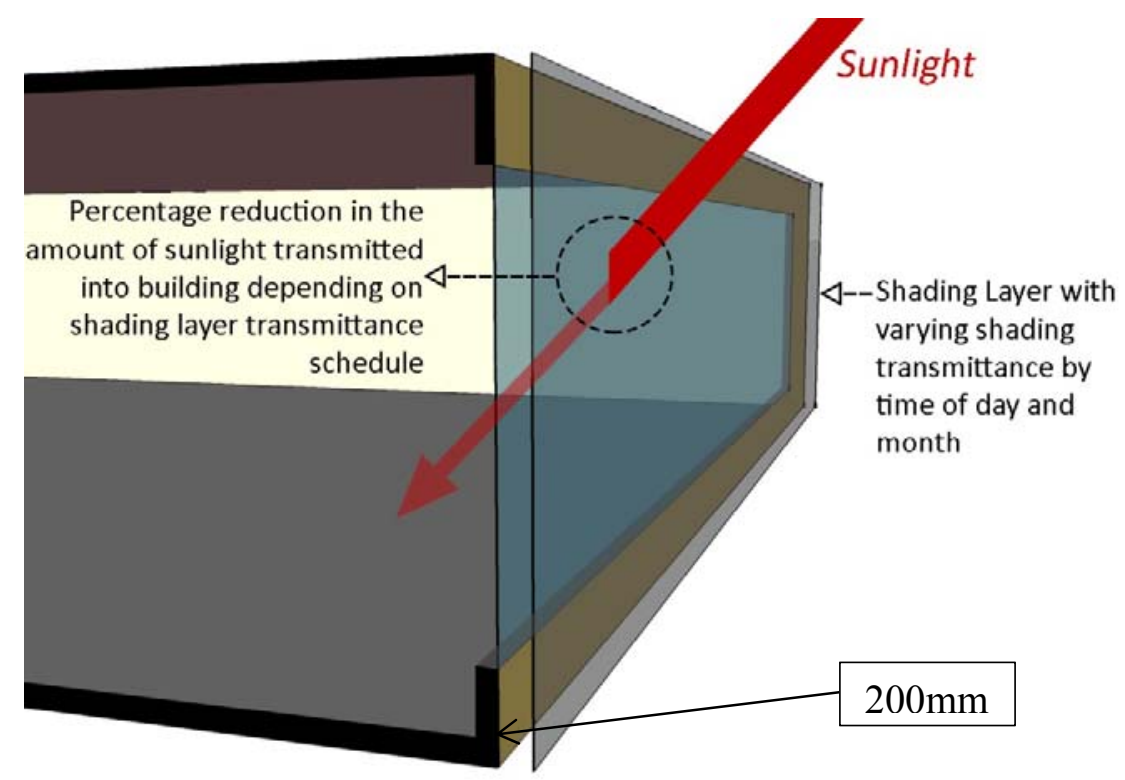

Figure 8-22 : Simplified shading system

The equation determined the portion (in length) of the window that was shaded from the direct sunlight. The portion of shaded window was then used to calculate the shading transmittance, represented as a percentage of the window that was shaded from direct sunlight. The calculation was performed for three time intervals of the day for each month of the year to allow for the daily cycle of sun movement from morning to night: $9 \mathrm{am}, 12 \mathrm{pm}$, and $3 \mathrm{pm}$. The sun angles were obtained for Wellington using the NIWA SolarView tool (National Science Centres 2014). Appendix 14.10 presents the sun angles and calculated shading percentage results used to create the shading transmittance schedule.

Table 8-5 displays the percentage difference in energy consumption between the two shading modelling techniques and highlights the difference between a model with and without electric lighting controls.

\begin{tabular}{|c|c|c|c|c|c|c|}
\hline & Total & Cooling & Heating & Lighting & Equipment & Fans \\
\hline Without Light Dimming & $0.2 \%$ & $0.9 \%$ & $-1.7 \%$ & $0.0 \%$ & $0.0 \%$ & $0.9 \%$ \\
\hline With Light Dimming & $0.3 \%$ & $1.1 \%$ & $-1.9 \%$ & $0.3 \%$ & $0.0 \%$ & $1.0 \%$ \\
\hline
\end{tabular}


The results from the tests indicated that using a louvre system or using a simple shade with a transmittance schedule simulates a difference in total energy consumption which was less than 1 percent in a model both with and without electric light dimming. At an individual energy end-use level, the difference ranges from \pm 0 to 2 percent. The largest impacted end-uses were cooling, heating and fans. Lighting was not impacted as greatly as the space conditioning end-uses. These differences in energy consumption were small compared to the calibration limit of $+/-5$ percent, and proved that using a simple shade sufficiently aided the speeding up of the modelling process without reducing accuracy significantly (it takes approximately two to ten times less time to model the single shading layer rather than individual louvres).

\subsection{1b Window optimisation technique}

The aim of the window optimisation technique QA test was to investigate the impact the placement of a single WWR had on energy consumption in a simple base case building. The reason for testing the two methods was to highlight the energy consumption differences that the placement of an optimised WWR window had when compared to a template model's centred WWR window.

Figure 8-23 displays the difference in WWR position on the facades of the model. One model had the centred WWR, while the other model had the same WWR moved upward to be placed $100 \mathrm{~mm}$ away from the façade/roof connection on all four facades. A WWR placed as close to the edge of the roof or floor was the most extreme change that GenOpt made during an optimisation.

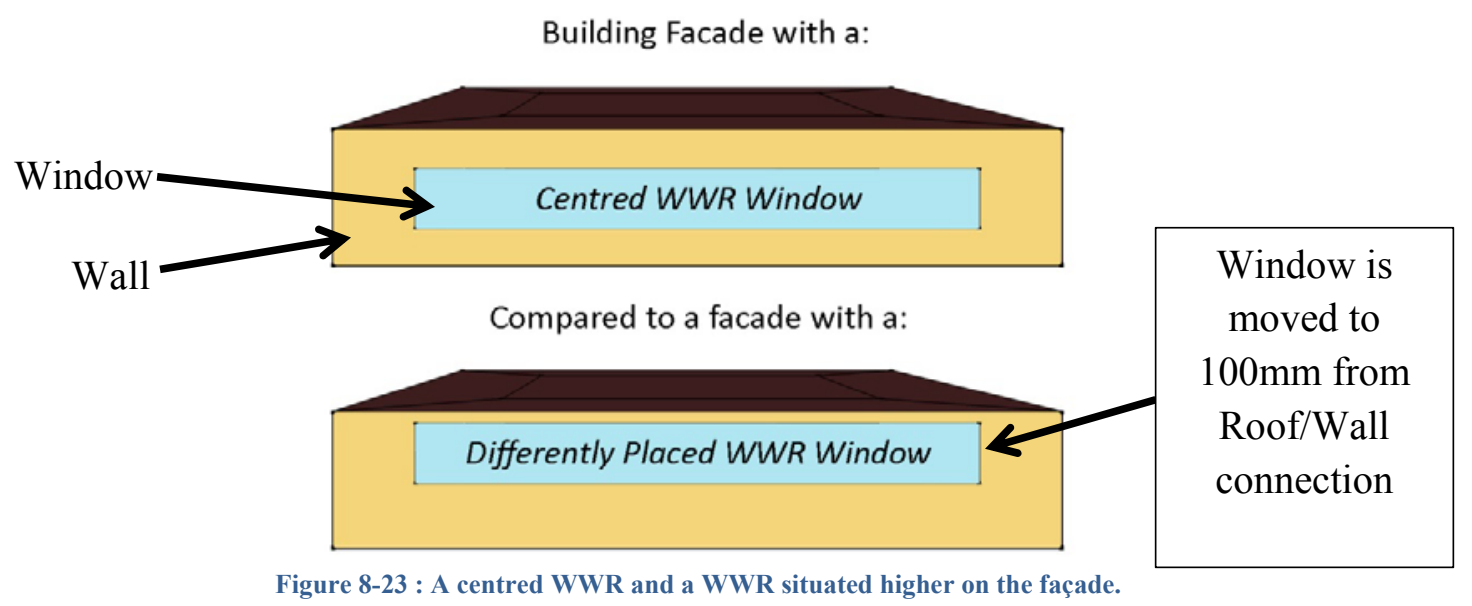

Table 8-6 displays the energy consumption differences of a single WWR window modelled in the centre of the wall and the WWR modelled in a different position. The highlighted red cells indicate if the difference was larger than \pm 5 percent.

\begin{tabular}{|c|c|c|c|c|c|c|}
\hline & Total & Cooling & Heating & Lighting & Equipment & Fans \\
\hline Without Light Dimming & $0.7 \%$ & $4.6 \%$ & $-1.6 \%$ & $0.0 \%$ & $0.0 \%$ & $4.8 \%$ \\
\hline With Light Dimming & $0.7 \%$ & $5.4 \%$ & $-0.8 \%$ & $-0.8 \%$ & $0.0 \%$ & $5.6 \%$ \\
\hline
\end{tabular}

Page $\mid 219$ 
The results demonstrate that the movement of the single WWR simulated a difference in energy which was less than 1 percent of the total energy consumption in both a model with and without electric light dimming. The energy end-use differences varied between the models with and without electric light dimming controls installed. The heating and lighting differences were within \pm 2 percent in models with and without the controls. The largest differences were seen in the cooling and fans energy end-uses, both with (4.6 percent and 4.8 percent respectively) and without (5.4 percent and 5.6 percent respectively) electric light dimming. The two end-uses were somewhat connected as the more cooling energy required, the more fan power needed to distribute the cooler air. However, they added up to be small when looking at the impact on the whole building energy consumption. The differences in energy consumption were again negligible when compared to the allowable calibration limits. This indicated that the location of the single WWR window, be it centred or offset on the façade, would not impact the energy consumption results dramatically, and the advantages in modelling speed outweighed any differences that may have occurred (it is approximately two to four times shorter to optimise two window points (head and sill) when compared to four window points (head, sill and jambs).

\subsection{1c Implications on the optimised parameters}

The two QA tests above highlight that the two modelling techniques had varying influences on energy consumption. The simple shading had a very small influence on end-use energy $( \pm 2$ percent), whereas the differently placed WWR window had a slightly larger influence $( \pm 6$ percent). However, at total energy consumption level they both influence energy slightly $( \pm 2$ percent). The small difference in energy consumption from using the simple shading system comes with the benefits of reducing the time it takes to create a complete energy model. The time savings were a result of only having a single shading geometry to model and optimise. It was estimated that the time taken to model the simple shading system was approximately 2 to 4 times faster compared to modelling different real shading systems, such as a fins or louvre system. Greater time savings were seen when modelling a large louvre system with many small shading elements. This factor coupled with the general lessons learned from the energy optimisation approach on a small case study (refer to Section 8.4.1) had implications on the set of parameters being optimised.

The first implication was that only passive design techniques were to be optimised. Therefore, only the solar shading, insulation level, window type, window size and window opening size were optimised. The second implication was that the solar shading parameter being optimised was the shading transmittance of a single shading layer placed $200 \mathrm{~mm}$ from each facade. As the shading was being optimised for all facades, a shading transmittance was optimised for morning (pre-12pm) and afternoon (post-12pm) for the four weather seasons (in New Zealand: Summer December to February; Winter - June to August; Autumn - March to May; and Spring September to November). The various transmittances were needed due to the differences in orientation and location. For example, more shading could be needed on the east façade in the morning due to the sun rising from the east, whereas more shading could be needed on the west 
façade in the afternoon due to the sun setting in the west. Additional shading could also be needed in summer compared to winter.

Tables 8-7 and 8-8 display the final set of ECM parameters that were optimised. Most of the ECM parameters were able to be continuously optimised, meaning the optimised value was between a minimum and maximum value range (Table 8-7). For example, the optimum insulation level could be any value between 0.1 and $4.65 \mathrm{~m}^{2}-\mathrm{K} / \mathrm{W}$ (based on a $200 \mathrm{~mm}$ thick external insulation layer (Weber Saint-Gobain 2014; Expol Ltd 2014).

\begin{tabular}{|c|c|}
\hline Building Parameter & Minimum and Maximum Parameter Values \\
\hline Shading transmittances (fraction) & $0.05-0.95$ \\
\hline $\begin{array}{l}\text { Wall and Roof R-Value Insulation } \\
\left(\mathrm{m}^{2}-\mathrm{K} / \mathrm{W}\right)\end{array}$ & $\begin{array}{l}0.1-4.65 \text { (maximum value based on a } 200 \mathrm{~mm} \text { layer of } \\
\text { polystyrene insulation)* }\end{array}$ \\
\hline WWR & $10-90 \%$ \\
\hline Window opening fraction & $0.1-0.8$ \\
\hline
\end{tabular}

*(Weber Saint-Gobain 2014; Expol Ltd 2014)

One ECM was discretely optimised, meaning a particular building design type or parameter is chosen. The Solution Set has an optimum choice of four window types to be retrofitted into the 48 BEES buildings. The four window types all have varying U-Values, visible transmittance, and SHGC. Table 8-8 displays the window parameters that make up each window type. The four window types that can be used are:

1. Clear Single glazing with aluminium frame;

2. Clear double glazed argon filled with aluminium frame;

3. Low-e double glazed argon filled with aluminium frame; and

4. Tinted Low-e double glazed argon filled with aluminium frame.

Table 8-8 : Building parameters being discretely optimised.

\begin{tabular}{|c|c|c|c|c|}
\hline Glazing types (to be selected) & 1 & 2 & 3 & 4 \\
\hline U-Value insulation $\left(\mathrm{W} / \mathrm{m}^{2}-\mathrm{K}\right)^{*}$ & 5.8 & 2.5 & 1.6 & 1.3 \\
\hline SHGC* & 0.82 & 0.71 & 0.61 & 0.32 \\
\hline Visible Transmittance* & 0.88 & 0.78 & 0.73 & 0.58 \\
\hline
\end{tabular}

*(CSR Building Products Ltd 2008; LBNL 2014)

The other passive ECMs, energy efficiency ECMs and renewable energy ECMs were not optimised and as such, they were simply modelled as a completed set of parameters. For example, the PV system was installed with a pre-set efficiency of 20 percent. Therefore, it was not optimised to establish the optimum efficiency. It was assumed to be 20 percent due to it being the most common high-efficiency PV efficiency. The set of ECM parameters and assumptions are found in Appendix 14.9. 


\subsubsection{Method for reducing the computation time of optimisations for a large group of optimisations}

The completion of all optimisations within a suitable timeframe was the most significant challenge faced in this thesis. While individual EnergyPlus simulations ran quickly, (5-20 minutes) individual optimisations within the chosen multi-parameter problem space run on a 24core machine, were seen to take over 100 hours to establish the optimum result. This was even with GenOpt running multiple simulations in parallel to reduce computation time. Given there was a total of 336 optimisations required (48 buildings optimised in seven New Zealand climates) to complete a NZE scenario's Stock Aggregation, the total optimisation time could have taken many months. For this reason, two non-GenOpt timesaving measures were undertaken. This optimisation time could have been reduced if greater computer power was available. For example, Oak Ridge National Laboratory developed a method for using a 27petaflop supercomputer to perform half a million EnergyPlus simulations for a range of standard building types in less than one hour and used nearly 300,000 CPU cores in parallel (Jones 2014).

Firstly, only the passive building design attributes were optimised, meaning fewer input parameters were optimised and less time was taken for GenOpt to establish the optimum design. Passive building design attributes were optimised because there were a large number of variables that impacted on their optimum design. Optimum passive design attributes were also affected by other passive design features. For example, the optimum level of insulation was affected by the amount of heat gain and loss that was optimal to lower the amount of heating and cooling energy consumption. The heat gains and losses were also affected by the size of the window as they allowed for more or less solar heat gains, and envelope heat gains and losses. If the window size changed, as it can do if more daylight is needed to lower electric lighting energy consumption, so did the optimum level of insulation. However, energy efficient technologies and renewable energy technologies were not optimised. This was due to the technologies being simple upgrades from higher energy consuming technologies to less energy consuming appliances or simple additions of technologies to lower the use of energy or the generate energy. For example, poorly performing lighting could be upgraded to the latest energy efficient lighting because it uses the least amount of energy.

Secondly, the 336 optimisations were spread across a High Performance Computing Facility computer cluster that allowed for multiple simulations from within the 336 optimisations to be run concurrently in an automated non-interactive batch-mode processing (Victoria University of Wellington 2013). Automated non-interactive batch-mode processing used multiple 24-core computers to automatically run the 336 optimisations concurrently and consecutively. The two computation time reduction measures significantly reduced the overall processing time. The savings came from GenOpt running more EnergyPlus iterations at one time across the multiple cores, and also from running multiple optimisations at one time. Running multiple simulations concurrently enabled more than one optimisation to be completed within the up to 400 hour timeframe it was seen to take an individual optimisation to run across 16 core machines. 
Appendix 14.11 provides the Linux script used to operate the automated non-interactive batchmode processing.

The optimisation of the 48 energy models in seven New Zealand climates (336 optimisations) was completed over approximately six months. If the simplifying measures (described in 8.4.1) were not undertaken, this time duration could have been at least twice as long. If the optimisations were not run concurrently on six to eight different computers, the time could have been at least six times longer than it was.

\subsection{Chapter summary}

Chapter 8 determined a suitable set of design changes to be applied as a retrofit/redesign of the 48 calibrated energy models. The set of design changes were established from assessing already proven to work solution sets of existing Net ZEBs from around the world. The solution sets used in the assessment were from commercial Net ZEBs in mixed heating and cooling climates (similar to New Zealand's climate), and a mixture of building site contexts and building sizes. The set of design changes are made up of:

- Seven passive Energy Conservation Measures (ECM): upgrade envelope insulation; upgrade glazing; solar shading; maximise passive solar heat gains; maximise daylight; natural ventilation; and advanced daylighting,

- Five energy efficient ECMs: Upgrade to efficient lighting, upgrade to efficient equipment, Install advanced lighting controls; heat recovery ventilation; and upgrade to efficient HVAC.

- One renewable ECM: Photovoltaics.

The chapter also outlined a quality assured process for the passive ECMs' optimisation to maximise energy reductions. The optimisation process uses computer software to automatically vary the passive design of the 48 energy models and runs as many energy simulations as it needs to determine the optimum combination of design parameters to maximise energy reductions. 
Figure 8-24 displays the connections between Chapters 6, 7, 8, 9, and 10.

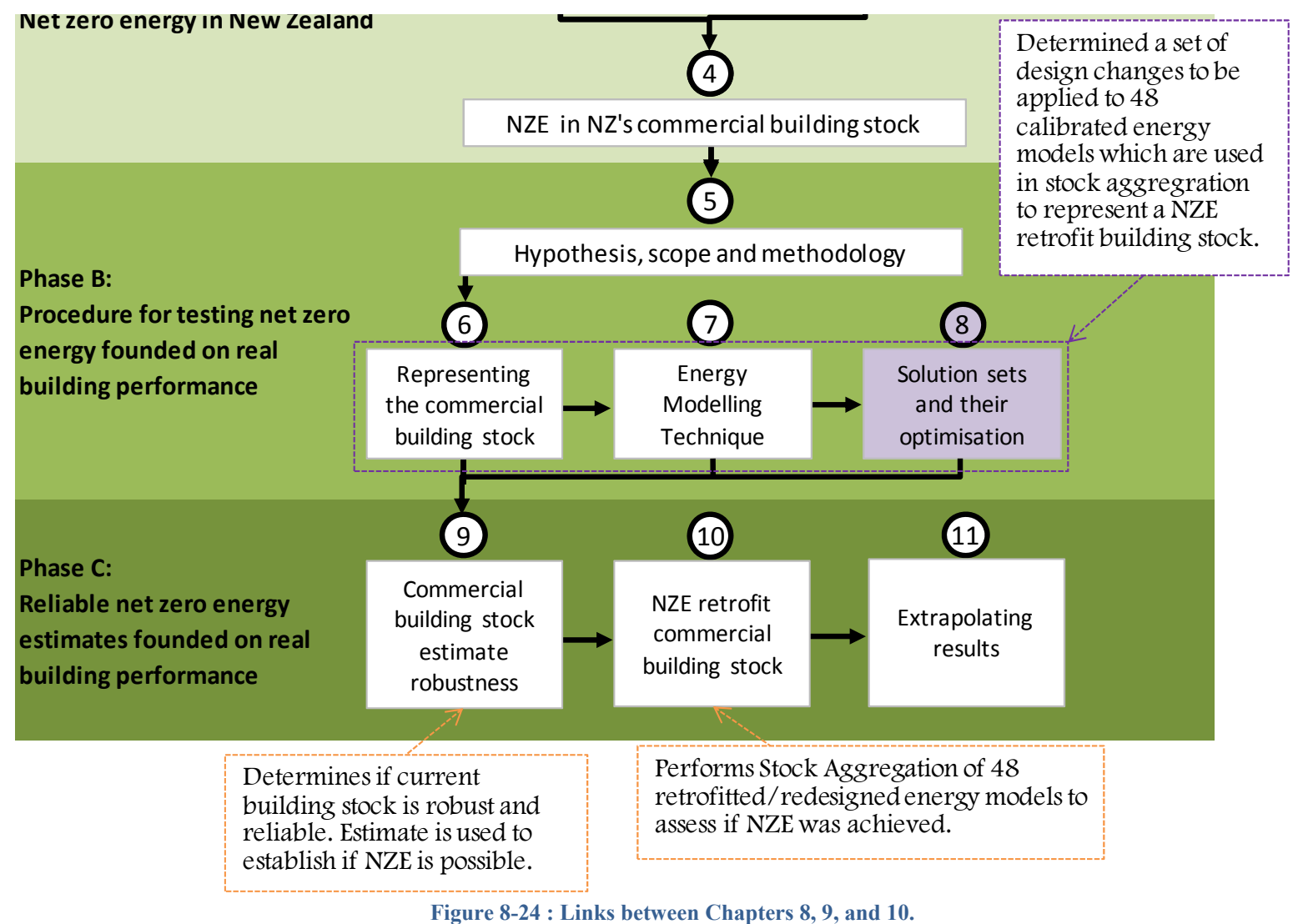

Chapter 9 is the start of Phase $\mathrm{C}$ - Reliable Net Zero Energy estimates founded on real building performance. Phase $\mathrm{C}$ presents the results of creating 48 calibrated energy models that match real building performance, and the retrofit of the 48 energy models to test the possibility of reaching NZE.

Chapter 9 undertakes a stock aggregation using the 48 calibrated energy models to represent the current commercial building stock. Chapter 9 estimates the current commercial building stock's energy performance and determines if it is a robust and reliable representation of reality. The estimate is compared to the NZE retrofit building stock estimate to ascertain if NZE is possible. Chapter 10 takes the 48 energy models and retrofits each building with the optimised set of design changes proposed in Chapter 8 . The resulting stock aggregated energy performance represents the NZE retrofit commercial building stock. Chapter 11 tests the NZE retrofit design and assesses its feasibility. 
RESEARCH PHASE C

Reliable net zero energy estimates

founded on real building Performance

Page | 225 



\section{CHAPTER 9. COMMERCIAL BUILDING STOCK ENERGY MODELLING RESULTS}

\subsection{Chapter Intent}

Chapter 9 presents a stock aggregated energy consumption estimate for the current New Zealand commercial building stock based on the real performance of New Zealand commercial buildings. The estimate provides the base case for the NZE retrofit to be compared against to determine if NZE is feasible. Figure 9-1 displays the links between Chapter 6, 7, and 9.

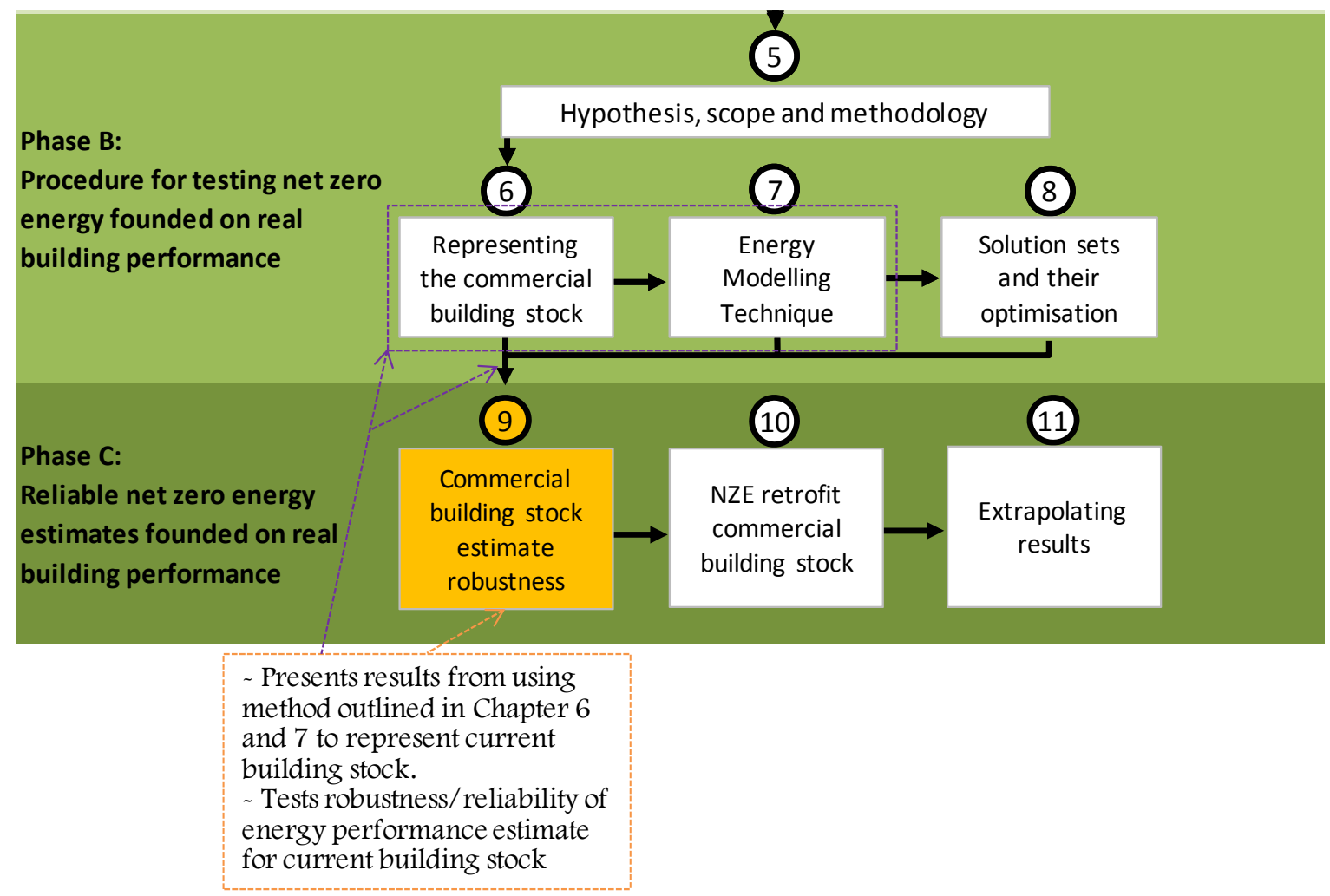

Figure 9-1 : Links between Chapters 6, 7 and 9.

This chapter provides a detailed illustration of the calibration process (as outlined in Chapter 7) for one of the 48 BEES building energy models. The case study is a worked example of the calibration process that was applied to all 48 BEES energy models. A summary of the results from the 48 BEES calibrated energy consumption models is presented along with comparative results for the performance of each real commercial building.

The calibrated energy models provided the energy consumption breakdown required to complete the Stock Aggregation, outlined in Chapter 6. The Stock Aggregation value was based on real performance data, with the 48 BEES building energy models calibrated to within an acceptable tolerance of the real energy performance of 48 real commercial buildings. An acceptable Page $\mid 226$ 
calibration tolerance was set out in Chapter 7 and defined a tolerance for when energy models were calibrated.

The robustness and reliability of the energy consumption estimate was investigated by comparing the stock aggregated estimate to an external estimated value of the energy consumption of the commercial building stock. The external estimate used a larger sample of buildings, and also included a number of added assumptions. The comparison was made to determine whether the Stock Aggregation result using the 48 BEES energy models was a reliable and robust estimate of energy consumption. The result was considered reliable and robust if the two estimates were within an acceptable confidence range (refer to Section 9.3).

This thesis was part of a larger external research project - BEES. The purpose of this thesis (as part of the larger BEES project) was to develop a systematic procedure to ensure the calibration of energy models that matched the BEES monitored buildings. The 48 BEES energy models used to represent the New Zealand commercial building stock were provided externally to assess the potential of NZE. The energy models were constructed by an external contractor to the BEES project; using the calibration method developed in this thesis. The calibration results presented in this chapter provide an overview of the results achieved by the external contractor using the developed calibration method outlined in Chapter 7. The database of 48 calibrated energy models and their detailed calibration steps are stored internally with BEES along with each building's detailed information (Section 7.2.1) (BEES 2014a)

\subsection{Modelling and calibration of the $\mathbf{4 8}$ case study buildings}

Modelling and calibration of the 48 BEES case study buildings was performed using a combination of two calibration techniques. These techniques informed the data needed to construct a calibrated model and also provided a method for identifying incorrect model input parameters. The following sections of this chapter demonstrate the calibration process undertaken and present the calibration results of the 48 energy models used to match real building energy performance.

\subsubsection{S2-O-1 case study calibration}

The case study presented in this section provides a working illustration of the calibration process applied to all 48 of the energy models used in this thesis. Because the BEES team agreed to ensure the confidentiality of all building owners and occupiers in the study it was not possible to identify the case study buildings included in this thesis and hence, a labelling convention was used. The case study used as an example was labelled S2-O-1. Table 9-1 explains the labelling of each BEES case study building. 'S2' referred to the size group. Size group 2 represented buildings from $650 \mathrm{~m}^{2}$ to $1499 \mathrm{~m}^{2}$. ' $\mathrm{O}$ ' referred to the building type subgroup, Office buildings. ' 1 ' was the number index of the building and referred to what number building it was out of the size group 2 (S2) Office case study buildings. Because it was possible for multiples of the same 
building types to be modelled within each size group, a number index (from 1 onward) was implemented.

Table 9-1 : Case study building labelling convention.

\begin{tabular}{|c|c|c|}
\hline Size Group & Type Subgroup & Building Index \\
\hline S1 = Building size group $1\left(5-649 m^{2}\right)$ & \multirow{2}{*}{$\mathrm{O}=$ Office } & 1 = First building of that size and type \\
\hline S2 = Building size group $2\left(650-1499 m^{2}\right)$ & & $2=$ Second building of that size and type \\
\hline S3 = Building size group $3\left(1500-3499 m^{2}\right)$ & \multirow{2}{*}{$\mathrm{R}=$ Retail } & $3=$ Third building of that size and type \\
\hline S4 = Building size group $4\left(3500-9000 \mathrm{~m}^{2}\right)$ & & $4=$ Fourth building of that size and type \\
\hline $\begin{array}{l}\text { S5 }=\text { Building size group } 5\left(9000 \mathrm{~m}^{2} \text { and }\right. \\
\text { greater) }\end{array}$ & $M=$ Mixed & $5=$ Fifth building of that size and type \\
\hline
\end{tabular}

9.2.1a Pre-simulation Calibration: Initial Results and Comparisons

To begin the calibration process, an energy model was first constructed using the modelling methodology outlined in Chapter 7. The construction of the energy model was designed to match as closely as possible to the materiality, construction, window size, building loads, patterns of use and HVAC system of the real building (Raftery, Keane, and Costa 2009). A time-of-use weather file, based on the building's location and year monitored, was then created in order to minimise any differences relating to the external environment (Raftery, Keane, and Costa 2009).

Monthly meter data, 10 minute monitoring data (collected by the BEES team), and annual EnPI (Energy performance Index) were used to compare the results in the calibration process. The monthly meter data for S2-O-1 was for the year 2009 (as this was the only year with a full set of data); and the monitoring data was taken over 10 minute intervals between 15 April to 5 May 2009.

Once the model had been constructed to represent the as-built building, it was then simulated using the custom time-of-use EnergyPlus weather file (created using Gates (2011) in Appendix 14.6 as defined in Section 7.4.1f). The simulated results were used to identify how the initial model compared to the real building energy data. This related to both the monthly meter data and the average weekday and weekend loads that were monitored by the BEES team.

\subsection{1b Calibration evaluation of initial energy model}

Figure 9-2 displays the monthly comparison between the real energy performance (black) and the initial energy model for S2-O-1 (blue). It also shows the calibration MBE (Mean Bias Error) limit of \pm 5 percent (dotted black line). The results indicated that for the year 2009, the calculated energy from the model significantly underestimated the real building's energy performance for 11 of the 12 months. January was the exception, with the simulated energy use overestimated during that month. The results also indicated that while there was no significant seasonal trend in the simulated energy results, there was a seasonal trend in the real energy performance (shown by low summer energy use and higher winter energy use). 


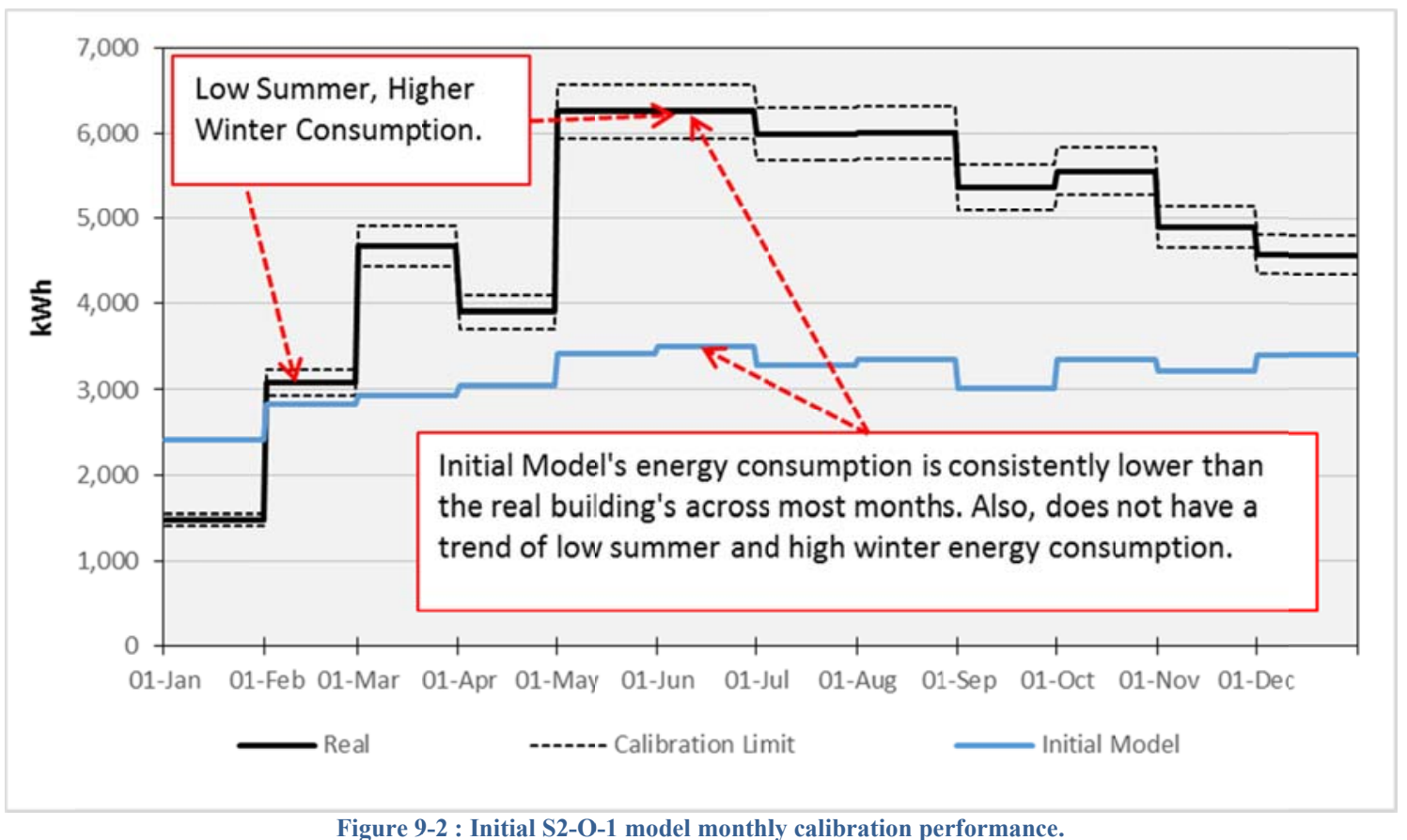

Figure 9-3 displays the four (A, B, C, and D) typical trends identified in the initially simulated energy consumption versus the real building monthly energy consumption across the other 47 energy models calibrated.

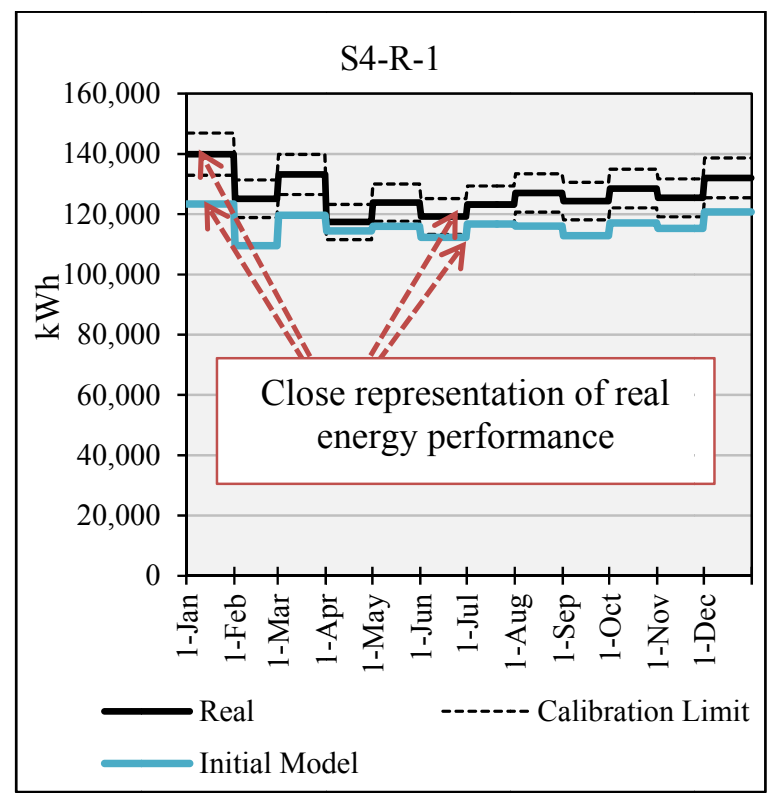

A. Trend closely matches initial energy model.

Figure 9-3 : Examples of various differences between the initial energy model and real building energy consumption.

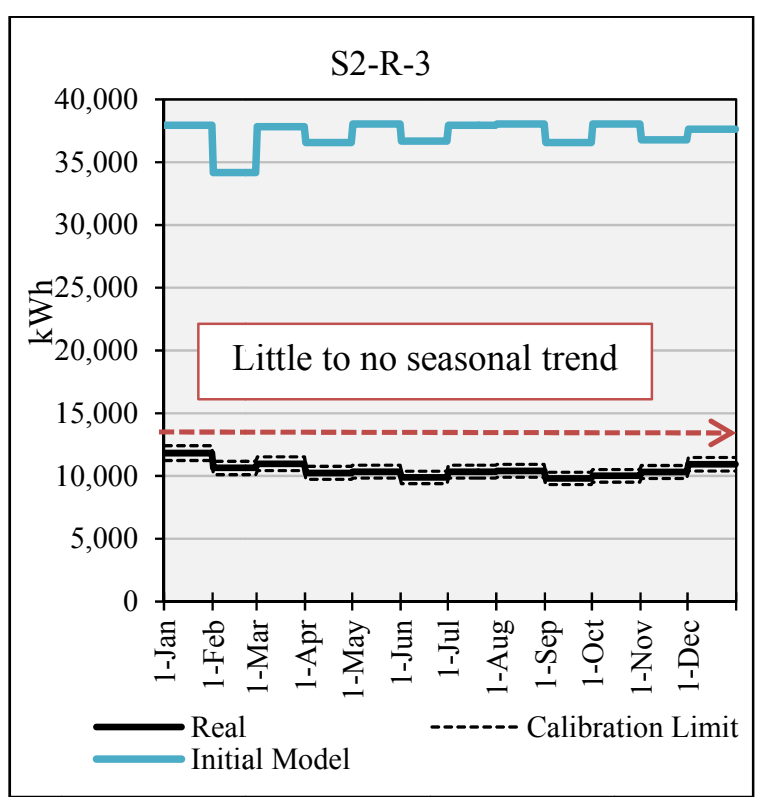

B. Little to no seasonal trend in initial energy model and real building. 


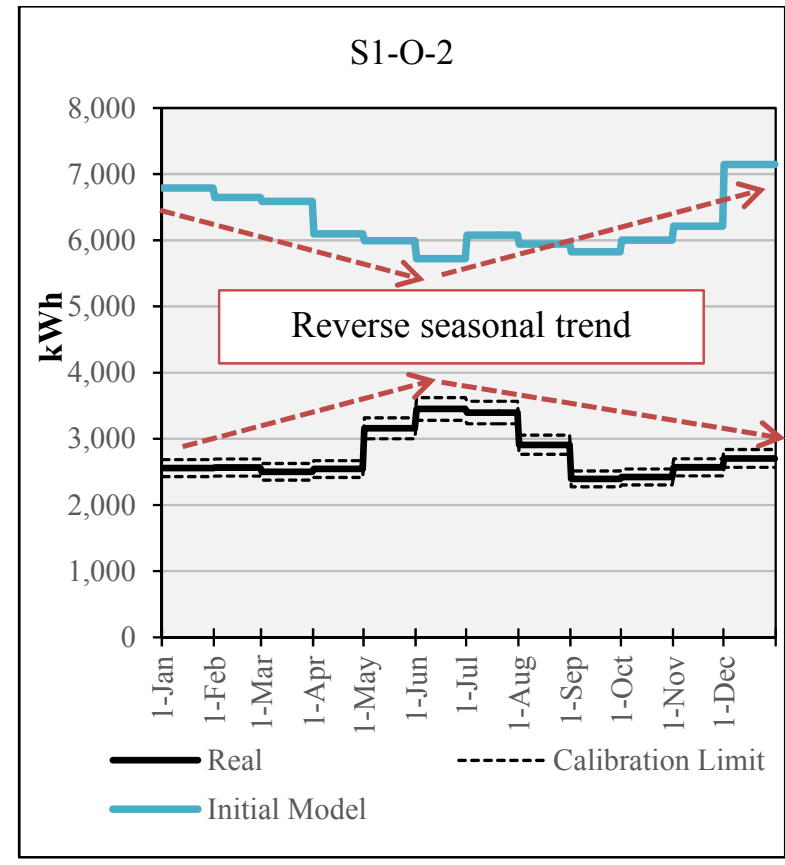

C. Reverse seasonal trend in initial energy model.

Figure 9-3 Continued : Examples of various differences between the initial energy model and real building energy consumption.

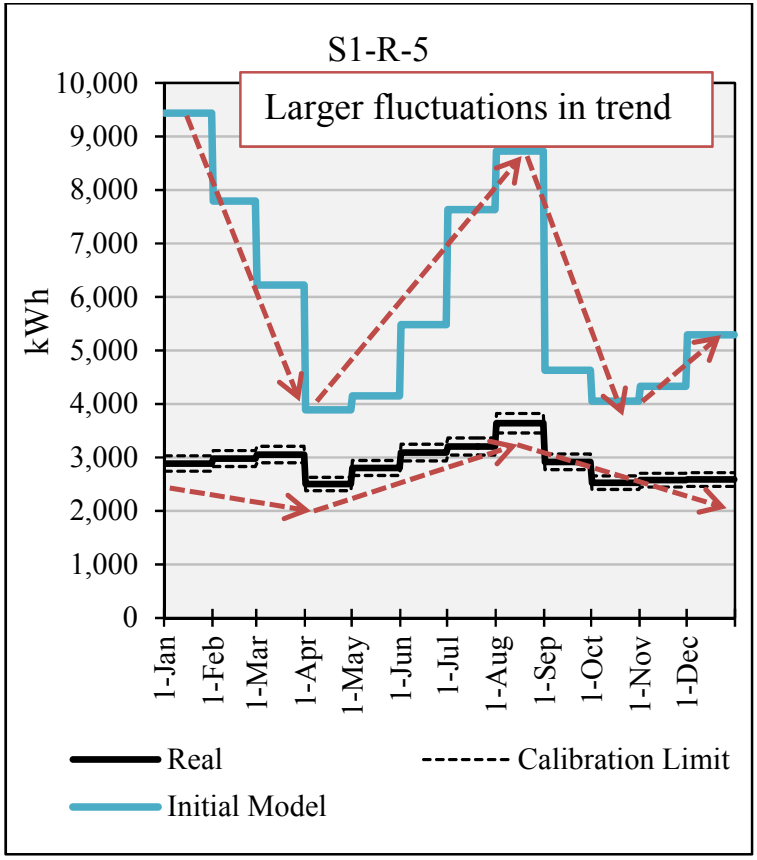

D. Larger seasonal trend in initial energy model.

The differences between the S2-O-1 initial model and the real building energy consumption illustrated the typical kinds of differences seen between the initial energy models and the real buildings for the other 47 calibrated energy models. Typically, the initial energy models had large differences in estimated energy consumption compared to their real building performance data, with some underestimating energy consumption and others overestimating energy consumption. In only three cases did the season trend of the initial energy model mirror that of their real building (Figure 9-3 A). It was more common that there were differences in the seasonal trends of the initial models compared to their real building counterparts.

Some of the initial energy models did not model the trend that was found in their real building (as was the case for S2-O-1 (Figure 9-2)); although some of the real buildings also showed very little seasonal trends (Figure 9-3 B). In other cases, a reverse seasonal trend was seen (Figure 9-3 C) due to the real building consuming more energy in the winter compared to what was initially modelled. There were also cases where the initial energy model had larger seasonal trends compared to the real building due to the real building using less energy than was modelled (Figure 9-3 D). These two differences in seasonal trends arose due to the short time period of detailed energy performance measurements provided for each of the BEES buildings. Specifically, the differences occurred due to the building being operated differently throughout the year than it had been operated during the 2-4 week monitoring period. The building loads did not change in use dramatically and as such, the differences in seasonal trends between the real building and the energy model were most typically due to incorrect HVAC model parameters, 
such as set points and HVAC operation. This illustrates the importance of the post-simulation calibration technique illustrated in Section 9.2.1b.

Table 9-2 presents the EnPI (Energy performance indicator) of the real building and the EnPI produced by the initial energy model. The EnPI was used as a measure to compare the annual energy consumption. The initial energy model consumed $24 \mathrm{kWh} / \mathrm{m}^{2} . \mathrm{yr}$ less energy than was consumed in reality. This indicated that the energy model underestimated the annual energy consumption by 35 percent and meant the monthly and annual results for the initial model were outside of acceptable calibration tolerances.

\begin{tabular}{|l|c|c|}
\multicolumn{1}{c|}{ Table 9-2 : Initial S2-O-1 model performance. } \\
\cline { 2 - 3 } \multicolumn{1}{c|}{} & Real Building & Initial Energy Model \\
\hline EnPI (kWh/m $\mathbf{2} . \mathbf{y r})$ & 68.6 & 44.6 \\
\hline Difference & - & $-35 \%$ \\
\hline
\end{tabular}

The other 47 initial energy models displayed a mixture of underestimation and overestimation in energy consumption. Of the 48 energy models, 18 initial models underestimated the energy consumption, and 30 overestimated the energy consumption. On average, the 48 initial energy models over-estimated energy consumption by 278 percent compared to the real building performance (Appendix 14.12). Using these initial energy models in the stock aggregation process would have resulted in a significant over-estimation of the energy consumed by the commercial building stock.

Figure 9-4 displays a comparison between the average weekday and weekend real (black) and simulated (blue) lighting and equipment loads for the period starting 15 April 2009 and ending 5 May 2009. The results excluded HVAC loads.

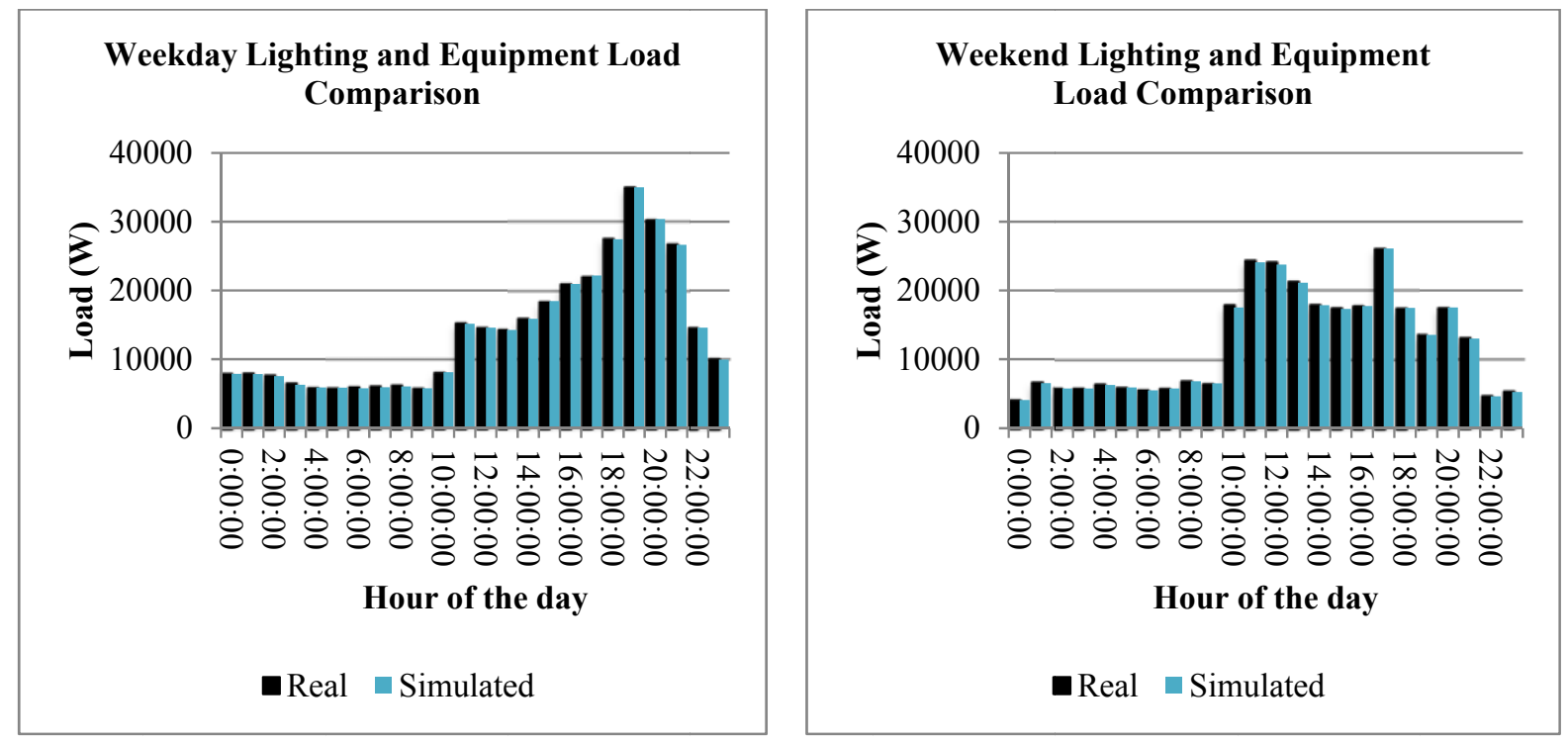

Figure 9-4 : S2-O-1 average hourly building load (excluding HVAC) comparison. 
The real building loads were produced as part of the BEES monitoring work and established the operational schedules and loads used in the model. Consequently, the intensity and patterns of operation between the real data and the simulated model data were extremely similar (on average to within 1 percent). This indicated that incorrect HVAC loads were the major cause of differentiation between the real buildings and the initial models. These results were consistent across all 48 of the initial energy models due to the detailed nature of the building load information and lack of detailed HVAC information provided on each BEES case study building.

\subsection{1c Post-simulation Calibration Process: Energy Signatures and iterations}

Following the preliminary comparison between the real and the initial energy model performance, the post simulation calibration process was applied. This began with the use of the BEES monitored data to identify how the model represented the building's real performance. Because the S2-O-1 model had a heat pump, the space conditioning energy signature library was used due to monitored energy not being split into heating and cooling end-uses. The various modelling inputs included in the library were tested to assess which input parameters were the likely cause for the difference in energy consumption between the energy model and the real building. The library of characteristic signatures was used to identify specific issues within the model and provide reasonable adjustments to the input parameters (Bensouda 2004). For S2-O-1, the energy signature library was made up of results which were obtained from iterating various HVAC input parameters. The HVAC input parameters included heating and cooling set points, outdoor air flow rate and the heating and cooling COP. Once the incorrect input parameters were identified, adjustments to the model's associated input parameters were made and the monthly energy consumption was compared once again.

Figure 9-5 displays the library of space conditioning energy signatures used to identify any incorrect model input parameters. The library displays the S2-O-1 calibration signature (green) and characteristic signatures (black) for the various tested input parameters. The use of the library (displayed in Figure 9-5) identified that factors associated with the heating and cooling set points were most likely to be incorrect. Figure 9-6 displays the comparison of the space conditioning energy signatures for the heating and cooling set points in more detail.

The set points were identified as being the most likely incorrect parameters because the characteristic signature (which represented the comparison between the initial energy model and the initial energy model with the set points altered) for the set points produced a signature shape very similar to the calibration signature (which represents the comparison between the real building and the initial energy model). The similarities were seen through an under-estimation of space conditioning energy and a declining trend towards higher ambient temperatures which followed the shape of the calibration signatures. The other conclusion drawn was that the calibration signature (comparison between the real building and initial energy model) indicated there was heating and cooling energy being consumed at lower temperatures in the real building and that this did not occur in the initial energy model. This was due to the HVAC not being operated at times when there were lower temperatures - specifically in the morning. The

Page $\mid 232$ 
following two changes were made to the initial model and were then tested to see if they corrected the inconsistencies:

- The HVAC operation schedule was updated to turn on when lower ambient temperatures occurred and;

- The heating and cooling set points were altered for each month.
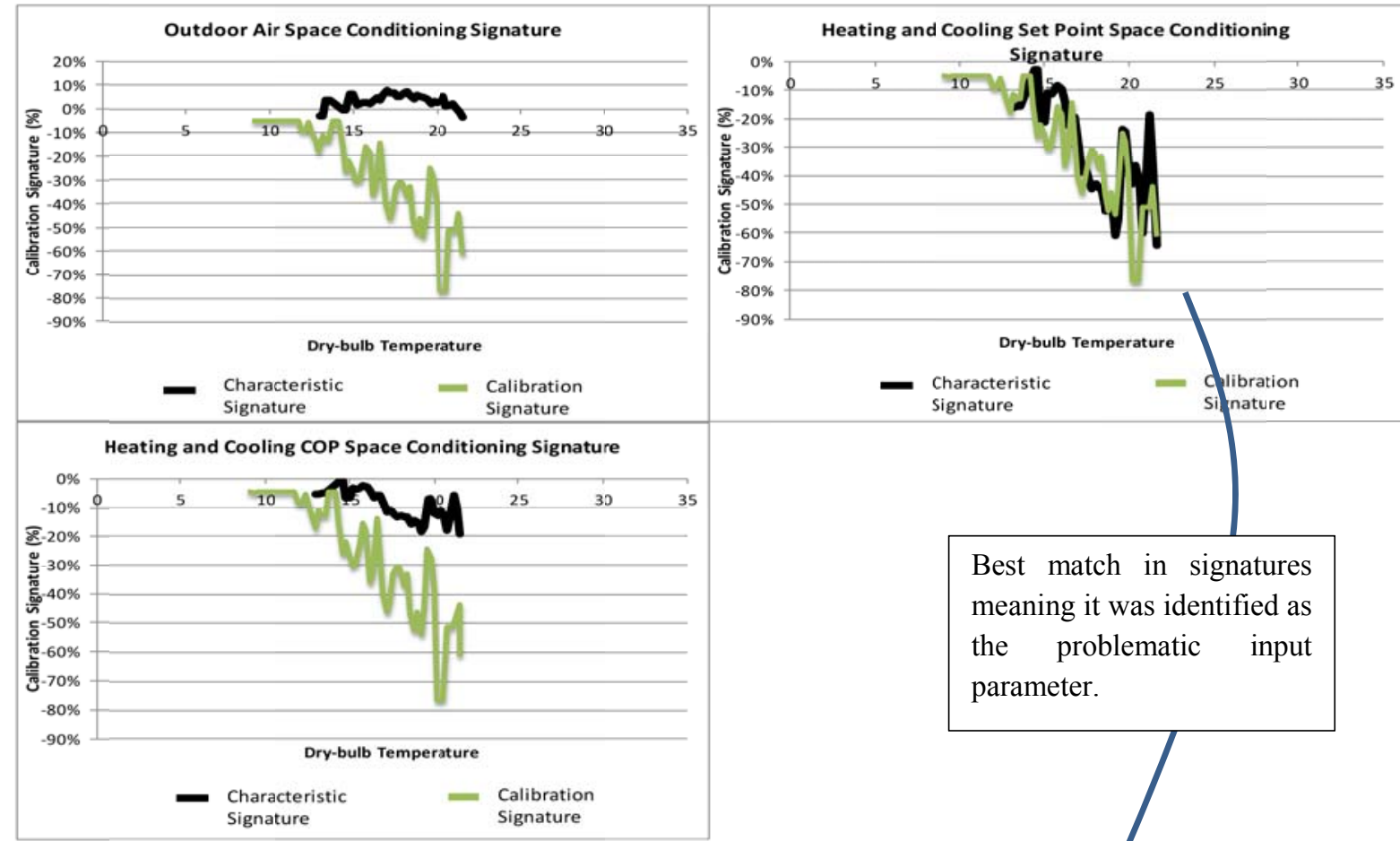

Best match in signatures meaning it was identified as the problematic input parameter.

Figure 9-5 : S2-O-1-V2 Library of Space conditioning energy signatures.

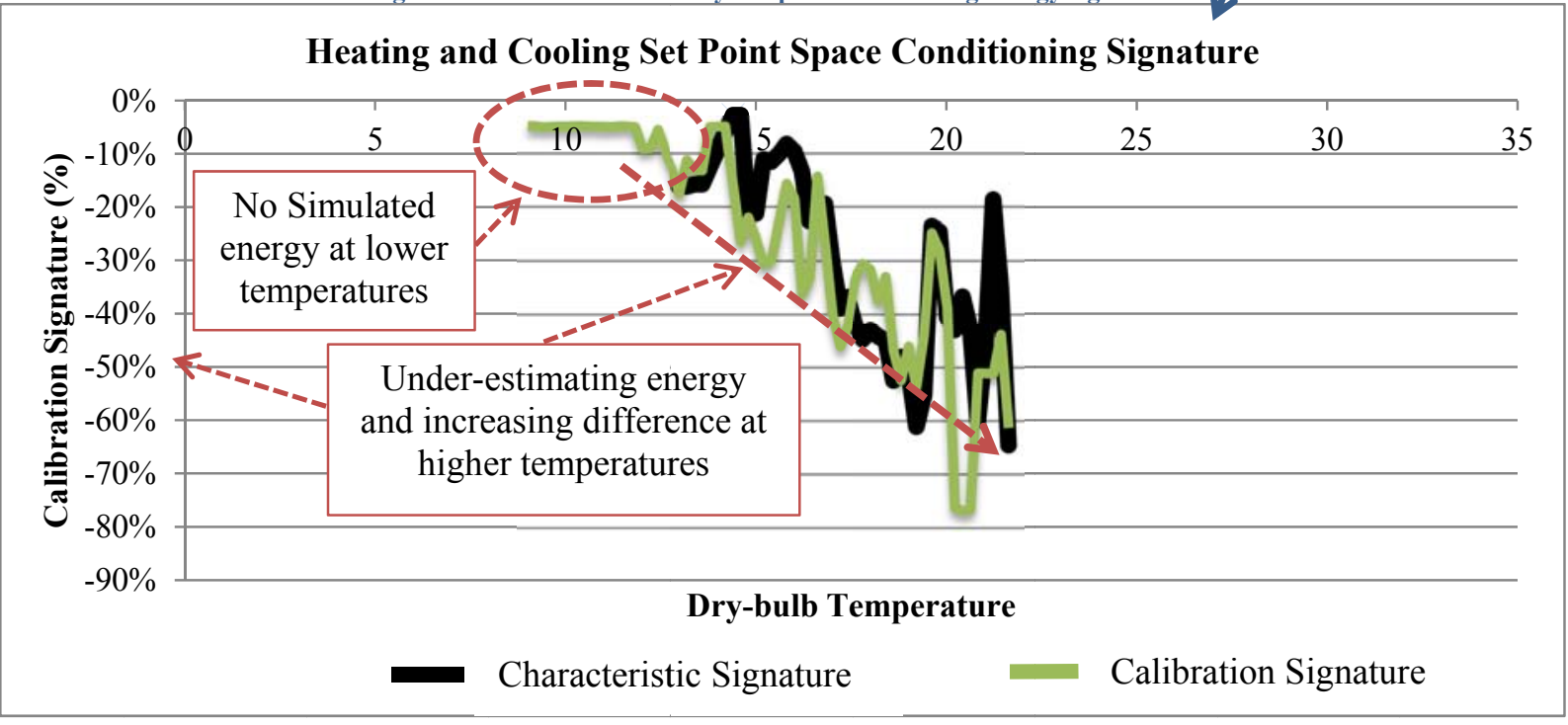

Figure 9-6 : Heating and cooling set point energy signature comparison for S2-O-1. 


\subsection{1d Calibration evaluation for various post-simulation energy model iterations}

Various iterations of HVAC operations and set points were undertaken, with Figure 9-7 displaying the two crucial changes made to move the energy model towards matching the real energy performance. Figure 9-7 shows a monthly energy comparison for various S2-O-1 iterations, including the monthly comparison between the real energy performance (black), the initial energy model (blue), the calibration MBE limit of $+/-5$ percent (dotted black line), a model with an updated HVAC operation schedule (red) and a model with the updated HVAC operation schedule with a set point dead band of $1-3^{\circ} \mathrm{C}$ (dependent on the month (Orange)).

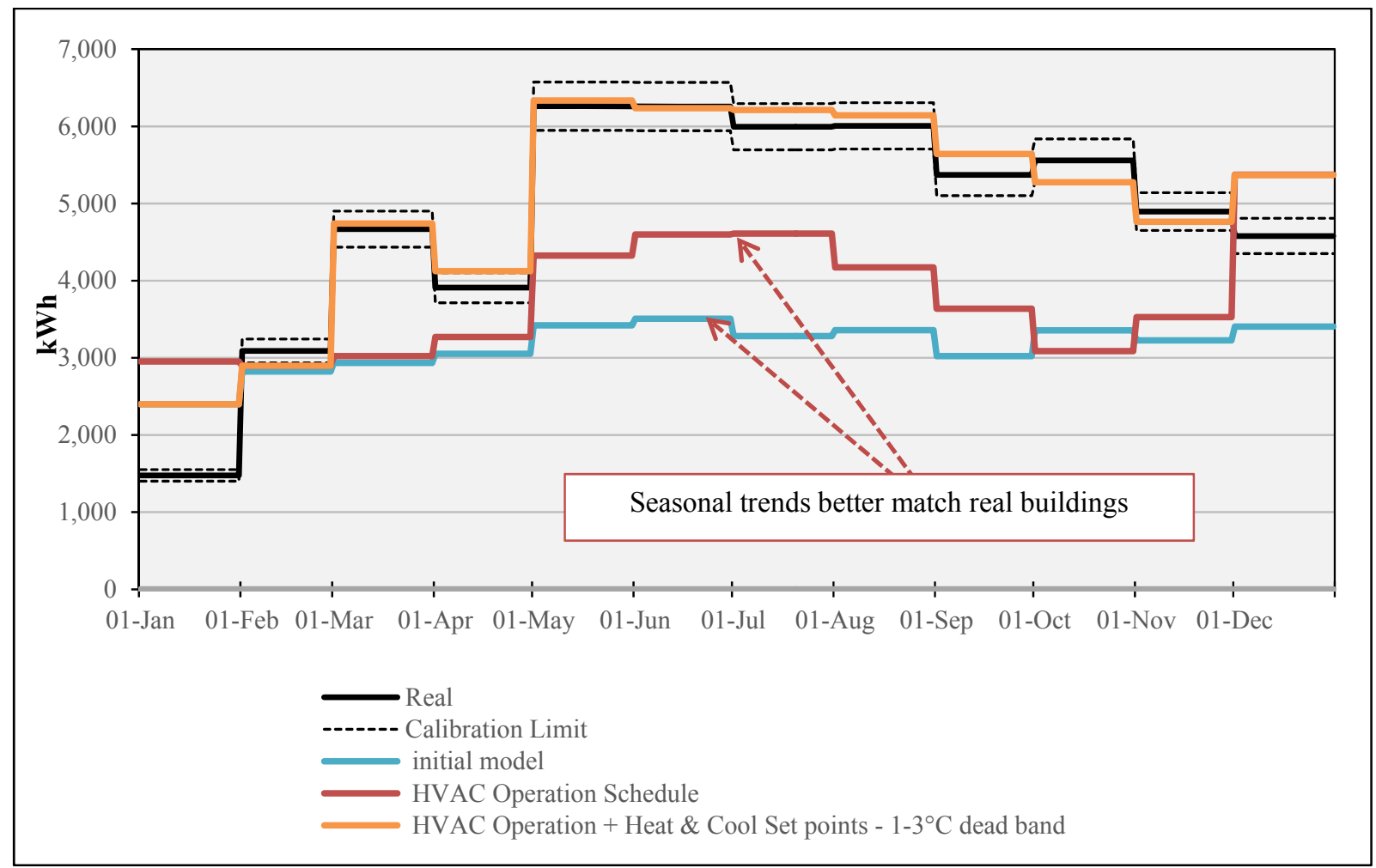

Figure 9-7: Monthly energy comparison for various S2-O-1 iterations.

After making the adjustments to the inputs identified by the energy signatures, the monthly comparisons showed that with the HVAC turned on from $7 \mathrm{am}$, the seasonal trend was closer to the real building's energy performance. The set points were then also adjusted in order to more closely match real performance. The adjustments focused on the heating and cooling set points between March and November. Because the HVAC energy was too low, the heating set point was increased and the cooling set point decreased. In the original model the heating set point was between $17-20^{\circ} \mathrm{C}$, while the cooling set point was between $23-26^{\circ} \mathrm{C}$ and was effectively turned off from May to July with a set point of $30^{\circ} \mathrm{C}$. The models showed that the best results were obtained with a temperature dead band of $1-3^{\circ} \mathrm{C}$ from March to November, with the heating set point increased to be between $19-21^{\circ} \mathrm{C}$ and the cooling set point decreased to between $21-23^{\circ} \mathrm{C}$ 
for the months between February and November. For a summary of the updates made to the input parameters within the calibrated models, refer to Appendix 14.13.

\subsection{1e Calibrated S2-0-1 Model}

With these changes to the HVAC operational schedule and to the set points the model was calibrated within the limits defined in Chapter 7. Table 9-3 displays the monthly and annual energy consumption of the real and calibrated models including the calculated error ranges. Error ranges outside of the calibration tolerance were shaded in red.

Table 9-3 : S1-O-1 calibration results.

\begin{tabular}{|l|c|c|c|}
\hline Time Period & $\begin{array}{c}\text { Real building monthly } \\
\text { energy consumption } \\
\text { (kWh) }\end{array}$ & $\begin{array}{c}\text { Calibrated model } \\
\text { monthly energy } \\
\text { consumption (kWh) }\end{array}$ & Mean Bias Error (\%) \\
\hline Jan & 1,477 & 2,399 & $62 \%$ \\
\hline Feb & 3,090 & 2,897 & $-6 \%$ \\
\hline Mar & 4,669 & 4,742 & $2 \%$ \\
\hline Apr & 3,909 & 4,124 & $6 \%$ \\
\hline May & 6,262 & 6,335 & $1 \%$ \\
\hline Jun & 6,257 & 6,236 & $0 \%$ \\
\hline Jul & 5,994 & 6,213 & $2 \%$ \\
\hline Aug & 6,006 & 6,145 & $5 \%$ \\
\hline Sep & 5,370 & 5,644 & $-5 \%$ \\
\hline Oct & 5,560 & 5,275 & $-3 \%$ \\
\hline Nov & 4,896 & 4,764 & $17 \%$ \\
\hline Dec & 4,580 & 5,369 & Bias Error $(\%)$ \\
\hline \multicolumn{4}{|l|}{} \\
\hline Annual & Real & Calibrated model & \multirow{2}{*}{$4 \%$} \\
\hline EnPI & $68,6 \mathrm{kWh} / \mathrm{m}^{2} . \mathrm{yr}$ & $71.0 \mathrm{kWh} / \mathrm{m}^{2} . \mathrm{yr}$ & \\
\hline
\end{tabular}

The adjustments made to the HVAC operational schedule and set points enabled the energy model to come within the calibration tolerances for eight of the 12 months as well as within the annual tolerance. For those four months which fell outside of the calibration tolerance, two were marginally outside of the 5 percent tolerance and the other two were considerably outside of the tolerance. The worst performing month was January which had 62 percent more energy being consumed in the model than was consumed by the real building. This difference was most likely due to the building being closed for the Christmas/New Year summer period which could easily account for 10 of the 30 working days over this period. However, as the calibration tolerance defined in Chapter 7 was met, further iterations to remedy the differences were not required.

It was common across the 48 calibrated energy models to have some occurrences where the monthly simulated energy consumption was outside of the acceptable tolerance. However, there were also a number of occurrences where the calibrated monthly simulated results met the acceptable calibration tolerance. On average, the 48 calibrated models met the acceptable 
tolerance for nine out of 12 months. The reason for some months not matching was due to unknown operation patterns. The unknown operation patterns occurred because the detailed load information provided on each building only captured data for a short period of time (2-4 weeks). If detailed information had been collected for each hour of the year, the difference in monthly energy consumption would likely be minimal.

The matching of the simulated energy consumption to the real building's energy consumption is the value of the method undertaken in this thesis. The simulation results are verified to determine if the energy models represent real buildings. If prototypical energy models were used their energy consumption would not be able to be scientifically verified and would likely not represent real buildings.

\subsubsection{Calibration results for the 48 BEES case study buildings}

This section presents an overview of how the 48 BEES calibrated energy models performed against the energy performance of their real building. The models' energy consumption results were used in the Stock Aggregation process and it was important that they matched reality as closely as possible. Stock Aggregation was the process used to estimate energy consumption of the current commercial building stock using a sample of buildings and hence, if the energy models did not match real building performance, the Stock Aggregation estimate would not match the performance of the real commercial building stock.

On commencement of the energy modelling, it was established by BEES that all 48 buildings would have 12 months of monthly meter data provided to complete the calibration exercise. However, this was only provided (by BEES) for 28 of the buildings, with less than 12 months' worth of meter data provided for 11 of the buildings, and no monthly meter data provided for the remaining 9 buildings.

\subsection{2a Buildings with 12 months of meter data}

Table 9-4 displays the achieved results for each of the 28 BEES energy models calibrated using the 12 months of meter data. The results show the real energy performance, the calibrated energy model performance, the number of months that were within the \pm 5 percent calibration tolerance, and the annual bias error.

As shown in Table 9-4, all 28 of the calibrated energy models' energy consumption results were within \pm 5 percent of the real buildings' annual energy consumption. Each model had a varying number of months that met the calibration tolerance of \pm 5 percent. Eighteen of the 28 models produced more than eight months of data that matched to within \pm 5 percent of the real buildings' monthly energy consumption; while the other ten had three models with as few as five months that met the acceptable tolerance. On average, across the 28 models, 9 months were calibrated to within \pm 5 percent of the real building energy consumption and resulted in an average annual difference of 0 percent. A difference of 0 percent meant there was no under-estimation or overestimation of annual energy consumption across the group of 28 energy models. 
Table 9-4 : Energy model calibration results for buildings with 12 months of meter data.

\begin{tabular}{|c|c|c|c|c|}
\hline Building & $\begin{array}{l}\text { Real building EnPI } \\
\quad(\mathrm{kWh} / \mathrm{m} 2 . y r)\end{array}$ & $\begin{array}{c}\text { Calibrated energy } \\
\text { model EnPI } \\
(\mathrm{kWh} / \mathrm{m} 2 . y r)\end{array}$ & $\begin{array}{c}\text { Number of months } \\
\text { with } \pm \mathbf{5 \%} \\
\text { tolerance }\end{array}$ & Annual Bias Error \\
\hline S1-0-1 & 51.0 & 51.5 & 8 & $1 \%$ \\
\hline S1-R-1 & 189.5 & 189.0 & 6 & $0 \%$ \\
\hline S1-R-2 & 207.3 & 215.5 & 9 & $4 \%$ \\
\hline S1-R-3 & 99.4 & 98.8 & 8 & $-1 \%$ \\
\hline S1-R-4 & 147.3 & 142.8 & 10 & $-3 \%$ \\
\hline S1-R-5 & 64.0 & 63.8 & 10 & $0 \%$ \\
\hline S2-O-1 & 21.1 & 20.6 & 6 & $-3 \%$ \\
\hline S2-O-2 & 131.4 & 134.1 & 9 & $2 \%$ \\
\hline S2-R-1 & 169.6 & 167.0 & 10 & $-2 \%$ \\
\hline S2-R-3 & 157.0 & 157.2 & 12 & $0 \%$ \\
\hline S2-R-4 & 233.4 & 235.7 & 10 & $1 \%$ \\
\hline S2-M-3 & 13.7 & 13.6 & 12 & $-1 \%$ \\
\hline S3-O-1 & 247 & 238 & 11 & $-4 \%$ \\
\hline S3-O-3 & 28.7 & 28.6 & 11 & $0 \%$ \\
\hline S3-R-2 & 61.8 & 61.6 & 10 & $0 \%$ \\
\hline S3-R-3 & 102.4 & 107.1 & 6 & $5 \%$ \\
\hline S3-M-1 & 36.4 & 36.3 & 5 & $0 \%$ \\
\hline S3-M-3 & 122.5 & 125.6 & 9 & $3 \%$ \\
\hline S4-O-1 & 168.6 & 163.0 & 7 & $-3 \%$ \\
\hline S4-O-3 & 118.8 & 121.7 & 10 & $2 \%$ \\
\hline S4-O-4 & 76.5 & 74.2 & 5 & $-3 \%$ \\
\hline S4-O-5 & 3.8 & 3.7 & 7 & $-3 \%$ \\
\hline S4-R-1 & 417.0 & 415.9 & 11 & $0 \%$ \\
\hline S5-O-3 & 182.2 & 189.1 & 9 & $4 \%$ \\
\hline S5-O-4 & 99.7 & 94.4 & 7 & $-5 \%$ \\
\hline S5-R-1 & 188.2 & 192.9 & 6 & $3 \%$ \\
\hline S5-M-1 & 47.0 & 47.4 & 10 & $1 \%$ \\
\hline S5-M-2 & 141.4 & 145.2 & 5 & $3 \%$ \\
\hline Average & 126 & 126 & 9 & $0 \%$ \\
\hline
\end{tabular}

The external contractor calibrating the models noted that the low monthly calibration achievements were due to the building operation changing significantly over a number of months, and given only 2-4 weeks of detailed measureable data was available; it was difficult to achieve a \pm 5 percent match for the months where the operating function of the building had differed. However, even with only 2-4 weeks of detailed measured building operation data, an adequate monthly and annual calibration of energy models was achieved using the calibration method proposed in this thesis.

It is also worth noting the range in energy performance across the 48 buildings. Some have a higher energy intensity and some have a very low energy intensity. This is due to the sample of 
real buildings incorporating the real world chaos of the buildings, whereas previous studies assessing existing building stocks are based on a theoretical 'average' building.

\subsection{2b Buildings with less than 12 months of meter data}

In the case of the eleven buildings with less than 12 months' worth of meter data, the energy models were calibrated for those months and the missing months were then interpolated to establish an annual energy consumption figure. The interpolation was performed in two ways:

1. If there was no seasonal fluctuation in monthly meter data, the missing months were calculated as the average energy consumption of the provided months' energy consumption.

2. If there was seasonal fluctuation in monthly meter data, the missing months were matched to the energy consumption of the next closest month.

Table 9-5 displays the achieved calibration results for each of the 11 BEES energy models calibrated using less than 12 months of meter data. The results show the interpolated real building EnPI, the calibrated energy model EnPI, the number of months that are within the \pm 5 percent calibration tolerance and the annual bias error. The table also includes the modeller's comments regarding the meter data.

\begin{tabular}{|l|c|c|c|c|l|}
\hline \multicolumn{2}{|c|}{ Table 9-5 : Energy model calibration results for buildings with less than 12 months of meter data. } \\
\hline Building & $\begin{array}{c}\text { Real } \\
\text { building } \\
\text { EnPI } \\
\text { (kWh/m2.yr) }\end{array}$ & $\begin{array}{c}\text { Calibrated } \\
\text { energy } \\
\text { model EnPI } \\
\text { (kWh/m2.yr) }\end{array}$ & $\begin{array}{c}\text { Number } \\
\text { of months } \\
\text { with } \pm \mathbf{5 \%} \\
\text { tolerance }\end{array}$ & $\begin{array}{c}\text { Annual } \\
\text { Bias } \\
\text { Error }\end{array}$ & \multicolumn{1}{|c|}{ Modeller's remarks about meter data } \\
\hline S1-O-3 & 15.7 & 17.1 & 6 & $9 \%$ & $\begin{array}{l}2 \text { months of missing data and } 2 \text { months } \\
\text { usage differs from typical use. }\end{array}$ \\
\hline S1-M-1 & 84.4 & 80.1 & 5 & $-5 \%$ & 3 months of missing data. \\
\hline S1-M-2 & 15.6 & 15.7 & 8 & $1 \%$ & 2.5 months of missing data. \\
\hline S2-M-1 & 10.2 & 12.6 & 1 & $24 \%$ & 7 months of missing data. \\
\hline S3-R-1 & 40.0 & 39.8 & 6 & $0 \%$ & $\begin{array}{l}4 \text { months building operation differs from } \\
\text { typical use. }\end{array}$ \\
\hline S3-R-4 & 9.55 & 10 & 8 & $5 \%$ & $\begin{array}{l}3 \text { months building operation differs from } \\
\text { typical use. }\end{array}$ \\
\hline S3-M-2 & 170.4 & 166.8 & 7 & $-2 \%$ & 4 and half months of missing data. \\
\hline S4-O-2 & 88.6 & 88.8 & 8 & $0 \%$ & 2.5 months of missing data. \\
\hline S4-M-1 & 52.6 & 53.3 & 4 & $1 \%$ & $2-3$ months usage differs from typical use \\
\hline S5-O-1 & 136.4 & 140.7 & 4 & $3 \%$ & 6 months of missing data. \\
\hline S5-M-3 & 99.7 & 109.6 & 5 & $10 \%$ & $\begin{array}{l}2 \text { months of missing data and 2-3 months } \\
\text { building operation differs from typical } \\
\text { use. }\end{array}$ \\
\hline Average & $\mathbf{6 6}$ & $\mathbf{6 7}$ & $\mathbf{6}$ & $\mathbf{4} \%$ & - \\
\hline
\end{tabular}

Eight of the 11 energy models had been calibrated to within \pm 5 percent of the real buildings' annual energy consumption. Of the other three energy models, two models were within \pm 10 
percent of the real annual energy performance and one was over 20 percent different. There was a trend in the achieved calibrated results established across the 12 models. The trend was seen when considering the amount of data the model was calibrated against. The more uncertainty in meter data, the less successful was the achieved calibration (Appendix 14.14). For example, S1M-2 and S4-O-2 achieved the best calibration results. They also had more data provided than any of the other nine models. Both cases were missing only 2.5 months of meter data and were calibrated to within \pm 1 percent annually and to within \pm 5 percent for 8 out of the 12 months. By comparison, S2-M-1 had the least successful calibration results and had the most uncertainty regarding the data. The model had an annual difference of 24 percent and only 1 month was calibrated to within \pm 5 percent of the real monthly meter data. Given this building was missing 7 months of meter data, the result was not surprising. Across the 11 energy models, on average 6 months were calibrated to within \pm 5 percent of the real meter data, with an annual difference of 4 percent. Even with the 4 percent difference, the eleven calibrated models' average EnPI was only $1 \mathrm{kWh} / \mathrm{m}^{2}$.yr higher than the eleven real buildings' average EnPI. This difference meant there was only a slight over-estimation in energy consumption across the group of energy models.

\subsection{2c 2-4 weeks detailed measured data and average meter data for buildings of that size}

Where possible, calibration was performed using monthly meter data and the development of calibrated models was only undertaken using monthly meter data. However, in reality this was not always attainable considering this study already had a small sample size of buildings to form a cross section of the building stock. The eight buildings with no monthly meter data were used to increase the sample size to reduce the error range of the stock aggregated estimate. Including these eight buildings did not bias the results in any way and means there was not a disadvantage by using them. The eight models were still better than creating prototypical models because prototypical models have none of the realism about variations in operational patterns, loads and site shading.

A process was established for dealing with the 'calibration' of the nine models which only had 24 weeks of measured data and no meter data. Firstly, like all the buildings, the models were calibrated against the hourly energy data obtained from site measurements taken by the BEES project for a 2-4 week period. This calibration involved the matching of simulated lighting and equipment loads for the monitored period. In addition, the correct HVAC system was installed and set points were derived from indoor temperature data measured during the 2-4 week period. The use of this measured data ensured the model still represented how the building was operated and also that it was consistent with the approach taken for the other energy models calibrated in this study.

Secondly, the simulated monthly energy consumption was compared and 'calibrated' to the average monthly meter data for buildings of the same size (for an example of the averaging procedure refer to Appendix 14.15). This second exercise was a cross check to determine if the results were close enough to reality. The term 'calibrated' was used loosely for these nine 
buildings because the monthly meter data did not represent the real building's operation. Instead, it represented an average commercial building of the same size.

Table 9-6 displays the achieved calibration results for each of the nine energy models calibrated using 2-4 weeks of detailed measured data and average meter data for buildings of the same size. The results show the real building EnPI (established using the average meter data from buildings of a similar size divided by the actual building's floor area), the calibrated energy model EnPI, the annual bias error and the modeller's comments regarding the meter data. ${ }^{7}$

\begin{tabular}{|c|c|c|c|c|}
\hline Building & $\begin{array}{c}\text { Real average } \\
\text { building of } \\
\text { same size } \\
\text { EnPI } \\
\text { (kWh/m2.yr) } \\
\end{array}$ & $\begin{array}{c}\text { Calibrated } \\
\text { energy } \\
\text { model EnPI } \\
(\mathbf{k W h} / \mathbf{m} 2 . y r)\end{array}$ & Annual Bias Error & Modellers comments about meter data \\
\hline S1-O-2 & 176.5 & 196.1 & $11 \%$ & \\
\hline S2-R-2 & 81.47 & 90.3 & $11 \%$ & \\
\hline S2-R-5 & 27.34 & 34.1 & $25 \%$ & \\
\hline S2-M-2 & 53.92 & 43.5 & $-19 \%$ & \\
\hline S3-O-2 & 132.94 & 164.7 & $24 \%$ & \\
\hline S4-R-2 & 571.36 & 595 & $4 \%$ & \\
\hline S4-M-2 & 60.51 & 251.2 & $315 \%$ & $\begin{array}{l}\text { Average meter data not realistic when } \\
\text { compared to the hourly measured loads }\end{array}$ \\
\hline S4-M-3 & 177.4 & 193.7 & $9 \%$ & \\
\hline S5-O-2 & 17.6 & 77.9 & $343 \%$ & $\begin{array}{l}\text { Average meter data not realistic when } \\
\text { compared to the hourly measured loads }\end{array}$ \\
\hline Average & 144 & 183 & $\begin{array}{c}80 \% \text { (9\% with two } \\
\text { outlier buildings } \\
\text { excluded) }\end{array}$ & \\
\hline
\end{tabular}

As shown in Table 9-6, only one of the nine buildings achieved an acceptable annual calibration result within \pm 5 percent of the real average building EnPI. The results for the remaining eight buildings varied, with differences ranging from 9 percent up to 343 percent. In most cases, the average meter data was a good comparison for the measured hourly loads and HVAC. However, in two cases the average meter data was not realistic when compared to the results produced from measured hourly loads. This meant that on average across the nine buildings, there was a difference of 80 percent. This difference was mainly due to two of the nine models having a difference of over 300 percent. However, because the average meter data was not a realistic comparison for these two models, they were ignored. The average difference with these two models ignored was 9 percent.

The stock aggregation result for this study was therefore not based on energy models calibrated to the same standard. However, all models were still founded on real performance data. Using

\footnotetext{
${ }^{7}$ The number of months that were within the $\pm 5 \%$ calibration tolerance was not presented for these nine energy models because the meter data they were compared against were not from the actual building it represented and instead the average for buildings in a similar size range.
}

Page $\mid 240$ 
real building performance and information minimised the assumptions needed in the energy models, meaning the 48 calibrated energy models provided a better base for a stock aggregation than prototypical models used in previous studies. This is because the models have the realism of variations in operational patterns and site shading built in, which is the limitation of the prototypical models.

\subsubsection{Stock Aggregation energy consumption estimate}

This section presents the results from the Stock Aggregation using the 48 energy models. The result formed the baseline for testing NZE. The Stock Aggregation result represented the current energy consumption of the New Zealand commercial building stock $^{8}$ and was performed using the procedure described in Chapter 6 . The procedure multiplied the average EnPI by the total amount of floor area for three building archetypes: Size, Type, and climate region (refer to Appendix 14.16.2 for the Stock Aggregation results for the current commercial building stock).

Figure 9-8 presents the Stock Aggregated energy consumption results for the commercial building stock (grey), the building type archetypes (red), the building size archetypes (green) and the climate region archetypes (blue). A 95 percent confidence interval provides a margin of error that is overlaid for each aggregation estimate (refer to Section 5.3.1c for confidence interval discussion and Appendix 14.17 for their calculation).

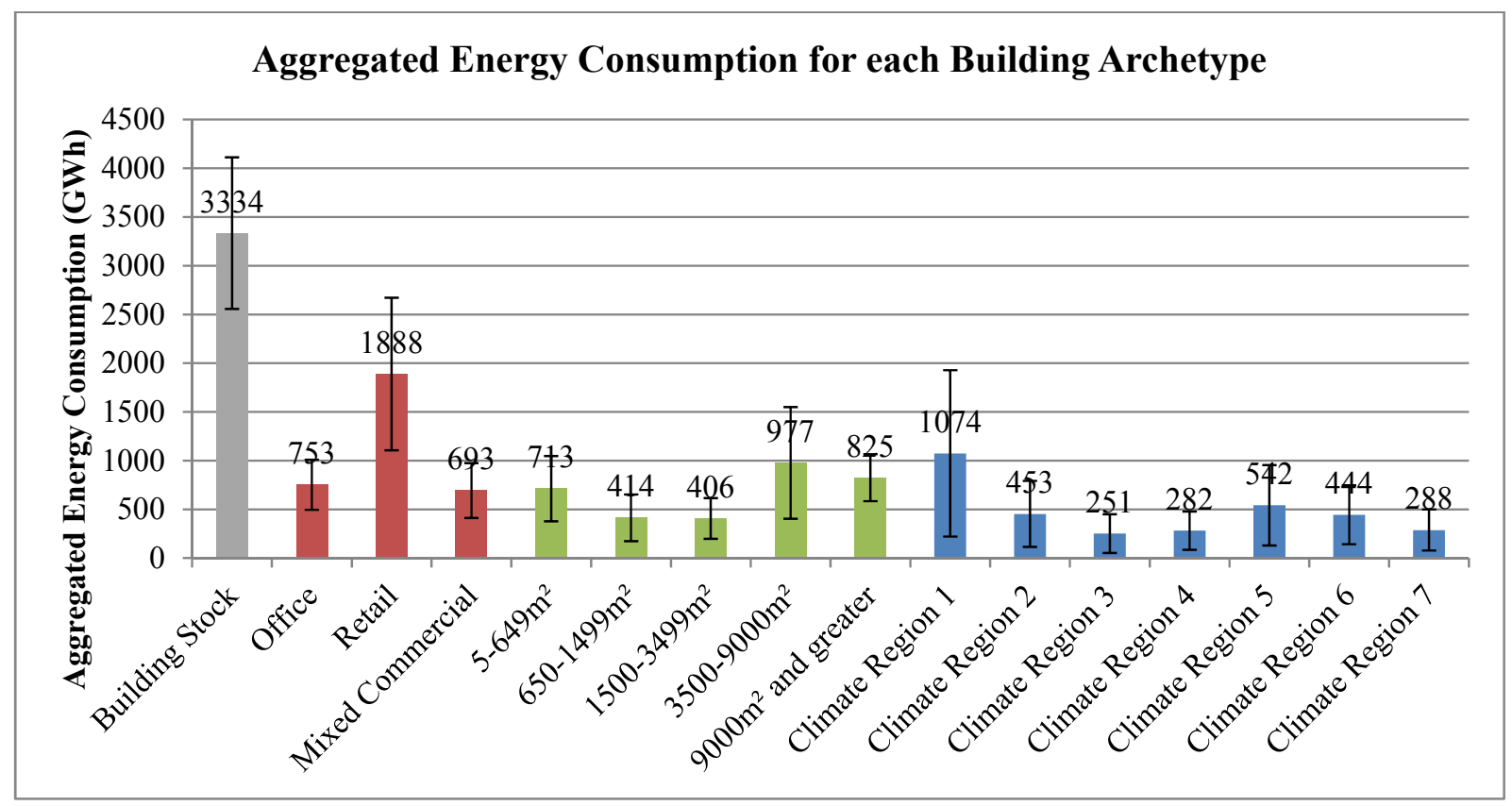

Figure 9-8 : Aggregated Energy Consumption for each Building Archetype.

\footnotetext{
${ }^{8}$ Note: Estimate is not meant to represent the whole commercial sector. Instead it represents the commercial building stock defined in Section 5.2.5.
}

Page | 241 


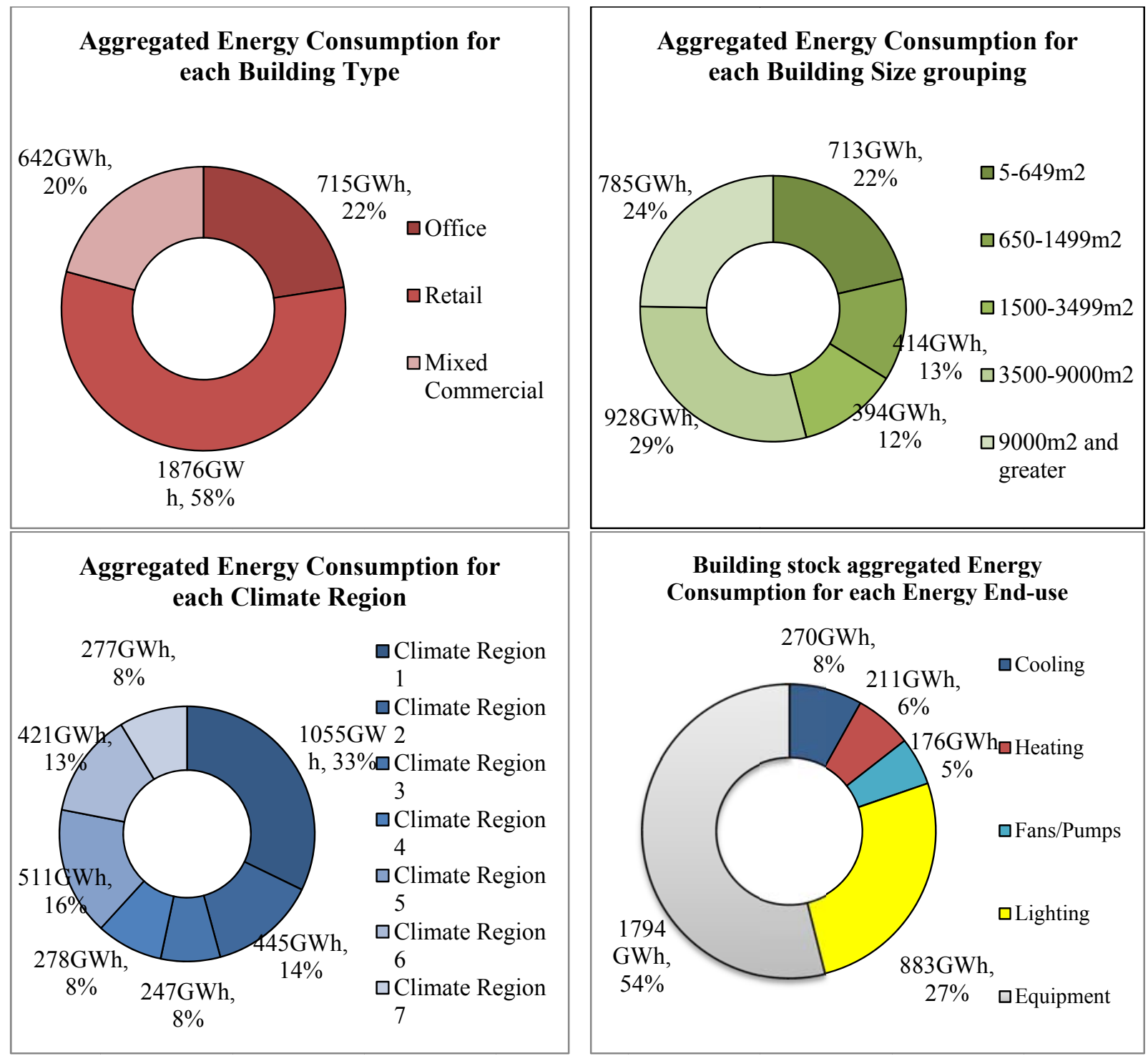

Figure 9-9 : Split of Aggregated Energy Use for each building type, energy end-use, building size, and climate region.

Figure 9-9 displays the split of Stock Aggregated energy consumption for the building type archetypes (red), the building size archetypes (green), the climate region archetypes (blue), and the energy end-uses (split into cooling (dark blue), heating (red), fans and pumps (light blue), lighting (yellow) and equipment ${ }^{9}$ (grey)).

The Stock Aggregation provided an estimated commercial building stock energy consumption of $3,334 \mathrm{GWh}$. Fifty eight percent of the energy consumed by the commercial building stock was consumed by retail buildings, followed by an almost even split between office buildings (22 percent) and mixed use buildings (20 percent). Large buildings consumed over half of all

\footnotetext{
${ }^{9}$ Please note: the equipment end-use incorporates all internal building equipment and plug-load, including: office equipment, miscellaneous equipment, plug-in heaters, plug-in fans, commercial refrigeration and hot water.
}

Page | 242 
commercial energy. For example, the largest energy consuming buildings ranged in size from $3500-9000 \mathrm{~m}^{2}$ and consumed 29 percent of all commercial energy while the second largest energy consumers were buildings equal to or over $9000 \mathrm{~m}^{2}$ which consumed 24 percent of all commercial energy. The third largest energy consuming buildings were those of the smallest size $\left(5-649 \mathrm{~m}^{2}\right)$ which consumed 22 percent of all commercial energy. Buildings $3500 \mathrm{~m}^{2}$ or larger accounted for 42 percent of the floor area and buildings less than $649 \mathrm{~m}^{2}$ accounted for 23 percent of the floor area. Thus larger buildings consumed more energy than was proportional to floor area compared to their smaller counterparts. This suggests that building size had implications on energy consumption. Climate region 1 (Auckland/Northland), climate region 5 (Wellington) and climate region 3 (Waikato/Bay of Plenty) consumed the largest proportion of energy (33 percent, 16 percent, and 14 percent respectively). This was expected given these three regions contained the largest amounts of commercial floor area in the country.

Table 9-7 displays a breakdown of a comparison between the whole commercial sector and the building stock estimates used. The commercial sector figure included all energy types (electricity, natural gas, coal, oil, and renewables (such as geothermal)).

Table 9-7 : Commercial Sector and commercial building stock estimate comparison.

\begin{tabular}{|c|c|c|c|}
\hline Estimate source & Estimate variables & $\begin{array}{c}\text { All Energy } \\
\text { types }\end{array}$ & $\begin{array}{l}\text { Electricity } \\
\text { and Gas }\end{array}$ \\
\hline $\begin{array}{l}\text { Commercial Sector estimate } \\
\text { (Energy Information and } \\
\text { Modelling Group 2012b) }\end{array}$ & $\begin{array}{l}\text { All energy types: electricity, } \\
\text { natural gas, coal, oil, and } \\
\text { renewables (such as } \\
\text { geothermal). } \\
\text { All commercial sector } \\
\text { consumers: Office, Retail, } \\
\text { mixed use, health, education, } \\
\text { and some industrial use } \\
\text { buildings; and commercial } \\
\text { transport. }\end{array}$ & $13,405 \mathrm{GWh}$ & $10,625 \mathrm{GWh}$ \\
\hline $\begin{array}{l}48 \text { BEES energy model stock } \\
\text { aggregated estimate for } \\
\text { commercial building stock }^{10}\end{array}$ & $\begin{array}{l}\text { Only electricity and natural } \\
\text { gas. } \\
\text { Only office, retail and } \\
\text { mixed use buildings. }\end{array}$ & - & 3,334GWh \\
\hline $\begin{array}{l}\text { Percentage of electricity and } \\
\text { gas }\end{array}$ & - & - & $31 \%$ \\
\hline
\end{tabular}

The stock aggregated figure of $3,334 \mathrm{GWh}$ only included electricity and natural gas. The commercial sector figure encompassed all energy consumers within the sector and meant that commercial buildings were not the only energy consumers in the estimate. While other

\footnotetext{
${ }^{10}$ Note: Estimate is not meant to represent the commercial sector. Instead it represents the commercial building stock defined in Section 5.2.5. The comparison is to illustrate what portion of the commercial sector's energy consumption this study's defined commercial building stock accounts for. Therefore, this study's definition of commercial building stock accounts for $31 \%$ of the commercial sector's energy consumption.
}

Page $\mid 243$ 
consumers of energy in the commercial sector included health and education buildings, some industrial use buildings and commercial transport, the stock aggregated estimate only included energy consumed by commercial office, retail and mixed use buildings. In 2011, the commercial sector consumed approximately 13,400 GWh of energy (Energy Information and Modelling Group 2012b), while the estimates calculated in this thesis suggest the commercial building stock consumes 3,334GWh. Thus commercial office, retail and mixed use buildings' electricity and natural gas consumption comprised 31 percent of all commercial sector electricity and gas consumption. The remaining 69 percent of commercial sector electricity and gas consumption is attributed to the other building types included in the commercial sector estimate (industrial, health, education, hotel), as well as any variances in the estimates. Note: although the commercial building stock in this thesis does only account for approximately 31 percent of all commercial sector energy consumption, if this research is successful the research can be applied to the remaining buildings which make up the commercial sector.

\subsection{Quality assurance test of the Stock Aggregation estimate}

To quality assure the stock aggregation estimate was reliable, the stock aggregated estimate for energy consumption calculated using the 48 energy models in seven climates was compared to an estimate for the commercial building stock's energy consumption that was independent from this thesis. The independent estimate was calculated by the BEES project. Both the estimate from the 48 energy models and BEES were calculated by independent groups of researchers. The two estimates were based on the same sampling process from the whole population of commercial office, retail, and mixed use buildings in New Zealand. However, each takes a very different approach to estimating the total energy use of the commercial building stock. Both estimates have different approaches to calculate the same estimate for the current commercial building stock's energy consumption. This is the reason the stock aggregation estimate from the energy models and the BEES estimate were compared; an independent calculation, like the BEES estimate, that agrees with the total energy use calculated using the energy modelling process can establish the reliability of the process. Both calculation procedures have differences which are discussed in the following sections.

The estimate calculated in this study was not considered quality assured if the 95 percent confidence interval was outside of the range of the BEES estimate's 95 percent confidence interval (refer to Section 5.3.1c for reliability discussion). If the results show that the two estimates had distinct differences, more investigation would be needed to determine which is correct. If they were in a similar range to each other, they were both reliable.

It is important to understand that regardless of the QA results, 45 percent of the current energy consumed by the commercial building stock (calculated in Section 9.2.3) will need to be reduced or offset before NZE is achieved. Therefore, the conclusion as to whether NZE is possible or not, will not change. This is due to the NZE target being a proportional target (percentage reduction across the estimated building stock's consumption - refer to Section 4.8.2), not a total reduction

Page | 244 
target (total energy reduction of the commercial sector). As well, the definition proviso set out in Section 4.7 requires all other buildings not included in this thesis definition of commercial building would need to meet the same proportional reduction as the buildings refurbished in this study.

Furthermore, the current and NZE commercial building stock estimates were still founded on real performance data regardless of whether the two estimates vary. This was because the energy models were constructed to match the real buildings' size, site context (shading etc...) and operation patterns. Each was then calibrated against real building performance and was not constructed to be a theoretical "typical" building which matches no real building.

\subsubsection{Sample and sample design}

The BEES estimate was calculated using a sample of 462 BEES criteria commercial buildings. This included the office, retail and mixed use building types focused on in this thesis, with two additional building types: industrial service and warehouse.

The 48 commercial buildings that comprise the energy models were drawn through the same sampling process from the same population as the sample of 462 buildings.

\subsubsection{Sample of building types}

The BEES estimate was drawn from the energy performance of the five building types (stated in above section). Industrial warehouse and service were included in the sample only when there was a secondary commercial activity identified (such as office or retail).

The energy model estimate did not include industrial warehouse and industrial service buildings; it only included commercial office, commercial retail, and commercial mixed buildings. To account for the large part of this difference, the industrial service and warehouse building floor area was removed from the BEES estimate of the total floor area for this exercise. This was undertaken by multiplying the BEES average commercial building EnPI estimate by the office, retail and mixed use building floor area, with the Industrial Service and Warehouse floor area removed (Appendix 14.18). However, it should be noted that the BEES estimate EnPI figure for the energy performance of the commercial building stock included these two additional building types.

\subsubsection{Sample of climate types}

Climate in the BEES estimate was represented by the random sample of buildings. Across the sample of 462 buildings each building was located in a specific location with a specific climate. By the logic of random sampling, there would be a representative number of buildings from each climate to represent the range of climates. For example, it would be expected that there would be more buildings from Auckland than Southland in the sample of 462 buildings. Auckland has a greater amount of commercial building floor area (40 percent of all floor area) than Southland (less than one percent of all floor area). 
Due to the sample of energy models only being 48 buildings, climate was represented differently. Each of the 48 buildings was simulated in seven New Zealand climates (Section 6.5.3) which creates 336 different energy performance results. This method was adopted from Moffat (2001). It is inherent in the energy modelling process that climate is accounted for through explicit climate location analysis.

\subsubsection{Individual building yearly meter data}

The BEES estimate was calculated against the last 12 months of available meter data when the data became available for each building (for example, June 2011 to June 2012). The 462 buildings in the BEES estimate represent a widely varying combination of 12 month periods. The energy models were calibrated and therefore calculated against a calendar year's monthly meter data (for example, January 2010 to December 2010). This can cause some differences in energy consumption because a building can between years:

- experience very different climates;

- change use;

- have varying occupancies; and/or

- have varying equipment densities.

Figure 9-10 displays an example of this yearly variation as seen in the 48 energy models. The example shows the difference in energy consumption between the yearly meter data used to calibrate the energy model, and yearly meter data used to calculate the whole building's energy consumption for the BEES estimate.

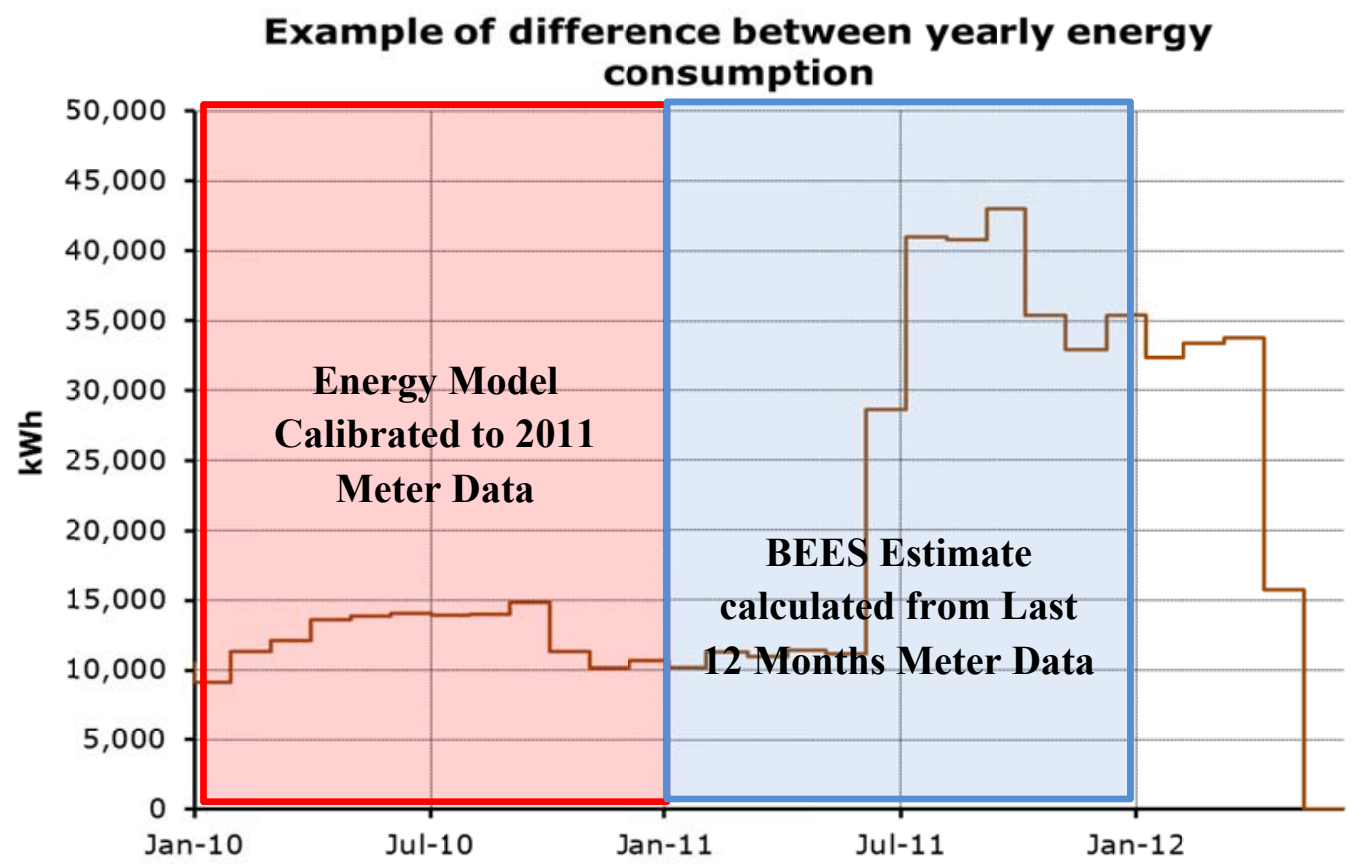

Figure 9-10 : Variation in energy consumption between the yearly meter data used by both estimates

Page $\mid 246$ 
As can be seen, the Energy Model was calibrated against and calculated its whole building consumption for meter data from January to December 2010, which had a maximum monthly energy consumption of approximately $15,000 \mathrm{kWh}$. 2010 was chosen because the onsite detailed measurements (of lighting, equipment, temperature etc...) used to construct the model to match the real building were conducted during 2010 and so the energy model was modelled and calibrated for this year. The BEES estimate for this example calculated the whole building energy consumption from the last 12 months of meter data (June 2011 to June 2012), which had a maximum monthly energy consumption of approximately $43,000 \mathrm{kWh}$. The result is the BEES estimate for the whole building energy consumption for this building is much higher than the energy model. This is one example of the differences that could occur. The opposite trend could occur in other cases (the energy model is calibrated to higher energy consumption when compared to the BEES estimate), and in some cases the energy consumption between years would not differ much at all. This is in the nature of random samples. Each is a snapshot of a particular time or situation. The randomness of the sampling process is intended to ensure these differences do not bias the representative nature of the sample. The increases and decreases for each building should balance out in each sample.

Additionally, the weather between years changes. For the example above, the building was located in Climate Region 3. The temperature difference in Climate Region 3 in 2011 compared to 2012 meant there was 6 percent more cooling and 15 percent more heating required in 2012 (calculated using the heating and cooling degree days - Appendix 14.19). Merely selecting different weather years between estimates can have this scale of effect.

Table 9-8 shows the individual building EnPI and the difference in EnPI between the energy model and BEES estimates resulting from the use of different yearly meter data in the calculation. Each of the buildings was a part of both the energy models and BEES building samples. The only difference between the BEES and energy model EnPIs in Table 9-8 is that they are calculated using different yearly meter data. 
Table 9-8 : Different Yearly Meter Data

\begin{tabular}{|c|c|c|c|}
\hline Building ID & $\begin{array}{l}\text { BEES Estimate EnPI } \\
\left(\mathrm{kWh} / \mathrm{m}^{2} . \mathrm{yr}\right)\end{array}$ & $\begin{array}{l}\text { Energy Model EnPI } \\
\quad\left(\mathrm{kWh} / \mathrm{m}^{2} . \mathrm{yr}\right)\end{array}$ & $\begin{array}{c}\text { Difference between } \\
\text { Energy Model and } \\
\text { External Estimate } \\
\text { EnPI (\%) }\end{array}$ \\
\hline S1-R-2 & 218 & 216 & $1 \%$ \\
\hline S1-R-3 & 115 & 99 & $17 \%$ \\
\hline S3-R-2 & 250 & 62 & $307 \%$ \\
\hline S1-R-4 & 144 & 143 & $1 \%$ \\
\hline S1-R-5 & 62 & 64 & $-3 \%$ \\
\hline S2-R-1 & 140 & 167 & $-16 \%$ \\
\hline S2-R-3 & 243 & 157 & $55 \%$ \\
\hline S2-R-4 & 64 & 236 & $-73 \%$ \\
\hline S2-M-3 & 14 & 14 & $2 \%$ \\
\hline S2-O-2 & 128 & 134 & $-5 \%$ \\
\hline S3-R-3 & 101 & 107 & $-6 \%$ \\
\hline S3-O-3 & 25 & 29 & $-12 \%$ \\
\hline S4-O-1 & 171 & 163 & $5 \%$ \\
\hline S2-R-4 & 72 & 235 & $-69 \%$ \\
\hline S4-M-3 & 165 & 193 & $-14 \%$ \\
\hline S1-0-3 & 60 & 17 & $251 \%$ \\
\hline S1-M-1 & 134 & 80 & $68 \%$ \\
\hline S3-R-1 & 36 & 39 & $-7 \%$ \\
\hline S3-R-4 & 487 & 10 & $4766 \%$ \\
\hline S3-M-2 & 142 & 166 & $-15 \%$ \\
\hline S3-R-2 & 250 & 62 & $305 \%$ \\
\hline S4-R-2 & 505 & 415 & $22 \%$ \\
\hline Average & 160 & 128 & $26 \%$ \\
\hline
\end{tabular}

As can be seen, there was a range of variances across the EnPIs for the 22 buildings. Some do not vary substantially; such as S1-R-2, and S1-R-4. Other EnPIs do vary significantly; such as S3-R-2 and S3-R-4. S3-R-4 is a special case; it varied by 4766 percent. This was due to the year modelled being during a period when the building was partly unoccupied, whereas the BEES estimate year was fully occupied. It is a good example of how different energy consumption can be from one year to the next. The building was modelled unoccupied because the representative sampling methodology requires modelling the building the way it was when it was sampled, as this is representative of what occurs in the building stock. The building could not be removed because the sample cannot be manipulated. Therefore, if one building has little energy use due to it being largely unoccupied, it is representative of the fact that some buildings in the building stock are largely unoccupied in reality. 
On average across these 22 individual buildings, and including the outlier described above, the Energy Model EnPIs were only 26 percent lower than the BEES EnPIs. Ignoring this outlier, the difference was only 8 percent.

\subsubsection{Individual building common and ineligible area and its energy consumption}

A further difference in the approaches was that the BEES estimate included an estimate for the energy use in building common areas, such as entrance ways, corridors, hallways, stair ways and shared kitchens. This estimate process multiplied any common area in a building by $450 \mathrm{kWh} / \mathrm{m}^{2}$.yr (Amitrano et al. 2014b) and added this to the energy consumption measured at the building as a means to determine the whole building energy consumption. The common area estimate of $450 \mathrm{kWh} / \mathrm{m}^{2}$.yr was based on billing data from 13 large (over $3500 \mathrm{~m}^{2}$ ) buildings (Property Council New Zealand 2008) and included all energy end-uses: heating, cooling, ventilation, lighting and equipment. Similarly there were areas in some commercial buildings which were ineligible areas because they were residential and were not related to commercial uses. In these areas, the external estimate assumed they consumed $100 \mathrm{kWh} / \mathrm{m}^{2} . \mathrm{yr}$ (Amitrano et al. 2014b).

The energy models, in this thesis research, take a completely different approach to the estimation of heating, cooling, ventilation, lighting and equipment energy use. Because these are all being calculated from first principles, hour by hour for a full year, an estimate based on a typical annual value for a common or ineligible area was inappropriate. The energy estimate is calibrated against monthly meter data and this would not have been possible if the common area annual energy use figure had been split into 12 monthly components. No matter how this figure was split, this splitting process would predetermine the very process that the dynamic simulation process is supposed to calculate.

Figures 9-11 and 9-12 display an example of why the common and ineligible area energy consumption estimate was not modelled in the manner adopted in the BEES estimate process. Figure 9-11 displays an example of a real building's monthly energy consumption profile throughout a year (blue line). Figure 9-12 displays an example of the same real building's monthly energy consumption profile throughout a year (blue line); with an added common and ineligible area energy consumption estimate used in the BEES estimate (Grey rectangle). 


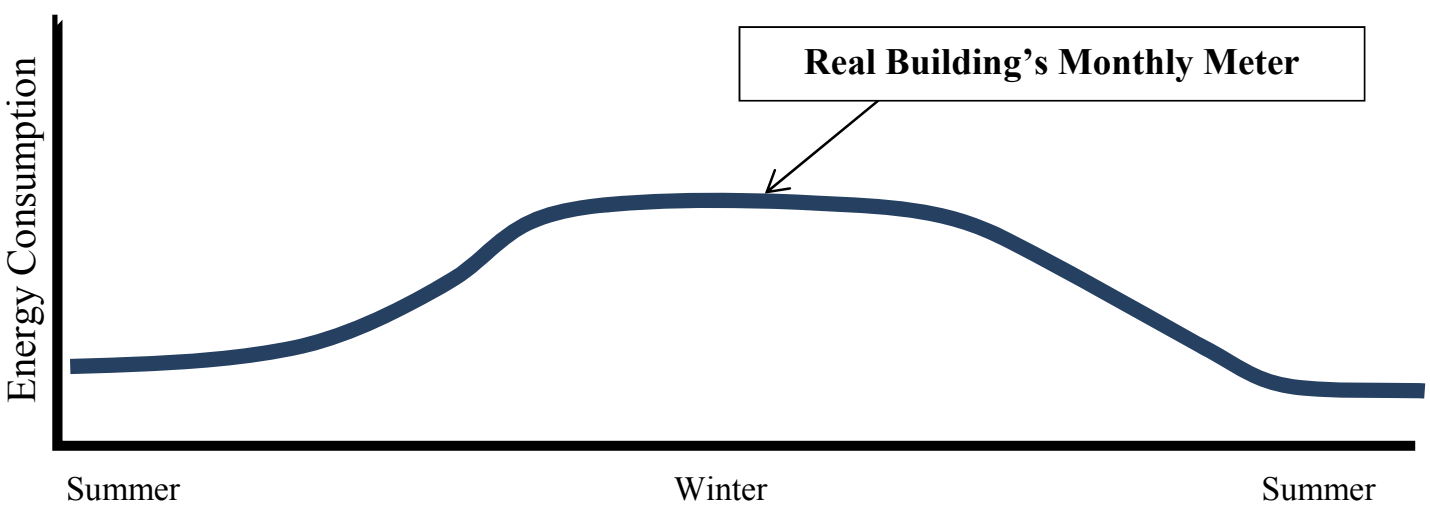

Figure 9-11 : Energy Model - calibrated to real buildings monthly energy consumption profile

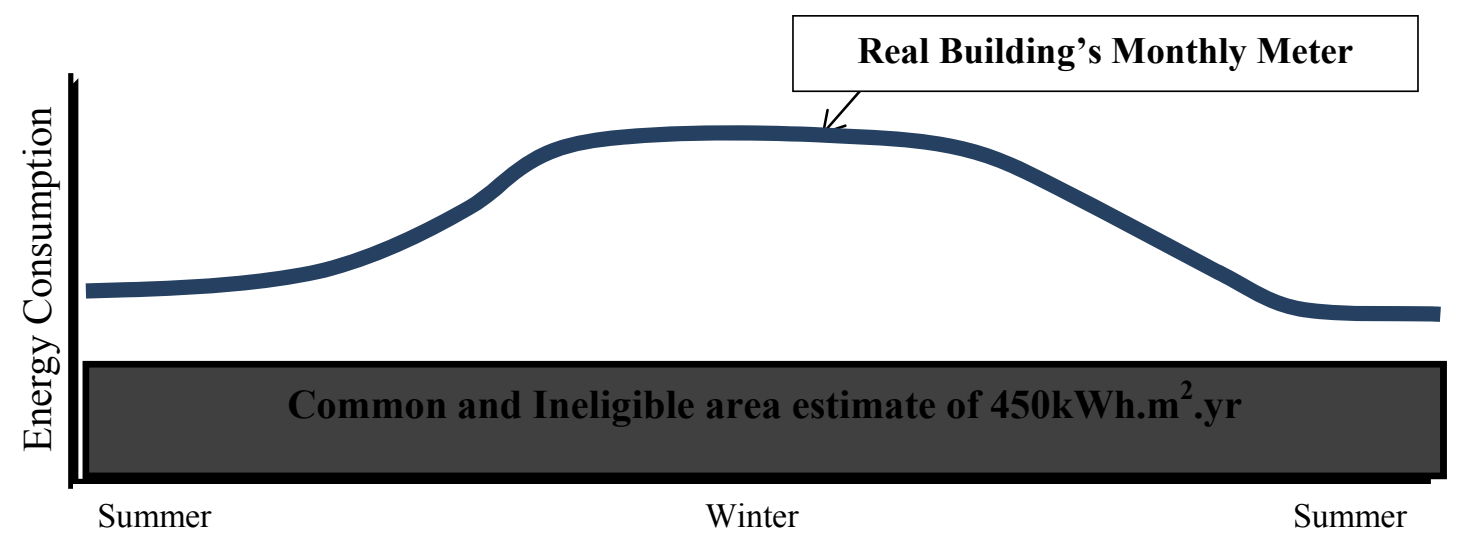

Figure 9-12 : External estimate - calculated using the real building monthly energy consumption, common and ineligible energy consumption.

As can be seen, the real monthly meter data (blue line), that the Energy Models are calibrated against, shows a seasonal trend of the building consuming more energy in winter than in summer, caused by a larger heating load in winter. In comparison, the external estimate is calculated using the real building's monthly energy consumption (blue line), but has a uniform estimate of energy consumed for common and ineligible areas throughout the whole year (grey area). The common and ineligible areas energy consumption has no monthly variation based on temperature or different patterns of operation; instead it can only be uniformly distributed across each month. Because the energy model was calculating the energy use from first principles, including the climate dependent heating, cooling and ventilation of the building, there was no mechanism for adding constant common area energy consumption in the energy models. The common areas were modelled in the same manner as the commercial area. The ineligible area was not modelled at all. The Energy Models therefore only represent the commercial and common areas. These differences caused the energy consumption of the individual buildings with common areas in the energy models and the BEES estimate for the matching buildings to be different. 
These differences are only relevant when a building has common or ineligible floor area. There were no differences when a building did not have any. The likely scale of the difference is illustrated in the next few paragraphs. An example building was used to calculate a scenario of the influence on the whole building energy consumption of the two different ways in which the heating, cooling and ventilation were estimated. The energy model and BEES estimate procedures allow for these (HVAC) services in the climate modelling process, and in the common area estimate respectively. A section through the example building is shown in Figure 9-13. The building consists of:

- $10,000 \mathrm{~m}^{2}$ of Commercial Office floor area that was measured to consume $120 \mathrm{kWh} / \mathrm{m}^{2} \cdot \mathrm{yr}$

- $1,000 \mathrm{~m}^{2}$ of common area that was assumed to consume $450 \mathrm{kWh} / \mathrm{m}^{2} . \mathrm{yr}$ (using the Property Council New Zealand (2008) estimate); and

- $500 \mathrm{~m}^{2}$ of Ineligible area (residential area) that was assumed to consume $100 \mathrm{kWh} / \mathrm{m}^{2} . \mathrm{yr}$ (Amitrano et al. 2014b).

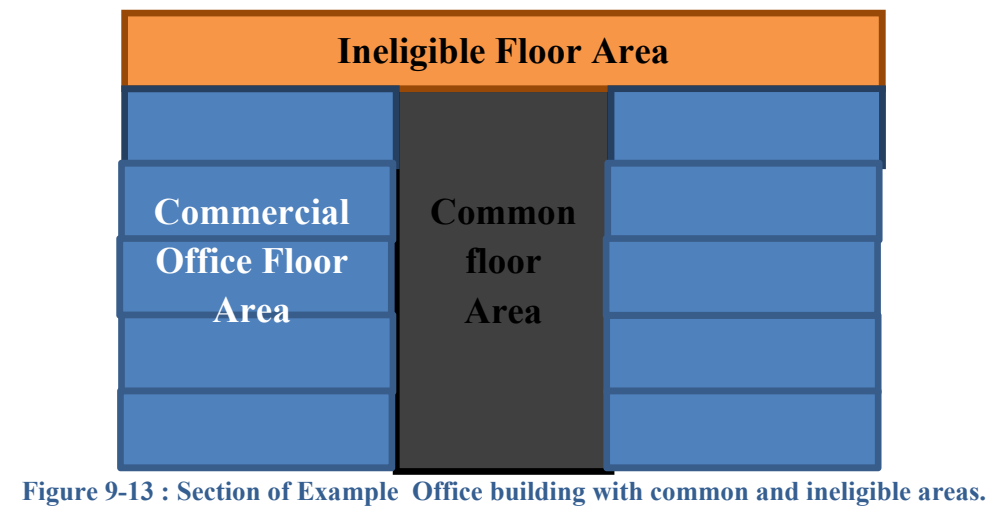

Table 9-9 presents the BEES calculation of the example building's energy consumption. Table 910 presents the energy model's calculation of the example building's energy consumption.

Table 9-9 : BEES Estimate - Example Commercial Office building

\begin{tabular}{|c|c|c|c|c|c|}
\hline Area Type & $\begin{array}{c}\text { EnPI } \\
\left(\mathrm{kWh} / \mathrm{m}^{2} \cdot \mathrm{yr}\right)\end{array}$ & $\begin{array}{c}\text { Multiply } \\
\text { by }\end{array}$ & $\begin{array}{c}\begin{array}{c}\text { Floor Area } \\
\left(\mathbf{m}^{2)}\right.\end{array} \\
\end{array}$ & Equals & $\begin{array}{c}\text { Energy } \\
\text { Consumption } \\
\end{array}$ \\
\hline Office & 120 & \multirow{3}{*}{$\mathrm{x}$} & 10,000 & \multirow{3}{*}{$=$} & $1,200,000$ \\
\hline Common & 450 & & 1,000 & & 450,000 \\
\hline Ineligible & 100 & & 500 & & 50,000 \\
\hline
\end{tabular}

All energy consumption and floor area added together to calculate whole building

\begin{tabular}{|l|c|c|c|c|r|}
\hline Whole Building & - & & 11,500 & & $1,700,000$ \\
\hline
\end{tabular}

Whole building energy consumption divided by whole building floor area to get whole

\begin{tabular}{|ll|l|}
\hline $\begin{array}{l}\text { Whole } \\
\text { EnPI }\end{array}$ & Building & 147.8 \\
\hline
\end{tabular}
building EnPI 
Table 9-10 : Energy Model's estimate - Example Commercial Office building

\begin{tabular}{|c|c|c|c|c|c|}
\hline Area Type & $\begin{array}{c}\text { EnPI } \\
\left(\mathrm{kWh} / \mathrm{m}^{2} . \mathrm{yr}\right)\end{array}$ & $\begin{array}{c}\text { Multiply } \\
\text { by }\end{array}$ & $\begin{array}{c}\text { Floor Area } \\
\left(\mathrm{m}^{2}\right)\end{array}$ & Equals & $\begin{array}{c}\text { Energy } \\
\text { Consumption } \\
\end{array}$ \\
\hline Office & \multirow{2}{*}{120} & \multirow{2}{*}{$\mathrm{x}$} & 10,000 & \multirow[b]{2}{*}{$=$} & $1,200,000$ \\
\hline Common & & & 1,000 & & 120,000 \\
\hline Ineligible & & & Not Modelled & & \\
\hline
\end{tabular}

All energy consumption and floor area added together to calculate whole building

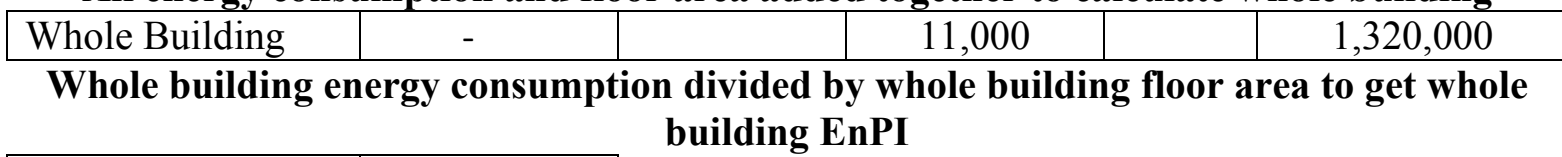

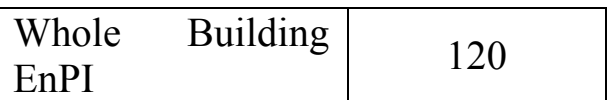

Each calculation multiplies the specific use EnPI by its floor area to calculate the different building areas' energy consumptions. Each area's energy consumption is added together to calculate the whole building's energy consumption. This energy consumption is finally divided by the whole building floor area to calculate the whole building EnPI.

As can be seen, the Energy Model's calculated energy consumption is lower than the BEES calculated energy consumption. It is due to the Energy model:

1. Not modelling any ineligible area (resulting in the building being $500 \mathrm{~m}^{2}$ smaller and not consuming 50,000kWh); and

2. Calculating the common area energy consumption at the same climate dependent $120 \mathrm{kWh} / \mathrm{m}^{2} . \mathrm{yr}$ as the rest of the building instead of $450 \mathrm{kWh} / \mathrm{m}^{2} . \mathrm{yr}$ including heating, cooling and ventilation which results in the common area energy consumption being $120,000 \mathrm{kWh}$ instead of $450,000 \mathrm{kWh}$.

Overall, these two differences result in the whole building EnPI being $120 \mathrm{kWh} / \mathrm{m}^{2}$.yr instead of $147.8 \mathrm{kWh} / \mathrm{m}^{2}$.yr. This difference in EnPI is another reason the BEES and Energy Model estimates will be different, because the Stock Aggregation process (outlined in Chapter 6) uses each building EnPI to calculate the commercial building stock's energy consumption. The estimated energy consumption for the commercial building stock using the energy model's EnPI will likely result in it being lower than the BEES Estimate. From the illustration it can be seen that the two estimates could at times differ significantly.

Not all buildings have common and ineligible area. This meant the calculation undertaken by the BEES and the energy model whole building energy consumption were the same. To illustrate this, the same calculations were made for an office building that has no common or ineligible areas (Figure 9-14). 
Figure 9-14 : Section of example Office building with no common and ineligible areas.

Table 9-11 presents the BEES calculation of the example building's energy consumption. Table 9-12 presents the energy model's calculation of the example building's energy consumption. As can be seen, both the BEES and energy model EnPIs of the whole building were the same $\left(120 \mathrm{kWh} / \mathrm{m}^{2} \cdot \mathrm{yr}\right)$.

Table 9-11 : BEES estimate - Example office building, without common or ineligible area

\begin{tabular}{|l|c|c|c|c|c|}
\hline Area Type & $\begin{array}{c}\text { EnPI } \\
\left(\mathbf{k W h} / \mathbf{m}^{\mathbf{2}} \mathbf{. y r}\right)\end{array}$ & $\begin{array}{c}\text { Multiply } \\
\text { by }\end{array}$ & $\begin{array}{c}\text { Floor Area } \\
\mathbf{( m}^{\mathbf{2}}\end{array}$ & Equals & $\begin{array}{c}\text { Energy } \\
\text { Consumption }\end{array}$ \\
\hline Office & 120 & $\mathrm{x}$ & 10,000 & $=$ & $1,200,000$ \\
\hline
\end{tabular}

All energy consumption and floor area added together to calculate whole building

\begin{tabular}{|l|c|c|c|c|r|}
\hline Whole Building & - & & 10,000 & & $1,200,000$ \\
\hline
\end{tabular}

Whole building energy consumption divided by whole building floor area to get whole building EnPI

\begin{tabular}{|ll|l|}
\hline $\begin{array}{l}\text { Whole } \\
\text { EnPI }\end{array}$ & Building & 120 \\
\hline
\end{tabular}

Table 9-12 : Energy Model's estimate - Example office building, without common or ineligible area

\begin{tabular}{|l|c|c|c|c|c|}
\hline Area Type & $\begin{array}{c}\text { EnPI } \\
\left(\mathbf{k W h} / \mathbf{m}^{\mathbf{2}} \mathbf{. y r}\right)\end{array}$ & $\begin{array}{c}\text { Multiply } \\
\text { by }\end{array}$ & $\begin{array}{c}\text { Floor Area } \\
\mathbf{( m}^{\mathbf{2})}\end{array}$ & Equals & $\begin{array}{c}\text { Energy } \\
\text { Consumption }\end{array}$ \\
\hline Office & 120 & $\mathrm{x}$ & 10,000 & $=$ & $1,200,000$ \\
\hline
\end{tabular}

All energy consumption and floor area added together to calculate whole building

\begin{tabular}{|c|c|c|c|}
\hline Whole Building & - & 10,000 & $1,200,000$ \\
\hline
\end{tabular}

\begin{tabular}{|ll|l|}
\hline $\begin{array}{l}\text { Whole } \\
\text { EnPI }\end{array}$ & Building & 120 \\
\hline
\end{tabular}




\subsubsection{Comparison against external estimate}

Figure 9-15 presents a comparison between the BEES estimate and the stock aggregated estimate using the 48 calibrated energy models simulated in the seven New Zealand climates. The 95 percent confidence interval was obtained from (Amitrano et al. 2014a) for the BEES estimate and calculated in Appendix 14.17 for the energy models.

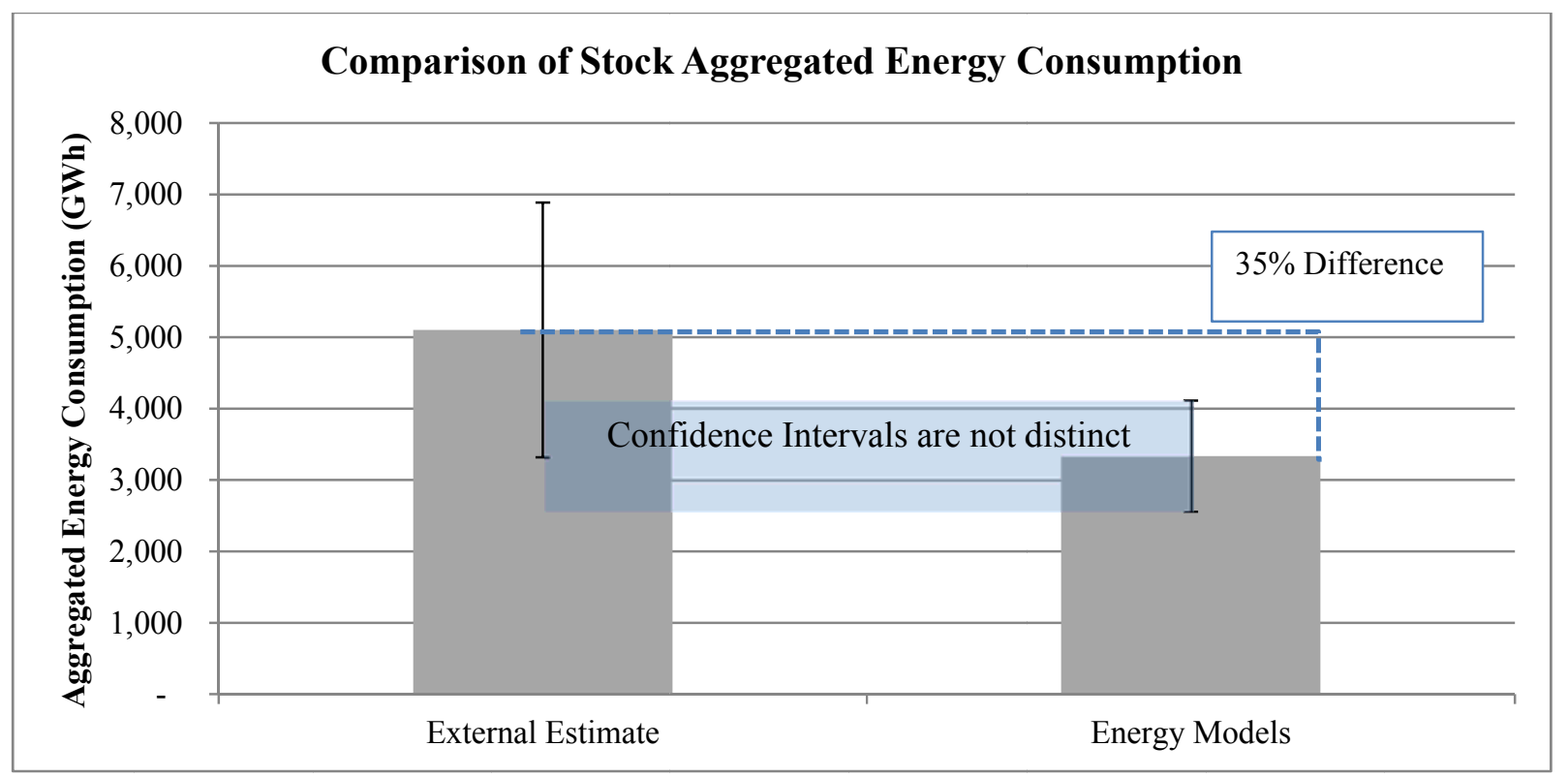

Figure 9-15 : Comparison of External and Energy Models stock aggregation estimates.

As shown in Figure 9-15, the estimate using the energy models was 35 percent lower than the BEES estimate. However, the energy model estimate and associated 95 percent confidence intervals were not distinct from the BEES estimate's 95 percent confidence interval. The confidence intervals of the two estimates overlap. The energy model's aggregated estimate was likely to be within the calculated variation of the BEES independent estimate. This indicated that the Stock Aggregation using the 48 energy models simulated in the New Zealand seven climates was a robust and reliable indication of the energy performance of the commercial building stock in New Zealand.

This result shows that the two different calculation approaches come to a similar conclusion as to how much energy the commercial building stock consumes. The energy model estimate was a reliable and quality assured estimate of New Zealand's commercial building stock energy consumption. The difference of 35 percent is not an issue with the energy models and its sample of 48 buildings simulated in seven climates; it can easily be attributed to the different yearly meter data and the differing estimates of the common area energy consumption. For example, the energy model's average EnPI difference of 26 percent lower than the BEES EnPIs (Table 9-8) from having different yearly meter data indicates it makes up a large proportion of the difference in the BEES and energy model results. The remaining difference between the model and the 
BEES EnPI is attributed to the other differences in the two calculation approaches, discussed in the Sections 9.3.1 to 9.3.4.

\subsubsection{Conclusions of robustness test}

Even with the limited amount of detailed data obtained for each building, the quality assurance tests demonstrated that the calibration method worked. The most reliable models were clearly those calibrated against 12 months of meter data. However, even when performed for buildings with less than 12 months meter data, the results were shown to still be within acceptable margins that would not compromise the whole exercise. Raftery, Keane, and Costa (2009) and Bensouda (2004) suggest that calibration needs to be undertaken using HVAC component hourly techniques. These techniques require detailed HVAC measured data for multiple periods throughout the year. This thesis incorporated an HVAC component hourly technique through the use of the calibration signatures, although it only calibrated HVAC against the 2-4 week period of captured data during the year. The results in this chapter have demonstrated that successful calibration is feasible for buildings with a more limited data set.

In addition, the estimated energy consumption of the New Zealand commercial building stock using the 48 calibrated energy models was shown to be robust and reliable. The estimate was founded on real building performance and not prototypical theoretical buildings. This meant the estimate represented reality and established a base scenario built on the real energy consumption of commercial buildings. To date, the Stock Aggregation process has been performed to create base scenarios using theoretical prototypical models which may not match what is occurring in real buildings (Moffat 2001; Griffith et al. 2008). Despite the, to be expected, limitations of real data (such as lack of 12 months of meter data) the errors introduced by the real world do not outweigh the value of this real world calibration. In prototypical buildings not only are buildings too perfect, with identical operating schedules and with perfectly running HVAC plant and with perfect thermostat setting, but also when these models are made, there is no independent check of the validity of the model. The Stock Aggregation adaptation proposed in this study did not have these limitations.

\subsection{Chapter summary}

Chapter 9 presented the results of performing a stock aggregation using a sample of 48 calibrated energy models that represented real building performance of New Zealand commercial buildings, as outlined in Chapter 6 and 7. The calibration and stock aggregation results show that part 1 of the hypothesis can be achieved: the stock aggregated estimate based on calibrated energy models was shown to be a robust and reliable representation of the current commercial building stock. The stock aggregated energy consumption estimate obtained by the energy models was reliable because it was within the 95 percent Confidence Interval of the independent BEES estimate for the commercial building stock's energy consumption. 
Figure 9-13 displays the links between Chapters 9 and 10.

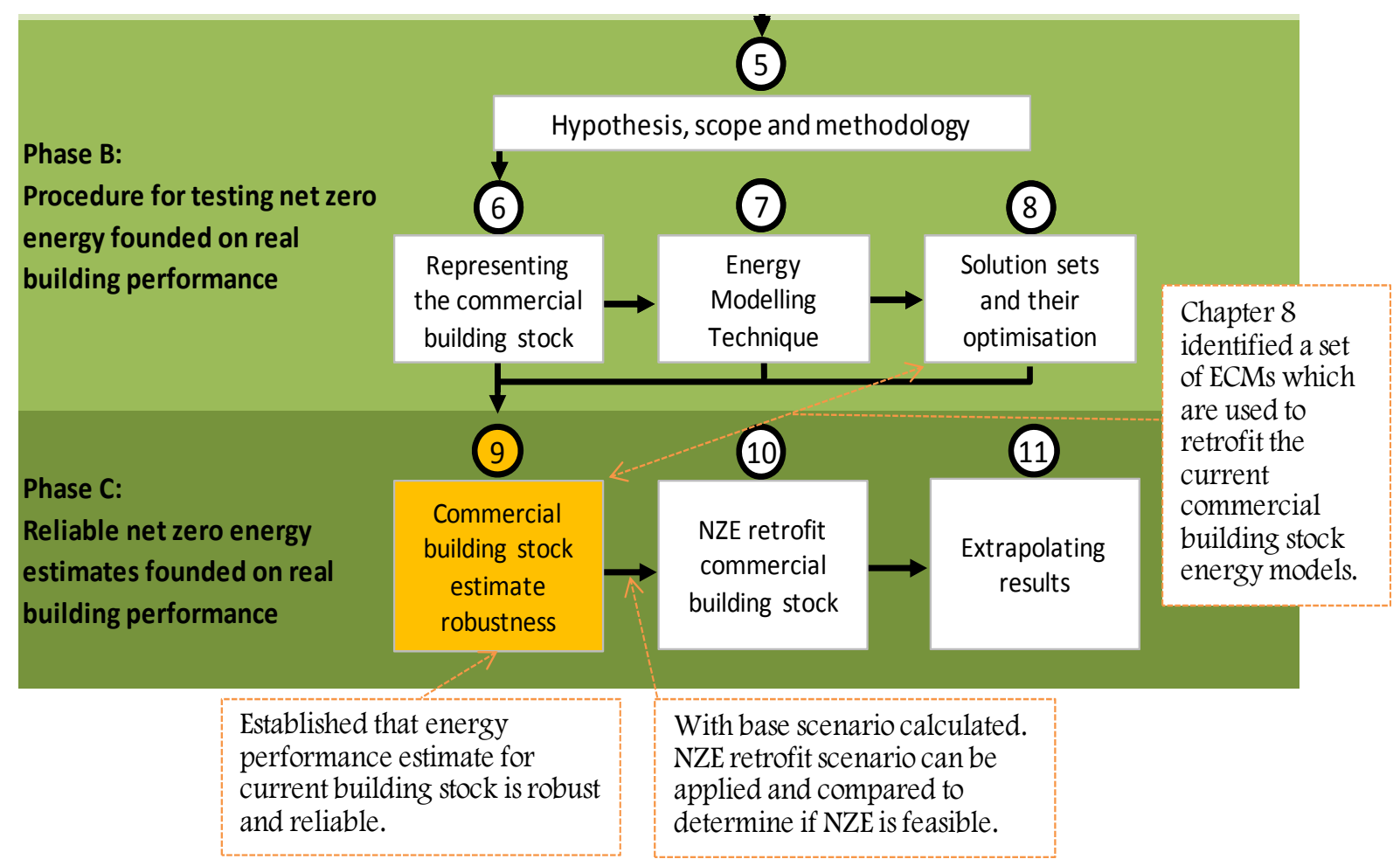

Figure 9-16 : Link between Chapters 8, 9 and 10.

The next step was to retrofit the commercial building stock using the set of design changes established in Chapter 8. Chapter 10 assesses the results of applying the set of retrofit design changes to determine whether NZE is feasible. The results in this chapter provide the base scenario that the NZE retrofit scenario is compared against. 



\section{CHAPTER 10. RESULTS OF CONVERTING TO NET ZERO ENERGY}

\subsection{Chapter Intent}

Chapter 10 aims to 1) demonstrate that the methodology system works and does allow examination of a whole building stock's potential for retrofit to Net Zero Energy, and 2) demonstrate reaching NZE is feasible in New Zealand. Figure 10-1 presents the connection between Chapters 8, 9 and 10 .

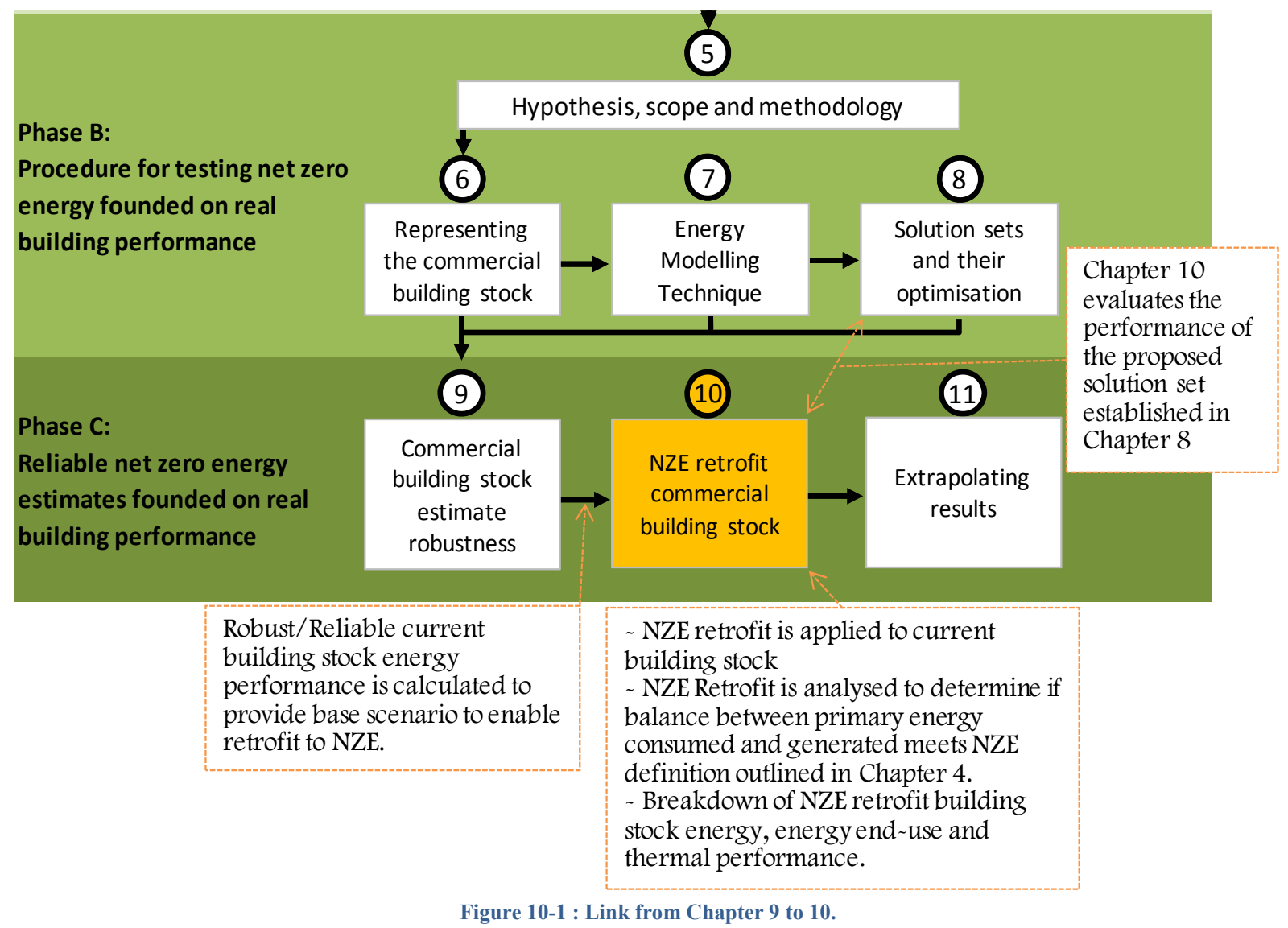

The results presented in this chapter were calculated by performing a stock aggregation using the 48 calibrated energy models (outlined in Chapters 6 and 7) that were retrofitted using the set of design changes established in Chapter 8 . This forms the scenario for the NZE retrofit commercial building stock. The energy consumption and users' thermal environment for the NZE retrofit scenario and current building stock were compared to evaluate the move towards NZE.

\subsection{NZE energy reduction and thermal environment}

This section compares the performance of the NZE retrofitted commercial building stock to the current commercial building stock. In particular, comparisons were made between the influence on energy consumption and the occupant thermal environment. Influences on the energy

Page $\mid 257$ 
consumption were measured through an assessment of the quantity of energy reduced by retrofitting towards NZE and whether the NZE goal was achieved. Influences on the occupant environment provided an example of how an improved level of thermal comfort can be achieved through retrofitting towards NZE.

Appendix 14.20 presents the final optimised retrofit design and retrofit energy performance for the 48 BEES buildings in each New Zealand climate. These optimised design results can be used to assess the issues surrounding solutions sets in different climates, for example, variations in insulation levels in cold climates and warm climates. However, this research focussed on the energy results and not the design results and this type of analysis was not undertaken.

The retrofit was performed in two scenarios to test the NZE definition outlined in Section 4.4.1 (and seen in bold in section 10.2.1 below). The first scenario applied only the demand-side ECMs outlined in Section 8.3 to test if NZE could be achieved by only consuming energy from New Zealand's existing emissions-free renewable energy infrastructure (refer to bold text 1 and 2a below and Appendix 14.16.3 for stock aggregation results for NZE retrofit building stock without onsite renewables). The second scenario applied the whole Net ZEB solution set (including the supply-side ECM - Photovoltaics (PV)) to determine if NZE could be achieved by consuming energy from New Zealand's existing emissions-free renewable energy infrastructure and additional onsite emission-free renewable energy generation (refer to bold text 1 and $2 \mathrm{~b}$ in Section 10.2.1 below and Appendix 14.16.4 for stock aggregation results for NZE retrofit building stock with onsite renewables).

\subsubsection{Calculated NZE balance}

As discussed in Chapter 4, a calculation needed to be made to quantify whether NZE was achieved. The calculation considered a number of factors. Firstly, a NZE commercial building stock was defined as being:

1. A community of buildings which have a greatly reduced demand for energy, and

2a) the building stock only consumes energy from the country's existing emissions-free renewable energy infrastructure; $O R$

2b) if it cannot meet $2 a$, it needs to produce at least as much emissions-free onsite renewable energy as consumed from emission-producing primary non-renewable energy sources.

Secondly, the boundary of the energy system was set at the community scale. A community scale boundary meant that all buildings connected to the current electrical grid could work together to reach the goal of NZE. Accordingly, not all buildings need to be Net ZEBs individually, but instead the more efficient buildings can compensate for the less efficient buildings to achieve NZE as a whole building stock. In addition, any existing renewable non- $\mathrm{CO}_{2}$ emitting energy 
supply, which makes up 55 percent of the current energy supplied to the commercial building stock, could be consumed by the retrofitted commercial building stock.

Thirdly, the estimate included all building and user related energy end-use consumption (heating, cooling, ventilation, lighting, and equipment - including hot water, refrigeration and cooking appliances).

It was calculated that 45 percent of the current primary energy supply consumed by the New Zealand commercial building stock emits $\mathrm{CO}_{2}$. This created a target for the reduction in energy consumption needed before the retrofitted building stock was considered NZE. The target was accounted for in the two NZE balance equations: Equation 3 and 4 (presented and discussed in Section 4.4.1). Equation 3 and 4 simply calculated the balance between renewable energy supply and the energy consumed by the commercial building stock. The difference between the two equations was Equation 3 which calculated whether NZE was reached without additional renewable energy generation. The retrofitted commercial building stock was considered NZE if the renewable energy supplied (by the existing infrastructure and onsite renewable ECMs) was equal to or greater than the energy consumed by the buildings. By entering the required variables, the NZE balance calculation was performed and was illustrated using the IEA definitions' energy balancing graph in Figure 10-2 (Sartori, Napolitano, and Voss 2012):

Calculation 1 was performed using Equation 3 presented in Section 4.4.1 to determine if NZE was achieved without any additional renewable energy generation. This meant NZE would be achieved by reducing the energy consumption of the current commercial building stock to fit within the available renewable energy supply for the current commercial building stock (refer to Section 4.8 for more information).

Current portion of commercial building stock renewable emissions-free energy supply $5,179 \mathrm{GWh}$ $\uparrow$

This is the percentage of current energy consumption that is supplied by renewable sources $-55 \%$ multiplied by the primary energy factors (Appendix 14.21)

$\begin{array}{cc}\begin{array}{c}\text { NZE Commercial building stock } \\ \text { primary energy consumption }\end{array} & \begin{array}{c}\text { Energy } \\ \text { Balance }\end{array} \\ 4,121 \mathrm{GWh} & 1,058 \mathrm{GWh} \quad \geq 0 \\ \uparrow & \begin{array}{c}\uparrow \\ \text { It is greater than zero }\end{array} \\ \begin{array}{c}\text { Theaning } N Z E \text { was } \\ \text { NZE retrofit energy }\end{array} \\ \text { consumption estimate (from the }\end{array}$
48 NZE retrofit energy models simulated in the seven New Zealand climates) multiplied by the primary energy factors (Appendix 14.21). 
Calculation 2 was performed using Equation 4 presented in Section 4.4.1 to determine if NZE could be achieved with additional renewable energy generation. This meant NZE would be achieved by reducing the energy consumption of the current commercial building stock and adding onsite renewable energy generation (Photovoltaic (PV)) to offset residual energy consumed from non-renewable $\mathrm{CO}_{2}$ emitting sources.

Calculation 2 : Annual NZE Balance with additional renewable generation:

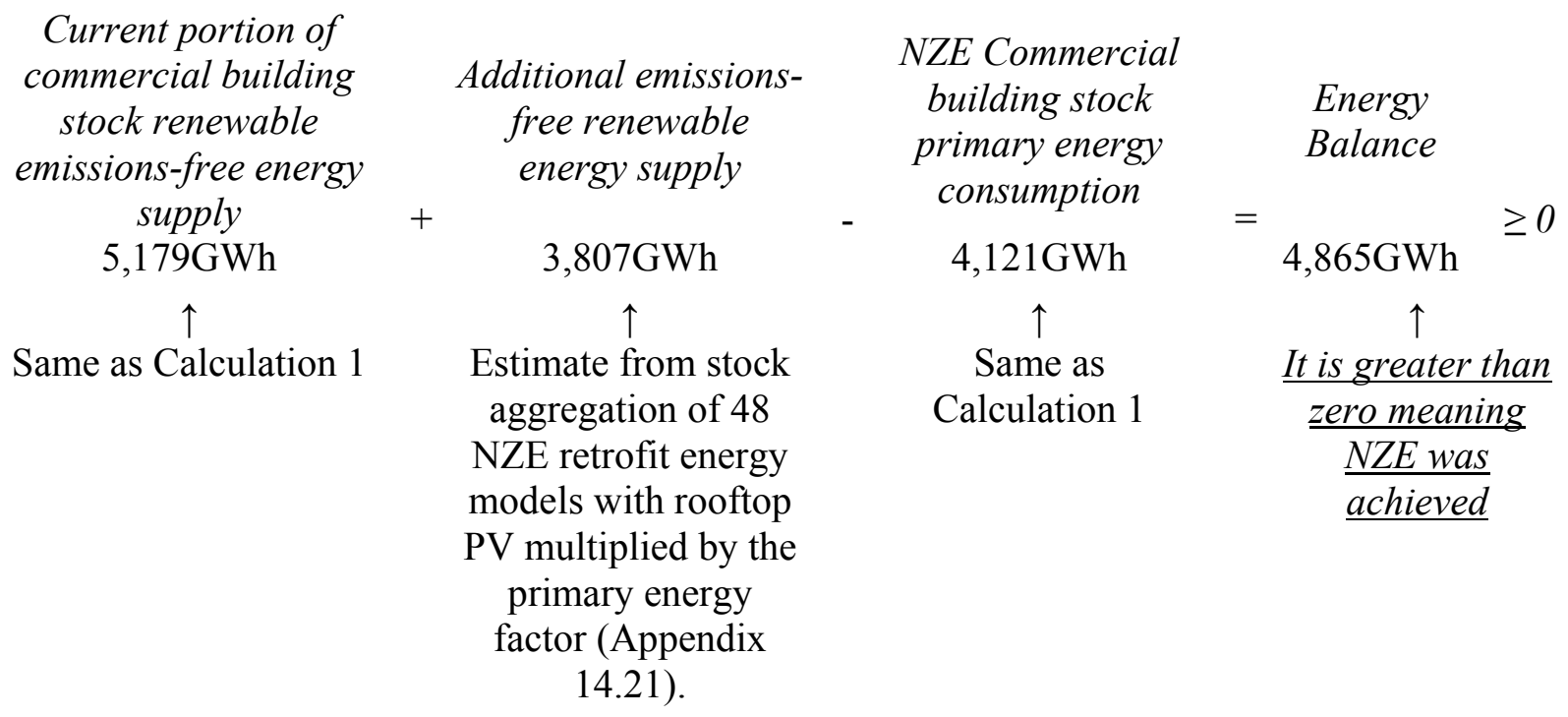

Figure 10-2 illustrates the balance of primary energy consumption (vertical axis) and primary energy generation (horizontal axis) for the current commercial building stock (red), the NZE retrofit building stock without additional renewable energy generation (blue), and the NZE retrofit building stock with additional renewable (PV) energy generation (green). If the mid-point plot between consumption and generation falls above the net zero energy line it is considered an energy consumer, if it falls below it is considered an energy producer or NZE. The current commercial building stock is presented as the base case. The energy balance graph for the current building stock (red) shows the amount of energy it is currently supplied from renewable energy does not equal its total consumption. The result is the building stock is an energy consumer. 

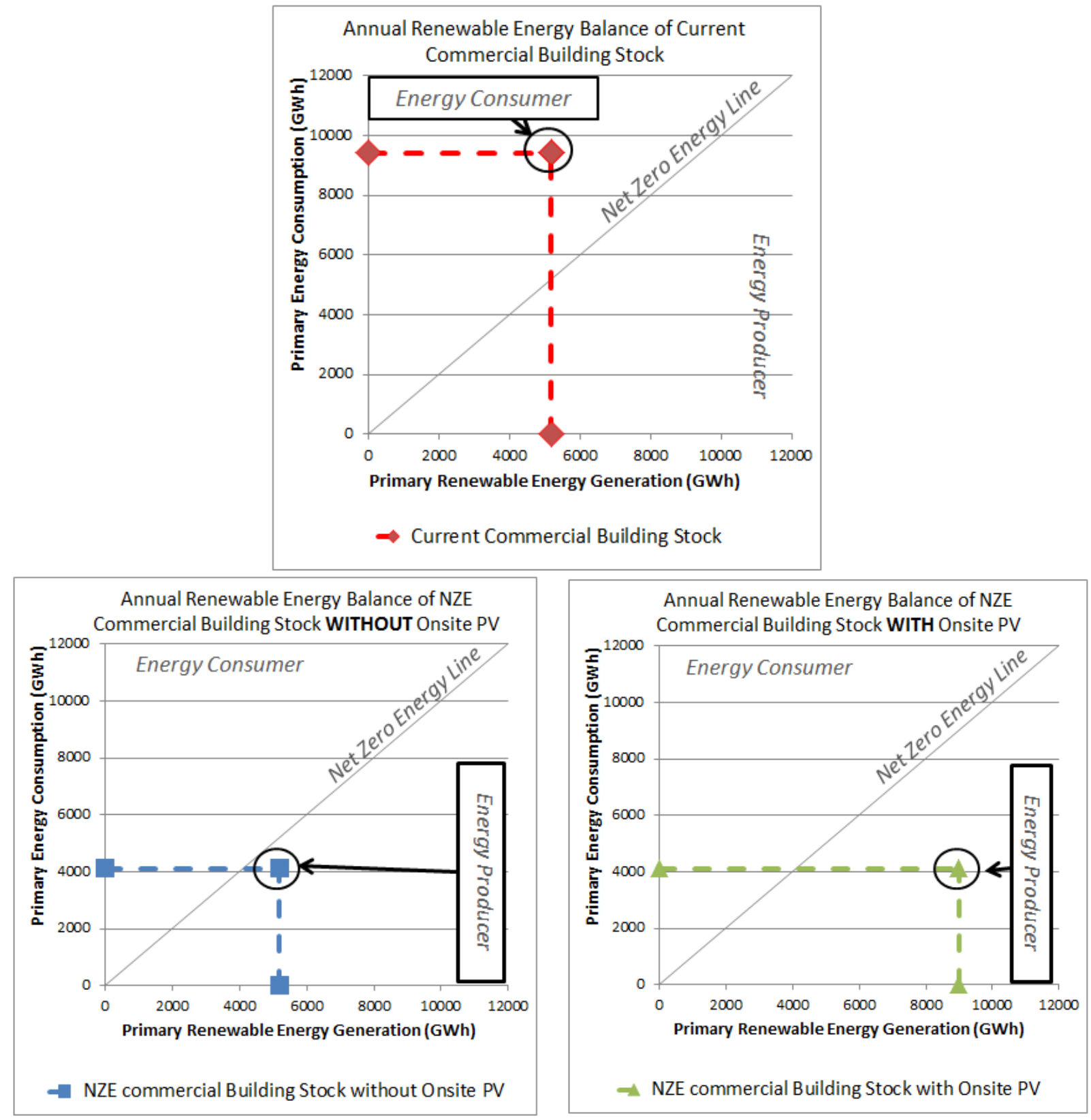

Figure 10-2 : NZE energy balance.

The NZE balance for the NZE retrofit building stock without additional renewable energy generation was higher than zero (as shown in Calculation 1). A balance of higher than zero meant it was considered NZE and that NZE can be achieved without additional renewable energy generation. The energy efficiency upgrades significantly reduced (over half) the energy consumption of the building stock to the point where the balance between consumption and generation was just below the net zero energy line. This indicated that NZE was achievable using the high proportion of current renewable energy generation already connected to the New Zealand commercial building stock. This proved that the current New Zealand commercial building stock, retrofitted using the proposed Net ZEB solution set without

Page $\mid 261$ 
onsite PV generation, would result in a retrofitted commercial building stock that was net zero energy. This shows that the use of efficiency measures within New Zealand commercial buildings could be a significant move toward having an electrical infrastructure that is not reliant on fossil fuels. Also, without the need for a PV system the conversion to NZE would be less costly (Section 11.3.2).

As seen in Calculation 2, the NZE balance for the NZE retrofit commercial building stock with additional renewable generation was much greater than zero, meaning that the retrofitted commercial building stock would provide a large amount of surplus renewable energy to the national electrical grid. As indicated in Figure 10-2, the additional renewable energy generation provided by covering half of every building's roof top with photovoltaics (PV) produced a large quantity of non- $\mathrm{CO}_{2}$ emitting renewable energy $(3,807 \mathrm{GWh})$ that could be supplied back to the grid. The building stock would be a positive energy building stock. A positive energy building stock was defined as a community of buildings which generated more renewable energy than it needed to consume (K Voss, Sartori, and Lollini 2012). Furthermore, the onsite renewable energy generation is close (within eight percent) to equalling the retrofitted commercial building stock's energy consumption. NZE could almost be achieved with just the onsite renewable energy generation, and no additional supply from the grid.

\subsubsection{Energy end-use consumption reductions}

Figure 10-3 displays a breakdown of the primary energy end-use consumption for the current and NZE retrofit building stocks.

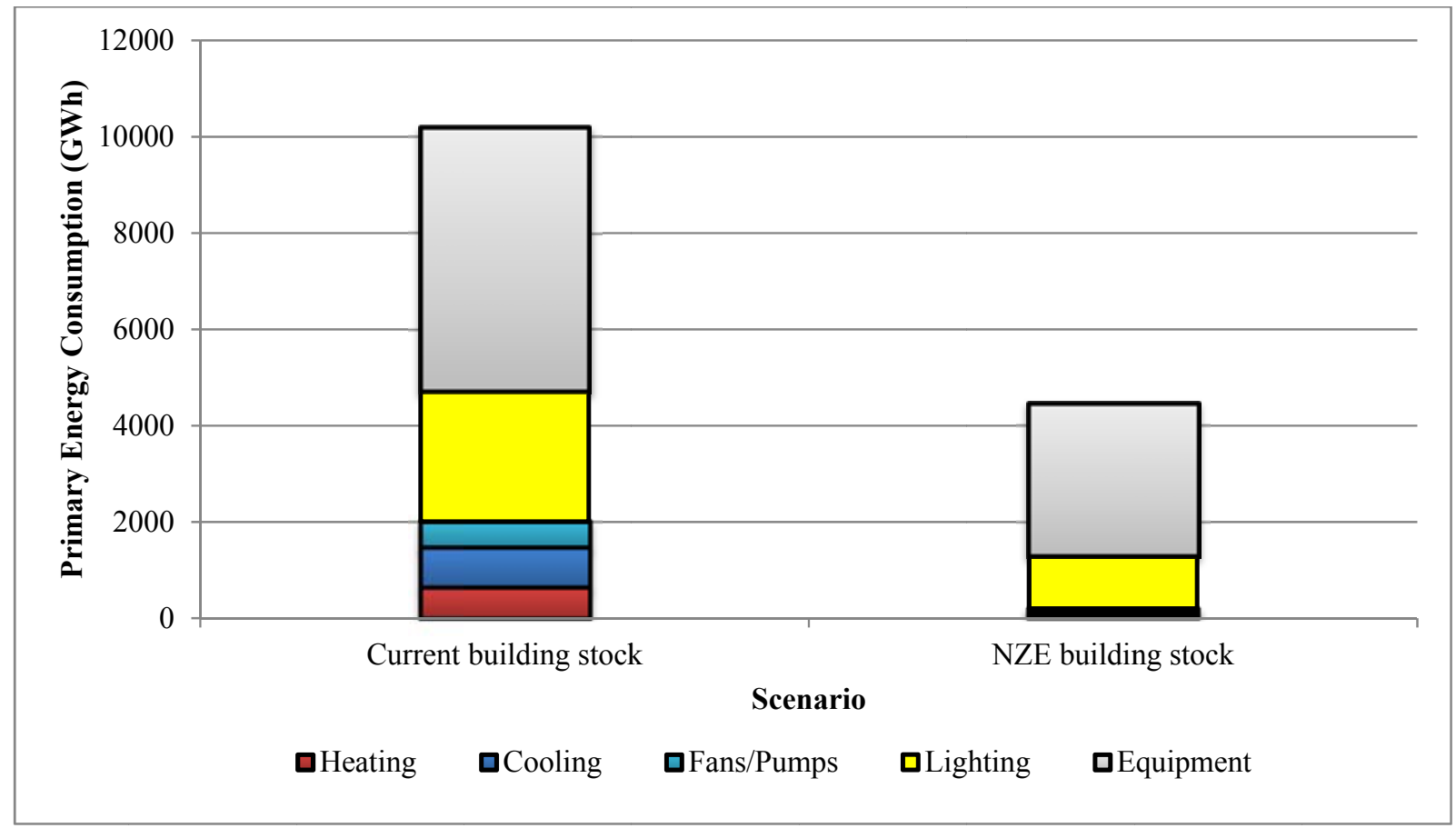

Figure 10-3 : Energy end-use breakdown for the current and NZE retrofit building stocks. 
The energy end-use breakdown highlighted that the main energy drivers in the current commercial building stock did not change when retrofitted to NZE. Equipment accounted for the largest amount of energy consumed, followed by lighting, and then the space conditioning enduses. This was consistent with how existing Net ZEBs have been found to perform at an energy end-use level (refer to Section 8.3.2). When design teams were asked for any lessons they had learned in their dealings with designing and operating Net ZEBs, they stated that equipment became the dominant energy end-use and Net ZEBs required very little to no space conditioning due to the passive nature of the building design (refer to Section 8.3.2). The majority (70 percent) of all energy consumed in the NZE commercial building stock was by equipment and the least (only 5 percent) consumed by space conditioning.

Figure 10-4 presents the reduction in primary energy consumed (GWh) by each energy end-use (x-axis) and the percentage (\%) of energy reduction (y-axis) achieved in each of the energy enduses by retrofitting to NZE.

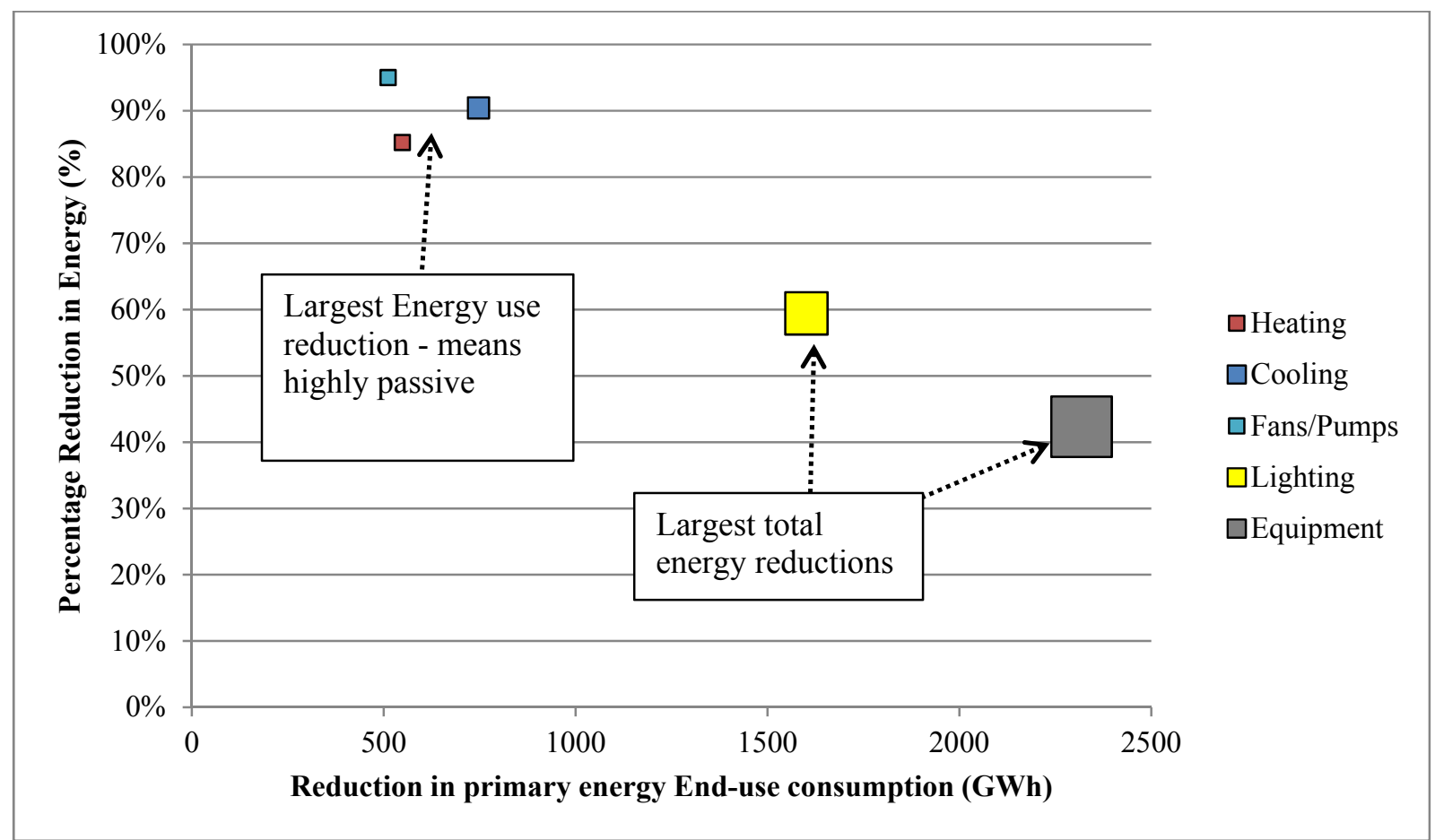

Figure 10-4 : Energy reduction achieved in each energy end-use.

To aid in the visualisation, the larger the energy end-use plot (square), the larger the energy reduction achieved in that end-use. For example, the equipment end-use plot (grey) is the largest because there was the largest quantity (approximately 2,300GWh) of energy reduced in that enduse. The majority of the energy reduction attained by retrofitting to NZE was achieved by improving the efficiency of the equipment end-use. The second largest total reductions were seen in the lighting end-use with a $1,600 \mathrm{GWh}$ reduction in energy; equating to a 59 percent reduction in energy end-use consumption. The remaining $1,800 \mathrm{GWh}$ of energy savings were seen in the HVAC end-uses. The HVAC energy end-uses were reduced by more than 80 percent compared

Page $\mid 263$ 
to the current HVAC end-use consumption. This indicated that a retrofitted NZE building stock would be highly passive, and was consistent with the lessons learned from the Net ZEB design teams (refer to Section 8.3.2).

\subsubsection{Energy performance of the different building types and sizes}

As identified in Figure 10-2, demand-side efficiency retrofitting can reduce energy consumption to a point where the current renewable energy generation can supply all of the building stock's energy. Onsite renewable energy generation enabled the retrofitted building stock to be positive energy and was within eight percent of being able to offset all energy consumed by the retrofitted building stock without the existing national renewable energy supply. As per the NZE definition (see Section 4.3 for discussion), communities of different building types and sizes all contributed to the overall commercial building stock NZE performance. However, each building size and type community performed differently. The difference in performance occurred from variations in the amount of floor area, building load and operation of the building types. The following assessment aimed to highlight the overall contribution each building size and type made to the overall NZE building stock performance. Each building type and size grouping formed a community within the larger community of the commercial building stock, and for this reason the building types and sizes were referred to as communities. For example, all office buildings in the commercial building stock were viewed as an office building community.

The following analysis assessed the differing demand-side and net energy performances for the different building type and size communities. Demand-side performance referred to the amount of energy reduced without the use of onsite renewable energy generation. This was achieved through Passive and Efficient ECMs as proposed in the Net ZEB solution set discussed in Section 8.3. The net energy performance referred to the energy reduction achieved using the whole Net ZEB solution set. The difference between the demand-side performance and the net energy performance was that the net energy reduction included the energy generated by the PV on each building's rooftop in the overall energy reduction. The assessment was split into demand and net energy reductions in order to compare the building size and type's ability to reduce demand and generate energy onsite. It also reflected the two scenarios set in the NZE definition (second paragraph of Section 10.2.1).

Page $\mid 264$ 
10.2.3a Building type

Figure 10-5 displays the percentage contribution of total energy reduction made by each building type community (office in pink, retail in dark red, and mixed commercial in light red).

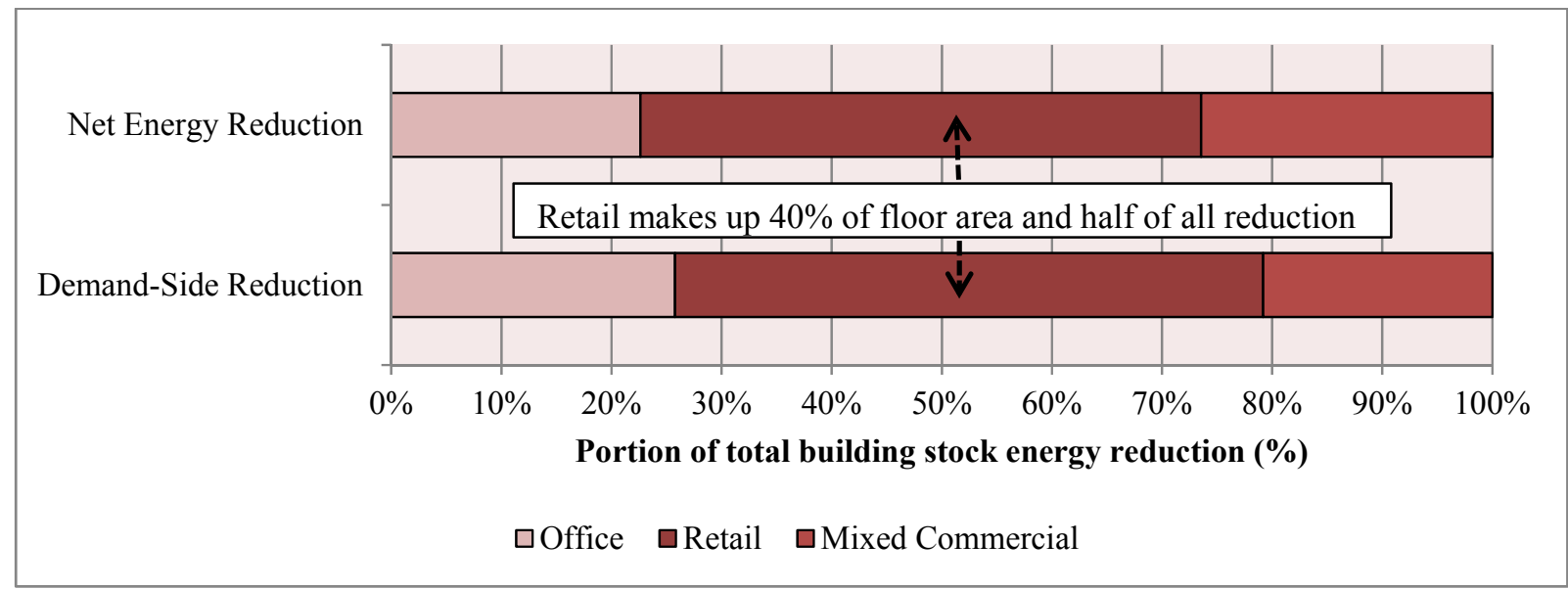

Figure 10-5 : Proportion of total demand and net energy reductions contributed from each bulding type.

As shown in Figure 10-5, the largest single contribution to the total NZE (approximately 50 percent) building stock reductions (both demand-side and net) comes from the retail building community. Retail makes up approximately 40 percent of all commercial building floor area. There is a difference in the office and mixed communities' contribution to net and demand-side reductions. The office community was estimated to have a larger contribution to demand-side reductions than the mixed community. However, the two building type communities share an approximate equal contribution in net energy savings. The reason for the mixed community having an equal contribution to the net energy reduction would be due to the community being able to generate more onsite renewable energy generation compared to the office community. Each of the 48 energy models were built with the real shading from surrounding buildings and 50 percent of all roof area was covered in PV. Due to this realism of the models, the results show the mixed buildings were not shaded as much as the office buildings and suggest that mixed buildings have an increased energy generation potential when compared to office buildings.

Figure 10-6 displays the demand-side and net energy reductions achieved in each of the building type communities. The graph background was shaded to highlight the reduction in current energy consumption required for each building type community to be NZE (45 percent). When a plot is inside the grey shading it indicates the community of buildings was an energy consumer, while a plot in the green shaded area would be NZE. If a reduction of 100 percent or greater was achieved, all energy consumed by the respective building type community would be offset entirely by onsite renewable energy generation. An energy plot in the white shading area indicates that over 100 percent energy reduction was achieved because it generated more energy on an annual basis than it consumed. 


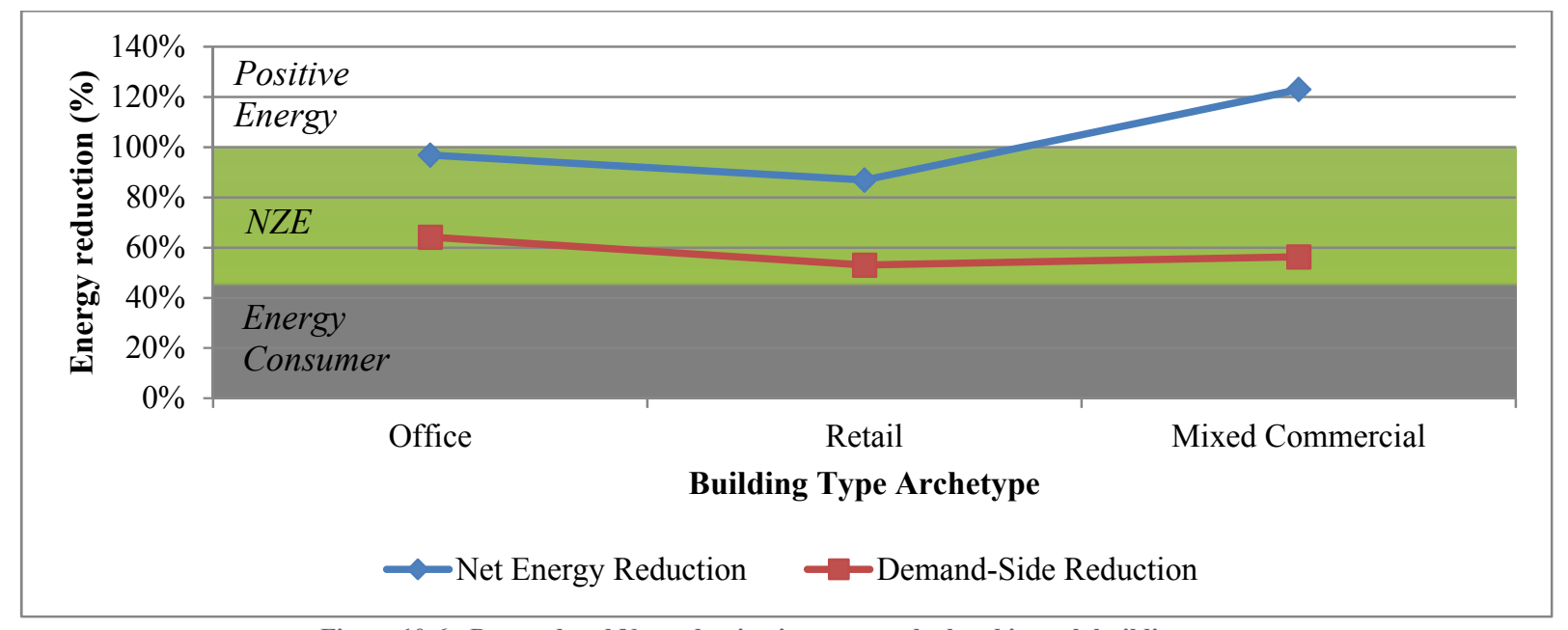

Figure 10-6 : Demand and Net reduction in energy calculated in each building type.

As shown in Figure 10-6, the net and demand-side energy reduction for all three building type communities was estimated to be above the required NZE reduction target (above the grey shaded area) meaning each building type community was NZE. There was significant variation in net energy performance across the three building types, with the largest net reductions seen in the mixed commercial building community. The mixed community could generate enough onsite renewable energy to offset its entire annual consumption of energy (shown by the net energy reduction being in the white shaded background or above 100 percent). However, the office and retail communities could not. This reinforces that mixed commercial buildings offer the greatest potential for onsite generation compared to the other two building types. The Mixed community onsite generation could produce approximately two times more energy per unit of floor area than office and retail buildings. This was due to mixed use buildings being lower in height and having less surrounding site shading impeding the PV systems' access to solar radiation.

The office building community had a larger reduction in demand-side energy compared to retail and mixed building communities. Office energy demand was reduced by 64 percent, mixed use by 56 percent, and retail 53 percent. All three building community building stocks could reach the NZE target of 45 percent reductions in current energy consumption, solely with demand-side efficiency strategies. 


\subsection{3b Building size}

Figure 10-7 displays the demand-side and net energy reductions achieved in each of the building size communities. The building size communities range in floor area sizes of $649 \mathrm{~m}^{2}$ or less to $9000 \mathrm{~m}^{2}$ or greater. Each building size group represents approximately 20 percent of all commercial floor area in New Zealand.

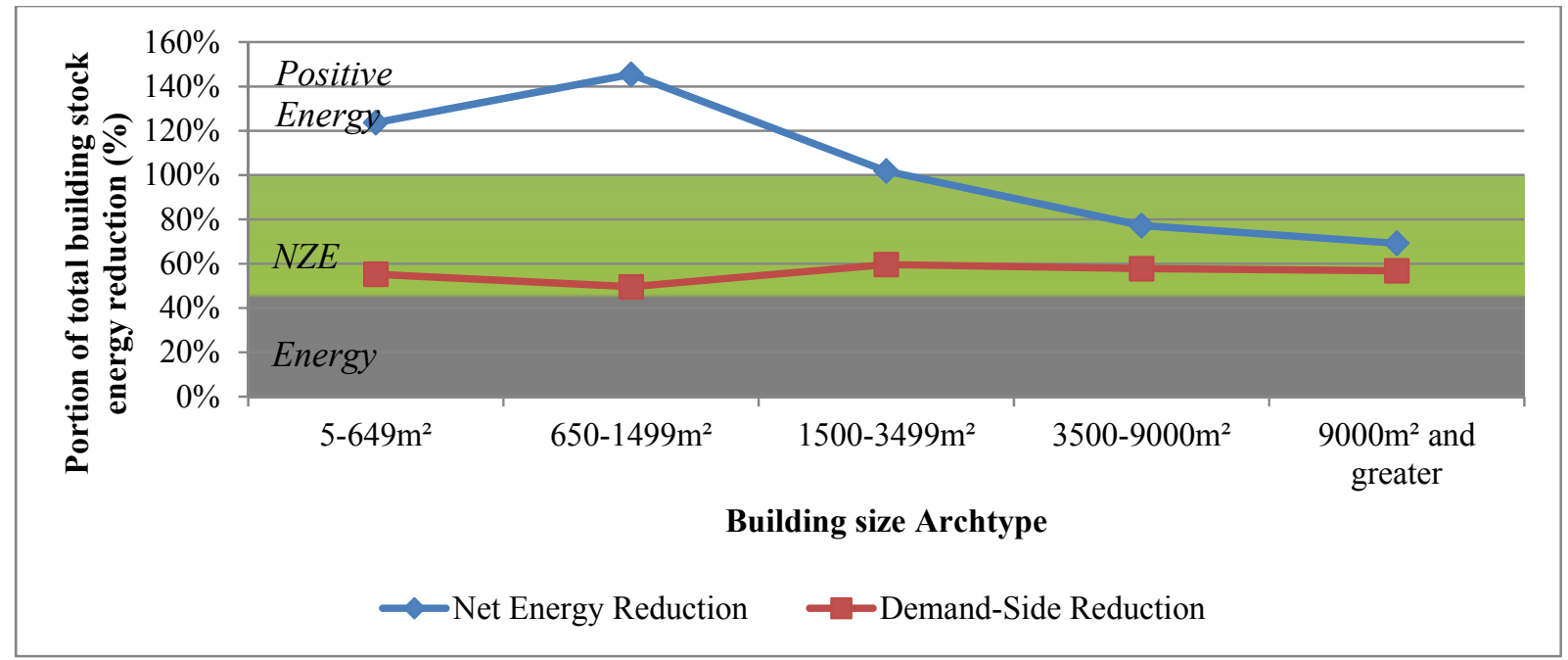

Figure 10-7 : Demand and Net reduction in energy calculated in each building size.

The net energy consumption for all building size communities was above the NZE reduction target of 45 percent. However, as the buildings got larger the net energy performance moved from being large enough to offset its community's annual energy consumption, to requiring existing grid renewable energy supply to supply some energy. This was due to the larger buildings generating less energy than the smaller buildings. Smaller buildings were largely 1-2 storeys in height and had a greater roof to floor area ratio, meaning they were better suited for onsite PV generation (Paul Torcellini et al. 2006). For this reason the smaller buildings have the largest potential for onsite renewable energy generation. It is important to note that $\mathrm{PV}$ is the only generation system tested and is not the only system that could be used in reality. These results might change if a different onsite energy generation system were to be tested (such as wind turbines).

The demand-side reduction in energy was between 50 and 60 percent depending on the building size. This indicates that the effectiveness of the demand-side efficiency measures was not affected greatly by the building size. All building size communities reached the NZE target reduction without the aid of onsite renewable energy generation. 
Figure 10-8 displays the percentage contribution of total energy reduction made by each building type community.

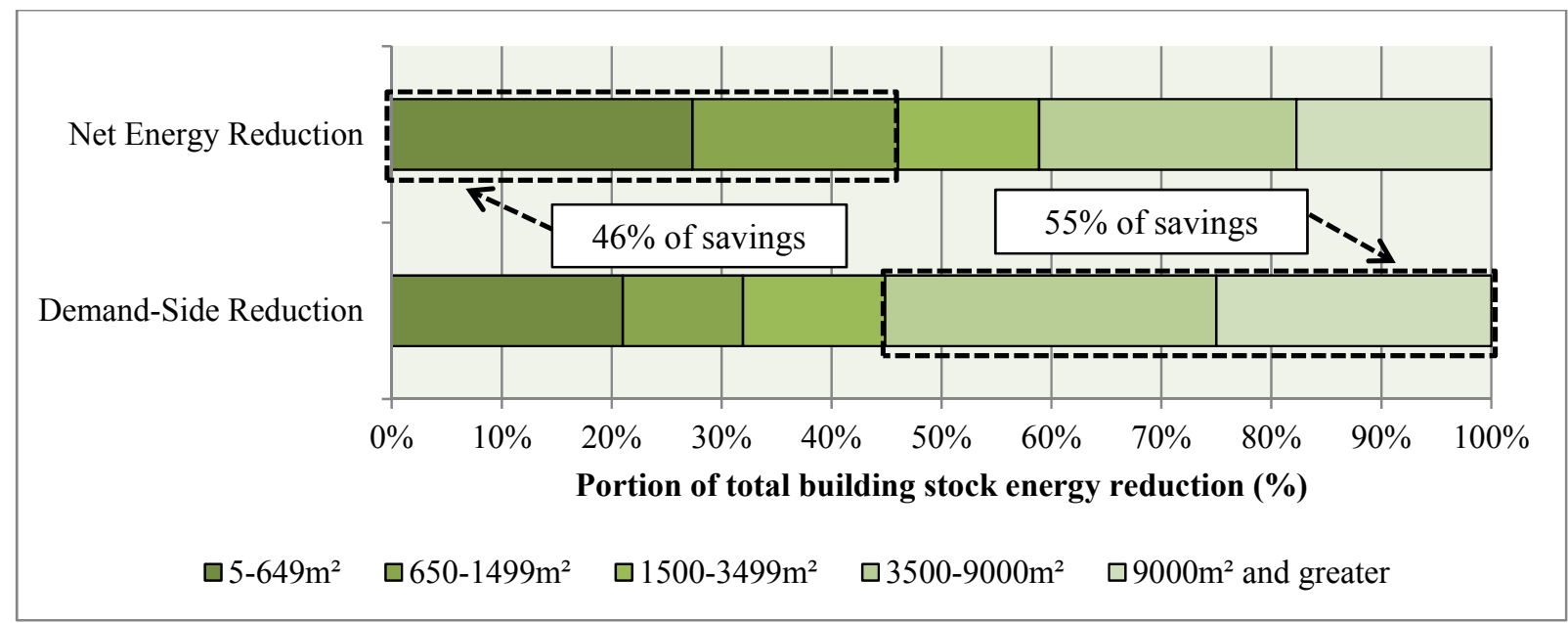

Figure 10-8 : Proportion of total demand and net energy reductions contributed from each bulding size.

Figure 10-8 indicates that retrofitting the fewer in number larger buildings is more effective than retrofitting the greater number of smaller buildings. Over half ( 55 percent) of all energy demand reduction was achieved by retrofitting buildings over $3,500 \mathrm{~m}^{2}$. There are approximately 1,200 buildings over $3,500 \mathrm{~m}^{2}$, which is only four percent of all commercial buildings. This shows that half of all NZE demand reductions could be achieved by retrofitting four percent of all commercial buildings. Therefore, these few large buildings could be targeted in a retrofit scheme with the aim of reducing over half the current commercial building stock's energy consumption.

The differences between demand-side and net energy reductions highlight the opportunities available for the differing sized commercial buildings. Smaller commercial buildings could generate more renewable energy onsite, whereas larger commercial buildings offer a greater opportunity for demand-side reduction.

\subsubsection{Thermal comfort in retrofitted commercial buildings}

The NZE definition prescribed that the NZE retrofit of commercial buildings must provide comfortable thermal temperatures for their occupants (Section 4.3.4). For this reason, this section presents an assessment of the indoor thermal comfort of the NZE retrofitted commercial building stock. The assessment highlights the change in thermal comfort in three case study buildings and the impact this had on their energy consumption. The case studies were chosen because they were representative of the differing levels of space conditioning (or HVAC systems) and thermal performances in the current commercial building stock. The buildings with a lack of space conditioning and poor thermal environments were retail and mixed buildings predominately less than $1500 \mathrm{~m}^{2}$ in building floor size. 
The poor thermal performance from a lack of adequate space conditioning services was remedied in the design changes implemented in the Net ZEB solution set (the combination of ECMs Section 8.3). The solution set installed or upgraded the current HVAC system to an efficient heat pump system and changed the current temperature set points to: $18^{\circ} \mathrm{C}$ for heating and $25^{\circ} \mathrm{C}$ for cooling (as based on an extended adaptive comfort model - Section 4.3.4). The current commercial building stock had a proportion of buildings (21 percent) which did not have any central space conditioning services (or HVAC). A further 29 percent of buildings had HVAC systems; however, they were controlled manually and as a consequence used temperature set points which were outside of what was deemed comfortable. The above two circumstances created an improved environment when retrofitted. Two case studies were presented to highlight the improved environment that was seen in some buildings across the building stock. Fifty of the commercial building stock had HVAC systems which controlled temperature to within the comfort levels of $18-25^{\circ} \mathrm{C}$. A third case study was presented to show the difference between an existing building with an HVAC system meeting comfort requirements (the particular building heated to $20^{\circ} \mathrm{C}$ and cooled to $21^{\circ} \mathrm{C}$ ), and the retrofit system using a more efficient HVAC system and an increased set point deadband of $18-25^{\circ} \mathrm{C}$.

Figures 10-9, 10-10, and 10-11 compare the ambient (outside), current and Net Zero Energy building (Net ZEB) retrofit indoor temperatures. They are presented (left graph) as the percentage of occupied hours that were "too cold" (less than $18^{\circ} \mathrm{C}$ ), "comfortable" (between $18^{\circ} \mathrm{C}$ and $25^{\circ} \mathrm{C}$ ), or "too hot" (over $25^{\circ} \mathrm{C}$ ). The ambient temperature aided in identifying how the building performed compared to the external temperature trends. Note: the results represent a building and climate average as described in Appendix 14.22. A comparison between the energy consumption of the current building and the Net ZEB retrofit building (right graph) is displayed. The energy consumption is presented as the Energy Performance Index (EnPI).
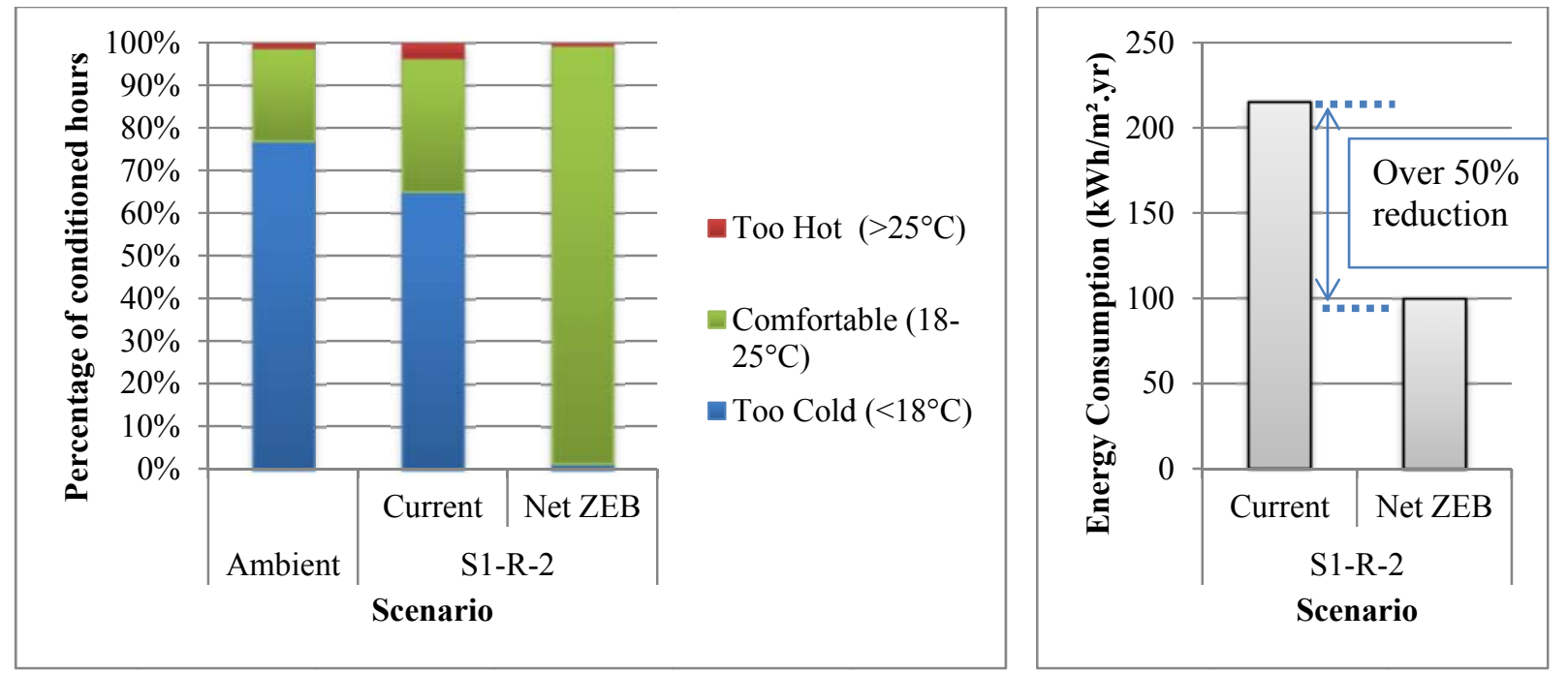

Figure 10-9 : Thermal comfort and energy consumption comparison for case study building S1-R-2 which has no HVAC in the current building. 
Figure 10-9 presents the thermal and energy consumption comparison for building case S1-R-2, which was a small one-storey retail building with a floor area less than $649 \mathrm{~m}^{2}$. While the current S1-R-2 building model did not have any HVAC system installed, the Net ZEB retrofit S1-R-2 building model had an efficient heat pump system installed with a heating and cooling set point of $18-25^{\circ} \mathrm{C}$ (as proposed in Section 9.3.4h). As shown in Figure 10-9, the ambient (outdoor) and current building occupied hours were dominated by temperatures that were "too cold" (77 and 65 percent respectively). There were also 22 percent of ambient and 31 percent of current building's occupied hours that were comfortable, and one percent of ambient and four percent of the current building's occupied hours that were "too hot". Due to there being no HVAC to condition the current building and the building not performing passively very well, the internal thermal environment of S1-R-2 followed the trends in ambient temperature. Once the building was retrofitted with an HVAC system, the building was close to having 100 percent of its occupied hours comfortable. Four percent of the hours in the Net ZEB retrofit were considered "Too Hot". They occurred during the middle of the occupied day, but were within 1 degree of the $25^{\circ} \mathrm{C}$ set point. It was hypothesised that these temperatures occurred due to the cyclic nature of the heat pump system not quite meeting the cooling requirements 100 percent of time in all the modelled spaces. This could be remedied by lowering the set point by one degree to $24^{\circ} \mathrm{C}$ (this scenario was tested in Section 11.2.1). The current building consumed $215 \mathrm{kWh} / \mathrm{m}^{2} . \mathrm{yr}$, and the Net ZEB retrofit consumed $100 \mathrm{kWh} / \mathrm{m}^{2}$.yr. The NZE building had over half the required need for energy, even with the installation of an HVAC system, and would provide better thermal comfort to its occupants. The increase in space conditioning energy consumption would be offset by large reductions in equipment and lighting energy consumption.

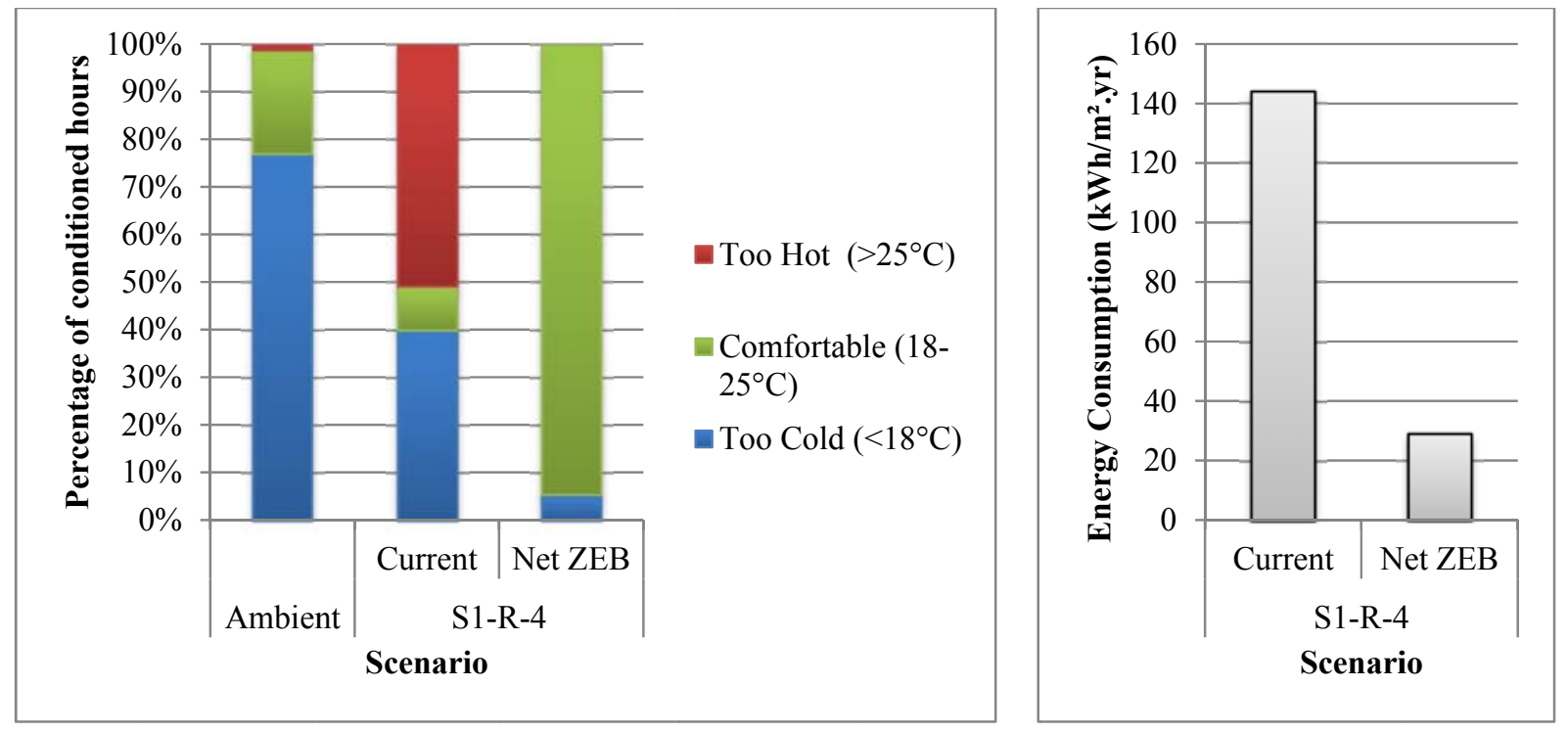

Figure 10-10 : Thermal comfort and energy consumption comparison for case study building S1-R-4 which uses heating and cooling set points outside of comfort criteria.

Figure 10-10 presents the thermal and energy consumption comparison for building case S1-R-4. The current S1-R-4 had an HVAC system installed, but the temperature set points were outside the comfort levels. The current building was heated by an occupant controlled heat pump to $16^{\circ} \mathrm{C}$

Page $\mid 270$ 
on average and there was no discernible cooling set point measured (in the BEES temperature measurements for this case building).

As can be seen, an increase in comfort hours was established in S1-R-4's Net ZEB retrofit. The current S1-R-4 had approximately 10 percent of its occupied hours within a "comfortable" temperature range. The remaining 90 percent was approximately split 50/50 between temperatures that were "too cold" and "too hot". The Net ZEB S1-R-4 had 95 percent of its occupied hours within a "comfortable" temperature and 5 percent that were considered "too cold". The hours in the S1-R-4 Net ZEB building that were "too cold" occurred during the first hour of each occupied day. All hours below $18^{\circ} \mathrm{C}$ were within 1 degree of the comfort temperature. As with the Net ZEB S1-R-2 case building, the hours that were "too cold" could be remedied by increasing the heating set point to $19^{\circ} \mathrm{C}$, which was tested in Section 11.2.1. The current S4-R-4 consumed approximately $145 \mathrm{kWh} / \mathrm{m}^{2}$.yr and once it was retrofitted it consumed approximately $30 \mathrm{kWh} / \mathrm{m}^{2} . \mathrm{yr}$. Even with better thermal comfort, the retrofitted building consumed 80 percent less energy. As was the case in S1-R-2, the increase in space conditioning energy consumption was offset by large reductions in equipment and lighting energy consumption. This reduction in energy consumption is important because 21 percent of all current buildings do not have any central HVAC systems, similar to S1-R-4.

Figure 10-11 presents the thermal and energy consumption comparison for building case S4-M3. The current S4-M-3 had a centrally controlled heat pump system heating the building to $20^{\circ} \mathrm{C}$ and cooling it to $21.4^{\circ} \mathrm{C}$. The Net ZEB retrofit had a more efficient heat pump installed and was conditioned to $18-25^{\circ} \mathrm{C}$.

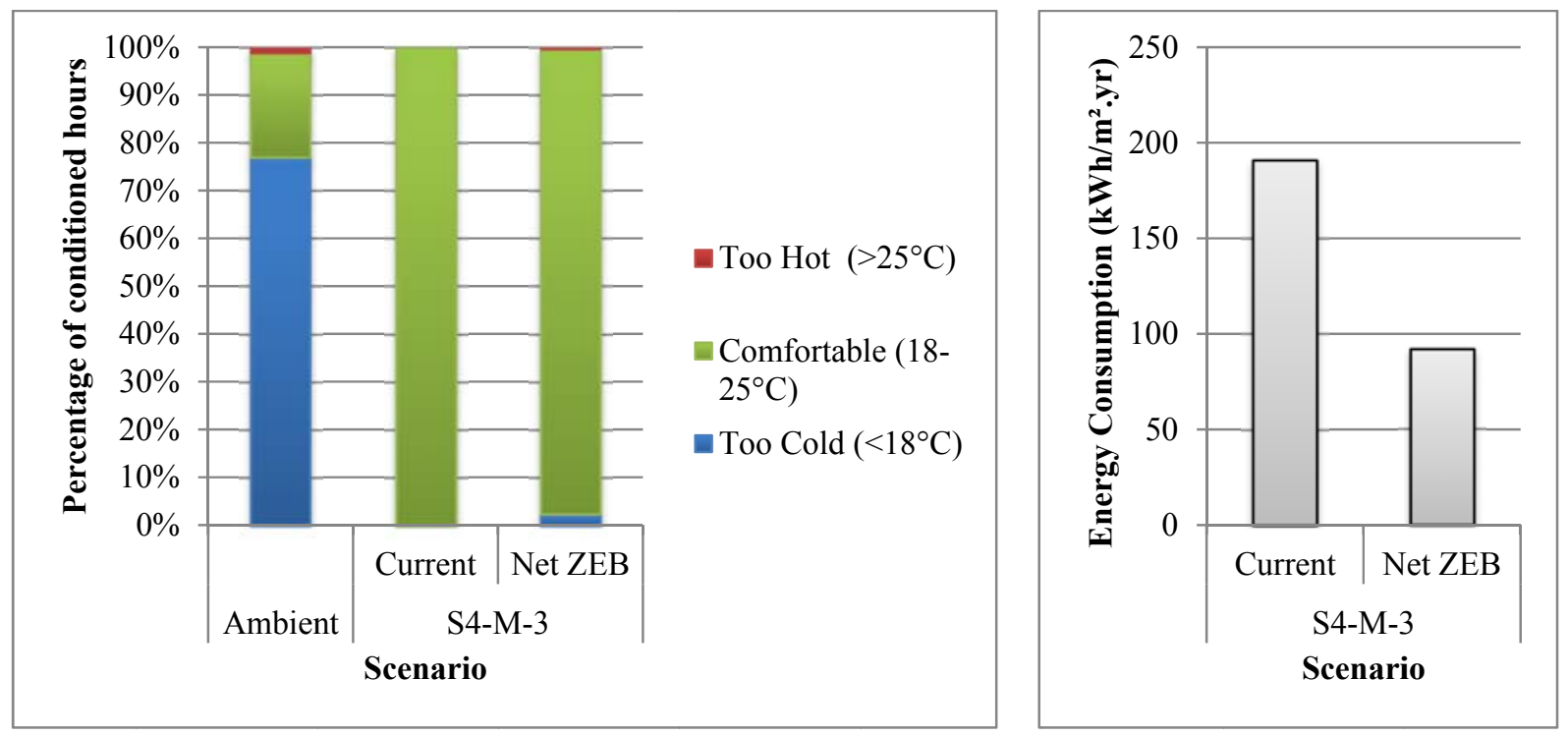

Figure 10-11 : Thermal comfort and energy consumption comparison for case study building S4-M-3 which uses set points that were within the comfort criteria. 
As shown in Figure 10-11, the current S4-M-3 had "comfortable" temperatures for 100 percent of the occupied hours. This resulted in the current building slightly out-performing the retrofitted building due to 2 percent of the occupied hours in the Net ZEB being "too cold". Once again, the "too cold" temperatures were within 1 degree below the $18^{\circ} \mathrm{C}$ set point. This indicated that the Net ZEB retrofit may in fact hinder the thermal performance of some current buildings, but should not do so considerably. Furthermore, the thermal comfort issue could be remedied by reducing the temperature set point deadband from $18-25^{\circ} \mathrm{C}$ to $19-24^{\circ} \mathrm{C}$, as assessed in Section 11.2.1.

The increased set point deadband implemented in the Net ZEB S4-M-3 building increased the building's energy efficiency. The current building consumed approximately $190 \mathrm{kWh} / \mathrm{m} 2 . \mathrm{yr}$, while the retrofitted building consumed approximately $90 \mathrm{kWh} / \mathrm{m} 2 . \mathrm{yr}$; a reduction of over 50 percent in energy demand. This reduction in energy consumption is important because 29 percent of all current buildings do not provide adequate thermal comfort similar to S4-M-3.

\subsubsection{Energy and thermal conclusions}

The energy modelling and stock aggregation methodology developed in this thesis has been used to examine the potential to retrofit the current New Zealand building stock to be NZE. The methodology has enabled an estimate of the robustness of the analysis. Because it is grounded in reality it is possible to conclude that if this building stock were retrofitted using Net ZEB solution sets then it would be plus energy overall. In fact, merely instituting energy efficiency measures brings the commercial building stock's primary energy use total to zero. Furthermore, NZE was possible even with thermal comfort improvements. The improved comfort was achieved in 21 percent of current buildings which currently had no HVAC and 29 percent of current buildings which had heating and cooling set points outside of the comfort range. The improved thermal comfort would be achieved while still meeting the study hypothesis that NZE primary energy consumption is possible in the current mixture of buildings.

\subsection{5a New Zealand and Commercial Sector energy consumption reduction}

The commercial building stock did not account for all energy consumed by the commercial sector. This was due to there being other building types associated with the commercial sector that are not assessed in this thesis. The estimations in this thesis indicated that the commercial building stock (offices, retail and mixed) accounted for six percent of all electricity and gas consumed in New Zealand and 31 percent of electricity and gas consumed by the commercial sector. Using these findings, it was possible to calculate the energy reductions achievable if the current commercial building stock was retrofitted to be NZE. 
Table 10-1 presents the total New Zealand energy reductions achievable and Table 10-2 presents the total commercial sector energy reductions achievable in an average year if the NZE retrofit were performed (Appendix 14.23 for calculations).

Table 10-1: New Zealand energy reductions achievable by retrofitting commercial building to NZE.

\begin{tabular}{|c|c|c|}
\hline \multirow[b]{2}{*}{ New Zealand wide benefits } & \multicolumn{2}{|c|}{ Final Energy Consumption (GWh) } \\
\hline & $\begin{array}{c}\text { NZE Retrofit } \\
\text { WITHOUT Onsite } \\
\text { PV }\end{array}$ & $\begin{array}{c}\text { NZE Retrofit } \\
\text { WITH Onsite } \\
\text { PV }\end{array}$ \\
\hline Total New Zealand Electricity and Gas & 55,233 & 55,233 \\
\hline $\begin{array}{l}\text { Total Electricity and Gas reductions from NZE retrofit } \\
\text { (with additional renewable energy generation) }\end{array}$ & 3,709 & 5,057 \\
\hline Percentage reduction & $7 \%$ & $9 \%$ \\
\hline
\end{tabular}

\begin{tabular}{|l|c|c|}
\hline \multirow{2}{*}{ Commercial Sector benefits } & \multicolumn{2}{|c|}{ Final Energy Consumption (GWh) } \\
\cline { 2 - 3 } & $\begin{array}{c}\text { NZE Retrofit } \\
\text { WITHOUT Onsite } \\
\text { PV }\end{array}$ & $\begin{array}{c}\text { NZE Retrofit } \\
\text { WITH Onsite } \\
\text { PV }\end{array}$ \\
\hline Total Commercial Sector Electricity and Gas & 11,109 & 11,109 \\
\hline $\begin{array}{l}\text { Total Electricity and Gas reductions from NZE retrofit } \\
\text { (with additional renewable energy generation) }\end{array}$ & 3,709 & 5,057 \\
\hline Percentage reduction & $\mathbf{3 3 \%}$ & $\mathbf{4 6 \%}$ \\
\hline
\end{tabular}

If the current commercial building stock were retrofitted to NZE, there would be either a seven percent or a nine percent reduction in ALL electricity and gas consumed in New Zealand depending on whether onsite PV were installed. This equates to either a 33 percent or a 46 percent reduction in ALL commercial sector electricity and gas consumption depending on whether onsite PV were installed. The other way of looking at these reductions is that there will be a six or eight percent surplus in energy supply to be used elsewhere in the country if NZE retrofit were to be implemented in the commercial building stock.

\subsection{5b Critique of building climate classification}

On completion of the thermal environment results analysis, a critique was completed on the Building Climate Classification method presented in Section 5.2.7. The climate classification method used a standardised reference energy model that represented the particular building types being assessed. The reference model was used to determine the likely indoor thermal climate of a particular building type in a particular climate location. The indoor thermal climate was then assessed and used to classify the building's climate into three types: heating dominated, mixed heating and cooling, and cooling dominated. The reference energy model was in essence a prototypical building. It represented how a particular building type would be typically constructed and operated. For example, the non-residential reference energy model had a high lighting and equipment load operated from $8 \mathrm{am}$ to $6 \mathrm{pm}$. By comparison; the residential reference

Page $\mid 273$ 
energy model had a low lighting and equipment load operated mostly at night and in the morning.

Using this system, the New Zealand climates were classified as being mostly mixed heating and cooling, and cooling dominated (refer to Section 8.3.1a). However, during the analysis of the 48 building sample of real buildings from across the commercial building stock, this was found to be not entirely correct. Some of the buildings were found to be heating dominated, and relied heavily on space heating. This was exemplified in the S1-R-2 case building assessed in Figure 10-9. These results highlight a further issue with hypothetical or prototypical buildings: that they are not representative of all real buildings.

\subsection{Ranking of energy conservation measures importance to the Net ZEB solution set}

This section ranks the importance of ECMs to the Net ZEB solution set from an energy perspective. The rank was sorted according to which Energy Conservation Measure (ECM) contributed the most energy savings to the overall solution set. The highest ranked ECMs saved the most energy across the whole commercial building stock, while the lowest ranked ECMs saved the least.

Figure 10-12 presents the ranking of the most effective to the least effective ECM. In particular, the ranking was formed by plotting the energy reduction contribution of each ECM (y-axis as GWh) against the proportion of total Solution Set (the combination of all the ECMs) energy reduction that the particular ECM contributed (x-axis as a percentage). As with Figure 10-4, the larger the plotted triangle the larger the contribution towards energy savings the particular ECM had made.

As shown in Figure 10-12, the two most effective ECMs were Energy Efficient Miscellaneous Equipment and Office Equipment. Efficient Miscellaneous Equipment proposed the replacement of inefficient cooking, refrigeration, freezers and other kitchen appliances with EnergyStar rated appliances. Efficient office equipment was the replacement of inefficient computing, printer and copying equipment with EnergyStar rated appliances (refer to Section 9.2.4g). Both ECMs contributed approximately 20 percent each to the total Solution Set energy reduction. The result was not surprising given the current building stock energy consumption was largely driven by the internal equipment. Additionally, the largest total energy reduction was seen in the equipment end-use (Figures 10-3 and 10-4). The two ECMs shared approximately 50 percent of the energy savings achieved in the equipment end-use, and over a third of the total reduction in energy by the whole Solution Set. 


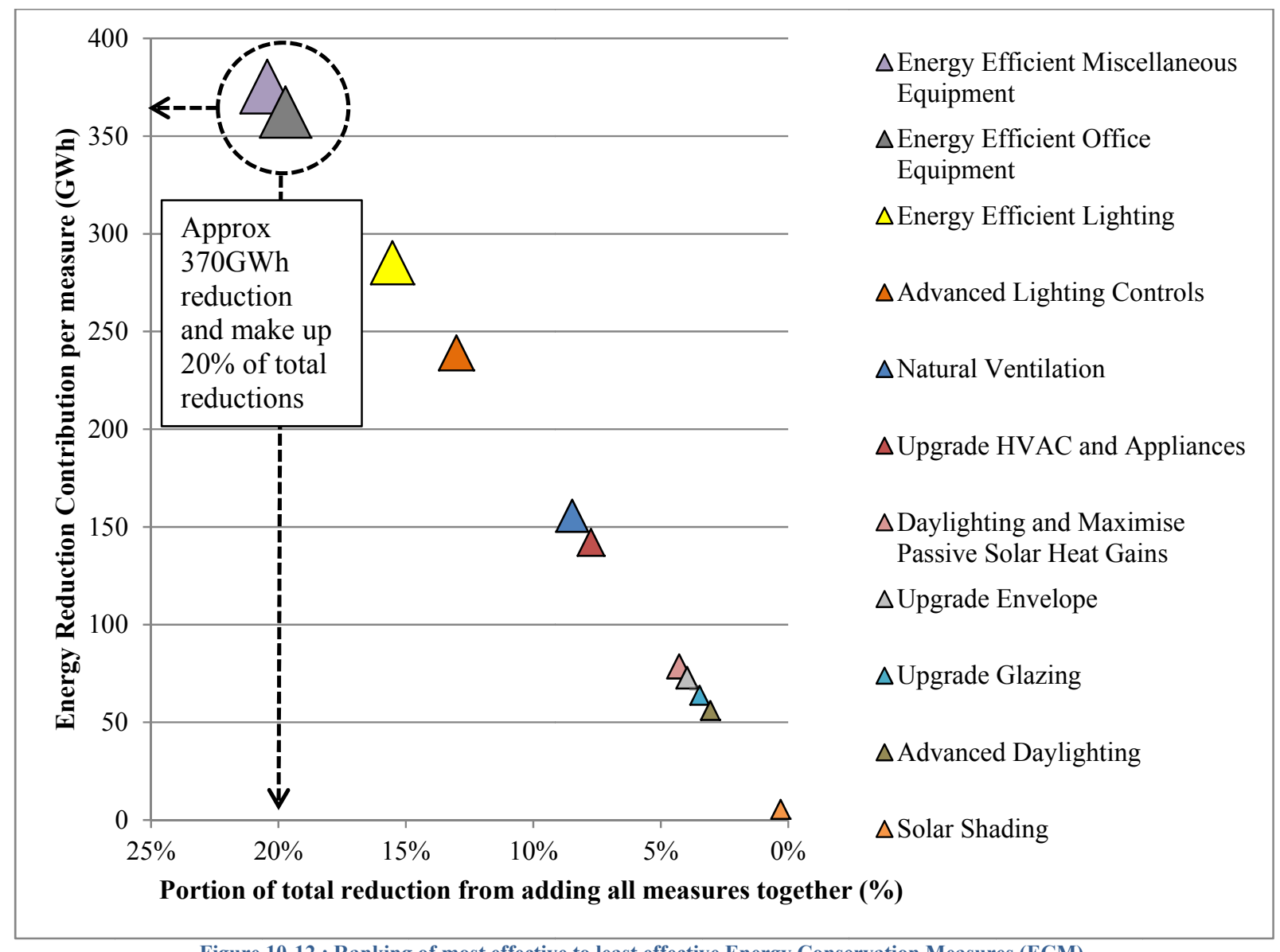

Figure 10-12 : Ranking of most effective to least effective Energy Conservation Measures (ECM).

The third and fourth most effective ECMs were Energy Efficient Lighting and Advanced Lighting Controls. Inefficient lighting sources such as incandescent and halogens were replaced with more efficient LEDs. Advanced lighting referred to the installation of electric light dimming through photo sensors when suitable daylight levels were present (refer to Section 9.2.4f). Efficient Lighting and Advanced Lighting Controls contributed approximately 15 percent each to the total Solution Set reductions. Again, it did not come as a surprise considering the Lighting end-use was the second largest energy consumer in the current commercial building stock and is the reason why the lighting end-use accounted for the second largest total Solution Set reduction (Figures 10-3 and 10-4).

The fifth most effective ECM was Natural Ventilation. Natural Ventilation was implemented by installing operable windows that allowed for fresh air and natural cooling (refer to Section 9.2.4d). It contributed to approximately 10 percent of the total Solution Set reduction. Natural Ventilation was the only passive design ECM that contributed over five percent of the total savings. This was significant as space conditioning end-uses only made up approximately 20 percent of the total energy consumed in the current building stock and five percent in the NZE building stock. The majority of the savings established in the space conditioning end-uses can

Page | 275 
therefore be attributed to Natural Ventilation. The importance of natural ventilation is consistent with what was seen in a retrofitted commercial building in New Zealand.

Aorangi House, located in Wellington, is a 1970s commercial building that was retrofitted in 2008 with a suite of energy efficiency measures. Aorangi House is a large 12 storey building. One of the biggest design changes was the switch from full HVAC to natural ventilation and supplementary heating and cooling (Baird et al. 2012; Alan Barbour 2011; Press Release: Property Council Of New Zealand 2010; Alan Barbour 2011). The energy performance of Aorangi House was shown to be half of what a typical commercial building of its size and type would consume in New Zealand (Marriage and Waldhauser 2010; Baird et al. 2012). The majority of the energy consumption was consumed by tenant end-uses, such as lighting and equipment (Baird et al. 2012). During 2013/14, the Aorangi House base building (HVAC and other services) consumed around 60 to $70 \mathrm{kWh} / \mathrm{m}^{2}$.yr, which compared favourably to a typical commercial office building at around $120 \mathrm{kWh} / \mathrm{m}^{2}$.yr (Masters 2014). Furthermore, the occupants found that natural venting air made for a more comfortable and satisfying working environment (Baird et al. 2012; Alan Barbour 2011). This was just one case where natural ventilation was shown to be feasible in a large commercial building in New Zealand.

The sixth most effective ECM was to upgrade the HVAC System and Appliances (refer to Section 9.2.4h) as it reduced the total energy by approximately 10 percent. Upgrading the HVAC System and Appliances reduced the energy required to convert electricity into space heating, cooling and ventilation.

The five least effective ECMs all pertained to the building envelope design and affected the passive design performance of the commercial buildings. Therefore, reducing the required energy to provide space conditioning could reduce more energy than optimising the passive design of the existing structure. The performances of the Passive Design ECMs optimised in this study were potentially hindered by the various building forms, constructions and orientations found in the commercial building sample. The building forms, constructions and orientations hindered performance because they were fixed and could not be optimised due to the scope of the retrofit definition (Section 5.2.3). Interestingly, solar shading was the lowest ranked ECM. The ineffectiveness of solar shading arose due to natural ventilation providing enough outdoor cool air to offset the impact of excess solar heat gains. It would be highly likely that if the building stock did not implement natural ventilation, solar shading would be a lot more effective. Future work could look into decoupling natural ventilation and solar shading in more depth by testing solar shading without Natural Ventilation. While the passive design measures did not have large energy benefits they would still be beneficial for occupant comfort and perception as was found in the case of Aorangi House (Baird et al. 2012; Alan Barbour 2011).

In summary, the most effective means to reduce energy in the current commercial building stock would be to install efficient equipment and lighting and reduce their operation using advanced control systems. It was estimated that an over 50 percent reduction in current energy

Page $\mid 276$ 
consumption could be achieved by implementing efficient building systems. Additionally, significant savings would be achieved by introducing the ability to naturally vent occupied spaces instead of relying on traditional closed off HVAC systems.

\subsubsection{Difference in ECM effectiveness for building size and types}

The difference between the six most effective ECMs for each building size and type is assessed in Tables 10-3 and 10-4. The six ECMs assessed were the six most effective ECMs at reducing the whole building stock's energy consumption, established in Figure 10-12. The following tables list the top six ECMs for reducing energy consumption across the whole building stock from Figure 10-12 and then their corresponding effectiveness ranking for each building size and type. The effectiveness ranking starts with 1, which means that particular ECM reduced the most energy for that building size or type. It finishes with 11, which means that ECM provided the least amount of energy reductions out of the eleven different ECM options as seen in Figure 1012.

Table 10-3 displays the ranking of the six most effective ECMs for reducing whole building stock energy consumption (Table 10-2) for each building size. It shows the six most effective ECMs for reducing energy consumption of the whole building stock (left most column in order 1 to 6) and each other column shows the ranking of that ECM for each building size ( $1=$ best, $11=$ worst).

Table 10-3 : Net ZEB retrofits top 6 most effective ECMs effectiveness for different building sizes.

\begin{tabular}{|c|c|c|c|c|c|}
\hline \multirow[b]{2}{*}{$\begin{array}{l}\text { Six most effective ECMs for } \\
\text { the Whole Building Stock }\end{array}$} & \multicolumn{5}{|c|}{ Building Size Ranking } \\
\hline & $5-649 m^{2}$ & $\begin{array}{c}650- \\
1499 m^{2}\end{array}$ & $\begin{array}{c}1500- \\
3499 m^{2}\end{array}$ & $\begin{array}{l}3500- \\
8999 m^{2}\end{array}$ & $\begin{array}{c}9000 \mathrm{~m}^{2} \\
\text { and } \\
\text { greater }\end{array}$ \\
\hline $\begin{array}{l}\text { Energy Efficient Miscellaneous } \\
\text { Equipment }\end{array}$ & 9 & 3 & 2 & 1 & 2 \\
\hline $\begin{array}{lll}\text { Energy Efficient } & \text { Office } \\
\text { Equipment } & & \\
\end{array}$ & 1 & 1 & 5 & 4 & 3 \\
\hline Energy Efficient Lighting & 6 & 5 & 3 & 3 & 1 \\
\hline Advanced Lighting Controls & 2 & 2 & 1 & 5 & 5 \\
\hline Natural Ventilation & 3 & 4 & 6 & 7 & 6 \\
\hline Upgrade HVAC and Appliances & 11 & 11 & 10 & 2 & 4 \\
\hline
\end{tabular}

The most effective ECM for reducing energy consumption of the whole building stock was Energy Efficient Miscellaneous Equipment. This was the same for buildings between 3500$8999 \mathrm{~m}^{2}$. But the rank differed for the other building sizes. For example, the smallest building size $\left(5-649 \mathrm{~m}^{2}\right)$ ranked Energy Efficient Miscellaneous Equipment as the $9^{\text {th }}$ effective ECM for reducing energy consumption. Upgrading HVAC and Appliances was the $6^{\text {th }}$ effective ECM for reducing energy consumption of the Whole Building Stock. However, this was not the case when assessing at the building size scale. It was the $11^{\text {th }}$ (or least) effective ECM in buildings from 5- 
$1499 \mathrm{~m}^{2}$, but was second in buildings between $3500-8999 \mathrm{~m}^{2}$. The HVAC upgrade rankings create a trend in effectiveness from less effective in smaller buildings, to more effective in larger buildings. This trend in the ranking of ECMs between smaller and larger buildings can be seen across all ECMs.

Firstly, upgrading equipment inside the buildings was more effective in larger buildings. This was shown by the Miscellaneous Equipment, Lighting, and HVAC upgrades being ranked higher in larger buildings than in smaller buildings. The exception was Office Equipment upgrades which were highly effective in all building sizes. Secondly, upgrading the building envelope design was more effective in smaller buildings. This was shown by Natural Ventilation and Advanced Lighting Controls (and other passive rankings found in Appendix 14.24) being ranked higher in small buildings. The Advanced Daylighting Controls is a form of efficient system, but it was more effective in smaller buildings because there was more floor area that was daylit compared to larger buildings. The ranking of the full set of eleven ECMs is found in Appendix 14.24 and reinforces the two trends seen in Table 10-3.

HVAC was ranked worst in small buildings because some small buildings did not have any heating and cooling. In these buildings an HVAC system was installed to provide better thermal conditions inside the buildings, but as a consequence meant the smaller buildings consumed more energy.

Table 10-4 displays the ranking of the six most effective ECMs for reducing whole building stock energy consumption (Table 10-2) for each building type.

Table 10-4 : Net ZEB retrofits top 6 most effective ECMs effectiveness for different building types.

\begin{tabular}{|l|c|c|c|}
\hline \multirow{2}{*}{$\begin{array}{l}\text { Six most effective ECMs for the } \\
\text { Whole Building Stock }\end{array}$} & Office & Retail & Mixed \\
\cline { 2 - 4 } $\begin{array}{l}\text { Energy Efficient Miscellaneous } \\
\text { Equipment }\end{array}$ & 8 & 1 & 4 \\
\hline $\begin{array}{l}\text { Energy Efficient Office } \\
\text { Equipment }\end{array}$ & 1 & 2 & 2 \\
\hline Energy Efficient Lighting & 4 & 3 & 1 \\
\hline Advanced Lighting Controls & 3 & 4 & 3 \\
\hline Natural Ventilation & 5 & 5 & 6 \\
\hline Upgrade HVAC and Appliances & 2 & 8 & 5 \\
\hline
\end{tabular}

The rankings of ECMs for office and retail building types were distinctive. The retail ranking followed the whole building stock's ranking for the top five effective ECMs. The only difference was the HVAC upgrades were not as effective in retail buildings, whereas, the HVAC upgrade was the second most effective ECM for reducing energy consumption in office buildings. This suggests that office buildings have a high HVAC related energy consumption and upgrading HVAC was important for reducing office building energy consumption.

Page $\mid 278$ 
The Miscellaneous Equipment upgrades, which include refrigeration and cooking, was the most effective in retail buildings. This was logical as retail contained most of the large refrigeration and cooking equipment uses. Similarly, Office Equipment upgrades were the most effective in office buildings, which are driven mainly by office equipment loads.

The general trend seen between the building types was:

- Upgrading to energy efficient lighting and equipment systems inside retail and mixed buildings was more effective than upgrading the building envelope and HVAC system.

- Upgrading to energy efficient lighting, equipment and HVAC systems inside office buildings was more effective than upgrading the building envelope.

\subsection{Chapter summary}

Chapter 10 identified that the study objective of retrofitting the current New Zealand commercial building stock using a set of design changes established from existing Net ZEBs can achieve part 2 of the hypothesis of achieving Net Zero Primary Energy Emissions. The results established that as a community of buildings, NZE was an attainable goal. The goal was achievable even without the use of onsite renewable energy generation. NZE would be achievable all while providing improved thermal comfort throughout the commercial building stock. Upgrading to energy efficient systems inside commercial buildings provided the largest energy reductions when compared to upgrading the envelope design of commercial buildings. Focusing on improving the efficiency of the systems inside commercial buildings would have the largest potential for energy reductions; not redesigning the buildings to perform better passively. 
Figure 10-13 presents the links between Chapters 10 and 11.

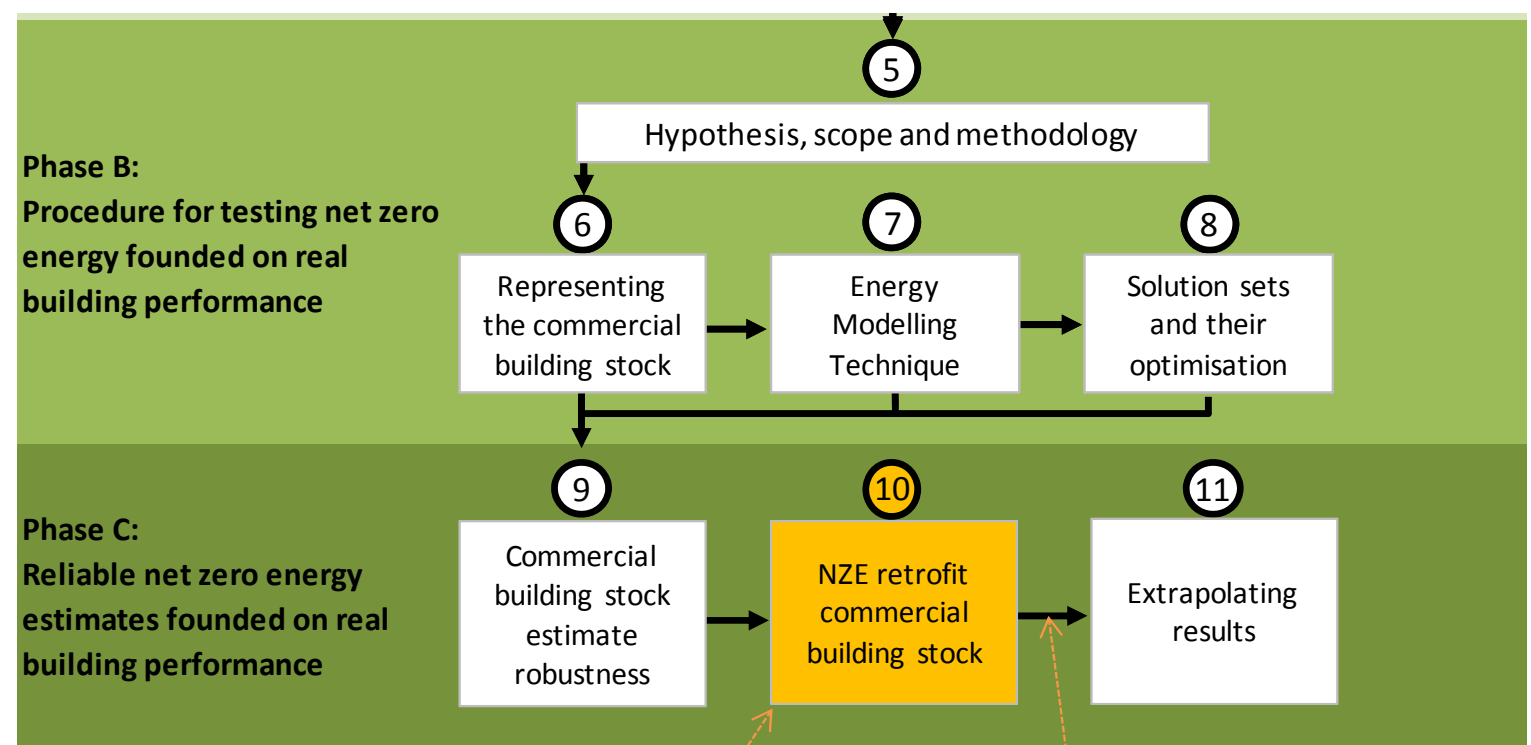

NZE was shown to be possible by determining the balance between primary energy consumption, with improved comfort, was outweighed by renewable generation.
NZE is possible, but is it sensitive to design changes and is it feasible from a temporal energy match or cost perspective?

Figure 10-13 : Chapter 10 and 11 links.

With the primary thesis aim completed (NZE retrofit is feasible), Chapter 11 performs tests to establish if the retrofit building stock is sensitive to design changes, whether it is beneficial to the national energy grid, and whether it makes economic sense. The tests in Chapter 11 provide insight into whether achieving NZE is feasible in reality. 


\section{CHAPTER 11. FEASIBILITY OF REACHING NET ZERO ENERGY}

\subsection{Chapter Intent}

Chapter 11 performs two series of tests to assess the feasibility of reaching NZE. One of these test series investigates if there were any sensitive aspects of the retrofit design parameters proposed in Chapter 8. The design changes relate to how buildings could be operated in reality. The second series of tests investigate whether the retrofitted building stock would be beneficial to the national electrical grid and economically beneficial. A beneficial relationship with the electrical grid would mean the retrofitted building stock would have a reduced reliance on the grid connection. For the retrofit building stock to be economically beneficial, the retrofit would need to be of similar cost to building a new energy generation system. Figure 11-1 displays the links between Chapters 8, 10 and 11.

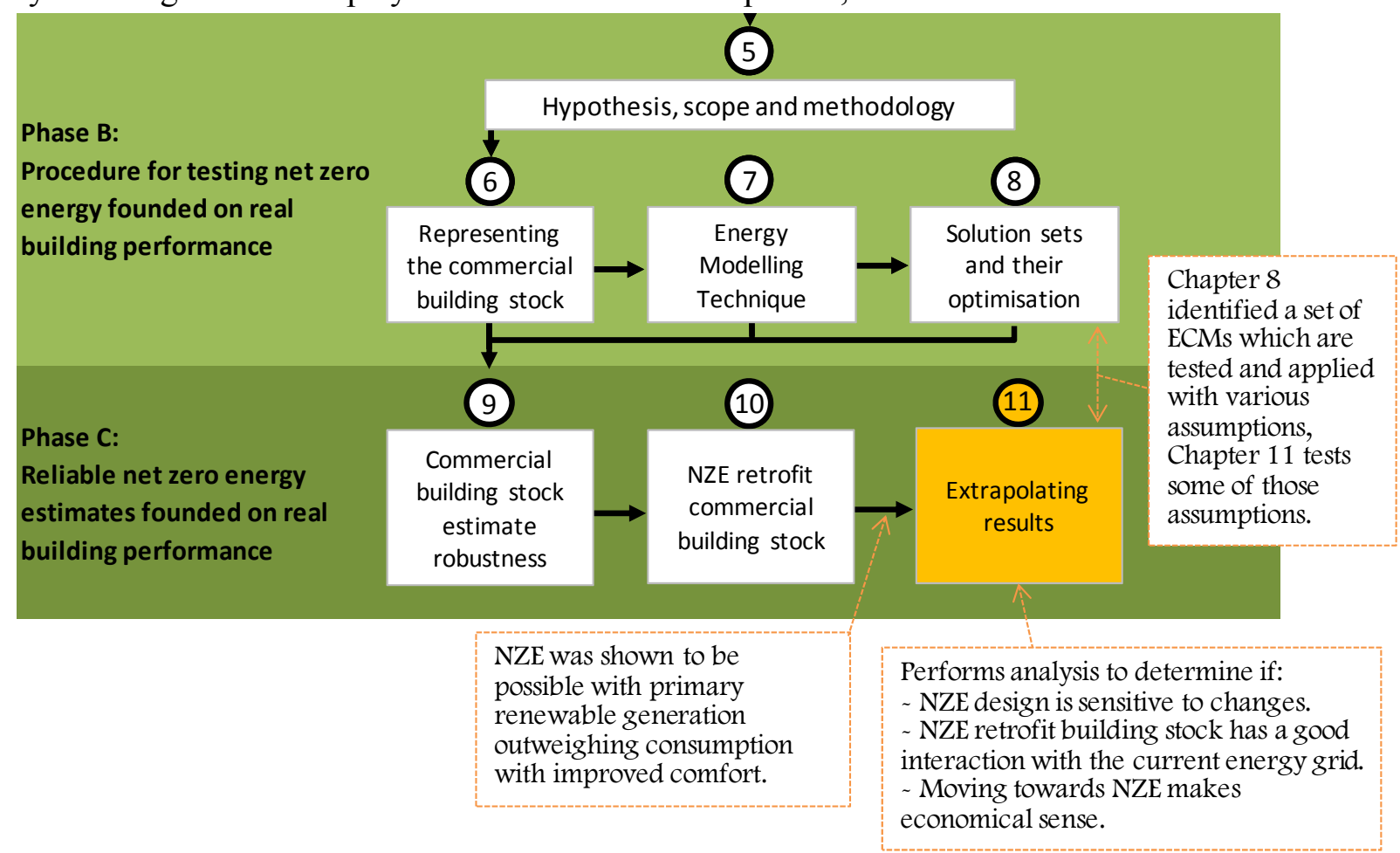

Figure 11-1 : Links of Chapters 8 and 10 to Chapter 11.

\subsection{Impact of varying the retrofit design}

In reality, the NZE retrofit buildings could potentially differ with regard to the way the ECMs are installed. While they could be different for a number of reasons, the main reason is likely to be due to the engineers, designers and/or manufacturers using different assumptions to the ones used in this thesis. The Sensitivity Analysis (SA) performed in this section (using the methodology outlined in Section 5.3.3b) identifies how different the predicted energy consumption results for the NZE retrofit commercial building stock could be if the currently 
applied retrofit design Approximations Assumptions and Simplifications (AAS) were changed. The solution set AASs identified for assessment included:

- Heating and cooling set points - the solution set implemented a consistent change of a heating and cooling set point deadband of $18-25^{\circ} \mathrm{C}$ based on the Givoni extended comfort criteria (Givoni 1998). Uncertainty was introduced as real buildings were not always operated in optimum conditions (as seen by the variation in set points installed in the current commercial building stock) and the definition of comfort was also contentious (especially when considering elderly and young people (ASHRAE 2010)). For this reason, an assessment for a range of set points was undertaken.

- Outdoor fresh air ventilation rate - the NZE retrofit commercial building stock implemented the same outdoor fresh air ventilation rates as the ventilation rates modelled in the current commercial building stock. The current ventilation rates were calculated using $\mathrm{CO}_{2}$ measurements from the monitored building, where available. The $\mathrm{CO}_{2}$ measurements had a certain level of error. In addition, the ventilation rate may have been updated during the calibration process and was therefore subject to potential change in real buildings. An assessment was undertaken to investigate the impact that changing the ventilation rate would have on reaching NZE.

- Task illumination comfort set point - the solution set applied in this thesis installed electric light dimming that was controlled by the amount of available daylight in the building. The electric light was dimmed when 350 Lux of available daylight was available in offices and 500 Lux was available in retail buildings. The illuminance set points were derived from building standards which prescribed the amount of task lighting required for different tasks undertaken in different building types (Standards Association of Australia and Standards New Zealand 2006; CIBSE 2002). The illuminance comfort criteria could be implemented differently in real commercial buildings (as identified in lessons learned by existing Net ZEB design teams) and hence, the illuminance set points for electric light dimming were assessed.

- Heat pump system type - The solution set applied to the 48 building energy models upgraded the current HVAC system in commercial buildings (where necessary) to an efficient air-to-air heat pump system. A simplification was made to keep the modelling methodology easy and standardised for retrofitting the energy models. The simplification converted the existing HVAC systems to an air-to-air heat pump split system. The split system is a common HVAC system type installed in New Zealand commercial buildings (A Gates 2013). However, in real commercial buildings it may be more feasible to install a different heat pump system, such as a Variable Refrigerant Volume or Flow (VRV or VRF) heat pump system. A VRF system has one outdoor unit which services multiple indoor units with varying amounts of refrigerant to meet the specific heating and cooling needs in a particular building space/room (Air Conditioning and Heat Pump Institute 2010). VRF systems could be more feasible in large commercial buildings as they offer more flexibility in space conditioning because each indoor unit can heat and cool 
independently of each other, and save space because they require fewer outdoor units (Hardy 2009; Daikin Industries Ltd 2014). A case study was undertaken that compared the energy consumption results of using a split system and a VRF system.

\subsubsection{Consequences of heating and cooling set point changes}

This section assesses the sensitivity of the chosen heating and cooling set points on reaching NZE. The retrofit commercial building stock used the assumption of a consistent heating and cooling set point deadband of $18-25^{\circ} \mathrm{C}$. The set points were based on the expanded Givoni comfort requirements which suggest that the set points used would provide healthy temperatures for fit occupants (Givoni 1998). In reality, buildings implement a range of set points. Three set point variations were tested:

1. The first set point SA scenario was identified through the analysis of the thermal comfort in Section 10.2.4. It highlighted that indoor temperatures deviated above and below the required comfort set point parameters. The deviation in all cases was less than $1^{\circ} \mathrm{C}$. This suggested that a new set point deadband of $19-24^{\circ} \mathrm{C}$ would remedy the issue. The SA tested whether changing the heating and cooling set point to $19-24^{\circ} \mathrm{C}$ provided the required indoor temperatures in the comfort range, without hindering the NZE performance.

2. The second set point SA scenario tested a narrow set point deadband case of $21-22^{\circ} \mathrm{C}$. These narrow set points were chosen due to the two temperatures being the midway temperature between $18-25^{\circ} \mathrm{C}$. This highlighted the effect of not using an extended comfort based set point system.

3. The third set point SA scenario returned the retrofitted set points of $18-25^{\circ} \mathrm{C}$ back to the set points modelled in the current building stock. The current buildings' set points all varied greatly. The results highlighted the impact of not changing the set points proposed to match the extended Givoni comfort criteria (Section4.3.4) in conjunction with the solution set. 
Figure 11-2 displays the energy balance for the retrofit set point $\left(18-25^{\circ} \mathrm{C}\right)$ and three variant set point scenarios $\left(19-24^{\circ} \mathrm{C}, 21-22^{\circ} \mathrm{C}\right.$, and the current set points modelled in the current commercial building stock).

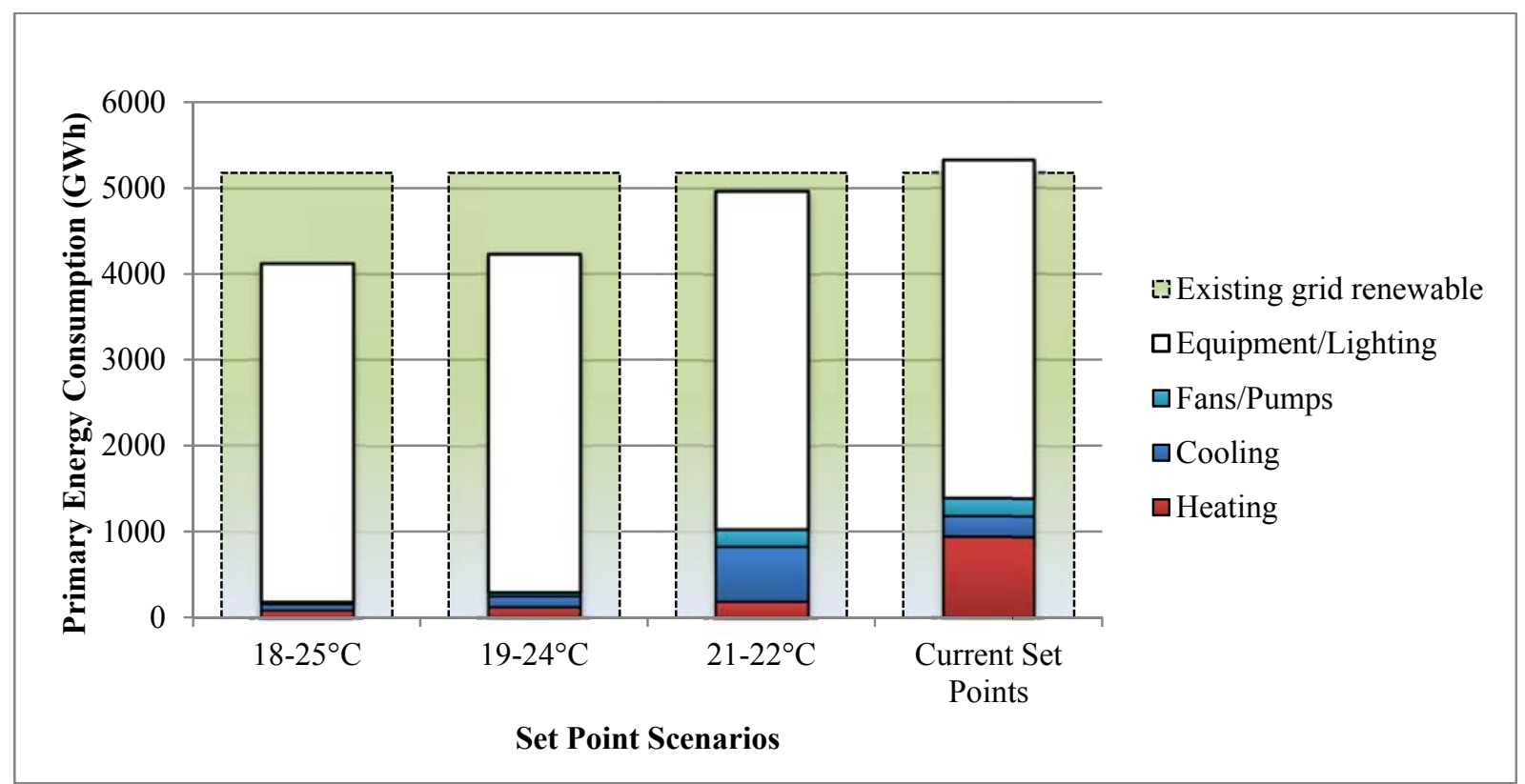

Figure 11-2 : Energy breakdown for the retrofit set point and three variant set point scenarios.

These three scenarios were tested by iterating each of the 48 energy models in the seven New Zealand climates and stock aggregating their results (Appendix 14.25.1a). The energy balance was split into the energy demand from each energy end-use (heating: red, cooling: dark blue, Fans/Pumps: light blue, Lighting and Equipment: white), with the renewable generation (existing grid) displayed in the background. Note: the onsite PV generation is not presented on the graph. If the onsite PV generation were to be included, the renewable energy generation bar would be at $8,986 \mathrm{GWh}$.

Figure 11-2 shows that as the set point deadband got tighter $\left(19-24^{\circ} \mathrm{C}\right.$ and $\left.21-22^{\circ} \mathrm{C}\right)$, the energy consumption increased. A change to $19-24^{\circ} \mathrm{C}$ made a three percent increase in energy consumption, and indicated that making a change of $1^{\circ} \mathrm{C}$ did not influence the predicted NZE results substantially. The change in set points was small because the heating, cooling, and fans/pumps energy end-uses made up such a small proportion of the total energy consumed in the retrofitted building stock. Additionally, the buildings were still naturally ventilating/cooling meaning that little cooling was needed.

However, changing the set points to $21-22^{\circ} \mathrm{C}$ had a large effect and increased the energy consumption by 20 percent. The largest impact was on the cooling energy end-use which had a seven fold increase in energy consumption. The increase in cooling energy use occurred due to the cooling set point $\left(22^{\circ} \mathrm{C}\right)$ being below the temperature when windows were opened to allow 
for natural ventilation/cooling $\left(23^{\circ} \mathrm{C}\right)$. Using the $21-22^{\circ} \mathrm{C}$ deadband effectively removed the ability of the building stock to naturally ventilate/cool to reduce energy consumption.

Similarly, if the current commercial building stock set points were used, this would have a large impact on energy consumption. An increase in energy consumption of 29 percent was predicted. The significant increase in energy consumption was largely attributed to the heating end-use which consumed nine times more energy. The large increase in heating was due to the heating set points of the current commercial building stock being close to or above the temperature at which the retrofit windows opened to naturally ventilate/cool. This meant the HVAC system had to heat a larger quantity of cooler outdoor air that would be entering the building through the windows. Both the Cooling and Fans/Pumps end-uses had an increase in energy consumption as well, but this was much smaller than the heating end-use.

Even with the increases in energy consumption resulting from the adoption of different heating and cooling set points, NZE was still achievable. NZE would be achievable because the onsite renewable energy generation (existing renewable plus onsite PV generation equals $8,986 \mathrm{GWh}$ ) can offset enough of the consumed energy. However, if onsite generation was not installed, using different set points would have had a large influence on the energy consumption of the commercial building stock (as shown by the consumption being above the existing grid renewable energy supply in Figure 11-2).

It is important to note that the greatest influence on energy consumption when set points were altered occurred from the ability to use natural ventilation optimally. If the set point variations were made in conjunction with natural ventilation design the impact on energy consumption would be reduced. For example, if the windows were set to open at a temperature which was less than the cooling set point in the $21-22^{\circ} \mathrm{C}$ set point scenario, the cooling energy end-use consumption would likely be much smaller.

\subsection{1a Thermal comfort cross-check}

The thermal comfort analysis undertaken in Section 10.2.4 highlighted that temperatures in the NZE retrofit commercial building stock could deviate slightly below and above the heating and cooling set points. The temperatures were less than 1 degree below or above the comfort set points. Nevertheless, it was necessary to undertake the SA to establish the likely impact of changing the $18-25^{\circ} \mathrm{C}$ set point deadband to $19-24^{\circ} \mathrm{C}$ and ensure the minimum comfort requirements were met for 100 percent of the occupied hours. The SA was performed on one case study building which was previously used in the thermal comfort assessment in Section 10.2.4. The case study building was S1-R-4. The current building had 91 percent of its occupied temperatures outside of the comfort requirement of $18-25^{\circ} \mathrm{C}$. When retrofitted to NZE, 95 percent of the occupied hours were within the comfort requirement of $18-25^{\circ} \mathrm{C}$. However, 5 percent of the occupied hours were "too cold" (below $18^{\circ} \mathrm{C}$ ). 
Figure 11-3 displays the thermal comfort results of the current building S1-R-4, its original NZE retrofitted building $\left(18-25^{\circ} \mathrm{C}\right)$, and an updated NZE retrofitted building with set points of 19$24^{\circ} \mathrm{C}$. It was done to only a single case study building to illustrate the difference that a slightly narrow heating and cooling deadband would have on the thermal performance of the buildings. The results were presented (left graph) as the percentage of hours that were "too cold" (less than $18^{\circ} \mathrm{C}$ ), "comfortable" (between $18^{\circ} \mathrm{C}$ and $25^{\circ} \mathrm{C}$ ), or "too hot" (over $25^{\circ} \mathrm{C}$ ). The ambient temperature aided in identifying how the building performed compared to the external temperatures. The energy consumption of the current and NZE retrofit building was also compared with different set point deadbands (right graph). Note: the results are from the case study building being simulated in each of the seven New Zealand climates and averaged to give a New Zealand climate wide analysis as discussed in Appendix 14.25.2a.

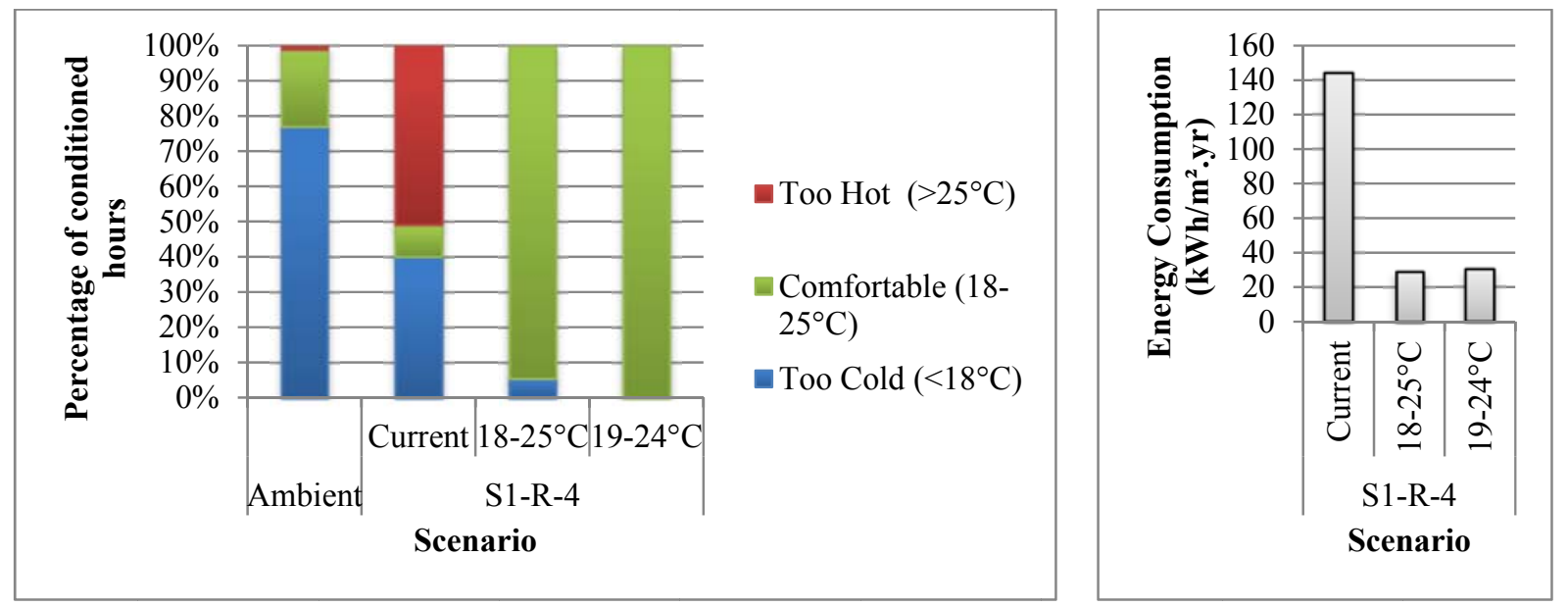

Figure 11-3 : Thermal comfort and energy consumption comparison for S1-R-4 with a decreased set point deadband of $19-14^{\circ} \mathrm{C}$.

As shown in Figure 11-3, with a decreased set point deadband of $19-24^{\circ} \mathrm{C}$, the indoor temperatures were within the comfort range of $18-24^{\circ} \mathrm{C}$. This highlighted that a minor change in set points would eliminate the 5 percent of hours that were "too cold". The increase in comfort was achieved without severely hindering the energy performance of the NZE retrofit design. The energy consumption comparison showed that there was an increase of approximately 1 percent in energy consumption when the set point deadband was tightened.

\subsubsection{Consequences of fresh air rate changes}

For commercial buildings in New Zealand to meet the New Zealand Building Code, they must comply with NZS4303. NZS4303 recommends an outdoor air ventilation rate of 10L/s.p in office buildings and a slightly lower rate of $8 \mathrm{~L} / \mathrm{s} . \mathrm{p}$ in retail buildings (Standards New Zealand 1990). The majority (75 percent) of the current buildings tested in this thesis had a ventilation rate of 10L/s.p. Like all legal requirements, the NZS4303 ventilation rate is the bare minimum. The ventilation rate was based on the health of the occupants (Standards New Zealand 1990) and meeting the bare minimum of the building code would not mean the building was well designed, but means the building provided an acceptably healthy indoor environment for the occupants. 
Various environmental rating schemes, such as GreenStar, LEED and BREEAM, reward improvement in fresh air ventilation rates compared to current building standards and codes. In New Zealand, the green rating scheme is GreenStar. GreenStar rewards three levels of improvement on the building code required ventilation rate. The largest rewards are offered to buildings with a 150 percent improvement on the current building code, meaning the current rate of $10 \mathrm{~L} / \mathrm{s} . \mathrm{p}$ would be increased to 25L/s.p (NZGBC 2014). It was this improvement to 25L/s.p which provided the basis for the SA on the outdoor fresh air ventilation rate. The SA increased the ventilation rate in buildings which had a rate of $10 \mathrm{~L} / \mathrm{s} . \mathrm{p}$ to $25 \mathrm{~L} / \mathrm{s}$.p, resulting in a 150 percent improvement in the required ventilation rate in office buildings and more than a 150 percent improvement in retail buildings. The SA tested the effect that implementing the improved outdoor air ventilation rate in the NZE retrofit had on the predicted energy consumption.

Table 11-1 displays the energy consumption of the retrofitted commercial building stock (represented by the 48 energy models in seven New Zealand climates) and the percentage change seen in the Total Energy Demand and HVAC related end-uses (Heating, Cooling and Fans/Pumps) when the buildings with a ventilation rate of $10 \mathrm{~L} / \mathrm{s} . \mathrm{p}$ were changed to $25 \mathrm{~L} / \mathrm{s} . \mathrm{p}$ (Appendix 14.25.1b).

Table 11-1 : Impact of fresh air ventilation rate on the NZE retrofitted commercial building stock's energy consumption.

\begin{tabular}{|l|c|c|c|c|}
\hline $\begin{array}{l}\text { Fresh Air } \\
\text { Ventilation Rate } \\
\text { Scenario }\end{array}$ & $\begin{array}{c}\text { Total Energy } \\
\text { Demand (GWH) }\end{array}$ & Heating (GWH) & Cooling (GWH) & $\begin{array}{c}\text { Fans/Pumps } \\
\text { (GWH) }\end{array}$ \\
\hline $\begin{array}{l}\text { Difference in Energy } \\
\text { Consumption }\end{array}$ & 3.70 & 2.97 & 0.50 & 0.23 \\
\hline $\begin{array}{l}\text { Percentage change } \\
\text { in Energy } \\
\text { Consumption }\end{array}$ & $0.1 \%$ & $3.1 \%$ & $0.6 \%$ & $0.8 \%$ \\
\hline
\end{tabular}

Table 11-1 shows that increasing the outdoor fresh air ventilation rate in the buildings only meeting the bare minimum of the NZBC had a minimal effect on the predicted energy consumption of the NZE retrofitted commercial buildings stock. As expected, the largest impact was on heating, however, this increase was minimal (3.1 percent). Heating was expected to be impacted the most because the more outdoor cooler air that entered the building, the cooler the building would be, and the more heating was required to keep the building at $18^{\circ} \mathrm{C}$. Overall, the passive nature of the retrofitted building stock and the fact that the building stock was driven largely by internal equipment meant the impact (and therefore the sensitivity) of the fresh air rate was minimal. This shows that reaching NZE could still be achieved with an increased fresh air rate in line with Green Rating tools.

\subsection{2a Influence of excessively high ventilation rates}

A number of building cases had much higher ventilation rates compared to the code. One large mixed building case (S4-M-2) supplied 6 times more outdoor fresh air than required by NZS4303. Because of the high ventilation rate in S4-M-2, it was chosen to perform a single case 
study sensitivity test to highlight the likely effect a high rate would have on energy consumption. The case study changed the current ventilation rate of $60 \mathrm{~L} / \mathrm{s} . \mathrm{p}$ to $10 \mathrm{~L} / \mathrm{s} . \mathrm{p}$ to reflect the same building meeting the bare minimum requirements of the NZBC.

Table 11-2 displays the energy breakdown for S4-M-2 with the current ventilation rate (60 L/s.p), and with the NZBC required rate (10 L/s.p) (Appendix 14.25.2b). It also displays the predicted percentage reduction in energy consumption if the change occurred.

Table 11-2 : Impact of fresh air ventilation rate in S4-M-2.

\begin{tabular}{|c|c|c|c|c|}
\hline \multirow[b]{2}{*}{$\begin{array}{l}\text { Fresh Air Ventilation Rate } \\
\text { Scenario }\end{array}$} & \multicolumn{4}{|c|}{ Energy end-use } \\
\hline & $\begin{array}{l}\text { Total Energy } \\
\text { Demand } \\
\left(\mathrm{kWh} / \mathrm{m}^{2} . \mathrm{yr}\right)\end{array}$ & $\begin{array}{c}\text { Heating } \\
\left(\mathrm{kWh} / \mathrm{m}^{2} \cdot \mathrm{yr}\right)\end{array}$ & $\begin{array}{c}\text { Cooling } \\
\left(\mathrm{kWh} / \mathrm{m}^{2} \cdot \mathrm{yr}\right)\end{array}$ & $\begin{array}{l}\text { Fans/Pumps } \\
\left(\mathrm{kWh} / \mathrm{m}^{2} \cdot \mathrm{yr}\right)\end{array}$ \\
\hline Current Buildings Rate (60 L/s.p) & 83.7 & 1.0 & 5.5 & 1.5 \\
\hline $\begin{array}{l}\text { New Zealand Building Code } \\
\text { Required Rate (10 L/s.p) }\end{array}$ & 82.9 & 0.9 & 4.9 & 1.3 \\
\hline $\begin{array}{l}\text { Percentage change in energy } \\
\text { consumption }\end{array}$ & $-1 \%$ & $-10 \%$ & $-10 \%$ & $-11 \%$ \\
\hline
\end{tabular}

As seen can be seen, the impact of the high ventilation rate on the NZE retrofit energy consumption was small at a whole building level. However, at an end-use level it was substantial. The Heating, Cooling and Fans/Pumps energy end-uses all had a reduction in energy consumption of approximately ten percent when the ventilation rate was lowered to $10 \mathrm{~L} / \mathrm{s} . \mathrm{p}$. Nevertheless, due to the NZE design, the retrofitted building would be passive in nature. This indicated that the building's energy consumption was dominated by lighting and equipment. This case study SA reinforces the outcomes seen in Table 11-1 and provides a more in-depth perspective on the impact of fresh air ventilation rates on the NZE retrofit buildings' energy consumption.

\subsubsection{Consequences of task illuminance set point changes}

NZE retrofit implemented a solution set derived from the various passive, energy efficient and renewable Energy Conservation Measures (ECM) found in real Net ZEBs worldwide. One of the ECMs established to be commonly used in net zero energy commercial buildings was daylight induced electric light dimming. When installing the dimming system into the 48 energy models, one of the AAS defined the illumination level at which the electrical lights begin to dim to reduce the energy consumed by the lighting. The illumination level used was obtained by considering the recommended illumination level suited for various tasks that building users would be undertaking. These recommended levels represented the point at which the building occupant could undertake their task comfortably.

In New Zealand, these recommendations for buildings to meet the NZBC are provided by NZS1680 (Standards Association of Australia and Standards New Zealand 2006). The levels provided in NZS1680 were derived by the published work of CIBSE (Standards Association of 
Australia and Standards New Zealand 2006; CIBSE 2002) and hence, the illuminance levels used in this thesis were considered internationally appropriate. It was established that the electric lights should dim when there was more than 350Lux in Office buildings, and 500Lux in Retail buildings. The office illuminance of 350Lux was at the lower end of the recommended spectrum of 320-500Lux (Standards Association of Australia and Standards New Zealand 2006; CIBSE 2002). The 350Lux was used as it reinforced energy savings and given modern offices utilise computer screens for everyday work, a lower illuminance level was appropriate (The Society of Light and Lighting 2005). However, it could be argued that high levels (500Lux maximum) of illuminance could be more appropriate (CIBSE 2002). Due to this argument, SA was performed to test the effect that using differing illuminance set points would have on the energy consumption of the NZE retrofit commercial building stock.

In assessing the lessons learned by Net ZEB design teams (refer to Section 8.3.2) it was also found that a rethink about the task illuminance comfort level could obtain further energy savings. One of the Net ZEB design teams offered a lesson regarding the rethink of the traditional task illuminance comfort levels. This particular Net ZEB lowered the illuminance comfort level to 200Lux, with no apparent or adverse effect to the occupants and their ability to complete their tasks (which comprised computer work, technical drawing and reporting). Due to this lesson learned, the SA tested the impact of lowering the task illuminance in office buildings to 200Lux.

Table 11-3 below presents the percentage change in the energy consumption of the retrofit commercial building stock when the current 350Lux illuminance set point was reduced to 200Lux or increased to 500Lux in office buildings (Appendix 14.25.1c).

Table 11-3: Impact of office buildings task illuminance set point on the NZE retrofitted commercial building stock's energy consumption.

\begin{tabular}{|l|c|c|c|c|c|}
\hline \multirow{2}{*}{$\begin{array}{l}\text { Task Illumination } \\
\text { Scenario }\end{array}$} & \multicolumn{4}{|c|}{ Percentage change in energy consumption } \\
\cline { 2 - 6 } & $\begin{array}{c}\text { Total } \\
\text { Energy } \\
\text { Demand }\end{array}$ & Heating & Cooling & $\begin{array}{c}\text { Fans/ } \\
\text { Pumps }\end{array}$ & Lighting \\
\hline $\begin{array}{l}\text { Decreasing Office to } \\
\text { 200Lux }\end{array}$ & $-0.5 \%$ & $1.7 \%$ & $-0.1 \%$ & $0.3 \%$ & $-2.3 \%$ \\
\hline $\begin{array}{l}\text { Increasing Office to } \\
\text { 500Lux }\end{array}$ & $0.6 \%$ & $1.0 \%$ & $0.9 \%$ & $0.9 \%$ & $2.3 \%$ \\
\hline
\end{tabular}

The results show that the effect of changing the task illuminance set point in offices from 350Lux to either 200Lux or 500Lux was minimal, with a change in total energy demand of less than one percent. The largest affected energy end-use was lighting, which had an increase and decrease of approximately two percent depending on whether the illuminance set point was decreased or increased. The results suggested there were relatively high levels (greater than 500Lux) of daylight penetrating the perimeter zones of commercial buildings that can be used to reduce the electric lighting energy consumption. However, the high levels of daylight could indicate that there may be discomfort glare issues. "Discomfort glare is a phenomenon arising 
from high luminance contrasts or unsuitable luminance distributions in the visual field causing discomfort" (Hirning, Isoardi, and Cowling 2014, p.427). "Glare happens when our eyes have adjusted to a certain general brightness, then some annoying, distracting, and sometimes blinding light appears within our visual field" (Suk, Schiler, and Kensek 2013, p.113). The potential high illuminance levels highlighted that further analysis into daylight comfort may be required if NZE was to be considered in reality.

\subsubsection{Consequences of Heat pump system type changes}

This section aimed to assess the impact the chosen air-to-air heat pump system has on the predicted NZE retrofit energy performance. The results established the likely effect on the energy consumption of the NZE retrofit building stock if a different air-to-air heat pump system were to be installed. The retrofitted commercial building stock used the simplification of installing a split system heat pump in all buildings. This heat pump was used because it was a commonly installed HVAC system in New Zealand (A Gates 2013) and also because the modelling methodology was consistent to implement across the 48 energy models. In reality, buildings could implement a different efficient air-to-air heat pump system. The most likely change in heat pump system would be seen in large commercial buildings. In large commercial buildings it could make more sense to install a VRF system (Hardy 2009; Daikin Industries Ltd 2014).

A single case study was undertaken using S5-O-4 as it was a large commercial building with a low to average NZE performance of approximately $28 \mathrm{kWh} / \mathrm{m}^{2}$.yr. S5-O-4 also presented a good case for the largest effects on energy consumption due to the building having the highest HVAC to equipment energy consumption ratio out of all of the large commercial buildings assessed in this thesis. This meant changes in HVAC energy use would have the largest effect in S5-O-4's total energy consumption compared to other large buildings modelled in this thesis. This means it is a worst case scenario of what would happen to total building energy consumption if the heat pump system were to change.

Table 11-4 : Impact of installing a split and variable refrigerant volume air-to-air heat pump systems in S5-O-4.

\begin{tabular}{|c|c|c|c|c|}
\hline \multirow[b]{2}{*}{ Heat pump system scenario } & \multicolumn{4}{|c|}{ Energy end-use } \\
\hline & $\begin{array}{l}\text { Total Energy } \\
\text { Demand } \\
\left(\mathrm{kWh} / \mathrm{m}^{2} \cdot \mathrm{yr}\right)\end{array}$ & $\begin{array}{c}\text { Heating } \\
\left(\mathrm{kWh} / \mathrm{m}^{2} \cdot \mathrm{yr}\right)\end{array}$ & $\begin{array}{c}\text { Cooling } \\
\left(\mathrm{kWh} / \mathrm{m}^{2} \cdot \mathrm{yr}\right)\end{array}$ & $\begin{array}{l}\text { Fans/Pumps } \\
\left(\mathrm{kWh} / \mathrm{m}^{2} . \mathrm{yr}\right)\end{array}$ \\
\hline Split System & 27.8 & 0.6 & 0.9 & 0.3 \\
\hline Variable Refrigerant Flow & 30.7 & 0.5 & 1.0 & 3.2 \\
\hline $\begin{array}{l}\text { Percentage change in energy } \\
\text { consumption }\end{array}$ & $10 \%$ & $-21 \%$ & $12 \%$ & $949 \%$ \\
\hline
\end{tabular}

Table 11-4 presents the NZE retrofit energy consumption results for S5-O-4 with both a split system installed and a VRF system installed, as well as the percentage change in energy consumption between the two case building models (Appendix 14.25.2c). 
As shown by Table 11-4, installing a VRF system instead of the Split System increased the building's total energy demand by 10 percent. This increase in energy demand occurred largely from the increased Fans/Pumps energy end-use consumption. The Fans/Pumps energy end-use in the VRF system consumed nine times more energy than the Split System. Smaller changes in energy consumption were seen in the heating and cooling end-uses, but these were insignificant compared to the total energy demand and Fans/Pumps end-use. These results indicate that installing a VRF heat pump system could increase energy consumption in the NZE retrofit commercial building stock. However, if a 10 percent increase in energy consumption was to occur in the large commercial building communities $\left(1500 \mathrm{~m}^{2}\right.$ and larger), NZE would still be achieved due to the surplus of renewable energy, as demonstrated in Figure 11-4.

Figure 11-4 displays the energy balance of the NZE retrofit building stock (48 energy models in seven New Zealand climates) with split system heat pumps installed, and with VRF heat pumps installed (Appendix 14.25.2d). The energy balance shows the energy demand (black foreground bar) and the existing grid renewable supply (green background bar). Note: the onsite PV generation is not presented on the graph. If the onsite PV generation were to be included, the renewable energy generation bar would be at $8,986 \mathrm{GWh}$.

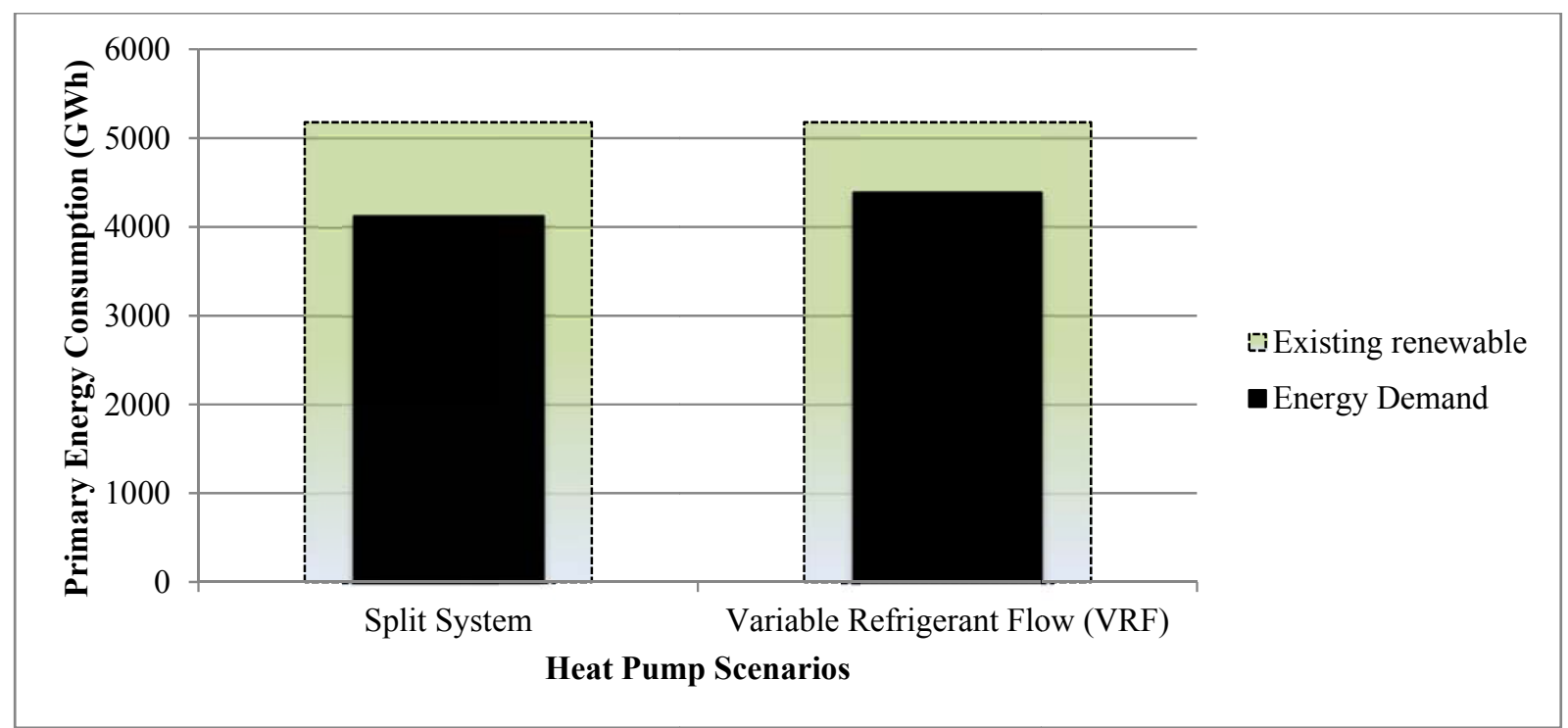

Figure 11-4 : Energy balance for NZE retrofit building stock with split system heat pumps installed, and with VRF heat pumps installed.

As can be seen, in both heat pump scenarios energy demand was below the renewable energy supply, meaning they both reached NZE. If the onsite PV generation were included, the energy demand would be far lower than the renewable energy supply of $8,986 \mathrm{GWh}$. Nevertheless, if no onsite renewables were to be installed, the impact of the VRF heat pump systems could be noteworthy as energy demand could increase by up to six percent across the whole NZE building stock. 


\subsubsection{Conclusions of the practicality testing for the retrofit design}

If any of the tested AAS were to be altered in the fashion described in Section 11.2, the change in energy performance would not prevent the retrofit commercial building stock from achieving NZE. NZE would still be achieved largely due to the surplus renewable energy able to be fed back into the energy grid by onsite renewable generation (onsite renewable ECM implemented was Photovoltaics (PV)). However, altering the AAS could have a considerable effect on the demand-side reduction capability of the NZE retrofit. For example, tightening the heating and cooling set point deadband from $18-25^{\circ} \mathrm{C}$ to $21-22^{\circ} \mathrm{C}$, could increase energy consumption by 20 percent. This highlights the importance of optimised building operation, but also provides a likely worst case scenario if all buildings were badly operated. Additionally, as demonstrated by the installation of a VRF heat pump system, the NZE potential is dependent on the selection of HVAC equipment. However, it needs to be emphasised that even in the worst case scenario NZE would be achieved with the relatively conservative rate of PV onsite renewable energy generation assumed for this study (Section 11.2.4)

\subsection{Temporal energy match and cost feasibility}

The results presented in Chapter 10 indicate that reaching NZE is possible. Determining whether reaching NZE is possible does not mean that it would be a feasible task. A feasibility assessment of reaching NZE was the next logical step in determining whether retrofitting a building stock would be a good option compared to other options which could be undertaken to increase energy security and reduce $\mathrm{CO}_{2}$ emissions. A detailed feasibility study was not undertaken in this thesis as it was outside the research scope, as set in Chapter 4. Nevertheless, there were important feasibility enquiries which were raised to put the results of this thesis into context. Two feasibility issues were explored:

1. The first feasibility issue investigated the temporal energy match of the NZE building stock. The temporal energy match detailed the impact of the exchange between the building and the energy infrastructure. It was identified in the literature on Net ZEB definitions that purely lowering energy demand and offsetting the residual demand with renewable energy generation should not be the sole focus for Net ZEB design. When considering an appropriate Net ZEB definition, some account should be taken of the temporal energy match. "Beside an annual energy or emission balance Net ZEBs are characterized by their different ability to match the load and to work beneficially with respect to the needs of the local grid infrastructure. (Sartori, Napolitano, and Voss 2012, p.227)" A case study was undertaken to indicate the likely matching or mismatching of the NZE retrofitted commercial building stock's load, its onsite generation and its interaction with the energy grid.

2. The second feasibility issue investigated the likely cost implications of retrofitting the current New Zealand commercial building stock to be NZE. Cost feasibility would be important as it is a driving factor for whether a government adopts an energy efficiency 
policy change (Combined Federal Campaign 2013; Business Analysis Team 2005). A cost study was undertaken to determine whether a move to NZE made financial sense compared to options of building a new energy generation plant.

\subsubsection{Net energy is not temporal energy}

As established in Section 4.6, net zero energy should consider the temporal energy match between building load, generation and the grid it is connected to. The benefits of a good temporal energy match mean the building(s) will most likely have more flexibility regarding when they need and do not need energy from the grid (Sartori, Napolitano, and Voss 2012). However, if there was a poor match or interaction of load and generation, the NZE retrofit buildings would still rely on the energy grid to supply the energy they needed. This is due to every building having its maximum generation at the same time and still demanding energy from the grid at the same time. As a result, the grid will require a complete and wasteful over capacity and may not be able to become completely renewable. The temporal energy match assessment was split into two studies:

- Load Matching - "the temporal match of the energy generation on site with the building load (Karsten Voss et al. 2010, p.2)" This analysis determines if the energy generation system supplies energy to the building when it is most needed and not at times when the building is not being used); and

- Grid Interaction - "the temporal match of the energy transferred to a grid with the needs of a grid. (Karsten Voss et al. 2010, p.2)" This analysis determines if the building's demand and onsite generation is beneficial to the grid or whether the building still requires energy from the grid at times when the grid is already under stress from other consumers demanding energy.

\subsection{1a Load Matching}

The Load Matching assessment was intended to establish whether there would be a good or poor match between the retrofitted NZE building's load and its onsite generation. "If load and generation were more correlated, the building would most likely have higher chances for fine tuning self-consumption, storage and export of energy in response to signals from the grid (Sartori, Napolitano, and Voss 2012, p.227)" This indicated that if the NZE retrofit commercial building stock were to have a good load matching, the impact on the existing grid infrastructure would be less. Less impact would mean the existing energy supply could be utilised in areas other than the NZE retrofit commercial building stock.

The assessment was undertaken by comparing the energy demand against the energy generation potential at a monthly interval and also at average winter and summer daily intervals. The comparison highlighted the issue of self-consumption and load matching. A small and a large building were chosen to investigate the impact that building size had on the ability of the onsite generation to offset its energy demand. The buildings chosen enabled a look at onsite generation which did not entirely meet all of the energy needs across all months of the year. The two 
buildings had varying NZE performances as shown in Table 11-5. The small building (case study building S1-O-1) had a predicted annual net energy performance of $-4.7 \mathrm{kWh} / \mathrm{m}^{2} . \mathrm{yr}$, meaning it was predicted to be a positive energy building that fed surplus energy generation back into the grid. The large building (case study building S5-O-4) had a predicted annual net energy performance of $19.1 \mathrm{kWh} / \mathrm{m}^{2}$.yr, meaning it was not a Net ZEB at the site and still required energy supplied from the grid.

Table 11-5 :Annual Net Energy Performance for the two case study buildings.

\begin{tabular}{|l|c|c|}
\hline Case study building & Small Building & Large Building \\
\hline Annual Net Energy Consumption & $-4.7 \mathrm{kWh} / \mathrm{m}^{2} . \mathrm{yr}$ & $19.1 \mathrm{kWh} / \mathrm{m}^{2} . \mathrm{yr}$ \\
\hline
\end{tabular}

Figure 11-5 displays the comparison of the monthly energy demand (black) and generation (green) for the NZE retrofit small (left) and large (right) buildings (Appendix 14.26.1).

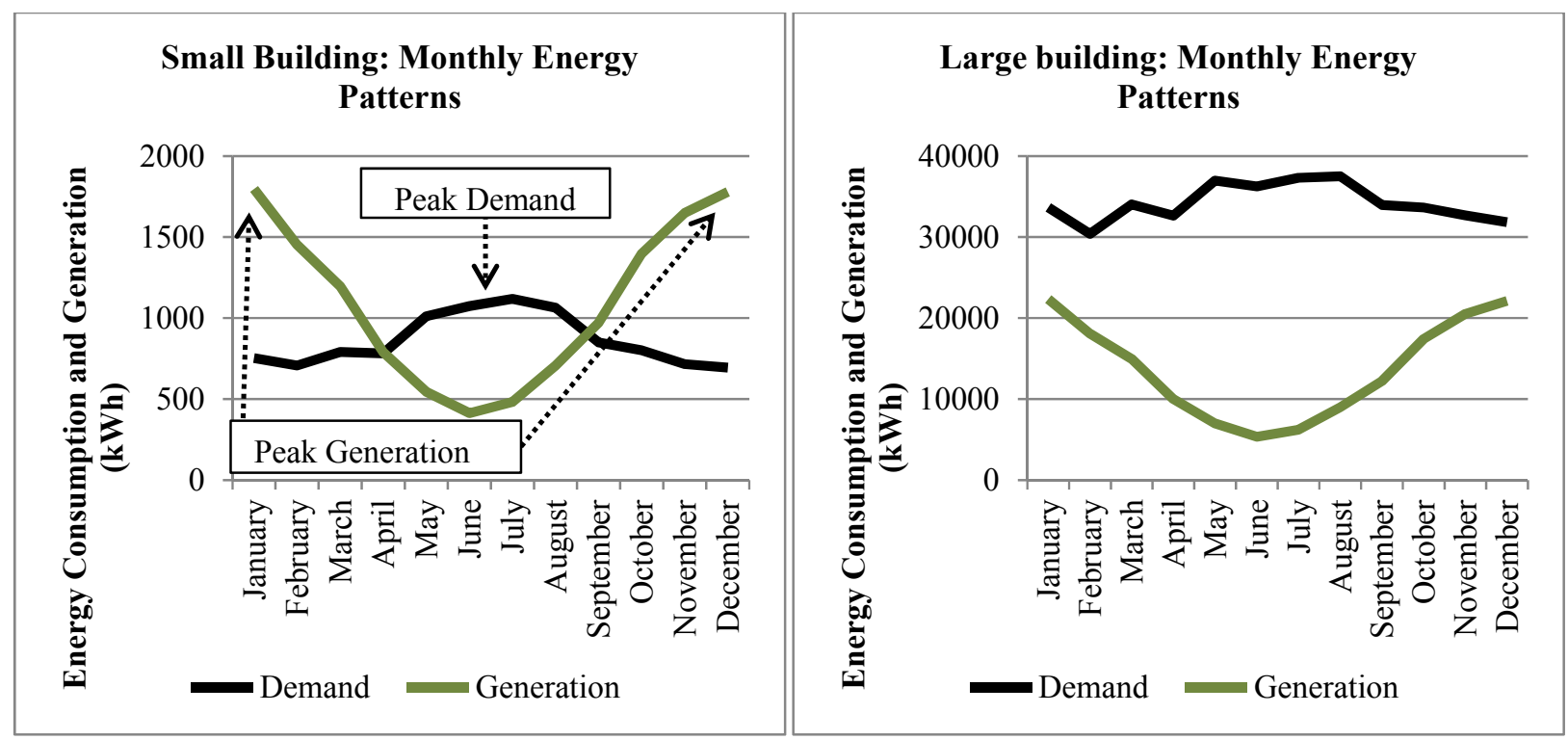

Figure 11-5 : Monthly energy demand and generation for a small and large building.

The comparison identified that at a monthly interval, there would be a poor match between load and generation in the two case buildings. A poor match was concluded by the two buildings' peak energy load occurring during the winter months (May to August), while the peak energy generation occurred during the summer months (November to February). This suggested that the passive nature of the building performed best during warm months, and they had higher heating requirements in winter. The higher summer generation potential was to be expected due to the onsite generation system being photovoltaics (PV) and in summer there would be higher solar radiation levels that could be converted into electricity.

The difference between the two building sizes was apparent. The small building produced excess energy generation during summer months which would be fed back into the grid. On an annual basis, it fed energy back into the grid as it was a positive energy building (see Table 11-5). By comparison, the large building did not have any monthly excess energy and still required energy 
supplied from the grid (refer to Table 11-5). This is an illustration of how a community of buildings could work together to reach NZE collectively. The buildings which did not have any excess energy generation would be compensated by buildings which did.

Figures 11-6 and 11-7 display the comparison of the winter and summer weekday hourly energy demand (black) and generation (green) profiles for the NZE retrofit small and large buildings (Appendix 14.26.2). The winter and summer energy profiles were the best time interval for analysing the temporal energy match as "the temporal match/mismatch occurred on a daily level - e.g. excess solar power generation during daytime with electricity needs from the grid during night - as well as on the seasonal level (in most climates)" (Karsten Voss et al. 2010, p.2).

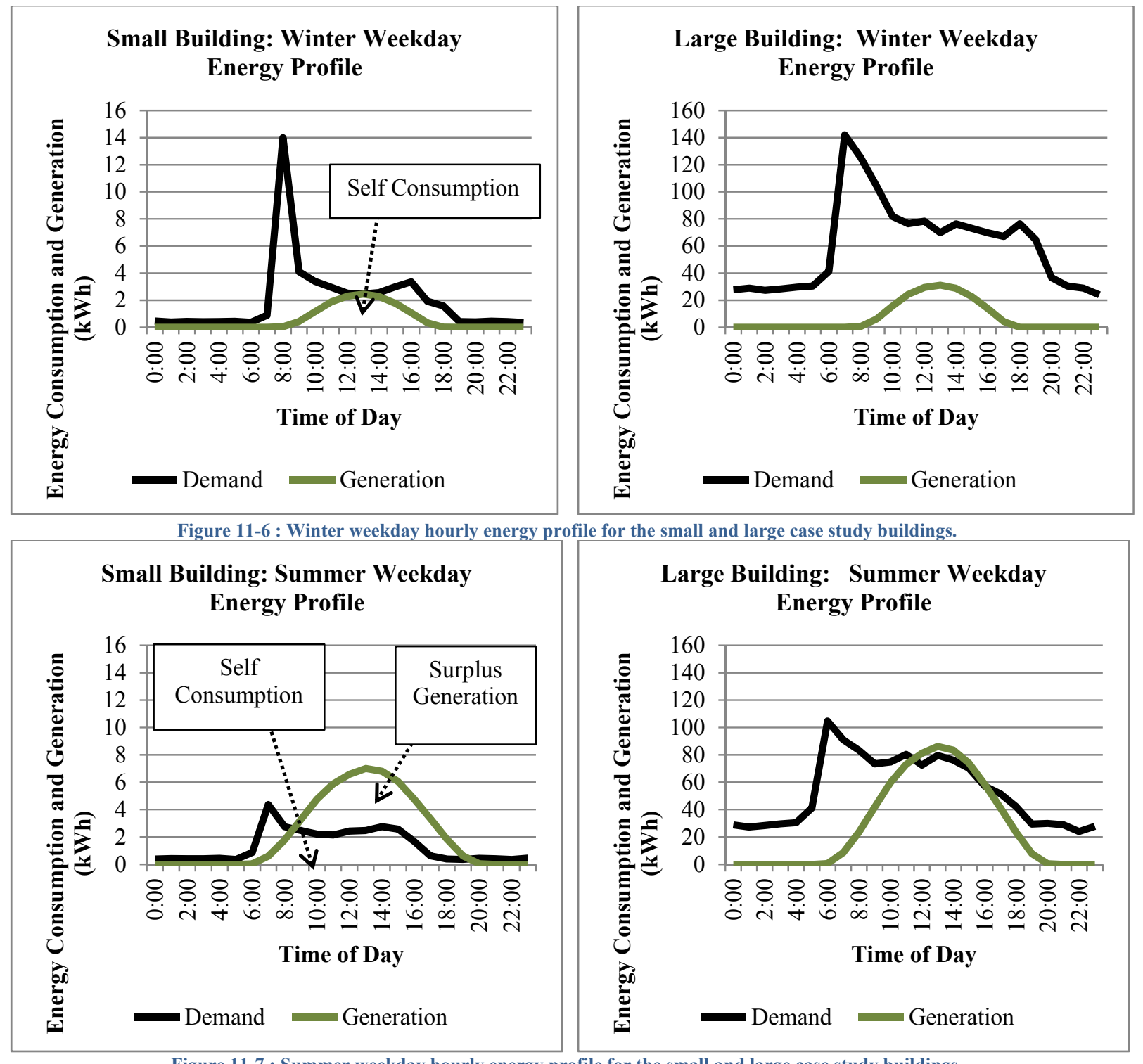

Figure 11-7 : Summer weekday hourly energy profile for the small and large case study buildings. 
As can be seen, the match between load and generation at an hourly interval had both positive and negative aspects. A positive aspect was that the generation generally occurred during the highest load hours of the two buildings; meaning there was a good correlation between the bulk of the load and generation hours. However, looking at the correlation in more detail it was identified that the peak generation occurred during midday (10am-3pm) which was a poor correlation to the peak load hours, which occurred during the early hours of the day (58am). Adding to this poor correlation was the seasonal peak generation which also had a poor correlation to the seasonal peak load (also highlighted in the monthly interval analysis); meaning there was a higher need for onsite generation in the winter, and that generation performed best during the summer months. This reinforced that there would be a mismatch between the peak load and generation of the NZE retrofit buildings. If the mismatch for the two case study buildings were representative, the NZE retrofit building stock could still potentially have a reliance on the existing grid infrastructure and little flexibility for when it needs energy from the grid. The large reliance arises from the building stock still having a large dependence on energy supplied from the grid during the early hours of the morning all year round, and substantially worse reliance during the winter months.

\subsection{1b Grid Interaction}

The grid interaction study further highlights the impact that the mismatch of generation to load would have on the existing energy grid infrastructure. Figures 11-8 and 11-9 display the hourly energy trends of the existing grid (red) (Electricity Authority 2014) and the Current (blue) and Net ZEB (red) retrofit scenarios of the two case study buildings ${ }^{11}$ : small building is presented on left, and large building is presented on the right (Appendix14.26.3).

\footnotetext{
${ }^{11}$ It is important to note that the quantity of energy differs between the grid and buildings. The grid energy trends were represented in GWh and the buildings in $\mathrm{kWh}$. The two units differed due to the case building energy trends only being for the individual building and not the whole building stock. Also, the grid's energy trends were for the whole grid which all energy consumers were attached to. Even with these differences, the comparison aided in identifying the correlation and interaction of the buildings with grid.
}

Page | 296 


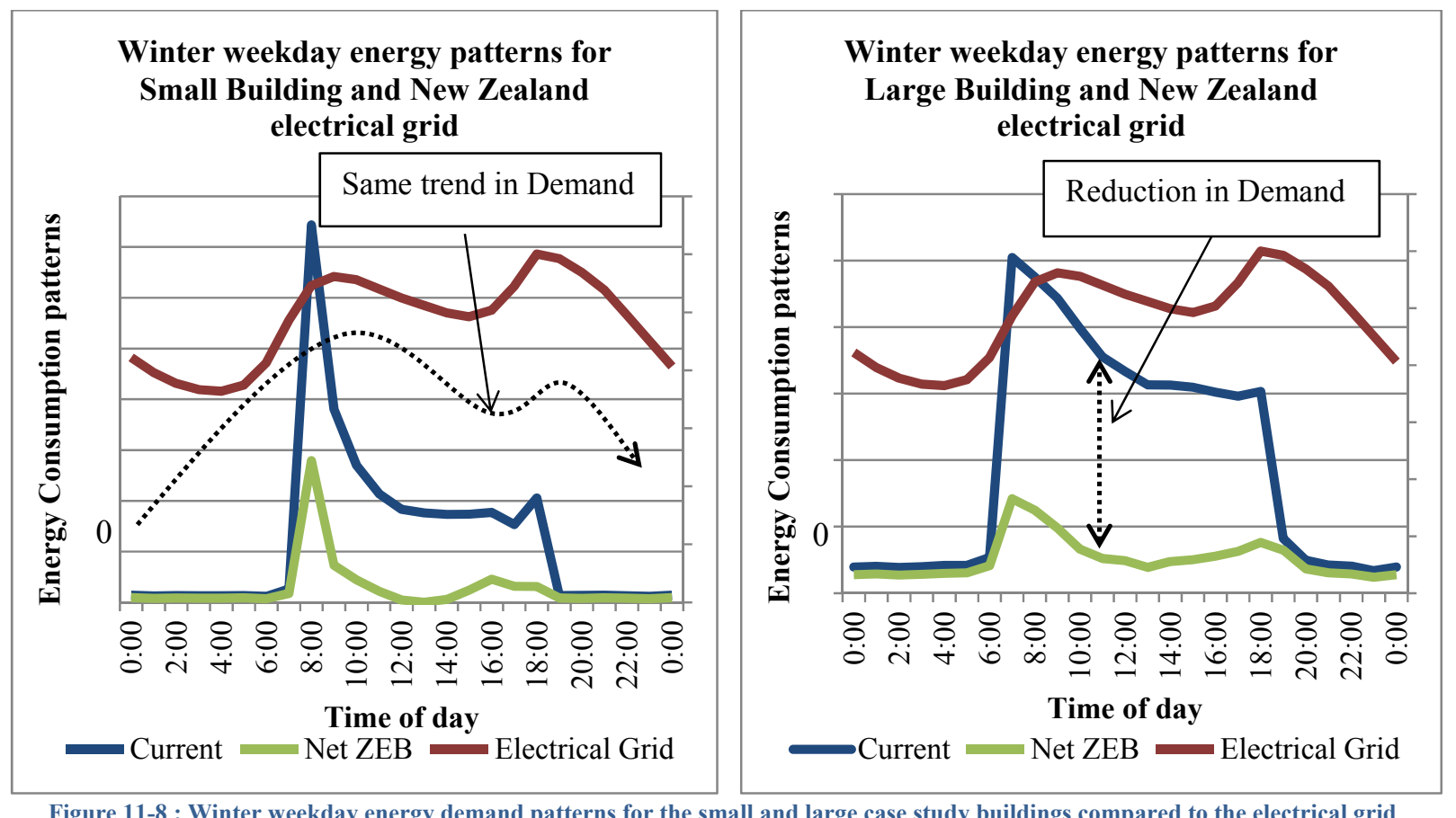

Figure 11-8 : Winter weekday energy demand patterns for the small and large case study buildings compared to the electrical grid demand.

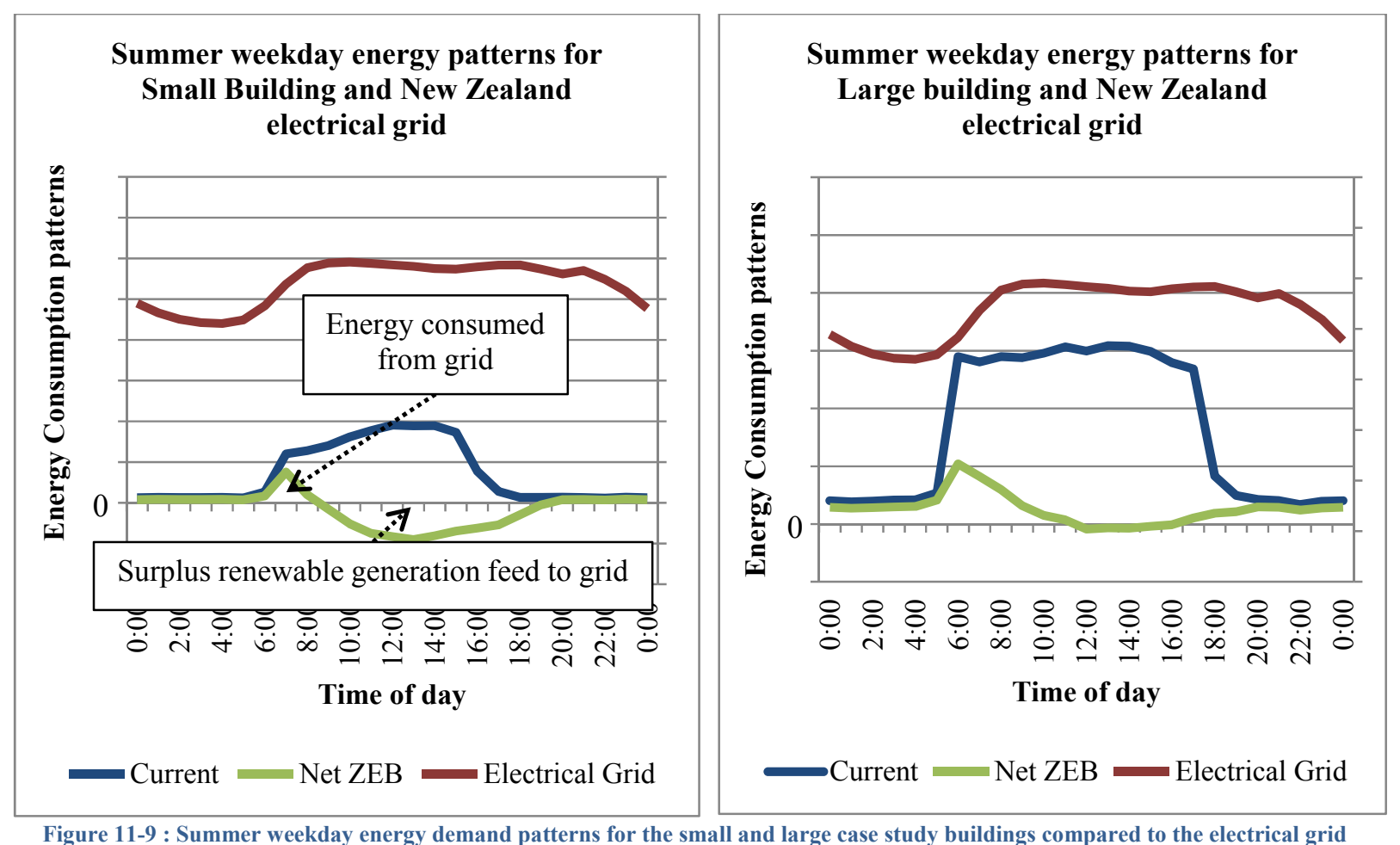

Figure 11-9 : Summer weekday energy demand patterns for the small and large case study buildings compared to the electrical grid demand. 
These energy patterns suggest there could be positive and negative interactions between the Net ZEB building stock and the grid. The positive interaction was seen by the large reduction in energy demand from the grid between the current buildings and the Net ZEB retrofit buildings. This highlights that the NZE retrofit building stock reduces its current impact and reliance on the grid. However, the positive interaction would be furthered by minimising the building's peak load timing to not coincide with the grid's main demand peaks in the morning and night. This coinciding of peak demand is an example of a poor grid interaction. The poor interaction is shown by the Net ZEB retrofit energy demand patterns of the two buildings mimicking the energy demand patterns of the electrical grid in winter (Figure 118). Similar demand patterns are shown by the building and grid's two peaks in energy demand, one in the morning from 5-8am and the other in the afternoon from $3-8 \mathrm{pm}$. This means the building would be relying on energy from the grid at the same time the other energy consumers were relying on the grid. Furthermore, any excess onsite generation is supplied during summer which is not when the peak demand occurred in the grid, with peak demand occurring in the winter. Although a positive interaction was that the exported energy (shown by green line being below the 0 demand line in Figure 11-9) was considered useful to the grid because the surplus renewable generation was fed back into the grid during the grid's summer daytime peak demand.

If these grid interaction results were representative of the whole building stock, it would signify that the NZE retrofit building stock would relieve stress on the grid as it requires less energy than the current building stock. However, it would also be highly likely that the building stock would not be able to respond to signals from the grid as indicated by the peak demand for energy still occurring during the peak demand on the grid from other energy consumers.

This study has looked at the simplest of innovations: individual Net ZEBs using the grid as an 'energy bank' depositing and withdrawing energy on an individual basis as needed locally and looking only to balance energy consumption annually. Hence, this study merely quantifies the risk of doing this without first planning for the grid's needs and the interaction of the building with the grid's needs. A full implementation of the NZE commercial building sector would require this type of analysis. It would be done by refocusing the Net ZEB solution set used to retrofit the building stock. The refocusing could provide better grid interaction and temporal energy match by choosing different ECMs to help shift the peak demand of the retrofitted buildings. An example would be to use batteries to store onsite energy generation that can be used during peak times to further reduce the buildings' reliance on the electrical grid.

\subsubsection{Possibility is not feasibility}

The results of this thesis have established that retrofitting the current commercial building stock to be NZE is possible. However, this does not necessarily mean it would be a feasible task. The temporal energy match results offer an insight into whether the conversion to NZE would be feasible from an existing energy grid infrastructure perspective. To add another feasibility angle to the established results, this section examines the likely cost of undertaking such a retrofit task.

Page | 298 
Cost feasibility of NZE could be considered in parallel with a typical commercial building maintenance upgrade. Typically, commercial buildings require a maintenance upgrade between 15-50 years depending on the type of building construction. The maintenance upgrade would be needed because different building cladding and structural materials have a limited lifespan. New Zealand commercial buildings are required to have a minimum lifespan/durability for structural elements of 50 years and 15 years for external cladding systems (Ministry of Business, Innovation \& Employment 2014). Maintenance upgrades are performed to ensure the continual cost effective life time of a commercial building. Maintenance upgrades would be cost effective as they prevent an older building from requiring demolition and rebuild. As at 2011 approximately 75 percent of commercial building floor area in New Zealand was within buildings aged over 13 years (refer to Section 3.2.1); meaning there would be a large number of commercial buildings requiring a maintenance upgrade in the next 10-20 years. If an investment in NZE were to be performed as a standard retrofit regime at the time of the maintenance upgrades, the cost of such a task would become more feasible.

An example of this can be seen in the Aorangi House maintenance upgrades in 2009. Instead of undertaking a typical upgrade to just maintain building integrity, Aorangi House executed an energy efficient upgrade. The upgrade was required because the building had reached a point in its lifecycle where the building envelope and systems needed maintenance and required a significant investment to keep the building in a rentable condition. At this stage, a full retrofit was required and replacement of the building envelope, windows, and building systems (HVAC, lighting etc.) became cost effective. An energy efficient upgrade was deemed by the owners to be cost feasible as there was a desirable payback for investing in energy efficient upgrades instead of upgrading to an inefficient energy design (Marriage and Waldhauser 2010). Aorangi House installed many of the same ECMs as the adopted Net ZEB solution set included within this thesis (Marriage and Waldhauser 2010). Similar to Aorangi House, this thesis proposed an energy efficient NZE upgrade instead of the retrofit to current building energy efficiency standards. This type of upgrade was proposed because if a total retrofit to NZE was to be undertaken while a building is rentable condition, it would be highly likely it would be unfeasible. This is due to the costs required to completely retrofit the building envelope and its systems when they could potentially still be in a rentable condition. However, eventually the envelope and building systems would require an upgrade and that would be the time to propose a NZE retrofit upgrade.

Figure 11-10 presents a comparison between the cost of conserving energy through retrofitting to NZE (dark green) and the cost of generating new energy from different non-renewable (grey) and renewable (light green) fuel types. NZE energy retrofit was split into two scenarios. The first was retrofitting with demand-side ECMs only (passive and efficiency). The second was retrofitting with both demand-side and supply-side ECMs (passive, efficiency, and renewable). Refer to Section 10.2 for further explanation of scenarios. Appendix 14.27 presents the calculations and assumptions performed to create Figure 11-10. 


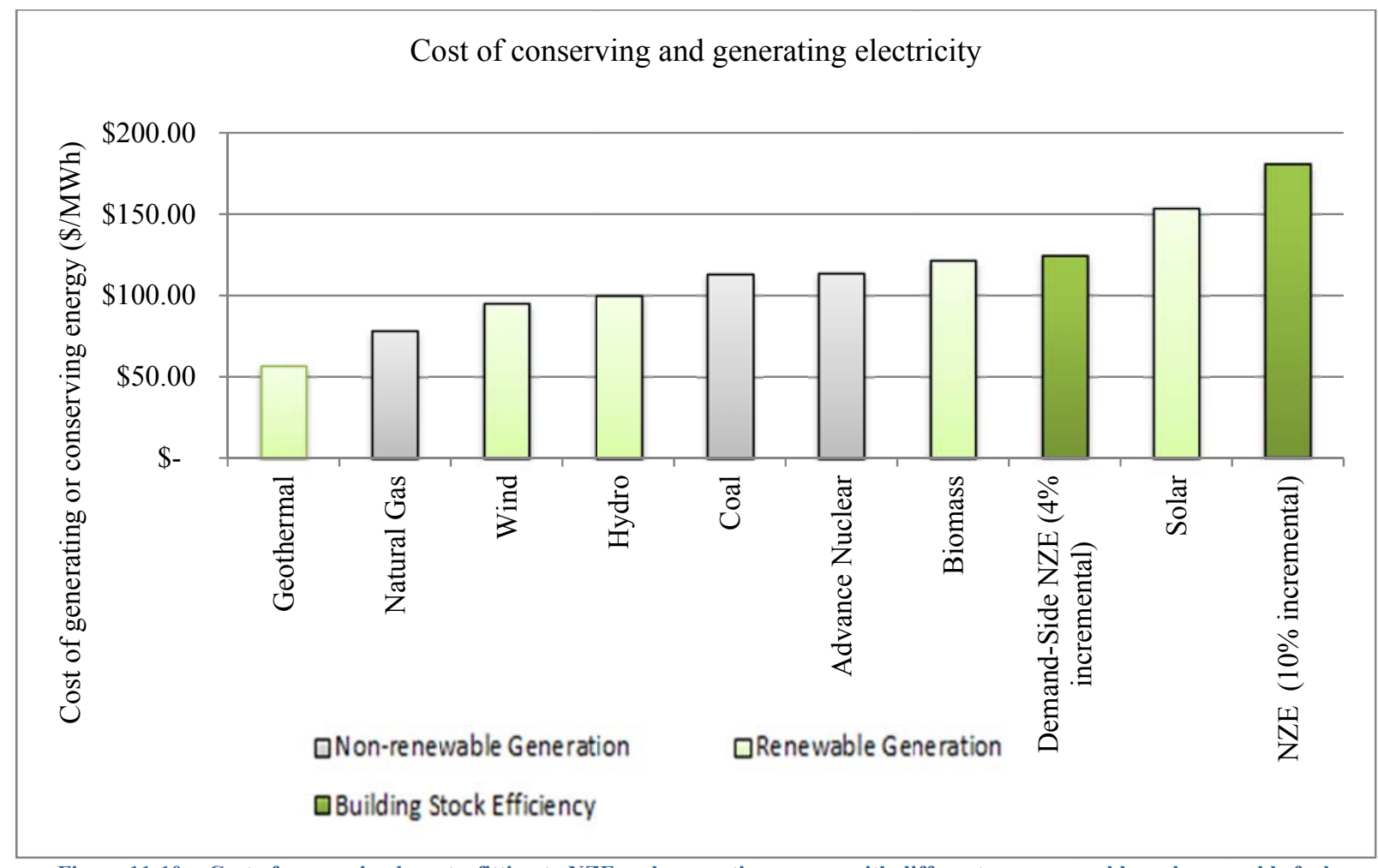

Figure 11-10 : Cost of conserving by retrofitting to NZE and generating energy with different non-renewable and renewable fuel sources. New generation plant cost information adapted from (U.S. Energy Information Administration 2014b).

As shown in Figure 11-10, the cost of conserving energy through NZE retrofit (based on an incremental cost of 10 percent (NBI Institute 2012), see Section 5.3.3d) would likely be more expensive than generating new energy from new grid tied generation plants. This was indicated by the lower cost of generating electricity (maximum cost of 120-150\$/MWh) compared to conserving energy (Minimum cost of 120-180\$/MWh). Non-renewable (Natural Gas, Coal and Nuclear) and renewable electricity (Geothermal, Wind, Hydro and Biomass) were considered less costly to invest in. However, reaching NZE without Onsite PV generation (based on an incremental cost of 4 percent (Hunt 2008), see Section 5.3.3d) is as cost effective as constructing a new Biomass generation plant, and more cost effective than building a Solar generation plant. The cost analysis highlighted that NZE was possible but may not be cost effective. However, the analysis does not include the benefits to the occupants through the retrofitted buildings providing better thermal comfort or an increase in productivity. For these reasons, further feasibility studies should focus on the cost as well as the benefits of each proposal.

\subsubsection{Feasibility conclusions}

The temporal energy match assessment identified that the load matching and grid interaction were poor. The seasonal mismatch between onsite generation and load lowered the ability of the NZE retrofit buildings to self-consume. This indicated that there would still be a reliance on the existing energy grid during peak demand times. The results suggested that achieving NZE should Page $\mid 300$ 
not be the sole focus. Further work should be undertaken to assess and adapt the NZE retrofit design to be more flexible in response to the grid's needs. A good interaction between the building stock and the grid could be achieved with the use of smart grids and informed planning. Informed planning is proposed in Lovins et al. (2011) - "Reinventing Fire: Bold Business Solutions For The New Energy Era", where managing the grid interaction was referred to as 'Conducting the symphony'. "The combination of diversifying variable renewables by type and location, forecasting their variation, and integrating them with dispatchable renewables, flexible fuelled generators, and demand response can together make a very powerful toolkit and create a power system that has the potential to meet our needs reliably" (Lovins et al. 2011, p.198). Figure 11-11 illustrates what 'conducting the symphony' might look like in reality.

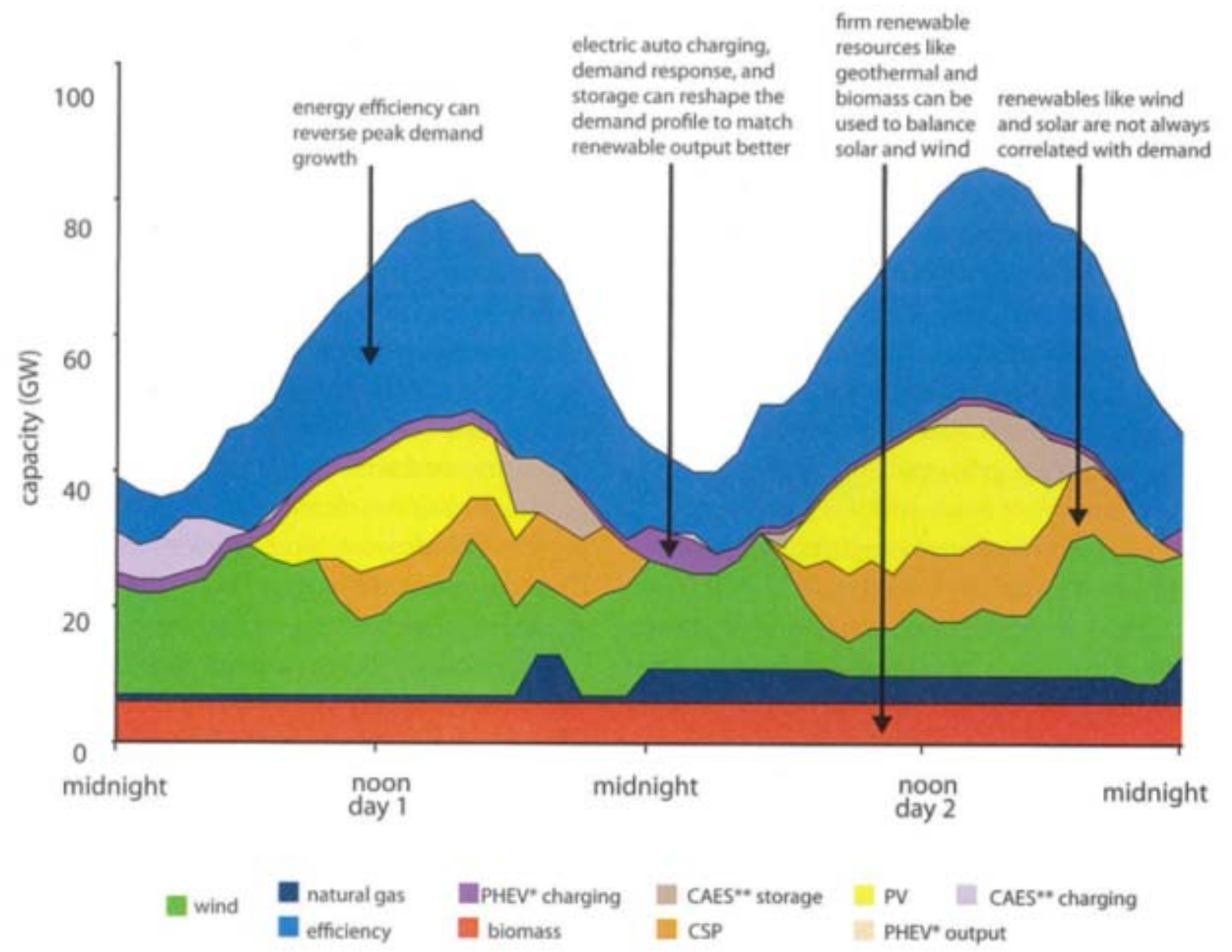

\footnotetext{
- Plug-in hybrid electric vehicle

* Compressed air energy storage
}

Figure 11-11 : Illustration of Conducting the Symphony (Lovins et al. 2011, p198). Figure is based on actual renewables data and projected 2050 loadshapes for the US.

Lovins et al. (2011) established that the first action to be undertaken in the US would be to use energy efficiency to reduce the total load that must be met (blue shaded area in Figure 11-11). The NZE retrofitted building stock would be one option to aid in achieving the reduction in total 
load. The load reduction achieved by a NZE building stock would be further enhanced if load matching and grid interaction were considered as a fundamental design goal of NZE. This illustrates how the grid interaction of a NZE building stock could aid in 'conducting the symphony' to achieve a reliable and energy secure energy infrastructure. This grid interaction aspect of building design is proposed to be studied in depth as a future IEA research Task/Annex called 'Energy Flexible \& Smart Grid/Energy Ready Buildings'. The aim of the Annex is to increase the knowledge, identify critical aspects and possible solutions concerning the flexibility that buildings can provide and the means to control this flexibility. This knowledge is important in order to be able to incorporate the flexibility of buildings in the future Smart Energy systems and thereby facilitate energy systems based entirely on renewable energy sources (Jensen and Marszal 2014).

Further feasibility assessments into the controlled conversion/retrofit of the commercial building stock could establish a method of reaching NZE over the next 20-30 years. As identified by the cost feasibility assessment, most commercial buildings will need a retrofit at some stage during their lifecycle. At this point the NZE options became more feasible as they established the incremental cost of going to zero energy instead of the full retrofit itself. Further cost analysis should identify the best economical way to retrofit to NZE. "Traditionally, governments have tried a combination of two approaches: forcing building owners to be more energy efficient through stricter building codes, while encouraging them to adopt conservation measures through mechanisms like tax breaks and grants. (Peterman 2013)" The analysis should be mindful that these approaches have been only mildly successful. Fulton et al. (2012) identified that in America there is still an estimated capital investment of \$279 Billion needed to upgrade and replace inefficient energy-consuming equipment. The payback would be a trillion-dollar reduction in energy costs over a decade, which is approximately one third of the annual energy expenditure in America, as well as the creation of more than 3.3 million cumulative job years (Fulton et al. 2012; Peterman 2013).

\subsection{Chapter summary}

Chapter 11 identified that achieving NZE should not be the sole focus. This chapter identified that a NZE retrofit commercial building stock which implements the existing set of design changes proposed in this study does reduce the building stock's impact and reliance on the national energy infrastructure. But it could still put stress on the energy infrastructure. This was due to the NZE building stock potentially not having an ideal load match or grid interaction. This was identified by the NZE building stock's peak demand times still occurring during the national electrical grid's peak demand times. This means that the NZE retrofit proposed in this thesis may not be flexible to the electrical grid's needs. Additionally, the monetary cost of moving to NZE could be expensive and may not be more economically viable than building new renewable energy generation systems. However, this does not include associated health and productivity benefits.

Page | 302 
Figure 11-12 displays the link from Chapter 11 to Chapter 12.

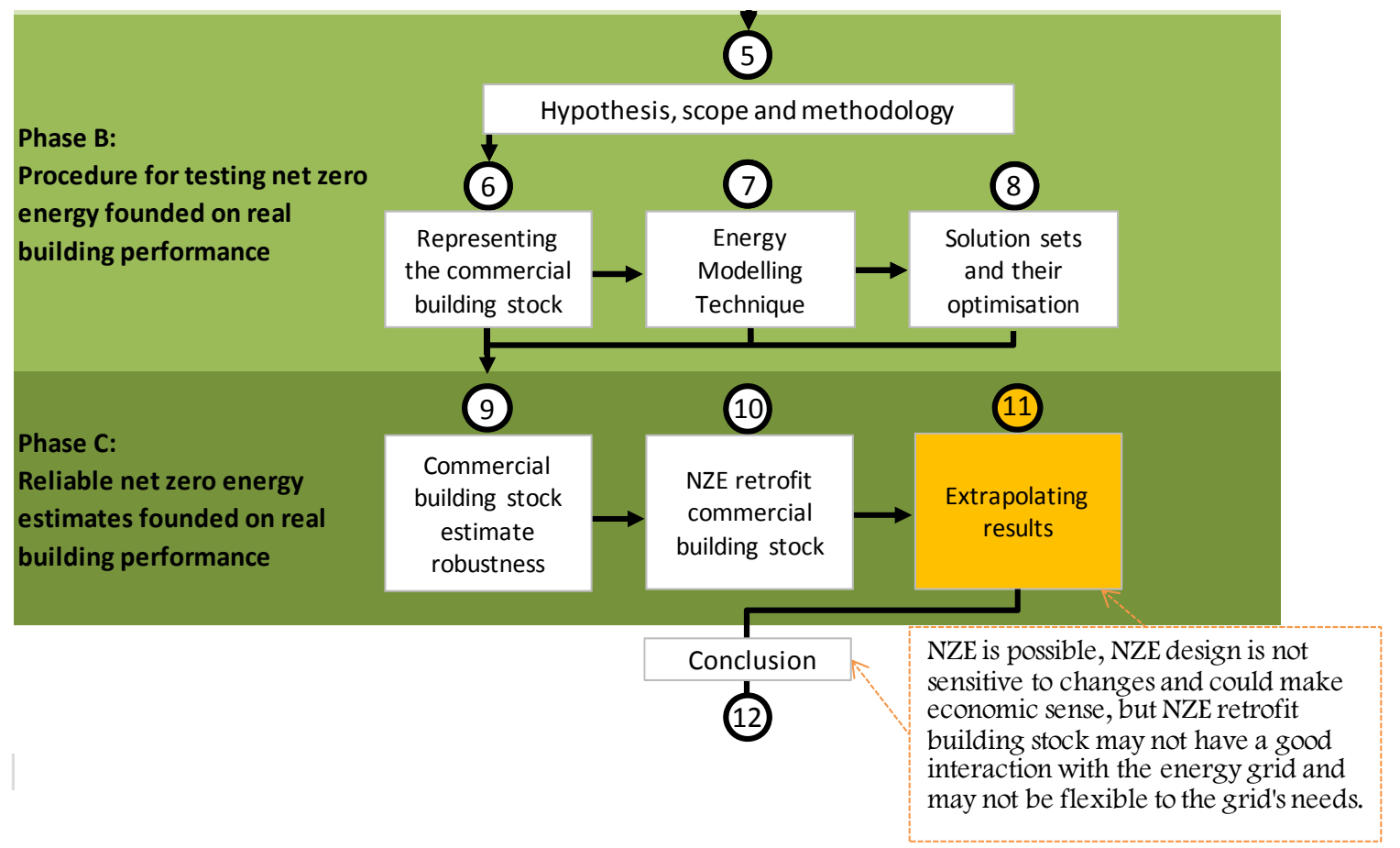

Figure 11-12 : Link of Chapter 11 to Chapter 12.

Further work into the feasibility of nationwide NZE retrofit should be undertaken as proposed in Chapter 12. Chapter 12 also relates the results established in this thesis to the research objectives, aims and hypothesis. 



\section{CHAPTER 12. CONCLUSIONS}

\subsection{Net Zero Energy in New Zealand}

In Chapter 4 of this thesis, a structured NZE definition for the existing building infrastructure in New Zealand was developed (and meets the secondary objective outlined in Section 1.3.3). The definition provided a prescriptive definition as drawn from Sartori, Napolitano, and Voss (2012) and a quantified balance between energy consumed and renewable energy generated. The definition provided boundaries to what, where and how NZE was measured in New Zealand's commercial building stock. The definition encompassed all existing buildings as a nationwide community, and considered all building and user related energy consumption in the balance. At a minimum, buildings were required to provide a similar level of service (through heating, cooling, lighting, hot water) and functionality (office and retail equipment) as they currently did for the same number of occupants. At the same time they were required to provide a minimum level of comfort, which was found to be better than the level of comfort in 50 percent of the current commercial buildings modelled in this thesis.

The balance between energy consumption and renewable energy generation aimed to exclude and offset the current annual $\mathrm{CO}_{2}$ emitting primary energy consumption. The balance put the focus on energy efficiency as the first priority by trying to solely utilise the current community renewable energy supply. This meant the NZE goal was for buildings to reduce energy consumption to a point where the proportion of current renewable energy supply was all that was needed to supply the building stock. This was important as New Zealand already has a high proportion of renewable energy supply. If the energy reduction could not solely achieve the NZE goal, the second focus was then to add additional renewable energy generation, if required.

The energy balance analysis enabled the quantification of a target which measured when NZE was achieved. The primary energy consumption reduction target was calculated to be 45 percent. This target reduction in current energy consumption could be used for a target in a wide range of New Zealand commercial sector activities including office, retail, mixed, and any other building activities associated with the commercial sector. It could also be used at different scales including individual, local, regional, and national.

This kind of NZE definition and calculation approach used to establish the commercial sector target could also be used for the other energy consuming sectors in New Zealand, such as residential, schools, health and industrial. The result would be a different primary energy reduction target for each sector with the aim of reducing and offsetting their primary $\mathrm{CO}_{2}$ emitting non-renewable energy consumption.

This definition does not account for the temporal energy match between renewable onsite generation, building energy demand, and the electricity grid. The consequence is that the resulting NZE commercial building stock may still have a negative impact on the current energy

Page | 304 
infrastructure in New Zealand. The definition could be updated to require community focused supply options such as wind farms or district heating grids that reduce the impact of the buildings on the grid. This is important as the onsite PV community generation, proposed in this thesis, was shown to provide enough energy to offset any potential non-renewable energy consumption. However, other renewable supply options could provide better load matching opportunities and an improved interaction with the current grid infrastructure.

\subsection{Proving the Hypothesis Part 1: Method founded on real building performance}

In Chapter 9 of this thesis, the primary objective of creating a national picture based on real building performance was met (outlined in Section 1.3.2), and the first half of the research hypothesis was proved:

\section{It $\underline{I S}$ possible to use a method founded on real building performance to base the retrofit to NZE on reality.}

The proof of this was the current commercial building stock energy consumption estimate that was compared to an independent BEES estimate to quality assure its reliability. The reliability assessment identified that the estimate calculated using a sample of calibrated energy models that match real buildings was within a quality assured confidence interval.

This thesis developed a method that combined a sample of calibrated energy models with a stock aggregation technique to represent reality. The calibrated energy models were the key to founding the test on real building performance. This was due to the calibrated energy models matching and representing real buildings and their energy performance. The current commercial building stock was represented by aggregating the energy consumption results of calibrated energy models that matched the building performance of a sample of real buildings. The resulting stock aggregated energy estimate provided a base scenario that was: 1) founded on real building performance; and 2) proven to be a robust and reliable calculation of the energy performance of the current commercial building stock ${ }^{12}$.

Using this method of founding the study on real building performance reduces the number of assumptions in the energy modelling technique. This meant the results of the study were not subjected to as many variances or inaccuracies compared to reality. The estimate was therefore NOT calculated using a hypothetical theoretical scenario that required weighting factors to deal with the range of differences across the stock. Instead, the model represented the range of real constraints that buildings are built with in reality. For example, hypothetical estimates have been produced using prototypical buildings modelled in open spaces with no surrounding buildings.

\footnotetext{
${ }^{12}$ Note: Estimate is not meant to represent the whole commercial sector. Instead it represents the commercial building stock defined in Section 5.2.5. Therefore, this study's definition of commercial building stock accounts for $31 \%$ of the commercial sector's energy consumption.
}

Page $\mid 305$ 
By comparison, the real estimates of this thesis used real buildings that represented real urban environments with varying street widths and surrounding buildings. The method performed in this thesis does not have gaps in building attributes as it contains various heights, constructions and energy performances found in the real building stock. This means the energy consumption is intended to be for all 100 percent of buildings in that stock of buildings, not 62 percent of buildings which was concluded in previous studies performed for the USA.

The real building energy models were retrofitted to form a NZE scenario. The results from the NZE scenario were grounded in reality as the retrofit had to deal with the range of real building constraints such as the urban environment street widths and surrounding shading. This therefore proved it $\underline{\mathbf{I S}}$ possible to base the retrofit to NZE on reality.

\subsection{Proving the Hypothesis Part 2: Net Zero Energy is feasible}

The NZE retrofit commercial building stock energy consumption estimate, outlined in Chapter 10 of this thesis, met the primary objective of retrofitting the New Zealand commercial building stock to be NZE (outlined in Section 1.3.1)) and proved the second half of the research hypothesis:

\section{It $\underline{I S}$ feasible to convert/retrofit the current electrical grid tied New Zealand commercial building stock to consume net zero $\mathrm{CO}_{2}$ emitting primary energy on an annual basis.}

A key outcome of this thesis demonstrated how a country could use a set of already proven ECMs to retrofit a building stock to be net zero energy. The set of ECMs further grounded the research on real buildings by adopting energy lowering passive design, energy efficient, and renewable energy technologies implemented in real Net ZEBs worldwide, and met the secondary objective outlined in Section 1.3.4. Net zero energy was shown to be achievable without the use of additional renewable energy supply. A large surplus of energy can be achieved with additional onsite renewable energy generation technologies included in the retrofit.

The NZE retrofit commercial building stock reduced non-renewable fossil fuel energy consumption, which would lead to an improved energy security and lower climate change inducing $\mathrm{CO}_{2}$ emissions. The reduction of the commercial building stock energy consumption can free up to approximately seven to nine percent of $\boldsymbol{A} \boldsymbol{L} \boldsymbol{L}$ the New Zealand electricity and gas supply. This new surplus energy can either be used elsewhere in New Zealand to power other energy consumers or not used in order to reduce climate change related Greenhouse Gas (GHG) emissions. Similar benefits can be seen in the commercial sector where NZE can reduce 33 to 46 percent of all that sector's electricity and gas consumption.

This NZE retrofit methodology could be replicated internationally. Non-renewable energy consumption and the associated GHG emissions could potentially be dramatically reduced using the methodology and results of this thesis. Existing buildings currently account for 
approximately 40 percent of all global GHG emissions (IPCC 2007a). If all the world's existing buildings were retrofitted as part of a nationwide scheme similar to that proposed in this thesis, this 40 percent portion of emissions could be removed thereby reducing their energy related impact on climate change.

\subsection{Retrofit design results}

As well as proving the hypothesis, this thesis produced some significant results which provided further specific New Zealand commercial building retrofit design and policy guidance.

\subsubsection{Upgrading the building envelope design is a small saver at a whole building stock scale}

In testing the NZE retrofit it was identified that most optimised passive design options only saved a small amount of energy when compared to other strategies at a whole building stock scale. The combination of additional insulation, passive heating, daylighting, and solar shading made up five percent of the total energy reduction. To put this into a real world example, this means that changing buildings with 100 percent glazed facades to have less glazing does not have a large impact when looking at the whole building stock scale. At an individual building scale it may be worth considering, but not at the scale of a whole building stock.

Natural ventilation/cooling contributed more than any other passive design technique tested in this study combined. Without the installation of natural ventilation almost ten percent of all energy savings were lost. This suggests that current New Zealand building standards and policy could focus on increasing the inclusion of natural ventilation in commercial buildings.

This did differ for smaller buildings. Natural Ventilation, Upgrading Envelope, and Daylighting and Maximising Passive Solar Heat Gains were in the top six most effective ECMs in buildings sized $5-649 \mathrm{~m}^{2}$. It highlighted that passive design options were important for smaller commercial buildings.

\subsubsection{Target large buildings for quick energy savings}

A fast way to achieve a 50 percent reduction in commercial building stock energy consumption would be to target the 1,200 buildings over $3,500 \mathrm{~m}^{2}$. These 1,200 large buildings account for four percent of all commercial buildings, but 40 percent of all commercial building floor area. The other 50 percent of energy reductions would be achieved by retrofitting the 26,000 buildings smaller than $3,500 \mathrm{~m}^{2}$ (which account for 60 percent of all commercial building floor area). Therefore, the fewer large buildings could be targeted in a retrofit scheme with the aim of reducing over half the current commercial building stock's energy consumption.

\subsubsection{Energy efficient systems inside all commercial buildings are important}

It was identified that upgrading inefficient building equipment and systems was important in reaching NZE. Over half of all energy reductions were achieved by replacing internal equipment 
with Greenstar rated appliances and laptops, replacing inefficient lighting with LEDs, installing daylight induced electric lighting controls, and installing a more efficient HVAC system. This indicates that the current New Zealand building standards and policy could increase the uptake of energy efficient technologies within commercial buildings.

A more efficient HVAC system was ranked the second most effective ECM for reducing energy consumption in office buildings and eighth effective in retail. This suggests that upgrading HVAC systems is important if just office buildings were being targeted.

\subsubsection{Net ZEB Solution Set could better consider temporal energy match feasibility}

While analysing the feasibility of NZE, it was identified that the proposed set of ECMs could better focus on the temporal energy match. To maximise the potential benefits of retrofitting to NZE, the temporal energy match could be considered. A retrofitted building stock does reduce its impact and reliance on the grid by reducing its current demand for energy. But it could further reduce its reliance on the energy grid by refocusing the analysis of the Net ZEB solution sets to increase the temporal energy match. It is likely that different renewable energy generation technologies, storage and demand-side management techniques would need to be implemented as indicated by Lovins et al. (2011).

\subsection{Further research recommendations}

Some avenues for further research were direct outcomes of the analyses included in this thesis. Five aspects of the research conducted in this thesis could be expanded to add clarity to the methodology and issue of feasibility.

\subsubsection{Comparing prototypical stock aggregation to calibrated stock aggregation}

The method developed in this thesis demonstrated that real building performance can be used to represent the current commercial building stock in New Zealand. This meant that the quantity and patterns of energy use across a sample of real buildings were aggregated to represent the whole building stock. This developed method differed from previously used methods as the energy performance estimates were not hypothetical representations of an average building, nor were they an assumption input by a modeller. As the method has been demonstrated to work, it could now be compared to previously applied methods using prototypical models, such as those used in Griffith et al. (2008); and Deru et al. (2007) to establish which method better represents a current building stock.

\subsubsection{Daylight and Glare Analysis}

It was highlighted in Section 10.2.3 that there could be high illuminance levels in the NZE retrofitted building stock. High illuminance levels can cause discomfort glare. However, this thesis did not perform an in-depth daylight analysis for the retrofitted building stock and it did not use a validated daylight simulation tool. It is suggested that further analysis of the daylight environment and its impact on occupant comfort be undertaken.

Page $\mid 308$ 


\subsubsection{Grid interaction analysis with focus on generation variability}

The grid interaction assessment performed in this in Section 11.3.1 had limitations. This was because it did not cover the whole building stock using the stock aggregation method and instead used two individual case study buildings. This meant it did not identify the exact reliance of the whole building stock on the energy grid and its non-renewable sources. It also did not take the location of electricity generation plants and main energy consumers into consideration. The following paragraphs provide an example of the importance for analysing the New Zealand energy generation capacity and its variability.

Figure 12-1 shows the 2011 estimated total electrical generation capacity by generation source for the North Island, South Island, and whole of New Zealand.

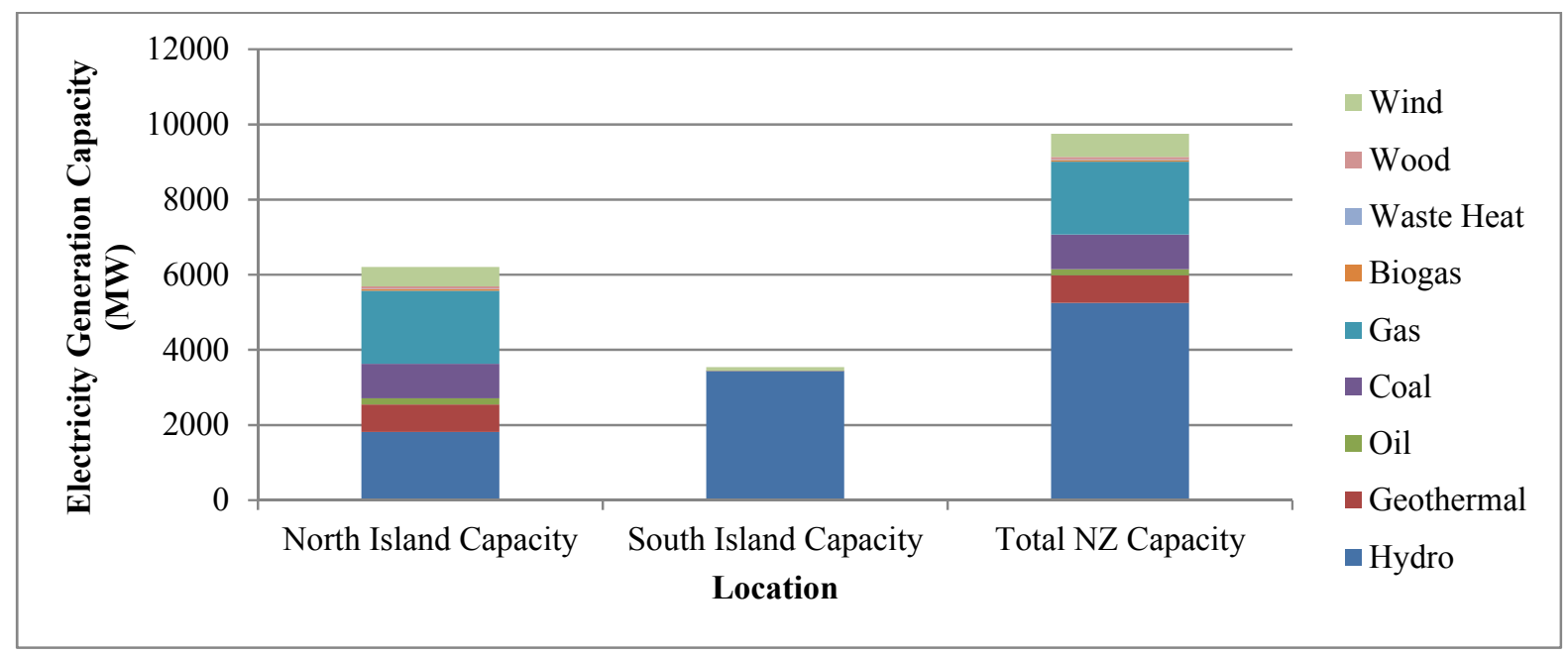

Figure 12-1 : Electrical generation capacity by generation source for 2011 by location. Figure created using (Energy Information and Modelling Group 2012b).

New Zealand had a total electrical capacity of 9,751 Megawatts (MW). Hydro made up 54 percent $(5,252 \mathrm{MW})$ of the total New Zealand capacity available, followed by gas with 1,942 MW of capacity. Sixty nine percent $(6,705$ MW) of all available capacity was provided by renewable sources (Hydro, Geothermal, Wind, Wood and Biogas). The majority of hydro generation was located in the South Island as seen in Figure 12-1 (3,434 MW, 65 percent) and was crucial as it supplied electricity to both the South Island and the North Island through the Inter-island transmission line. However, the electricity generation of the North Island was made up of 47 percent $(3,171 \mathrm{MW})$ renewable sources, with the inclusion of geothermal, wind, wood and biogas. In 2011, "nearly 3,000 MW of installed capacity comes from fossil fuel thermal plants, which provided 23 percent of New Zealand's total electricity supply" (Energy Information and Modelling Group 2012b, p.113). Almost 100 percent (99.7 percent or 3037 MW) of non-renewable generation capacity is located in the North Island. This was due to the majority of electricity consumers being located in the North Island which required a larger peak supply demand.

Page | 309 
Further analysis into the grid interaction should take these aspects of the current New Zealand renewable infrastructure into consideration. Given the large proportion of renewable electricity capacity is located in the South Island (a long distance (approximately 1,500km) away from the main energy consumers in the North Island), future analysis would benefit from a regional breakdown of the capacity and demand. Furthermore, the analysis should study the impact of variations in different weather years. A large concern, from an electricity capacity perspective, is the variability in supply. Hydro accounts for over half of all electricity capacity.

Figure 12-2 illustrates the variation in the potential amount of total hydro electricity supply; calculated from how much inflow of water occurred across three different years.

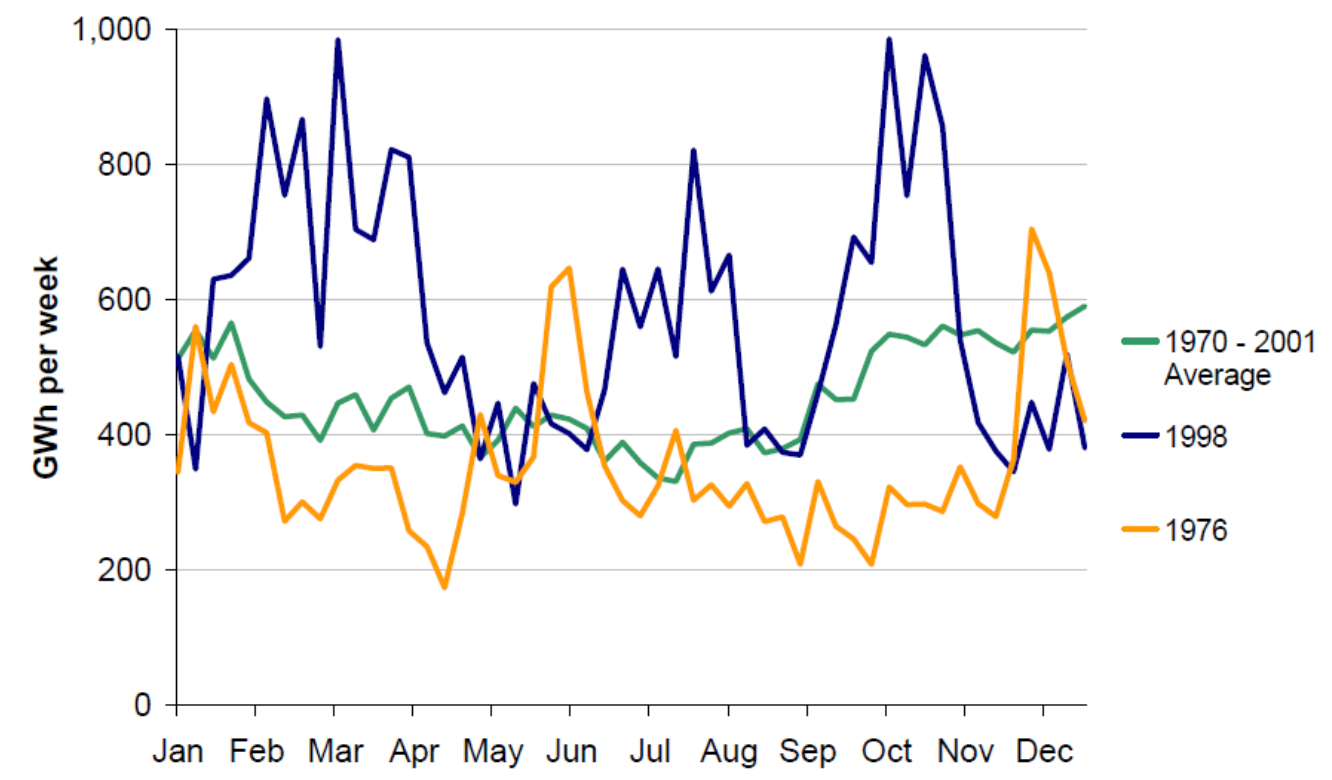

Figure 12-2 : Variation of the Hydro water inflow that occurred in three different years (Concept Consulting Group 2003).

It illustrates how much total hydro supply variance there was between each month in each of the time periods. Hydro electric supply is dependent on rainfall and snow melt and consequently, total hydro-electricity supply varies significantly between years and even over shorter timeframes. Full hydro storage reservoirs in New Zealand can supply approximately 10 percent of the annual national electricity demand. This equates to approximately 5 weeks of electricity consumed in New Zealand. In addition, over 40 percent of New Zealand's hydro inflows are uncontrollable flows and do not pass through the major hydro storage lakes. Both of these factors limit the ability to smooth out inflow variability and to manage storage to match supply to electricity demand compared to the annual variability of potential electricity supply (Concept Consulting Group 2003). 


\subsubsection{Cost benefit analysis}

The incremental cost study undertaken in Section 11.3.2 indicated that it may be more economical to build a new renewable generation plant instead of converting commercial buildings to NZE. However, a full cost benefit analysis was not undertaken, meaning the benefits of converting to NZE were not counted. Benefits of better buildings can include decreased health costs to the nation, and increased productivity of employees as well as many other benefits (refer to Section 1.4.4). These benefits may outweigh the additional costs of retrofitting to NZE compared to building new generation plants. Further analysis into the costs and benefits should be undertaken to assess the real world implications of reaching NZE in the commercial building stock.

\subsubsection{Future of New Zealand Building Standards}

The results established in this thesis could be further used to reshape and update the New Zealand building code requirements for energy efficiency. This is important because New Zealand is behind on provisions for energy efficiency when compared internationally. Building codes for energy efficiency differ between countries with some countries mandating different building types and more building components. It is important to understand how stringent the New Zealand Building Code (NZBC) energy efficiency requirements are comparative to other energy efficiency building codes. This is due to Net ZEBs becoming more prevalent and awareness around the concept becoming the new normal or standard increasing (Hayden 2014; Glazer 2014). The energy efficiency building standards for two international regions were compared to New Zealand's energy efficiency building standards. The comparison highlighted how stringent the NZBC was on mandating energy efficiency in buildings. The two international building codes and associated regions were the EPBD (not strictly a building code, but a recommendation for member states to create their own standards) in Europe and ASHRAE Standard 90.1 in the USA.

As mentioned in Chapter 1, the EPBD set standards for energy efficiency in buildings in Europe. Each EU member state sets the level of energy efficiency requirements for its country. But all EU member states must take into account various compliance items and building components. The EPBD required these elements to be set for both new and existing residential and nonresidential buildings. Each EU member state must revise and upgrade its level of energy efficiency requirements every five years (European Commission 2008).

ASHRAE Standard 90.1 is an ASHRAE standard for energy efficiency for Non-residential Buildings that can be used by different states in the USA as its minimum requirements for energy efficiency. However, the standard was not published for any specific state or country and can be used anywhere in the world. Every three years it is revised and upgraded with the intent of reaching the design levels of Net ZEBs by the year 2030 (ASHRAE 2011). 
Table 12-1 compares the mandated energy efficiency requirements between NZS 4243, EPBD, and ASHRAE 90.1. The comparison was of the various compliance items of building components with a specific building component, it was highlighted red if it was not mandated.

\begin{tabular}{|c|c|c|c|c|}
\hline $\begin{array}{l}\text { Compliance } \\
\text { Item }\end{array}$ & Building Component & $\begin{array}{c}\text { New } \\
\text { Zealand } \\
\text { (NZS4243) }\end{array}$ & $\begin{array}{l}\text { USA (ASHRAE } \\
90.1 \text { and IECC) }\end{array}$ & $\begin{array}{l}\text { Europe } \\
\text { (EPBD) }\end{array}$ \\
\hline \multirow{10}{*}{$\begin{array}{l}\text { Building } \\
\text { Envelope }\end{array}$} & Roof Insulation & Yes & Yes & Yes \\
\hline & Wall Insulation & Yes & Yes & Yes \\
\hline & Floor Insulation & Yes & Yes & Yes \\
\hline & Door Insulation & No & Yes & Yes \\
\hline & Window Insulation & Yes & Yes & Yes \\
\hline & Window SHGC & No & Yes & No \\
\hline & Skylight Insulation & No & Yes & No \\
\hline & Skylight SHGC & No & Yes & No \\
\hline & Maximum Envelope Thermal Bridging & No & Yes & Yes \\
\hline & $\begin{array}{l}\text { Maximum Envelope Infiltration or Air } \\
\text { Tightness }\end{array}$ & No & Yes & Yes \\
\hline \multirow{5}{*}{$\begin{array}{l}\text { Installed } \\
\text { Equipment }\end{array}$} & Maximum LPD & Yes & Yes & Yes \\
\hline & Type of Light Source (Linear Fluorescent) & No & Yes & No \\
\hline & Type of Light Ballast & No & Yes & No \\
\hline & Presence of Daylight Control & No & Yes & Yes \\
\hline & Presence of Occupancy Controls & No & Yes & No \\
\hline \multirow{9}{*}{$\begin{array}{l}\text { HVAC } \\
\text { System }\end{array}$} & Air-conditioner / Chiller Efficiency & No & Yes & Yes \\
\hline & Heat Pump Efficiency & No & Yes & No \\
\hline & Boiler Efficiency & No & Yes & Yes \\
\hline & Presence of Heat Recovery & No & Yes & Yes \\
\hline & Presence of Outdoor Air Damper & No & Yes & Yes \\
\hline & Air Handling Unit (AHU) performance & No & Yes & Yes \\
\hline & Fan Coil Unit (FCU) performance & No & Yes & Yes \\
\hline & Presence of Demand Control & No & Yes & No \\
\hline & Duct Insulation & No & Yes & Yes \\
\hline \multicolumn{5}{|c|}{ Extra Net ZEB Guideline Compliance Items } \\
\hline \multirow{4}{*}{$\begin{array}{l}\text { Passive } \\
\text { Design }\end{array}$} & Passive solar and solar protection & No & No & Yes \\
\hline & Positioning and orientation of building & No & No & Yes \\
\hline & Natural Ventilation & No & No & Yes \\
\hline & Daylighting & No & No & Yes \\
\hline $\begin{array}{l}\text { Renewable } \\
\text { Energy }\end{array}$ & Onsite renewable generation technologies & No & No & Yes \\
\hline
\end{tabular}

NZS 4243 was quite different to the other two international building codes. New Zealand energy efficiency compliance was not as in-depth. The two international criteria mandated more building environmental aspects through the compliance items and building components. New Zealand only mandated some building envelope and installed equipment compliance items. In comparison, EPBD and ASHRAE 90.1 mandated more building envelope and installed equipment compliance items, as well as HVAC system and renewable energy compliance items. 
The envelope and lighting requirements of NZS 4243 were somewhat similar to EPBD and ASHRAE 90.1. All three building codes mandated insulation levels for different building envelope components. All three also mandated the maximum allowable amount of total lighting power. However, ASHRAE 90.1 and the EPBD mandated more building envelope and lighting building components than NZS 4243. The extra building components were: windows, skylights and door insulation; window and skylight Solar Heat Gains Coefficient (SHGC); envelope thermal bridging; envelope air tightness; and the presence of lighting controls. EPBD and ASHRAE 90.1 also mandated specific HVAC appliance efficiencies (heat pumps, chillers, boilers etc.) and distribution insulation levels for ducts and piping.

Due to the EPBD targeting nearly zero and net zero energy buildings for the building standard, it can be used to draw comparisons to what building elements and items need to be mandated in order to be a Net ZEB building code. There were also a number of design guidelines for improving on ASHRAE 90.1 in order to get closer to net zero energy; such as (B. Thornton et al. 2010; Leach et al. 2010; B. Thornton et al. 2009; ASHRAE 2013; Hale et al. 2008; Hale et al. 2009; Zhang et al. 2010; ASHRAE Special Project 102 2008; ASHRAE Special Project 133 2011). Each design guideline had two extra compliance associated items, mandating passive solar design and renewable energy technologies.

Net ZEB building standards mandate the whole building design rather than just particular building components. Therefore, the NZBC requirements are not close to enabling net zero energy design and can be updated using the findings of this thesis. 


\section{CHAPTER 13. BIBLIOGRAPHY}

Aamodt, Agnar, and Enric Plaza. 1994. "Case-Based Reasoning: Foundational Issues, Methodological Variations, and System Approaches.” AI Communications 7 (1): 39-59.

Abramovitz, J. 1996. "Imperiled Waters, Impoverished Future: The Decline of Freshwater Ecosystems (Worldwatch Paper No. 128).” Washington D.C: Worldwatch Institute.

Ahmad, Mushtaq. 2003. "Systematic Time-Based Study for Quantifying the Uncertainty of Uncalibrated Models in Building Energy Simulations." Texas A\&M University. http://txspace.di.tamu.edu/handle/1969.1/1191.

Ahmad, Mushtaq, and Charles H. Culp. 2006. "Uncalibrated Building Energy Simulation Modeling Results." HVAC\&R Research 12 (4): 1141-55. doi:10.1080/10789669.2006.10391455.

Air Conditioning and Heat Pump Institute. 2010. "VRV/VRF Variable Refrigerant Volume (or Flow) Technology." Institutional. Institute of Refrigeration. April. http://www.ior.org.uk/app/images/pdf/VRV\%20VRF\%20achpi6\%20FINAL.pdf.

Alan Barbour. 2011. "Retrofitting Commercial Buildings." BUILD Magazine, March.

Alcorn, J. Andrew. 2010. "Global Sustainability and the New Zealand House." http://researcharchive.vuw.ac.nz/handle/10063/1871.

Alcott, Blake. 2005. “Jevons' Paradox.” Ecological Economics 54 (1): 9-21.

AllBusiness.com Inc. 2014. "Incremental Cost." allBusiness - Your Small Business Advantage. http://www.allbusiness.com/glossaries/incremental-cost/4962784-1.html.

Amitrano, L, N Isaacs, K Saville-Smith, M Donn, M Camilleri, A Pollard, M Babylon, et al. 2014a. "Building Energy End-Use Study (BEES) Part 1: Final Report." BRANZ Study Report SR297/1 (2014). Judgeford, New Zealand: BRANZ. http://www.branz.co.nz/cms_show_download.php?id=182d3ae296d4d92be905477582ae $2453 \mathrm{c} 0671 \mathrm{~d} 58$.

. 2014b. "Building Energy End-Use Study (BEES) Part 2: Final Report." BRANZ Study Report SR297/2 (2014). Judgeford, New Zealand: BRANZ. http://www.branz.co.nz/cms_show_download.php?id=182d3ae296d4d92be905477582ae $2453 \mathrm{c} 0671 \mathrm{~d} 58$.

AREA Science Park, and Jožef Stefan Institute. 2013. "Worldwide Energy Efficiency Technology Roadmap." Italy: AREA Science Park. www.emilieproject.eu.

ASHRAE. 2002. ASHRAE Guideline 14-2002 for Measurement of Energy and Demand Savings. Atlanta, GA: American Society of Heating, Refrigeration and Air Conditioning Engineers.

2006. ASHRAE GreenGuide: The Design, Construction, and Operation Of Sustainable Buildings. USA: Elsevier.

. 2010. ANSI/ ASHRAE Standard 55-2010, Thermal Comfort Conditions for Human Occupancy. American Society of Heating, Air-Conditioning, and Refrigeration Engineers, Inc.

2011. "ASHRAE Strategic Plan." Atlanta, GA: ASHRAE. http://www.ashrae.org/File\%20Library/docLib/StrategicPlan/Strategic-Plan-Amended2011-06-26--new-logo-.pdf.

. 2013. "Advanced Energy Design Guides." ASHRAE - Standards, Research and Technology. https://www.ashrae.org/standards-research--technology/advanced-energydesign-guides.

Page | 314 
2015. "Standards, Research \& Technology - 50 Percent AEDG Free Download." ASHRAE. https://www.ashrae.org/standards-research--technology/advanced-energydesign-guides/50-percent-aedg-free-download.

ASHRAE Special Project 102. 2008. Advanced Energy Design Guide for Small Office Buildings Achieving 30\% Energy Savings Over ANSI/ASHRAE/IESNA Standard 90.1-1999. Atlanta, GA: American Society of Heating, Refrigerating, and Air-Conditioning Engineers, Inc. https://www.ashrae.org/standards-research--technology/advanced-energydesign-guides.

ASHRAE Special Project 133. 2011. Advanced Energy Design Guide for Small to Medium Office Buildings - Achieving 50\% Energy Savings Toward a Net Zero Energy Building. Atlanta, GA: American Society of Heating, Refrigerating, and Air-Conditioning Engineers, Inc. https://www.ashrae.org/standards-research--technology/advanced-energydesign-guides.

Attia, S. 2011. "State of the Art of Existing Early Design Simulation Tools for Net Zero Energy Buildings: A Comparison of Ten Tools." Louvain La Neuve, Belgium: Université catholique de Louvain.

Baird, George, Guy Marriage, Ben Masters, and Clare Dykes. 2012. "Environmental Re-Design and Performance of the Refurbished Aorangi House, Wellington, New Zealand." In . Griffith University, Gold Coast.: ASA 2012.

BEES. 2013a. "Phone Survey." BRANZ Ltd. . 2013b. "Web-Search." BRANZ Ltd.

. 2014a. "Building Energy End-Use Study (BEES): Database of 48 Calibrated Energy Models." Internal Report. Judgeford, New Zealand: BRANZ.

. 2014b. "Building Energy End-Use Study (BEES): Targeted Commercial Building Survey Database." Internal Report. Judgeford, New Zealand: BRANZ.

Bellenger, L. 2011. "Building Energy Modelling Innovation Summit- Vision Statements." Rocky Mountain Institute. http://www.rmi.org/BEMSummitConferenceLogistics.

Bennett, A. 2007. "Meridian Boss Hails Deal with Smelter - Energy - NZ Herald News." The New Zealand Herald. http://www.webcitation.org/mainframe.php.

Bensouda, Nabil. 2004. "Extending and Formalizing the Energy Signature Method for Calibrating Simulations and Illustrating with Application for Three California Climates." Texas A\&M University.

Benton, Michael J. 2003. When Life Nearly Died. New York: Thames and Hudson.

Black Diamond Technologies Limited. 2014. "Compare Heating Options.” Mitsubishi Electric. http://www.mitsubishi-electric.co.nz/heatpump/benefits.aspx\#efficiency_info.

Bloomfield, K, J Moore, and R Neilson. 2003. "Geothermal Energy Reduces Greenhouse Gases." Geothermal Resources Council (GRC) Bulletin March/April 2003. http://geothermal.org/PDFs/Articles/greenhousegases.pdf.

Bradshaw, Vaughn. 2006. The Building Environment: Active and Passive Control Systems. Third Edition. New Jersey: John Wiley \& Sons Ltd.

Brager, Gail S., and Richard J. de Dear. 1998. "Thermal Adaptation in the Built Environment: A Literature Review." Energy and Buildings 27 (1): 83-96. doi:10.1016/S03787788(97)00053-4.

BRANZ Ltd. 2013a. "Building Energy End-Use Study (BEES).” Article. BRANZ. March 31. http://www.branz.co.nz/BEES. 
- 2013b. "BEES for Energy Modelling." Article. April 1. http://www.branz.co.nz/cms display.php?sn=169\&st=1\&pg=9690.

2013c. "Process for Template Modelling | OpenStudio | SketchUp | EnergyPlus." Article. April 1. http://www.branz.co.nz/cms_display.php?sn=169\&st=1\&pg=9706.

Briggs, R, D Crawley, and D Belzer. 1987. "Analyses and Categorization of the Office Building Stock." GRI-87/0244, October. Chicago: Gas Research Institute (GRI).

Briggs, R, D Crawley, and J Schliesing. 1992. "Energy Requirements for Office Buildings, Volume 1, Existing Buildings.” GRI-90/0236.1, February. Chicago: Gas Research Institute (GRI).

Bronson, D, S. B Hinchey, J. S. Haberl, and D. L O’Neal. 1992. "Procedure for Calibrating the DOE-2 Simulation Program to Non-Weather Dependent Measured Loads." ASHRAE Transactions: Symposia, 636-52.

Brown, N. 2009. "Performance by Design - An Energy Analysis of AIA/COTE Top Ten Projects." Washington D.C, USA: The American Institute of Architects. http://www.aia.org/aiaucmp/groups/aia/documents/pdf/aiab081492.pdf.

Brundtland, Gro Harlem. 1987. Our Common Future: The World Commission on Environment and Development. First Edition. Oxford, UK: Oxford University Press.

Business Analysis Team. 2005. "Cost Benefit Analysis Primer." Departmental Crown's Financial and Information System release. Wellington [N.Z.]: New Zealand Treasury. http://www.treasury.govt.nz/publications/guidance/planning/costbenefitanalysis/primer/c ba-primer-v12.pdf.

Caughey, J L. 2015. "Degree Days Seasonal Summary (18 Base)." Wairoa Weather. http://wairoa.net/weather/degreeseason.php.

CEN. 2011. BS EN 12464-1:2011 - Light and Lighting - Lighting of Work Places - Part 1: Indoor Work Places. Brussels, Belgium: European Committee for Standardization (CEN).

Chartered Institution of Building Services Engineers. 1998. Building Energy and Environmental Modelling - Appliations Manual AM1 1: 1998. London, UK: CIBSE.

. 1999. Guide A: Environmental Design - Chapter 3: Thermal Properties of Building Structures (Appendix 3:A7 Table 3.41-3.44). London, UK: CIBSE.

Choi, A. S, K. D Song, and Y. S Kim. 2005. "The Characteristics of Photosensors and Electronic Dimming Ballasts in Daylight Responsive Dimming Systems." Building and Environment 40: 39-50.

CIBSE. 2002. Code for Lighting. 1 edition. Oxford; Boston: Butterworth-Heinemann.

Coakley, Daniel, Paul Raftery, and Marcus Keane. 2014. "A Review of Methods to Match Building Energy Simulation Models to Measured Data." Renewable and Sustainable Energy Reviews 37 (September): 123-41. doi:10.1016/j.rser.2014.05.007.

Combined Federal Campaign. 2013. "Cost-Benefit Analysis | Center for Effective Government." http://www.foreffectivegov.org/node/3470.

Concept Consulting Group. 2003. "An Electricity Emission Factor." New Zealand Climate Change Office (NZCCO). http://www.mfe.govt.nz/publications/climate/electricityemissions-factor-reports/electricity-factor-aug03.pdf.

Corrado, Vincenzo, and Houcem Eddine Mechri. 2009. "Uncertainty and Sensitivity Analysis for Building Energy Rating." Journal of Building Physics 33 (2): 125-56. doi:10.1177/1744259109104884. 
Cory, S. 2009. "Urban Net Zero Energy Commercial Buildings, Are They Possible?" Honours, Wellington, N.Z.: Victoria University of Wellington.

. 2012. "Selection of BEES Buildings to Model: A Comparison of BEES Targeted Buildings Energy Driving Attributes to Two Auxiliary Data Sets (Web-Search And Phone Survey)." Internal Report. Wellington, N.Z: Centre for Building Performance Research.

Cory, S, M Donn, and A Pollard. 2014. "Comparison of NZ's Energy Efficiency Regulation and Verification Assumptions to Real Building Loads and Operation." In . Auckland, New Zealand.

Cory, S, A Gates, and M Donn. 2011. "The Creation Of Generic Energy Simulation Models Which Represent Typical Commercial Buildings And Their Calibration Against Real Energy Data." In Proceedings of Building Simulation 2011: 12th Conference of International Building Performance Simulation Association, Sydney, 1473-80. Sydney, Australia: IBPSA. http://www.ibpsa.org/proceedings/BS2011/P_1492.pdf.

Cory, S, C Hsu, and M Donn. 2009. "Template Files for Commercial Building Stock Energy Simulations." Wellington [N.Z.]: Centre for Building Performance Research.

Cory, S, A Lenoir, M Donn, and F Garde. 2011. "Formulating a Building Climate Classification Method." In Proceedings of Building Simulation 2011: 12th Conference of International Building Performance Simulation Association, Sydney, 1662-69. Sydney, Australia: IBPSA. http://www.ibpsa.org/proceedings/BS2011/P_1550.pdf.

Cory, S, A Munn, A Gates, and M Donn. 2012. "Building Energy End-Use Study (BEES) Year 5: Building Design Optimisation.” BRANZ Study Report SR 277/6 (2012). Judgeford, New Zealand: BRANZ. http://www.branz.co.nz/cms_show_download.php?id=9b5abc1a4a3897b63b8cea2dbeb24 $609 f 763 b 792$.

Coxall, Helen K., Paul A. Wilson, Heiko Pälike, Caroline H. Lear, and Jan Backman. 2005. "Rapid Stepwise Onset of Antarctic Glaciation and Deeper Calcite Compensation in the Pacific Ocean." Nature 433 (7021): 53-57. doi:10.1038/nature03135.

Crawford, Robert. 2011. Life Cycle Assessment in the Built Environment. 1 edition. London; New York: Routledge.

Crawley, Drury B., Jon W. Hand, Michaël Kummert, and Brent T. Griffith. 2008. "Contrasting the Capabilities of Building Energy Performance Simulation Programs." Building and Environment 43 (4): 661-73. doi:10.1016/j.buildenv.2006.10.027.

Crawley, Drury B., Linda K. Lawrie, Frederick C. Winkelmann, W.F. Buhl, Y.Joe Huang, Curtis O. Pedersen, Richard K. Strand, et al. 2001. "EnergyPlus: Creating a New-Generation Building Energy Simulation Program." Energy and Buildings 33 (4): 319-31. doi:10.1016/S0378-7788(00)00114-6.

Crawley, D, and J Schliesing. 1992. "Energy Requirements for Office Buildings, Volume 2, Recent and Future Buildings." GRI-90/0236.2, March. Chicago: Gas Research Institute (GRI).

Creswell, J. 2009. Research Design - Qualitative, Quantitative, and Mixed Methods Approaches. Third. New Delhi: Sage Publications Inc.

CSR Building Products Ltd. 2008. "Viridian Products." Veridian - New World Glass. http://viridianglass.com/products/Default.aspx.

Daikin Industries Ltd. 2014. "VRV Multi-Split Type Air Conditioners." Manufacturer. Daikin. http://www.daikin.com/products/ac/lineup/vrv/index.html. 
Daniels, K. 1997. The Technology of Ecological Building: Basic Principles and Measures, Examples and Ideas. Berlin: Birkhauser Verlag.

David Nelson. 2013. "Energy Efficient Lighting." Whole Building Design Guide - A Program of the National Institute of Building Sciences. http://www.wbdg.org/resources/efficientlighting.php.

Delmas, A, and M Donn. 2013. "NZ Building Stock Energy Consumption Dashboard." Final Year Internship Report. Wellington [N.Z.]: Victoria University of Wellington.

Department for Communities and Local Government. 2013. "Energy Performance of Buildings Directive (recast) - Cost Optimal Calculations: UK Report to European Commission." London, UK: Department for Communities and Local Government. http://ec.europa.eu/energy/efficiency/buildings/implementation_en.htm.

Department of Building and Housing. 2009. "Building Regulations 1992. Amended 2009." Wellington [N.Z.]: Department of Building and Housing. http://www.legislation.govt.nz/regulation/public/1992/0150/latest/versions.aspx. . 2011. Compliance Document for New Zealand Building Code Clause H1: Energy Efficiency. Third Edition. AS/NZS 1680.1:2006. Wellington, N.Z: Department of Building and Housing. http://www.dbh.govt.nz/UserFiles/File/Publications/Building/Compliancedocuments/H1-energy-efficiency-3rd-edition-amendment-2.pdf.

Deru, M., K Field, D Studer, K Benne, B Griffith, P Torcellini, B Liu, et al. 2011. "U.S. Department of Energy Commercial Reference Building Models of the National Building Stock.” NREL/TP-5500-46861. Golden, CO: NREL.

Deru, Michael P., Paul Torcellini, R Judkoff, D Crawley, and J Ryan. 2007. "Assessment of the Technical Potential for Achieving Net Zero-Energy Buildings in the Commercial Sector." Technical Report NREL/TP-550-41957. Golden, CO: National Renewable Energy Laboratory Golden, CO.

Deru, M, R Judkoff, and P Torcellini. 2002. "SUNREL: Technical Reference Manual." NREL/BK-550-30193. Golden, CO: National Renewable Energy Laboratory.

DesignBuilder Software Ltd. 2010. "Paramteric Analysis." DesignBuilder. http://www.designbuilder.co.uk/helpv3/Content/Parametric\%20Analysis.htm.

Djongyang, Noël, René Tchinda, and Donatien Njomo. 2010. "Thermal Comfort: A Review Paper." Renewable and Sustainable Energy Reviews 14 (9): 2626-40. doi:10.1016/j.rser.2010.07.040.

DOE, NREL, and PNNL. 2015. “Advanced Energy Design Guides.” U.S. Department of Energy. http://energy.gov/eere/buildings/advanced-energy-design-guides.

Donn, M. 1999. "Quality Assurance - Simulation and the Real World." In Proceedings of Building Simulation 1999: Conference of International Building Performance Simulation Association. Kyoto, Japan: IBPSA.

Douthwaite, Richard. 2012. "Degrowth and the Supply of Money in an Energy-Scarce World." Ecological Economics 84 (December): 187-93. doi:10.1016/j.ecolecon.2011.03.020.

Duffield, Wendell A., and John H. Sass. 2003. "Geothermal Energy-Clean Power From the Earth's Heat." C1249. Denver, CO: U.S. Geological Survey. http://pubs.usgs.gov/circ/2004/c1249/c1249.pdf.

Electricity Authority. 2014. "EMI." Electricity Authority. http://www.emi.ea.govt.nz/. 
Energy Information and Modelling Group. 2012a. "Energy Sector Greenhouse Gas Emissions Net Position Report 2012." Wellington, N.Z.: Ministry of Economic Development. http://www.mfe.govt.nz/issues/climate/greenhouse-gas-emissions/net-position/. . 2012b. "New Zealand Energy Data File 2011." Wellington, N.Z.: Ministry of Economic Development. $\quad$ http://www.med.govt.nz/sectors-industries/energy/energymodelling/publications/energy-data-file.

Energy Research Group. 1999. A Green Vitruvius - Principles and Practice of Sustainable Architectural Design. London, UK: James and James.

European Commission. 2008. "Proposal for a DIRECTIVE OF THE EUROPEAN PARLIAMENT AND OF THE COUNCIL on the Energy Performance of Buildings (Recast)." Brussels: European Commission.

. 2013. "What Is Adaptive Comfort?" BUILD UP - Energy Solutions for Better Buildings: . http://www.buildup.eu/faq/european-countries/6642.

European Council for an Energy Efficient Economy (eceee). 2009. "Steering through the Maze \# 2: Net Zero Energy Buildings: Definitions, Issues and Experience.” Sweden: European Council for an Energy Efficient Economy (eceee).

Expol Ltd. 2014. "R Values for Expanded Polystyrene." Expol. http://www.expol.co.nz/pdfs/R_Values_for_EPS.pdf.

Farlex Inc. 2014. "Incremental Costs and Benefits." The Free Dictionary by Farlex. $\mathrm{http}$ //financial-dictionary.thefreedictionary.com/Incremental+costs+and+benefits.

finda limited. 2013. "Finda - New Zealand Business Directory, Listings and Reviews." Business Directory. Finda. http://www.finda.co.nz/.

Fosdick, Judy. 2013. "Passive Solar Heating." Whole Building Design Guide - A Program of the National Institute of Building Sciences. http://www.wbdg.org/resources/psheating.php.

Frey, Patrice. 2008. "Building Reuse: Finding a Place on American Climate Policy Agendas." Washington D.C: Natinoal Trust for Historic Preservation. https://www.heritagecanada.org/sites/www.heritagecanada.org/files/Building\%20Reuse\% 20-\%20Frey.pdf.

Fulton, M, J Baker, M Brandenburg, R Herbst, J Cleveland, J Rogers, and C Onyeagoro. 2012. "United States Building Energy Efficiency Retrofits: Market Sizing and Financing Models." New York, U.S: The Rockefeller Foundation; DB Climate Change Advisors. http://www.rockefellerfoundation.org/uploads/files/791d15ac-90e1-4998-89325379bcd654c9-building.pdf.

García-Olivares, Antonio, and Joaquim Ballabrera-Poy. 2015. "Energy and Mineral Peaks, and a Future Steady State Economy." Technological Forecasting and Social Change 90, Part B (January): 587-98. doi:10.1016/j.techfore.2014.02.013.

Garde, F, and M Donn. 2014. "Solution Sets and Net Zero Energy Buildings : A Review of 30 Net ZEBs Case Studies Worldwide." A Technical Report of Subtask C DC.TR1. Le Tampon, Reunion: IEA Task 40/Annex52 Towards Net Zero Energy Solar Buildings. http://task40.iea-shc.org/data/sites/1/publications/T40A52-DC-TR1-30-Net-ZEBs.pdf.

Garde, F, A Lenoir, A Scognamiglio, D Aelenei, D Waldren, H Rostvik, J Ayoub, L Aelenei, M Donn, and S Cory. 2015. "How to Design a Net Zero Energy Building? Solution Sets and Case Studies: Experience and Feedback of the IEA Task40/Annex52." Energy Procedia 61: 995-98. doi:10.1016/j.egypro.2014.11.1011. 
Garde, F, E Ottenwelter, and A Bornarel. 2012. "Integrated Building Design in Tropical Climates: Lessons Learned from the ENERPOS Net Zero Energy Building." ASHRAE Transactions 118 (1): 81.

Gates, A. 2013. "Determining the Modelling Input Parameters for Heating, Ventilation, and Air Conditioning Systems in New Zealand Commercial Buildings." Masters, Victoria University of Wellington. http://researcharchive.vuw.ac.nz/handle/10063/2642.

Gates, A, S Cory, and M Donn. 2012. "Building Energy End-Use Study (BEES) Year 5: Modelling Detail Analysis.” BRANZ Study Report SR 277/5 (2012). Judgeford, New Zealand:

BRANZ. http://www.branz.co.nz/cms_show_download.php?id=19ca5d6f8ac73110529beb3877d8a 1df8da38702.

Gates, Anthony. 2011. "Creating Custom Energy Plus Weather Files.” Unpublished. Wellington, N.Z.: Victoria University of Wellington.

GBPN. 2013. "More and Deeper Renovation." Global Buildings Performance Network. http://www.gbpn.org/laboratory/more-and-deeper-renovation.

Gibson, Todd, and Moncef Krarti. 2015. "Comparative Analysis of Prediction Accuracy from Daylighting Simulation Tools." LEUKOS $11 \quad$ (2): 49-60. doi:10.1080/15502724.2014.986274.

Givoni, B. 1998. Climate Considerations in Building and Urban Design. First. New York City, NY: John Wiley \& Sons Ltd.

Glazer, B. 2014. "Net-Zero and Beyond.” Ideas+Buildings. http://blog.perkinswill.com/net-zeroand-beyond/.

Google. 2013a. "Google Earth." Google.com. http://www.google.com/earth/index.html.

- 2013b. "Google Maps with Street vVew." Google.com. http://maps.google.co.nz/intl/en/help/maps/streetview/.

Grbich, C. 2007. Qualitative Data Analysis: An Introduction. Third. London, UK: Sage Publications Inc.

Gregg D. Ander. 2013a. "Daylighting." Whole Building Design Guide - A Program of the National Institute of Building Sciences. http://www.wbdg.org/resources/daylighting.php. . 2013b. "Daylighting Photosensor." Whole Building Design Guide - A Program of the National Institute of Building Sciences. http://www.wbdg.org/ccb/ARMYCOE/COETN/technote01.pdf. . 2013c. "Windows and Glazing." Whole Building Design Guide - A Program of the National Institute of Building Sciences. http://www.wbdg.org/resources/windows.php.

Griffith, B, N Long, P. Torcellini, R Judkoff, D Crawley, and J Ryan. 2008. "Methodology for Modeling Building Energy Performance across the Commercial Sector." Technical Report NREL/TP-550-41956. Golden, CO: NREL.

Grocon. 2014. "PIXEL - a Piece of Tomorrow, Today." Pixel Technologies. http://www.pixelbuilding.com.au/.

GRUNDFOS Holding A/S. 2014. "COP (Coefficient of Performance)." GRUNDFOS. $\mathrm{http}$ //www.grundfos.com/service-support/encyclopedia-search/cop-coefficientofperformance.html.

Gunther, Marc. 2009. "The World's Looming 'Water Gap." GreenBiz. http://www.greenbiz.com/blog/2009/11/25/worlds-looming-water-gap.

Haberl, Jeff S., Charles Culp, and David E. Caridge. 2005. "ASHRAE's Guideline 14-2002 for Measurement of Energy and Demand Savings: How to Determine What Was Really 
Saved by the Retrofit." Pittsburgh Pennsylvania, October. http://repository.tamu.edu/handle/1969.1/5147.

Hale, E, M Leach, A Hirsch, and P Torcellini. 2009. "General Merchandise 50\% Energy Savings: Technical Support Document.” Technical Report NREL/TP-550-46100. Golden, CO: National Renewable Energy Laboratory.

Hale, E, D Macumber, N Long, B Griffith, K Benne, S Pless, and P Torcellini. 2008. "Technical Support Document: Development of the Advanced Energy Design Guide for Medium Box Retail-50\% Energy Savings." Technical Report NREL/TP-550-42828. Golden, CO: National Renewable Energy Laboratory.

Hamilton-MacLaren, Fiona, Dennis L. Loveday, and Monjur Mourshed. 2009. "The Calculation of Embodied Energy in New Build UK Housing." In Proceedings of the 25th Annual ARCOM Conference, Nottingham, September 2009. ARCOM. https://dspace.lboro.ac.uk/dspace-jspui/bitstream/2134/6570/1/McLaren-LovedayMourshed-2009-Preprint\%5B1\%5D.pdf.

Hanitsch, R, D Schulz, and U Siegfried. 2001. "Shading Effects on Output Power of Grid Connected Photovoltaic Generator Systems." Renewable and Sustainable Energy Reviews: Power Engineering, 93-99.

Hardy, M. 2009. "A Practical Guide to Multi-Split Systems and Variable Refrigerant Volume (VRV) Systems." Ambthair Services Ltd. http://www.ambthair.com/multisplit_and_vrv_systems.html\#outside.

Hayden, Andrew. 2014. "Net Zero Energy Buildings: The New Standard?" The National Law Review. http://www.natlawreview.com/article/net-zero-energy-buildings-new-standard.

Henninger, Robert H, Michael J Witte, and Drury B Crawley. 2004. "Analytical and Comparative Testing of EnergyPlus Using IEA HVAC BESTEST E100-E200 Test Suite." Energy and Buildings 36 (8): 855-63. doi:10.1016/j.enbuild.2004.01.025.

Henninger, R, M Witte, and D Crawley. 2003. "EXPERIENCE TESTING ENERGYPLUS WITH THE IEA HVAC BESTEST E100-E200 SERIES.” In Proceedings of the 8th IBPSA Conference, 467-74. Eindhoven, Netherlands: IBPSA. http://apps1.eere.energy.gov/buildings/energyplus/pdfs/bibliography/bs03_henninger_04 67 474.pdf.

Heo, Y., R. Choudhary, and G.A. Augenbroe. 2012. "Calibration of Building Energy Models for Retrofit Analysis under Uncertainty." Energy and Buildings 47 (April): 550-60. doi:10.1016/j.enbuild.2011.12.029.

Herring, E Horace. 1998. "Does Energy Efficiency Save Energy: The Implications of Accepting the Khazzoom-Brookes Postulate'." Energy Journal, 1 (4): 21-39.

Hills, A. 2013. "Visualising the Invisible: Displaying Building Resource-Use Benchmarks in a 3D City Visualisation." Master of Building Science, Wellington, N.Z: Victoria University of Wellington.

Hirning, M. B., G. L. Isoardi, and I. Cowling. 2014. "Discomfort Glare in Open Plan Green Buildings." Energy and Buildings 70 (February): 427-40. doi:10.1016/j.enbuild.2013.11.053.

Holm, A, D Jennejohn, and L Blodgett. 2012. "Geothermal Energy and Greenhouse Gas Emissions." Washington D.C, USA: Geothermal Energy Associated. http://geoenergy.org/reports/GeothermalGreenhouseEmissionsNov2012GEA web.pdf.

Holton, Glyn. 2014. "Bias, Standard Error and Mean Squared Error." Value-at-Risk: Theory and Practice. Accessed May 29. http://value-at-risk.net/bias/. 
Hopkinson, R.G., J Longmore, and P Petherbridge. 1954. "An Empirical Formula for the Computation of the Indirect Component of Daylight Factors." Trans. Illum. Eng. Soc. (London) 19: 201.

Hua, K, B Faltings, and I Smith. 1996. "CADRE: Case-Based Geometric Design." Artificial Intelligence in Engineering 10: 171-83. doi:10.1016/0954-1810(95)00026-7.

Huang, J, and E Franconi. 1999. "Commercial Heating and Cooling Loads Component Analysis." LBL-37208. Berkeley, CA: Lawrence Berkeley National Laboratory. http://simulationresearch.lbl.gov/dirpubs/37208.pdf.

Hunt, W.D. 2008. "Literature Review of Data on the Incremental Costs to Design and Build Low-Energy Buildings.” PNNL-17502. Richland, WA: Pacific Northwest National Laboratory. http://www.pnl.gov/main/publications/external/technical_reports/PNNL17502.pdf.

Huppert, m. 2012. "The Greenest Building: Quantifying The Environmental Value of Building Reuse - Advancing Deep Energy Retrofits for Commercial Buildings." Case Study Presentation presented at the Advancing Deep Energy Retrofits for Commercial Buildings Summit 2012, Webinar. http://newbuildings.org/index.php?q=suggestedreading-deep-energy-savings-existing-buildings.

Ibn-Mohammed, T., R. Greenough, S. Taylor, L. Ozawa-Meida, and A. Acquaye. 2013. "Operational vs. Embodied Emissions in buildings-A Review of Current Trends." Energy and Buildings 66 (November): 232-45. doi:10.1016/j.enbuild.2013.07.026.

IEA. 2011. "Technology Roadmap - Energy-Efficient Buildings: Heating and Cooling Equipment." France: OECD/IEA. http://www.iea.org/publications/freepublications/publication/buildings_roadmap.pdf.

IEA-SHC. 2013a. "Net Zero Energy Buildings Database." International Energy Agency (IEA) Solar Heating and Cooling Programme (SHC). http://iea40.buildinggreen.com. . 2013b. "Project (Task) Subtasks." International Energy Agency (IEA) - Solar Heating and Cooling Programme (SHC). http://task40.iea-shc.org/subtasks.

. 2013c. "Task40: Net Zero Energy Solar Buildings." International Energy Agency (IEA) - Solar Heating and Cooling Programme (SHC). http://task40.iea-shc.org/.

Inhabitat LLC. 2014. "Solatube Skylights." Inhabitat - Sustainable Design Innovation, Eco Architecture, Green Building. http://inhabitat.com/solar-tube/solar-tube-solatube-solarpipe-skylight-daylight-daylighting-natural-light-architectural-daylighting-solutions/.

International Energy Agency. 2004. International Energy Agency: Annex 31 Energy-Related Environmental Impact of Buildings: Environmental Framework. Canada: Canada Mortgage and Housing Corporation.

INTERNATIONAL ENERGY AGENCY. 2012. "KEY WORLD ENERGY STATISTICS." Paris, France: INTERNATIONAL ENERGY AGENCY. http://coprocem.org/documents/key_stats_2007.pdf.

IPCC. 2007a. "Climate Change 2007: Synthesis Report - An Assessment of the Intergovernmental Panel on Climate Change." IPCC Plenary XXVII Fourth Assessment Report. Geneva, Switzerland: IPCC.

. 2007b. Climate Change 2007: The Physical Science Basis - Contribution of Working Group I to the Fourth Assessment Report of the Intergovernmental Panel on Climate Change. Cambridge, United Kingdom and New York, NY, USA: Cambridge University Press. www1.eere.energy.gov/femp/. 
Isaacs, N. 2011. "Building Energy End-Use Study (BEES) Year 4: From Warehouses to Shops Changing Uses in the Non-Residential Buildings Sector." BRANZ Study Report SR260/7. Judgeford, New Zealand: http://www.branz.co.nz/cms_show_download.php?id=634e7f4c8365d23969ca45ea87e58 547588bbd6e.

Isaacs, N, K Saville-Smith, R Bishop, M Camilleri, J Jowett, A Hills, D Moore, et al. 2009. "Building Energy End-Use Study (BEES) Years 1 \& 2." BRANZ Study Report SR 224 (2009). Judgeford, New Zealand: BRANZ. http://www.branz.co.nz/cms_display.php?sn=126\&st=1\&pg=9647.

Isaacs, N, K Saville-Smith, R Bishop, M Camilleri, J Jowett, D Moore, M Babylon, M Donn, and H Roberti. 2010. "Building Energy End-Use Study (BEES) Year 3." BRANZ Study Report SR 236 (2010). Judgeford, New Zealand: BRANZ. http://www.branz.co.nz/cms_show_download.php?id=9d706b57ff49eb53be922bddc5fd9 45918e106f7.

Jensen, S, and A.J. Marszal. 2014. "Energy Flexible Buildings.” Factsheet. Denmark: Danish Technological Institute. http://www.ieaebc.org/fileadmin/user_upload/docs/Facts/EBC_Annex_67_Factsheet.pdf.

Jevons, W. S. 1865. The Coal Question: An Inquiry Concerning the Progress of the Nation, and the Probably Exhaustion of Our Coal-Mines. New York: Augustus M. Kelley.

J Lynes. 1979. “A Sequence for Daylighting Design.” Lighting Research and Technology 11 (2): $102-6$.

Johansson, T, A Patwardhan, N Nakicenovic, and L Gomez-Echeverri. 2012. Global Energy Assessment: Toward a Sustainable Future. Cambridge University Press, Cambridge, UK and New York, USA and the International Institute for Applied Systems Analysis, Laxenburg, Austria. http://www.iiasa.ac.at/web/home/research/Flagship-Projects/GlobalEnergy-Assessment/Home-GEA.en.html.

Jones, Katie. 2014. "ORNL Researchers Develop 'Autotune' Software to Make It Quicker, Easier and Cheaper to Model Energy Use of Buildings." Oak Ridge National Laboratory. http://www.ornl.gov/ornl/news/features/2014/cb8f55ed-c9f2-4e74-a373-3df68666afb7.

Kilkis, S. 2007. "A New Metric for Net- Zero Carbon Buildings.” In Proceedings of ES2007, 219-24. Long Beach, California: U.S. Government. http://www.udayton.edu/engineering/building_energy/resources/pdf/ES200736077_CostOptNetZeroHouse.pdf.

2011. "A Rational Exergy Management Model to Curb CO2 Emissions in the ExergyAware Built Environments of the Future." PhD, Stockholm, Sweden: KTH Royal Institute of Technology. http://www.divaportal.org/smash/get/diva2:447136/FULLTEXT01.pdf.

Kim, D. 2010. "Optimizing Cost Effective Energy Conservation Measures for Building Envelope." Energy Engineering: Journal of the Association of Energy Engineering, 7080.

Kolodner, J. L. 1991. "Improving Human Decision Making through Case-Based Decision Aiding." AI Magazine 12 (2): 52.

Krueger, Charles W. 1992. "Software Reuse." ACM Computing Surveys (CSUR) 24 (2): 131-83. doi:10.1145/130844.130856. 
Lam, Joseph C., and Sam C. M. Hui. 1996. "Sensitivity Analysis of Energy Performance of Office Buildings." Building and Environment 31 (1): 27-39. doi:10.1016/03601323(95)00031-3.

LANL Site Planning and Construction Committee. 2002. "LANL Sustainable Design Guide." LA-UR 02-6914. Los Alamos, NM: Los Alamos National Laboratory. www.eere.energy.gov/buildings/highperformance/lanl_sustainable_guide.html.

Laustsen, J. 2008. "ENERGY EFFICIENCY REQUIREMENTS IN BUILDING CODES, ENERGY EFFICIENCY POLICIES FOR NEW BUILDINGS.” IEA Information paper. Paris: International Energy Agency.

Lawrence Berkeley National Laboratory. 2011. "GenOpt - Generic Optimization Program." http://gundog.lbl.gov/GO/.

LBNL. $2014 . \quad$ "Window." Windows and Daghting. http://windows.lbl.gov/software/window/window.html.

Leach, M, C Lobato, A Hirsh, S Pless, and P Torcellini. 2010. "Technical Support Document: Strategies for 50\% Energy Savings in Large Office Buildings." Technical Report NREL/TP-550-49213. Golden, CO: National Renewable Energy Laboratory.

Levine, M, S de la Rue de Can, N Zheng, C Williams, J Amann, and D Staniaszek. 2012. "Building Energy-Efficiency Best Practice Policies and Policy Packages." LBNL-6006E. Berkeley, CA: Lawrence Berkeley National Laboratory; U.S. DOE; GBPN. http://www.gbpn.org/sites/default/files/06.BuildingsForOurFurture_Low.pdf.

Liddament, Martin W. 1996. AIVC, Guide GV: A Guide to Energy Efficient Ventilation. Great Britain: Oscar Faber Consulting.

Liley, J Ben, Hisako Shiona, James Sturman, and David S Wratt. 2008. "Typical Meteorological Years for the New Zealand Home Energy Rating Scheme." Prepared for the Energy Efficiency and Conservation Authority. NIWA Client Report: LAU2008-01-JBL. Omakau, New Zealand: NIWA.

Lixing, G. 2007. "Airflow Network Modeling in EnergyPlus." In 10th International Building Performance Simulation Association Conference and Exhibition, 10:967-72. Beijing, China. http://www.fsec.ucf.edu/en/publications/pdf/FSEC-PF-428-07.pdf.

Lockwood, Charles, S Nagarajan, and C Park. 2008. "The Dollars and Sense of Green Retrofits." Deloittes July 2008 Report. Deloitte. http://campbellfilm.com/wpcontent/uploads/2012/01/dollarssenseretrofits.pdf.

Loutzenhiser, Peter G., Gregory M. Maxwell, and Heinrich Manz. 2007. "An Empirical Validation of the Daylighting Algorithms and Associated Interactions in Building Energy Simulation Programs Using Various Shading Devices and Windows." Energy 32 (10): 1855-70. doi:10.1016/j.energy.2007.02.005.

Lovins, Amory, Rocky Mountain Institute, Marvin Odum, and John W. Rowe. 2011. Reinventing Fire: Bold Business Solutions for the New Energy Era. 1 edition. White River Junction, Vt: Chelsea Green Publishing.

Lund, H. 2013. "The Role of Sustainable Buildings in 100\% Renewable Energy Systems." Aalborg, Denmark: Aalborg University. http://vbn.aau.dk/files/45122802/Lund_BuildingsAndEnergySystems_1_.pdf.

Lynes, J.A. 1968. Principles of Natural Lighting. London, UK: Applied Science Publishers, Ltd. Macdonald, Iain, and Paul Strachan. 2001. "Practical Application of Uncertainty Analysis." Energy and Buildings 33 (3): 219-27. doi:10.1016/S0378-7788(00)00085-2. 
Maher, M. L, and A. G de Silva Garza. 1997. "Case-Based Reasoning in Design." IEEE Intelligent Systems 12 (2): 34-41.

Maile, Tobias, Martin Fischer, John Haymaker, and Vladimir Bazjanac. 2010. "Formalizing Approximations, Assumptions, and Simplifications to Document Limitations in Building Energy Performance Simulation." CIFE Working Paper \#WO126. Stanford, CA: Center for Integrated Facility Engineering, Stanford University.

Manke, J, and D Hittle. 1996. "Calibrating Building Energy Analysis Models Using Short-Term Test Data." In Proceedings of the 1996 International Solar Energy Conference. San Antonio, TX.

Mann, D. 2005. "Someone, Somewhere Really Did Already Invent the Wheel You're about to Re-Invent." In . Hong Kong: Hong Kong Institute of Value Management (HKIVM).

Mara, T.A., and S. Tarantola. 2008. "Application of Global Sensitivity Analysis of Model Output to Building Thermal Simulations." Building Simulation 1 (4): 290-302.

Marriage, Guy, and Stefan Waldhauser. 2010. "Aorangi House - Wellington's Recycled Building." Conference Presentation presented at the Sustainable Building 2010, Wellington http://www.cmnzl.co.nz/assets/sm/5756/61/1045StefanWaldhauser.pdf.

Marszal, A.J., P. Heiselberg, J.S. Bourrelle, E. Musall, K. Voss, I. Sartori, and A. Napolitano. 2011. "Zero Energy Building - A Review of Definitions and Calculation Methodologies." Energy and Buildings 43 (4): 971-79. doi:10.1016/j.enbuild.2010.12.022.

Masters, Ben. 2014. Aorangi House Design and Energy ConsumptionPersonal Communication.

Math Open Reference. 2009. "Trigonometry Functions - Introduction." Math Open Reference. http://www.mathopenref.com/trigfunctions.html.

McGlade, Christophe, and Paul Ekins. 2015. "The Geographical Distribution of Fossil Fuels Unused When Limiting Global Warming to $2{ }^{\circ} \mathrm{C} . "$ Nature 517 (7533): 187-90. doi:10.1038/nature14016.

McKinsey\&Company. 2009. "Pathways to a Low-Carbon Economy - Version 2 of the Global Greenhouse Gas Abatement Cost Curve." McKinsey\&Company. http://www.mckinsey.com/client_service/sustainability/latest_thinking/greenhouse_gas_a batement_cost_curves.

Meier, Alan Kevin. 1982. "Supply Curves of Conserved Energy." Ph.D. dissertation, Berkeley, CA: University of California, Berkeley. http://escholarship.org/uc/item/20b1j10d.

. 1984. "The Cost of Conserved Energy as an Investment Statistic." In , 2:636-41. Houston, TX. http://repository.tamu.edu/bitstream/handle/1969.1/94751/ESL-IE-84-04109.pdf? sequence $=1$.

Mertz, G, G Raffio, and K Kissock. 2007. "Cost Optimization of Net-Zero Energy House.” In Proceedings of ES2007, 477-88. Long Beach, California: U.S. Government. http://www.udayton.edu/engineering/building_energy/resources/pdf/ES200736077_CostOptNetZeroHouse.pdf.

Mihaly, Warwick. 2014. "Pixel Building." Panfilocastaldi. Accessed June 11. http://panfilocastaldi.wordpress.com/2011/03/13/pixel-building/.

Mills, E. 2009. "Building Commissioning: A Golden Opportunity for Reducing Energy Costs and Greenhouse Gas Emissions." Berkeley, CA: Lawrence Berkeley National Laboratory. http://cx.lbl.gov/documents/2009-assessment/lbnl-cx-cost-benefit.pdf. 
Ministry for Culture and Heritage. 2013. "New Zealand's Climate." Te Ara. http://www.teara.govt.nz/en/climate/1.

Ministry of Business, Innovation \& Employment. 2014. Acceptable Solutions and Verification Methods For New Zealand Building Code Clause B2 Durability. Second Edition. Wellington, N.Z: Ministry of Business, Innovation \& Employment. http://www.dbh.govt.nz/UserFiles/File/Publications/Building/Compliancedocuments/H1-energy-efficiency-3rd-edition-amendment-2.pdf.

Ministry of Climate, Energy and Building Design and Layout. 2013. Accelerating Green Energy Towards 2020 - The Danish Energy Agreement of March 2012. Copenhagen, Denmark: Solid Media Solutions. http://www.ens.dk/.

Mithraratne, N. 2007. "Looking Further than the Initial Dollars." BUILD Magazine, September. Modelling \& Sector Trends. 2014. "Energy in NewZealand 2013." ISSN 2324-5913. Wellington, N.Z.: Ministry of Business, Innovation and Employment. http://www.med.govt.nz/sectors-industries/energy/energy-modelling/publications/energyin-new-zealand/Energy-in-New-Zealand-2014.pdf.

Moffat, S. 2001. "Stock Aggregation: Methods for Evaluating the Environmental Performance of Building Stocks." Background report from the International Energy Agency's Annex 31 Energy-Related Environmental Impact of Buildings. International Energy Agency. http://annex31.wiwi.unikarlsruhe.de/pdf/PDF\%20version\%20Background\%20Reports\%20\%20Annex\%2031\%20Stock\%20Aggregation.pdf.

Nabi, A, and J Mardaljevic. 2006. "Useful Daylight Illuminances: A Replacement for Daylight Factors." Energy and Buildings 38: 905-13.

Najam, A, S Huq, and Y Sokona. 2003. "Climate Negotiations beyond Kyoto: Developing Countries Concerns and Interests." Climate Policy 3: 22-31.

National Science Centres. 2014. "SolarView." NIWA. https://www.niwa.co.nz/ourservices/online-services/solarview.

Natural Frequency. 2013. "WeatherTool: Psychometry." Natural Frequency: Weather Tool Help. http://wiki.naturalfrequency.com/wiki/WeatherTool/Psychrometry.

NBI Institute. 2012. "Getting to Zero 2012 Status Update: A First Look at the Costs and Features of Zero Energy Commercial Buildings." Research Report. Vancouver, WA, Canada: NBI Institute. http://newbuildings.org/.

New Zealand Green Building Council. 2013. "Case Studies.” New Zealand Green Building Council.

http://www.nzgbc.org.nz/index.php?option=com_content\&view=article\&id=46\&Itemid= 116.

Nexant Inc. 2008. M\&V Guidelines: Measurement and Verification for Federal Energy Projects Version 3.0. Three. Boulder, CO: U.S. Department of Energy. www1.eere.energy.gov/femp/.

Neymark, J, and R Judkoff. 2002. "International Energy Agency Building Energy Simulation Test and Diagnostic Method for Heating, Ventilating, and Air-Conditioning Equipment Models (HVAC BESTEST); Volume 1: Cases E100-E200." Technical Report NREL/TP550-30152. National Renewable Energy Laboratory (NREL), Golden, CO. http://www.nrel.gov/docs/fy02osti/30152.pdf.

. 2004. "International Energy Agency Building Energy Simulation Test and Diagnostic Method for Heating, Ventilating, and Air-Conditioning Equipment Models (HVAC 
BESTEST); Volume 2: Cases E300-E545." Technical Report NREL/TP-550-36754. National Renewable Energy Laboratory (NREL), Golden, CO. http://www.nrel.gov/docs/fy05osti/36754.pdf.

Neymark, J, R Judkoff, G Knabe, T Le, M Durig, A Glass, and G Zweifel. 2001. "HVAC BESTEST: A Procedure for Testing the Ability of Whole Building Energy Simulation Programs to Model Space Conditioning Equipment." Conference Paper NREL/CP-55029828. National Renewable Energy Laboratory (NREL), Golden, CO. http://www.nrel.gov/docs/fy01osti/29828.pdf.

Nielsen, Jakob, and Thomas K. Landauer. 1993. "A Mathematical Model of the Finding of Usability Problems." In Proceedings of the INTERACT '93 and CHI '93 Conference on Human Factors in Computing Systems, 206-13. CHI '93. New York, NY, USA: ACM. doi:10.1145/169059.169166.

NIWA. 2011. "The National Climate Database." http://cliflo.niwa.co.nz/. . 2013. "NIWA - Taihoro Nukurangi." http://www.niwa.co.nz/.

Norford, L. K., R. H. Socolow, E. S. Hsieh, and G. V. Spadaro. 1994. "Two-to-One Discrepancy between Measured and Predicted Performance of a 'low-Energy' Office Building: Insights from a Reconciliation Based on the DOE-2 Model." Energy and Buildings 21 (2): 121-31. doi:10.1016/0378-7788(94)90005-1.

NREL. 2014. "Best Research Cell Efficiency." NREL - National Center for Photovoltaics. http://www.nrel.gov/ncpv/.

NREL - Commercial Buildings Research and Software Development. 2010. Setting Surface Matching and Outside Boundary Conditions with the OpenStudio SketchUp Plug-In. Web-video.

https://www.youtube.com/watch?v=rCNpFTyyKuM\&index=5\&list=PL8E0CF6931B633 $24 \mathrm{D}$.

NZGBC. 2014. "Office Interiors 2009 Green Star Rating Tool." New Zealand Green BUilding Council.

http://www.nzgbc.org.nz/index.php?option=com_content\&view=article\&id=19\&Itemid= 86.

Overbey, Daniel. 2014. "Every Energy Model Is Wrong-And Here Is Why They're Indispensable."

Blog. http://digital.bnpmedia.com/article/Every_Energy_Model_Is_Wrong\%E2\%80\%94And_ Here_Is_Why_They\%E2\%80\%99re_Indispensable_/1766594/218561/article.html.

Peterman, A. 2013. "The Roles within: Building Energy Conservation in the United States through Alliance Networks and Other Voluntary Strategies." Ph.D. dissertation, Stanford, CA: Stanford University, Dept. of Civil and Environmental Engineering. http://www.arupconnect.com/2014/10/30/building-energy-efficiency-through-alliancenetworks/.

PNNL, PECI, and U.S. Department of Energy. 2011. "Advanced Energy Retrofit Guides: Practical Ways to Improve Energy Performance - Office Buildings.” PNNL-20761. Richland, WA: Pacific Northwest National Laboratory (PNNL).

Press Release: Property Council Of New Zealand. 2010. "New Standards Set for Sustainable Buildings." "Scoop" Independent News. June. http://www.scoop.co.nz/stories/SC1006/S00030/new-standards-set-for-sustainablebuildings.htm. 
Project Auditors. 2014. "Technical Feasibility." Project Auditors LLC. http://www.projectauditors.com/Dictionary2/1.8/index.php/term/,62555c9cae535f6f6855 5aae5a575f.xhtml.

Property Council New Zealand. 2008. "2008 Operating Expenses Benchmark.” Auckland, New Zealand: Property Council New Zealand Incorporated.

Prowler, Don. 2013. "Sun Control and Shading Devices." Whole Building Design Guide - A Program of the National Institute of Building Sciences. http://www.wbdg.org/resources/suncontrol.php.

QV. 2008. "Quotable Value.” http://www.qv.co.nz.

Raftery, Paul, Marcus Keane, and Andrea Costa. 2009. "Calibration of a Detailed Simulation Model to Energy Monitoring System Data: A Methodology and Case Study." In Proceedings of the 11th IBPSA Conference, Glasgow, UK. https://www.ibpsa.org/proceedings/BS2009/BS09_1199_1206.pdf.

. 2011. "Calibrating Whole Building Energy Models: Detailed Case Study Using Hourly Measured Data." Energy and Buildings 43 (12): 3666-79. doi:10.1016/j.enbuild.2011.09.039.

Rajapaksha, U, R Hyde, and N Groenhout. 2012. "Design Solution Sets for Bioclimatic Retrofit." In Sustainable Retrofitting of Commercial Buildings Warm Climates, 61-88. UK: Earthscan Ltd.

Rajkovich, N, R Diamond, and B Burke. 2010. "Zero Net Energy Myths and Modes of Thought." Proceedings from 2010 ACEEE Summer Study on Energy Efficiency in Buildings. American Council for an Energy-Efficient Economy. http://aceee.org/files/proceedings/2010/data/papers/2125.pdf.

Reddy, M. 2005. "Literature Review on Calibration of Building Energy Simulation Programs: Uses, Problems, Procedures, Uncertainty, and Tools,." ASHRAE Transactions 112 (2): 226-40.

Reinhart, C. 2011. "Simulation-Based Daylight Performance Predictions." In J. Hensen, \& R. Lamberts - Building Performance Simulation for Design and Operation, 235-53. New York City, NY: Routledge - Taylor \& Francis Group.

Reinhart, C. F., and V. R. M. LoVerso. 2010. "A Rules of Thumb-Based Design Sequence for Diffuse Daylight." Lighting Research and Technology 42 (1): 7-31. doi:10.1177/1477153509104765.

Riedy, C, A Lederwasch, and N Ison. 2011. "Defining Zero Emission Buildings - Review and Recommendations: Final Report." Sydney, Australia: Prepared for Sustainability Victoria by the Institute for Sustainable Futures, University of Technology.

Roe, Shawn. 2014. "Most Efficient Solar Panels Comparison." SRoeCo Solar. http://sroeco.com/solar/most-efficient-solar-panels.

Rosenbaum, M. 2003. "Understanding the Energy Modeling Process: Simulation Literacy." In The Pittsburgh Papers, 116. Brattleboro, VT: BuildingGreen.

RT 2012. 2013. Réglementation Thermique - RT2012.

Saltelli, A, K Chan, and E.M Scott. 2000. Sensitivity Analysis. Chichester, UK: John Wiley and Sons.

Sartori, Igor, Assunta Napolitano, Anna Joanna Marszal, Shanti Pless, Paul Torcellini, and Karsten Voss. 2010. "Criteria for Definition of Net Zero Energy Buildings.” In . Graz, Austria: IEA-SHC. 
Sartori, Igor, Assunta Napolitano, and Karsten Voss. 2012. "Net Zero Energy Buildings: A Consistent Definition Framework." Energy and Buildings 48 (May): 220-32. doi:10.1016/j.enbuild.2012.01.032.

Saville-Smith, K, and Ruth Fraser. 2010. "Building Energy End-Use Study (BEES) Year 5: Buildings - Size, Management and Use.” BRANZ Study Report SR 277/1 (2012). Judgeford, New Zealand: BRANZ. http://www.branz.co.nz/cms_show_download.php?id=9d706b57ff49eb53be922bddc5fd9 $45918 \mathrm{e} 106 \mathrm{f} 7$.

SBE. 2014. "Energy Conservation Measures." SBE - Site Based Energy. http://www.sitebasedenergy.com/content/Energy+Services/energy_service/ecm.

SEANZ. 2014. "Solar Photovoltaics." Sustainable Electricity Association New Zealand. http://www.seanz.org.nz/intrototechnologies/pv.

SMA Solar Technology AG. n.d. "Shade Management - Efficient Operation of Partially Shaded PV Plants with OptiTrac Global Peak." Technical Report. Germany: SMA Solar Technology AG. http://www.sma.de/en.html.

Solatube International Inc. 2009. "Solatube - Residential \& Commercial Idea Book." CA, USA: Solatube International Inc. www.solatube.com.

Soundvision Productions. 2013. "Energy Sources and the Environment." BURN An Energy Journal. Accessed November 24. http://burnanenergyjournal.com/what-kind-of-energymakes-the-least-greenhouse-gas/.

Spence, W.P. 1998. Construction - Materials, Methods and Technologies. New York, US.: Delmar Publishers.

Stamats Communications Inc. 2007. "Zero-Energy Buildings Defined." Buildings Smarter Facility

Management. http://www.buildings.com/ArticleDetails/tabid/3321/ArticleID/4987/Default.aspx.

Standards Association of Australia, and Standards New Zealand. 2006. NZS 1680.1: Interior and Workplace Lighting. Australian/New Zealand Standard, AS/NZS 1680.1:2006. Sydney, N.S.W. : Wellington, N.Z: Standards Australia ; Standards New Zealand. . 2009. NZS 1680.0: Interior Lighting. 2nd ed. Australian/New Zealand Standard, AS/NZS 1680.0:2009. Sydney, NSW : Wellington, N.Z: Standards Australia; Standards New Zealand. . 2014. NZS 3598.1: Energy Audits. Australian/New Zealand Standard, AS/NZS 3598.1:2014. Sydney, N.S.W.: Wellington, N.Z: Standards Australia; Standards New Zealand.

Standards New Zealand. 1990. NZS 4303: Ventilation for Acceptable Indoor Air Quality. Wellington [N.Z.]: Standards New Zealand.

2006. NZS 4214: Methods of Determining the Total Thermal Resistance of Parts of Buildings. Wellington [N.Z.]: Standards New Zealand.

. 2007a. NZS 4243: Part 1: Energy Efficiency: Large Buildings. Wellington [N.Z.]: Standards New Zealand.

. 2007b. NZS 4243: Part 2: Energy Efficeincy: Large Buildings. Wellington [N.Z.]: Standards New Zealand.

Statistics How To. 2014. "Confidence Interval For a Sample." Statistics How To - Elementary Statistics for the Rest of Us!. http://www.statisticshowto.com/how-to-find-a-confidenceinterval-for-a-sample/. 
Statistics New Zealand. 2013. "Defining Urban and Rural New Zealand." Statistics New Zealand.

http://www.stats.govt.nz/browse_for_stats/people_and_communities/Geographicareas/urban-rural-profile/defining-urban-rural-nz.aspx.

Steadman, Philip, Harry R Bruhns, Senino Holtier, Bratislav Gakovic, Peter A Rickaby, and Frank E Brown. 2000. "A Classification of Built Forms." Environment and Planning B: Planning and Design 27 (1): 73-91. doi:10.1068/bst7.

Stocker, T, Q Dahe, and G Plattner. 2013. "CLIMATE CHANGE 2013: THE PHYSICAL SCIENCE BASIS.” Technical Summary IPCC WGI Fifth Assessment Report. Stockholm: Intergovernmental Panel on Climate Change (IPCC). http://www.ipcc.ch/report/ar5/wg1/\#.UkzhuiRmh8G.

Sukhatme, Pandurang Vasudeo, and Balkrishna V. Sukhatme. 1970. Sampling Theory of Surveys: With Applications. 2nd Edition. India: Asia Pub. House.

Suk, Jae Yong, Marc Schiler, and Karen Kensek. 2013. "Development of New Daylight Glare Analysis Methodology Using Absolute Glare Factor and Relative Glare Factor." Energy and Buildings 64 (September): 113-22. doi:10.1016/j.enbuild.2013.04.020.

Sun, K, and B Faltings. 1994. "Supporting Creative Mechanical Design." In In Artficial Intelligence in Design '94, 39-56. Kluwer, Amsterdam.

Taylor, John Robert. 1997. An Introduction to Error Analysis: The Study of Uncertainties in Physical Measurements. University Science Books.

Thamilseran, S. 1999. "An Inverse Bin Methodology to Measure the Savings from Energy Conservation Retrofits in Commercial Buildings." Ph.D. dissertation, College Station, TX: Texas A\&M University.

The American Institute of Architects. 1982a. The Architect's Handbook of Energy Practice: Analysis - Energy Analysis. Washington D.C, USA: The American Institute of Architects. . 1982b. The Architect's Handbook of Energy Practice: Design - HVAC Systems. Washington D.C, USA: The American Institute of Architects.

1982c. The Architect's Handbook of Energy Practice: Predesign - Climate and Site. Washington D.C, USA: The American Institute of Architects.

The Ministry of Economic Development. 2013. "New Zealand Energy Greenhouse Gas Emissions - 2011 Calender Year Edition.” Annual Publication ISSN 1179-4011. Wellington [N.Z.]: The Ministry of Economic Development. http://www.med.govt.nz/sectors-industries/energy/energy-modelling/publications/energygreenhouse-gas-emissions.

The Society of Light and Lighting. 2005. "Lighting Guide 7 : Office Lighting." Oxford; Boston: CIBSE.

Thornton, Brian A., Weimin Wang, Michael D. Lane, Michael I. Rosenberg, and Bing Liu. 2009. Technical Support Document: 50\% Energy Savings Design Technology Packages for Medium Office Buildings. Pacific Northwest National Laboratory. http://www.pnl.gov/main/publications/external/technical_reports/PNNL-19004.pdf.

Thornton, B, W Wang, Y Huang, M Lane, and B Liu. 2010. "Technical Suport Document: 50\% Energy Savings for Small Office Buildings." PNNL - 19341. Richland, WA: Pacific Northwest National Laboratory.

Thornton, B, W Wang, M Lane, M Rosenberg, and B Liu. 2009. "Technical Support Document: 50\% Energy Savings Design Technology Packages for Medium Office Buildings." Richland, WA: Pacific Northwest National Laboratory. 
Tian, Wei. 2013. "A Review of Sensitivity Analysis Methods in Building Energy Analysis." Renewable and Sustainable Energy Reviews 20 (April): 411-19. doi:10.1016/j.rser.2012.12.014.

Torcellini, Paul, Shanti Pless, Michael Deru, and Drury Crawley. 2006. "Zero Energy Buildings: A Critical Look at the Definition." Preprint. ACEEE Summer Study Pacific Grove. California, USA, August, 14-18.

Torcellini, P, M. Deru, B Griffith, K Benne, M Halverson, D Winiarski, and D Crawley. 2008. "DOE Commercial Building Benchmark Models." NREL/CP-550-43291. Golden, CO: NREL.

Torcellini, P, S Pless, M. Deru, B Griffith, N Long, and R Judkoff. 2006. "Lessons Learned from Case Studies of Six High-Performance Buildings.pdf." Technical Report NREL/TP-55037542. Golden, CO: NREL.

Transpower. 2013. "Major Electricity Transmission Network in New Zealand." Transpower. https://www.transpower.co.nz/f41,2209/2209_existing-national-grid.pdf.

Turner, C, and H Reichmuth. 2009. "Using Measured Whole-Building Performance for Green Building Program Evaluation." In , 751-63. Portland: New Building Institute (nbi).

UNFCCC. 2008. KYOTO PROTOCOL REFERENCE MANUAL ON ACCOUNTING OF EMISSIONS AND ASSIGNED AMOUNT. Germany: United Nations Framework Convention on Climate Change. $\mathrm{http} / / / \mathrm{unfccc}$.int/resource/docs/publications/08 unfecc kp ref manual.pdf.

United Nations. 1998. "KYOTO PROTOCOL TO THE UNITED NATIONS FRAMEWORK CONVENTION ON CLIMATE CHANGE." United Nations. http://unfccc.int/kyoto_protocol/items/2830.php.

United Nations Department of Economic and Social Affairs/Population Division. 2015. "World Population Prospects: The 2015 Revision, Key Findings and Advance Tables." Working Paper No. ESA/P/WP.241. New York, U.S: United Nations.

Urdan, Timothy C. 2010. Statistics in Plain English, Third Edition. 3 edition. New York: Routledge.

U.S. Department of Energy. 2013a. "About the Commercial Buildings Energy Consumption Survey." U.S. Energy Information Administration. http://www.eia.gov/consumption/commercial/about.cfm.

. 2013b. "Solid-State Lighting - LED Basics." U.S. Department of Energy: Energy Efficiency and Renewable Energy. http://www1.eere.energy.gov/buildings/ssl/sslbasics_ledbasics.html.

. 2013c. "Technologies Program SOLID-STATE LIGHTING TECHNOLOGY FACT SHEET: Energy Efficiency of LEDs." Factsheet PNNL-SA-94206. Washington D.C, USA: U.S. Department of Energy. http://apps1.eere.energy.gov/buildings/publications/pdfs/ssl/led_energy_efficiency.pdf. . 2014a. "New Zealand NIWA Climate Zones." EnergyPlus Energy Simulation Software. http://apps1.eere.energy.gov/buildings/energyplus/images/NZL_NIWA_ClimateZones.pn g.

2014b. "Weather Data Sources." EnergyPlus Energy Simulation Software. http://apps1.eere.energy.gov/buildings/energyplus/weatherdata_sources.cfm.

U.S. Department of Energy Federal Energy Management Program. 2013. "Photovoltaics." Whole Building Design Guide - A Program of the National Institute of Building Sciences. http://www.wbdg.org/resources/photovoltaics.php. 
US DOE. 2013a. "EnergyPlus Energy Simulation Software." Government. US Department of Energy - Energy Efficiency and Renewable Energy. $\mathrm{http} / / /$ apps1.eere.energy.gov/buildings/energyplus/.

. 2013b. "EnergyPlus Energy Simulation Software - EnergyPlus Documentation: Input/Output Reference." Government. US Department of Energy - Energy Efficiency and Renewable Energy. http://apps1.eere.energy.gov/buildings/energyplus/pdfs/inputoutputreference.pdf.

U.S. Energy Information Administration. 2013a. "2003 CBECS Survey Data." Commercial Buildings Energy Consumption Survey (CBECS). http://www.eia.gov/consumption/commercial/data/2003/\#a1.

. 2013b. "International Energy Outlook 2013: World Energy Demand and Economic Outlook." DOE/EIA-0484(2013). Washington D.C, USA: U.S. Energy Information Administration. http://www.eia.doe.gov/oiaf/ieo/world.html.

.2014a. "Annual Energy Outlook 2014 with Projections to 2040.” DOE/EIA-0383(2014). Washington D.C, USA: U.S. Department of Energy. http://www.eia.gov/forecasts/aeo/pdf/electricity_generation.pdf.

. 2014b. "Levelized Cost and Levelized Avoided Cost of New Generation Resources in the Annual Energy Outlook 2014." Washington D.C, USA: U.S. Department of Energy. http://www.eia.gov/forecasts/aeo/pdf/electricity_generation.pdf.

2015. "How Much Carbon Dioxide Is Produced When Different Fuels Are Burned?" Government. U.S. Energy Information Administration. https://www.eia.gov/tools/faqs/faq.cfm?id=73\&t=11.

U.S. Green Building Council. 2007. "Building Design Leaders Collaborating on Carbon-Neutral Buildings by 2030 Goal to Meet Specific Energy Reduction Targets." Press Release. EDC - The Official Magazine for the LEED Professional. May 7. $\mathrm{http}$ //www.edcmag.com/articles/building-design-leaders-collaborating-on-carbonneutral-buildings-by-2030-goal-to-meet-specific-energy-reduction-targets.

. 2013. "LEED - Rating Systems." LEED. http://www.usgbc.org/leed/rating-systems.

Versage, R, A Melo, and R Lamberts. 2010. "IMPACT OF DIFFERENT DAYLIGHTING SIMULATION RESULTS ON THE PREDICTION OF TOTAL ENERGY CONSUMPTION.” In , 1-7. New York City, NY: IBPSA.

Victoria University of Wellington. 2013. "Science Faculty HPC Facility." Victoria University of Wellington. http://ecs.victoria.ac.nz/EResearch/ScienceFacultyHPCFacility.

Voss, Karsten, Igor Sartori, Assunta Napolitano, S Geier, H Gonzalves, Monika Hall, Per Heiselberg, et al. 2010. "Load Matching and Grid Interaction of Net Zero Energy Buildings." In . Graz, Austria: IEA-SHC.

Voss, K, I. Sartori, and R Lollini. 2012. "Nearly-Zero, Net Zero and Plus Energy Buildings How Definitions \& Regulations Affect the Solutions." REHVA Journal December 2012: 23-37.

Voss, K, I. Sartori, A Napolitano, S Geier, H Gonzalves, M Hall, P Heiselberg, et al. 2010. "Net Zero Energy Buildings - Load Matching and Grid Interaction." Conference Presentation presented at the EuroSUN - International Conference on Solar Heating, Cooling and Buildings, Graz, Austria.

Walker, Andy. 2013. "Natural Ventilation." Whole Building Design Guide - A Program of the National Institute of Building Sciences. http://www.wbdg.org/resources/naturalventilation.php. 
Weber Saint-Gobain. 2014. "External Wall Insulation (EWI) Systems." Weber Saint-Gobain. https://www.netweber.co.uk/external-wall-insulation-systems/systems/weberthermexternal-wall-insulation-ewi-systems.html.

Wei, G., M. Liu, and D. E. Claridge. 1998. "Signatures of Heating and Cooling Energy Consumption for Typical AHUs." In In Proceedings of 11th Symposium on Improving Building Systems in Hot and Humid Climates, Fort Worth, Texas. http://repository.tamu.edu/handle/1969.1/6752.

Wetter, M. 2000. "Design Optimization with GenOpt." Building Energy Simulation User News 21: $10-28$.

- 2004. "Simulation Based Building Energy Optimization." PhD, Berkeley, CA: University of California, Berkeley.

Witte, M, R Henninger, J Glazer, and D Crawley. 2001. "TESTING AND VALIDATION OF A NEW BUILDING ENERGY SIMULATION PROGRAM." In Proceedings of the 7th IBPSA Conference, 353-60. Rio de Janeiro, Brazil: IBPSA. http://citeseerx.ist.psu.edu/viewdoc/download?doi=10.1.1.127.1734\&rep=rep1\&type=pdf

Woodroof, E. A. 2009. Green Facilities Handbook: Simple and Profitable Strategies for Managers. Lilburn, GA: The Fairmount Press.

World Water Council. 2014. "Water Crisis." World Water Council. http://www.worldwatercouncil.org/library/archives/water-crisis/.

Yip, S, and S Cory. 2013. "Use of Net Zero Energy Solution Sets for the Redesign of the Reunion Island ENERPOS Building in Christchurch." In Proceedings of Building Simulation 2013: 13th Conference of International Building Performance Simulation Association, Chambery, France, August 26-28, 1662-69. IBPSA. http://www.ibpsa.org/proceedings/BS2013/p_2135.pdf.

Yoon, Jongho, E. J. Lee, and D. E. Claridge. 2003. "Calibration Procedure for Energy Performance Simulation of a Commercial Building." Journal of Solar Energy Engineering 125 (3): 251-57. doi:10.1115/1.1564076.

Zhang, H, D Zabrowski, D Schrock, M Lane, D Fisher, R Athalye, A Livchak, and B Liu. 2010. "Technical Support Document: 50\% Energy Savings for Quick-Service Restaurants." Richland, WA: Pacific Northwest National Laboratory. 


\section{CHAPTER 14. APPENDIX}

\section{Appendix 14.1 New Zealand commercial building stock Net Zero Energy target}

\subsubsection{Dry and average years}

To calculate the net zero energy target, the split of electricity generated by renewable and nonrenewable sources was determined (Table 14-1). The split was used to calculate the proportion of commercial sector electricity consumption that was supplied from renewable and non-renewable fuels.

Table 14-1 : split of renewable and non-renewable electricity generation observed in the past 5 years (Energy Information and Modelling Group 2012b)

\begin{tabular}{|c|c|c|c|c|c|c|}
\hline Year & $\mathbf{2 0 0 7}$ & $\mathbf{2 0 0 8}$ & $\mathbf{2 0 0 9}$ & $\mathbf{2 0 1 0}$ & $\mathbf{2 0 1 1}$ & Average \\
\hline \% Non-renewable & $44 \%$ & $44 \%$ & $35 \%$ & $31 \%$ & $28 \%$ & $36 \%$ \\
\hline$\%$ Renewable & $56 \%$ & $56 \%$ & $65 \%$ & $69 \%$ & $72 \%$ & $64 \%$ \\
\hline
\end{tabular}

With the electricity split by renewable and non-renewable sources, the split of renewable and non-renewable fuels consumed by the commercial sector was differentiated. The results were used to calculate a dry and average weather year from the last five years. A dry year would have higher non-renewable proportion due to less hydro-electric generation from less rain fall. The average weather year would be the closet to the five year average proportion. It was identified that 2008 was a dry year, and 2009 was the closest to an average weather year.

As the Net Zero Energy (NZE) target is to reflect the worst case scenario for renewable energy generation supply, the dry year was used to calculate the primary energy NZE target.

\subsubsection{Primary energy target}

The first step in calculating the NZE target was to determine the final energy consumed by the commercial sector during the dry year. This includes all energy fuels, not just electricity. The final energy consumption was then multiplied by their associated primary energy and transmission losses factors to calculate their primary energy consumption values.

The electricity information was not split into various generation sources (Hydro-electric, wind, gas, coal etc...) for the commercial sector. Instead, only a total electricity consumption value is provided (Energy Information and Modelling Group 2012b). As all electricity generation is supplied to the same national grid, the proportion of generation from different sources and their primary energy factors were used to determine the commercial sector's electricity primary energy consumption.

Table 14-2 displays the final energy supply from the various generation sources in 2008 and their conversion to primary energy. 
Table 14-2: Final energy supply from the various generation sources in 2008 and their conversion to primary energy

\begin{tabular}{|c|c|c|c|c|c|c|c|}
\hline Year & 2008 (Dry & ear) (Ener & y Informatio & and Mode & ing Group & (12b) & \\
\hline $\begin{array}{l}\text { Electricity } \\
\text { generated by } \\
\text { Fuel type }\end{array}$ & $\begin{array}{c}\text { Final Energy } \\
\text { (PJ) (Energy } \\
\text { Information } \\
\text { and } \\
\text { Modelling } \\
\text { Group } \\
2012 \mathrm{~b} \text { ) }\end{array}$ & \multirow{10}{*}{$\begin{array}{l}\text { Convert } \\
\text { Final Energy } \\
\text { to Primary } \\
\text { Energy to } \\
\text { calculate } \\
\text { Percentage } \\
\text { split of } \\
\text { primary } \\
\text { energy } \\
\text { electricity } \\
\text { supply to } \\
\text { commercial } \\
\text { building } \\
\text { sector }\end{array}$} & $\begin{array}{l}\text { Transmission } \\
\text { Losses } \\
\text { (Energy } \\
\text { Information } \\
\text { and Modelling } \\
\text { Group 2012b) }\end{array}$ & $\begin{array}{c}\text { Default } \\
\text { Efficiency } \\
\text { (Energy } \\
\text { Information } \\
\text { and } \\
\text { Modelling } \\
\text { Group } \\
\text { 2012b) }\end{array}$ & $\begin{array}{c}\text { Primary } \\
\text { Energy } \\
\text { Factor } \\
\text { (Energy } \\
\text { Information } \\
\text { and } \\
\text { Modelling } \\
\text { Group } \\
\text { 2012b) }\end{array}$ & \multirow{10}{*}{$\begin{array}{c}\text { Multiply Final } \\
\text { energy by } \\
\text { Primary Energy } \\
\text { Factor and } \\
\text { Transmission } \\
\text { Losses }\end{array}$} & $\begin{array}{c}\text { Primary } \\
\text { Energy } \\
(\mathrm{PJ})\end{array}$ \\
\hline Hydro & 79.6 & & 1.01 & 1.00 & 1.00 & & 80.4 \\
\hline Geothermal & 14.3 & & 1.06 & 0.14 & 6.93 & & 104.8 \\
\hline Biogas & 0.7 & & 1.07 & 0.30 & 3.33 & & 2.6 \\
\hline Wood & 1.2 & & 1.07 & 0.25 & 4.00 & & 5.0 \\
\hline Wind & 3.8 & & 1.01 & 1.00 & 1.00 & & 3.8 \\
\hline Oil & 0.4 & & 1.07 & 0.32 & 3.13 & & 1.5 \\
\hline Coal & 16.3 & & 1.07 & 0.29 & 3.42 & & 59.5 \\
\hline Gas & 35.8 & & 1.07 & 0.41 & 2.41 & & 92.5 \\
\hline Waste Heat & 0.2 & & 1.07 & 0.15 & 6.67 & & 1.4 \\
\hline
\end{tabular}

Table 14-3 displays the calculated Renewable and Non-renewable electricity Primary Energy Factors. The factors were calculated by averaging renewable and non-renewable Primary Energy Factor and Transmission Losses factors. Primary Energy Factor + Transmission Losses was calculated by multiplying factors together

Table 14-3 : Calculated Renewable and Non-renewable electricity Primary Energy Factors

\begin{tabular}{|c|c|c|c|}
\hline Electricity Source Type & $\begin{array}{c}\text { Transmission } \\
\text { Losses }\end{array}$ & $\begin{array}{c}\text { Primary Energy } \\
\text { Factor }\end{array}$ & $\begin{array}{c}\text { Primary Energy } \\
\text { Factor }+ \\
\text { Transmission } \\
\text { Losses }\end{array}$ \\
\hline Renewable & 1.04 & 3.25 & 3.40 \\
\hline Non-renewable & 1.07 & 3.91 & 4.18 \\
\hline
\end{tabular}

Page $\mid 335$ 
Table 14-4 presents the final energy and calculated primary energy consumed by the commercial sector in 2008.

Table 14-4 : Commercial Sector Energy Consumption (Energy Information and Modelling Group 2012b)

\begin{tabular}{|c|l|l|l|}
\hline Fuel types & $\begin{array}{l}\text { Primary Energy } \\
\text { Factor } \\
\text { Transmission } \\
\text { Losses } \\
\text { (Obtained from } \\
\text { (Energy Information } \\
\text { and Modelling Group } \\
\text { 2012b)) }\end{array}$ & $\begin{array}{l}\text { Final } \\
\text { (Obtained from } \\
\text { (Energy Information } \\
\text { and Modelling Group } \\
\text { 2012b)) }\end{array}$ & $\begin{array}{l}\text { Primary (GWh) } \\
\text { (Calculated by } \\
\text { multiplying final } \\
\text { energy by primary } \\
\text { energy factor) }\end{array}$ \\
& 1.03 & $1,257.9$ & $1,298.9$ \\
\hline Coal & 1.03 & $1,529.2$ & $1,579.0$ \\
\hline Oil & 1.10 & $1,214.0$ & $1,332.3$ \\
\hline Natural Gas & & 685.5 & 685.5 \\
\hline Direct Geothermal & & 91.6 & 91.6 \\
\hline Direct Biogas & & &
\end{tabular}

\begin{tabular}{|c|c|c|c|}
\hline Total Electricity & & $9,276.5$ & \\
\hline $\begin{array}{c}\text { Renewable Electricity } \\
\text { (Calculated by } \\
\text { multiplying total final } \\
\text { electricity by percentage } \\
\text { renewable) }\end{array}$ & $\begin{array}{c}\text { 3.40 (From Table 14- } \\
\text { 2) }\end{array}$ & $6,064.3$ & $20,588.8$ \\
\hline $\begin{array}{c}\text { Non-renewable } \\
\text { Electricity (Calculated } \\
\text { by multiplying total final } \\
\text { electricity by percentage } \\
\text { non-renewable) }\end{array}$ & $\begin{array}{c}4.18 \text { (From Table 14- } \\
\text { 2) }\end{array}$ & $3,212.2$ & $13,424.7$ \\
\hline $\begin{array}{c}\text { Total Commercial } \\
\text { Sector }\end{array}$ & & $14,054.8$ & $39,000.8$ \\
\hline
\end{tabular}

\begin{tabular}{|c|c|c|c|}
\hline $\begin{array}{c}\text { Percentage of Supply } \\
\text { that is Renewable }\end{array}$ & - & $49 \%$ & $55 \%$ \\
\hline $\begin{array}{c}\text { Percentage of Supply } \\
\text { that is Non-Renewable }\end{array}$ & - & $51 \%$ & $45 \%$ \\
\hline
\end{tabular}




\subsubsection{Commercial Sector Primary Energy Factor}

All results obtained from the 48 energy models were presented in final energy. To convert the final energy to primary energy for the NZE balance, a primary energy factor was needed. Table 14-5 displays the calculated primary energy consumption for the commercial sector and therefore the commercial building stock.

Table 14-5 : calculated primary energy consumption for the commercial sector

\begin{tabular}{|l|c|cc|}
\cline { 2 - 4 } \multicolumn{1}{l|}{} & $\begin{array}{l}\text { Final energy consumption } \\
(\mathrm{GWh})\end{array}$ & $\begin{array}{l}\text { Primary } \\
(\mathrm{GWh})\end{array}$ & \multicolumn{2}{c|}{$39,000.8$} \\
\hline $\begin{array}{l}\text { Total Commercial } \\
\text { Sector }\end{array}$ & \multicolumn{1}{|c|}{$14,054.8$} & consumption \\
\hline $\begin{array}{l}\text { Divide total Primary energy by Total Final energy to obtain Commercial Sector's Primary } \\
\text { Energy Factor }\end{array}$ \\
$\begin{array}{l}\text { Commercial Sector } \\
\text { Primary energy factor }\end{array}$
\end{tabular}

\section{Appendix 14.2 Lessons learned - survey building information and questions}

\section{Appendix 14.2a Characteristics of lessons learned - surveyed buildings}

Table 14-5a displays the characteristics of each of the seven participating buildings. They range from a $200 \mathrm{~m}^{2}$ single storey building to a ten storey building over $5000 \mathrm{~m}^{2}$ in area. Three of the buildings are educational buildings and four are office buildings. All buildings were either constructed or renovated after the year 2001.

\begin{tabular}{|c|c|c|c|c|c|}
\hline & $\begin{array}{c}\text { Building Climate } \\
\text { Type } \\
\text { (External Climate } \\
\text { Type) } \\
\end{array}$ & $\begin{array}{l}\text { Building } \\
\text { Use }\end{array}$ & $\begin{array}{l}\text { Floor } \\
\text { Area }\end{array}$ & $\begin{array}{l}\mathbf{N}^{0} \text { of } \\
\text { storeys }\end{array}$ & $\begin{array}{c}\text { Construction/ } \\
\text { Renovation } \\
\text { Year }\end{array}$ \\
\hline Building 1 & $\begin{array}{l}\text { Mixed Heating and } \\
\text { Cooling (Moderate) }\end{array}$ & Educational & $204 \mathrm{~m}^{2}$ & 1 & 2001 \\
\hline Building 2 & $\begin{array}{l}\text { Mixed Heating and } \\
\text { Cooling (Moderate) }\end{array}$ & $\begin{array}{c}\text { Office } \\
\text { Building }\end{array}$ & $609 \mathrm{~m}^{2}$ & 2 & 2007 \\
\hline Building 3 & $\begin{array}{l}\text { Cooling Dominated } \\
\text { (Hot) }\end{array}$ & Educational & $681 \mathrm{~m}^{2}$ & 3 & 2009 \\
\hline Building 4 & $\begin{array}{l}\text { Mixed Heating and } \\
\text { Cooling (Cold) }\end{array}$ & Education & $\begin{array}{c}2959 \\
\mathrm{~m}^{2}\end{array}$ & $3-4$ & 2010 \\
\hline Building 5 & $\begin{array}{l}\text { Mixed Heating and } \\
\text { Cooling (Cold) }\end{array}$ & $\begin{array}{c}\text { Office } \\
\text { Building }\end{array}$ & $\begin{array}{l}5246 \\
\mathrm{~m}^{2}\end{array}$ & 4 & 2007 \\
\hline Building 6 & $\begin{array}{l}\text { Mixed Heating and } \\
\text { Cooling (Cold) }\end{array}$ & $\begin{array}{c}\text { Office } \\
\text { Building }\end{array}$ & $\begin{array}{l}3983 \\
\mathrm{~m}^{2}\end{array}$ & 7 & 2011 \\
\hline Building 7 & $\begin{array}{l}\text { Mixed Heating and } \\
\text { Cooling (Cold) }\end{array}$ & $\begin{array}{c}\text { Office } \\
\text { Building }\end{array}$ & $\begin{array}{c}5000 \\
\mathrm{~m}^{2}\end{array}$ & 10 & 2009 \\
\hline
\end{tabular}

Page | 337 


\section{Appendix 14.2b Energy balances for lessons learned - surveyed buildings}

Figure 14-0 displays the primary energy balance for each of the seven buildings. The graph presents the primary energy consumed (red) as positive consumption, the primary energy generated (green) in negative primary energy consumption, and the energy balance (yellow dot) as the positive energy consumption minus the negative energy consumption. Therefore, if the energy balance (yellow dot) is equal to zero on the graph, the building is a net zero energy building. If the energy balance it is below zero, it is a positive energy building. If the energy balance is above zero, it is an energy consuming building and therefore not classed as a Net ZEB.

Figure 14-0- Energy balance for the seven participating buildings

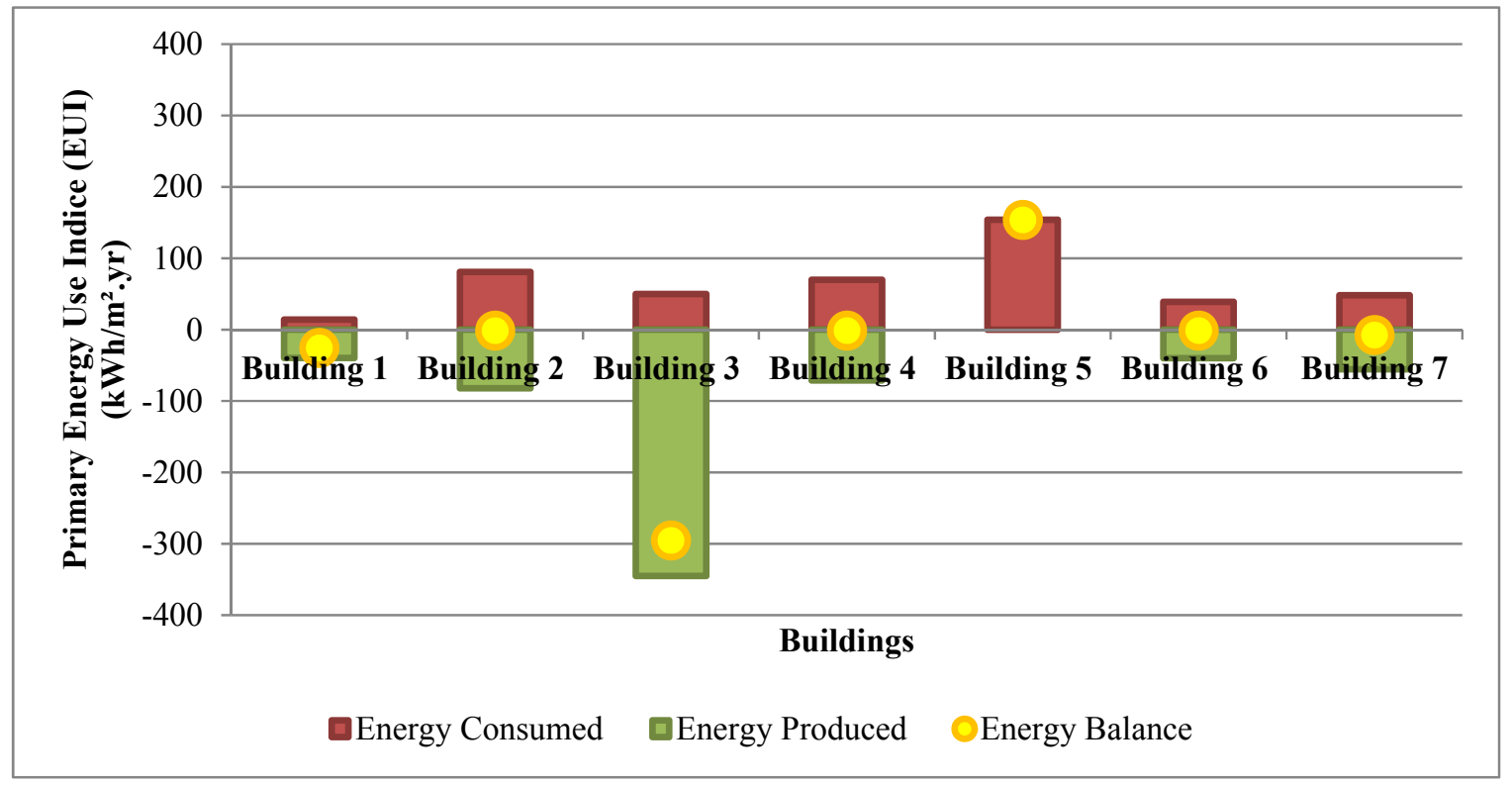

As can be seen, six of the seven buildings are Net ZEB. In reality, all seven are Net ZEBs depending on what Net ZEB definition is applied. Buildings 1, 2, 3, and 4 are net zero onsite energy buildings (all onsite energy use is offset with onsite renewable energy generation). Building 5 is a net zero offsite energy building (all onsite energy use is offset with offsite renewable energy generation). Buildings 6 and 7 are net zero central services energy buildings (all onsite central services energy use is offset with onsite renewable energy generation).

Building 5 has a small $5 \mathrm{~kW}$ Photovoltaic (PV) array on the roof, but energy data was not available for this study. Even with the small PV array, the building is not net zero energy onsite. However, the building sources its electricity from a renewable energy company which produces its local energy from a large wind turbine farm $10 \mathrm{~km}$ from the building site.

Page $\mid 338$ 
Building 6 uses a local policy definition of what a Net ZEB is. The definition requires that only the services related to the use of the building be offset; this excludes any services used by the tenant (in this case, the office equipment). Therefore, if all energy end-uses were included in the energy balance, building 6 would not be net zero energy as the residual building energy would not entirely be offset by the renewable energy generation. Building 7 uses the same local policy Net ZEB definition and if the office equipment was included in the balance it would not reach net zero energy.

\section{Appendix 14.2c Survey questionnaire for lessons learned by Net ZEB design teams}

Net ZEB Design Process

1. What was the design intent of the building?

a. Was it built around the tenants?

b. Was it built simply to achieve a green star rating?

c. What was your aim with this building? Why design green?

2. Was there anything in the design you thought about doing, but couldn't do, or decided not to do? Why?

3. What was removed for budgetary reasons, but is regretted? What was too expensive but believed would work well?

\section{Net ZEB Design and Technological Solutions}

4. What Passive systems work well in your building? Why?

5. What Energy Efficiency Technologies work well in your building? Why?

6. What Renewable Energy Generation systems work well in your building? Why?

\section{Post-Construction evaluation of the Net ZEBs}

7. What would you do again? Why? For which type of buildings? In which climates?

8. What would you not do again? Why? For which type of buildings? In which climates?

9. With the solution that does not work, what would you do now instead?

10. Is there anything you would do or do differently if you were going to do this building again? Why?

11. What recommendations do you have for designers of future Net ZEBs that are to be built in a similar climate and has the same activity?

12. In your opinion what are the 'selling' features of the building?

13. What simulation tool(s) did you use for the early design, developed design and finalized design stages for the design of the energy, daylighting, natural ventilation and HVAC performance? 


\section{Appendix 14.3 Impact of energy consumption on stock aggregation using floor area}

\subsubsection{Impact of different energy consumption in five percent of all floor area on}

the stock aggregation estimate

As seen in Table 14-6 below, if the energy consumed by 5 percent of the floor area was twice as high as the rest, it would produce a 5 percent difference in aggregated energy consumption.

Table 14-6 : Stock aggregation of with 5 percent of floor area having twice as high energy consumption

\begin{tabular}{|c|c|c|c|c|c|c|}
\hline Location & $\begin{array}{l}\text { EnPI floor } \\
\text { area split }\end{array}$ & Floor area & Energy Use & $\begin{array}{r}\text { EnPI floor } \\
\text { area combine }\end{array}$ & Energy Use & \multirow{8}{*}{$\begin{array}{r}\text { Difference } \\
\text { between } \\
\text { total energy } \\
\text { use }\end{array}$} \\
\hline $\begin{array}{l}\text { Northland } \\
\text { \& Auckland }\end{array}$ & 100 & $12,097,863$ & $1,209,786,389$ & 100 & $1,209,786,389$ & \\
\hline $\begin{array}{r}\text { Waikato \& } \\
\text { Bay of } \\
\text { Plenty }\end{array}$ & 100 & $2,886,308$ & $288,630,836$ & 100 & $288,630,836$ & \\
\hline $\begin{array}{r}\text { East Coast } \\
\text { / Napier \& } \\
\text { Nelson \& } \\
\text { West Coast }\end{array}$ & 100 & $1,784,312$ & $178,431,219$ & 100 & $178,431,219$ & \\
\hline $\begin{array}{r}\text { Taranaki \& } \\
\text { Manawatu- } \\
\text { Wanganui } \\
\text { (5\% of all } \\
\text { floor area } \\
\text { in New } \\
\text { Zealand) }\end{array}$ & 200 & $1,336,576$ & $267,315,200$ & 100 & $133,657,607$ & \\
\hline $\begin{array}{r}\text { Wellington } \\
\& \\
\text { Waiarapa } \\
\end{array}$ & 100 & $7,444,195$ & $744,419,506$ & 100 & $744,419,506$ & \\
\hline Canterbury & 100 & $2,866,520$ & $286,652,074$ & 100 & $286,652,074$ & \\
\hline $\begin{array}{r}\text { Southland } \\
\text { \& Otago }\end{array}$ & 100 & $1,276,223$ & $127,622,369$ & 100 & $127,622,369$ & \\
\hline Total & - & - & $3,102,857,593$ & - & $2,969,200,000$ & $5 \%$ \\
\hline
\end{tabular}




\subsubsection{Impact of Lauder's small percentage of floor area on the stock aggregation estimate}

Table 14-7 presents a theoretical test aggregation made with and without the Lauder/Queenstown climates split. If the energy consumption in Lauder was twice as high as the energy consumption across the rest of the country, it would make a 0.9 percent difference to the aggregated annual energy consumption.

\begin{tabular}{|c|c|c|c|c|c|c|}
\hline Location & $\begin{array}{l}\text { EnPI floor } \\
\text { area split }\end{array}$ & Floor area & Energy Use & $\begin{array}{r}\text { EnPI floor area } \\
\text { combine }\end{array}$ & Energy Use & \multirow{9}{*}{$\begin{array}{r}\text { Difference } \\
\text { between tota } \\
\text { energy use }\end{array}$} \\
\hline $\begin{array}{l}\text { Northland } \\
\text { \& Auckland }\end{array}$ & 100 & $12,097,863$ & $\begin{array}{r}1,209,786,38 \\
9\end{array}$ & 100 & $\begin{array}{r}1,209,786,38 \\
9\end{array}$ & \\
\hline $\begin{array}{r}\text { Waikato \& } \\
\text { Bay of } \\
\text { Plenty }\end{array}$ & 100 & $2,886,308$ & $288,630,836$ & 100 & $288,630,836$ & \\
\hline $\begin{array}{r}\text { East Coast } \\
\text { / Napier \& } \\
\text { Nelson \& } \\
\text { West Coast }\end{array}$ & 100 & $1,784,312$ & $178,431,219$ & 100 & $178,431,219$ & \\
\hline $\begin{array}{r}\text { Taranaki \& } \\
\text { Manawatu- } \\
\text { Wanganui }\end{array}$ & 100 & $1,336,576$ & $133,657,607$ & 100 & $133,657,607$ & \\
\hline $\begin{array}{r}\text { Wellington } \\
\& \\
\text { Waiarapa }\end{array}$ & 100 & $7,444,195$ & $744,419,506$ & 100 & $744,419,506$ & \\
\hline Canterbury & 100 & $2,866,520$ & $286,652,074$ & 100 & $286,652,074$ & \\
\hline $\begin{array}{r}\text { Southland } \\
\text { \& Otago } \\
\text { (without } \\
\text { Queenstow } \\
\text { n) }\end{array}$ & 100 & $1,018,330$ & $127,622,369$ & 100 & $127,622,369$ & \\
\hline $\begin{array}{r}\text { Queenstow } \\
\text { n/Lauder }\end{array}$ & 200 & 257,893 & $51,578,600$ & 100 & $25,789,300$ & \\
\hline Total & - & - & $\begin{array}{r}3,020,778,60 \\
0\end{array}$ & - & $\begin{array}{r}2,994,989,30 \\
0\end{array}$ & $0.9 \%$ \\
\hline
\end{tabular}

Page | 341 


\section{Appendix 14.4 Example of real building information used to create EnergyPlus model of 48 BEES case study buildings}

Figure 14-1 to 14-4 presents the building information for an example case study building. The example building was a single premise building which means the data was for the whole building. On multi-premise buildings, all data for both premises was obtained to calculate the appropriate load averages and patterns of use.

\begin{tabular}{|c|c|c|c|}
\hline \multicolumn{4}{|c|}{ Geometry } \\
\hline & Built Form & OP5_Heat Pump & $\overline{T e m p l a t e}$ Geometry to Uze \\
\hline & Building Orientation & 300 & $\overline{D e g r e c e}_{\text {- Clockwise from North, } 0=\text { North }}$ \\
\hline & Totol Building Floor Ares & 599 & $\overline{\mathrm{m}^{2}}$ Input into spesdshect - ModelGeonetry_Calculations \\
\hline & Total Number of Storeys & $\mathbf{1}$ & \# Input into spesdsheet - ModelGeonetry_Calculations \\
\hline & Building Height & 4.75 & $\mathrm{~m}$ Input into spesdsheet - ModelGeometry_Calculations \\
\hline \multirow{4}{*}{ Glseing Percentoge } & $\mathrm{N}$ & $70 \%$ & $\overline{8}$ Input into spesdsheet - ModelGeonetry_Calculations \\
\hline & E & $5 \%$ & * Input into spesdshect - ModelGeonetry_Calculations \\
\hline & s & $15 \%$ & * Input into spesdsheet - ModelGeometry_Calculations \\
\hline & $\mathrm{w}$ & $20 \%$ & 7. Input into spesdshect - ModelGeonetry_Calculations \\
\hline \multicolumn{3}{|c|}{ Constructions } & \\
\hline Primary Euilding Fobric & Façade material & Brick & \\
\hline \multirow{2}{*}{ Secondary Euilding Fabric } & Façade material & NHA & \\
\hline & Insulated & Don't Knoy & \\
\hline \multirow{2}{*}{ Roof Construction } & Moteris| & Steel/G-Iron & \\
\hline & Inzulsted & Don't Knoy & \\
\hline \multirow{2}{*}{$\begin{array}{l}\text { Foundstion / Ground / Bssement } \\
\text { floor } \\
\end{array}$} & Moteris| & Suspended timber & \\
\hline & Insulsted & Don't Know & \\
\hline \multirow{4}{*}{ Glsaing Type } & $\mathrm{N}$ & Single & \\
\hline & $\mathrm{E}$ & Single & \\
\hline & s & Single & \\
\hline & $\mathrm{w}^{\prime}$ & Single & \\
\hline \multirow{4}{*}{ Glszing Froming Moterisl } & $\mathrm{N}$ & Yood or PYC & \\
\hline & $\mathrm{E}$ & Yood or PYC & \\
\hline & s & Yood or PYC & \\
\hline & $w$ & Yood or PYC & \\
\hline & & & \\
\hline \multirow{4}{*}{ Glseing Tint } & $\mathrm{N}$ & Heavy & \\
\hline & $\mathrm{E}$ & None & \\
\hline & s & None & \\
\hline & $\mathrm{w}^{\prime}$ & None & \\
\hline \multirow{4}{*}{ Glszing Reflective Tint } & $\mathrm{N}$ & None & \\
\hline & E & None & \\
\hline & s & None & \\
\hline & $\mathrm{w}^{\prime}$ & None & \\
\hline
\end{tabular}

Figure 14-1 : Building Geometry and construction 


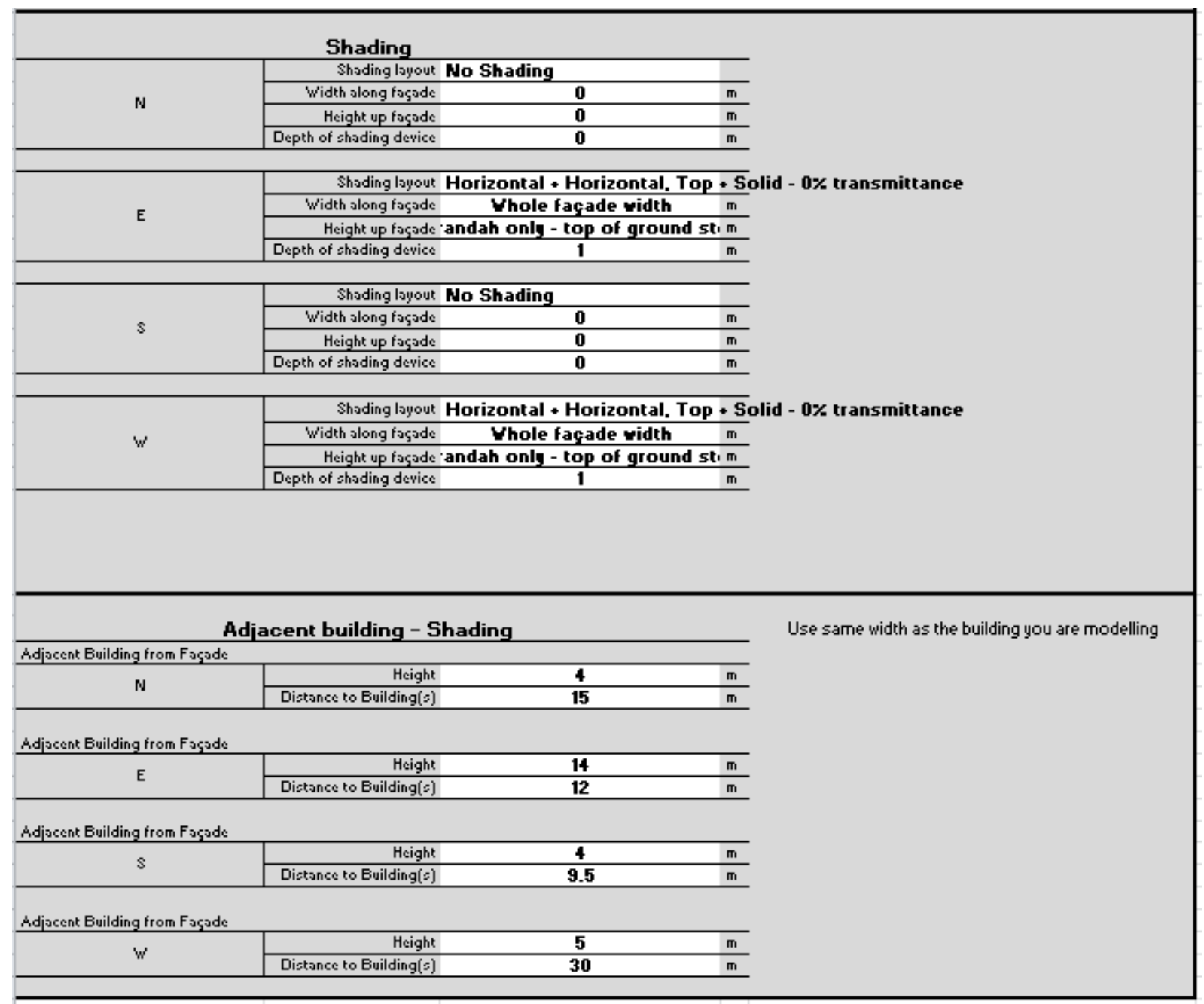

Figure 14-2 : Building shading

Page | 343 


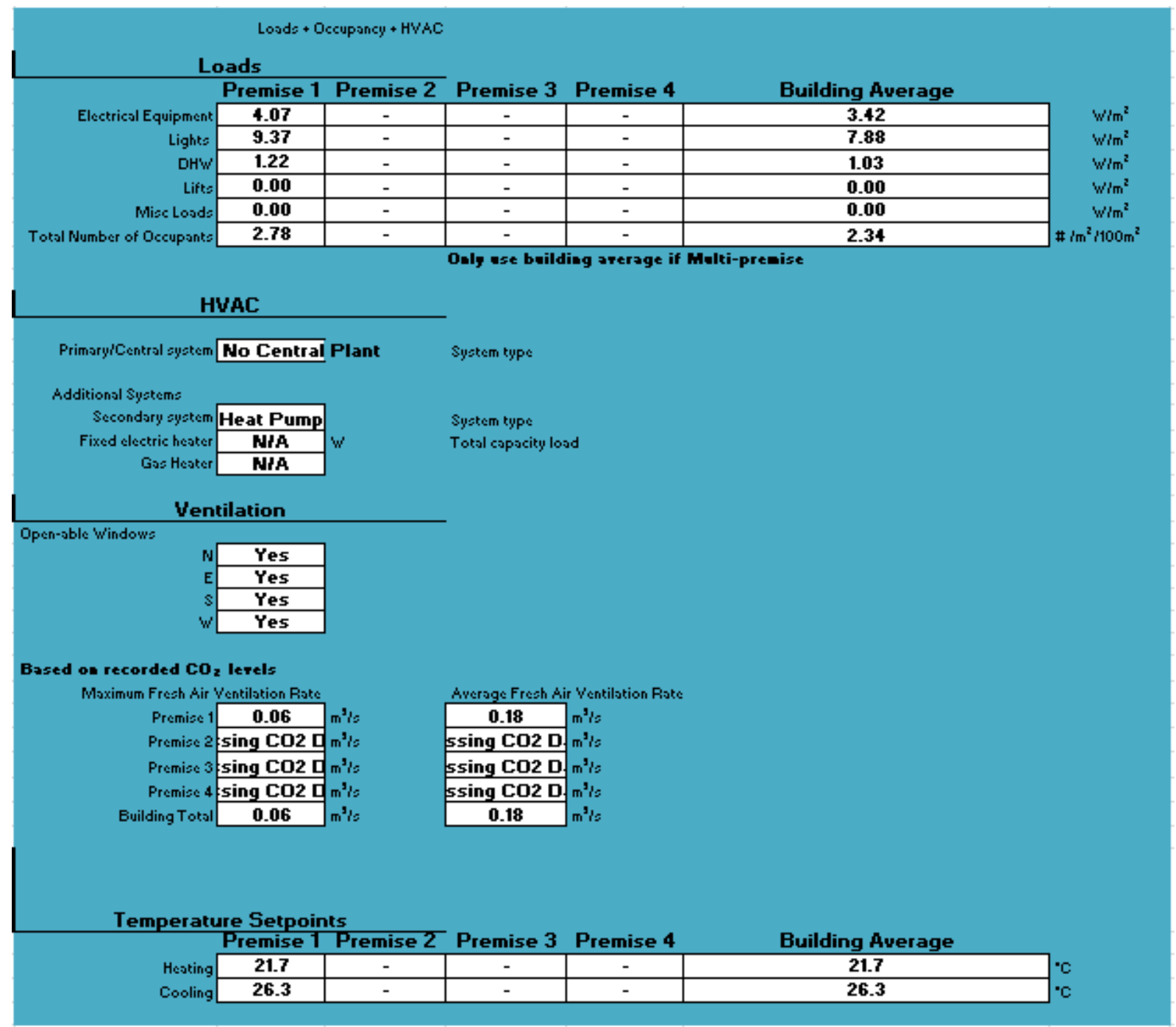

Figure 14-3 : Building load, HVAC, and heating and cooling set points 


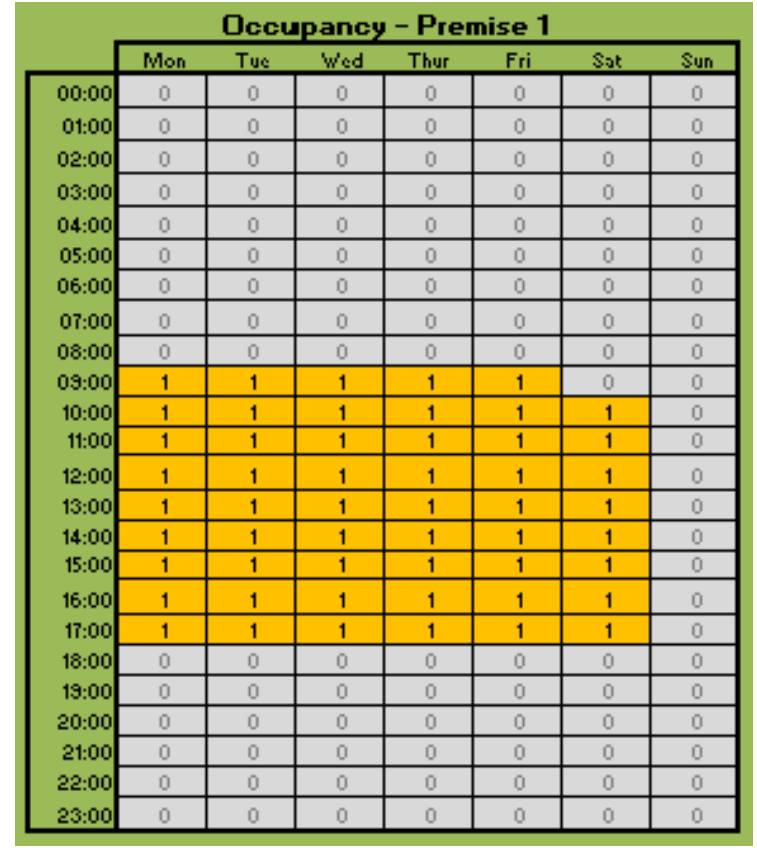

Schedules $=$ EnergyPlus terminology for patterns of operation. For example, $1=$ $100 \%$ load on.

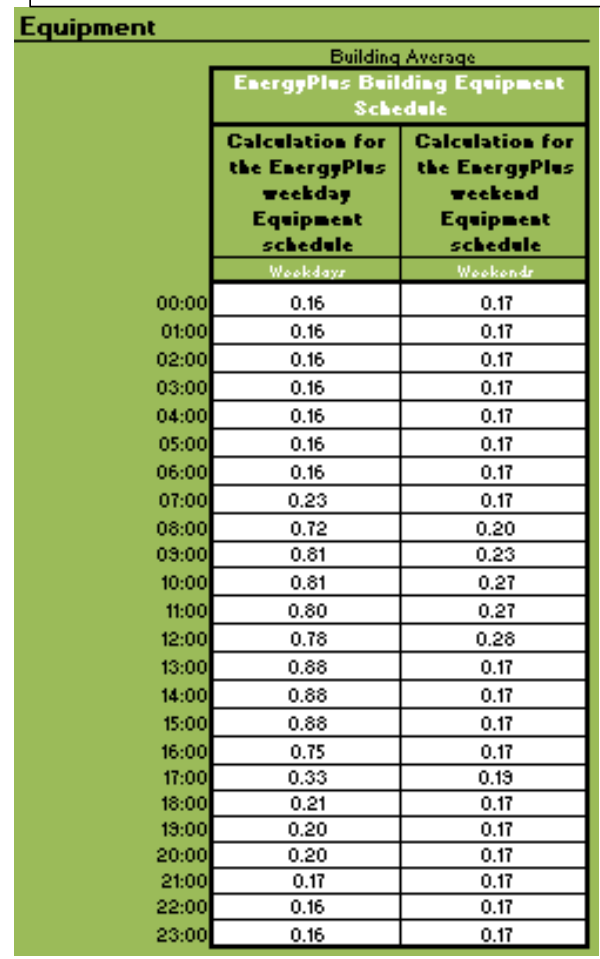

Figure 14-4 : Building load operation patterns and occupied hours
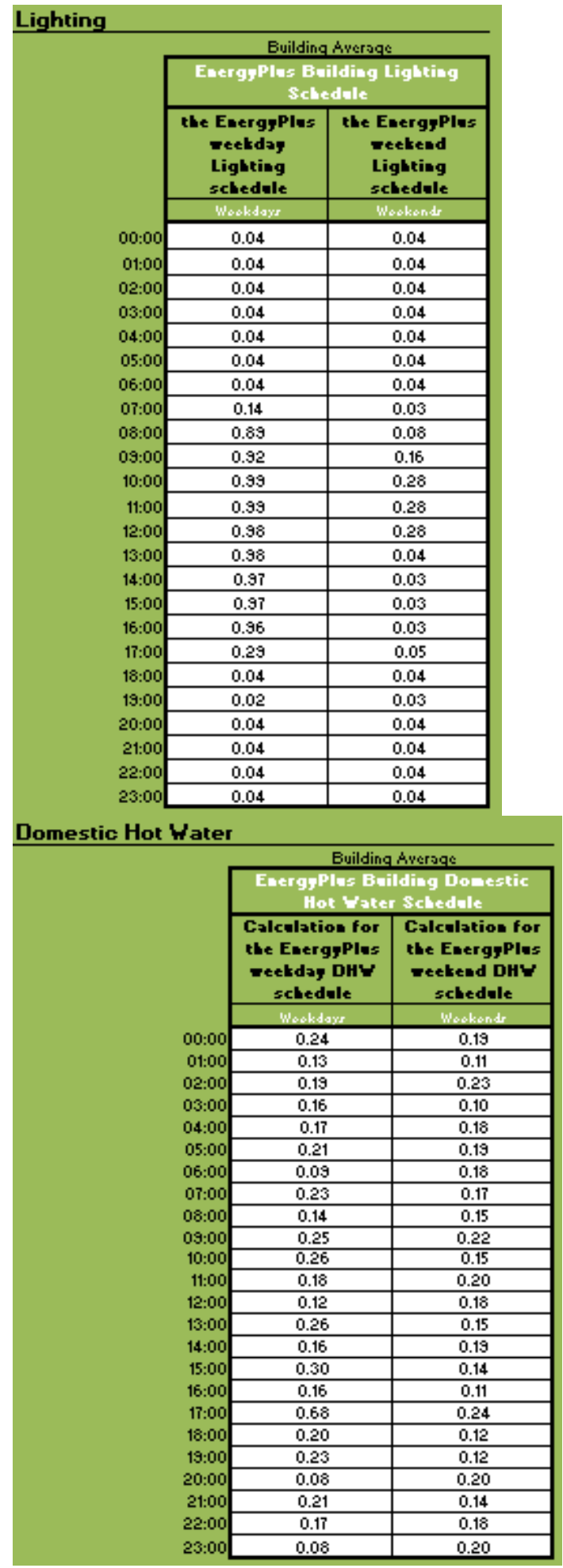

ned. 


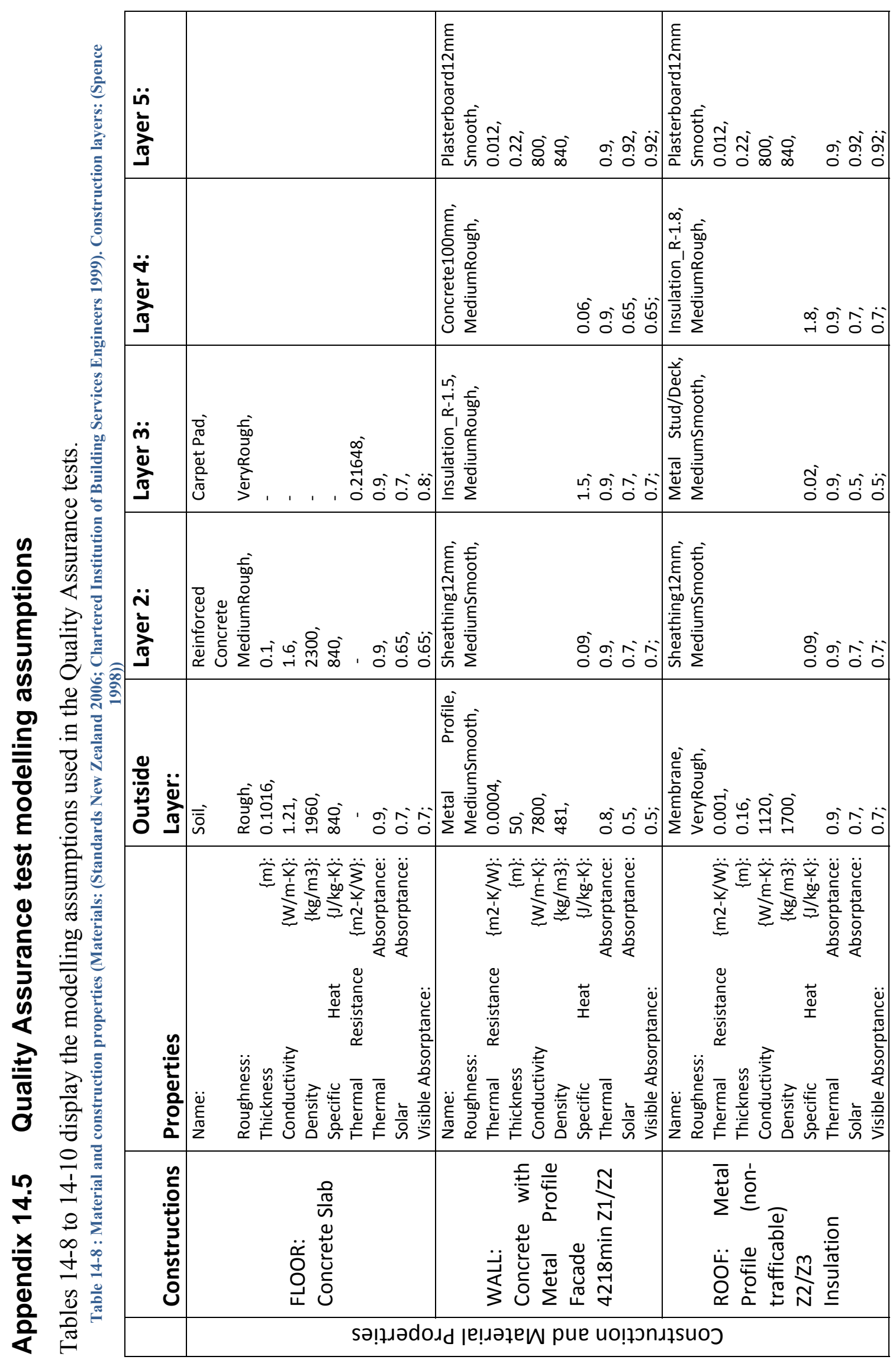

$\frac{0}{4}$ 

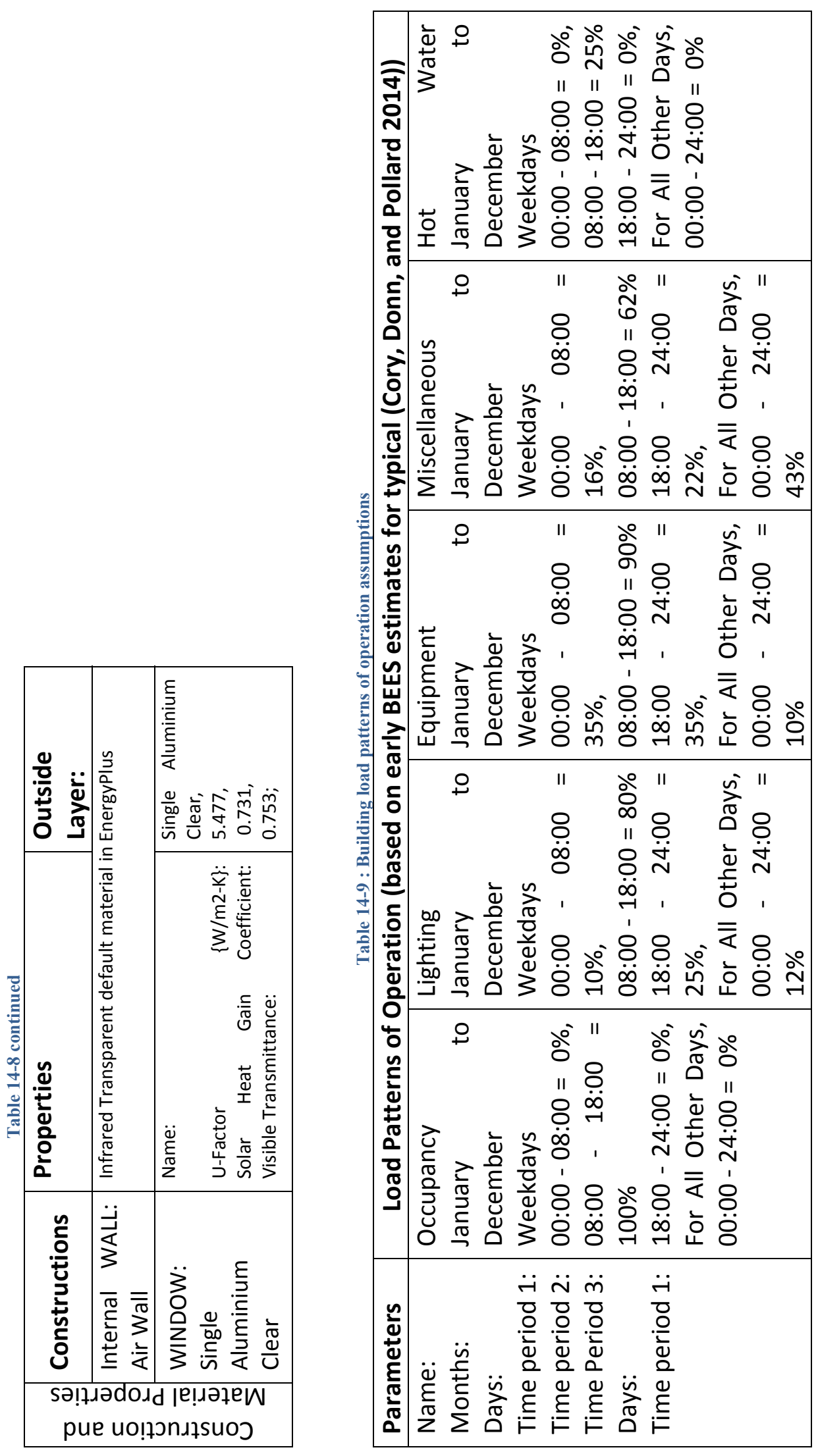


\begin{tabular}{|c|c|}
\hline Parameters & Assumptions \\
\hline WWR & 50\% (Standards New Zealand 2007a) \\
\hline Infiltration & 0.5ACH (Standards New Zealand 2007a) \\
\hline Ventilation & 10l/s.p (Standards New Zealand 1990) \\
\hline People & $\begin{array}{l}\text { People per Zone Floor Area } \text { \{person/m2\}: } 0.1, \text { (Standards New } \\
\text { Zealand } \\
\text { Fraction } \quad \text { Radiant: } \\
\text { Activity Level Schedule Name: }\end{array}$ \\
\hline LPD & $\begin{array}{l}\text { Watts per Zone Floor Area }\{\mathrm{W} / \mathrm{m} 2\} \text { : } 12.0 \text {, (Standards New Zealand } \\
2007 \mathrm{~b})\end{array}$ \\
\hline EPD & $\begin{array}{l}\text { Watts per Zone Floor Area }\{\mathrm{W} / \mathrm{m} 2\} \text { : } 8.5 \text {, (Standards New Zealand } \\
\text { 2007a) }\end{array}$ \\
\hline MPD & $\begin{array}{l}\text { Watts per Zone Floor Area }\{\mathrm{W} / \mathrm{m} 2\} \text { : } 4 \text {,(Based on early BEES } \\
\text { estimates for typical (Cory, Donn, and Pollard 2014) }\end{array}$ \\
\hline HW & $\begin{array}{l}\text { Watts per Zone Floor Area }\{\mathrm{W} / \mathrm{m} 2\} \text { : } 2.3 \text {, (Based on early BEES } \\
\text { estimates for typical (Cory, Donn, and Pollard 2014) }\end{array}$ \\
\hline Lighting Controls & $\begin{array}{l}\text { Daylight set point: 350Lux (Standards Association of Australia and } \\
\text { Standards New 2009) } \\
\text { Control Type: Continuous/Off - The overhead lights dim continuously } \\
\text { and linearly from (maximum electric power, maximum light output) to } \\
\text { (minimum electric power, minimum light output) as the daylight } \\
\text { illuminance increases. Lights switch off completely when the } \\
\text { minimum dimming point is reached (US DOE 2013b). }\end{array}$ \\
\hline Thermostat & $18-25^{\circ} \mathrm{C}$ (based on (Givoni 1998) expanded comfort) \\
\hline HVAC & New Zealand Split System Heat Pump (A Gates 2013) \\
\hline
\end{tabular}




\section{Appendix 14.6 Process for creating custom EnergyPlus weather files}

\section{Author: Anthony Gates (2011)}

\section{Convert .epw to csv. Collect real time data. Input real time data into csv. Convert csv to}

.epw.

\section{Convert .epw to .csv.}

EnergyPlus weather converter - convert any standard EnergyPlus weather (.epw) file into a .csv file.

EP-Launch -> Utilities -> Weather drop down -> Run Weather.

In EnergyPlus weather converter.

- Select file to convert -> select any .epw file -> open

- Select output format -> CSV format of EPW data

- Save file as -> save location / name -> open

- Convert file.

This is now the template file used to create custom weather files with real data.

\section{Collect real time data.}

The weather file data must match the timeframe that the data for the building was collected. eg. if the measured energy consumption is from 2009, 2009 weather data is needed.

Raw data is obtained from NIWA -> CliFlo. a login account is need to retrieve the data.

Once logged in $->$ there are 4 sections to fill in.

1. Data type $->$ select datatypes $->$ daily and hourly obs $\rightarrow>$ The data Parameters required are:

- Dry-bulb Air Temperature

D

- Dew-point Temperature

$\mathrm{E}$

- Relative Humidity F

- Atmospheric Pressure

$\mathrm{G}$ convert-hPa to $\mathrm{Pa}(\mathrm{x} 10)$

- Solar Radiation - Global + Direct + Diffused $\mathrm{K}+\mathrm{L}+\mathrm{M}$ convert -MJ to W/m2 (x27.778?)

- Wind Direction

- Wind Speed 
- Sky Cover

- Ceiling Height
$\mathrm{T}$

$\mathrm{W}$

Not all weather stations have this data. So multiple stations may be required to collect all data.

2. Location $->$ choose stations $->$ search.

3. Date and time $->$ specify start / end -> 00:00 1 Jan year to 00:00 1 Jan following year

4. Format -> NZST, Excel (d/m/yyyy hh), No date/time column, Excel file, Station name, Date/station, no ticks.

Send query -> download / save file.

NOTE: Limited amount of data that can be collected in a single query so multiple queries need to be sent. Recommend one for each parameter. Individually save and name the station and parameter.

\section{Input real time data into csv.}

- Open csv template file and all weather data from NIWA in excel.

- Check that there are 8,760 rows of data in all files.

- Ensure units are correct. Convert where needed. eg. Radiation, MJ -> $\mathrm{Wh} / \mathrm{m}^{2}$.

- Copy over the real data into the correct columns in the template file. Columns used are D, E, F, G, K, L, M, R, S, T, W. Refer to 2.1 datatype list for what columns relate to.

- Certain real data will need to be converted for the template from one unit to another; G-hPa to $\mathrm{Pa}$ (x10); K, L \&M -MJ to W/m² (x27.778?); Ttake average of total skycover in all layers(You'll get more than one);

- Parameters that are not changed need to be replaced by default values that are not read during the calculations. Assign all digits as 9's. eg. if the unit is $123->999$ or $1234->9999$.

- Save as -> name appropriately.

NOTE: Design days are assumed to not be used in a calibrated model so ignore those values at the top of the spreadsheet. 


\section{Convert csv to .epw.}

EP-Launch -> Utilities -> Weather drop down -> Run Weather.

In EnergyPlus weather converter.

- Select file to convert -> select the new csv file -> open

- Override Default Type -> EnergyPlus comma separated variable (CSV) format

- Select output format -> EnergyPlus weather format (EPW)

- Save file as -> save location / name -> open

- Convert file.

This file can now be used in the simulating of energy consumption for a specific year or timeframe within a specific year.

NOTE: design days cannot be simulated using these weather files without further input.

Page | 351 


\section{Appendix 14.7 Energy signature}

\subsubsection{Worked example of creating calibration signatures}

Figure 14-5 presents the variables and calculation needed to develop a calibration signature. The variables and calculation are universal between the heating, cooling and space conditioning calibration signatures. This means that the measured and simulated energy consumption could be either heating, cooling, or space conditioning.

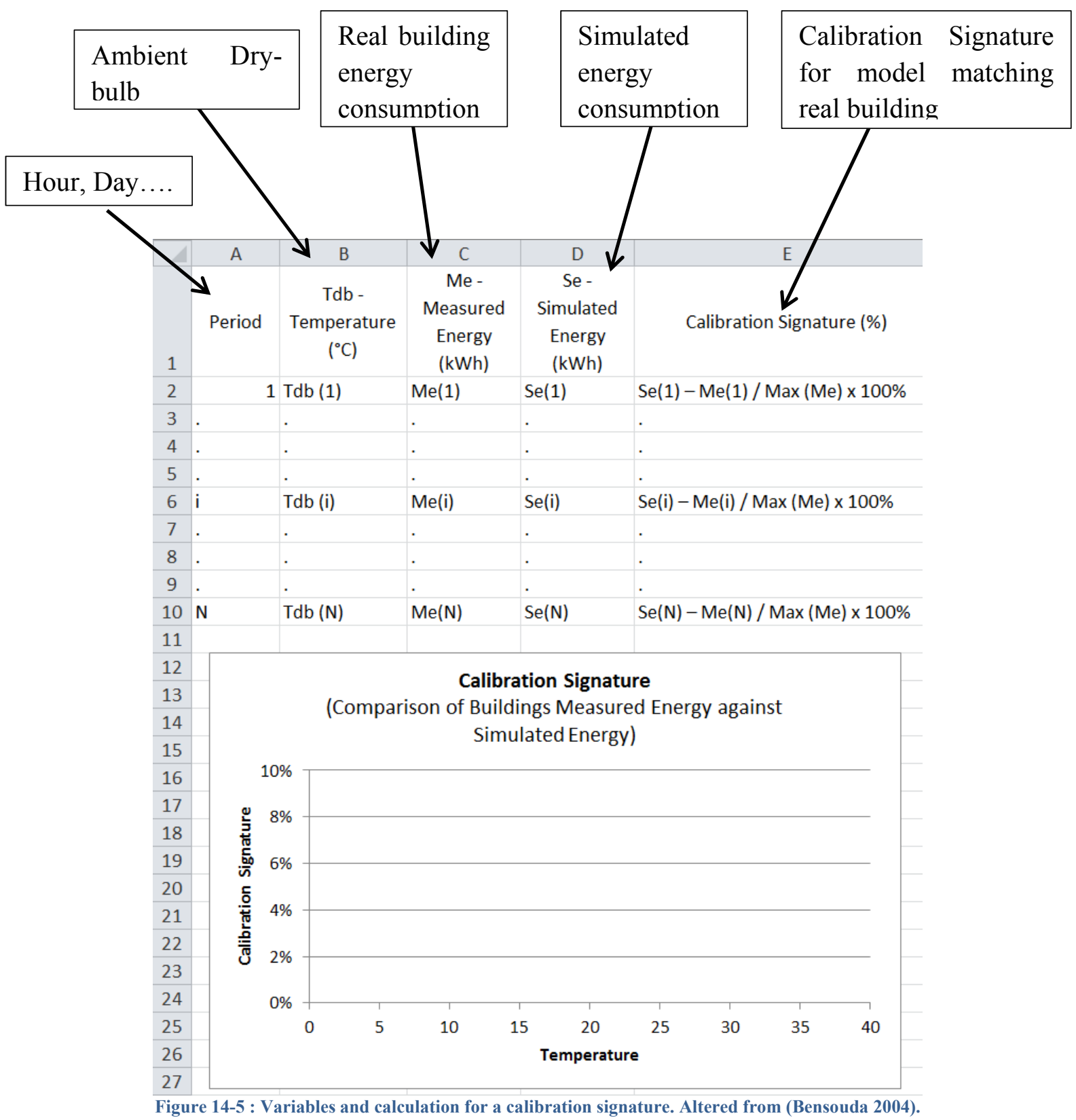

Page $\mid 352$ 
Figure 14-6 presents a worked example of a calibration signature. The data displayed are not related to any real building, they are completely hypothetical.

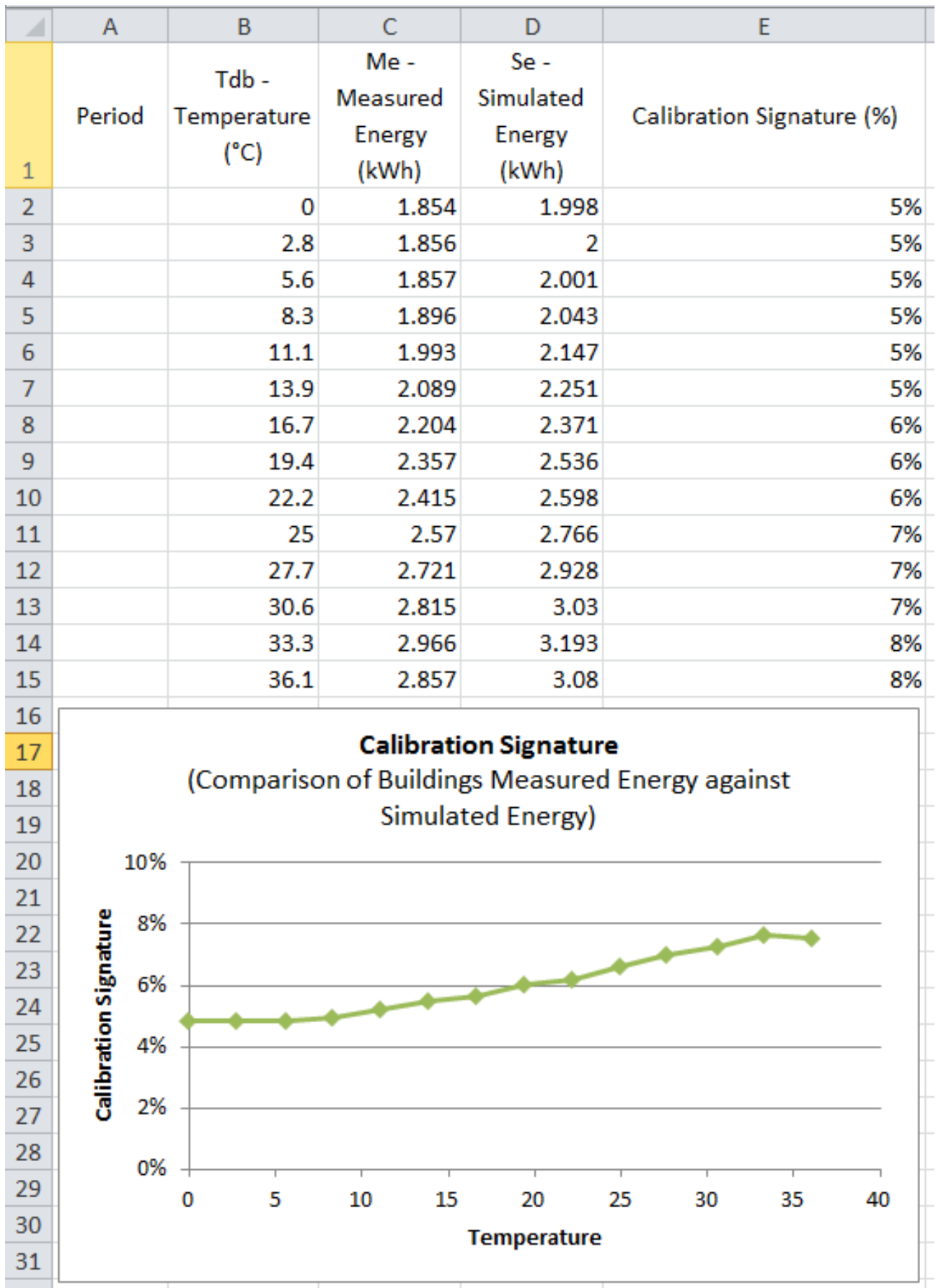

Figure 14-6 : Worked example of a calibration signature. Altered from (Bensouda 2004).

Page $\mid 353$ 


\subsubsection{Worked example of creating characteristic signatures}

Figure 14-7 presents the variables and calculation needed to develop a characteristic signature. The variables and calculation are universal meaning that the energy consumption could be either heating, cooling, or space conditioning.

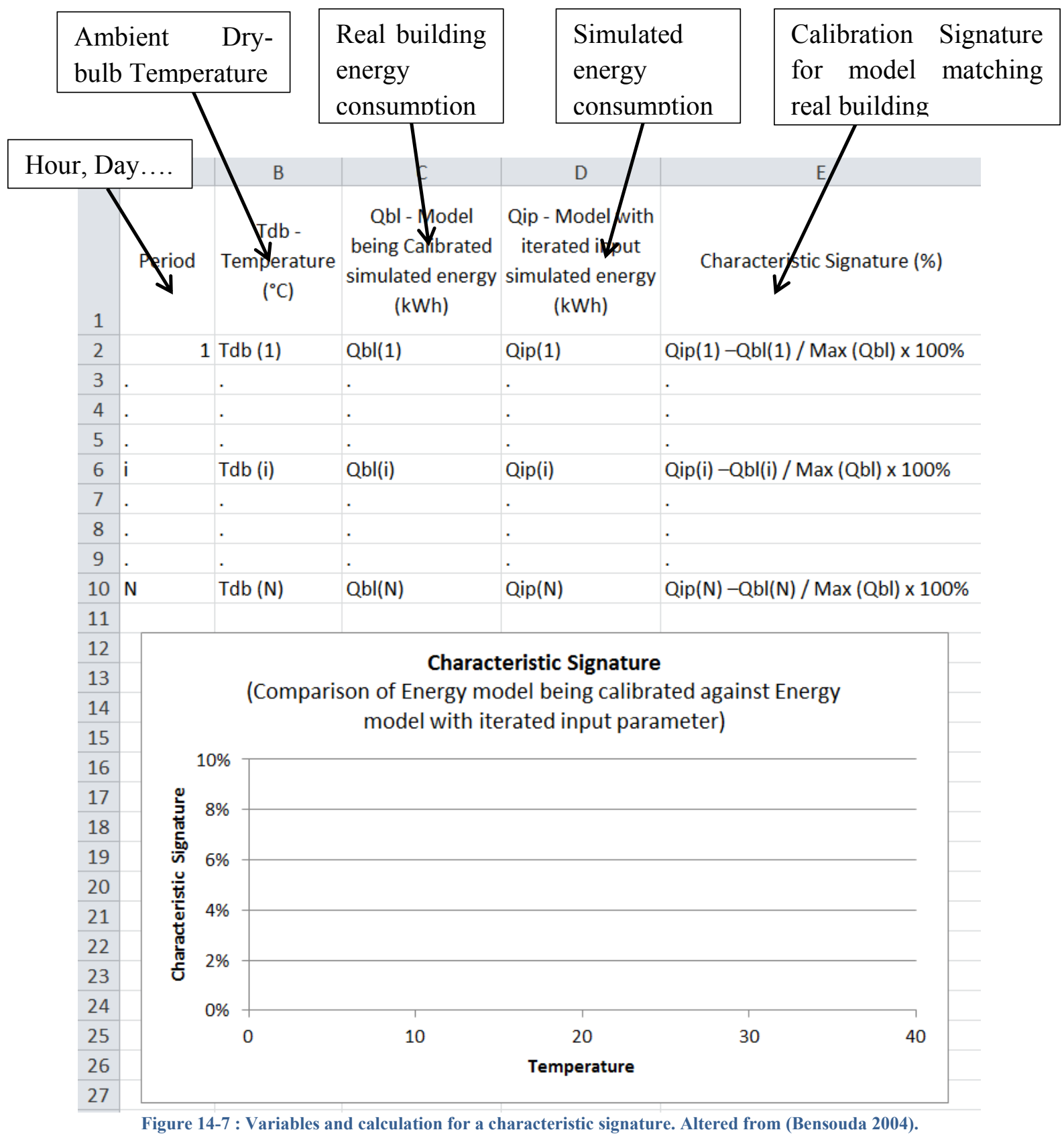

Page $\mid 354$ 
Figure 14-8 presents a worked example of a characteristic signature. The data displayed are not related to any real building, they are completely hypothetical.

\begin{tabular}{|c|c|c|c|c|c|c|}
\hline$\Delta$ & A & B & C & D & $E$ & \\
\hline 1 & Period & $\begin{array}{c}\text { Tdb - Temperature } \\
\left({ }^{\circ} \mathrm{C}\right)\end{array}$ & $\begin{array}{c}\text { Qbl - Model being } \\
\text { Calibrated simulated } \\
\text { energy }(\mathrm{kWh})\end{array}$ & $\begin{array}{l}\text { Qip - Model with } \\
\text { iterated input } \\
\text { simulated energy } \\
\text { (kWh) }\end{array}$ & \multicolumn{2}{|c|}{ Characteristic Signature (\%) } \\
\hline 2 & & 0 & 1.954 & 1.998 & & $1 \%$ \\
\hline 3 & & 2.8 & 1.956 & 2 & & $1 \%$ \\
\hline 4 & & 5.6 & 1.957 & 2.001 & & $1 \%$ \\
\hline 5 & & 8.3 & 1.996 & 2.043 & & $2 \%$ \\
\hline 6 & & 11.1 & 2.093 & 2.147 & & $2 \%$ \\
\hline 7 & & 13.9 & 2.189 & 2.251 & & $2 \%$ \\
\hline 8 & & 16.7 & 2.304 & 2.371 & & $2 \%$ \\
\hline 9 & & 19.4 & 2.457 & 2.536 & & $3 \%$ \\
\hline 10 & & 22.2 & 2.515 & 2.598 & & $3 \%$ \\
\hline 11 & & 25 & 2.67 & 2.766 & & $3 \%$ \\
\hline 12 & & 27.7 & 2.821 & 2.928 & & $3 \%$ \\
\hline 13 & & 30.6 & 2.915 & 3.03 & & $4 \%$ \\
\hline 14 & & 33.3 & 3.066 & 3.193 & & $4 \%$ \\
\hline 15 & & 36.1 & 2.957 & 3.08 & & $4 \%$ \\
\hline 16 & & & & & & \\
\hline 17 & \multirow{14}{*}{ 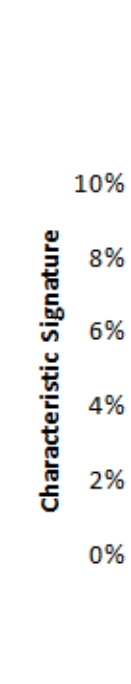 } & \multirow{3}{*}{\multicolumn{4}{|c|}{$\begin{array}{c}\text { Characteristic Signature } \\
\text { (Comparison of Energy model being calibrated against Energy model with } \\
\text { iterated input parameter) }\end{array}$}} & \\
\hline 18 & & & & & & \\
\hline 19 & & & & & & \\
\hline 21 & & & & & & \\
\hline 22 & & & & & & \\
\hline 23 & & & & & & \\
\hline 24 & & & & & & \\
\hline 25 & & & & & & \\
\hline 26 & & & & & & \\
\hline $\begin{array}{l}27 \\
28\end{array}$ & & & & & & \\
\hline 29 & & & & & & \\
\hline 30 & & 0 & 10 & 25 & 40 & \\
\hline 31 & & & Temp & rature & & \\
\hline 32 & & & & & & \\
\hline
\end{tabular}

Page $\mid 355$ 


\subsubsection{Comparing Energy Signatures}

Figure 14-9 compares the two signature types (calibration and characteristic) to identify similar patterns and trends that may indicate if that particular input parameter is problematic. The data displayed are not related to any real building, they are completely hypothetical. As can be seen, the hypothetical example shows there are some similarities between the two signatures. Firstly, both signatures are positive. Secondly, they both have increasing percentages at higher temperatures.

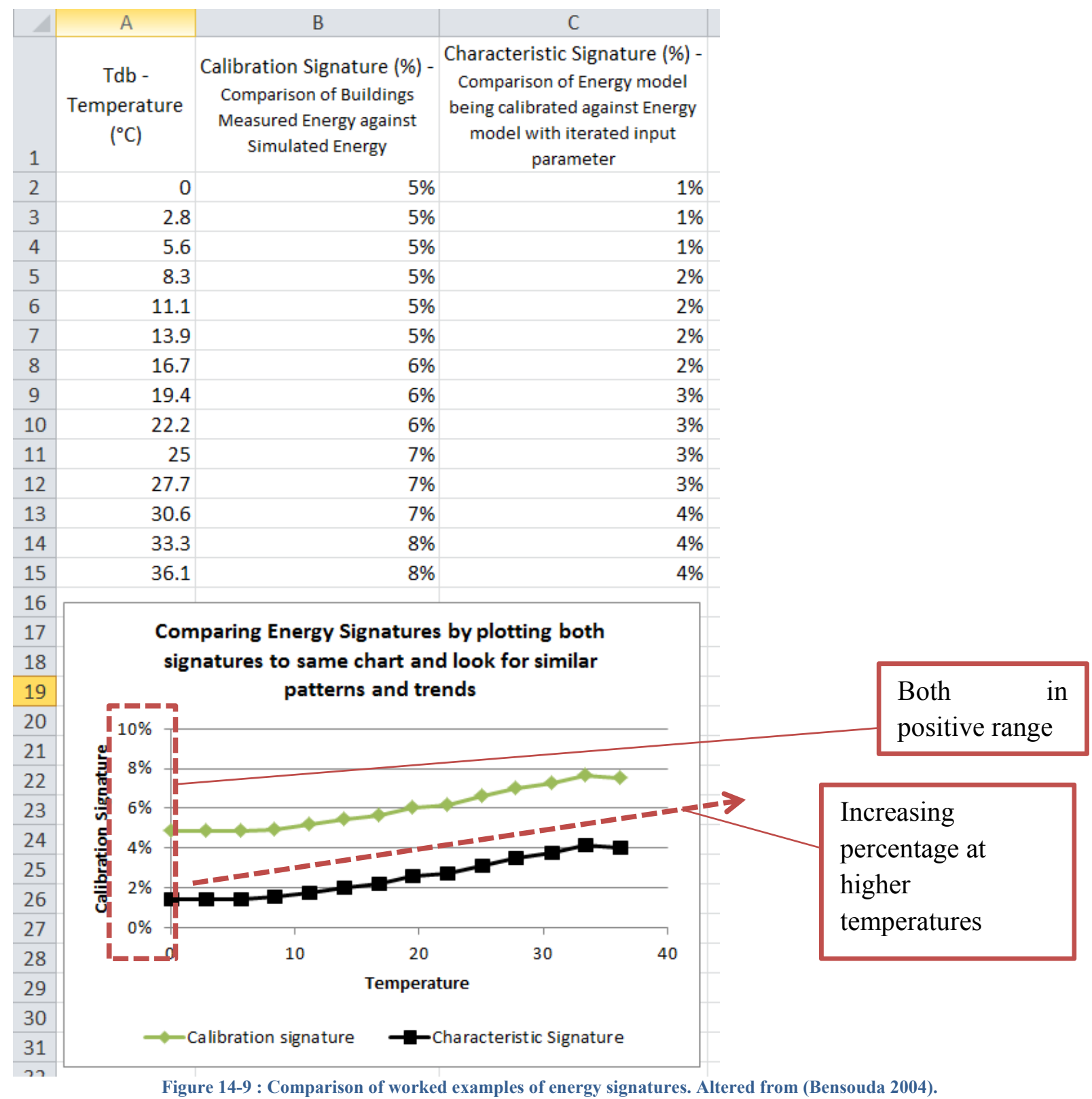

Figure 14-9 : Comparison of worked examples of energy signatures. Altered from (Bensouda 2004). 


\subsubsection{Method used to bin hourly data into temperature groups}

Figure 14-10 displays the format of the hourly monitored and simulated energy consumption. As can be seen, each hour of the day has a temperature and associated energy consumption. These need to be grouped or binned into various temperature ranges for them to be used in the calibration and characteristic signatures (refer to Figure 14-11).

\begin{tabular}{|c|c|c|c|}
\hline 4 & A & B & $\mathrm{C}$ \\
\hline 1 & Period & Temperature & Measured Energy (kWh) \\
\hline 2 & 04/15 15:00:00 & 21.2 & 10666 \\
\hline 3 & 04/15 16:00:00 & 21.1 & 10691 \\
\hline 4 & 04/15 17:00:00 & 20.4 & 10833 \\
\hline 5 & 04/15 18:00:00 & 18.7 & 10969 \\
\hline 6 & 04/15 19:00:00 & 17.3 & 7853 \\
\hline 7 & 04/15 20:00:00 & 16.4 & 701 \\
\hline 8 & 04/15 21:00:00 & 15.4 & 843 \\
\hline 9 & 04/15 22:00:00 & 14.4 & 737 \\
\hline 10 & 04/15 23:00:00 & 14.0 & 707 \\
\hline 11 & 04/15 24:00:00 & 13.9 & 706 \\
\hline 12 & 04/16 01:00:00 & 12.8 & 4174 \\
\hline 13 & 04/16 02:00:00 & 12.6 & 701 \\
\hline 14 & 04/16 03:00:00 & 13.0 & 702 \\
\hline 15 & 04/16 04:00:00 & 12.4 & 705 \\
\hline 16 & 04/16 05:00:00 & 12.0 & 702 \\
\hline 17 & 04/16 06:00:00 & 13.1 & 702 \\
\hline 18 & 04/16 07:00:00 & 13.3 & 697 \\
\hline 19 & 04/16 08:00:00 & 14.2 & 676 \\
\hline 20 & 04/16 09:00:00 & 16.5 & 673 \\
\hline 21 & 04/16 10:00:00 & 18.4 & 2901 \\
\hline 22 & 04/16 11:00:00 & 19.0 & 10790 \\
\hline 23 & 04/16 12:00:00 & 20.2 & 10786 \\
\hline 24 & 04/16 13:00:00 & 21.0 & 10763 \\
\hline 25 & $04 / 16$ 14:00:00 & 20.4 & 10796 \\
\hline 26 & 04/16 15:00:00 & 19.9 & 10860 \\
\hline 27 & 04/16 16:00:00 & 20.5 & 10959 \\
\hline 28 & 04/16 17:00:00 & 19.8 & 8322 \\
\hline 29 & 04/16 18:00:00 & 17.5 & 7966 \\
\hline 30 & 04/16 19:00:00 & 16.2 & 10720 \\
\hline 31 & 04/16 20:00:00 & 15.4 & 704 \\
\hline 32 & 04/16 21:00:00 & 14.4 & 775 \\
\hline 33 & 04/16 22:00:00 & 14.0 & 747 \\
\hline 34 & 04/16 23:00:00 & 14.0 & 708 \\
\hline 35 & 04/16 24:00:00 & 13.7 & 706 \\
\hline
\end{tabular}

Figure 14-10 : Example of hourly data from monitoring and simulations 


\begin{tabular}{|c|c|c|c|c|c|c|}
\hline & & & & \multicolumn{3}{|c|}{$\begin{array}{l}\text { Average each } \mathrm{kWh} \text { value that is in a } \\
\text { temperature between the } 0.2^{\circ} \mathrm{C} \text {. }\end{array}$} \\
\hline & \multicolumn{2}{|c|}{$\begin{array}{l}\text { Temperature is } \\
\text { binned in } \\
\text { n }{ }^{\circ} \mathrm{C} \text { intervals }\end{array}$} & & \multicolumn{3}{|c|}{$\begin{array}{l}\text { Example: Excel AverageIfs function } \\
\text { AVERAGEIFS(average_range, criteria_range1, } \\
\text { criteria1, [criteria_range2, criteria2], . . . ) }\end{array}$} \\
\hline 4 & A & $\mathrm{B}$ & C & $E$ & $\mathrm{~F}$ & \\
\hline 1 & Period & Temperature & $\begin{array}{c}\text { Measured } \\
\text { Energy (kWh) }\end{array}$ & Temperature $^{-} \mathrm{C}$ ) & $\begin{array}{c}\text { Measured } \\
\text { Energy (kWh) }\end{array}$ & \\
\hline 2 & 04/15 15:00:00 & 21.2 & 10666 & $12.0^{\prime}$ & \#DIV/o! & \\
\hline 3 & 04/15 16:00:00 & 21.1 & 10691 & $12.2^{I}$ & \#Dlvio! & \\
\hline 4 & 04/15 17:00:00 & 20.4 & 10833 & 12.4 & $703 . b$ & \\
\hline 5 & 04/15 18:00:00 & 18.7 & 10969 & 12.6 & 4174.0 & \\
\hline 6 & 04/15 19:00:00 & 17.3 & 7853 & $12.8^{\prime}$ & \#DIVlo! & \\
\hline 7 & 04/15 20:00:00 & 16.4 & 701 & 13.0 & 702.0 & \\
\hline 8 & 04/15 21:00:00 & 15.4 & 843 & 13.2 & 697.0 & \\
\hline 9 & 04/15 22:00:00 & 14.4 & 737 & $13.4^{\prime}$ & \#Dlvio! & \\
\hline 10 & 04/15 23:00:00 & 14.0 & 707 & 13.6 & 706.0 & \\
\hline 11 & 04/15 24:00:00 & 13.9 & 706 & 13.8 & 706.0 & \\
\hline 12 & 04/16 01:00:00 & 12.8 & 4174 & 14.0 & 676.0 & \\
\hline 13 & 04/16 02:00:00 & 12.6 & 701 & 14.2 & 737.0 & \\
\hline 14 & 04/16 03:00:00 & 13.0 & 702 & 14.4 & 775.0 & No number \\
\hline 15 & 04/16 04:00:00 & 12.4 & 705 & $14.6^{T}$ & \#DIVlo! $\Leftarrow$ & \\
\hline 16 & 04/16 05:00:00 & 12.0 & 702 & $14.8^{T}$ & \#[Dlvio! & because there is \\
\hline 17 & 04/16 06:00:00 & 13.1 & 702 & $15.0^{r}$ & \#[DIVlo! & \\
\hline 18 & 04/16 07:00:00 & 13.3 & 697 & 15.2 & 843.0 & no temperature \\
\hline 19 & 04/16 08:00:00 & 14.2 & 676 & 15.4 & 704.0 & to average. \\
\hline 20 & 04/16 09:00:00 & 16.5 & 673 & $15.6^{N}$ & \#[IVlo! & \\
\hline 21 & 04/16 10:00:00 & 18.4 & 2901 & $15.8^{r}$ & \#DIVio! & \\
\hline 22 & 04/16 11:00:00 & 19.0 & 10790 & 16.0 & 10720.0 & \\
\hline 23 & 04/16 12:00:00 & 20.2 & 10786 & $16.2^{r}$ & \#[IVlo! & \\
\hline 24 & 04/16 13:00:00 & 21.0 & 10763 & 16.4 & 687.0 & \\
\hline 25 & 04/16 14:00:00 & 20.4 & 10796 & $16.6^{r}$ & \#DIVlo! & \\
\hline 26 & 04/16 15:00:00 & 19.9 & 10860 & $16.8^{r}$ & \#[Dlvio! & \\
\hline 27 & 04/16 16:00:00 & 20.5 & 10959 & $17.0^{N}$ & \#Dlvio! & \\
\hline 28 & 04/16 17:00:00 & 19.8 & 8322 & 17.2 & 7853.0 & \\
\hline 29 & 04/16 18:00:00 & 17.5 & 7966 & 17.4 & 7966.0 & \\
\hline 30 & 04/16 19:00:00 & 16.2 & 10720 & $17.6^{7}$ & \#Dlvio! & \\
\hline 31 & 04/16 20:00:00 & 15.4 & 704 & $17.8^{\prime}$ & \#DIVIO! & \\
\hline 32 & 04/16 21:00:00 & 14.4 & 775 & $18.0^{\mathrm{V}}$ & \#Dlvio! & \\
\hline 33 & 04/16 22:00:00 & 14.0 & 747 & $18.2^{r}$ & \#Dlv/0! & \\
\hline 34 & 04/16 23:00:00 & 14.0 & 708 & 18.4 & 2901.0 & \\
\hline 35 & 04/16 24:00:00 & 13.7 & 706 & 18.6 & 10969.0 & \\
\hline 36 & & & & $18.8^{\prime}$ & \#DIVlo! & \\
\hline 77 & & & & $\tan n$ & וחו" וחו & \\
\hline
\end{tabular}

Figure 14-11 : Worked example of Temperature bins 


\section{Appendix 14.8 Calibration procedure test results}

\subsubsection{Monthly calibration results for Buildings 2 to 6}

Figure 14-12 to 14-16 presents the comparison of Building 2 to 6's monthly calibration results between the initial and calibrated template (Blue) and detailed (Red) models with reference to the calibration limits (Black dotted line). The calibration results are presented as the percentage difference between the real building's monthly energy consumption and the energy model's energy consumption.

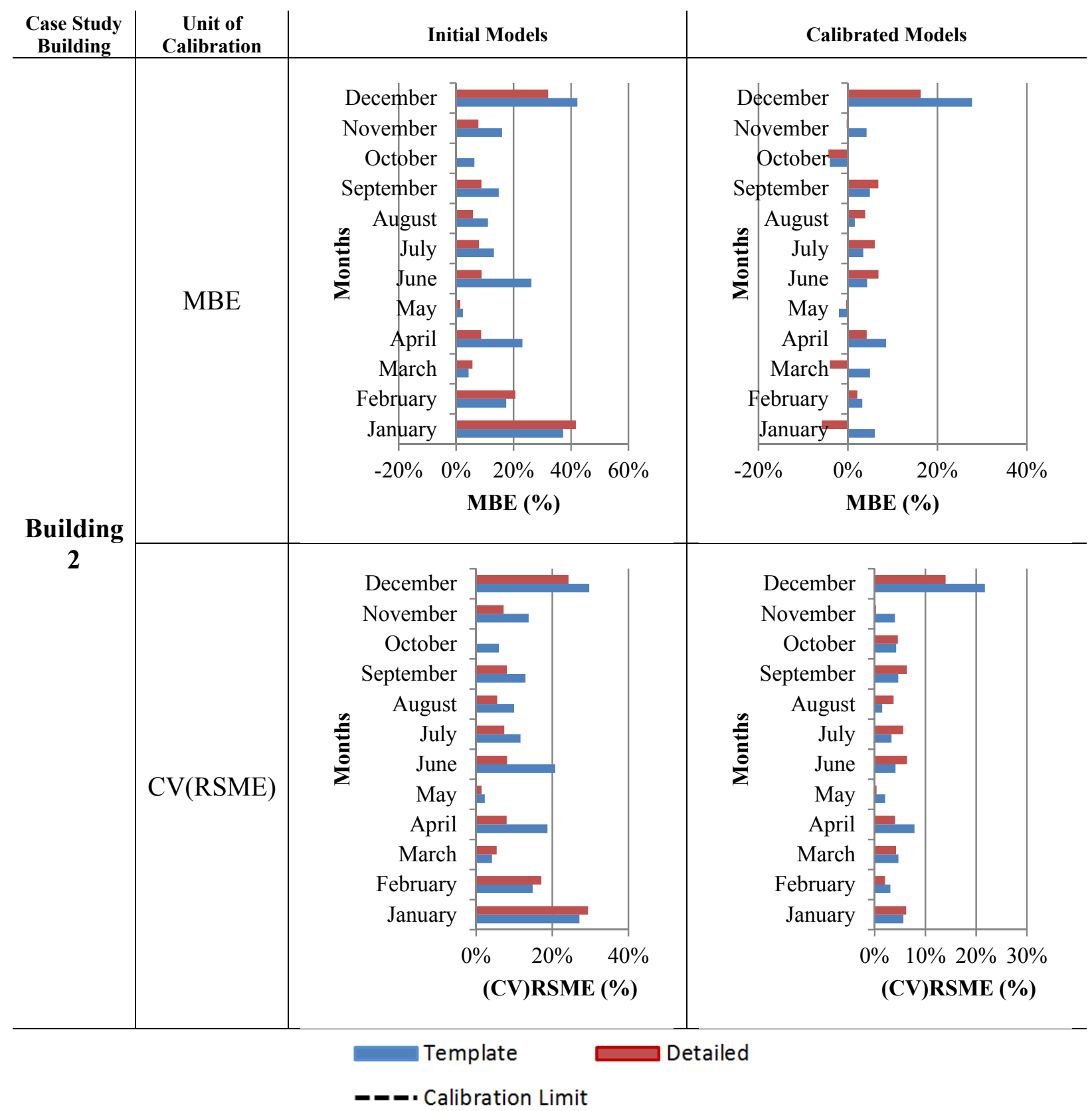

Figure 14-12 : Comparison of Building 2's monthly calibration results between initial and calibrated template and detailed models. 


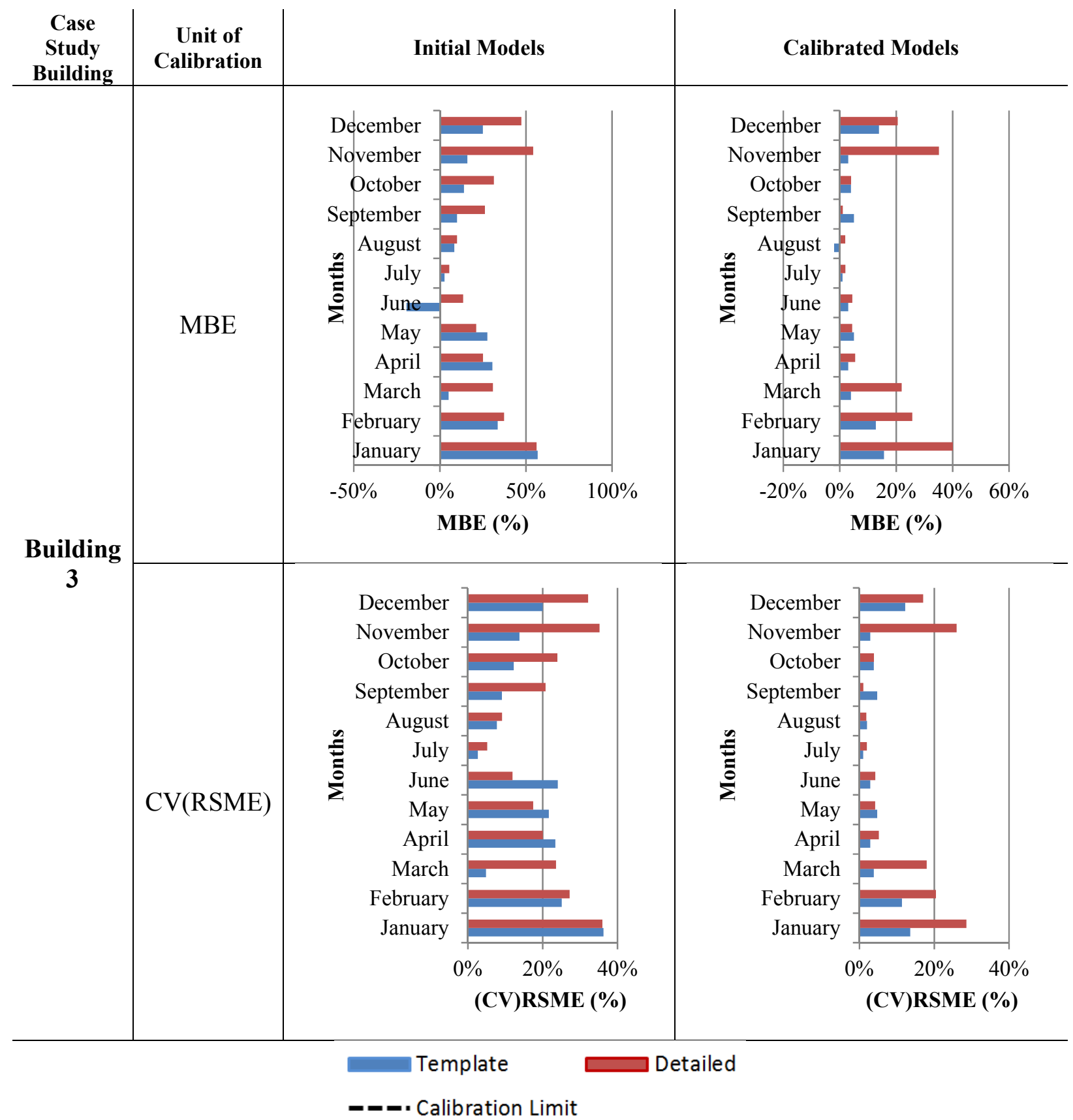

Figure 14-13 : Comparison of Building 3's monthly calibration results between initial and calibrated template and detailed models.

Page | 360 


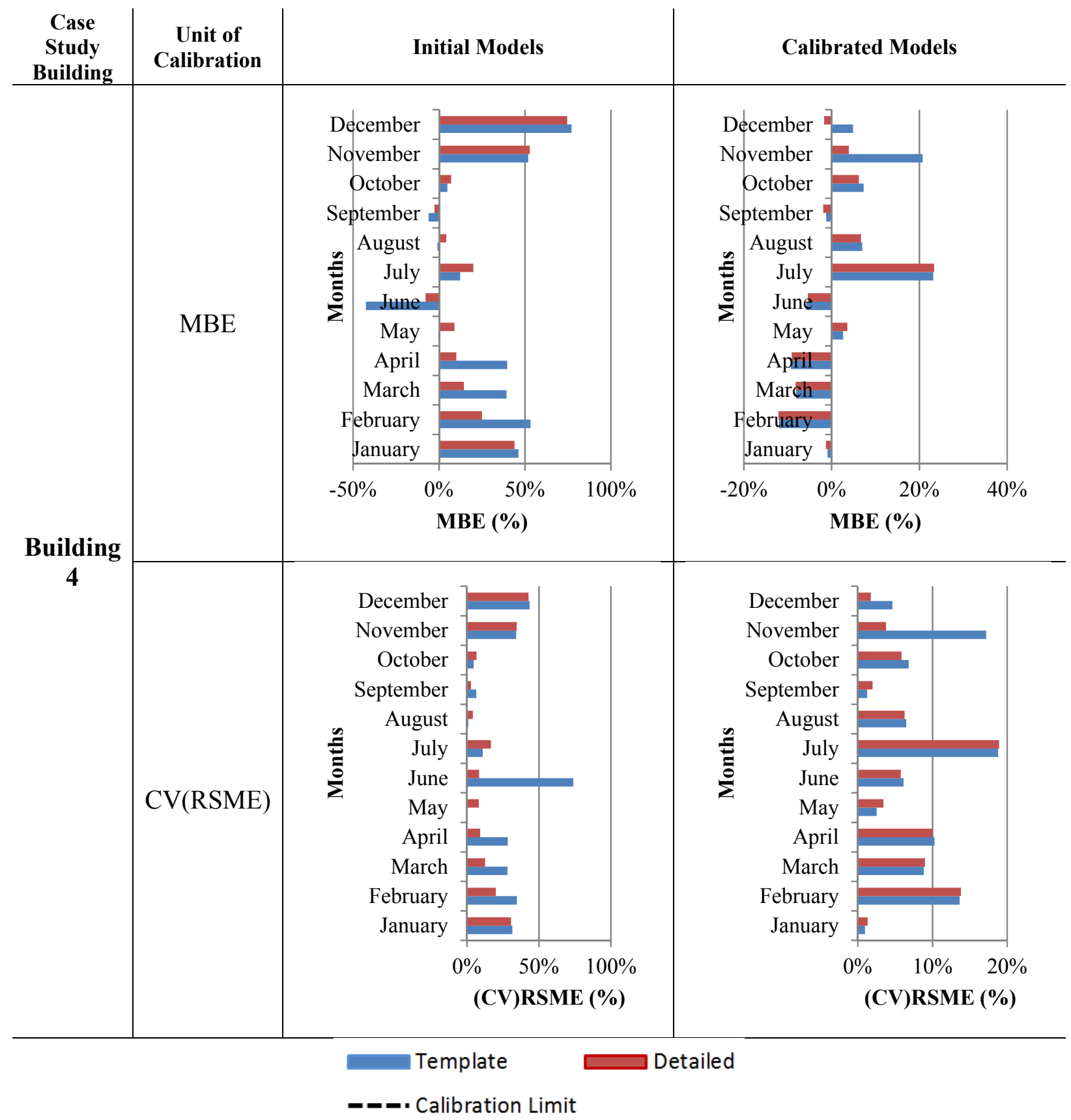

Figure 14-14 : Comparison of Building 4's monthly calibration results between initial and calibrated template and detailed models.

Page | 361 


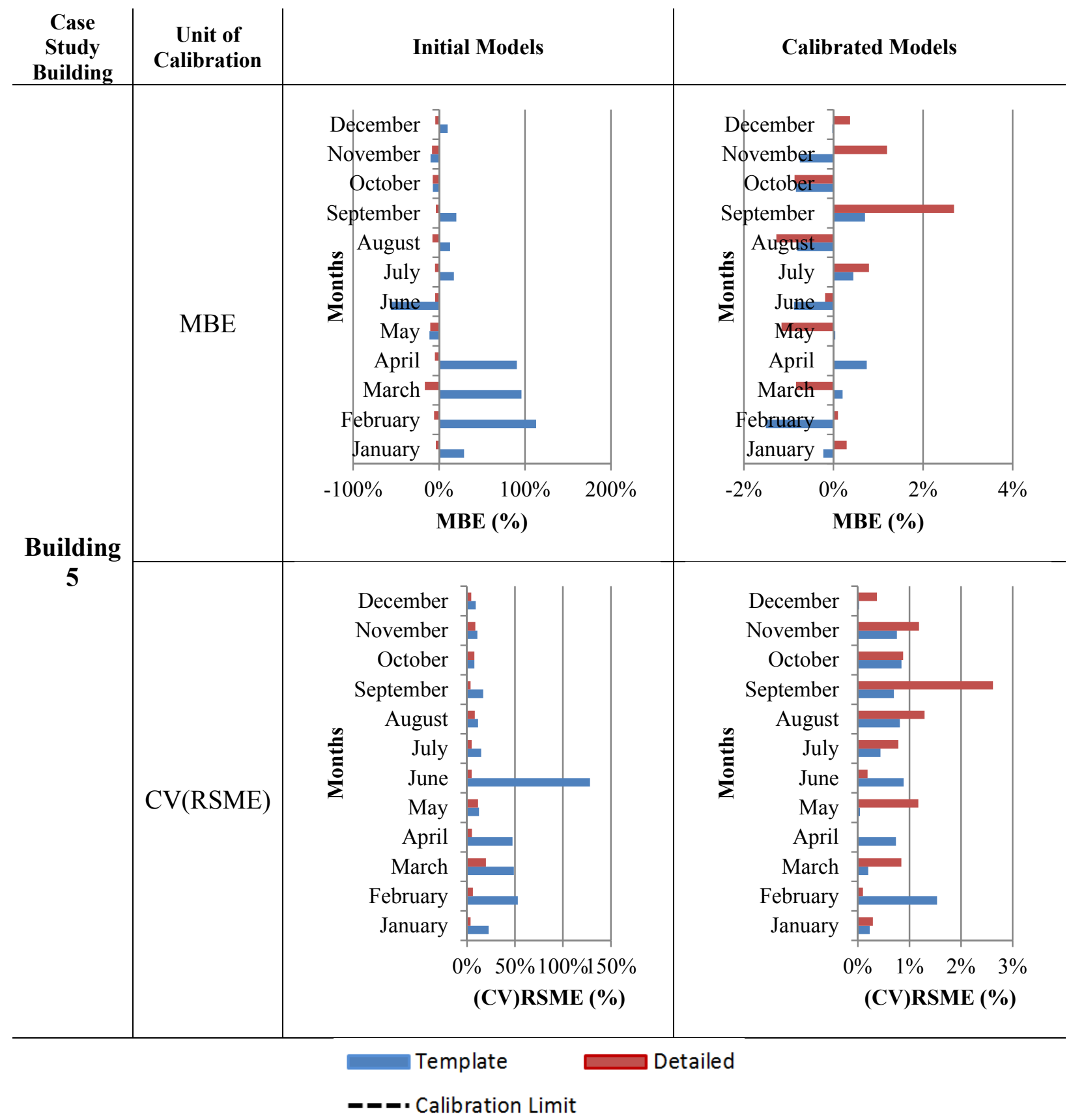

Figure 14-15 : Comparison of Building 5's monthly calibration results between initial and calibrated template and detailed models.

Page | 362 


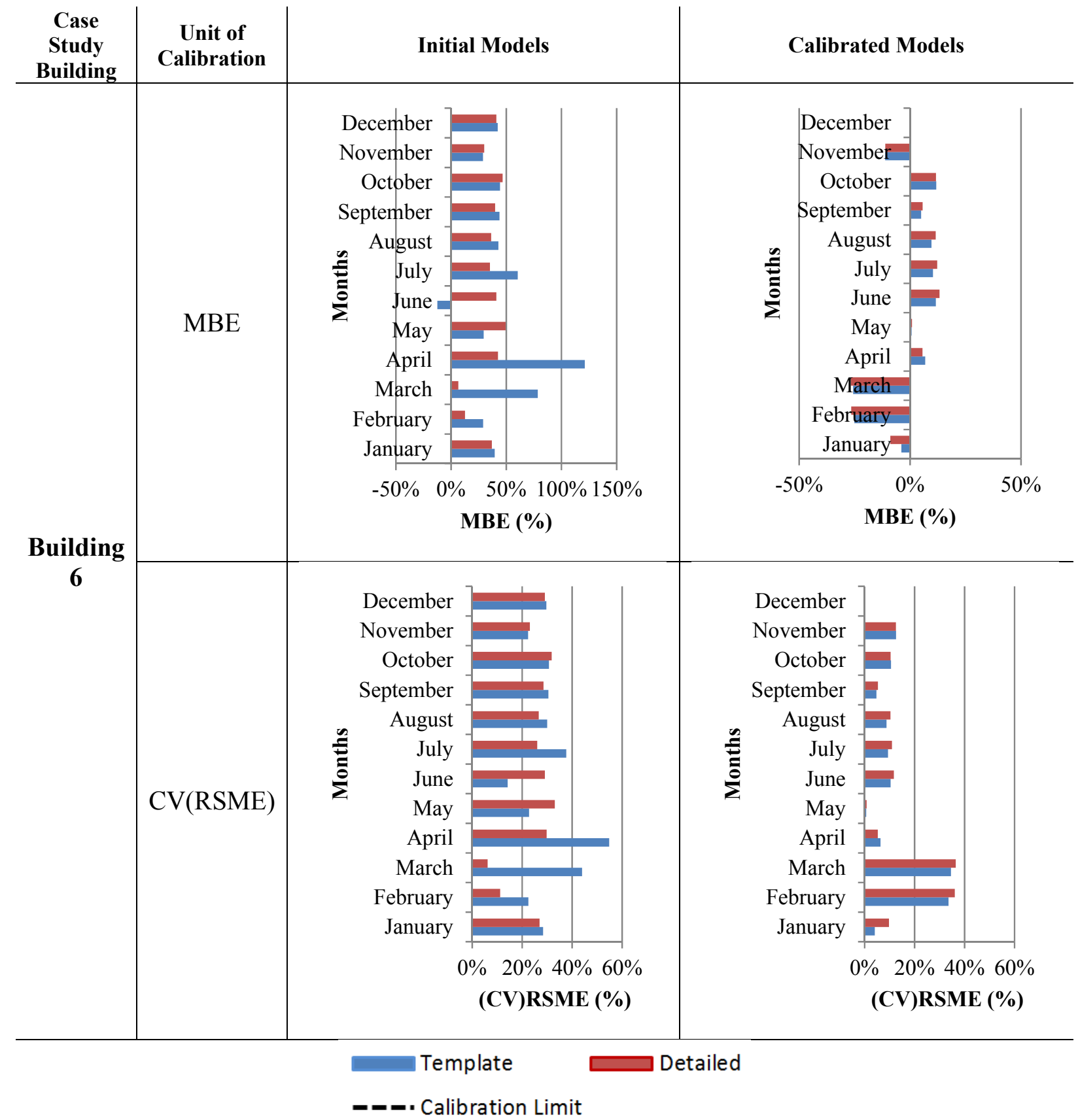

Figure 14-16 : Comparison of Building 6's monthly calibration results between initial and calibrated template and detailed models

Page | 363 


\subsubsection{Average number of months that meet the monthly MBE and CV(RSME) across the 6 case study buildings}

Table 14-11 shows the number of months that meet the MBE monthly calibration tolerance for each of the six participant's building models.

\begin{tabular}{|l|l|c|c|c|}
\cline { 2 - 5 } \multicolumn{1}{c|}{} & $\begin{array}{l}\text { Initial } \\
\text { Template } \\
\text { Model }\end{array}$ & $\begin{array}{l}\text { Table 14-11 : Number of months inside monthly MBE } \\
\text { Inial Detailed }\end{array}$ & $\begin{array}{l}\text { Calibrated } \\
\text { Template }\end{array}$ & $\begin{array}{l}\text { Calibrated } \\
\text { Detailed }\end{array}$ \\
\hline Building 1 & 4 & 4 & 4 & 5 \\
\hline Building 2 & 2 & 2 & 9 & 7 \\
\hline Building 3 & 1 & - & 9 & 6 \\
\hline Building 4 & 3 & 2 & 4 & 5 \\
\hline Building 5 & - & 6 & 12 & 12 \\
\hline Building 6 & - & - & 4 & 2 \\
\hline
\end{tabular}

\begin{tabular}{|l|l|l|l|l|}
\hline Average & 2 & 2 & 7 & 6 \\
\hline
\end{tabular}

Table 14-12 shows the number of months that meet the CV(RSME) monthly calibration tolerance for each of the six participant's building models.

\begin{tabular}{|l|c|c|c|c|}
\multicolumn{1}{c|}{} & \multicolumn{4}{l}{ Table 14-12 : Number of months inside monthly CV(RSME) } \\
\cline { 2 - 5 } \multicolumn{1}{c|}{} & $\begin{array}{l}\text { Initial Template } \\
\text { Model }\end{array}$ & $\begin{array}{l}\text { Initial Detailed } \\
\text { Model }\end{array}$ & $\begin{array}{l}\text { Calibrated } \\
\text { Template }\end{array}$ & $\begin{array}{l}\text { Calibrated } \\
\text { Detailed }\end{array}$ \\
\hline Building 1 & 9 & 11 & 11 & 11 \\
\hline Building 2 & 8 & 9 & 11 & 12 \\
\hline Building 3 & 6 & 3 & 12 & 7 \\
\hline Building 4 & 5 & 7 & 10 & 11 \\
\hline Building 5 & 6 & 11 & 12 & 12 \\
\hline Building 6 & 1 & 2 & 10 & 10 \\
\hline
\end{tabular}

\begin{tabular}{|l|l|l|l|l|}
\hline Average & 6 & 7 & 11 & 11 \\
\hline
\end{tabular}

Page | 364 


\subsubsection{Average annual BE across the 6 case study buildings}

Table 14-13 shows the annual Bias Error results for each of the six participant's building models. The Bias Error shows the percentage difference between the energy models' simulation energy consumption compared to the real buildings' energy consumption.

\begin{tabular}{|c|c|c|c|c|}
\hline & $\begin{array}{l}\text { Initial } \\
\text { Template } \\
\text { Model }\end{array}$ & $\begin{array}{l}\text { Table 14-13 : Annual } \\
\text { Initial Detailed } \\
\text { Model }\end{array}$ & $\begin{array}{l}\text { Calibrated } \\
\text { Template }\end{array}$ & $\begin{array}{l}\text { Calibrated } \\
\text { Detailed }\end{array}$ \\
\hline Building 1 & $7 \%$ & $-2 \%$ & $2 \%$ & $-2 \%$ \\
\hline Building 2 & $18 \%$ & $12 \%$ & $5 \%$ & $3 \%$ \\
\hline Building 3 & $18 \%$ & $30 \%$ & $6 \%$ & $14 \%$ \\
\hline Building 4 & $23 \%$ & $21 \%$ & $2 \%$ & $0 \%$ \\
\hline Building 5 & $25 \%$ & $-7 \%$ & $0 \%$ & $0 \%$ \\
\hline Building 6 & $46 \%$ & $35 \%$ & $-1 \%$ & $-1 \%$ \\
\hline Average & $23 \%$ & $14 \%$ & $3 \%$ & $3 \%$ \\
\hline
\end{tabular}

\subsubsection{Calibration exercise participants' transcripts regarding the Template and Detailed model usability}

The discussion that follows of participants' thoughts from Calibration exercise

\subsection{1a Building 1 Modeller}

Since both models are within acceptable limits the ease of building the template model as opposed to the detailed model has to be stressed. With regards to time spent on developing the model, both setting up the geometry as well as developing the systems needed in the models favours using template models. This conclusion confirms the general conclusion of Cory, Gates and Donn (2011). However, this study also exemplifies situations when precautions using template models are needed. In this case when changes are made to small HVAC systems positioned in different areas of a building. In most modern commercial buildings this would not be an issue as most commercial modern buildings would have a central HVAC system for large parts of the building instead of just having small zones conditioned. The template model was also simpler to calibrate due to its lesser complexity. The template model will also have advantages for other users, apart from the user developing the model, as it will be easier to understand.

It was three times as time consuming building the detailed model. If you want a very detailed model it would probably be more.

\subsection{1b Building 2 Modeller}

For developing an energy model, the template model was less time consuming due to the regular geometry allowing the model to be easily surface matched. The detailed model however was more challenging to build as there were irregular shapes which needed to be surface matched. 
In comparison the geometry was more time consuming to create for the detailed model. As each zone had to represent the zones in Rutherford House, irregular shaped zones had to be created. Except for a separate heating and cooling set point for offices from circulation spaces in Rutherford House, all parameters were the same between the template and detailed model. Therefore the time which it took to apply these parameters was the same for both the template and detailed models.

The template model tool a day, and the detailed model took 2-3 days - So the template model was noticeably quicker. Although I'd say that it's the matching of surfaces which always takes me the longest and that there were the same amount of surfaces to be matched in the template and detailed (the connection between the 'tower' and foyer').

\subsection{1c Building 3 Modeller}

However it was found that the ease of use with a template model and the simple geometry it was able to be modelled more accurately than the detailed model. The templates already had around $60 \%$ of the data entered into them (COP, materials, geometry, constructions and schedules) which needed to be changed for the use within an education building, because the templates from BEES were designed for commercial buildings. However the ease of use with the templates, so they only needed scaling, floors added and changing the schedules, occupants, lighting, DHW, lifts etc. makes the modelling process easy to use, quick to simulate and results accurate. Template models are already built and it is easy to change parameters within the building when it comes to calibration, as all the systems are done. With a detailed model, first there is modelling the building to as-built information, then coming back and changing these models when calibrating. This is extra time but also brings human error within the system.

The speed at which template models can be used compared to detailed models is enormous, as $60 \%$ of the information is within the template model, and only needs slight adjustment for the buildings. Detailed models have no inbuilt information so they need to be constructed from scratch with all information entered, geometry drawn and construction types defined. This process is slow and took the author approximately 4 times to 5 times longer than a template model. For post-simulation the calibration took longer in a detailed model compared to a template model because of the extra zones, so the change in information in multiple places. This leads to human error and so error in the software being used, in turn more time taken to fix errors.

\subsection{1d Building 4 Modeller}

Using the template model was easier and faster than the detailed model. Due to the regular geometry of the template model and the simplification of internal walls to all be 'air walls' it was much easier to match surfaces in OpenStudio. This also eliminated the need to resolve errors, which occur when the two sides of a wall are different materials, in the detailed model when changing the edges of a zone from air-walls to physical partitions. 
If the option was available the author would always use the template models because it saves modelling time, saves error fixing time and provides a valuable resource of likely HVAC parameters.

The major difference I recall is the time saved modelling the geometry of the building. The template model was much faster to draw and surface match. I had numerous problems with the detailed model getting it to surface match because of the complex inter-floor matching required (the zones were different shapes on every floor). Because I had to manually surface match parts of my detailed model the template methodology was significantly faster.

Also drawing the template model from scratch was faster than resizing it because the perimeter zones needed to remain the right size.

\subsection{1e Building 5 Modeller}

The calibration process for each model ended up focusing on the schedules over set-points, though this was not surprising considering the large influence the users have on the equipment. This also felt like the calibration was trying to rationalise this chaotic and variable factor for each month.

The template model was simple to set up and ended up resulting in similar levels of calibration. The results from the improvements indicated that it was performing as anticipated and it did not vary too much from the detailed model. The only difficulty was during the modelling process where changing the size of the exterior zones to being 7 metres deep resulted in having to reshape all the zones and manually match the geometry after.

The detailed model did take several times longer than the template model and felt like it took about 4 times longer to complete.

The template model was something that I remember being able to construct in an afternoon (or less), while the detailed model took the better part of a day, mainly to get the geometry, surface matching and inputs correct.

\subsection{1f Building 6 Modeller}

Following the carrying out of these calibrations, it can be asserted with surety that a proper calibration lies predominantly on a suitable definition of schedules. Otherwise, the simulated model will differ from the real behaviour of the building.

Another determining factor for calibrating energy models is the power densities which most of the times account for significant discrepancies between real and simulated data. As a consequence, the calibration process can be considered as a means of verifying approximations concerning power rating assigned to the different end-uses in a building. 


\section{Appendix 14.9 Net ZEB retrofit solution set assumptions}

\subsubsection{Net ZEB solution set retrofit modelling assumptions and parameters}

Table 14-14 displays the retrofit ECM modelling inputs and associated assumptions.

\begin{tabular}{|c|c|}
\hline $\mathrm{ECM}$ & Modelling and optimisation \\
\hline $\begin{array}{l}\text { Improved/Advanced } \\
\text { Envelope }\end{array}$ & $\begin{array}{l}\text { External insulation system: } \\
\text { EPS Insulation - R-value varies depending on materiality. As study is } \\
\text { focusing on Net ZEB and Sustainable design the value will be } \\
\text { obtained from EPS containing } 50 \% \text { recycled material (Expol Ltd } \\
\text { 2014): R-Value is } 100 \mathrm{~mm}=2.325 \text {, and 200mm }=4.65 \\
\text { Optimise } \\
\text { Min } \\
\text { Max }=4.65\end{array}$ \\
\hline Advanced Glazing & $\begin{array}{l}\text { Window types with set U-value, Visible Transmittance and Solar } \\
\text { Heat Gain Coefficient were optimised (refer to Section 8.4.1c) }\end{array}$ \\
\hline $\begin{array}{l}\text { Maximization of } \\
\text { Passive Solar Heat Gain }\end{array}$ & $\begin{array}{l}\text { Each façade WWR is optimised using the method outlined in Section } \\
\text { 8.4.1b and 8.4.1c and glazing shading coefficient is optimised (using } \\
\text { the method outlined in Section } 8.4 .1 \mathrm{c} \text { ) to allow maximum passive } \\
\text { solar heat gain without overheating. }\end{array}$ \\
\hline Solar Shading & $\begin{array}{l}\text { Transmittance of Solar shading layer is optimised (refer to Section } \\
8.4 \text { ) }\end{array}$ \\
\hline Natural Ventilation & $\begin{array}{l}\text { All vertical windows can open to optimised size: as little as } 0 \% \text { and } \\
\text { as large as } 85 \% \text {. Each window varies its opening size depending on } \\
\text { the temperature inside and outside in each thermal zone (US DOE } \\
2013 \mathrm{~b} \text { ). } \\
\text { If Indoor and Outdoor Temperature Difference is } 2^{\circ} \mathrm{C} \text {, Maximum } \\
\text { Venting Open Factor is used = up to } 85 \text { percent of window can open } \\
\text { depending on optimised window opening factor. } \\
\text { Indoor and Outdoor Temperature is } 18^{\circ} \mathrm{C} \text { Difference, Minimum } \\
\text { Venting Open Factor is used = as little as } 0 \text { percent can open } \\
\text { Windows can only open if indoor temperature is above } 23^{\circ} \mathrm{C} \text { and } \\
\text { the outdoor temperature is lower than the indoor temperature. } \\
\text { All other input parameters were set to default (refer to Section } \\
\text { 14.12.2) }\end{array}$ \\
\hline
\end{tabular}


Table 14-45 continued

\begin{tabular}{|c|c|}
\hline Advance Daylighting & 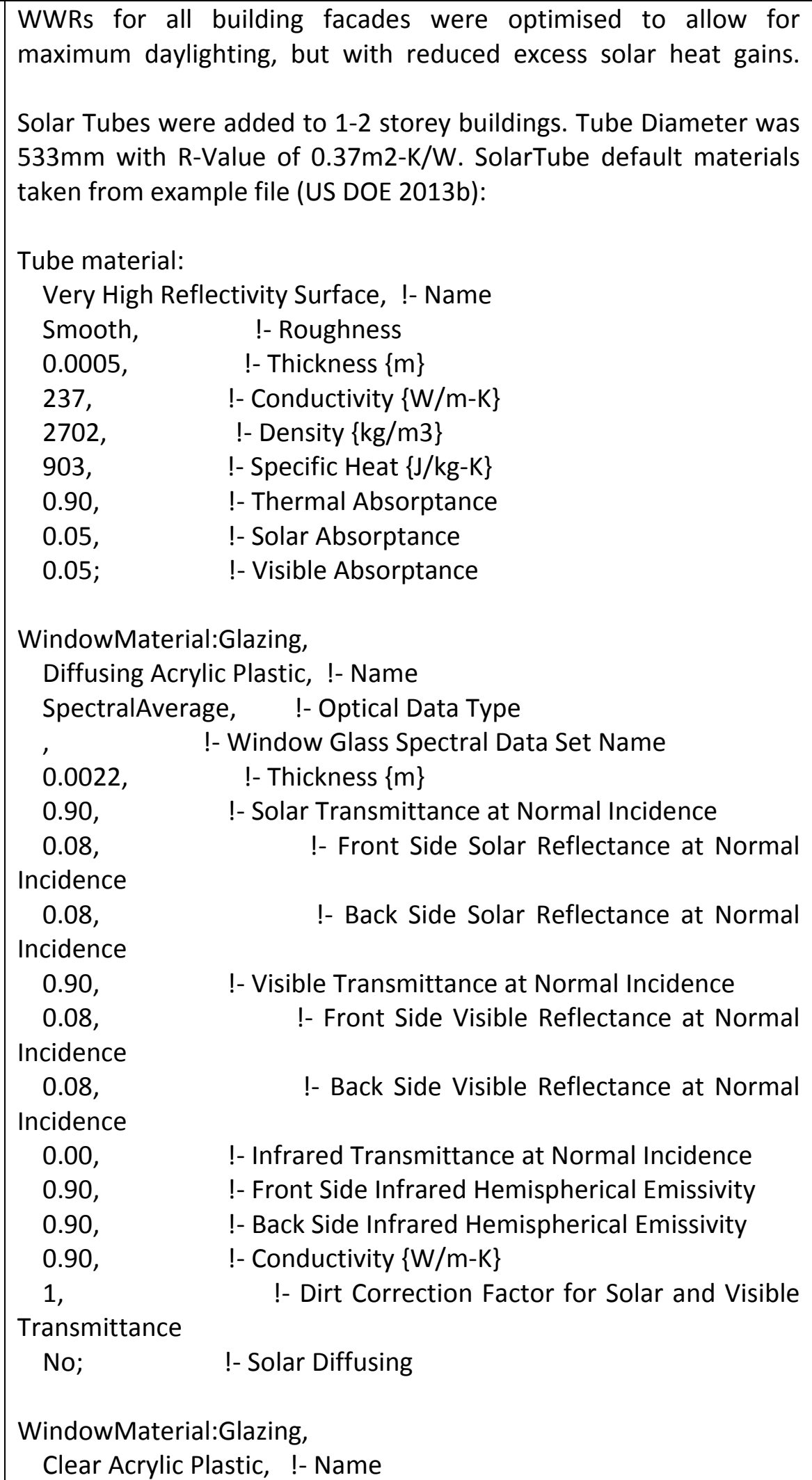 \\
\hline
\end{tabular}

Page | 369 


\begin{tabular}{|c|c|}
\hline & $\begin{array}{cc}\begin{array}{c}\text { SpectralAverage, } \\
\text { !- } \text { Optical Data Type }\end{array} \\
0.003, & \text { !- Window Glass Spectral Data Set Name } \\
0.92, & \text { !- Thickness }\{\text { m }\} \\
0.05, & \text { !- Solar Transmittance at Normal Incidence } \\
\text { Incidence } & \\
0.05, & \text { !- Back Side Solar Reflectance at Normal } \\
\text { Incidence } & \\
0.92, & \text { !- Visible Transmittance at Normal Incidence } \\
0.05, & \text { !- Front Side Visible Reflectance at Normal } \\
\text { Incidence } & \\
0.05, & \text { !- Back Side Visible Reflectance at Normal } \\
\text { Incidence } & \\
0.00, & \text { !- Infrared Transmittance at Normal Incidence } \\
0.90, & \text { !- Front Side Infrared Hemispherical Emissivity } \\
0.90, & \text { !- Back Side Infrared Hemispherical Emissivity } \\
0.90, & \text { !- Conductivity }\{\text { W/m-K\} } \\
1, & \text { !- Dirt Correction Factor for Solar and Visible } \\
\text { Transmittance } & \\
\text { No; } & \text { !- Solar Diffusing } \\
\end{array}$ \\
\hline $\begin{array}{l}\text { Energy Efficient } \\
\text { Lighting }\end{array}$ & Refer to Section 14.12 .3 for retrofit LPDs \\
\hline $\begin{array}{l}\text { Efficient Office } \\
\text { Equipment }\end{array}$ & Refer to Section 14.12 .3 for retrofit EPDs \\
\hline $\begin{array}{l}\text { Advanced Lighting } \\
\text { Controls }\end{array}$ & 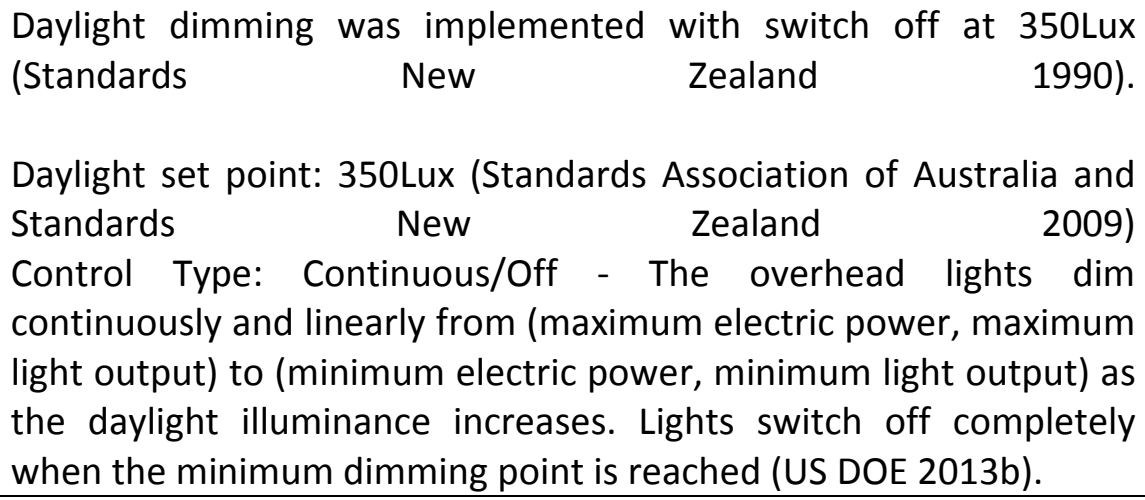 \\
\hline Efficient HVAC & $\begin{array}{l}\text { Gates (2013) split system HVAC template model installed with } \\
\text { Heating COP of } 4.35 \text { and Cooling COP of } 4.27 \text { (Efficient VRV Heat } \\
\text { pump ranging from } 15 \mathrm{~kW} \text { to } 100 \mathrm{~kW} \text { (Daikin Industries Ltd 2014). } \\
\text { Heating set point : } 18^{\circ} \mathrm{C} \text { (Based in Givoni Expanded Comfort) } \\
\text { Cooling Set point: } 25^{\circ} \mathrm{C} \text { (Based in Givoni Expanded Comfort) } \\
\text { Fresh air rates are the same as the current buildings }\end{array}$ \\
\hline Photo & $\begin{array}{l}50 \text { percent of roof area is covered in } 200 \mathrm{~W} \text { PV panels (refer to } \\
\text { Section 8.3.4i). }\end{array}$ \\
\hline
\end{tabular}

Page | 370 


\subsubsection{Airflow Network Assumptions}

Table 14-15 displays the modelling inputs and assumptions used in the Airflow Network modelling inputs.

\begin{tabular}{|c|c|}
\hline Simulation Control & 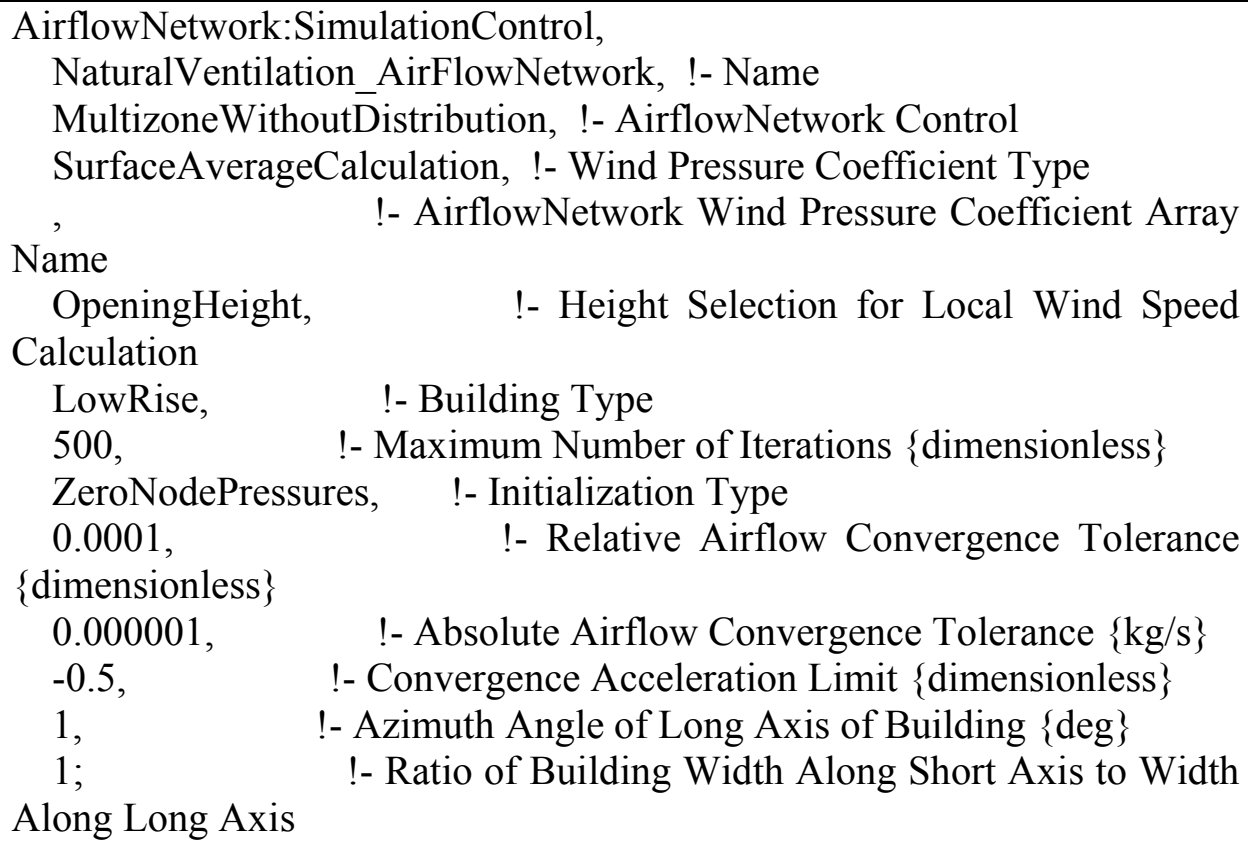 \\
\hline $\begin{array}{l}\text { Crack or Effective } \\
\text { Leakage Area }\end{array}$ & $\begin{array}{ll}\text { AirflowNetwork:MultiZone:Surface:EffectiveLeakageArea, } \\
\text { ELA-1, } \\
0.0001, & \text { !- Name } \\
0.0001, & \text { !- Effective Leakage Area }\{\mathrm{m} 2\} \\
0.0001, & \text { !- Reference Pressure Difference }\{\mathrm{Pa}\} \\
0.5 ; & \text { !- Air Mass Flow Exponent }\{\text { dimensionless }\end{array}$ \\
\hline Window type & 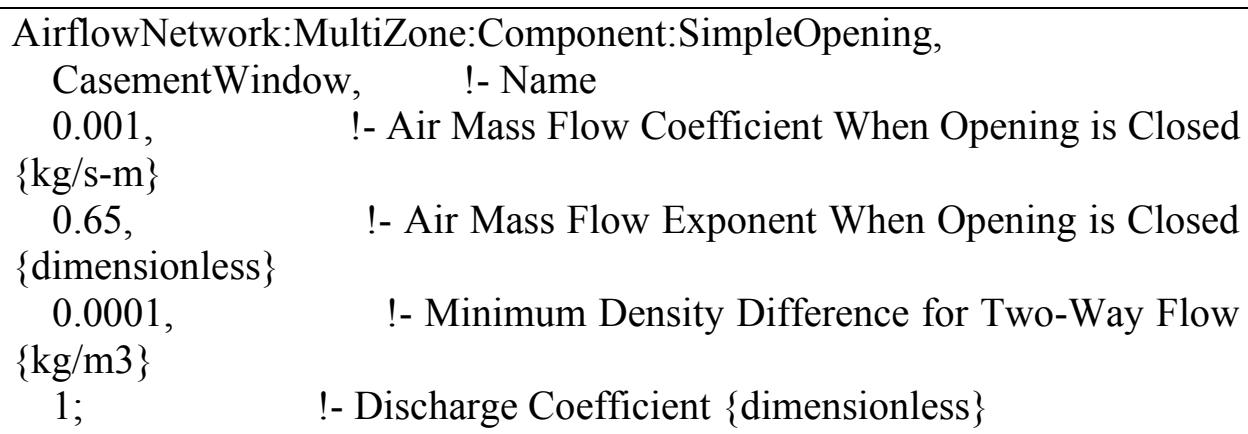 \\
\hline $\begin{array}{l}\text { Energy } \\
\text { Management } \\
\text { system to control }\end{array}$ & $\begin{array}{l}\text { IF (ZONE_Sensor }<=23), \text { !- Program Line } 1 \\
\text { SET ZONE_OpenControl }=0, \text { !- Program Line } 2 \\
\text { ELSEIF (ZONE_Sensor }>=23.1) \& \&(\text { ZONE_Sensor }<=26.9) \quad \& \&\end{array}$ \\
\hline
\end{tabular}

Page | 371 
when windows can $\quad$ (Outside_Sensor $<$ ZONE_Sensor), !- A4

open.

SET ZONE_OpenControl $=1, !$ - A5

ELSEIF (ZŌNE_Sensor $>$ 27) \&\& (Outside_Sensor $<$ ZONE_Sensor), !- A6

SET ZONE_OpenControl $=1, !$ - A7

ELSEIF (ZONE_Sensor $>27) \& \&$ (Outside_Sensor $>=$ ZONE_Sensor), !- A8

SET ZONE_OpenControl $=0$, !- A9

ENDIF; !- A10

\subsubsection{Original and retrofitted Lighting and Equipment Power Density for each of the 48 BEES buildings}

Table 14-16 displays the original and retrofitted Equipment Power Density, Lighting Power Density, and Miscellaneous Power Density for each of the 48 BEES buildings.

Table 14-16 : original and retrofitted Equipment Power Density, Lighting Power Density, and Miscellaneous Power Density for each of the 48 BEES buildings

\begin{tabular}{|l|c|c|c|c|c|c|}
\hline \multirow{2}{*}{ Buildings } & \multicolumn{7}{|c|}{ Power Density $\left(\mathbf{W} / \mathbf{m}^{2}\right)$} \\
\cline { 2 - 7 } & $\begin{array}{c}\text { Original } \\
\text { EPD }\end{array}$ & $\begin{array}{c}\text { Retrofit } \\
\text { EPD }\end{array}$ & $\begin{array}{c}\text { Original } \\
\text { LPD }\end{array}$ & $\begin{array}{c}\text { Retrofit } \\
\text { LPD }\end{array}$ & $\begin{array}{c}\text { Original } \\
\text { MPD }\end{array}$ & $\begin{array}{c}\text { Retrofit } \\
\text { MPD }\end{array}$ \\
\hline S2-M-1 & 0.25 & 0.06 & 2.04 & 0.95 & 0.00 & 0.00 \\
\hline S3-R-1 & 0 & 0.00 & 11.02 & 4.95 & 0.01 & 0.01 \\
\hline S1-O-1 & 4.07 & 1.94 & 9.37 & 6.87 & 0.00 & 0.00 \\
\hline S2-0-1 & 5.5 & 3.05 & 4.90 & 4.57 & 0.06 & 0.04 \\
\hline S1-O-2 & 20.12 & 4.94 & 7.61 & 5.39 & 16.93 & 14.48 \\
\hline S1-O-3 & 9.11 & 4.90 & 1.58 & 1.00 & 0.00 & 0.00 \\
\hline S3-R-2 & 4.3 & 2.06 & 9.04 & 4.30 & 0.03 & 0.02 \\
\hline S4-O-1 & 6.98 & 2.46 & 10.00 & 8.83 & 10.99 & 7.56 \\
\hline S3-O-1 & 8.35 & 3.56 & 14.50 & 13.02 & 9.56 & 6.50 \\
\hline S1-R-1 & 41.98 & 0.00 & 18.71 & 12.04 & 0.00 & 0.00 \\
\hline S4-M-1 & 1.84 & 0.56 & 7.22 & 4.65 & 0.22 & 0.11 \\
\hline S5-M-1 & 2.62 & 1.09 & 4.96 & 4.37 & 0.12 & 0.09 \\
\hline S1-R-2 & 22.3 & 9.80 & 25.71 & 17.77 & 0.09 & 0.06 \\
\hline S2-R-1 & 9.313 & 5.50 & 19.44 & 19.39 & 8.06 & 5.21 \\
\hline S3-M-1 & 0.45 & 0.20 & 1.17 & 0.78 & 0.60 & 0.43 \\
\hline S1-R-3 & 4.72 & 2.25 & 12.84 & 10.44 & 1.87 & 1.26 \\
\hline S3-M-2 & 5.48 & 2.48 & 42.48 & 24.28 & 0.00 & 0.00 \\
\hline S4-O-2 & 2.25 & 0.81 & 3.16 & 2.81 & 3.18 & 2.72 \\
\hline S1-R-4 & 14.97 & 7.81 & 27.93 & 16.53 & 0.00 & 0.00 \\
\hline S1-R-5 & 4.58 & 2.40 & 7.01 & 4.90 & 1.58 & 1.13 \\
\hline S3-R-3 & 2.12 & 1.26 & 16.64 & 14.34 & 1.63 & 0.77 \\
\hline S5-O-1 & 2.6 & 1.01 & 5.56 & 4.88 & 0.00 & 0.00 \\
\hline & & & & & & \\
\hline
\end{tabular}

Page $\mid 372$ 


\begin{tabular}{|l|c|c|c|c|c|c|} 
S2-M-2 & 8.53 & 4.30 & 2.37 & 1.55 & 0.00 & 0.00 \\
\hline S4-R-1 & 4.7 & 2.06 & 6.77 & 1.87 & 38.38 & 6.79 \\
\hline S2-R-2 & 13.77 & 8.60 & 1.83 & 0.89 & 21.40 & 14.39 \\
\hline S3-R-4 & 0.2 & 0.09 & 1.73 & 1.22 & 0.00 & 0.00 \\
\hline S4-M-2 & 7.7 & 4.06 & 15.39 & 14.36 & 18.14 & 11.86 \\
\hline S1-M-1 & 25.9 & 14.00 & 3.40 & 2.21 & 0.00 & 0.00 \\
\hline S3-O-2 & 2.04 & 0.86 & 6.78 & 5.70 & 9.94 & 7.06 \\
\hline S3-M-3 & 19.29 & 19.29 & 2.78 & 1.42 & 197.57 & 67.69 \\
\hline S2-R-3 & 3.66 & 1.79 & 5.45 & 4.25 & 17.30 & 12.77 \\
\hline S2-R-4 & 22.73 & 10.46 & 22.38 & 11.71 & 22.55 & 16.60 \\
\hline S4-M-3 & 2.23 & 1.00 & 14.33 & 11.95 & 13.58 & 10.98 \\
\hline S4-R-2 & 21.25 & 11.85 & 9.77 & 6.64 & 79.59 & 59.51 \\
\hline S2-M-3 & 1.41 & 0.73 & 2.68 & 1.69 & 0.07 & 0.03 \\
\hline S4-O-3 & 7.42 & 3.09 & 8.50 & 7.48 & 11.41 & 7.95 \\
\hline S4-O-4 & 1.35 & 0.58 & 3.04 & 2.67 & 0.17 & 0.12 \\
\hline S3-O-3 & 1.46 & 0.74 & 3.17 & 2.36 & 0.00 & 0.00 \\
\hline S2-O-2 & 8.13 & 4.44 & 18.34 & 15.42 & 3.51 & 2.50 \\
\hline S4-O-5 & 0.15 & 0.07 & 0.48 & 0.19 & 0.13 & 0.09 \\
\hline S1-M-2 & 4.84 & 2.14 & 0.86 & 0.22 & 0.00 & 0.00 \\
\hline S2-R-5 & 1.74 & 1.05 & 6.95 & 4.90 & 0.79 & 0.38 \\
\hline S5-O-2 & 3.15 & 1.48 & 5.85 & 5.32 & 0.19 & 0.14 \\
\hline S5-M-2 & 5.73 & 2.76 & 15.20 & 11.82 & 0.00 & 0.00 \\
\hline S5-M-3 & 13.31 & 7.76 & 1.56 & 1.43 & 0.00 & 0.00 \\
\hline S5-R-1 & 5.61 & 2.62 & 11.58 & 6.53 & 23.47 & 12.05 \\
\hline S5-O-3 & 12.91 & 4.65 & 18.45 & 14.18 & 1.08 & 0.40 \\
\hline S5-O-4 & 3.04 & 1.18 & 5.95 & 5.20 & 0.0046 & 0.0046 \\
\hline
\end{tabular}




\section{Appendix 14.10 Shading percentage calculation for Quality Assurance Test}

Tables 14-17 to 14-19 present the sun angles and calculated shading percentage results used to create the shading transmittance schedule for the Quality Assurance Test. Refer to Section 8.3.1a for equation used to calculate $\mathrm{mm}$ distance.

Table 14-17 : North façade: 9am shading transmittance calculation

\begin{tabular}{|c|c|c|c|c|}
\hline Month & $\begin{array}{l}\text { Sun Angle } \\
\text { (Degrees) }\end{array}$ & $\begin{array}{l}\text { Sun angle } \\
\text { (Radians) }\end{array}$ & $\begin{array}{l}\text { Window } \\
\text { Height } \\
\text { Shaded } \\
(\mathrm{mm})\end{array}$ & $\begin{array}{l}\text { Percentage of Window } \\
\text { Shaded } \\
(0=100 \% \text { shaded, } 1= \\
100 \% \text { clear })\end{array}$ \\
\hline Jan & 46.1 & 0.80 & 520 & $61 \%$ \\
\hline Feb & 39.4 & 0.69 & 411 & $69 \%$ \\
\hline Mar & 32.4 & 0.57 & 317 & $76 \%$ \\
\hline Apr & 24.2 & 0.42 & 225 & $83 \%$ \\
\hline May & 17.4 & 0.30 & 157 & $88 \%$ \\
\hline Jun & 13.9 & 0.24 & 124 & $91 \%$ \\
\hline Jul & 15.7 & 0.27 & 141 & $89 \%$ \\
\hline Aug & 23 & 0.40 & 212 & $84 \%$ \\
\hline Sep & 33.7 & 0.59 & 333 & $75 \%$ \\
\hline Oct & 44 & 0.77 & 483 & $64 \%$ \\
\hline Nov & 50.5 & 0.88 & 607 & $54 \%$ \\
\hline Dec & 50.7 & 0.88 & 611 & $54 \%$ \\
\hline
\end{tabular}

\begin{tabular}{|c|c|c|c|c|}
\hline Month & $\begin{array}{l}\text { Sun Angle } \\
\text { (Degrees) }\end{array}$ & $\begin{array}{l}\text { Sun angle } \\
\text { (Radians) }\end{array}$ & $\begin{array}{l}\text { Window } \\
\text { Height } \\
\text { Shaded }(\mathrm{mm}) \\
\end{array}$ & $\begin{array}{l}\text { Percentage of Window } \\
\text { Shaded } \\
(0=100 \% \text { shaded, } 1= \\
100 \% \text { clear })\end{array}$ \\
\hline Jan & 68.7 & 1.2 & 1282 & $4 \%$ \\
\hline Feb & 59.5 & 1.0 & 849 & $36 \%$ \\
\hline Mar & 48.7 & 0.8 & 569 & $57 \%$ \\
\hline Apr & 37 & 0.6 & 377 & $72 \%$ \\
\hline May & 28.6 & 0.5 & 273 & $80 \%$ \\
\hline Jun & 25.3 & 0.4 & 236 & $82 \%$ \\
\hline Jul & 28.1 & 0.5 & 267 & $80 \%$ \\
\hline Aug & 26.4 & 0.5 & 248 & $81 \%$ \\
\hline Sep & 47.6 & 0.8 & 548 & $59 \%$ \\
\hline Oct & 58.7 & 1.0 & 822 & $38 \%$ \\
\hline Nov & 67.9 & 1.2 & 1231 & $7 \%$ \\
\hline Dec & 72 & 1.3 & 1539 & $-16 \%$ \\
\hline
\end{tabular}


Table 14-19 : North façade: $3 \mathrm{pm}$ shading transmittance calculation

\begin{tabular}{|c|c|c|c|c|}
\hline Month & $\begin{array}{l}\text { Sun Angle } \\
\text { (Degrees) }\end{array}$ & $\begin{array}{l}\text { Sun angle } \\
\text { (Radians) }\end{array}$ & $\begin{array}{l}\text { Window } \\
\text { Height } \\
\text { Shaded } \\
(\mathrm{mm})\end{array}$ & $\begin{array}{l}\text { Percentage of Window } \\
\text { Shaded } \\
(0=100 \% \text { shaded, } 1= \\
100 \% \text { clear })\end{array}$ \\
\hline Jan & 46.9 & 0.8 & 534 & $60 \%$ \\
\hline Feb & 41 & 0.7 & 435 & $67 \%$ \\
\hline Mar & 31.7 & 0.6 & 309 & $77 \%$ \\
\hline Apr & 21.3 & 0.4 & 195 & $85 \%$ \\
\hline May & 14.1 & 0.2 & 126 & $91 \%$ \\
\hline Jun & 12 & 0.2 & 106 & $92 \%$ \\
\hline Jul & 15 & 0.3 & 134 & $90 \%$ \\
\hline Aug & 21.4 & 0.4 & 196 & $85 \%$ \\
\hline Sep & 28.9 & 0.5 & 276 & $79 \%$ \\
\hline Oct & 35.8 & 0.6 & 361 & $73 \%$ \\
\hline Nov & 42.1 & 0.7 & 452 & $66 \%$ \\
\hline Dec & 46.5 & 0.8 & 527 & $60 \%$ \\
\hline
\end{tabular}

\section{Appendix 14.11 Linux script for automated non-interactive batch-mode processing of Genopt}

The following text was the Linux scripting language used to run GenOpt Optimisations concurrently and consecutively.

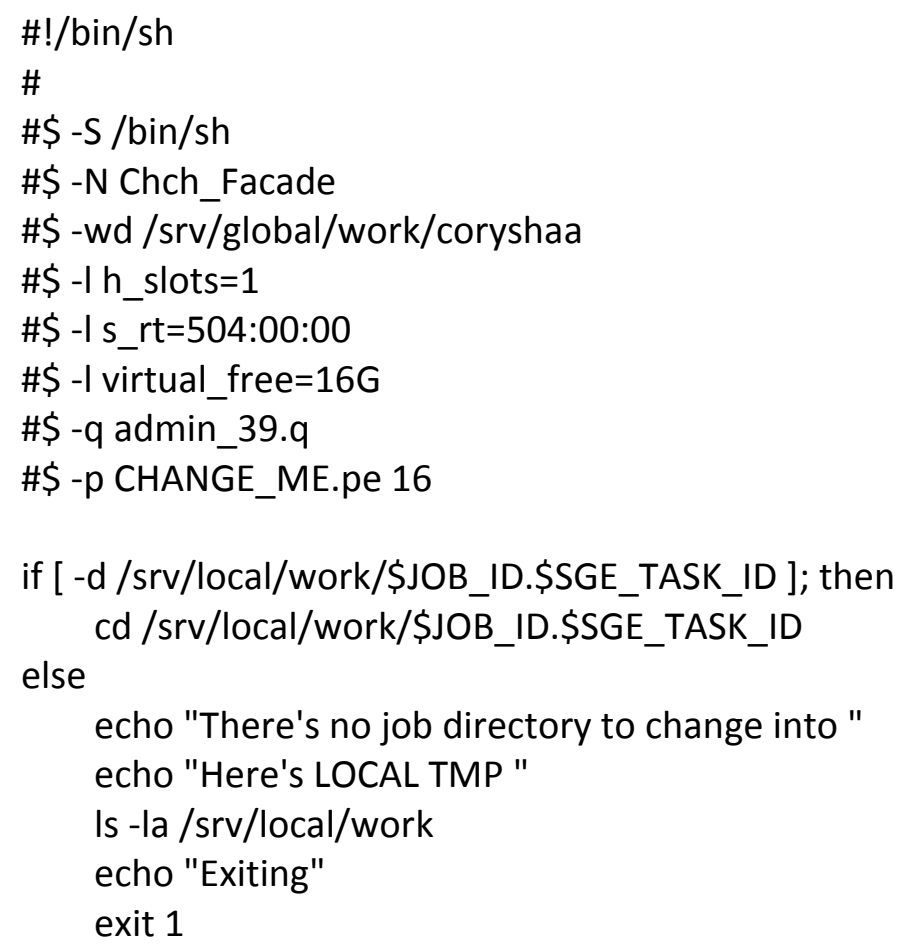

Page | 375 


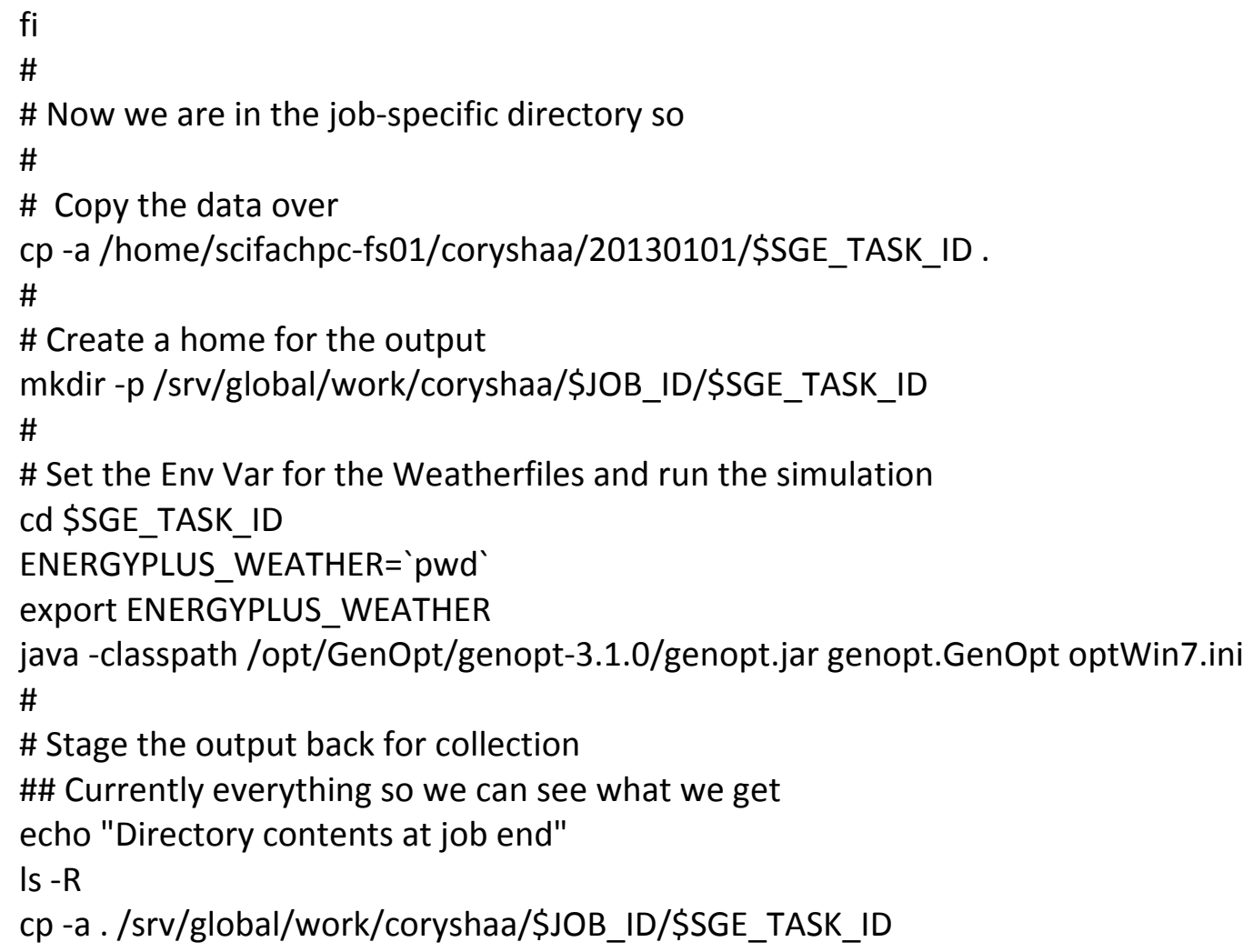

\section{Appendix 14.12 Initial energy calibration results for 48 BEES building models}

Table 14-20 displays the 48 initial energy models and the average energy consumptions across the 48 energy models. It identified the initial energy models (which have not been postsimulation calibrated using the energy signatures) over-estimated compared to the real energy consumption by 278 percent.

\begin{tabular}{|c|c|c|c|}
\hline Building & Real Performance & $\begin{array}{l}\text { Initial Energy Model } \\
\text { Performance }\end{array}$ & Annual Bias Error \\
\hline S1-0-1 & 51.0 & 61.9 & $21 \%$ \\
\hline S1-0-2 & 176.5 & 399.4 & $126 \%$ \\
\hline S1-0-3 & 13.1 & 109.2 & $733 \%$ \\
\hline S1-R-1 & 189.5 & 150.2 & $-21 \%$ \\
\hline S1-R-2 & 207.3 & 81.2 & $-66 \%$ \\
\hline S1-R-3 & 99.4 & 89.5 & $-10 \%$ \\
\hline S1-R-4 & 147.3 & 114.1 & $-22 \%$ \\
\hline S1-R-5 & 64.0 & 131.9 & $106 \%$ \\
\hline S1-M-1 & 70.4 & 187.9 & $167 \%$ \\
\hline S1-M-2 & 12.5 & 17.0 & $36 \%$ \\
\hline
\end{tabular}




\begin{tabular}{|c|c|c|c|}
\hline S2-0-1 & 21.1 & 46.1 & $118 \%$ \\
\hline S2-0-2 & 131.4 & 138.8 & $6 \%$ \\
\hline S2-R-1 & 169.6 & 251.3 & $48 \%$ \\
\hline S2-R-2 & 81.5 & 176.7 & $117 \%$ \\
\hline S2-R-3 & 157.0 & 557.3 & $255 \%$ \\
\hline S2-R-4 & 233.4 & 49.6 & $-79 \%$ \\
\hline S2-R-5 & 27.3 & 60.3 & $120 \%$ \\
\hline S2-M-1 & 4.3 & 184.7 & $4245 \%$ \\
\hline S2-M-2 & 53.9 & 225.0 & $317 \%$ \\
\hline S2-M-3 & 13.7 & 9.1 & $-33 \%$ \\
\hline S3-O-1 & 247.0 & 2911.8 & $1079 \%$ \\
\hline S3-0-2 & 132.9 & 277.3 & $109 \%$ \\
\hline S3-0-3 & 28.7 & 26.4 & $-8 \%$ \\
\hline S3-R-1 & 37.6 & 27.1 & $-28 \%$ \\
\hline S3-R-2 & 61.8 & 30.0 & $-51 \%$ \\
\hline S3-R-3 & 102.4 & 115.5 & $13 \%$ \\
\hline S3-R-4 & 15.2 & 63.4 & $318 \%$ \\
\hline S3-M-1 & 36.4 & 59.3 & $63 \%$ \\
\hline S3-M-2 & 102.0 & 140.7 & $38 \%$ \\
\hline S3-M-3 & 122.5 & 325.6 & $166 \%$ \\
\hline S4-0-1 & 168.6 & 88.9 & $-47 \%$ \\
\hline S4-0-2 & 71.3 & 93.5 & $31 \%$ \\
\hline S4-0-3 & 118.8 & 51.6 & $-56 \%$ \\
\hline S4-0-4 & 76.5 & 273.6 & $257 \%$ \\
\hline S4-0-5 & 3.8 & 19.7 & $421 \%$ \\
\hline S4-R-1 & 417.0 & 382.7 & $-8 \%$ \\
\hline S4-R-2 & 571.4 & 426.5 & $-25 \%$ \\
\hline S4-M-1 & 46.4 & 1801.8 & $3784 \%$ \\
\hline S4-M-2 & 60.5 & 258.4 & $327 \%$ \\
\hline S4-M-3 & 194.0 & 120.2 & $-32 \%$ \\
\hline S5-0-1 & 68.5 & 95.5 & $39 \%$ \\
\hline S5-0-2 & 17.6 & 132.5 & $653 \%$ \\
\hline S5-0-3 & 182.2 & 169.6 & $-7 \%$ \\
\hline S5-0-4-V1 & 99.7 & 45.0 & $-55 \%$ \\
\hline S5-R-1 & 188.2 & 307.1 & $63 \%$ \\
\hline S5-M-1-V1 & 47.0 & 44.4 & $-5 \%$ \\
\hline S5-M-2 & 141.4 & 128.8 & $-9 \%$ \\
\hline S5-M-3 & 77.2 & 186.0 & $141 \%$ \\
\hline Average & 111.7 & 242.6 & $278 \%$ \\
\hline
\end{tabular}




\section{Appendix 14.13 S2-0-1 input parameter updates}

Table 14-21 displays a summary of the updated HVAC operation and heating and cooling set points.

Table 14-21 : S2-O-1 initial and calibrated input parameters

\begin{tabular}{|c|c|c|c|c|c|c|}
\hline \multicolumn{2}{|l|}{ Parameter } & \multicolumn{2}{|l|}{ Initial Model } & \multicolumn{3}{|l|}{ Calibrated Model } \\
\hline \multicolumn{2}{|l|}{ Name: } & \multicolumn{5}{|c|}{ HVAC Operation } \\
\hline Months: & & January & & January & & \\
\hline Days: & & All & Days & All & & Days \\
\hline period & 1: & $00: 00-24: 00$ & Off & $00: 00-24: 00$ & $=$ & Off \\
\hline Months: & & February-December & & February-December & & \\
\hline period & 1: & Weekdays & & Weekdays & & \\
\hline Period & 2: & 00:00-10:00 & Off & 00:00-07:00 & $=$ & Off \\
\hline Period & 3: & $10: 00-22: 00$ & On & $07: 00-22: 00$ & $=$ & On \\
\hline Days: & & $22: 00-24: 00$ & Off & $22: 00-24: 00$ & $=$ & On \\
\hline period & 1: & Other & Days & Other & & Days \\
\hline Period & 2: & 00:00-10:00 & Off & 00:00-10:00 & $=$ & Off \\
\hline \multicolumn{2}{|l|}{ Time Period 3: } & $\begin{array}{l}10: 00-21: 00 \\
21: 00-24: 00=\text { Off }\end{array}$ & On & $\begin{array}{l}10: 00-21: 00 \\
21: 00-24: 00=\text { Off }\end{array}$ & $=$ & On \\
\hline \multicolumn{7}{|c|}{ Heating to Cooling Set point Deadband } \\
\hline Months: & & January-February & & January-February & & \\
\hline Days: & & All & Days & All & & Days \\
\hline $\begin{array}{l}\text { Time } \\
\text { Months: }\end{array}$ & 1: & $\begin{array}{l}\text { 00:00-24:00 } \\
\text { March }\end{array}$ & $13-28^{\circ} \mathrm{C}$ & $\begin{array}{l}\text { 00:00-24:00 } \\
\text { March }\end{array}$ & $=$ & $15-28^{\circ} \mathrm{C}$ \\
\hline Days: & & All & Days & All & & Days \\
\hline $\begin{array}{l}\text { Time period } \\
\text { Months: }\end{array}$ & 2: & $\begin{array}{l}\text { 00:00-24:00 } \\
\text { April }\end{array}$ & $18-26^{\circ} \mathrm{C}$ & $\begin{array}{l}\text { 00:00-24:00 } \\
\text { April }\end{array}$ & $=$ & $18-22^{\circ} \mathrm{C}$ \\
\hline Days: & & All & Days & All & & Days \\
\hline $\begin{array}{l}\text { Time period } \\
\text { Months: }\end{array}$ & 3: & $\begin{array}{l}\text { 00:00-24:00 } \\
\text { May }\end{array}$ & $18-22.5^{\circ} \mathrm{C}$ & $\begin{array}{l}\text { 00:00-24:00 } \\
\text { May }\end{array}$ & & $21-22.5^{\circ} \mathrm{C}$ \\
\hline Days: & & All & Days & All & & Days \\
\hline $\begin{array}{l}\text { Time } \quad \text { period } \\
\text { Months: }\end{array}$ & 4: & $\begin{array}{l}\text { 00:00-24:00 } \\
\text { June-July }\end{array}$ & $19-30^{\circ} \mathrm{C}$ & $\begin{array}{l}\text { 00:00-24:00 } \\
\text { June-July }\end{array}$ & $=$ & $21-22^{\circ} \mathrm{C}$ \\
\hline Days: & & All & Days & All & & Days \\
\hline $\begin{array}{l}\text { Time period } \\
\text { Months: }\end{array}$ & 5: & $\begin{array}{l}\text { 00:00-24:00 = } \\
\text { August-September }\end{array}$ & $17-30^{\circ} \mathrm{C}$ & $\begin{array}{l}\text { 00:00-24:00 } \\
\text { August-September }\end{array}$ & $=$ & $19-23^{\circ} \mathrm{C}$ \\
\hline Days: & & All & Days & All & & Days \\
\hline $\begin{array}{l}\text { Time period } \\
\text { Months: }\end{array}$ & 6: & $\begin{array}{l}\text { 00:00-24:00 } \\
\text { October }\end{array}$ & $18.7-24^{\circ} \mathrm{C}$ & $\begin{array}{l}\text { 00:00-24:00 } \\
\text { October }\end{array}$ & $=$ & $21-22^{\circ} \mathrm{C}$ \\
\hline Days: & & All & Days & All & & Days \\
\hline $\begin{array}{l}\text { Time period } \\
\text { Months: }\end{array}$ & 7: & $\begin{array}{l}\text { 00:00-24:00 } \\
\text { November }\end{array}$ & $20.5-26^{\circ} \mathrm{C}$ & $\begin{array}{l}\text { 00:00-24:00 } \\
\text { November }\end{array}$ & $=$ & $21-22^{\circ} \mathrm{C}$ \\
\hline Days: & & All & Days & All & & Days \\
\hline $\begin{array}{l}\text { Time period } \\
\text { Months: }\end{array}$ & 8: & $\begin{array}{l}\text { 00:00-24:00 } \\
\text { December }\end{array}$ & $19-23^{\circ} \mathrm{C}$ & $\begin{array}{l}\text { 00:00-24:00 } \\
\text { December }\end{array}$ & $=$ & $20-21^{\circ} \mathrm{C}$ \\
\hline Days: & & & Days & All & & Days \\
\hline Time period 1: & & $00: 00-24: 00=15-24.5^{\circ} \mathrm{C}$ & & $00: 00-24: 00=15-21^{\circ} \mathrm{C}$ & & \\
\hline
\end{tabular}




\section{Appendix 14.14 Impact of available meter data on calibration results of 48 BEES building models}

Table 14-22 displays the trend in calibration results for buildings which have less than 12 months of meter data available for the calibration process. The cells shaded green show the buildings with over six months inside the calibration limit and that meet the 5 percent annual error rate (or meet the target calibration tolerance). They are coloured red if they do not and did not meet the calibration tolerance. The trend identified was the buildings with more meter data were able to be calibrated to the targeted tolerance set in Chapter 8 .

\begin{tabular}{|c|c|c|c|c|}
\hline Building & $\begin{array}{c}\text { Number of } \\
\text { months with } \\
\pm 5 \% \\
\text { tolerance }\end{array}$ & $\begin{array}{l}\text { Annual Bias } \\
\text { Error }\end{array}$ & $\begin{array}{l}\text { Quality = Number of months of } \\
\text { missing/uncertain meter data }\end{array}$ & $\begin{array}{l}\text { Trend in } \\
\text { calibration } \\
\text { results }\end{array}$ \\
\hline S1-M-2 & 8 & $1 \%$ & 2.5 months of missing data. & \multirow{10}{*}{$\begin{array}{l}\text { More } \\
\text { months } \\
\text { within 5\% }\end{array}$} \\
\hline S4-0-2 & 8 & $0 \%$ & 2.5 months of missing data. & \\
\hline S1-M-1 & 5 & $-5 \%$ & 3 months of missing data. & \\
\hline S3-R-4 & 8 & $5 \%$ & $\begin{array}{c}3 \text { months building operation differs } \\
\text { to typical use.. }\end{array}$ & \\
\hline S4-M-1 & 4 & $1 \%$ & $\begin{array}{c}\text { 2-3 months usage differs to typical } \\
\text { use }\end{array}$ & \\
\hline S1-0-3 & 6 & $9 \%$ & $\begin{array}{l}2 \text { months of missing data and } 2 \\
\text { months usage differs to typical use. }\end{array}$ & \\
\hline S3-R-1 & 6 & $0 \%$ & $\begin{array}{c}4 \text { months building operation differs } \\
\text { to typical use.. }\end{array}$ & \\
\hline S3-M-2 & 7 & $-2 \%$ & 4 and half months of missing data. & \\
\hline S5-M-3 & 5 & $10 \%$ & $\begin{array}{l}2 \text { months of missing data and } 2-3 \\
\text { months building operation differs } \\
\text { to typical use. }\end{array}$ & \\
\hline S5-O-1 & 4 & $3 \%$ & 6 months of missing data. & \\
\hline S2-M-1 & 1 & $24 \%$ & 7 months of missing data. & $\begin{array}{l}\text { less months } \\
\text { within } 5 \%\end{array}$ \\
\hline
\end{tabular}




\section{Appendix 14.15 Example of averaging meter data}

Table 14-23 presents an example of how monthly meter data was average for calibrating buildings with no meter data.

Table 14-23 : Example of averaging monthly meter data for calibration of buildings with no meter data

\begin{tabular}{|r|c|c|c|c|c|c|c|c|c|c|}
\hline & S1-M-2 & S1-R-5 & S1-R-4 & S1-R-2 & S1-O-3 & S1-M-1 & S1-R-1 & S1-R-3 & S1-O-1 & Average \\
\hline Jan & - & 2,886 & 4,255 & 4,030 & 316 & 1,290 & 2,041 & 3,695 & 1,944 & 2,557 \\
\hline Feb & - & 2,978 & 4,677 & 4,112 & 266 & 1,165 & 1,761 & 3,379 & 2,194 & 2,567 \\
\hline Mar & 346 & 3,053 & 4,610 & 5,361 & 278 & 1,527 & 1,896 & 3,560 & 1,896 & 2,503 \\
\hline Apr & 336 & 2,503 & 4,532 & 5,434 & 289 & 1,604 & 1,808 & 3,244 & 3,152 & 2,545 \\
\hline May & 481 & 2,802 & 3,714 & 6,317 & - & - & 1,884 & 3,464 & 3,454 & 3,159 \\
\hline Jun & 485 & 3,089 & 5,286 & 6,190 & - & - & 1,979 & 3,489 & 3,643 & 3,452 \\
\hline Jul & 780 & 3,203 & 4,675 & 6,655 & - & - & 1,971 & 3,327 & 3,169 & 3,397 \\
\hline Aug & 822 & 3,638 & 4,796 & 6,307 & 213 & - & 2,002 & 3,033 & 2,474 & 2,911 \\
\hline Sep & 445 & 2,917 & 4,295 & 5,397 & 347 & 1,082 & 2,013 & 2,698 & 2,359 & 2,395 \\
\hline Oct & 447 & 2,527 & 4,048 & 5,616 & 325 & 1,951 & 2,097 & 2,825 & 1,970 & 2,423 \\
\hline Nov & - & 2,576 & 3,807 & 5,516 & 291 & 1,492 & 2,079 & 2,715 & 2,076 & 2,569 \\
\hline Dec & - & 2,585 & 4,614 & 5,820 & 300 & 1,270 & 1,967 & 2,839 & 2,244 & 2,705 \\
\hline
\end{tabular}

Page $\mid 380$ 


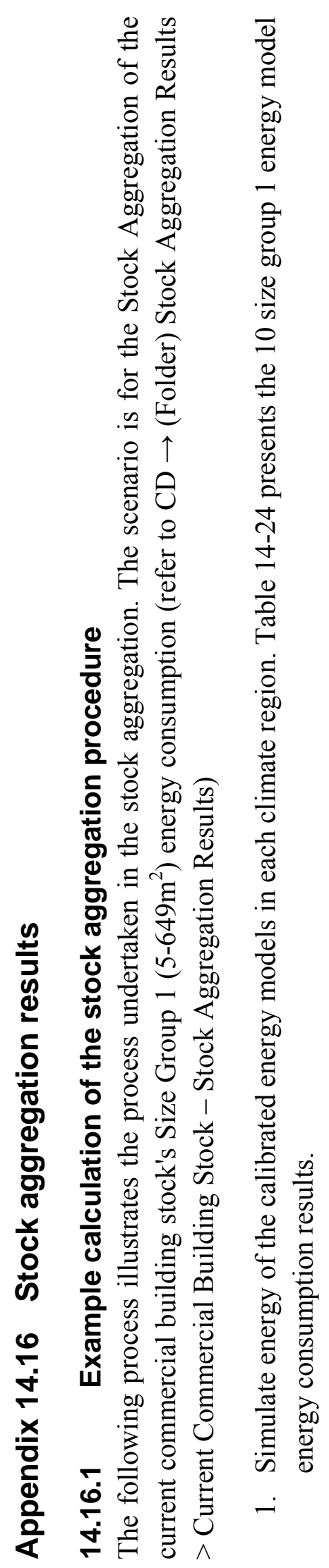

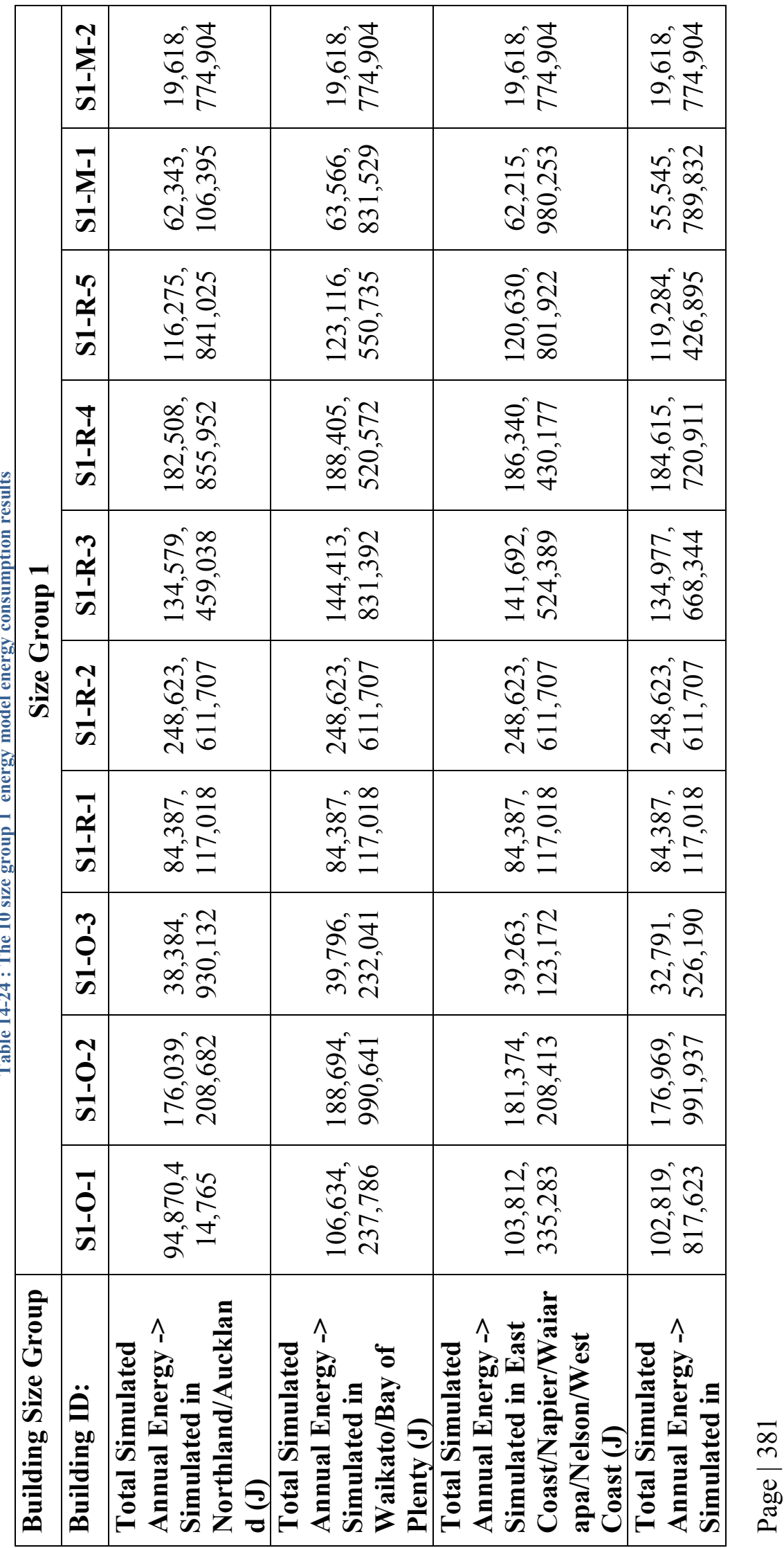




\begin{tabular}{|c|c|c|c|c|}
\hline & $\begin{array}{l}\infty \\
0 \\
\sigma \\
\sigma \\
\sigma \\
\sigma\end{array}$ & 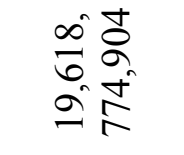 & $\begin{array}{l}\infty \\
\infty \\
\sigma \\
\sigma \\
\sigma \\
\sigma\end{array}$ & \\
\hline & 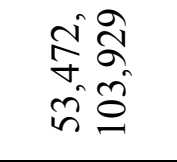 & 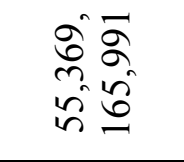 & 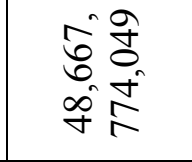 & \\
\hline & $\begin{array}{l}\dot{\nabla} \bar{m} \\
\dot{\sigma} \\
\infty \\
=\infty \\
= \\
=\end{array}$ & 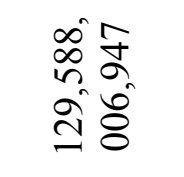 & 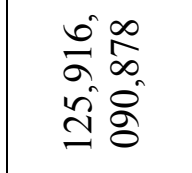 & \\
\hline & 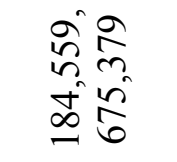 & 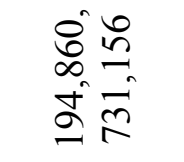 & 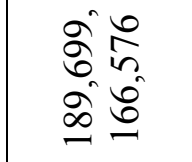 & \\
\hline & 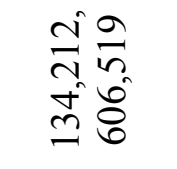 & 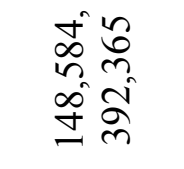 & 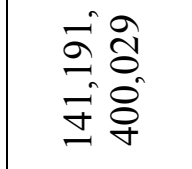 & \\
\hline & 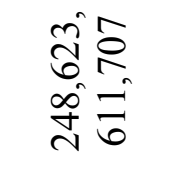 & 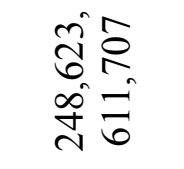 & 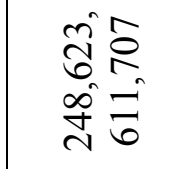 & \\
\hline & $\begin{array}{l}\hat{\infty}^{\infty}= \\
\tilde{0} \\
\dot{\infty}=\end{array}$ & $\begin{array}{l}\hat{\infty}= \\
\tilde{0} \\
\dot{\infty}=\end{array}$ & $\begin{array}{l}\infty \\
\infty \\
\cdots \\
\infty \\
\infty\end{array}$ & \\
\hline & 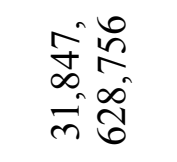 & 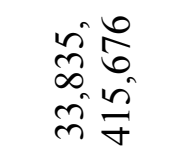 & 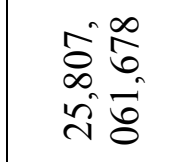 & \\
\hline & $\begin{array}{l}\hat{n} \sigma \\
\hat{\sigma} \sigma \\
\hat{\sigma} \sigma\end{array}$ & 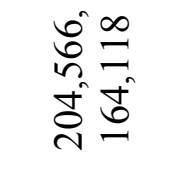 & 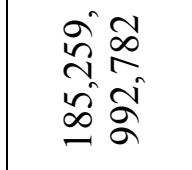 & \\
\hline & 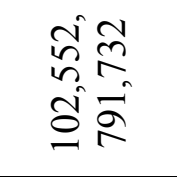 & 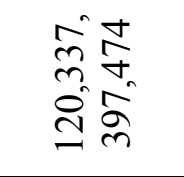 & 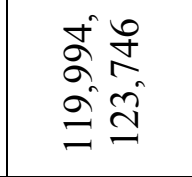 & \\
\hline 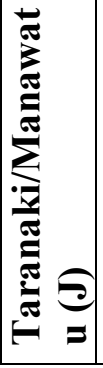 & 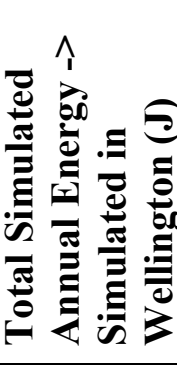 & 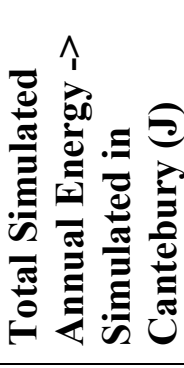 & 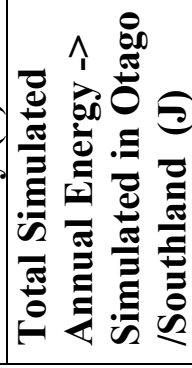 & \\
\hline
\end{tabular}

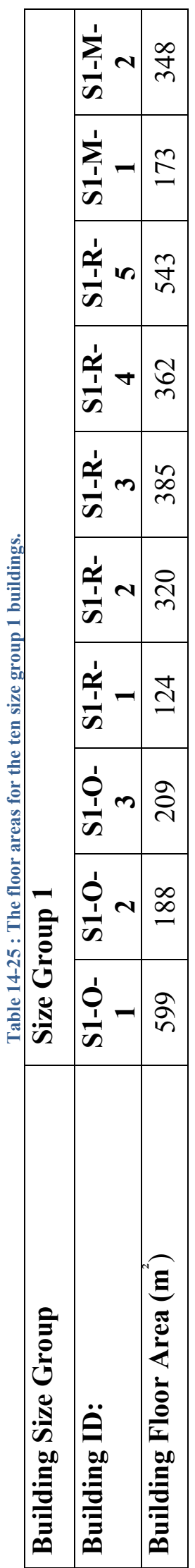




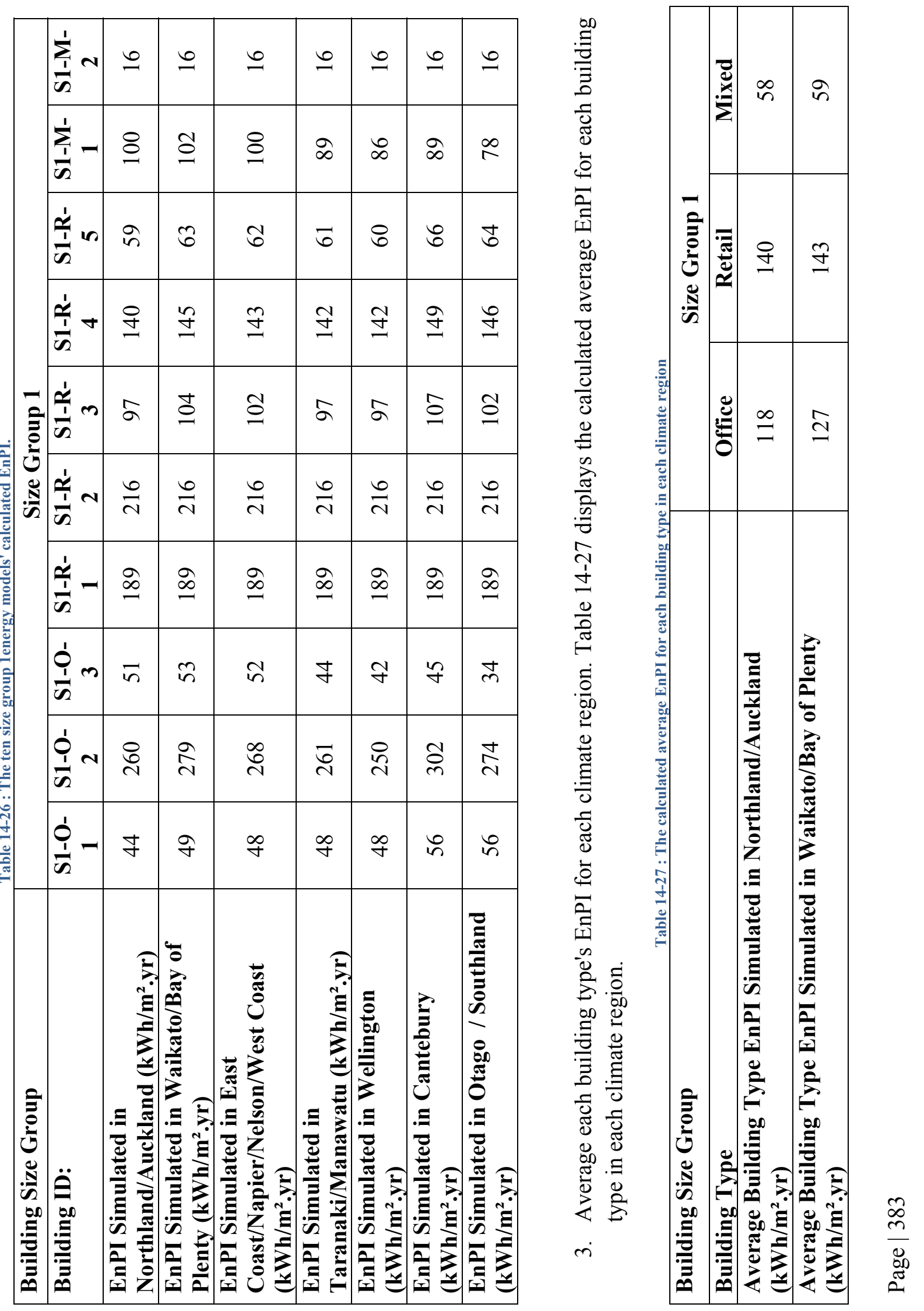



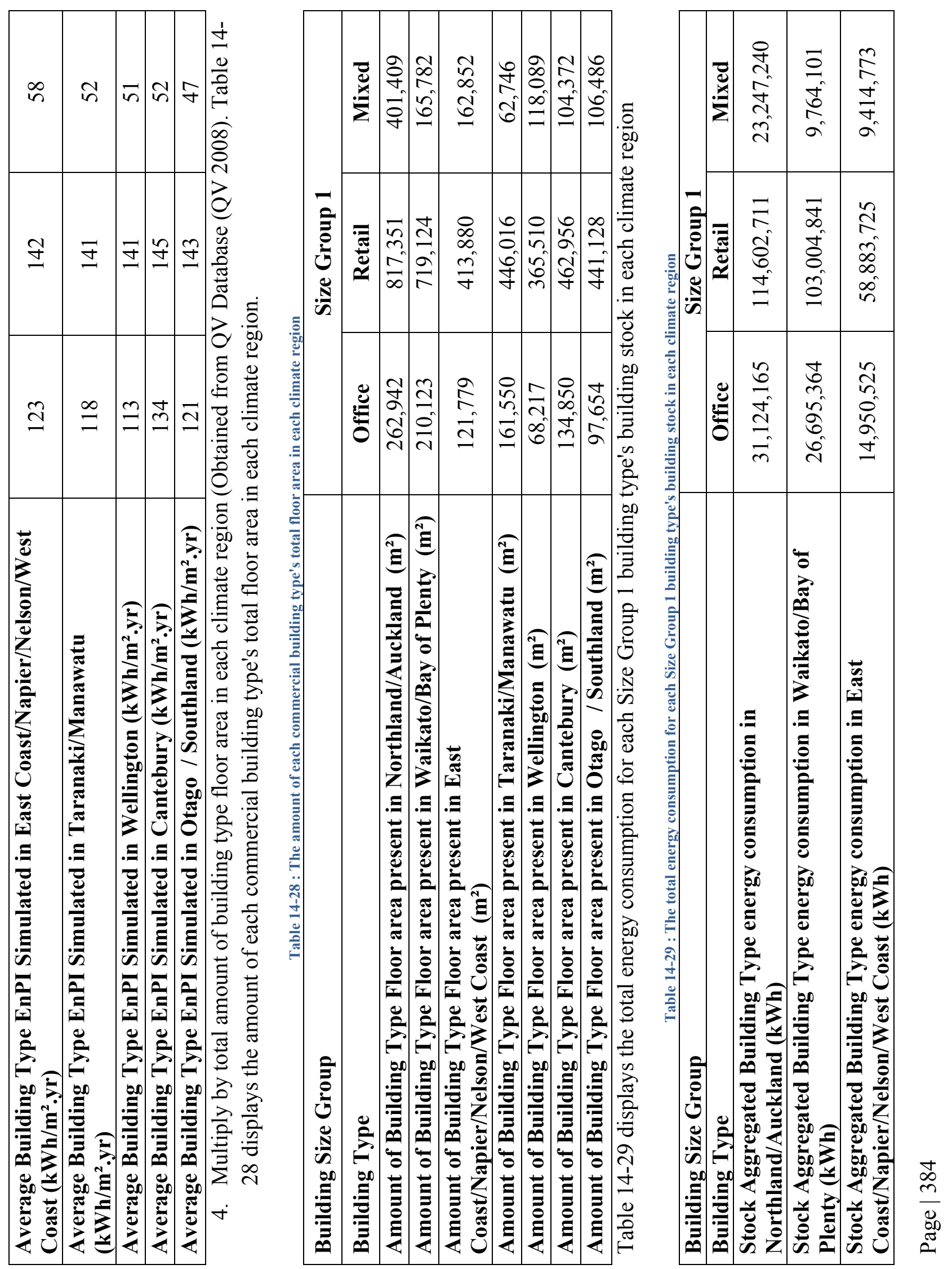


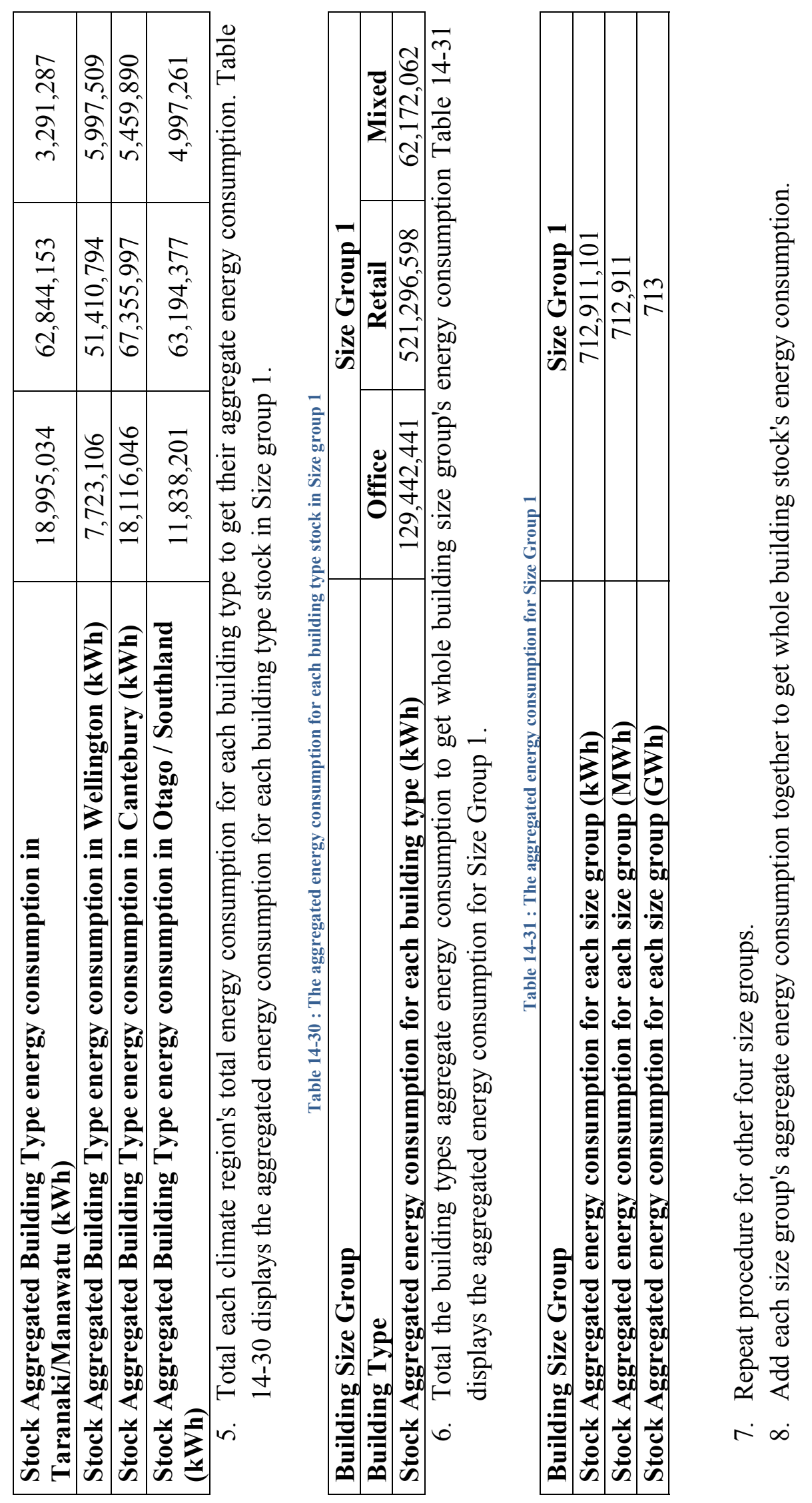

$n$
$\infty$
$\infty$
0
$\infty$
0
0 
Each energy end-use (heating, cooling, fans/pumps, lighting, and equipment) is stock aggregated in different sheets within each scenario's stock aggregation results spreadsheet. Figure 14-17 displays the naming convention for each energy end-use's stock aggregation results in the spreadsheet.

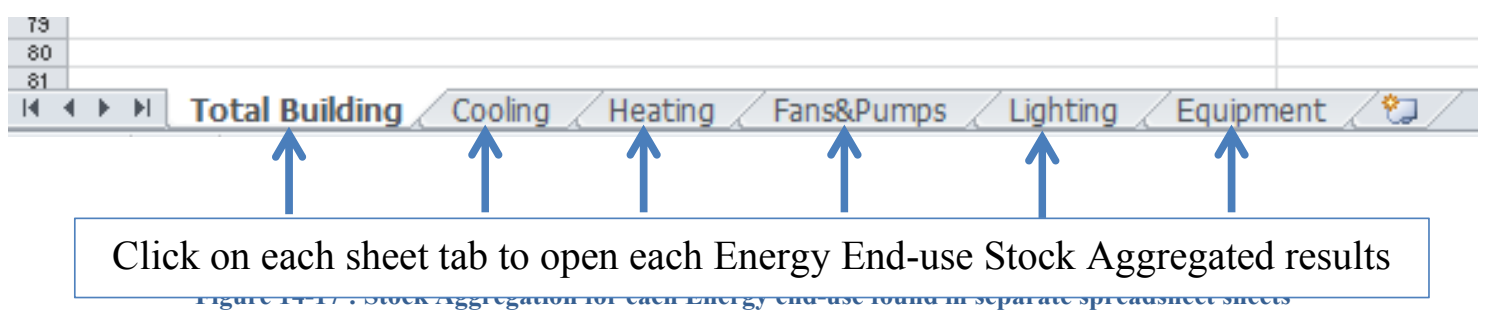

\subsubsection{Current Commercial Building Stock}

Refer to CD $>$ (folder) Stock Aggregation Results $>$ (File) Current Commercial Building Stock Stock Aggregation Results

\subsubsection{NZE Commercial Building Stock Without Onsite Renewables}

Refer to CD > (folder) Stock Aggregation Results > (File) NZE Commercial Building Stock WITH onsite renewables - Stock Aggregation Results

\subsubsection{NZE Commercial Building Stock With Onsite Renewables}

Refer to $\mathrm{CD}>$ (folder) Stock Aggregation Results $>$ (File) NZE Commercial Building Stock WITH onsite renewables - Stock Aggregation Results

\subsubsection{Stock Aggregation results with ECMs removed for ranking of effectiveness}

To rank each of the ECM's effectiveness, each ECM was removed from each of the 48 energy models that make up the NZE retrofit building stock. The stock aggregation results for each ECM removed from the NZE retrofit building stock can be found at:

\section{Advanced Daylighting removed}

Refer to CD > (folder) Stock Aggregation Results $>$ (File) NZE without Advanced Daylighting Stock Aggregation Results

\section{Efficient Miscellaneous Equipment removed}

Refer to $\mathrm{CD}>$ (folder) Stock Aggregation Results $>$ (File) NZE without Efficient Misc Equipment - Stock Aggregation Results

\section{Efficient Office Equipment removed}

Refer to $\mathrm{CD}>$ (folder) Stock Aggregation Results > (File) NZE without Efficient Office Equipment - Stock Aggregation Results 


\section{Efficient Lighting removed}

Refer to CD > (folder) Stock Aggregation Results $>$ (File) NZE without Efficient Lighting Stock Aggregation Results

\section{Advanced Lighting Controls removed}

Refer to $\mathrm{CD}>$ (folder) Stock Aggregation Results $>$ (File) NZE without Advanced Lighting Controls - Stock Aggregation Results

\section{Efficient HVAC removed}

Refer to CD $>$ (folder) Stock Aggregation Results $>$ (File) NZE without Efficient HVAC - Stock Aggregation Results

\section{Improved Envelope removed}

Refer to CD > (folder) Stock Aggregation Results $>$ (File) NZE without Improved Envelope Stock Aggregation Results

\section{Maximising Passive Solar and Daylighting removed}

Refer to CD > (folder) Stock Aggregation Results $>$ (File) NZE without Maximising Passive Solar and Daylighting - Stock Aggregation Results

\section{Natural Ventilation removed}

Refer to CD > (folder) Stock Aggregation Results $>$ (File) NZE without Natural Ventilation Stock Aggregation Results

\section{Solar Shading removed}

Refer to CD > (folder) Stock Aggregation Results $>$ (File) NZE without Solar Shading - Stock Aggregation Results

\section{Upgraded Glazing removed}

Refer to CD > (folder) Stock Aggregation Results $>$ (File) NZE without Upgraded Glazing Stock Aggregation Results 


\section{Appendix 14.1795 percent confidence Intervals}

The average EnPI of the various Building Stock Group Scenarios presented in Section 9.3.1 was required to calculate the 95 percent confidence interval for the sample of 48 energy models (Table 14-32)

Table 14-32: Average EnPI for different building stock scenarios (type, size, climate)

\begin{tabular}{|l|c|c|c|}
\hline $\begin{array}{l}\text { Building Stock } \\
\text { Group Scenario }\end{array}$ & $\begin{array}{c}\text { Total Energy } \\
(\mathbf{G W h})\end{array}$ & Floor area (m2) & $\begin{array}{c}\text { Average EnPI } \\
\left(\mathbf{k W h} / \mathbf{m}^{2} \cdot \mathbf{y r}\right)\end{array}$ \\
\hline Building Stock & 3,334 & $25,133,144$ & 133 \\
\hline Office & 753 & $6,945,120$ & 108 \\
\hline Retail & 1,888 & $10,672,118$ & 177 \\
\hline Mixed Commercial & 693 & $7,515,905$ & 122 \\
\hline $5-649 \mathrm{~m}^{2}$ & 713 & $5,844,815$ & 92 \\
\hline $650-1499 \mathrm{~m}^{2}$ & 414 & $4,481,363$ & 96 \\
\hline $1500-3499 \mathrm{~m}^{2}$ & 406 & $4,242,697$ & 210 \\
\hline $3500-9000 \mathrm{~m}^{2}$ & 977 & $4,642,547$ & 139 \\
\hline $9000 \mathrm{~m}^{2}$ and greater & 825 & $5,921,722$ & 136 \\
\hline Climate Region 1 & 1,074 & $8,538,658$ & 127 \\
\hline Climate Region 2 & 453 & $3,345,028$ & 143 \\
\hline Climate Region 3 & 251 & $1,971,570$ & 130 \\
\hline Climate Region 4 & 282 & $1,972,079$ & 148 \\
\hline Climate Region 5 & 542 & $4,181,698$ & 136 \\
\hline Climate Region 6 & 444 & $2,997,906$ & \\
\hline Climate Region 7 & 288 & $2,126,205$ & \\
\hline
\end{tabular}


Table 14-33 presents the variables and calculated 95\% confidence interval for the various building stock grouping scenarios. The confidence intervals were calculated using the Confidence Interval calculation procedure ((Urdan 2010; Statistics How To 2014).

Table 14-33 : Calculation of the 95\% confidence interval for different Building Stock Group Scenarios (type, size, climate)

\begin{tabular}{|c|c|c|c|c|c|c|c|c|c|}
\hline \multirow{2}{*}{$\begin{array}{l}\text { Building } \\
\text { Stock Group } \\
\text { Scenario }\end{array}$} & $\begin{array}{c}\text { Ave } \\
\text { EnPI } \\
\end{array}$ & STD & \multirow{2}{*}{$\begin{array}{c}\text { Sample } \\
\text { size }\end{array}$} & \multicolumn{2}{|c|}{ Standard Error } & \multirow{2}{*}{$\begin{array}{l}\text { Degrees of } \\
\text { Freedom } \\
\text { (sample size } \\
\text { minus 1) }\end{array}$} & \multirow{2}{*}{$\begin{array}{c}\text { T- } \\
\text { distribution } \\
\text { for } \alpha= \\
\mathbf{0 . 0 2 5}\end{array}$} & \multicolumn{2}{|c|}{$\begin{array}{c}95 \% \\
\text { Confidence } \\
\text { level }\end{array}$} \\
\hline & $\mathbf{k W}$ & $n^{2} . y r$ & & $\begin{array}{l}\mathbf{k W h} / \\
\mathbf{m}^{2} . \mathbf{y r}\end{array}$ & $\%$ & & & $\begin{array}{l}\mathrm{kWh} / \mathrm{m} \\
{ }^{2} \cdot \mathrm{yr}\end{array}$ & $\%$ \\
\hline $\begin{array}{l}\text { Building } \\
\text { Stock }\end{array}$ & 133 & 106 & 48 & 15 & $12 \%$ & 47 & 2.021 & 31 & $23 \%$ \\
\hline Office & 108 & 72 & 17 & 17 & $16 \%$ & 16 & 2.120 & 37 & $34 \%$ \\
\hline Retail & 177 & 143 & 17 & 35 & $20 \%$ & 16 & 2.120 & 73 & $41 \%$ \\
\hline $\begin{array}{l}\text { Mixed } \\
\text { Commercial }\end{array}$ & 92 & 65 & 14 & 17 & $19 \%$ & 13 & 2.16 & 37 & $41 \%$ \\
\hline $5-649 m^{2}$ & 122 & 80 & 10 & 25 & $21 \%$ & 9 & 2.26 & 57 & $47 \%$ \\
\hline $650-1499 \mathrm{~m}^{2}$ & 92 & 75 & 10 & 24 & $26 \%$ & 9 & 2.26 & 53 & $58 \%$ \\
\hline $\begin{array}{l}1500- \\
3499 \mathrm{~m}^{2}\end{array}$ & 96 & 69 & 10 & 22 & $23 \%$ & 9 & 2.26 & 49 & $51 \%$ \\
\hline $\begin{array}{l}3500- \\
9000 \mathrm{~m}^{2}\end{array}$ & 210 & 173 & 10 & 55 & $26 \%$ & 9 & 2.26 & 124 & $59 \%$ \\
\hline $\begin{array}{l}9000 \mathrm{~m}^{2} \text { and } \\
\text { greater }\end{array}$ & 139 & 49 & 8 & 17 & $12 \%$ & 7 & 2.37 & 41 & $29 \%$ \\
\hline $\begin{array}{l}\text { Climate } \\
\text { Region } 1\end{array}$ & 126 & 107 & 7 & 41 & $33 \%$ & 6 & 2.45 & 100 & $80 \%$ \\
\hline $\begin{array}{l}\text { Climate } \\
\text { Region } 2\end{array}$ & 136 & 108 & 7 & 41 & $31 \%$ & 6 & 2.45 & 101 & $75 \%$ \\
\hline $\begin{array}{l}\text { Climate } \\
\text { Region } 3\end{array}$ & 127 & 108 & 7 & 41 & $32 \%$ & 6 & 2.45 & 101 & $79 \%$ \\
\hline $\begin{array}{l}\text { Climate } \\
\text { Region } 4\end{array}$ & 143 & 106 & 7 & 41 & $28 \%$ & 6 & 2.45 & 99 & $69 \%$ \\
\hline $\begin{array}{l}\text { Climate } \\
\text { Region } 5\end{array}$ & 130 & 106 & 7 & 40 & $31 \%$ & 6 & 2.45 & 99 & $76 \%$ \\
\hline $\begin{array}{l}\text { Climate } \\
\text { Region } 6\end{array}$ & 148 & 108 & 7 & 41 & $28 \%$ & 6 & 2.45 & 101 & $68 \%$ \\
\hline $\begin{array}{l}\text { Climate } \\
\text { Region } 7\end{array}$ & 136 & 106 & 7 & 41 & $30 \%$ & 6 & 2.45 & 99 & $73 \%$ \\
\hline
\end{tabular}

The first step was to calculate the Standard Error Rate of the sample by dividing the STD by the Square Root of the sample size. Then the $95 \%$ confidence interval was calculated by multiplying the standard error rate by the critical value of the T-distribution, which was looked up using the degrees of freedom (df) for the sample size in the T-distribution table.

Page $\mid 389$ 


\section{Appendix 14.18 Floor area correction of external studies commercial estimate}

The external estimate obtained from the Final BEES report - part 1 was calculated using a larger floor area sample size. To correct this for the comparison undertaken in Section 9.3, the floor area was changed to the amount used in this thesis and recalculated (undertaken in part [2] below). Note: the example used below is for the Electricity. The same process was used for the Electricity + Gas consumption, but using $203 \mathrm{kWh} / \mathrm{m}^{2}$.yr as presented in (Amitrano, et al., 2014).

\section{[1] Original External Estimate Values}

External estimates average EnPI for commercial buildings' electricity consumption = $173 \mathrm{kWh} / \mathrm{m}^{2} . \mathrm{yr}$

Thesis floor area $=39,930,000$

$173 \mathrm{kWh} / \mathrm{m}^{2} \cdot \mathrm{yr} \quad \mathrm{X} \quad 39,930,000 \mathrm{~m}^{2}=6,867,960,000 \mathrm{kWh} \quad$ OR $6,868 \mathrm{GWh}$

[2] Thesis Floor Area Corrected Consumption Values

External estimates average EnPI for commercial buildings' electricity consumption = $173 \mathrm{kWh} / \mathrm{m}^{2} . \mathrm{yr}$

Thesis floor area $=25,133,144 \mathrm{~m}^{2}$

$173 \mathrm{kWh} / \mathrm{m}^{2} . \mathrm{yr} \quad \mathrm{X} \quad 25,133,144 \mathrm{~m}^{2}=4,348,033,934 \mathrm{kWh} \quad$ OR $4,348 \mathrm{GWh}$

\section{Appendix 14.19 Heating and cooling degree days for Climate Region 3}

Table 14-34 below displays the difference in heating and cooling degree days for Climate Region 3.

Table 14-34 : Difference in Heating and cooling degree days for Climate Region 3 between 2010 and 2012 (Caughey 2015)

\begin{tabular}{|l|c|c|}
\hline Year & Heating Degree Days & Cooling Degree Days \\
\hline 2012 & $1,660.5$ & 247.7 \\
\hline 2010 & $1,434.5$ & 233.0 \\
\hline Percentage change & $16 \%$ more heating in 2012 & $6 \%$ more cooling in 2012 \\
\hline
\end{tabular}

Appendix 14.20 Optimised passive design of retrofitted BEES building models

The results of the 48 energy models optimised passive design in the seven New Zealand climates is found at:

Refer to $\mathrm{CD}>$ (folder) OptimisationResults $>$ (File) OptimisedDesignParameters. 


\section{Appendix 14.21 Final energy balance to primary energy balance}

Table 14-35 displays the calculation for converting the final energy values used in the NZE balance to Primary energy values to calculate if Net Zero Primary Energy was achieved.

Table 14-35: The calculation for converting the final energy values to Primary energy for use in the NZE balance

\begin{tabular}{|c|c|c|c|c|}
\hline Energy Metric & $\begin{array}{l}\text { Stock Aggregated - } \\
\text { Current Energy } \\
\text { Consumption } \\
\text { (GWh) }\end{array}$ & $\begin{array}{l}\text { Stock Aggregated - } \\
\text { NZE Cnergy } \\
\text { Consumption } \\
\text { (GWh) }\end{array}$ & \begin{tabular}{lr}
\multicolumn{3}{l}{ Stock Aggregated - } \\
Onsite r PV \\
Generation (GWh) \\
(Additional \\
renewable r to \\
current renewable \\
supply)
\end{tabular} & $\begin{array}{l}\text { Current renewable } \\
\text { energy supply: } \\
\text { Current renewable } \\
\text { energy supply is } \\
55 \% \\
\begin{array}{l}\text { consumption } \\
\text { (calculated }\end{array} \\
\text { Appendix 14.1) } \\
\end{array}$ \\
\hline Final Energy & 3,334 & 1,460 & 1,348 & 1,834 \\
\hline
\end{tabular}

Calculate Primary Energy by multiplying by Primary Energy Factor (calculated in Appendix 14.1.3)

\begin{tabular}{|c|c|c|c|c|}
\hline Primary Energy & \multicolumn{4}{|l|}{2.8} \\
\hline Primary Energy & $\begin{array}{l}\text { Stock } \\
\text { Aggregated - } \\
\text { Current Energy } \\
\text { Consumption }\end{array}$ & $\begin{array}{l}\text { Stock } \\
\text { Aggregated - } \\
\text { NZE Energy } \\
\text { Consumption }\end{array}$ & $\begin{array}{lr}\text { Stock } & \\
\text { Aggregated } & - \\
\text { Onsite } & \text { PV } \\
\text { Generation } & \end{array}$ & $\begin{array}{l}\text { Current Energy } \\
\text { Supply }\end{array}$ \\
\hline & 9,416 & 4,122 & 3,808 & 5,179 \\
\hline
\end{tabular}




\section{Appendix 14.22 Building and climate average calculation procedure}

The Current and Net Zero Energy Thermal performance (Too Cold, Comfortable, and Too Hot) results from each energy model's thermal zones simulated in each of the seven climate regions for New Zealand are gathered. The results from the thermal zones are averaged to get a whole building thermal performance result.

Figure 14-18 displays the thermal performance results for the current S1-R-4 and Net ZEB S1-R4 energy model thermal zones (East and West) and building average.

\begin{tabular}{|c|c|c|c|c|c|c|c|c|}
\hline & & & Current & & & & et ZEB & \\
\hline & Zones & West & East & Building Average & & West & East & Building Average \\
\hline & Too Cold $\left(<188^{\circ} \mathrm{C}\right)$ & 1110 & 1110 & 1110 & Too Cold $(<18 \mathrm{C})$ & 127 & 130 & 128.5 \\
\hline & Comfortable $\left(18-25^{\circ} \mathrm{C}\right)$ & 245 & 245 & 245 & Comfortable $\left(18-25^{\circ} \mathrm{C}\right)$ & 2645 & 2642 & 2643.5 \\
\hline $\mathrm{S} 1-\mathrm{R}-4$ & Too Hot $(>25 \mathrm{C})$ & 1417 & 1417 & 1417 & Too Hot $(>25 \mathrm{C})$ & 0 & 0 & 0 \\
\hline
\end{tabular}

\begin{tabular}{|c|c|c|c|c|c|c|c|c|}
\hline & & & Current & & & & et ZEB & \\
\hline & Zones & West & East & Building Average & & West & East & Building Average \\
\hline & Too Cold $\left(<18^{\circ} \mathrm{C}\right)$ & 1111 & 1111 & 1111 & Too Cold (<18 C) & 139 & 140 & 139.5 \\
\hline & Comfortable $\left(18-25^{\circ} \mathrm{C}\right)$ & 251 & 252 & 252 & Comfortable $\left(18-25^{\circ} \mathrm{C}\right)$ & 2633 & 2632 & 2632.5 \\
\hline S1-R-4 & Too Hot $(>25 \mathrm{C})$ & 1410 & 1409 & 1409 & Too Hot $(>25 \mathrm{C})$ & 0 & 0 & 0 \\
\hline
\end{tabular}

\begin{tabular}{|c|c|c|c|c|c|c|c|c|}
\hline & \multicolumn{4}{|c|}{ Current } & \multicolumn{4}{|c|}{ Net ZEB } \\
\hline & Zones & West & East & Building Average & & West & East & Building Average \\
\hline & Too Cold $(<18 \mathrm{C})$ & 1107 & 1109 & 1109 & Too Cold $(<18 . \mathrm{C})$ & 121 & 124 & 122.5 \\
\hline & Comfortable $(18-25 \mathrm{C})$ & 253 & 251 & 251 & Comfortable $\left(18-25^{\circ} \mathrm{C}\right)$ & 2651 & 2648 & 2649.5 \\
\hline S1-R-4 & Too Hot $(>25 \mathrm{C})$ & 1412 & 1412 & 1412 & Too Hot $(>25 \mathrm{C})$ & 0 & 0 & 0 \\
\hline
\end{tabular}

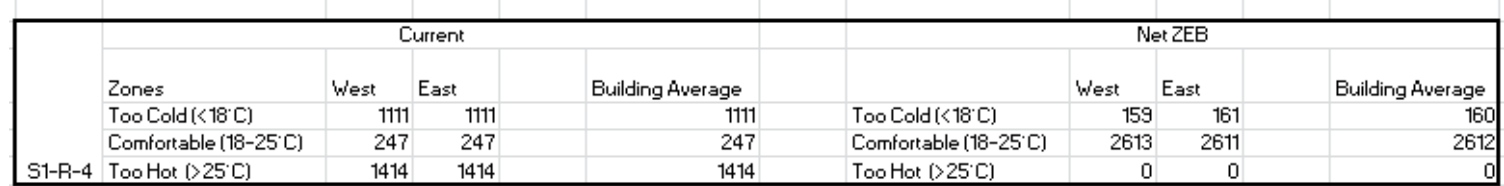

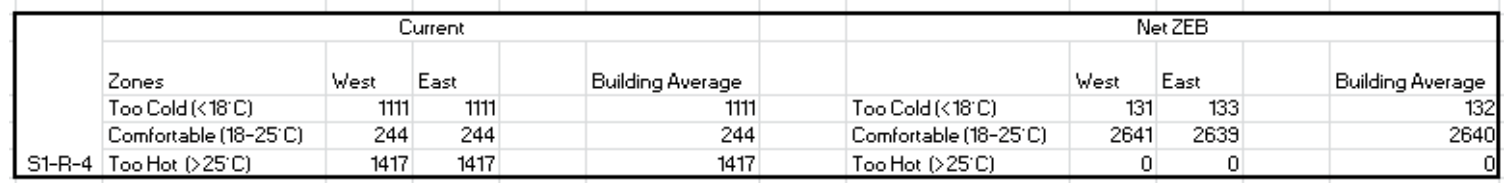

\begin{tabular}{|c|c|c|c|c|c|c|c|c|}
\hline & \multicolumn{4}{|c|}{ Current } & \multicolumn{4}{|c|}{ Net ZEB } \\
\hline & Zones & West & East & Building Average & & West & East & Building Average \\
\hline & Too Cold $\left(<18^{\circ} \mathrm{C}\right)$ & 1105 & 1105 & 1105 & Too Cold $\left(\left\langle 18^{\circ} \mathrm{C}\right)\right.$ & 182 & 184 & 183 \\
\hline & Comfortable $\left(18-25^{\circ} \mathrm{C}\right)$ & 263 & 264 & 264 & Comfortable $\left(18-25^{\circ} \mathrm{C}\right)$ & 2590 & 2588 & 2589 \\
\hline S1-R-4 & Too Hot $(>25 \mathrm{C})$ & 1404 & 1403 & 1403 & Too Hot $\left(>25^{\circ} \mathrm{C}\right)$ & 0 & 0 & 0 \\
\hline
\end{tabular}

\begin{tabular}{|c|c|c|c|c|c|c|c|c|}
\hline & \multicolumn{4}{|c|}{ Current } & \multicolumn{4}{|c|}{ Net ZEB } \\
\hline & Zones & West & East & Building Average & & West & East & Building Average \\
\hline & Too Cold $(<18 \mathrm{C})$ & 1103 & 1102 & 1102 & Too Cold $(<18 . \mathrm{C})$ & 179 & 184 & 181.5 \\
\hline & Comfortable $(18-25 \mathrm{C})$ & 260 & 260 & 260 & Comfortable $\left(18-25^{\circ} \mathrm{C}\right)$ & 2593 & 2588 & 2590.5 \\
\hline S1-R-4 & Too Hot $[>25 \mathrm{C}]$ & 1409 & 1410 & 1410 & Too Hot $(>25 \mathrm{C})$ & 0 & 0 & 0 \\
\hline
\end{tabular}

Figure 14-18 : Thermal performance results for the current S1-R-4 and Net ZEB S1-R-4 energy models 
The building's average Ambient and Building Average temperatures that are Too Cold, Comfortable, and Too Hot are added together to get whole New Zealand value which is used to analyse the thermal performance of the building.

Figure 14-19 displays the total number of hours the S1-R-4 building is Too Cold, Comfortable, and Too Hot in the seven New Zealand climate regions.

\begin{tabular}{|l|r|lr|r|}
\hline & & \multicolumn{3}{|c|}{ S1-R-4 } \\
\cline { 3 - 5 } Thermal Performances & Ambient & Current & & Net ZEB \\
\hline Too Cold $\left(<18^{\circ} \mathrm{C}\right)$ & 14935 & 7759 & 1047 \\
\hline Comfortable $\left(18-25^{\circ} \mathrm{C}\right)$ & 4240 & 1763 & 18357 \\
\hline Too Hot $\left(>25^{\circ} \mathrm{C}\right)$ & 229 & 9882 & 0 \\
\hline
\end{tabular}

Figure 14-19 : displays the total number of hours the S1-R-4 building is Too Cold, Comfortable, and Too Hot in the seven New Zealand climate regions.

The calculations and analysis results for all of the thermal comfort analysis in Section 10.2.4 can be found at:

Refer to $\mathrm{CD}>$ (folder) Thermal Comfort Analysis $>$ (File) Thermal Comfort Comparisons

\section{Appendix 14.23 New Zealand and Commercial Sector energy reductions}

Table 14-36 below presents the energy consumption by fuel type for New Zealand and the commercial sector.

Table 14-36 : Energy consumption by fuel type for New Zealand and the commercial sector.
\begin{tabular}{|l|l|}
\hline New Zealand & Final Energy Consumption 2009 (GWh) \\
\hline Electricity & 39,125 \\
\hline Natural Gas & 16,108 \\
\hline Total & 55,233 \\
\hline
\end{tabular}

\begin{tabular}{|l|c|}
\hline $\begin{array}{l}\text { Commercial sector energy } \\
\text { consumption }\end{array}$ & Final Energy Consumption 2009 (GWh) \\
\hline Natural Gas & 1,686 \\
\hline Electricity & 9,423 \\
\hline Total & 11,109 \\
\hline
\end{tabular}


Table 14-37 displays the stock aggregated energy consumption for the current and NZE building stocks, as well as the existing grid renewable energy supply and additional onsite generation achievable from 50 percent roof coverage of PV.

Table 14-37 : Stock aggregated energy consumption and generation, as well as existing grid renewable supply

\begin{tabular}{|l|c|}
\hline Building Stock Scenarios & $\begin{array}{c}\text { Stock Aggregated Final Energy consumption } \\
\text { and supply (GWh) }\end{array}$ \\
\hline $\begin{array}{l}\text { Current commercial building stock } \\
\text { estimate }\end{array}$ & 3,334 \\
\hline NZE retrofit building stock consumption & 1,460 \\
\hline Existing grid renewable & 1,834 \\
\hline Additional onsite renewable & 1,348 \\
\hline
\end{tabular}

Table 14-38 displays the calculated surplus energy from retrofitting to NZE (with and without Onsite PV). The surplus energy was calculated by subtracting the existing grid renewable and additional onsite energy generation from the NZE retrofit consumption.

Table 14-38 : Calculated surplus energy from retrofitting to NZE (with and without Onsite PV)

NZE balance (Surplus energy)

\begin{tabular}{|c|c|}
$\begin{array}{c}\text { NZE Retrofit } \\
\text { WITHOUT Onsite } \\
\text { PV }\end{array}$ & $\begin{array}{c}\text { NZE Retrofit WITH } \\
\text { Onsite PV }\end{array}$ \\
\hline-374 & $-1,723$ \\
\hline
\end{tabular}

Table 14-39 display the energy reductions achieved from retrofitting to NZE (with and without Onsite PV). The surplus energy was added to the current commercial building stock energy consumption to calculate the amount of reduced energy consumption (and freed supply) that was achieved from retrofitting to NZE.

Table 14-39 : energy reductions achieved from retrofitting to NZE (with and without Onsite PV)

\begin{tabular}{|l|r|c|}
\hline New Zealand wide benefits & \multicolumn{2}{|c|}{ Final Energy Consumption (GWh) } \\
\cline { 2 - 3 } & NZE Retrofit WITHOUT Onsite & $\begin{array}{c}\text { NZE Retrofit } \\
\text { PITH Onsite } \\
\text { PV }\end{array}$ \\
\hline $\begin{array}{l}\text { Total Electricity and Gas reductions from } \\
\text { NZE retrofit (with additional renewable } \\
\text { energy generation) }\end{array}$ & 3,709 & 5,057 \\
\hline
\end{tabular}

The NZE reductions were then compared to the New Zealand and commercial sector energy consumption to calculate the percentage of reduced energy consumption (and freed supply) in the two scenarios (refer to Section 10.2.5a). 


\section{Appendix 14.24 Net ZEB retrofits Top 6 most effective ECM effectiveness for different building sizes and types}

Table 14-40 shows the ranking of the energy reductions from implementing ECM in different sized buildings.

Table 14-40 : Reduction in energy consumption by implementing each ECM in different sized buildings

\begin{tabular}{|c|c|c|c|c|c|}
\hline \multirow[b]{2}{*}{ ECMs } & \multicolumn{5}{|c|}{ Reduction in Energy (GWh) } \\
\hline & $5-649 m^{2}$ & $650-1499 m^{2}$ & $\begin{array}{c}1500- \\
3499 m^{2}\end{array}$ & $\begin{array}{c}3500- \\
8999 m^{2}\end{array}$ & $\begin{array}{c}9000 \mathrm{~m}^{2} \\
\text { and } \\
\text { greater }\end{array}$ \\
\hline Upgrade Envelope & 30 & 16 & 14 & 9 & 3 \\
\hline Natural Ventilation & 57 & 26 & 24 & 29 & 21 \\
\hline Solar Shading & 1 & 0 & -1 & 2 & 3 \\
\hline Advanced Daylighting & 10 & 7 & 4 & 35 & 0 \\
\hline Upgrade Glazing & 10 & 12 & 12 & 19 & 11 \\
\hline $\begin{array}{l}\text { Daylighting and Maximise } \\
\text { Passive Solar Heat Gains }\end{array}$ & 33 & 9 & 27 & 4 & 4 \\
\hline Energy Efficient Lighting & 28 & 18 & 30 & 86 & 123 \\
\hline Advanced Lighting Controls & 83 & 40 & 46 & 36 & 34 \\
\hline $\begin{array}{lll}\text { Energy Efficient } & \text { Office } \\
\text { Equipment } & & \\
\end{array}$ & 145 & 53 & 26 & 63 & 76 \\
\hline $\begin{array}{l}\text { Energy Efficient Micellaneuous } \\
\text { Equipment }\end{array}$ & 6 & 29 & 38 & 181 & 122 \\
\hline Upgrade HVAC and Appliances & -10 & -6 & 1 & 86 & 71 \\
\hline & $\begin{array}{r}\text { Buildings with } \\
\text { have }\end{array}$ & $\begin{array}{l}\text { ut HVAC now } \\
\text { IVAC }\end{array}$ & & & \\
\hline
\end{tabular}


Table 14-41 shows the ranking of the most effective to least effective ECMs in different sized buildings.

\begin{tabular}{|c|c|c|c|c|c|}
\hline Rank & $5-649 m^{2}$ & $650-1499 m^{2}$ & $1500-3499 m^{2}$ & $3500-8999 \mathrm{~m}^{2}$ & $\begin{array}{l}9000 \mathrm{~m}^{2} \text { and } \\
\text { greater }\end{array}$ \\
\hline 1 & $\begin{array}{l}\text { Energy Efficient } \\
\text { Office } \\
\text { Equipment }\end{array}$ & $\begin{array}{l}\text { Energy Efficient } \\
\text { Office } \\
\text { Equipment }\end{array}$ & $\begin{array}{l}\text { Advanced } \\
\text { Lighting } \\
\text { Controls }\end{array}$ & $\begin{array}{l}\text { Energy Efficient } \\
\text { Miscellaneous } \\
\text { Equipment }\end{array}$ & $\begin{array}{l}\text { Energy Efficient } \\
\text { Lighting }\end{array}$ \\
\hline 2 & $\begin{array}{l}\text { Advanced } \\
\text { Lighting } \\
\text { Controls }\end{array}$ & $\begin{array}{l}\text { Advanced } \\
\text { Lighting } \\
\text { Controls }\end{array}$ & $\begin{array}{l}\text { Energy Efficient } \\
\text { Miscellaneous } \\
\text { Equipment }\end{array}$ & $\begin{array}{l}\text { Upgrade HVAC } \\
\text { and Appliances }\end{array}$ & $\begin{array}{l}\text { Energy Efficient } \\
\text { Miscellaneous } \\
\text { Equipment }\end{array}$ \\
\hline 3 & $\begin{array}{l}\text { Natural } \\
\text { Ventilation }\end{array}$ & $\begin{array}{l}\text { Energy Efficient } \\
\text { Miscellaneous } \\
\text { Equipment }\end{array}$ & $\begin{array}{l}\text { Energy Efficient } \\
\text { Lighting }\end{array}$ & $\begin{array}{l}\text { Energy Efficient } \\
\text { Lighting }\end{array}$ & $\begin{array}{l}\text { Energy Efficient } \\
\text { Office } \\
\text { Equipment }\end{array}$ \\
\hline 4 & $\begin{array}{l}\text { Daylighting and } \\
\text { Maximise } \\
\text { Passive Solar } \\
\text { Heat Gains } \\
\end{array}$ & $\begin{array}{l}\text { Natural } \\
\text { Ventilation }\end{array}$ & $\begin{array}{l}\text { Daylighting and } \\
\text { Maximise } \\
\text { Passive Solar } \\
\text { Heat Gains } \\
\end{array}$ & $\begin{array}{l}\text { Energy Efficient } \\
\text { Office } \\
\text { Equipment }\end{array}$ & $\begin{array}{l}\text { Upgrade HVAC } \\
\text { and Appliances }\end{array}$ \\
\hline 5 & $\begin{array}{l}\text { Upgrade } \\
\text { Envelope }\end{array}$ & $\begin{array}{l}\text { Energy Efficient } \\
\text { Lighting }\end{array}$ & $\begin{array}{l}\text { Energy Efficient } \\
\text { Office } \\
\text { Equipment }\end{array}$ & $\begin{array}{l}\text { Advanced } \\
\text { Lighting } \\
\text { Controls } \\
\end{array}$ & $\begin{array}{l}\text { Advanced } \\
\text { Lighting } \\
\text { Controls } \\
\end{array}$ \\
\hline 6 & $\begin{array}{l}\text { Energy Efficient } \\
\text { Lighting }\end{array}$ & $\begin{array}{l}\text { Upgrade } \\
\text { Envelope }\end{array}$ & $\begin{array}{l}\text { Natural } \\
\text { Ventilation }\end{array}$ & $\begin{array}{l}\text { Advanced } \\
\text { Daylighting }\end{array}$ & $\begin{array}{l}\text { Natural } \\
\text { Ventilation }\end{array}$ \\
\hline 7 & $\begin{array}{l}\text { Advanced } \\
\text { Daylighting }\end{array}$ & Upgrade Glazing & $\begin{array}{l}\text { Upgrade } \\
\text { Envelope }\end{array}$ & $\begin{array}{l}\text { Natural } \\
\text { Ventilation }\end{array}$ & Upgrade Glazing \\
\hline 8 & Upgrade Glazing & $\begin{array}{l}\text { Daylighting and } \\
\text { Maximise } \\
\text { Passive Solar } \\
\text { Heat Gains }\end{array}$ & Upgrade Glazing & Upgrade Glazing & $\begin{array}{l}\text { Daylighting and } \\
\text { Maximise } \\
\text { Passive Solar } \\
\text { Heat Gains }\end{array}$ \\
\hline 9 & $\begin{array}{l}\text { Energy Efficient } \\
\text { Miscellaneous } \\
\text { Equipment }\end{array}$ & $\begin{array}{l}\text { Advanced } \\
\text { Daylighting }\end{array}$ & $\begin{array}{l}\text { Advanced } \\
\text { Daylighting }\end{array}$ & $\begin{array}{l}\text { Upgrade } \\
\text { Envelope }\end{array}$ & $\begin{array}{l}\text { Upgrade } \\
\text { Envelope }\end{array}$ \\
\hline 10 & Solar Shading & Solar Shading & $\begin{array}{l}\text { Upgrade HVAC } \\
\text { and Appliances }\end{array}$ & $\begin{array}{l}\text { Daylighting and } \\
\text { Maximise } \\
\text { Passive Solar } \\
\text { Heat Gains }\end{array}$ & Solar Shading \\
\hline 11 & $\begin{array}{l}\text { Upgrade HVAC } \\
\text { and Appliances }\end{array}$ & $\begin{array}{l}\text { Upgrade HVAC } \\
\text { and Appliances }\end{array}$ & Solar Shading & Solar Shading & $\begin{array}{l}\text { Advanced } \\
\text { Daylighting }\end{array}$ \\
\hline
\end{tabular}


Table 14-42 shows the ranking of the energy reductions from implementing ECMs in different building types.

\begin{tabular}{|l|r|r|r|}
\hline \multirow{2}{*}{\multicolumn{1}{|c|}{ ECMs }} & \multicolumn{3}{c|}{ Reduction in Energy (GWh) } \\
\cline { 2 - 4 } \multicolumn{1}{|c|}{ Oable 14-42 : Reduction in energy consumption by implementing each ECM in different building types } \\
\hline Upgrade Envelope & 19 & 33 & Mixed \\
\hline Natural Ventilation & 58 & 65 & 21 \\
\hline Solar Shading & 2 & 0 & 33 \\
\hline Advanced Daylighting & 5 & 24 & 27 \\
\hline Upgrade Glazing & 27 & 17 & 20 \\
\hline Daylighting and Maximise Passive Solar & & & \\
Heat Gains & 33 & 31 & 15 \\
\hline Energy Efficient Lighting & 63 & 151 & 71 \\
\hline Advanced Lighting Controls & 69 & 114 & 56 \\
\hline Energy Efficient Office Equipment & 85 & 207 & 70 \\
\hline Energy Efficient Miscellaneous Equipment & 21 & 307 & 47 \\
\hline Upgrade HVAC and Appliances & 79 & 26 & 38 \\
\hline
\end{tabular}

Table 14-43 shows the ranking of the most effective to least effective ECM in different building types.

\begin{tabular}{|c|c|c|c|}
\hline Rank & Office & Retail & Mixed \\
\hline 1 & $\begin{array}{l}\text { Energy Efficient Office } \\
\text { Equipment }\end{array}$ & $\begin{array}{l}\text { Energy } \quad \text { Efficient } \\
\text { Miscellaneous Equipment }\end{array}$ & Energy Efficient Lighting \\
\hline 2 & $\begin{array}{lll}\text { Upgrade } & \text { HVAC } & \text { and } \\
\text { Appliances } & & \\
\end{array}$ & $\begin{array}{l}\text { Energy Efficient Office } \\
\text { Equipment }\end{array}$ & $\begin{array}{l}\text { Energy Efficient Office } \\
\text { Equipment }\end{array}$ \\
\hline 3 & Advanced Lighting Controls & Energy Efficient Lighting & Advanced Lighting Controls \\
\hline 4 & Energy Efficient Lighting & Advanced Lighting Controls & $\begin{array}{l}\text { Energy Efficient } \\
\text { Miscellaneous Equipment }\end{array}$ \\
\hline 5 & Natural Ventilation & Natural Ventilation & $\begin{array}{lll}\text { Upgrade } & \text { HVAC } & \text { and } \\
\text { Appliances } & & \end{array}$ \\
\hline 6 & $\begin{array}{l}\text { Daylighting and Maximise } \\
\text { Passive Solar Heat Gains }\end{array}$ & Upgrade Envelope & Natural Ventilation \\
\hline 7 & Upgrade Glazing & $\begin{array}{l}\text { Daylighting and Maximise } \\
\text { Passive Solar Heat Gains }\end{array}$ & Advanced Daylighting \\
\hline 8 & $\begin{array}{l}\text { Energy Efficient } \\
\text { Miscellaneous Equipment }\end{array}$ & $\begin{array}{lll}\text { Upgrade } & \text { HVAC } & \text { and } \\
\text { Appliances } & & \end{array}$ & Upgrade Envelope \\
\hline 9 & Upgrade Envelope & Advanced Daylighting & Upgrade Glazing \\
\hline 10 & Advanced Daylighting & Upgrade Glazing & $\begin{array}{l}\text { Daylighting and Maximise } \\
\text { Passive Solar Heat Gains }\end{array}$ \\
\hline 11 & Solar Shading & Solar Shading & Solar Shading \\
\hline
\end{tabular}




\section{Appendix 14.25 Sensitivity Analysis calculations and results}

The results used to perform the Sensitivity Analysis (SA) were obtained in the following forms.

\subsubsection{Comparison of Stock Aggregation from iterations to original NZE}

The first form of SA result was used for the analysis of heating and cooling set points, Fresh Air Rate, and Task Illuminance. All results were obtained by iterating the 48 energy models in each 7 climates and re-simulating. Each stock aggregation of the iterated parameters (example: heating and cooling set point) were compared to the original NZE stock aggregation to establish the impact that changing that parameter has on the NZE result. The results were processed in the same fashion as the Stock Aggregation results.

\subsection{1a Heating and cooling set points}

Refer to CD > (folder) Sensitivity Analysis $>$ Stock Aggregation > (File) NZE with 1924oC HVAC Temp Set Points - Stock Aggregation Results

Refer to $\mathrm{CD}>$ (folder) Sensitivity Analysis $>$ Stock Aggregation $>$ (File) NZE with Current Buildings HVAC Temp Set Points - Stock Aggregation Results

The results from the comparison can be found at:

Refer to $\mathrm{CD}>$ (folder) Sensitivity Analysis $>$ Stock Aggregation $>$ (File) Heating and Cooling set point - Stock Aggregated comparison

\subsection{1b Fresh Air Rate}

Refer to $\mathrm{CD}>$ (folder) Sensitivity Analysis $>$ Stock Aggregation $>$ (File) NZE with Increased Fresh Air Rate - Stock Aggregation Results

The results from the comparison can be found at:

Refer to CD > (folder) Sensitivity Analysis $>$ Stock Aggregation > (File) Fresh Air Rate Stock Aggregated comparison

\subsection{1c Illuminance set points}

Refer to $\mathrm{CD}>$ (folder) Sensitivity Analysis $>$ Stock Aggregation $>$ (File) NZE with Lower Illuminance Set Point - Stock Aggregation Results

Refer to $\mathrm{CD}>$ (folder) Sensitivity Analysis $>$ Stock Aggregation $>$ (File) NZE with Higher Illuminance Set Point - Stock Aggregation Results

The results from the comparison can be found at:

Refer to CD $>$ (folder) Sensitivity Analysis $>$ Stock Aggregation $>$ (File) Illuminance set point - Stock Aggregated comparison 


\subsubsection{Comparison of individual case study buildings to their original NZE}

The second form of SA result was used for the analysis of individual case study buildings' energy consumption and thermal performance. Each case study building was iterated to represent the scenario discussed in Section 11.2 and the result was compared to the original NZE result. The results from the comparison can be found at:

\subsection{2a Thermal Comfort with $19-24^{\circ} \mathrm{C}$ heating and cooling set points}

Refer to CD > (folder) Sensitivity Analysis > Individual Building Case Studies > (File) Set Point Thermal Comfort Comparison

\subsection{2b High fresh air ventilation rate}

Refer to CD > (folder) Sensitivity Analysis $>$ Individual Building Case Studies $>$ (File) High Fresh Air Rate Case study

\subsection{2c Split system versus VRF}

Refer to CD > (folder) Sensitivity Analysis $>$ Individual Building Case Studies $>$ (File) VRF Case study Results

\subsection{2d Impact of changing to VRF in all large buildings}

Refer to CD > (folder) Sensitivity Analysis > Individual Building Case Studies > (File) VRF Whole Building Stock Example

\section{Appendix 14.26 Temporal Energy Match}

\subsubsection{Monthly Load Matching}

The load matching analyses were undertaken by determining the climate average energy demand and generation for the two case study buildings.

Table 14-44 displays the monthly climate average energy demand and generation for S1-O-1 and S5-O-4. The climate average was undertaken using the similar process to Appendix 14.25.

\begin{tabular}{|l|c|c|c|c|}
\multicolumn{7}{l}{ Table 14-44 : Monthly climate average energy demand and generation for S1-O-1 and S5-O-4 } \\
\hline Building & \multicolumn{2}{|c|}{ Small Building - S1-O-1 } & \multicolumn{2}{c|}{ Large Building - S5-O-4 } \\
\hline Month & Demand (kWh) & Generation (kWh) & Demand (kWh) & Generation (kWh) \\
\hline January & 752 & 1,797 & 33,682 & 22,337 \\
\hline February & 707 & 1,452 & 30,398 & 18,072 \\
\hline March & 791 & 1,195 & 34,029 & 14,971 \\
\hline April & 783 & 789 & 32,650 & 9,993 \\
\hline May & 1,011 & 544 & 36,989 & 6,979 \\
\hline June & 1,074 & 413 & 36,245 & 5,350 \\
\hline July & 1,118 & 481 & 37,319 & 6,207 \\
\hline August & 1,064 & 706 & 37,513 & 8,975 \\
\hline September & 849 & 972 & 33,976 & 12,219 \\
\hline October & 802 & 1,396 & 33,656 & 17,424 \\
\hline
\end{tabular}




\begin{tabular}{|l|l|l|l|l|} 
November & 716 & 1,649 & 32,686 & 20,513 \\
\hline December & 694 & 1,779 & 31,836 & 22,135 \\
\hline
\end{tabular}

\subsubsection{Daily Load Matching}

Table 14-45 displays the weekday hourly climate average energy demand and generation for S1$\mathrm{O}-1$ in July and February. The climate average was undertaken using the similar process to Appendix 14.25.

\begin{tabular}{|c|c|c|c|c|}
\hline \multirow{2}{*}{ Table 14-45 : Weekday hourly climate average energy demand and generation for S1-O-1 in July and February } \\
\cline { 2 - 5 } $\begin{array}{c}\text { Time of } \\
\text { Day }\end{array}$ & \multicolumn{5}{|c|}{ Weekday } \\
\cline { 2 - 5 } & Demily Climate Average for July & \multicolumn{2}{c|}{ Daily Climate Average for February } \\
\hline $0: 00$ & 0.5 & 0.0 & 0.4 & 0.0 \\
\hline $1: 00$ & 0.4 & 0.0 & 0.4 & 0.0 \\
\hline $2: 00$ & 0.4 & 0.0 & 0.4 & 0.0 \\
\hline $3: 00$ & 0.4 & 0.0 & 0.4 & 0.0 \\
\hline $4: 00$ & 0.4 & 0.0 & 0.4 & 0.0 \\
\hline $5: 00$ & 0.4 & 0.0 & 0.4 & 0.0 \\
\hline $6: 00$ & 0.4 & 0.0 & 0.9 & 0.0 \\
\hline $7: 00$ & 0.9 & 0.0 & 4.4 & 0.6 \\
\hline $8: 00$ & 14.0 & 0.0 & 2.8 & 1.8 \\
\hline $9: 00$ & 4.1 & 0.4 & 2.5 & 3.3 \\
\hline $10: 00$ & 3.4 & 1.2 & 2.2 & 4.8 \\
\hline $11: 00$ & 3.0 & 1.9 & 2.2 & 5.9 \\
\hline $12: 00$ & 2.5 & 2.3 & 2.4 & 6.6 \\
\hline $13: 00$ & 2.5 & 2.4 & 2.5 & 7.0 \\
\hline $14: 00$ & 2.6 & 2.3 & 2.8 & 6.8 \\
\hline $15: 00$ & 3.0 & 1.8 & 2.6 & 6.0 \\
\hline $16: 00$ & 3.4 & 1.1 & 1.7 & 4.8 \\
\hline $17: 00$ & 1.9 & 0.3 & 0.6 & 3.3 \\
\hline $18: 00$ & 1.6 & 0.0 & 0.4 & 1.9 \\
\hline $19: 00$ & 0.4 & 0.0 & 0.4 & 0.6 \\
\hline $20: 00$ & 0.4 & 0.0 & 0.4 & 0.0 \\
\hline $21: 00$ & 0.5 & 0.0 & 0.4 & 0.0 \\
\hline $22: 00$ & 0.4 & 0.0 & 0.4 & 0.0 \\
\hline $23: 00$ & 0.4 & 0.0 & 0.5 & \\
\hline & & & & Demand (kWh) \\
\hline
\end{tabular}


Table 14-46 displays the weekday hourly climate average energy demand and generation for S5O-4 in July and February. The climate average was undertaken using the similar process to Appendix 14.25.

Table 14-46 : Weekday hourly climate average energy demand and generation for S5-O-4in July and February

\begin{tabular}{|c|c|c|c|c|}
\hline \multirow{3}{*}{$\begin{array}{c}\text { Time of } \\
\text { Day }\end{array}$} & \multicolumn{4}{|c|}{ Weekday } \\
\hline & \multicolumn{2}{|c|}{ Daily Climate Average for July } & \multicolumn{2}{|c|}{ Daily Climate Average for February } \\
\hline & Demand (kWh) & Generation (kWh) & Demand (kWh) & Generation (kWh) \\
\hline $0: 00$ & 27.8 & 0.0 & 28.9 & 0.0 \\
\hline $1: 00$ & 28.9 & 0.0 & 27.3 & 0.0 \\
\hline 2:00 & 27.3 & 0.0 & 28.4 & 0.0 \\
\hline 3:00 & 28.4 & 0.0 & 29.6 & 0.0 \\
\hline 4:00 & 29.6 & 0.0 & 30.5 & 0.0 \\
\hline $5: 00$ & 30.5 & 0.0 & 41.2 & 0.0 \\
\hline $6: 00$ & 41.2 & 0.0 & 104.7 & 0.6 \\
\hline 7:00 & 142.1 & 0.0 & 90.9 & 8.6 \\
\hline $8: 00$ & 125.5 & 0.6 & 83.4 & 23.6 \\
\hline 9:00 & 104.5 & 6.1 & 73.4 & 41.8 \\
\hline $10: 00$ & 81.9 & 15.7 & 74.9 & 59.8 \\
\hline $11: 00$ & 76.5 & 24.4 & 80.4 & 73.0 \\
\hline $12: 00$ & 78.3 & 29.4 & 72.6 & 81.2 \\
\hline $13: 00$ & 69.8 & 31.1 & 79.6 & 86.1 \\
\hline $14: 00$ & 76.3 & 28.8 & 76.1 & 83.5 \\
\hline $15: 00$ & 73.0 & 22.6 & 70.1 & 73.9 \\
\hline $16: 00$ & 69.7 & 13.8 & 57.1 & 58.3 \\
\hline $17: 00$ & 67.1 & 4.2 & 51.5 & 41.1 \\
\hline $18: 00$ & 76.4 & 0.0 & 42.2 & 23.3 \\
\hline $19: 00$ & 64.7 & 0.0 & 29.4 & 7.9 \\
\hline $20: 00$ & 36.7 & 0.0 & 30.0 & 0.5 \\
\hline 21:00 & 30.5 & 0.0 & 28.9 & 0.0 \\
\hline $22: 00$ & 28.9 & 0.0 & 24.0 & 0.0 \\
\hline $23: 00$ & 24.0 & 0.0 & 27.8 & 0.0 \\
\hline
\end{tabular}

\subsubsection{Daily Grid Interaction}

The grid interaction analysis was undertaken by subtracting the climate average weekday hourly generation from the demand to calculate the net hourly energy demand of each case study building and comparing it to the average weekday hourly electrical grid demand (Electricity Authority 2014).

Table 14-47 displays the weekday hourly climate average net energy demand and generation for S1-O-1 and S5-O-4, and average weekday electrical grid demand in July. The climate average was undertaken using the similar process to Appendix 14.25.

Page $\mid 401$ 
Table 14-47 : Weekday hourly climate average net energy demand and generation for S1-O-1 and S5-O-4, and average weekday electrical grid demand in July

\begin{tabular}{|c|c|c|c|c|c|}
\hline \multirow[b]{3}{*}{$\begin{array}{c}\text { Time of } \\
\text { Day }\end{array}$} & \multirow[b]{3}{*}{$\begin{array}{l}\text { July Weekday } \\
\text { Average } \\
\text { Electrical Grid } \\
\text { Demand } \\
\text { (GWh) }\end{array}$} & \multicolumn{4}{|c|}{ July Weekday Climate Average } \\
\hline & & \multicolumn{2}{|c|}{ Small building - S1-O-1 } & \multicolumn{2}{|c|}{ Large building - S5-O4 } \\
\hline & & $\begin{array}{c}\text { Current } \\
\text { Building } \\
\text { Energy } \\
\text { Demand } \\
\text { (kWh) }\end{array}$ & $\begin{array}{c}\text { Net ZEB } \\
\text { Energy } \\
\text { Demand } \\
\text { (kWh) }\end{array}$ & $\begin{array}{c}\text { Current } \\
\text { Building } \\
\text { Energy } \\
\text { Demand } \\
\text { (kWh) }\end{array}$ & $\begin{array}{c}\text { Net ZEB } \\
\text { Energy } \\
\text { Demand } \\
\text { (kWh) }\end{array}$ \\
\hline $0: 00$ & 4.2 & 0.7 & 0.5 & 39.4 & 27.8 \\
\hline $1: 00$ & 4.0 & 0.6 & 0.4 & 40.4 & 28.9 \\
\hline $2: 00$ & 3.8 & 0.7 & 0.4 & 38.7 & 27.3 \\
\hline $3: 00$ & 3.7 & 0.6 & 0.4 & 39.8 & 28.4 \\
\hline 4:00 & 3.6 & 0.6 & 0.4 & 41.7 & 29.6 \\
\hline 5:00 & 3.7 & 0.7 & 0.4 & 41.9 & 30.5 \\
\hline $6: 00$ & 4.1 & 0.6 & 0.4 & 53.5 & 41.2 \\
\hline 7:00 & 4.9 & 1.3 & 0.9 & 504.6 & 142.1 \\
\hline $8: 00$ & 5.5 & 37.2 & 14.0 & 475.5 & 124.8 \\
\hline 9:00 & 5.6 & 19.0 & 3.7 & 443.5 & 98.3 \\
\hline $10: 00$ & 5.6 & 13.5 & 2.2 & 398.0 & 66.1 \\
\hline $11: 00$ & 5.4 & 10.7 & 1.1 & 355.0 & 52.1 \\
\hline $12: 00$ & 5.2 & 9.2 & 0.2 & 333.6 & 48.9 \\
\hline $13: 00$ & 5.1 & 8.8 & 0.0 & 313.2 & 38.7 \\
\hline $14: 00$ & 5.0 & 8.7 & 0.3 & 312.9 & 47.5 \\
\hline $15: 00$ & 4.9 & 8.7 & 1.2 & 309.5 & 50.4 \\
\hline $16: 00$ & 5.0 & 8.9 & 2.3 & 302.1 & 55.9 \\
\hline $17: 00$ & 5.5 & 7.7 & 1.6 & 296.2 & 62.9 \\
\hline $18: 00$ & 6.0 & 10.3 & 1.6 & 303.3 & 76.4 \\
\hline $19: 00$ & 5.9 & 0.7 & 0.4 & 82.4 & 64.7 \\
\hline $20: 00$ & 5.7 & 0.7 & 0.4 & 49.4 & 36.7 \\
\hline $21: 00$ & 5.4 & 0.7 & 0.5 & 42.5 & 30.5 \\
\hline $22: 00$ & 5.0 & 0.6 & 0.4 & 40.7 & 28.9 \\
\hline $23: 00$ & 4.5 & 0.6 & 0.4 & 33.8 & 24.0 \\
\hline $0: 00$ & 4.1 & 0.7 & 0.5 & 39.4 & 27.8 \\
\hline
\end{tabular}


Table 14-48 displays the weekday hourly climate average net energy demand and generation for S1-O-1 and S5-O-4, and average weekday electrical grid demand in February. The climate average was undertaken using the similar process to Appendix 14.25.

Table 14-48 - Weekday hourly climate average net energy demand and generation for S1-O-1 and S5-O-4, and average weekday electrical grid demand in February

\begin{tabular}{|c|c|c|c|c|c|}
\hline \multirow[b]{3}{*}{$\begin{array}{c}\text { Time of } \\
\text { Day }\end{array}$} & \multirow{3}{*}{$\begin{array}{l}\text { February } \\
\text { Weekday } \\
\text { Average } \\
\text { Electrical Grid } \\
\text { Demand } \\
\text { (GWh) }\end{array}$} & \multicolumn{4}{|c|}{ February Weekday Climate Average } \\
\hline & & \multicolumn{2}{|c|}{ Small building - S1-O-1 } & \multicolumn{2}{|c|}{ Large building - S5-O4 } \\
\hline & & $\begin{array}{l}\text { Current } \\
\text { Building } \\
\text { Energy } \\
\text { Demand } \\
\text { (kWh) }\end{array}$ & $\begin{array}{l}\text { Net ZEB } \\
\text { Energy } \\
\text { Demand } \\
\text { (kWh) }\end{array}$ & $\begin{array}{c}\text { Current } \\
\text { Building } \\
\text { Energy } \\
\text { Demand } \\
\text { (kWh) }\end{array}$ & $\begin{array}{l}\text { Net ZEB } \\
\text { Energy } \\
\text { Demand } \\
\text { (kWh) }\end{array}$ \\
\hline 0:00 & 3.9 & 0.6 & 0.4 & 40.4 & 28.9 \\
\hline $1: 00$ & 3.7 & 0.7 & 0.4 & 38.6 & 27.3 \\
\hline $2: 00$ & 3.5 & 0.6 & 0.4 & 39.8 & 28.4 \\
\hline 3:00 & 3.4 & 0.6 & 0.4 & 41.7 & 29.6 \\
\hline 4:00 & 3.4 & 0.7 & 0.4 & 41.9 & 30.5 \\
\hline 5:00 & 3.5 & 0.6 & 0.4 & 53.7 & 41.2 \\
\hline $6: 00$ & 3.8 & 1.3 & 0.8 & 289.7 & 104.1 \\
\hline 7:00 & 4.4 & 6.0 & 3.8 & 280.3 & 82.3 \\
\hline $8: 00$ & 4.8 & 6.4 & 1.0 & 289.5 & 59.7 \\
\hline 9:00 & 4.9 & 7.0 & -0.8 & 287.7 & 31.6 \\
\hline $10: 00$ & 4.9 & 8.1 & -2.6 & 295.7 & 15.0 \\
\hline $11: 00$ & 4.9 & 8.9 & -3.7 & 306.5 & 7.3 \\
\hline $12: 00$ & 4.8 & 9.5 & -4.1 & 299.3 & -8.6 \\
\hline $13: 00$ & 4.8 & 9.5 & -4.5 & 308.5 & -6.6 \\
\hline $14: 00$ & 4.7 & 9.5 & -4.0 & 307.6 & -7.4 \\
\hline $15: 00$ & 4.7 & 8.7 & -3.5 & 298.8 & -3.8 \\
\hline $16: 00$ & 4.8 & 3.9 & -3.1 & 279.0 & -1.2 \\
\hline $17: 00$ & 4.8 & 1.4 & -2.7 & 268.2 & 10.5 \\
\hline $18: 00$ & 4.8 & 0.7 & -1.5 & 83.1 & 18.8 \\
\hline 19:00 & 4.7 & 0.7 & -0.3 & 49.5 & 21.5 \\
\hline $20: 00$ & 4.6 & 0.7 & 0.4 & 42.5 & 29.5 \\
\hline $21: 00$ & 4.7 & 0.6 & 0.4 & 40.6 & 28.9 \\
\hline $22: 00$ & 4.5 & 0.6 & 0.4 & 33.6 & 24.0 \\
\hline $23: 00$ & 4.2 & 0.7 & 0.5 & 39.4 & 27.8 \\
\hline 0:00 & 3.8 & 0.6 & 0.4 & 40.4 & 28.9 \\
\hline
\end{tabular}




\section{Appendix 14.27 Cost of conserved energy calculation and assumptions}

The costs per square metre for 15 of the Net ZEB case study buildings from (Garde and Donn, 2013) were multiplied by $4 \%$ and $10 \%$ to calculate how much incremental cost is associated with building a Net ZEB (Table 14-49).

Table 14-49: Cost per square metre to construct 15 Net ZEBs and calculated incremental costs.

\begin{tabular}{|l|c|c|c|}
\hline Task 40 database Buildings & $\begin{array}{c}\text { Net ZEB Cost (US } \\
\text { \$per square metre) }\end{array}$ & $\begin{array}{c}4 \% \text { incremental } \\
\text { cost for low energy } \\
\text { buildings }\end{array}$ & $10 \%$ incremental \\
\hline Ile du centre & 2309 & 92 & 231 \\
\hline Enerpos & 4581 & 183 & 458 \\
\hline ZEB@BCA & 1880 & 75 & 188 \\
\hline PIXEL & 4556 & 182 & 456 \\
\hline Elithis Tower & 1843 & 74 & 184 \\
\hline Green Office & 2109 & 84 & 211 \\
\hline Solar XXI & 1100 & 44 & 256 \\
\hline Lycee Kyoto high school & 2564 & 103 & 292 \\
\hline Lemeil Brevanne & 2921 & 117 & 486 \\
\hline Pantin Primary School & 4859 & 194 & 105 \\
\hline Schiestlhaus & 1000 & 160 & 130 \\
\hline $\begin{array}{l}\text { Villach Offices and } \\
\text { Appartments }\end{array}$ & 1050 & 42 & 296 \\
\hline $\begin{array}{l}\text { primary school in Hohen } \\
\text { Neuendorf }\end{array}$ & 1300 & 52 & 306 \\
\hline $\begin{array}{l}\text { Day Care centre Die } \\
\text { Sprosslinge }\end{array}$ & 2961 & 118 & 122 \\
\hline Primary school if Laion & 3056 & & \\
\hline
\end{tabular}

The median incremental cost was taken as the amount it would cost to retrofit a square metre of the current commercial building stock to be Net Zero Energy. It was converted from US dollars to NZ dollars using the exchange rate conversion in August 2014 of 1.18168 (Table 14-50).

Table 14-50 : Median incremental cost per square metre to constructed Net ZEBs
\begin{tabular}{|l|c|c|}
\hline Median Cost $/ \mathrm{m}^{2}$ & NZE without PV & NZE with PV \\
\hline US $\$ / \mathrm{m}^{2}$ & 103 & 256 \\
\hline $\mathrm{NZ} \$ \mathrm{~m}^{2}$ & 121 & 303 \\
\hline
\end{tabular}

The incremental costs per square metre were multiplied by the total amount of floor area (Table 14-51) to calculate the total investment cost of retrofitting the whole commercial building stock to be NZE (Table 14-52). 
Table 14-51: Total commercial building stock floor area

\begin{tabular}{|l|c|}
\hline Floor area & Whole Building Stock $\left(\mathrm{m}^{2}\right)$ \\
\cline { 2 - 2 } & $25,133,144.13$ \\
\hline
\end{tabular}

Table 14-52 : Incremental cost investment to retrofit the current commercial building stock to be NZE

\begin{tabular}{|l|l|c|c|}
\hline \multirow{5}{*}{ Investment } & $\begin{array}{l}\text { Based on Median } \\
\text { Incremental }\end{array}$ & $\mathrm{NZ} \$ / \mathrm{m}^{2}$ & $\mathrm{NZ} \$$ \\
\cline { 2 - 4 } & NZE energy without PV & $\$$ & $\$$ \\
& NZE With PV & $\$ 21$ & $3,045,963,670$ \\
\cline { 2 - 4 } & 303 & $7,614,909,174$ \\
\hline
\end{tabular}

The cost of conserved energy was calculated using the following equation and variables in Tables 14-53 and 14-54.

Equation 17 - Cost of Conserved Energy

Cost of Conserved Energy $=($ Investment $(\$) \div$ Annual Energy Savings $(\mathrm{kWh})) \mathrm{x}$ (discount rate $\div 1-(1+$ discount rate $)$-amortization time)

\begin{tabular}{|c|c|c|c|c|}
\hline \multicolumn{2}{|c|}{$\begin{array}{l}\text { Discount rate (rate of return - } \\
\text { that could be earned on an } \\
\text { investment in the financial } \\
\text { markets with similar risk) }\end{array}$} & & & \multirow{2}{*}{$\begin{array}{l}\text { Values are same as } \\
\text { those used in the } \\
\text { Levelised Cost of } \\
\text { Generating Energy } \\
\text { for direct comparison } \\
\text { (U.S. Energy } \\
\text { Information } \\
\text { Administration } \\
2014 \mathrm{~b} \text { ). }\end{array}$} \\
\hline \multicolumn{2}{|c|}{$\begin{array}{l}\text { Amortization time (time of cash } \\
\text { flow - building life span in } \\
\text { years) }\end{array}$} & \multicolumn{2}{|c|}{30} & \\
\hline \multirow{4}{*}{$\begin{array}{l}\text { Annual Energy savings } \\
(\mathrm{kWh})-\text { Calculated } \\
\text { from stock Aggregation } \\
\text { of } 48 \text { energy models in } \\
\text { seven climates }\end{array}$} & \multirow{2}{*}{\multicolumn{2}{|c|}{ Scenario }} & g to NZE & \\
\hline & & & $\mathrm{kWh}$ & MWh \\
\hline & \multicolumn{2}{|c|}{ NZE energy without PV } & $1,874,835,423.86$ & $1,874,835.42$ \\
\hline & \multicolumn{2}{|c|}{ NZE With PV } & $3,223,283,903$ & $3,223,283.90$ \\
\hline
\end{tabular}

The Cost of Conserved Energy results are displayed in Table 14-55.

Table 14-55 : Cost of Conserved Energy of retrofitting to NZE

\begin{tabular}{|c|c|c|c|}
\hline \multirow{3}{*}{$\begin{array}{l}\text { Cost of Conserved } \\
\text { Energy }\end{array}$} & Median & $\mathrm{CCE} \$ / \mathrm{kWh}$ & CCE \$/MWh \\
\hline & NZE energy without PV & $\begin{array}{c}\$ \\
0.12\end{array}$ & $\begin{array}{c}\$ \\
124.41\end{array}$ \\
\hline & NZE With PV & $\begin{array}{c}\$ \\
0.18\end{array}$ & $\begin{array}{c}\$ \\
180.91\end{array}$ \\
\hline
\end{tabular}


Table 14-56 : Cost of Generating Energy for different generation plants (U.S. Energy Information Administration 2014b).

\begin{tabular}{|l|r|r|}
\hline Generation plant & US\$/MWh & NZ\$/MWh \\
\hline Coal & 95.6 & 112.9686 \\
\hline Natural Gas & 66.3 & 78.34538 \\
\hline Advance Nuclear & 96.1 & 113.5594 \\
\hline Geothermal & 47.9 & 56.60247 \\
\hline Biomass & 102.6 & 121.2404 \\
\hline Wind & 80.3 & 94.8889 \\
\hline Solar & 130 & 153.6184 \\
\hline Hydro & 84.5 & 99.85196 \\
\hline
\end{tabular}

Page | 406 


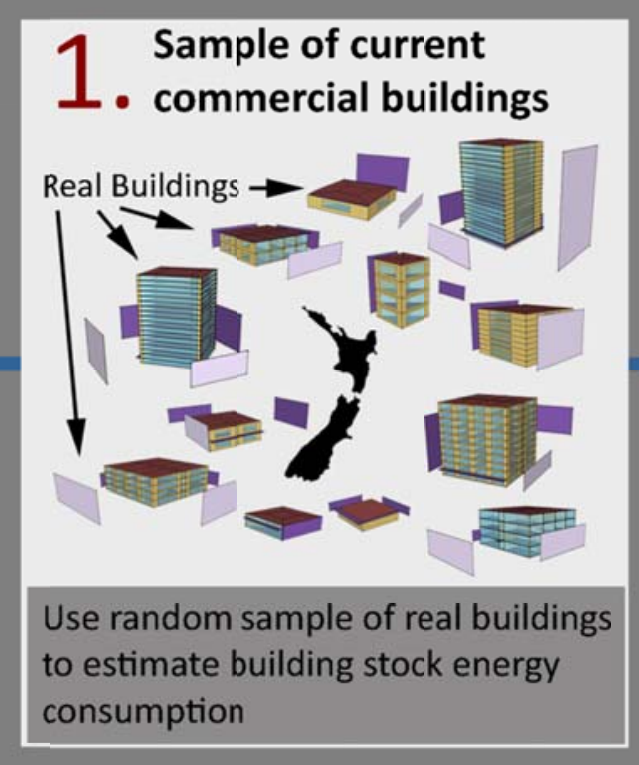

\section{Technique for modelling}

- existing buildings

Real 3 storey

Building

1)

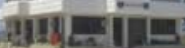

Energy Model is

constructed to match

the real building's

attributes (envelope,

operation and

systems) and its

energy consumption match 3 storey

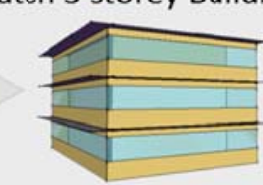

Calibrate energy callo

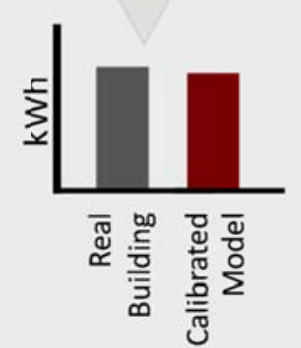

\section{Reliable model of the current \\ . Commercial Building Stock}

Energy consumption of

calibrated models

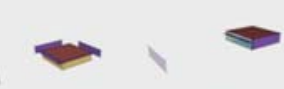

एᄂ II मां

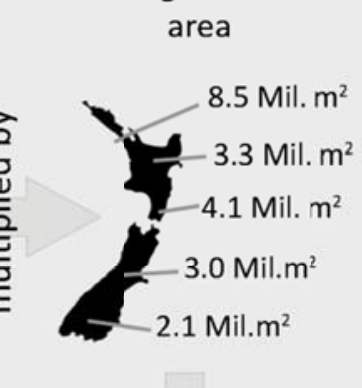

Reliable estimate as it is based on a statistical sample of real building energy consumption AND Statistical analysis can be performed

Stock Aggregated Consumption
Energy optimisation of current 4. commercial building stock

Sample of calibrated

energy models

Set of ECMs

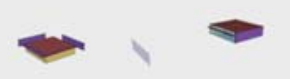

Insulation

Insulation
fficient Equipment

Solar Tubes

Avanced Glazing Heat Pumps

Photovoltaics Optimised for lowest

Each calibrated

model is retrofit

with a set

of Energy

Conservation

Measures (ECM)

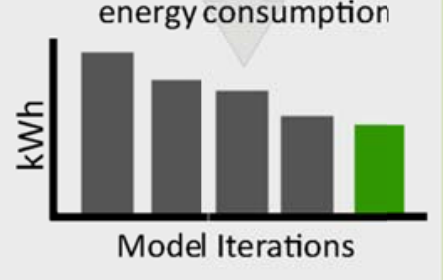

5 Selecting appropriate 5. Net ZEB solution sets

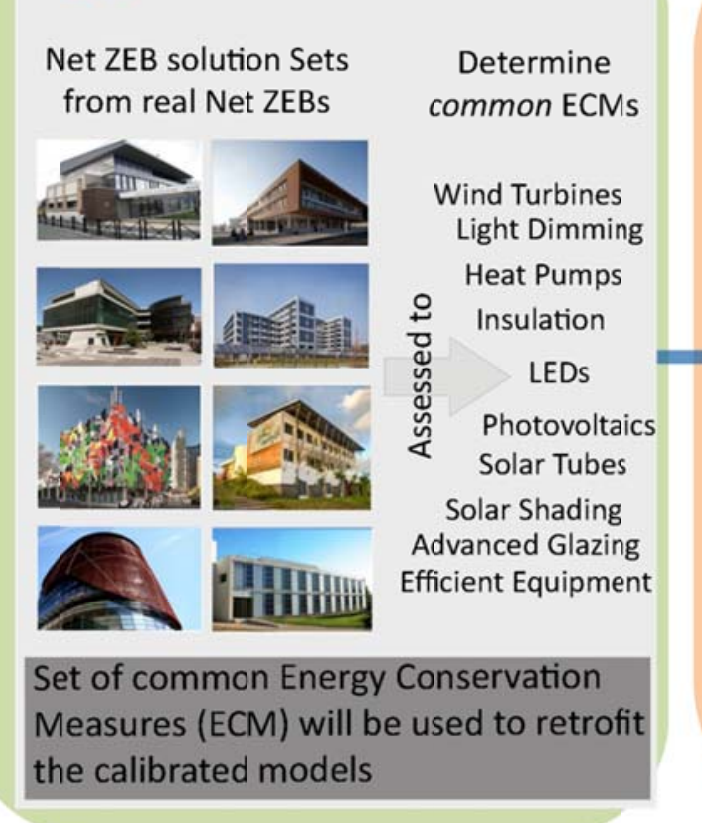

Measures (ECM) will be used to retrofit

the calibrated models
E. Energy optimised commercial 0 . building stock

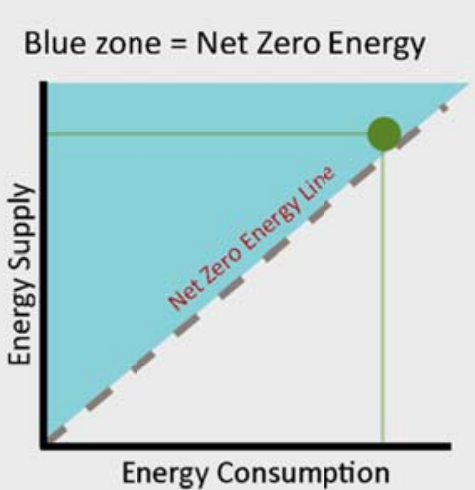

Analyse the results of the retrofit building stock.

- Is Net Zero Energy possible?

What building type has the largest energy savings?

What ECM's give the largest energy recuctions?

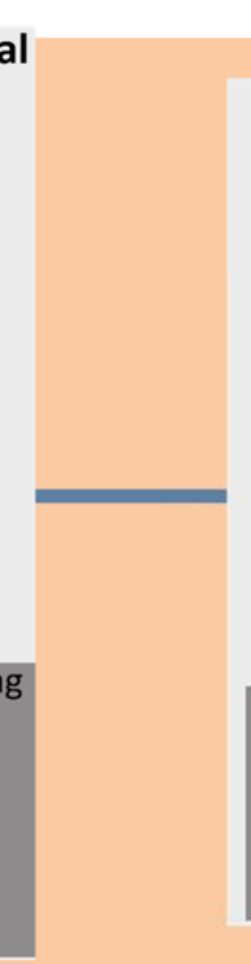

\section{Robustness of models} Electric Lights Switch there is:
350Lux or 200 Lux of daylight?

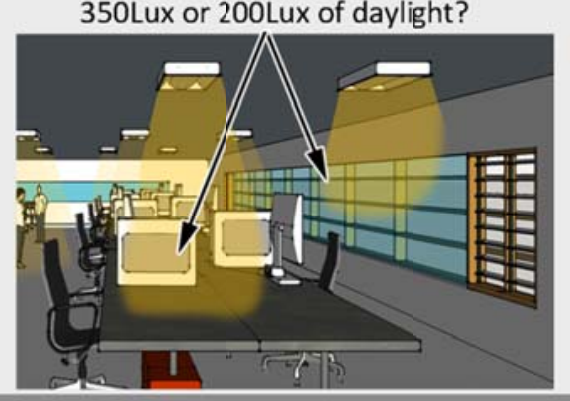

Test different modelling assumptions: - Heat and Cool Set Points

- Fresh Air Ventilation

- Task llumination

- Heat pump system
Feasibility of moving towards 8. Net Zero Energy

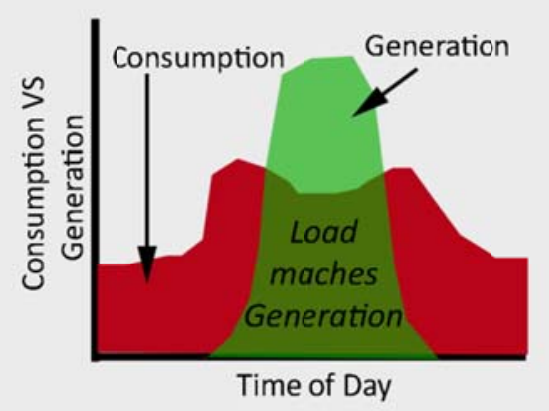

Test feasibility of retrofit commercial buildings to determine if the move towards Net Zero Energy is likely to be beneficial 


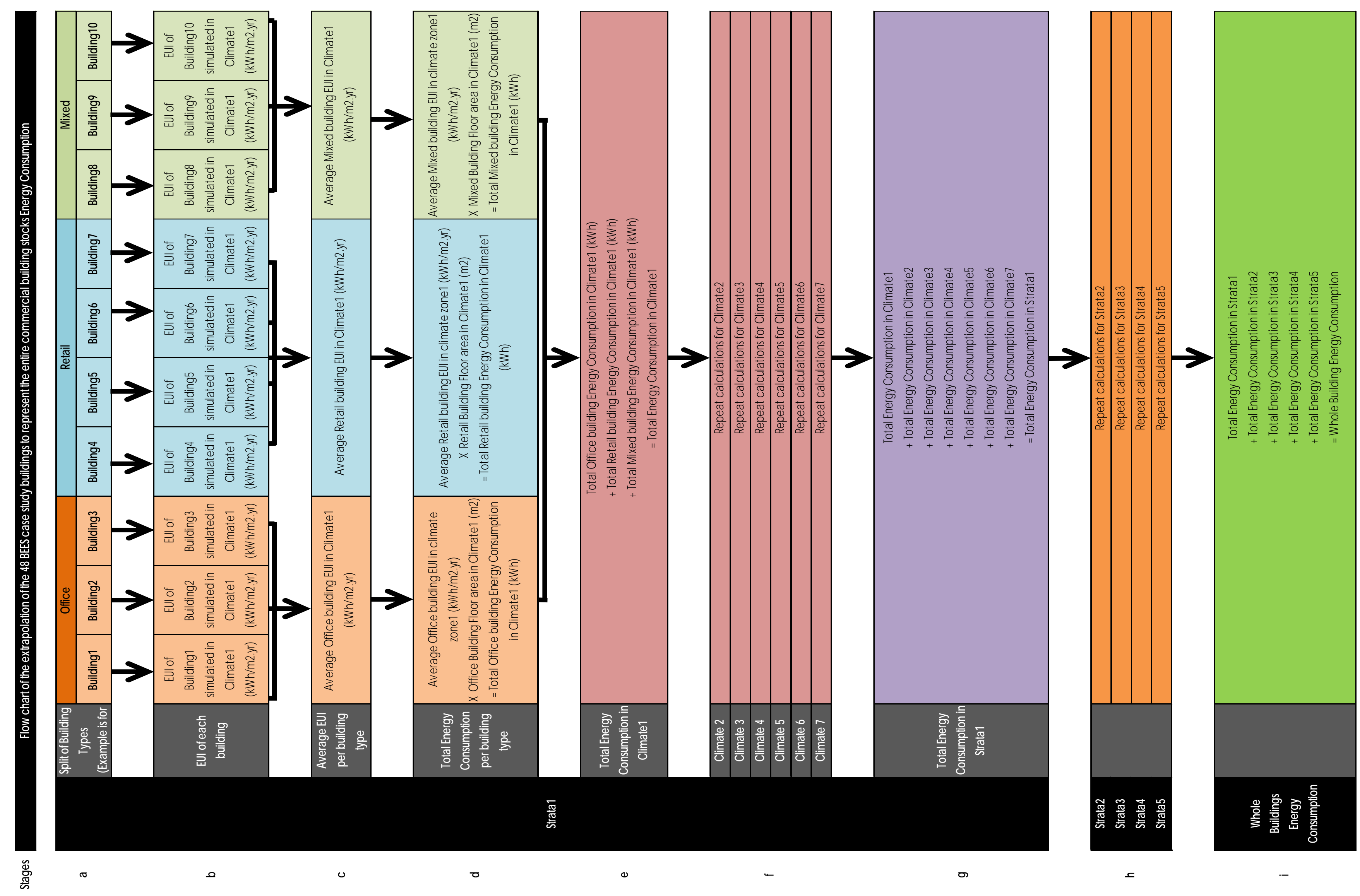

